\title{
TOWARDS SUSTAINABLE SOLVENT-BASED AFFINITY SEPARATIONS
}

Thomas Brouwer 



\title{
TOWARDS SUSTAINABLE SOLVENT-BASED AFFINITY SEPARATIONS
}

\section{PROEFSCHRIFT}

\author{
ter verkrijging van \\ de graad van doctor aan de Universiteit Twente, \\ op gezag van de rector magnificus, \\ prof. dr. ir. A. Veldkamp \\ volgens besluit van het College voor Promoties, \\ in het openbaar te verdedigen \\ op donderdag 8 april 2021 om 16:45 uur
}

door

Thomas Brouwer geboren op 5 april 1991 te Deventer, Nederland 
Dit proefschrift is goedgekeurd door de promotoren

prof. dr. ir. Boelo Schuur (promotor)

prof. dr. Sascha R. A. Kersten (promotor)

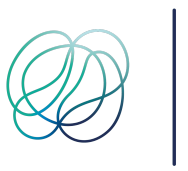

Institute for

Sustainable

Process Technology

This has been an ISPT (Institute for Sustainable Process Technology) project (TEEI314006/BL-20-07), cofunded by the Topsector Energy by the Dutch Ministry of Economic Affairs and Climate Policy

Towards Sustainable Solvent-Based Affinity Separations

Cover Design: Thomas van Tilburg

Printed by: Gildeprint

ISBN: $\quad 978-90-365-5123-6$

DOI: $\quad 10.3990 / 1.9789036551236$

URL: $\quad$ https://doi.org/10.3990/1.9789036551236

(C) 2021 Thomas Brouwer, Enschede, The Netherlands. All rights reserved. No parts of this thesis may be reproduced, stored in a retrieval system or transmitted in any form or by any means without permission of the author. Alle rechten voorbehouden. Niets uit deze uitgave mag worden vermenigvuldigd, in enige vorm of op enige wijze, zonder voorafgaande schriftelijke toestemming van de auteur. 


\section{Promotiecomissie}

Voorzitter: prof. dr. J.L. Herek Universiteit Twente

Promotor: prof. dr. ir. B. Schuur Universiteit Twente

prof. dr. S.R.A. Kersten Universiteit Twente

Leden: $\quad$ prof. dr. ir. H.A. Kooijman Shell / Clarkson University

prof. dr. ir. N.E. Benes Universiteit Twente

prof. dr. ing. M.B. Franke Universiteit Twente

prof. dr. ir. I.M. Marrucho University of Lisbon

prof. dr. ir. G. Bargeman Nouryon / Universiteit Twente 

"I learned very early the difference between knowing the name of something and knowing something",

Richard P. Feynman, (1918 - 1988) 



\section{Summary}

In the present, a global effort towards a sustainable future is high on the agenda. The Paris Agreement aims for an emission reduction of $40 \%$ of greenhouse gasses (compared to 1990 levels). To achieve this, all sectors need to pitch in and the chemical industry is certainly not excluded. Separation processes in the chemical industry are one of the main energy consumers, with up to $50 \%$ of the total energy usage within a chemical plant, and about $15 \%$ of the global energy consumption. Hence, any improvement in separation processes can make a considerable contribution towards reducing global energy consumption. The world is however not only dependent on energy, but also raw materials are essential to facilitate our way of living. Currently, a major part of the raw materials is produced from fossil resources. Not only is the use of fossil resources not sustainable, as it is finite, also fossil-based chemicals are eventually burned and add to the increasing amount of $\mathrm{CO}_{2}$ in the atmosphere. A switch towards sustainable resources is required. These resources need to be part of the current circular environment, which entails that the resources are produced from the same products after being discarded, recycled, or burned. In this situation, greenhouse gasses are still emitted but are in balance with the withdrawal of these gasses by nature. This dissertation will focus on creating specific separation processes, called Solvent-based Affinity Processes, in which not only the energy requirements will be lower than current state-of-the-art processes, but also evaluate the use of sustainable solvents which can be produced from sustainable resources.

Solvent-based Affinity Processes apply separation methods in which the addition of a solvent is essential. The adding of a solvent changes the characteristics of the separation by either changing the relative volatility in a distillation column or causing a phase split and consequently can selectively extract cer- 
tain molecules. To understand the effect a solvent has on the separation, the interactions between the solvent molecule and the other molecules need to be understood. The search towards alternative, better functioning, solvents is therefore not a new research topic and has been done for many decades. In Chapter 3, we start by taking a look backward and evaluate all solvents which have been assessed over the last decades. A comprehensive database is compiled of infinite diluted activity coefficients $\left(\gamma_{i}^{\infty}\right)$ which is a highly specific parameter that describes interactions between the solute and solvent. From this database, it was realized that these $\gamma_{i}^{\infty}$ are reported at many different temperatures. Knowing that the $\gamma_{i}^{\infty}$ is temperature dependent, this disabled a fair comparison of as many solvents as possible at the same temperature. Hence, a data analysis algorithm was written to significantly increase the amount of $\gamma_{i}^{\infty}$ at room temperature, $298.15 \mathrm{~K}$, via inter- and extrapolation using the Van 't Hoff equation. Ultimately, several general trends could be distinguished and visualized for a wide range of solutes which may act as a guide for selecting appropriate solvents. A particular potential was identified for ionic liquids with multivalent cations. These ionic liquids show to be able to lower the activity coefficient without losing the particular selective interactions. Often these two characteristics compete with each other and this seems not to be so in this case.

The use of $\gamma_{i}^{\infty}$ is however limited, as they describe an industrially unreachable situation of infinitely high solvent to feed ratios. Hence, in Chapter 4, a methodology using the 3-component Margules equation was developed to extend the applicability of the $\gamma_{i}^{\infty}$ towards realistic solvent to feed ratios, or in other words, finite concentrations. This methodology verified various industrially used solvents, hence confirming its applicability. In the vast variety of cation-anion combinations in ionic liquids and deep eutectic solvents, the morpholinium and ammonium-type cations were additionally identified to have the highest potential in sense of inducing desired relative volatility of several separation cases. Overall, the method proposed in this chapter serves as a pre-selection for solvents to focus the research in the field of solventbased affinity separations in which rigorous experimentation and simulations with new solvents are essential.

Experimentally determining $\gamma_{i}^{\infty}$ requires however specialized equipment and 
is not easy, hence in Chapter 5 the possibility of predicting these $\gamma_{i}^{\infty}$ by using theoretical models was investigated. Eight different models were assessed and the average relative deviation of each model to the combination of a wide range of different solvents and solutes was determined. Overall, for traditional (or molecular) solvents the Abraham model performed most accurately, while the MOSCED model was appropriate for ionic liquids. Still, the average relative deviation easily exceeds $65 \%$ for the prediction of $\gamma_{i}^{\infty}$ in ionic liquids, and screening of ionic liquids using these predictions should be done with care.

In Chapter 6, a different methodology was evaluated which attempts to screen solvents from another angle. The activity coefficients $\left(\gamma_{i}\right)$ are not estimated from theoretical models but correlated from a very simple experiment where the heat of mixing is measured between 2 molecules. These activity coefficients were then combined with the pure component vapor pressures to predict a vapor-liquid equilibrium. Following the Gibbs equation, the only unknown parameter to do this is the entropy. This entropic term cannot be measured but can be defined by the choice of a thermodynamic model. Liquid activity coefficient models, such as NRTL, were however observed to be inappropriate, as they are dependent on the initial guess values, and multiple local solutions could be found when correlating the enthalpy of mixing. For this reason, the robust cubic equation of states where used and found to perform well for systems where all molecules could not self-associate. This problem can be resolved by extended to a cubic equation of state to include an association term, via either the CPA-model or PC-SAFT.

All previous chapters were highly theoretical by nature, though experimental work was certainly done. In Chapter 7, 25 biobased solvents were screened for 2 industrially important separation, namely a aliphatic/aromatic (methylcyclohexane/toluene) and paraffin/olefin (n-heptane/1-heptene) separation. Cyrene was seen to most effectively entrain toluene by inducing an excellent relative volatility of $3.17 \pm 0.16$ (at a 50/50 wt. \% feed mixture), being even higher than the industrial state-of-the-art Sulfolane. Especially at higher methylcyclohexane fractions, Cyrene significantly increases the relative volatility in the system, whereas the use of Sulfolane in this composition range results in a pinch point. The absence of the pinch point when 
using Cyrene lowers the minimum reflux ratio from 2.21 for Sulfolane to 1.25 for Cyrene, corresponding to an expected energy usage reduction of approximately $30 \%$. A relative volatility towards n-heptane over 1-heptene was increased from 0.83 to 1.03 and 1.20 for a Cyrene to feed ratio of 1 and 3 respectively. Though this is less than the state-of-the-art solvent $\mathrm{n}$ methylpyrrolidone, we expect that the use of Cyrene for the industrially highly relevant butadiene (another olefin) splitting from n-butane is still suitable. This offers the opportunity to replace n-methylpyrrolidone, which is subject to strong environmental restrictions.

The search for biobased solvents continued for polar systems in Chapter 8, where the industrial separation case of acetone/diisopropyl ether was performed. Polar hydrogen-bonding solvents induce less repulsion towards the more dipolar aprotic polar compound (acetone) compared to the less polar aprotic compound (diisopropyl ether), while apolar solvents repel the more polar compound. In the full (quasi-) binary vapor-liquid equilibrium, the azeotrope in the acetone/diisopropyl ether separation was only broken by DLlimonene because it was selectively repelling the low boiling compound (acetone). Hence, DL-limonene was fitted with the NRTL and UNIQUAC model as it is adequate as a biobased solvent for the acetone/diisopropyl ether separation.

Due to the fact, Cyrene was seen to be a biobased solvent with a high potential for apolar separation, the evaluation of this solvent was extended in Chapter 9 to liquid-liquid extractions. Four biphasic ternary systems have been assessed in which methylcyclohexane and Cyrene were kept constant. As third compound toluene, cyclohexanol, cyclohexanone and cyclopentyl methyl ether were applied. For each ternary system a selective extraction was found at the three studied temperatures of $298.15 \mathrm{~K}, 323.15 \mathrm{~K}$ and $348.15 \mathrm{~K}$. Cyclohexanol and cyclohexanone were most selectively extracted, while toluene and cyclopentyl methyl ether were extracted with considerably lower selectivity. While Cyrene was outperformed by Sulfolane and several ionic liquids in the extraction of toluene, the potential of Cyrene in the cyclohexanol/cyclohexanone systems was observed. Although a lower selectivity was seen than with water, due to the high boiling point of Cyrene, recovery can be much less costly. Overall, we conclude that Cyrene can be applied as a 
biobased extraction solvent for a variety of separations, although for several systems the phase envelop is relatively narrow and narrower at higher temperatures.

In Chapter 10, the evaluation of Cyrene to separate the apolar mixture methylcyclohexane/toluene was scaled up and process simulations were performed and compared to the state-of-the-art industrial solvent Sulfolane. Both liquidliquid extraction (LLX)-based and extractive distillation (ED)-based processes have been simulated and the total annual costs (TAC) are compared. The Cyrene-based LLX process was economically least feasible due to the large miscibility region reported earlier. The Cyrene-based ED process was seen to be more efficient than the Sulfolane-based equivalent due to the absence of the pinch point in the vapor-liquid equilibrium, which reduced the solvent requirements. Also, the lower boiling point of Cyrene allowed for less reboiler duty. Eventually, the earlier mentioned 30\% energy reduction was not achieved due to heat integration. The Sulfolane-based LLX-process is however still the most economically attractive option if the aromatic feed content is below $30 \mathrm{~mol} \%$, mainly due to the large immiscibility of Sulfolane and the saturated hydrocarbon 



\section{Samenvatting}

Tegenwoordig staat de wereldwijde inspanning voor een duurzamere toekomst hoog op de agenda. Het Akkoord van Parijs beoogt niet voor niets een emissiereductie van $40 \%$ van de broeikasgassen (ten opzichte van 1990). Om dit te bereiken moeten alle sectoren hun steentje bijdragen en de chemische industrie is zeker niet uitgesloten. Scheidingsprocessen in de chemische industrie zijn een van de grootste energieverbruikers, met tot wel $50 \%$ van het totale energieverbruik binnen een chemische fabriek en ongeveer 15\% op globaal niveau. Daarom kan elke verbetering van deze scheidingsprocessen een aanzienlijke bijdrage leveren aan het verminderen van het wereldwijde energieverbruik. De wereld is echter niet alleen afhankelijk van energie, ook grondstoffen zijn essentieel om door te gaan met onze manier van leven. Momenteel wordt het grootste deel van de grondstoffen geproduceerd uit fossiele bronnen. Niet alleen is het gebruik van fossiele bronnen niet duurzaam, het is ook eindig. Verder worden fossiele chemicaliën uiteindelijk verbrand en dragen ze bij aan de toenemende hoeveelheid $\mathrm{CO}_{2}$ in de atmosfeer. Een omschakeling naar duurzame bronnen is daarom vereist. Deze bronnen maken deel uit van de huidige circulaire omgeving, wat inhoudt dat deze bronnen, waar vanuit de chemicaliën worden gemaakt, zijn ontstaan uit dezelfde producten nadat ze zijn weggegooid, hergebruikt of verbrand. In deze situatie worden nog steeds broeikasgassen uitgestoten, maar deze zijn in evenwicht met dezelfde gassen die zijn onttrokken uit de natuur. Dit proefschrift zal zich richten op het ontwikkelen van specifieke scheidingsprocessen, zogeheten oplosmiddelgebaseerde affiniteitsprocessen, waarbij niet alleen de energiebehoefte lager zal zijn dan de huidige industriële processen, maar ook het gebruik van duurzame, natuurlijke oplosmiddelen die geproduceerd kunnen worden uit de circulaire economie. 
Oplosmiddelgebaseerde affiniteitsprocessen passen gespecialiseerde scheidingsmethoden toe waarvan een oplosmiddel essentieel is. Het toevoegen van een oplosmiddel verandert de karakteristieken van de scheiding door ofwel de relatieve vluchtigheid in een destillatie kolom te veranderen, ofwel een vloeibare fasescheiding te veroorzaken. Om het effect van een oplosmiddel op een scheiding te begrijpen moeten de interacties tussen het oplosmiddel molecuul en de andere moleculen worden begrepen. De zoektocht naar alternatieve en beter werkende oplosmiddelen is daarom geen nieuw onderzoeksthema en wordt al decennia bedreven. In Hoofdstuk 3 kijken we eerst terug in de tijd en evalueren we alle oplosmiddelen die reeds zijn onderzocht. Een uitgebreide databank is samengesteld met oneindig verdunde activiteitscoëfficiënten $\left(\gamma_{i}^{\infty}\right)$, wat een zeer specifieke parameter is die de interacties beschrijft tussen een opgelost molecuul en het oplosmiddel molecuul. Uit deze databank bleek dat deze $\gamma_{i}^{\infty}$ bij veel verschillende temperaturen wordt gerapporteerd. Wetende dat de $\gamma_{i}^{\infty}$ temperatuurafhankelijk is, maakt dit een eerlijke vergelijking van zoveel mogelijk oplosmiddelen bij dezelfde temperatuur lastig. Daarom werd een data analyse algoritme geschreven om de hoeveelheid $\gamma_{i}^{\infty}$ bij kamertemperatuur, dat is $25^{\circ} \mathrm{C}$ of $298.15 \mathrm{~K}$, significant te verhogen via inter- en extrapolatie door middel van de Van 't Hoff-vergelijking. Uiteindelijk zijn verschillende algemene trends gevisualiseerd voor een breed scala aan opgeloste moleculen in bepaalde oplosmiddelen die als richtlijn kan dienen voor het selecteren van geschikte oplosmiddelen. Een bijzonder potentieel werd geïdentificeerd voor ionische vloeistoffen met meerwaardige kationen. Deze ionische vloeistoffen blijken namelijk in staat de activiteitscoëfficiënt te verlagen zonder de specifieke selectieve interacties te verminderen. Vaak zijn deze twee kenmerken namelijk in concurrentie met elkaar en dit bleek met deze oplosmiddelen minder het geval te zijn.

Het gebruik van de $\gamma_{i}^{\infty}$ heeft echter limitaties, aangezien deze parameters een industrieel onpraktische situatie beschrijven van een oneindig hoge verhouding tussen oplosmiddel en voeding. Daarom is in Hoofdstuk 4 een methodiek ontwikkeld die gebruik maakt van de 3-componenten Margules vergelijking. Zodoende kan de toepasbaarheid van de $\gamma_{i}^{\infty}$ uit worden gebreid naar realistische verhoudingen tussen oplosmiddel en voeding, of m.a.w. eindige concentraties. Deze methodiek identificeerde verschillende reeds toegepaste industriële oplosmiddelen, en bevestigde daarmee de toepasbaarheid ervan. In de 
enorme verscheidenheid aan kation-anion combinaties in ionische vloeistoffen en combinaties mogelijk in diep eutactische vloeistoffen, werd bovendien geïdentificeerd dat het morfolinium en ammonium-type kation een hoog potentieel heeft. Een potentieel in de zin van het opwekken van de gewenste relatieve vluchtigheid van verschillende scheidingen. Over het algemeen dient deze methodiek als een voorselectie van oplosmiddelen met als doel het onderzoek scherp te stellen op het gebied van affiniteitsscheidingen, waarbij rigoureus experimenteren en simuleren met nieuwe oplosmiddelen essentieel zijn.

Het experimenteel bepalen van $\gamma_{i}^{\infty}$ vereist echter gespecialiseerde apparatuur en is niet eenvoudig, vandaar dat in Hoofdstuk 5 de mogelijkheid om deze $\gamma_{i}^{\infty}$ te bepalen met behulp van theoretische modellen is onderzocht. Acht verschillende modellen werden beoordeeld en de gemiddelde relatieve afwijking van elk model is bepaald. De globale afwijking is weergegeven, maar ook de specifieke afwijking met betrekking tot specifieke combinaties van oplosmiddelen en opgeloste moleculen. Over het algemeen presteerde het Abraham model voor traditionele (of moleculaire) oplosmiddelen het meest nauwkeurig, terwijl het MOSCED model het meest geschikt was voor ionische vloeistoffen. Toch overschrijdt de gemiddelde relatieve afwijking voor ionische vloeistoffen gemakkelijk 65\% en zodoende moet het beoordelen van ionische vloeistoffen met behulp van deze voorspellingen met zorg gebeuren.

In Hoofdstuk 6 werd een andere methodiek geëvalueerd die probeert oplosmiddelen via een andere hoek door te lichten. De activiteitscoëfficiënten $\left(\gamma_{i}\right)$ worden niet geschat op basis van theoretische modellen, maar gecorreleerd op basis van de mengwarmte tussen twee moleculen. Deze activiteitscoëfficiënten worden vervolgens gecombineerd met de dampdrukken van de zuivere componenten om een damp-vloeistof evenwicht te voorspellen. Volgens de Gibbs vergelijking is de enige onbekende parameter om dit te doen de entropie. Deze entropische term kan echter niet worden gemeten, maar kan gedefinieerd worden door de keuze van een thermodynamisch model. Vloeibare activiteitscoëfficiënt modellen, zoals het NRTL model, bleken echter ongeschikt te zijn, omdat ze o.a. afhankelijk waren van de initiële gokwaarden, en er meerdere lokale oplossingen gevonden konden worden. Om deze reden werden robuuste kubische toestandsvergelijkingen gebruikt en deze 
bleken goed te presteren voor systemen waarin alle moleculen geen zelfassociatie gedrag vertoonden. Dit probleem kan wellicht worden opgelost door de kubische toestandsvergelijking uit te breiden met een associatie term, via bijvoorbeeld het CPA-model of PC-SAFT model.

Alle voorgaande hoofdstukken waren theoretisch van aard, terwijl er ook zeker experimenteel werk is verricht. In Hoofdstuk 7 werden veel natuurlijke oplosmiddelen door gelicht op twee industrieel belangrijke scheidingen, namelijk een alifatische/aromatische scheiding, bijvoorbeeld die van methylcyclohexaan (MCH) en tolueen (TOL) en een paraffine/olefine (n-heptaan/1hepteen) scheiding. Cyreen bleek het meest effectief tolueen te kunnen afvangen met een uitstekende relatieve vluchtigheid van $3.17 \pm 0.16$ te induceren (bij een 50/50 g.\% voedingsmengsel). Dit is zelfs hoger dan het industriële Sulfolaan oplosmiddel. Vooral bij hogere $\mathrm{MCH}$ fracties induceert Cyreen een significante relatieve vluchtigheid in het systeem, terwijl gebruikmakend van Sulfolaan in deze samenstellingsgebied resulteert in een raakpunt met de evenwichtigslijn. De afwezigheid van dit raakpunt bij gebruik van Cyreen verlaagt de minimale terugvloei verhouding van 2.21 voor Sulfolaan tot 1.25 voor Cyreen. Dit komt overeen met een verwachte energieverbruik vermindering van ongeveer $30 \%$. Een relatieve vluchtigheid ten opzichte van n-heptaan ten opzichte van 1-hepteen werd verhoogd van 0.83 tot 1.03 en 1.20 voor een verhouding van Cyreen tot voeding van respectievelijk 1 en 3 . Hoewel dit minder is dan het industriële oplosmiddel n-methylpyrrolidon, verwachten we dat het gebruik van Cyreen voor de industrieel zeer relevante butadieen (een andere olefine) scheiding nog steeds geschikt is. Dit biedt de mogelijkheid om n-methylpyrrolidon (gedeeltelijk) te vervangen.

De zoektocht naar biogebaseerd of natuurlijke oplosmiddelen ging verder voor polaire systemen in Hoofdstuk 8, waar de industrieel relevante aceton/diisopropyl ether scheiding werd geëvalueerd. Polaire waterstofbindende oplosmiddelen induceerde een minder hevige afstoting naar de meer aprotische polaire verbinding (aceton). Terwijl apolaire oplosmiddelen de meer polaire verbinding afstootten. In het volledige (quasi-) binaire damp-vloeistof evenwicht werd de azeotroop in de aceton/ diisopropyl ether scheiding enkel verbroken door het oplosmiddel DL-limoneen. Dit was vanwege het feit dat het selectief de laagkokende verbinding (aceton) afstootte. Daarom is het 
damp-vloeistof evenwicht van DL-limoneen gecorreleerd met het UNIQUAC en NRTL modellen en is het geschikt voor de scheiding van aceton en diisopropyl ether.

Omdat Cyreen werd gezien als een natuurlijk oplosmiddel met een hoog potentieel voor apolaire scheiding, werd de evaluatie van dit oplosmiddel in Hoofdstuk 9 uitgebreid tot vloeistof-vloeistof extracties. Er zijn vier bifasische ternaire systemen onderzocht waarin methylcyclohexaan en Cyreen constant werden gehouden. Als derde verbinding werden of tolueen, of cyclohexanol, of cyclohexanon, of cyclopentylmethyl ether toegepast. Voor elk ternair systeem werd een selectieve extractie gevonden bij de drie bestudeerde temperaturen van $298.15 \mathrm{~K}, 323.15 \mathrm{~K}$ en $348.15 \mathrm{~K}$. Cyclohexanol en cyclohexanon werden het meest selectief geëxtraheerd, terwijl tolueen en cyclopentylmethyl ether met aanzienlijk lagere selectiviteit werden geëxtraheerd. Ondanks dat Cyreen minder presteerde dan Sulfolaan en verschillende ionische vloeistoffen bij de extractie van tolueen, werd het potentieel van Cyreen in de cyclohexanol and cyclohexanon systemen waargenomen. Hoewel een lagere selectiviteit werd waargenomen dan met water als oplosmiddel, kan de terugwinning door het hoge kookpunt van Cyreen veel minder duur zijn. Al met al concluderen we dat Cyreen kan worden toegepast als natuurlijk oplosmiddel voor een verscheidenheid aan scheidingen, hoewel voor verschillende systemen het fasescheidingsgebied relatief smal is en nog smaller wordt bij hogere temperaturen.

In Hoofdstuk 10 werd de evaluatie van Cyreen om het apolaire mengsel $\mathrm{MCH}$ / TOL te scheiden opgeschaald en werden processimulaties gedaan en vergeleken met het industriële oplosmiddel Sulfolaan. Zowel het op vloeistofvloeistof extractie (LLX)-gebaseerde proces als het op extractieve destillatie (ED)-gebaseerde proces zijn gesimuleerd en de totale jaarlijkse kosten (TAC) werden vergeleken. Het op Cyreen-gebaseerde LLX-proces was economisch het minst haalbaar vanwege de grote mengbaarheid die eerder werd gerapporteerd. Het op Cyreen gebaseerde ED-proces bleek efficiënter te zijn dan het op Sulfolaan gebaseerde equivalent. Dit is vanwege de afwezigheid van het knelpunt in het damp-vloeistof evenwicht, waardoor er minder oplosmiddel nodig was. Ook zorgde het lagere kookpunt van Cyreen voor een lagere energiehoeveelheid op de reboilers. Uiteindelijk werd de eerder genoemde 
$30 \%$ energiereductie niet behaald door warmte-integratie. Het op Sulfolaangebaseerde LLX proces is echter nog steeds het economisch meest aantrekkelijk als het aromaat gehalte in de voeding lager is dan $30 \mathrm{~mol} \%$. Dit is voornamelijk vanwege de grote onmengbaarheid van Sulfolaan en de verzadigde koolwaterstof. 




\section{Table of Contents}

1 Introduction 1

2 Theory 9

3 Literature Review and Visualisation $\quad 25$

4 Solvent Pre-Selection for Extractive Distillation 59

5 Comparison of $\gamma^{\infty}$ Prediction Methods 91

6 VLE Prediction from the Heat of Mixing 123

7 Biobased Entrainers for Apolar Separations 157

8 Biobased Entrainers for Polar Separations 177

9 Liquid-Liquid Extractions with Cyrene $\quad 197$

10 Process Simulation of Solvent-Based Affinity Processes 221

11 Conclusion, Reflection and Perspective 257

$\begin{array}{ll}12 \text { Appendices } & 275\end{array}$

13 Acknowledgements $\quad 337$ 




\subsection{Towards a Sustainable Future}

During the twentieth century, humankind went through a magnificent lifestyle transformation. Nowadays, it is not uncommon that our dinner has been cultivated around the globe and that we go on a long weekend trip by plane to another part of Europe or even another continent. We enjoy this luxurious lifestyle, however, this comes at a price. The global consumption of resources has increased 14-fold between 1900 and 2015, and is estimated to double towards 2050 relative to $2015 .{ }^{1}$ The enormous consumption of fossil resources results in emitting a tremendous amount of greenhouse gasses into our environment. Furthermore, there is a large overuse of freshwater supplies.

In an attempt to formulate necessary steps towards a more sustainable way of living, the United Nations have set up the 2030 Agenda for Sustainable Development in September 2015 during the United Nations General Assembly. In this agenda, countries around the world agreed on 17 Sustainable Development Goals, see Figure 1.1. ${ }^{1}$ Among these goals are social, humanitarian aims such as to end poverty, eliminate hunger, and gender equality, but also goals which may require technical solutions such as to provide everyone with clean water and sanitation, affordable and clean energy, take climate action, and the introduction of new technologies in industries, innovation and infrastructure.

Together with the Paris Agreement on Climate Change, ${ }^{2}$ these policies are the current road-maps to guide the way towards a more sustainable future. Following the Paris Agreement, the European Union (EU) aims to reduce greenhouse gas emissions by $40 \%$ in 2030 (compared to 1990 levels). ${ }^{2}$ With about $24 \%$ of the total energy use in the EU allocated to industrial activities, improving the energy efficiency of the industry will have a tremendous impact. ${ }^{3}$ In the chemical industry, separation processes are significant energy consumers where these processes can be responsible for up to $50 \%$ of the total energy cost of the plant. ${ }^{4}$

Sholl and Lively report a global energy usage, allocated to separation processes, of $10-15 \%{ }^{5}$ which may be a highly rough estimation. A significant amount of this energy usage can be traced back to the working-horse of the chemical separations, namely the distillation column where molecules are 

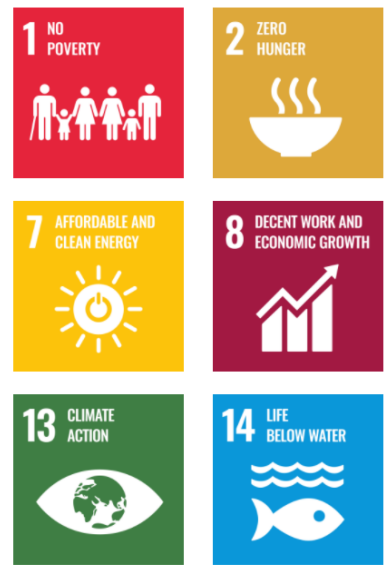
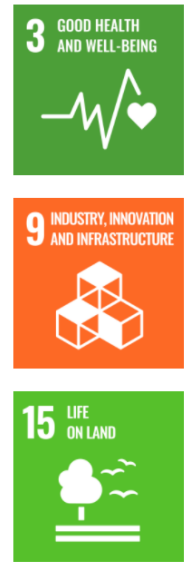
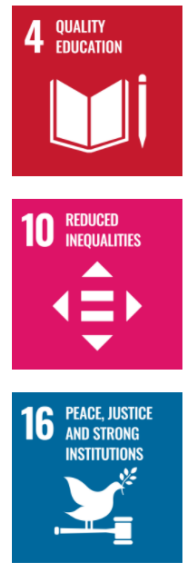
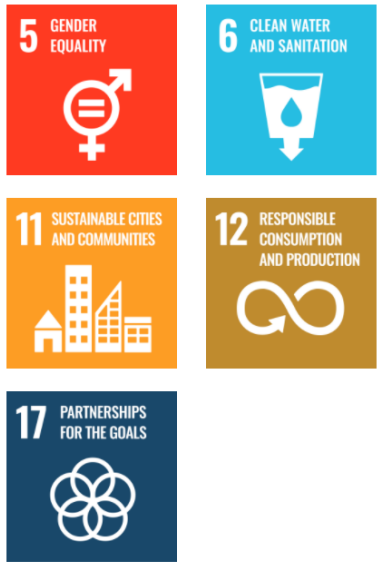

Figure 1.1: The 17 sustainable development goals within the 2030 UN Agenda for Sustainable Development. ${ }^{1}$

separated using their differences in boiling point. The main employer of distillation columns is the petrochemical industry. Hence, an accurate estimation of the energy cost allocated to separation processes, is highly dependent on e.g. the complexity of the process and the extent of heat integration. Nevertheless, due to the sheer size of the chemical industry, enabling improvements for even a small fraction of the total energy costs is still significant. Hence, in this dissertation, I investigate not only a way of increasing the efficiency of these distillation columns by adding a solvent, but also systematically show why certain solvents increase the efficiency and why other solvents do not. Solely these improvements will not allow us to reach the goals set by the Paris agreement, but they will contribute to the overall integral efforts.

The aim of higher energy efficiency is evident (defined as the energy (or work) introduced in the distillation column compared to the thermodynamic minimum $\left.^{6}\right)$. In this dissertation I also assess the efficiency of the path towards new processes. Ideally, a chemical engineer knows all required data without any error margin to optimally design a new (distillation) process. This is however not the case, as experimental data points are often laborious to obtain, and time costs money. Hence, I investigate from several angles different screen- 
ing methods that can help chemical engineers to focus their design process and reduce the required amount of expensive, time-consuming experimental efforts. Improving the energy efficiency of separation processes must not negatively affect other sustainability aspects. As currently, we are dependent on fossil resources, and it would be preferential to switch to sustainable resources. Resources, such as biomass, take up $\mathrm{CO}_{2}$ from the atmosphere in the same period as the $\mathrm{CO}_{2}$ is expelled by using these resources. For this reason, we know biomass to be sustainable, while fossil resources are not.

In this dissertation, I combine the search for ways of increasing the energyefficiency of separation processes primarily by finding alternative, biobased, solvents produced from sustainable resources and the application of the various screening methods to speed up the design processes. Ultimately, several industrial relevant examples were examined to assess the potential of these sustainable alternative solvents.

\subsection{Thesis Outline}

In this dissertation, I will first give a short introduction to separation processes in Chapter 2. The screening of molecules that can act as solvents in separation processes has been done for a long time, therefore in Chapter 3, I started with the collection of the previously done screening reported in literature. The focus was on the temperature-dependent infinite dilution activity coefficient $\left(\gamma^{\infty}\right)$, which is a molecular descriptor of the solvent interactions with other molecules. The initially scattered data is now present in an extensive database, which in combination with a data handling algorithm, made it possible to compare a vast amount of solvents and assess their potential in fluid separations.

In Chapter 4, a new screening methodology is proposed, which does not require any sophisticated software package and uses the $\gamma^{\infty}$-database collected in the previous chapter. The extended Margules equation was applied to convert the solvent effects from infinite dilution to realistic industrial conditions. Consequently, I could estimate the minimal required amount of solvent for an energy-efficient distillation operation. 
The previous two chapter focus on the infinite dilution activity coefficient $\left(\gamma^{\infty}\right)$, which is an experimentally determined data point, though is not easily measured. Hence, I assessed in Chapter 5 the possibility of using various mathematical models to approximate these data points. Eight models were systematically assessed and their accuracy for various solvent-solute combinations were determined.

In Chapter 6, a second new screening methodology was developed, which does not focus upon the infinite dilution activity coefficient $\left(\gamma_{i}^{\infty}\right)$, but attempts to predict vapor-liquid equilibria (VLE) from solely the amount of energy that is released upon mixing. A throughout assessment of cubic equation of states and liquid activity model is done and a considerable amount of binary systems could be accurately predicted. However, an inability to predict the phase equilibria of self-associating molecules was observed, which may be resolved by using more advanced models that include association effects.

All this theoretical work is complemented by an experimental screening of 23 biobased solvents for apolar separations in Chapter 7. The biobased solvent, dihydrolevoglucosenone or Cyrene, was seen to have a comparable ability to separate aromatic and aliphatic compounds than the industrial benchmark solvent Sulfolane. Chapter 8 extended the experimental screening of 35 biobased solvents to the polar separation of acetone and diisopropyl ether. Water and ethylene carbonate were observed to be able to entrain acetone, while DL-limonene could entrain diisopropyl ether. Only the latter, was able to break the azeotrope of the system and has the potential of being an adequate biobased solvent for this separation. In Chapter 9, the investigation into the biobased solvent Cyrene was extended towards liquid-liquid extraction applications. Although a limited operating window was observed for apolar systems, the potential of Cyrene in the separation of cyclohexanol and cyclohexanone was shown.

Chapter 10 is a continuation of the evaluation of Cyrene as an entrainer for the separation of aliphatic and aromatic compounds. As the potential of Cyrene is already established, a detailed comparison on a process level is performed here. A liquid-liquid extraction-based process and an extractive distillation- 
based process using either Cyrene or Sulfolane were simulated. From the evaluation of the total annual costs, it was seen that the Sulfolane-based liquidliquid extraction process is most economically attractive until an aromatic feed content of $30 \mathrm{~mol} \%$. For higher aromatic feed contents, the Cyrene-based extractive distillation is most attractive, outperforming the Sulfolane-based equivalent.

A reflection and perspective will be given in Chapter 11, as there are still many subjects to be evaluated and ideas to be worked out. Understanding fluid separations, the equilibria behind each operation, and the non-ideal behavior behind these phase separations are not possible without a throughout knowledge of thermodynamics and the model derived from this mathematical description of our everyday life. For this reason, Chapter 12 is written to allow for more background knowledge which has been used throughout this dissertation.

\subsection{References}

[1] European Commission, "Reflection Paper Towards a Sustainable Europe by 2030," Jan. 2019.

[2] United Nations, "Paris Agreement on Climate Change," Dec. 2015.

[3] European Environment Agency, "Final energy consumption by sector and fuel in Europe," 2020.

[4] A. A. Kiss, J.-P. Lange, B. Schuur, D. W. F. Brilman, A. G. van der Ham, and S. R. Kersten, "Separation technology-making a difference in biorefineries," Biomass and Bioenergy, vol. 95, pp. 296-309, 2016.

[5] D. S. Sholl and R. P. Lively, "Seven chemical separations to change the world," Nature, vol. 532, no. 7600, pp. 435-437, 2016.

[6] R. Agrawal and R. T. Gooty, "Misconceptions about efficiency and maturity of distillation," AIChE Journal, p. e16294. 





\subsection{Introduction}

Chemistry is for many as mysterious as magic, due to the fact you cannot see what is going on. Still, throughout many millennia, people have performed alchemy or attempted to do this. In ancient China and Egypt, alchemists tried to transform cheap metals into high-valuable silver and gold. Nowadays, we know this can be done via nuclear reactions which are not very cost-effective and cheap, but back then it was completely impossible. Another, more practical, branch of alchemy was to constantly improve instruments such as heating methods. Eventually, these instruments were refined into, for example, an alembic (see Figure 2.1), which is a very crude heater and condenser which could concentrate alcohol to produce aqua vitae which can be compared to vodka or to distill the fragrance of roses and produce perfume. ${ }^{1}$

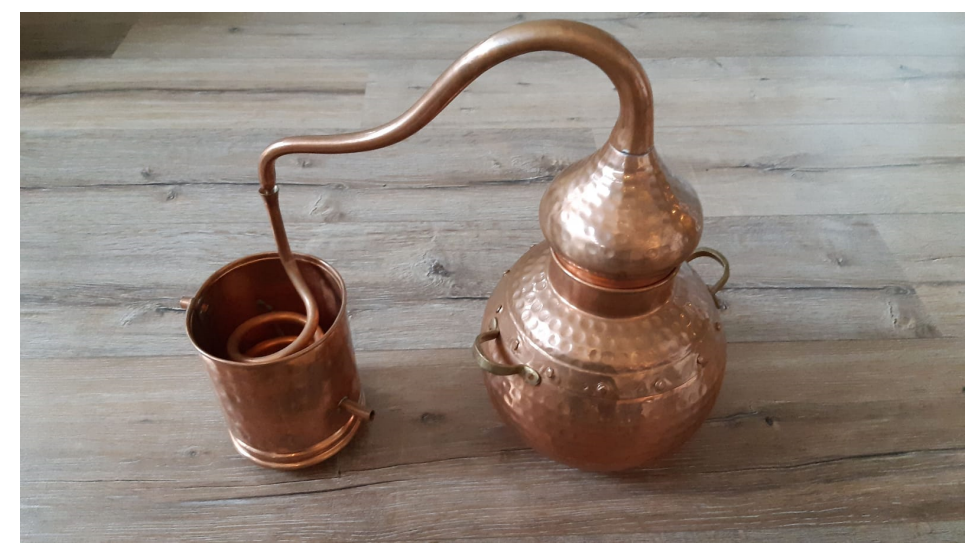

Figure 2.1: An example of an alembic, with (left) a condenser and (right) the kettle in which the liquid is heated up. The picture was taken (with my own permission) of my own alembic.

Where the alchemists started with the improvement of their instruments, chemical engineers are still attempting to improve their instruments. Although the alembic has been replaced by distillation towers in most industrial applications of distillation, and the essence of roses can also be extracted with solvents in extraction columns, the aim to improve these separation techniques still exists. In the following sections, an introduction will be made into some general aspects of separation techniques, and specifically solvent-based separation techniques. The behavior of fluids in the separation techniques 
can be traced back to the intermolecular interactions and therefore the most predominant interactions will be introduced.

\subsection{General Separation Techniques}

In the chemical industry, many different aspects related to the production processes are of importance for the overall performance. Generally, a feedstock, which can either be a pure component or a mixture, is entered into processes. Various processing stages then take place. These can be a (pre-)treatment of the feedstock, a reaction, and one or more separation operation(s). Furthermore, operations like heat exchange operations enhances the efficiency by minimizing the total energy requirement of the plant. Conditional to the topic of this thesis, the focus in this section is on the separation operations. A variety of basic separation techniques may be identified. Each technique has its unique way of facilitating the separation of a mixture. Separations always require an effort, being in the form of heat or work to separate a chaotic mixture into orderly pure components as this is not a spontaneous process. The description of spontaneity can be expressed through the Gibbs energy $(\mathrm{G})$. This Gibbs energy is a function of the temperature $(\mathrm{T})$, enthalpy $(\mathrm{H})$ and entropy (S), as can be seen in Equation 2.1.

$$
\Delta G=\Delta H-T \Delta S
$$

where the enthalpy is the quantity that describes the energy content of the components, while the entropy describes the amount of chaos. It is common practice to only indicate the difference in Gibbs energy $(\Delta G)$, enthalpy $(\Delta H)$ and entropy $(\Delta S$ ), as we are only interested in the difference between two (or more) situations and not the absolute value. A chemical system (or mixture) will always end up in the lowest possible Gibbs energy state. Hence, a mixture will often not spontaneously separate into its components, of course, exceptions are known, and overcome the Gibbs energy of mixing, see Figure 2.2. The entire essence of separation technology and the affiliated research is performing and/or finding a way of delivering the required Gibbs energy to separate a mixture as efficiently as possible. To overcome the Gibbs energy of mixing most efficiently is however not straight-forward and several techniques can be applied. Seader, Henley and Roper ${ }^{2}$ describe five basic separa- 


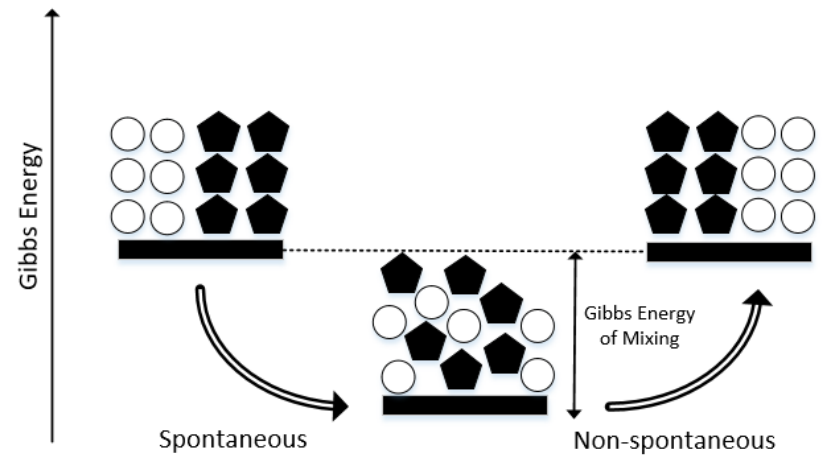

Figure 2.2: A schematic representation of the relative Gibbs energy levels between segregated and mixed compounds, which is the Gibbs energy of mixing.

tion strategies, which cover in general all methods of performing a separation. These strategies are;
1. Phase Creation
4. Solid Agent
2. Phase Addition
5. Force field or Gradient
3. Barrier

The first technique covers the heating or cooling of the mixture to create a second phase. The alchemist already did this in an alembic. Nowadays common operations are distillation (where a liquid mixture is partly vaporized) and crystallization (where a liquid mixture is partly solidified). ${ }^{2}$

The second technique adds a phase to the mixture. This phase can be either liquid or gas. The added liquid, or solvent, to a liquid mixture may be immiscible and a 2-layer system will be formed. This is the basis of a common separation technique named liquid-liquid extraction (LLX). Other examples where a phase is added are stripping (where an additional gas phase is introduced to partly strip the liquid mixture) and absorption (where an additional liquid phase is added to the gas mixture to partly absorb the gas mixture). ${ }^{2}$ The last three options contain techniques such as (3) membrane separations e.g. removal of medicinal traces from water, ${ }^{3}(4)$ the capture of $\mathrm{CO}_{2}$ from the air with solid particles, ${ }^{4}$ and (5) refinement of uranium isotopes with ultracentrifuges. ${ }^{5}$ This thesis will focus on the addition and/or creation of a liquid 
phase or often referred to as a solvent. The latter three will be excluded, though this doesn't mean that these have no potential. Often a combination of multiple techniques can be applied for a separation challenge.

\subsection{Solvent-Based Affinity Separations}

The addition of a solvent is the cornerstones in solvent-based affinity separations. When a solvent is applied to distillation, this preferably results in a single liquid phase, whereas in liquid-liquid extraction, the addition of a second liquid phase is aimed for. In the following subsections, more details will be given on the fundamentals of (advanced) distillation (see: phase creation) and liquid-liquid extraction (see: phase addition).

\subsubsection{Distillation}

In the most simple words, distillation is heating a mixture, evaporating part of the mixture and collecting (and condensing) it separately from the remaining liquid. Consequentially, the composition of the mixtures obtained from the evaporated fraction and the remaining liquid differ, which is essential to induce a separation. The development of this separation method cannot be detached from the history of alcohol which has been used in medicine or to "enjoy". Chemists from the Alexandrian time or early Asiatic (see Chinese) people have been credited to know about alcohol and therefore distillation (see the alembic), however, these stories may be part of legends. The discovery of alcohol and thus the scientific understanding of distillation can be traced back to the South of Italy in the $11^{\text {th }}$ of $12^{\text {th }}$ century. ${ }^{6}$ Although, this technique is mature and a proven separation technique, still research is being performed in this field. ${ }^{7}$

As mentioned before, distillation is a method that heats a liquid mixture and consequently condenses the gas phase and cools down the remaining liquid. Therefore, a certain amount of energy needs to be added to the mixture and afterward has to be withdrawn from the system. These amounts can be different, but also equal under equal molar overflow and saturated liquid feed. The separation work required to overcome the Gibbs energy of mixing originates from the work potential. It is linked to the flow of high-temperature energy at the reboiler to the energy at a lower temperature in the cooler (or condenser), 


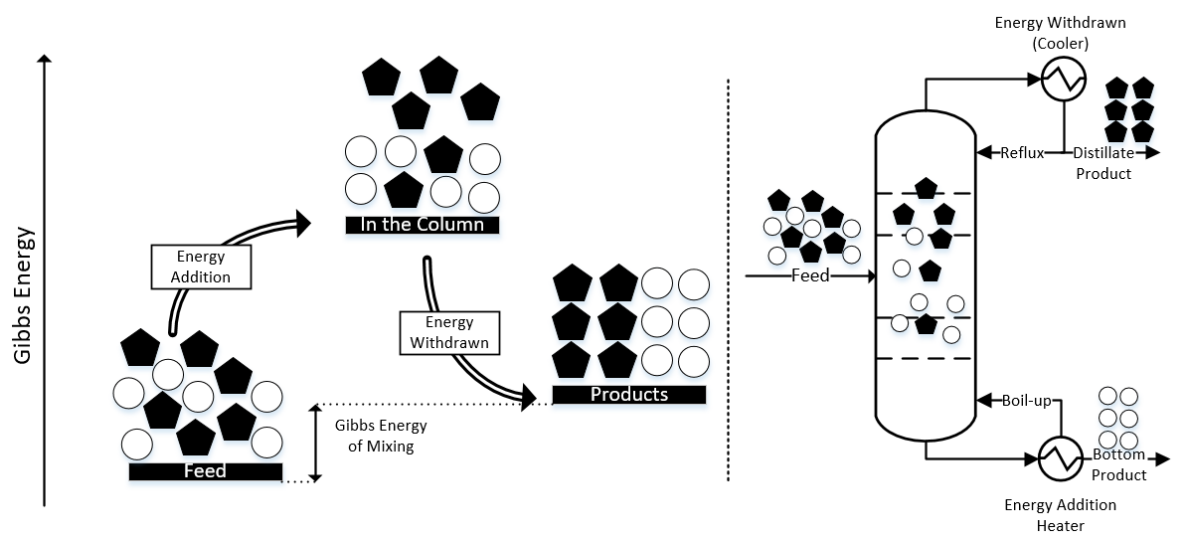

Figure 2.3: (left) A schematic representation of the Gibbs energy levels between liquid mixed compounds, the heated (partly evaporated) mixture and the liquid segregated mixture. (right) A schematic representation of a corresponding distillation column, where the feed and products as shown, and also the reflux and boil-up streams are indicated.

as can be seen in Figure 2.3.

The amount of energy required to (partly) evaporates the mixture is highly dependent on the components present in the mixture. For instance, the amount of energy required to evaporate compounds (enthalpy of evaporation, $\Delta_{v a p} H$ ) and the relative tendency of compounds to move from the liquid to the gas phase at a specific temperature (relative volatility, $\alpha$ ) are among the crucial parameters, as can be seen in Equation 2.2, ${ }^{8}$

$$
\dot{Q}_{r e b}=\dot{n}_{F} x_{F A}\left(\frac{1}{x_{F A}(\alpha-1)}+1\right) \Delta_{v a p} H_{A}
$$

where $\dot{Q}_{r e b}$ is the reboiler duty $(\mathrm{J} / \mathrm{s}), \dot{n}_{F}$ is the molar feed flow $(\mathrm{mol} / \mathrm{s}), x_{F A}$ is the mole fraction in the feed of compound $\mathrm{A}, \alpha$ is the relative volatility and $\Delta_{v a p} H_{A}(\mathrm{~J} / \mathrm{mol})$ is the enthalpy of evaporation of compound A.

The overall costs of a distillation column can be minimized by reducing the number of trays (lowers the Capital Expenditures, CAPEX) and by keeping 
the reflux ratio close to minimum (affects the Operational Expenditure, OPEX). Distillation is currently the most used separation method in the chemical industry, however, it has limitations. First of all, the relative volatility $(\alpha)$ which is a measure of the partial pressures $\left(P^{o}\right)$ and the activity coefficient $\left(\gamma_{A}\right)$, see Equation 2.3, needs to be (preferably much) unequal to 1, otherwise, the number of trays and the reflux ratio will be too high for an economically feasible operation.

$$
\alpha=\frac{P_{A}^{o} \gamma_{A}}{P_{B}^{o} \gamma_{B}}
$$

In non-ideal cases, the vapor-liquid equilibrium may include (a) curve(s) (pinchpoint(s)) or may even cross the equal composition (diagonal) line (azeotrope), see Figure 2.4. These phenomena can complicate the distillation operations and can result in more trays, higher reflux ratios, and may even (in the azeotrope case) make distillation impossible.

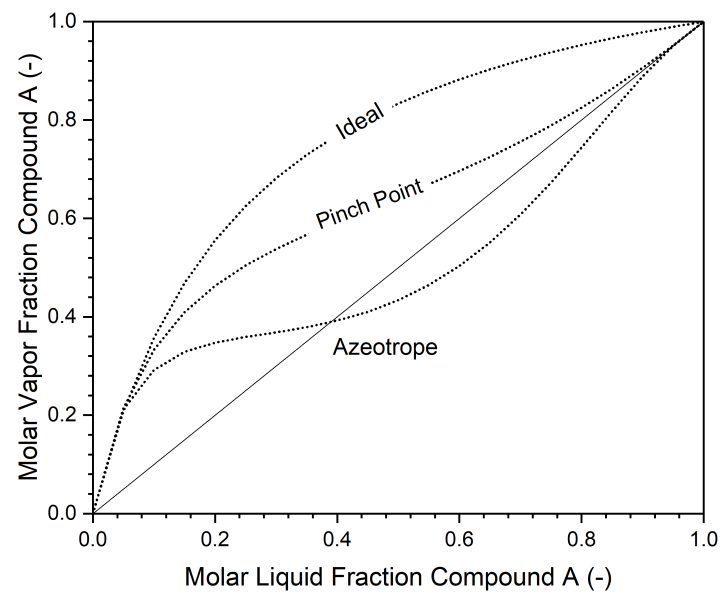

Figure 2.4: A schematic representation of three types of vapor-liquid equilibria. An ideal case, a case including a pinch-point and an azeotrope.

In these cases adding a solvent can solve these problems. The addition of a solvent may solve such problems by altering the relative volatility of the mixture to be separated. Another limitation, that will not be addressed here, 
is the challenge of sensitive separations. The separation of mixtures which are unstable at higher temperatures (such as delicate (bio)molecules), or are prone to undergo (undesired) reactions.

\subsubsection{Advanced Distillation}

As mentioned earlier, one is not limited to a single separation technique, hence advanced distillation techniques are being applied and researched to minimize the required energy that is needed to perform a specific separation. Many of these advanced distillation techniques combine several basic techniques with the most mature (distillation) technique, such as Azeotropic Distillation (Phase addition), ${ }^{9}$ Extractive Distillation (Phase addition), ${ }^{10}$ Membrane Distillation (Barrier), ${ }^{11}$ HiGee Distillation (Force Field or Gradient). ${ }^{12}$ Not all of these advanced distillation techniques will be reviewed, but only the solvent-based extractive and azeotropic distillation will be discussed in a little more detail. Extractive distillation is a technique that combines a solvent that has a higher boiling point than the components in the feed, see Figure 2.5, and consequently, the feed and the solvent are introduced in a distillation column at different locations. A high-boiling solvent is often fed above the feed stage at a low temperature.

The solvent affects the relative volatility of the feed by changing the activity coefficients of the components. As previously stated, these activity coefficients are a measure of the non-ideality of the mixture, thus the solvent changes the non-ideality of the overall mixture and this advanced distillation technique attempts to benefit from it. However, it can also be seen that an additional distillation column is required to separate eventually the solvent from (one of) the components. Initially, this may seem to be irrational to replace a single (traditional) distillation column, with an extractive distillation operation that has an additional solvent and 2 columns. The justification lays in the efficiency of these operations. Blahušiak et al. ${ }^{8}$, and King ${ }^{13}$ in a more general sense regarding reversible heat engines, showed the minimum reboiler duty of an extractive distillation column (Equation 2.4a) including solvent regeneration (Equation 2.4b) to be a function of the $\dot{n}_{F, E D}$ which is the molar feed flow entering the extractive distillation (ED) column ( $\mathrm{mol} / \mathrm{s}), x_{i}$ which are the various mole fractions of either the high-boiling compound B or low-boiling 

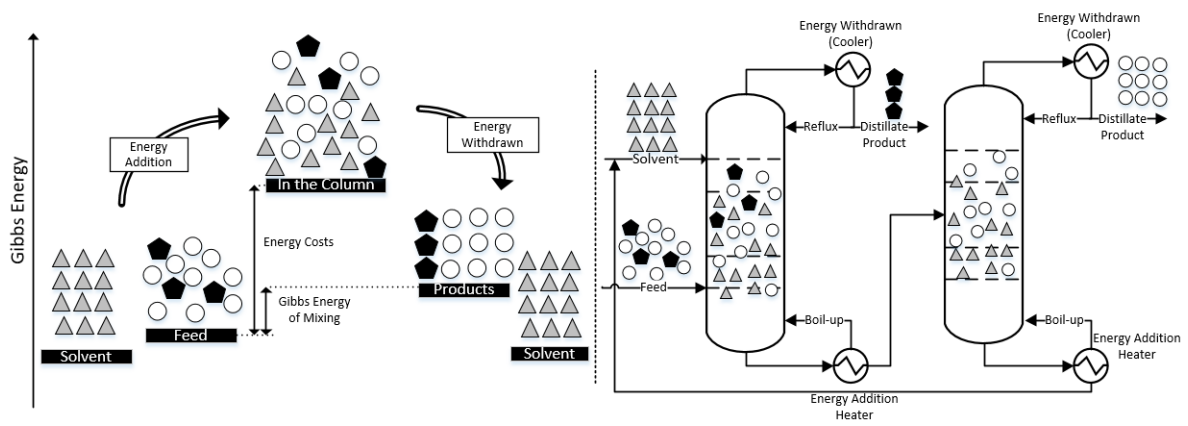

Figure 2.5: (left) A schematic representation of the Gibbs energy levels between the liquid mixture (incl. solvent), the heated (partly evaporated) mixture and the liquid segregated mixture. (right) A schematic representation of a corresponding extractive distillation column and the solvent recovery column, where the heavy boiling component and solvent are separated.

compound $\mathrm{A}, \alpha$ which is the relative volatility between either compound $\mathrm{B}$ and the solvent $\left(\alpha_{B S}\right)$ or in the ED column $\left(\alpha_{E D}\right)$, the solvent-to-feed ratio $(\mathrm{S} / \mathrm{F})$ and $\Delta_{v a p} H_{i}$ is the enthalpy of evaporation $(\mathrm{J} / \mathrm{mol})$ of compound $\mathrm{i}$.

ED:

$$
\begin{aligned}
& \dot{Q}_{r e b}=\dot{n}_{F, E D}\left(\frac{1}{\alpha_{E D}-1}+x_{F A}\right) \Delta_{v a p} H_{A} \\
& \dot{Q}_{r e b}=\dot{n}_{F, E D}\left(\frac{x_{F B}+S / F}{\alpha_{B S}-1}+x_{F B}\right) \Delta_{v a p} H_{B}
\end{aligned}
$$

As the $\alpha_{E D}$ is enhanced by the solvent, and the $\alpha_{B S}$ is high due to the low volatility of the chosen solvent, the reboiler duties of both columns $\left(\dot{Q}_{r e b}\right)$ can be lower than a single distillation column which a low $\alpha_{A B}$. The vapor phase non-ideality was neglected in this mathematical framework, and consequently for systems which behave highly non-ideally in the vapor phase, see carboxylic acids, these equations are not applicable.

Azeotropic distillation is also a technique that adds a solvent to a distillation column, though this solvent has a lower boiling point than the feed mixture. Often these solvents cause a low boiling azeotrope with a specific component 
in the feed mixture and hence this facilitates the separation and increases the efficiency of the column. Again, an additional distillation column is required to separate the solvent and one of the components (homogeneous azeotropic distillation), though sometimes (after cooling) a phase split occurs (see LLX) which can be used (heterogeneous azeotropic distillation). Also for these advanced distillation operations, the McCabe-Thiele methods can be used to obtain initial design specifications of the distillation column through the liquid and vapor flow of the solvent should also be included.

\subsubsection{Liquid-Liquid Extraction}

An entirely different separation technique uses the addition of a (liquid) phase, see solvent, to induce a separation. This phenomenon seems exotic to most, however, is quite common in the kitchen. For instance, after cooking Italian dough in water, a little bit of (olive)oil can be added to prevent agglomeration of the fancy Italian dough wisps or shards. By doing this, you will see that the oil will not mix with the water. This is exactly the cornerstone of liquid-liquid extraction (LLX). The first extractions, although being solid-liquid extraction, have been done millennia ago as proven by Mesopotamian remains which showed a hot-water extractor for organic matter $(3500 \mathrm{BC}) .{ }^{14}$ An automated procedure is however accredited to a German chemist Franz Ritter von Soxhlet (1848-1926) who developed the first procedure to separate fats from milk solids, although this idea was already pitched by the French chemist Anselme Payen (1795-1871). ${ }^{14}$

As can be seen in Figure 2.6, a LLX will never be a stand-alone operation. At least one distillation column is required to obtain all components in a pure form. This is due to the fact, even though 2 liquid phases are formed, all components will distribute between both liquids phases and additional purification is required. Nevertheless, this operation can be more efficient than a single distillation. A LLX procedure will, therefore, (counter-intuitively) initially worsen the separation problem as an additional component is added to a mixture. This can be compensated by the increase in regeneration efficiency and overall the separation will be more efficient.

Blahušiak et al. ${ }^{8}$ have shown, see Equation 2.5, that the separation work $\left(\dot{W}_{\text {sep }}\right)$ required to deliver the reboiler duty $\left(\dot{Q}_{\text {reb }}\right)$ is subjected to two differ- 


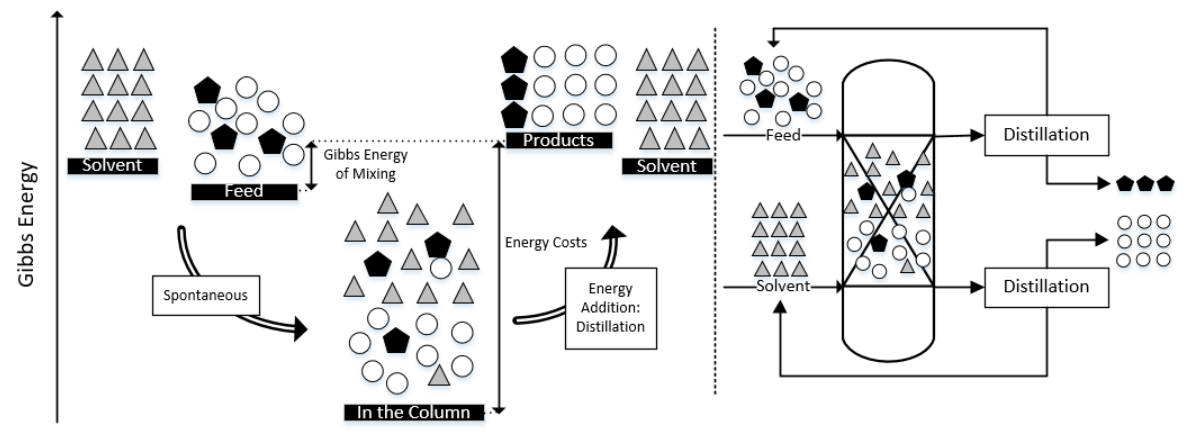

Figure 2.6: (left) A schematic representation of the relative Gibbs energy levels between liquid mixed compounds and a solvent, the created 2 liquid phases (I and II) system and the liquid segregated mixture. (right) A schematic representation of a corresponding LiquidLiquid Extraction column, where the feed, solvent and products as show which are obtained after distillation, Figure 2.3

ent efficiencies, namely the Carnot efficiency $\left(\eta_{C}\right)$ and the internal efficiency $\left(\eta_{I}\right)$.

$$
\dot{W}_{\text {sep }}=\dot{Q}_{\text {reb }} \eta_{C} \eta_{I}
$$

While the Carnot efficiency is predefined as a function of the ratio in temperature present in the top and bottom of the column, the internal efficiency is strongly correlated to the relative volatility $(\alpha)$ and the molar fraction in the feed $\left(x_{F A}\right)$ see Equation 2.6. ${ }^{8}$

$$
\eta_{I}=-\frac{x_{F A} \ln \left(x_{F A}\right)+\left(1-x_{F A}\right) \ln \left(1-x_{F A}\right)}{\ln (\alpha) \cdot\left(\frac{1}{(\alpha-1)}+x_{F A}\right)}
$$

Here, it can be seen that an increase in the relative volatility increases the internal efficiency of the distillation column, which is key in a LLX process. In the LLX itself, the distribution of the components between both phases is a key parameter. In essence, at equilibrium, all compounds will have the same activity in each phase. This means that for every compound the following equation holds,

$$
\left[x_{i} \gamma_{i}\right]_{I}=\left[x_{i} \gamma_{i}\right]_{I I} \vee a_{i, I}=a_{i, I I}
$$


where the activity $\left(a_{i}\right)$ which is defined as the product of the mole fraction $\left(x_{i}\right)$ and activity coefficient $\left(\gamma_{i}\right)$ of each compound is equal in both phases. The distribution coefficient is consequently defined as in Equation 2.8,

$$
K_{D, i}=\frac{\left[x_{i}\right]_{I}}{\left[x_{i}\right]_{I I}}=\frac{\left[\gamma_{i}\right]_{I I}}{\left[\gamma_{i}\right]_{I}}
$$

where the distribution coefficient $\left(K_{D}\right)$ is the ratio between the (molar or weight) concentration of compound $\mathrm{x}$ in phases I and II. Commonly, the solvent phase is called the extract (E) phase, while the remainder (which is not extracted) is called the raffinate $(R)$ phase.

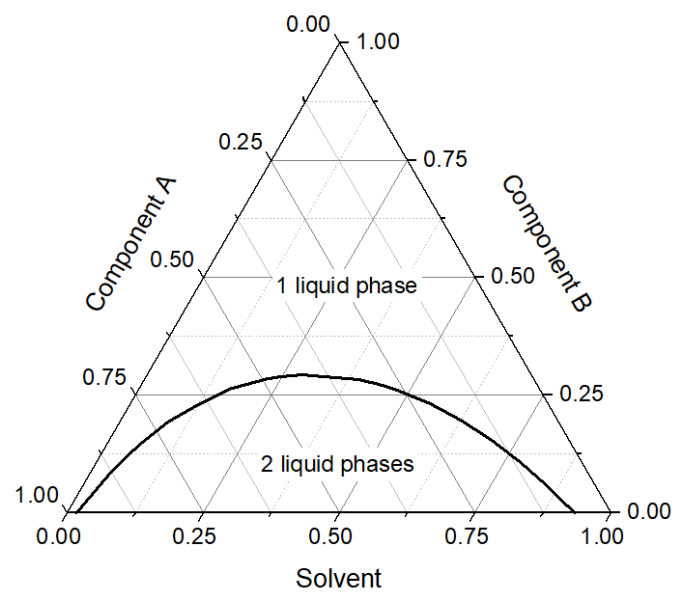

Figure 2.7: (left) A schematic representation of a type I ternary diagram between compounds $A$ and $B$, and a solvent.

In the case of a binary mixture, a $K_{D}$ value will be obtained for 2 components and the ratio between these $K_{D}$ values is called the selectivity, see Equation 2.9,

$$
S_{i j}=\frac{K_{D, i}}{K_{D, j}}=\frac{\left(\frac{\gamma_{i}}{\gamma_{j}}\right)_{I}}{\left(\frac{\gamma_{i}}{\gamma_{j}}\right)_{I I}}
$$

Additionally, it can be seen that also the selectivity is a function of the activity coefficients $\left(\gamma_{i}\right.$ and $\left.\gamma_{j}\right)$, almost identically as seen in the non-ideal term of the 
relative volatility in distillation.

Similarly to the distillation column, a single LLX stage is not sufficient due to the fact the distribution coefficient is not large enough or the selectivity is not sufficient. It is therefore often required to repeat the extraction procedure several times. An ideal solvent has a large $K_{D}$ value, an infinite selectivity and is completely immiscible with the other liquid phase. This is however never the case and the "best" trade-off between these parameters should be found. A ternary diagram, see Figure 2.7, is the most illustrative way of giving a significant amount of information regarding the equilibrium between 2 partly miscible liquids (LLE) and the corresponding LLX between both liquids. In a specific composition region, a phase split will occur, while the remainder of the compositions is miscible. These diagrams will be used in the thesis.

\subsubsection{Concluding remarks}

In this chapter, I only explained the most basic theory regarding fluid separations. Much more will be explained in the course of this dissertation, but is outside of the scope of this chapter. Throughout this chapter, it is (hopefully) clear that the activity coefficient $(\gamma)$ is such an important parameter and not surprisingly many types of thermodynamic models with various degrees of complexity have been developed over the years. Many models have been applied in this dissertation and will be discussed in the appropriate sections. In Chapter 3, we will apply the Van 't Hoff equation in a data handling algorithm, while in Chapter 4 the (extended) Margules equation will be used. Chapter 5 includes a comparison of eight different models, while Chapter 6 includes next to twelve different cubic equation of states combined with eight different mixing rules, also various liquid activity models. An additional appendix is written about this work in Chapter 12. State-of-the-art models such as UNIQUAC and NRTL are primarily used in Chapters 7, 8, 9 and 10 to enable accurate phase equilibria. 


\subsection{References}

[1] F. Aftalion, A history of the international chemical industry. Chemical Heritage Foundation, 2001.

[2] J. D. Seader, E. J. Henley, and D. K. Roper, Separation process principles, vol. 25. Wiley New York, 1998.

[3] J. De Grooth, M. G. Elshof, and H. D. W. Roesink, "Polyelectrolyte multilayer (pem) membranes and their use," May 28 2020. US Patent App. 16/613,727.

[4] M. Bos, S. Pietersen, and D. Brilman, "Production of high purity $\mathrm{co} 2$ from air using solid amine sorbents," Chemical Engineering Science: X, vol. 2, p. 100020, 2019.

[5] S. Whitley, "The uranium ultracentrifuge," Physics in Technology, vol. 10, no. 1, pp. 26-33, 1979.

[6] A. J. Liebmann, "History of distillation," Journal of Chemical Education, vol. 33, no. 4, p. 166, 1956.

[7] A. A. Kiss, "Distillation technology-still young and full of breakthrough opportunities," Journal of Chemical Technology \& Biotechnology, vol. 89, no. 4, pp. 479-498, 2014.

[8] M. Blahušiak, A. A. Kiss, K. Babic, S. R. Kersten, G. Bargeman, and B. Schuur, "Insights into the selection and design of fluid separation processes," Separation and purification technology, vol. 194, pp. 301-318, 2018.

[9] S. Widagdo and W. D. Seider, "Journal review. azeotropic distillation," AIChE Journal, vol. 42, no. 1, pp. 96-130, 1996.

[10] Z. Lei, C. Li, and B. Chen, "Extractive distillation: a review," Separation E Purification Reviews, vol. 32, no. 2, pp. 121-213, 2003.

[11] A. Alkhudhiri, N. Darwish, and N. Hilal, “Membrane distillation: A comprehensive review," Desalination, vol. 287, pp. 2-18, 2012.

[12] G. E. Cortes Garcia, J. van der Schaaf, and A. A. Kiss, "A review on process intensification in higee distillation," Journal of Chemical Technology E Biotechnology, vol. 92, no. 6, pp. 1136-1156, 2017.

[13] C. J. King, Separation Processes, ch. Energy requirements of Separation Processes. McGraw-Hill Chemical Engineering, McGraw-Hill, 2nd ed., 1980.

[14] W. B. Jensen, "The origin of the soxhlet extractor," Journal of chemical education, vol. 84, no. 12, p. 1913, 2007. 





\subsection{Introduction}

The chemical industry produces large quantities of chemical compounds. Though processes have been operated and constantly optimized for many decades, the pursuit of reducing energy usage and lessen the environmental impact is a constant endeavor. Separation processes are among the most energy-intensive operations which can account for up to $50 \%$ of the total costs of the chemical plant. ${ }^{1}$ Even on a global scale in the production of chemicals and fuels, these separation processes account for $10-15 \%$ of the world's energy usage. ${ }^{2}$ Solvent-based affinity processes aim to enhance the separation efficiency by selectively tuning the interactions present in the separation mixture which is done via the addition of a solvent. ${ }^{3}$ For example, in applications where azeotropic behavior is encountered, the addition of a solvent can enable separation by distillation, and proper solvent selection has a significant impact on the overall energy demand of the process. Recently, we projected ${ }^{4}$ that by replacing fossil-based Sulfolane in an oil refinery extractive distillation by bio-based solvent Cyrene, a maximum of 30\% energy savings can be achieved. This projection can be found in Figure 7.7. However, how to select a solvent is not straight-forward, and is typically labor- and time-intensive.

To reduce the labor intensity of the solvent screening process, a prompt solvent pre-selection is crucial in the early development and/or improvement of novel solvent-based affinity processes. Pre-selection can be done using activity coefficients. These activity coefficients of the molecules in the mixture are compared in different solvents, hence the solvent performances in a solventbased separation can be evaluated. Generally, the maximum effect can be achieved by having a close to the pure solvent present. Thus, the solute will only interact with solvent molecules. The close to pure solvent situation corresponds to an infinite dilution of the individual solutes and therefore, the infinite dilution activity coefficient $\left(\gamma_{i}^{\infty}\right)$ is a good first measure of the achievable separation performance of the solvent. ${ }^{5}$ Some systems containing selfassociation and/or complexation behavior show a maximum deviation from ideality at a composition different from infinite dilution. ${ }^{6}$ However, these systems are exceptions and these effects have not been taken into consideration in our current study focusing on the infinite dilution activity coefficient. 
The activity coefficient, interpreted by Lewis in 1901 as "the tendency to escape the phase in which it is in", 7 is an important feature in biphasic systems because it describes deviations from Raoult's law. The tendency of the solute to escape the phase in which it is in is reduced when the attractive intermolecular interaction between the solute and solvent is stronger than those between the solvent molecules. The $\gamma_{i}$ will in this situation be lower than unity, $\gamma_{i}<1$. Oppositely, if the tendency is enhanced and the attractive interaction between the solvent molecules is stronger, then a net repulsion is induced and a positive deviation from Raoult's law is seen. This is described by a $\gamma_{i}$ higher than unity, $\gamma_{i}>1$. In the ideal situation, where no intermolecular interactions occur (as in an ideal gas), or they are all identical, $\gamma_{i}=1$.

The $\gamma_{i}$ is, however, both temperature and composition-dependent and the $\gamma_{i}^{\infty}$ simplifies this to a single compositional point. Although the $\gamma_{i}^{\infty}$ can be used to find the maximum separation performance of solvents, it does not reflect the actual values that may be observed in real separations, since for infinite dilutions a solute mole fraction between $10^{-7}$ and $10^{-4}$ may suffice, depending on the relative molar weights of solute and solvent. ${ }^{8}$ Often, actual concentrations are much larger, although in several chemical processes such as stripping operations and the extraction of highly dilute species, this quantity may be directly used. ${ }^{9}$ However, in this manuscript, the $\gamma_{i}^{\infty}$ will be used as a molecular descriptor for solvent pre-selection for solvent-based affinity separations.

Several experimental techniques are available to determine the temperaturedependent $\gamma_{i}^{\infty}$, such as Gas-Liquid Chromatography ${ }^{10}$, Inert Gas Stripping Method $^{11,12}$, Headspace Analysis Method ${ }^{13}$, Indirect Headspace Chromatography ${ }^{14}$, Dew Point Method ${ }^{15}$, Differential Static Cell Method ${ }^{16}$, Differential Ebulliometry Method ${ }^{17}$ and Rayleigh Distillation Method ${ }^{18}$. An excellent review of all techniques is given by Dohnal. ${ }^{19}$ Mathematical models are also present which can predict $\gamma_{i}^{\infty}$, such as several UNIFAC variations ${ }^{20-22}$, the Abraham model $^{23}$, MOSCED ${ }^{24}$ and COSMO-RS. ${ }^{25}$ Significant deviations between simulated values and experimental values occur however for several classes of molecules and care should be taken when using these estimations. ${ }^{26}$ Due to the rich literature on experimental $\gamma_{i}^{\infty}$, proper analysis of literature data might give good insights, and allow for trend analysis in various sol- 
vents of the same family and between different solvent families. To map these trends, it is of importance to have comparable data available, which entails isothermal $\gamma_{i}^{\infty}$ at for instance $298.15 \mathrm{~K}$.

Several literature reviews with the focus on $\gamma_{i}^{\infty}$ in particular ionic liquids (ILs) are present, though often with another emphasis. Various reviews emphasized the differences between various ILs on the n-hexane/1-hexene 27,28 or aliphatic/aromatic separation. ${ }^{28}$ Heintz $^{29}$ reviewed ILs for more thermophysical properties and focused on alkanes, aromatic molecules and alcohols. Articles describing the $\gamma_{i}^{\infty}$ of molecular solvents generally focus on one solvent, several solvents or combinations of several molecular solvents. ${ }^{5,30}$ Pierotti et al. ${ }^{31}$ showed a methodology of evaluating $\gamma_{i}^{\infty}$ trends of certain solute-solvent combination as function of the number of carbon atoms. Moreover, an important limitation to the use of literature data is that the data is not always available at the same temperature. To enable a trend map for a wide range of solvents, and having ample data present, but not at the right temperature, an approach needs to be developed. In recent years, Deep Eutectic Solvents (DES's) have been introduced as a new type of solvent. However, only a very limited amount of $\gamma_{i}^{\infty}$ for solutes in DES's have been published ${ }^{32-35}$, hence these solvents are excluded from this evaluation.

In this work, we have developed a data analysis algorithm, and applied it to analyze a large set of data for the $\gamma_{i}^{\infty}$ of five solutes, being $\mathrm{n}$-hexane, benzene, chloroform, acetone and ethanol, see Figure 3.1, in many solvents. The solutes have been selected as examples of respectively apolar saturated hydrocarbons, slightly polar unsaturated hydrocarbons, halogenated molecules, aprotic polar molecules and protic polar molecules. For these molecules, the $\gamma_{i}^{\infty}$ at $298.15 \mathrm{~K}$ is mapped for a wide range of molecular solvents and ILs. The resulting overview enables a discussion on the impact of solute and/or solvent molecular structural changes on the $\gamma_{i}^{\infty}$ of the solutes. 

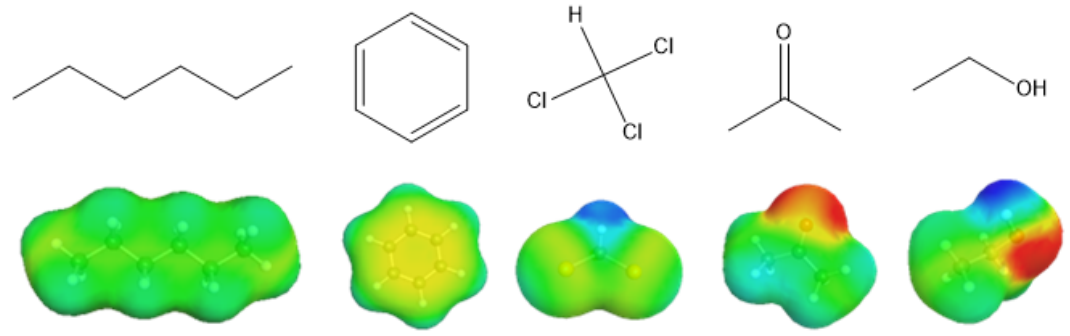

Figure 3.1: The investigated molecules, from left to right n-hexane, benzene, chloroform, acetone and ethanol. The electron distribution profile was generated by COSMOthermX C30_1705 with a TZVP parameterization. The color indicators are a range from electronegative (red), slightly electronegative (yellow), neutral (green) to electropositive (blue) regions.

\subsection{Data Collection and Data Analysis Algorithm}

The largest collection of $\gamma_{i}^{\infty}$ is part of the Dortmund Databank. Although this collection is comprehensive, it is commercial and not open-access. Hence, as part of this work we created an alternative open-acces database. This database of $\gamma_{i}^{\infty}$ parameters from literature, given in the section 3.5, was accumulated by searching for the key-words "infinite dilution coefficient" or "limiting activity coefficient" with a timeframe until 2020. Each data point is cited to the original article in which it was published. In order to expand the dataset of available $\gamma_{i}^{\infty}$ at $298.15 \mathrm{~K}$, the available thermodynamic information at other condition(s) was used to calculate the corresponding $\gamma_{i}^{\infty}$ at $298.15 \mathrm{~K}$ for systems where it was not directly available. Only directly determined $\gamma_{i}^{\infty}$ from dedicated experimental techniques ${ }^{10-17}$, also $\gamma_{i}^{\infty}$ were included as extrapolated $\gamma_{i}^{\infty}$ from phase equilibria may be quite inaccurate. ${ }^{9}$ This database includes $77.173 \gamma_{i}^{\infty}$ values over the temperature interval $243.15 \mathrm{~K}<\mathrm{T}<555.6 \mathrm{~K}$ for 268 solutes and 692 solvents. The most-reported temperature of $\gamma_{i}^{\infty}$ is $298.15 \mathrm{~K}$, although this is only $5.4 \%$ of all data points in our database. Although several methods for the determination of $\gamma_{i}^{\infty}$ are known ${ }^{10-18}$, no distinction was made between the originally applied experimental method of measurement in this evaluation process.

The algorithm detects whether $\gamma_{i}^{\infty}$ was reported at $298.15 \mathrm{~K}$. For proper data analysis of available data in open literature it is essential to include data ac- 
curacy properly. If only a single $\gamma_{i}^{\infty}$ was reported at $298.15 \mathrm{~K}$, an error of $5 \%$ was assumed, in line with reported typical experimental error margins of $1-6 \% .{ }^{11,36,37}$ When multiple data points were reported, the average value and the standard deviation was determined, which could not be lower than $5 \%$, as this is the accuracy of a single data point. When no data was available at $298.15 \mathrm{~K}$, but data at other temperatures were available, the infinite dilution dissolution enthalpy $\left(\Delta H_{i}^{\infty}\right)$ and entropy $\left(\Delta S_{i}^{\infty}\right)$ were calculated for systems with data at different (at least 3) temperatures and a minimal temperature difference of $20 \mathrm{~K}$ by performing a non-linear last square minimization $^{38}$ routine in combination with the Van ' $t$ Hoff equation (Equation 3.1). A temperature-independent $\Delta H_{i}^{\infty}$ and $\Delta S_{i}^{\infty}$ were assumed. This is generally a good approximation, although this may be invalid for aqueous or complexing systems. This limitation can be surpassed by taking into consideration the changes in heat capacity 39,40 , this was however not included here as it required additional data.

$$
\ln \gamma_{i}^{\infty}=\frac{\Delta H_{i}^{\infty}}{R T}-\frac{\Delta S_{i}^{\infty}}{R}
$$

The average of multiple $\gamma_{i}^{\infty}$ at $298.15 \mathrm{~K}$ was preferred over the $\gamma_{i}^{\infty}$ obtained from the Van ' $t$ Hoff correlation. Generally, this is can only be statistically justified by large data sets, still this is done as this is the most straight-forward method of including all data-points. Using the algorithm, the amount of data point at $298.15 \mathrm{~K}$ increases from $5.4 \%$ of all data points to $23.5 \%$ of the reported solute-solvent combinations within an accuracy of 5\%.

\subsection{Mapping solute $\gamma_{i}^{\infty}$ confidence intervals for solvent families}

Rather than considering a single solvent in a solvent pre-screening, valuable insight can be gained by mapping the $\gamma_{i}^{\infty}$ for a family of solvents, and to plot the $\gamma_{i}^{\infty}$ confidence interval as a function of the molar weight. A similar approach was also done by Pierotti et al. ${ }^{31}$ which used the number of carbon atoms. This was done for all five solutes investigated in this study, and for a range of solvent families. In this subsection, we elaborate on the approach for n-hexane in alcohols, see Figure 3.2, as an example of the data analysis 


\section{LITERATURE REVIEW AND VISUALISATION}

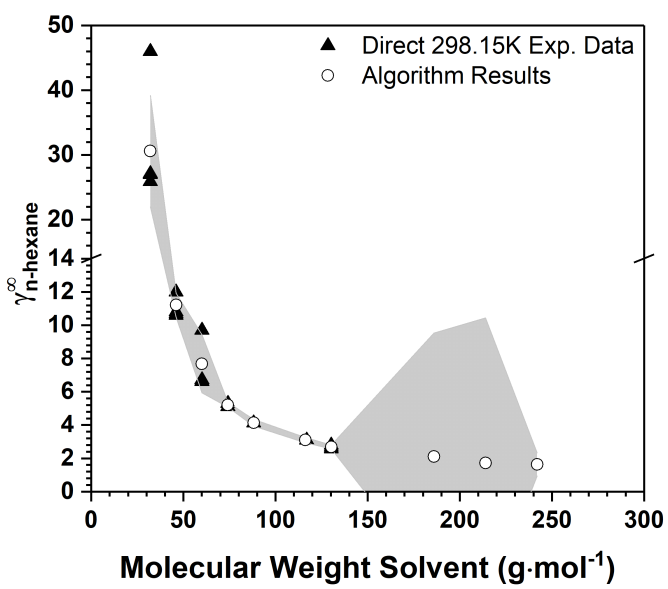

Figure 3.2: The infinite dilution activity coefficient of $n$-hexane $\left(\gamma_{n \text {-hexane }}^{\infty}\right)$ in various alcohol solvents as a function of the molecular weight of the solvent. The experimental values ${ }^{41-49,63-71}$ are depicted as well as, and tableted in Table 3.1.

\begin{tabular}{|l|l|l|l|l|}
\hline \multirow{2}{*}{ Alcohol $\left(\mathrm{C}_{n}\right)$} & \multicolumn{2}{|c|}{$\gamma_{i}^{\infty}(298.15 \mathrm{~K})$} & $\Delta H_{i}^{\infty}$ & $\Delta S_{i}^{\infty}$ \\
\cline { 2 - 5 } & Exp. (range $; \mathrm{nr})$ & Algorithm & $\left(\mathrm{kJ} \cdot \mathrm{mol}^{-1}\right)$ & $\left(\mathrm{J} \cdot \mathrm{mol}^{-1} \cdot \mathrm{K}^{-1}\right)$ \\
\hline $\mathrm{C}_{1}$ & $25.9-46.0 ; 5$ & $30.6 \pm 8.61$ & $16.3 \pm 5.24$ & $27.8 \pm 16.9$ \\
\hline $\mathrm{C}_{2}$ & $10.6-12.0 ; 5$ & $11.2 \pm 0.72$ & $6.45 \pm 0.91$ & $1.39 \pm 2.9$ \\
\hline $\mathrm{C}_{3}$ & $6.73-9.70 ; 3$ & $7.68 \pm 1.75$ & $-0.30 \pm 4.65$ & $-17.8 \pm 15.0$ \\
\hline $\mathrm{C}_{4}$ & $5.12-5.31 ; 3$ & $5.21 \pm 0.14$ & $0.02 \pm 1.55$ & $-13.4 \pm 4.99$ \\
\hline $\mathrm{C}_{5}$ & $4.14 ; 1$ & $4.14 \pm 0.21$ & n.a. & n.a. \\
\hline $\mathrm{C}_{7}$ & $3.07-3.10 ; 2$ & $3.10 \pm 0.15$ & n.a. & n.a. \\
\hline $\mathrm{C}_{8}$ & $2.58-2.80 ; 5$ & $2.68 \pm 0.11$ & $0.63 \pm 1.05$ & $-6.04 \pm 3.45$ \\
\hline $\mathrm{C}_{12}$ & n.a. & $2.11 \pm 7.41$ & $-0.63 \pm 1.90$ & $-4.12 \pm 6.03$ \\
\hline $\mathrm{C}_{14}$ & n.a. & $1.71 \pm 8.72$ & $0.09 \pm 2.36$ & $-4.46 \pm 7.09$ \\
\hline $\mathrm{C}_{16}$ & n.a. & $1.63 \pm 0.70$ & $0.62 \pm 0.48$ & $-1.99 \pm 1.33$ \\
\hline $\mathrm{C}_{18}$ & n.a. & $1.26 \pm 2 \cdot 10^{3}$ & $2.55 \pm 9.5$ & $6.66 \pm 27.8$ \\
\hline
\end{tabular}

Table 3.1: The infinite dilution activity coefficient of $n$-hexane in various linear saturated alcohol solvents as function of the molecular weight of the solvent. The experimental values ${ }^{41-49,63-71}$ are depicted as well as the $\gamma_{i}^{\infty}$, dissolution enthalpy $\left(\Delta H_{i}^{\infty}\right)$ and dissolution entropy $\left(\Delta S_{i}^{\infty}\right)$ values generated by the data handling algorithm. 
algorithm. The $\gamma_{i}^{\infty}$ at $298.15 \mathrm{~K}$ of $\mathrm{n}$-hexane in 10 different normal alcohols are published in 9 different papers. ${ }^{41-49}$ Nevertheless, additional experimental data is available at different temperatures. ${ }^{18,50-62}$

The Van 't Hoff fitting algorithm resulted in an extension of the known $\gamma_{i}^{\infty}$ at $298.15 \mathrm{~K}$ by 4 normal alcohols, n-dodecanol $\left(\mathrm{C}_{12}\right)$, n-tetradecanol $\left(\mathrm{C}_{14}\right), \mathrm{n}$ hexadecanol $\left(\mathrm{C}_{16}\right)$ and n-octadecanol $\left(\mathrm{C}_{18}\right)$ which fall precisely in the expected trend. Though fitting inaccuracies can cause significant errors, of which only $\mathrm{n}$-hexadecanol $\left(\mathrm{C}_{16}\right)$ with an $\gamma_{n \text {-hexane }}^{\infty}$ of $1.63 \pm 0.70$ is reasonably accurate. For methanol it is seen that based on five data points, the average $\gamma_{n \text {-hexane }}^{\infty}$ is 30.6 and the upper confidence limit is 39.2 , indeed one of the five reported data points even lies outside the confidence interval. For these trends, isomers are not included. Similarly, for all solutes for a range of solvent families, the $\gamma_{i}^{\infty}$ confidence intervals were calculated and plotted in Figure 3.3. For $\gamma_{i}^{\infty}$ with too large error margins, the data have been excluded as they may be unreliable.

\subsubsection{Influence of Molecular Structure on the $\gamma_{i}^{\infty}$}

A method to classify groups of molecules is by differentiating all potential solvents by their functional groups, or moieties. These groups of molecules will be referred to as a solvent family. In the first section (3.3.1.1), the focus is on molecules, which in essence are all potential solvents, which have either a single functional group or no functionality (saturated hydrocarbons) and are nonionic species. This allows for a thorough analysis of the effect of both the functional group and the molecular size on the $\gamma_{i}^{\infty}$ of the five aforementioned molecules. In the second section (3.3.1.2), the analysis is extended towards ionic liquids (ILs). These ionic species are characterized by their ionic nature, but can also contain functional groups. The additional effect of ionic interactions of both the anion and cation will therefore be discussed in this section.

\subsubsection{Molecular Solvents}

For solvent families, the $\gamma_{i}^{\infty}$ of each of the five molecules (that were introduced in Figure 3.1) is plotted against the molecular weight of the solvent in Figure 3.3. A similar approach was also applied by Pierotti et al. ${ }^{31}$ who used the number of carbon atoms instead of molecular weight. We have converted 
the available correlations proposed by Pierotti et al. ${ }^{31}$ from carbon number to molecular weight for systems evaluated by us. The results can be seen in Figure 3.3 where four of the converted Pierotti correlations (for n-hexane in ketone solvents, ethanol in alkane solvents, and acetone in alcohol and alkane solvents, respectively) are shown. The molecular weight of the solvent was chosen as the parameter to display the variation within the families. In this case, maintaining a single moiety and increasing the hydrocarbon backbone in a family results in a polarity decrease of the solvent. Therefore, the impact of the London dispersion forces increases with increasing molecular weight. These dispersion forces will reduce the impact of intermolecular interactions associated with specific functional groups, and accordingly limit the impact of these interactions on the $\gamma_{i}^{\infty}$.
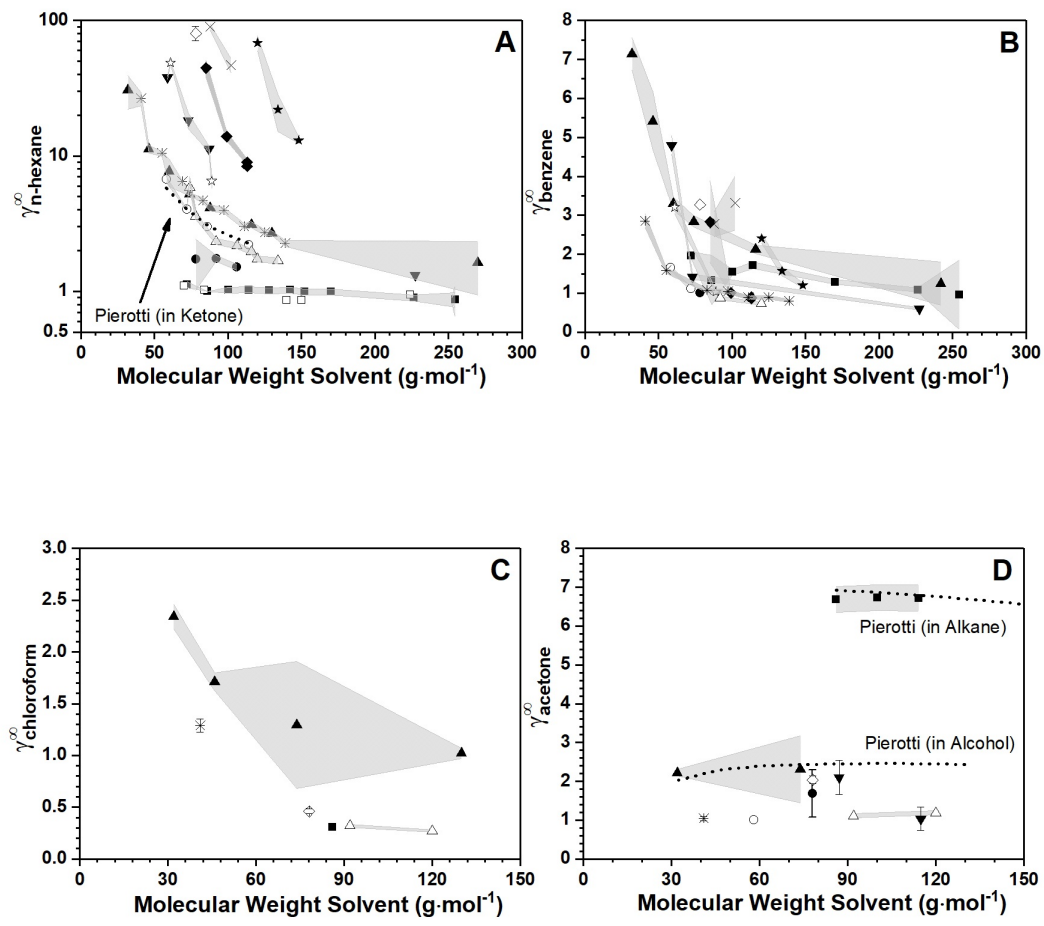


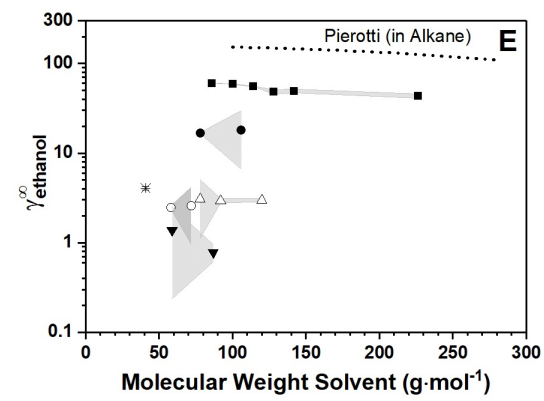

- Alkane $\square$ Alkene

- Aromatic Ketone

- Alcohol $\triangle$ Ester

$\nabla$ Chloro $\quad \nabla$ Amide $(\mathrm{L})$

- Amide (C) $\diamond$ Sulfoxide

$\star$ Sulfone (C) मs Nitro

Carbonate (C) * Nitrile

..... Mathematical descriptions of Pierotti et al.

Figure 3.3: The infinite dilution activity coefficient of (A) n-hexane, (B) benzene, (C) chloroform, (D) acetone and (E) ethanol as function of the molecular weight of the solvent. Homologue series of solvents having no or a single functional group. Within the legend, cyclic solvents are indicated with $(C)$, and linear amides are specifically noted with $(L)$. Additionally, the trends predicted by Pierotti et al. ${ }^{31}$ are included.

In Figure 3.3, it can be seen that a declining effect in $\gamma_{i}^{\infty}$ for an increase in solvent molecular weight for $n$-hexane, benzene and chloroform in several solvent families, whereas for acetone and ethanol another effect is visible. The significant observed decline is associated with the most dissimilar solventsolute combination, as well as for the lightest solvents. The increased hydrocarbon $\left(-\mathrm{CH}_{2}\right)$ fraction in heavier solvents causes the mitigation of the nonideality. For acetone and ethanol the trend is seen to be largely independent of the hydrocarbon fraction of the solvent, indicating that the non-ideality is not mitigated by additional hydrocarbon groups.

The relative extent of this effect can be related to the overall apolar character of the solute (see the electron density profiles in Figure 3.1), which is most significant for $\mathrm{n}$-hexane, having an almost absent multipole moment, while benzene has a significant quadrupole moment, and chloroform with its dipole moment shows the smallest impact. The effect of the solvent molecular weight on the $\gamma_{i}^{\infty}$ for ethanol and acetone is even smaller.

For these solutes, the non-ideal behavior is predominately characterized by dipole and hydrogen bond interactions, though dispersive interactions are still omnipresent. ${ }^{72}$ Several solvent families and solute combinations, for in- 
stance, chloroform in esters, show a net attractive interaction, $\left(\gamma_{\text {chloroform }}^{\infty}<1\right)$, which intensifies with the increasing molecular weight of the solvent. This may be due to the fact, that the liquid ester structure is stabilized by dipole interactions. These interactions become less pronounced as the hydrocarbon fraction is increased. As the solvent-solvent interactions are mitigated, the net attraction of the chloroform is enhanced which results in a lower $\gamma_{\text {chloroform }}^{\infty}$

For each compound, the difference between the absolute values of the $\gamma_{i}^{\infty}$ between the solvent families stems from a change in the Gibbs energy caused by the introduction of an infinitely small quantity of the solute molecule in the liquid solvent matrix. This change reflects the change in the sum of all interactions in the system (interactions between the solvent and solute and the interactions between the solvent molecules). The stability of the liquid structure of the solvent changes due to the changed interactions upon introduction of the solute, and is, therefore, an important aspect in understanding the overall behavior of mixtures. ${ }^{72}$ A highly stable liquid solvent structure can be induced by hydrogen bonds, i.e. in amides ${ }^{73,74}$ and alcohols ${ }^{74-77}$, or by strong dipole-dipole interactions, i.e. with dimethylsulfoxide ${ }^{78}$ or nitromethane. ${ }^{79}$ The relative stability of the liquid structures can differ, as the $\mathrm{O}-\mathrm{H} \cdots \mathrm{O}$ hydrogen bond in alcohols are stronger than the $\mathrm{N}-H \cdots O$ and $N-H \cdots N$ hydrogen bonds possibly present in amides. ${ }^{80}$

The combined effect of the dispersive, multipole and hydrogen bonding interactions results in the non-ideality observed in Figure 3.3. n-Hexane cannot form hydrogen bonds, is neutrally charged and lacks a significant dipole moment. Therefore, solvents with a small hydrocarbon backbone and a significant electronegative moiety, such as sulfones, amides and carbonates, induce the most significant $\gamma_{n \text {-hexane }}^{\infty}$, see Figure 3.3A. The highest activity coefficient corresponds to the most intense net repulsive interaction. Also, it can be seen that the trend of Pierotti et al. ${ }^{31}$ for alkanes (in this case $n$-hexane) in ketones closely follows the visualization. In Figure 3.3B, it can be seen that less severe net repulsive interactions are induced for benzene, due to the mitigating effect of a slightly electronegative region induced by the quadruple moment of the $\pi$-ring which allows multipole interactions with solvent moieties. Small alcohols which have a highly structured liquid structure through hydrogen bonding ${ }^{74-77}$, in which benzene is unable to partake, induce the largest $\gamma_{\text {benzene }}^{\infty}$. 
Chloroform has a strong dipolar character with relatively large electronegative chlorine atoms, which withdraw the electron from the remaining proton, hence creating an electropositive region. These halogen atoms can participate in dipole interactions and can also form hydrogen bonds, although these bonds are less strong than oxygen- or nitrogen-based bonds. ${ }^{81}$ These interactions (see Figure 3.3C) induce a net attractive interaction with amides, ${ }^{82}$ resulting in a $\gamma_{\text {chloroform }}^{\infty}$ lower than unity, as explained earlier. Similarly, dissolving a halogenated solute in solvents with a considerable dipole moment such as esters, dimethylsulfoxide and ketones is energetically favorable. Solvents lacking a dipole moment, such as alkanes, induce net repulsive interactions towards the electropositive proton. Furthermore, strongly hydrogen bonding solvents, including alcohols, induce a net repulsion as well since the hydrogen bond strength of the chloroform is lower than that of the alcohols themselves.

Acetone has a significant dipole moment and is solely a hydrogen bond acceptor, indicated by the highly electronegative oxygen. In Figure 3.3D it can be seen that most solvent families are almost indifferent to include acetone in their liquid structure and therefore induce either a $\gamma_{\text {acetone }}^{\infty}$ of around unity or slightly above. Acetone is however repelled by alkane solvents due to the ineptness of these solvents to accommodate the strong dipole moment of acetone in their liquid structure. The results for acetone in alkane solvents and in alcohol solvents reported in this study are also in these cases in line with results of Pierotti et al. ${ }^{31}$ (see Figure 3.3D).

Ethanol can either accept, due to a strong electronegative region, or donate, due to a strong electropositive region, hydrogen bonds and therefore has a strong hydrogen bonding network. This results in a highly stable and ordered liquid structure for pure ethanol. ${ }^{83}$ The relatively small alcohol with relatively polar areas within the molecule is therefore easily repelled by apolar solvents as can be seen in Figure 3.3E, where significant $\gamma_{\text {ethanol }}^{\infty}$ are induced by apolar solvents. Other protic polar solvents, such as amides ${ }^{73,74}$, allow interactions between the dipole and the hydrogen bonding capability of the ethanol. Although ethanol will disturb the liquid solvent structure, it can be accommodated hence the induced $\gamma_{\text {ethanol }}^{\infty}$ is around or even below unity. The 
results for ethanol in alkane solvents obtained in this study and the results of Pierotti et al. ${ }^{31}$ both show strong repulsion of the ethanol by the alkanes, however, reported $\gamma_{\text {ethanol }}^{\infty}$ differ more strongly than the maximum deviation of $7.5 \%$ reported by Pierotti et al. ${ }^{31}$ (see Figure 3.3E).

Summarizing, Figure 3.3 gives an overview of the $\gamma_{i}^{\infty}$ of the five investigated molecules in various solvent families. It enables immediate comparison of the effect different functional groups have on the $\gamma_{i}^{\infty}$. Additionally, if a particular $\gamma_{i}^{\infty}$ is targeted, the observed trends allow a pre-selection of the required functional group and molecular weight of the solvent. The SES holds $\gamma_{i}^{\infty}$ of many other solutes and therefore these analyses can be extended to other solutes and solvents. In the next section, the discussion is extended towards ionic interactions by mapping the effect of various cations and anions on the same five example molecules.

\subsubsection{Ionic Liquids (ILs)}

Regularly, ILs are named green solvents due to the negligible vapor pressure. ${ }^{84}$ Although the classification as green solvents needs to be used with care as some ILs are much less environmentally benign than others, ${ }^{85}$ ILs certainly form a solvent class that is of interest to fluid separation scientists and technologists. The flexibility of independently changing either the cation or anion gives a vast amount of possible ILs which can be tuned to a specific separation. For this reason, ILs are also called designer solvents. ${ }^{86}$ The influence of the cation structure on the $\gamma_{i}^{\infty}$ is discussed in subsubsection 3.3.1.3, while the influence of the anion structure on the $\gamma_{i}^{\infty}$ is discussed in subsubsection 3.3.1.4.

\subsubsection{Cations}

To fairly compare cations of different natures, cations with equal combined lengths of the alkyl tails attached to the central cationic structure were studied, see Table 3.2. In total ten different central cation structures combined with the bis(trifluorosulfonyl)-imide anion $\left(\mathrm{NT}_{2}^{-}\right)$have been reviewed.

More specifically, the $\gamma_{i}^{\infty}$ of the five solutes are evaluated for ILs with cations with a methyl and a butyl hydrocarbon tails except for the 1,2,3-tris(diethylamino)cyclopropenylium [TDC] $]^{+}$and methyl-1,3,5-triazabicyclo[4.4.0]dec-5-ene 


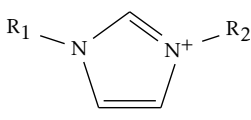

(dialkyl-)Imidazolium $\left[R_{1} R_{2} I M\right]^{+}$

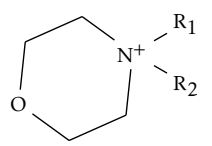

(dialkyl-)Morpholinium $\left[R_{1} R_{2} \text { Mor }\right]^{+}$

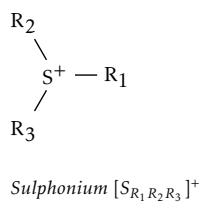

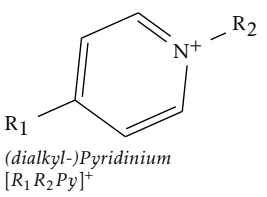

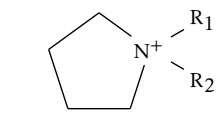

(dialkyl-)Pyrrolidinium $\left[R_{1} R_{2} \text { Pyr }\right]^{+}$<smiles>[R1][N+]([R1])([R1])[R3]</smiles>

Ammonium $\left[N_{R_{1} R_{2} R_{3} R_{4}}\right]^{+}$

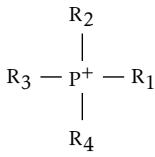

Phosphonium

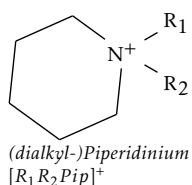

$\left[P_{R_{1}} R_{2} R_{3} R_{4}\right]^{+}$

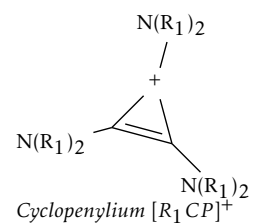

Table 3.2: The ten classes of cations (in combination with the bis(trifluorosulfonyl)-imide anion) have been included in the evaluation concerning the $\gamma_{i}^{\infty}$ of all solutes.

$[\mathrm{MTBDH}]^{+}$cations, where the alkyl tails do not exactly match. The comparison is displayed in Figure 3.4 .

The morpholinium [BMMor $]^{+}$cation appears to induce a slightly larger $\gamma_{n \text {-hexane }}^{\infty}$ than the other cations. An effect may be induced by the distinct negative charge on the oxygen atom. The presence of a distinct localized negative charge in an overall positively charged cation creates the possibility of selfassociating behavior, ${ }^{87}$ which enhances the liquid structure of the ILs. This can for instance be seen from a relatively high morpholinium ILs viscosity as compared to other ILs. ${ }^{88}$ Consequently, larger $\gamma_{i}^{\infty}$ are induced for solutes that cannot participate in (self-)associative interactions that stabilize the (ionic-) liquid structure. [TDC $]^{+}$seems to induce a smaller $\gamma_{n \text {-hexane, }}^{\infty}$ although the accuracy range for obtained $\gamma_{n \text {-hexane }}^{\infty}$ for several ILs is relatively large and the 
$\gamma_{n-h e x a n e}^{\infty}$ value falls within this range. This seemingly low value might be due to not only the larger amount of alkyl tails, but also the delocalized charge density over all three carbon atoms. ${ }^{89}$ The $\gamma_{i}^{\infty}$ of benzene, chloroform and acetone show net attractive interactions independent of cationic nature. This indicates significant ion-multipole interactions, ${ }^{90}$ because net repulsive interactions were seen in molecular solvents.
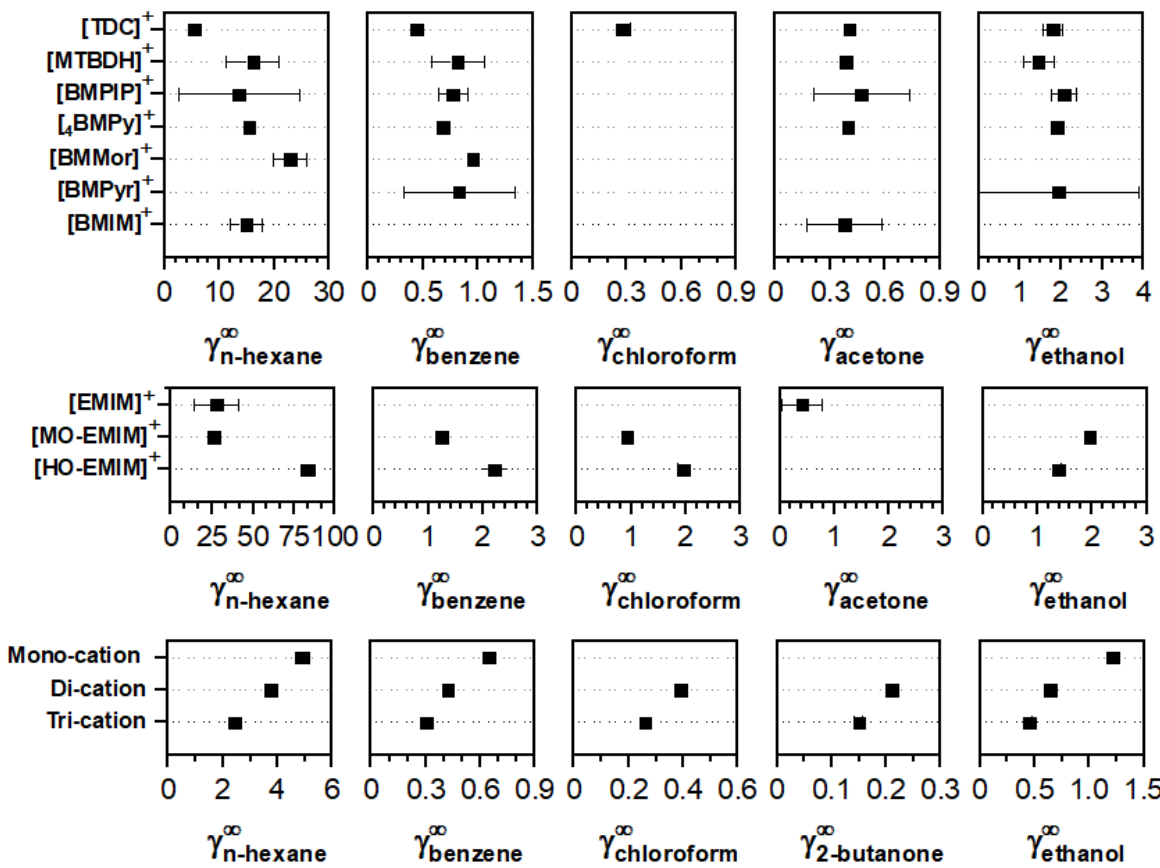

$\begin{array}{llllll}0 & 0.3 & 0.6 & 0.90 & 0\end{array}$

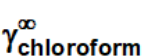

$\gamma_{2 \text {-butanone }}^{\infty}$

$\gamma_{\text {ethanol }}^{\infty}$

Figure 3.4: The $\gamma_{i}^{\infty}$ of (left to right) n-hexane, benzene, chloroform, acetone and ethanol for thirteen different cations from nine classes. Additionally, 3 functionalized cations and 2 multivalent cations are assessed. All cations are coupled with a (or multiple) bis(trifluoromethanesulfonyl)imide [NTf $]_{2}^{-}$anion(s) at 298.15K.The values of the multifunctional cations are at $323.15 \mathrm{~K}$.

Ethanol shows a $\gamma_{i}^{\infty}>1$, even though it does exhibit a dipole moment. An explanation for this observation is that ethanol interacts predominately through 
hydrogen bonding, whereas ILs have stronger internal ionic interactions (approx. 300-400 kJ.mol ${ }^{-1}$ ). ${ }^{91,92}$ An IL needs to give up (partly) the ionic interactions to accept a hydrogen bond of ethanol, which is less favorable, resulting in a net negative interaction. Consequently, apolar solutes and strongly hydrogen bonding solutes show a $\gamma_{i}^{\infty}>1$, whereas polar molecules with no hydrogen bonding donation ability show a $\gamma_{i}^{\infty}<1$.

Various functionalizations of the alkyl chain on the cation have been reported, e.g. by adding a chlorine ${ }^{93}$, silicon ${ }^{94}$, ether ${ }^{95}$, cyano ${ }^{96-98}$, alcohol ${ }^{98-100}$, boronic acid ${ }^{101}$ or sulfone ${ }^{102}$ group. Unfortunately, is was not possible to compare all functionalizations at the same conditions. Yet, as can be seen in Figure 3.4, the etherification of the alkyl chain appears to have an insignificant effect concerning the $\gamma_{i}^{\infty}$, as the $\gamma_{n \text {-hexane }}^{\infty}$ for $[\mathrm{EMIM}]^{+}\left[\mathrm{NTf}_{2}\right]^{-}$and $[\mathrm{MO}-\mathrm{EMIM}]^{+}\left[\mathrm{NTf}_{2}\right]^{-}$are $27.9 \pm 13.6^{\varkappa}$ and $25.9 \pm 1.29^{\varkappa}$, respectively, although it is effective in reducing the viscosity of the IL. ${ }^{103}$ The addition of an alcohol moiety, such as in $[\mathrm{HO}-\mathrm{EMIM}]^{+}\left[\mathrm{NTf}_{2}\right]^{-}$, does have a significant effect on the $\gamma_{i}^{\infty}$, as it elevates the $\gamma_{n-h e x a n e}^{\infty}$ from $27.9 \pm 13.6^{\varkappa}$ to $83.6 \pm 4.18^{\varkappa}$, and appears to lower the $\gamma_{\text {ethanol }}^{\infty}$ from $1.96 \pm 0.10^{\varkappa}$ to $1.38 \pm 0.07^{\varkappa}$ in comparison to the functionalized $[\mathrm{MO}-\mathrm{EMIM}]^{+}\left[\mathrm{NTf}_{2}\right]^{-}$. The enhanced polarity of the alcoholfunctionalized IL and the associated solvent-to-solvent hydrogen bond formation causes an increase in $\gamma_{i}^{\infty}$ of the non-hydrogen bonding solutes, whereas ethanol can take part in the hydrogen bond network, resulting in a lower $\gamma_{\text {ethanol }}^{\infty}$

Combining these results with all trends observed in section 3.3.1.1, enables a better insight in the way that the $\gamma_{i}^{\infty}$ adapts to a structural cation change. The addition of other highly polar moieties, such as cyano- ${ }^{96-98}$, boronic acid- 101 or sulfone- ${ }^{102}$ groups, will most likely elevate the $\gamma_{i}^{\infty}$ for apolar and slightly polar hydrocarbons. These functionalizations may however lower the $\gamma_{i}^{\infty}$ for protic polar molecules, such as ethanol, compared to unfunctionalized ILs. Furthermore, elongation of the length of the alkyl tails will probably lower the $\gamma_{i}^{\infty}$ for apolar and slightly polar hydrocarbon solutes. An estimation of the relative effect of the functional group addition may be guided by the trends seen in Figure 3.4, where the $\gamma_{i}^{\infty}$ of numerous solvent families are compared.

As an additional structural adaption possibility, multivalent cations have been 
introduced by Mutelet et al. ${ }^{104-106}$ and Heydar et al. ${ }^{107}$ as a novel extension to the ILs. Direct comparison between various multivalent ILs is difficult due to the additional molecular structure combining the local positively charged (monovalent) centers. However, the combined effect of the bridging structure and molar ratio change of the anions and (multivalent) cations in combination with the $\left[N T f_{2}\right]^{-}$anion(s) appears to decrease the $\gamma_{i}^{\infty}$ of all solutes, as can be seen in Figure 3.4. When multiple solutes in a mixture show a similar reduction in $\gamma_{i}^{\infty}$, this implies that the capacity is increased while maintaining the selectivity. ${ }^{108}$ This approach may therefore be a way to counteract a low solute capacity in an IL due to high $\gamma_{i}^{\infty}$.

Lastly, in Figure 3.5, ammonium, phosphonium and sulphonium cations are assessed. These cations were taken separately, due to the fact a large variety of these ILs are described in literature. ${ }^{95,109-120}$ It can be seen that the $\gamma_{i}^{\infty}$ of n-hexane, benzene and chloroform decreases as the molecular weight of the ammonium, phosphonium and sulphonium cations increase. Exactly, the same trend is observed for molecular solvents in section 3.3.1.1, indicating that the central nitrogen, phosphorus or sulfur atom acts like a moiety and becomes insignificant at high molecular weights of the solvent. Still, understanding the effect of the central atom is required when a well-consideration choice between these ILs is required.

Carvalho et al. ${ }^{112}$ discussed the effect of the central atom in these cations and determined with molecular simulations that the smaller nitrogen atom has a higher electron density and therefore is more strongly polarized than the larger phosphonium atom. This causes a stronger cation-anion interaction
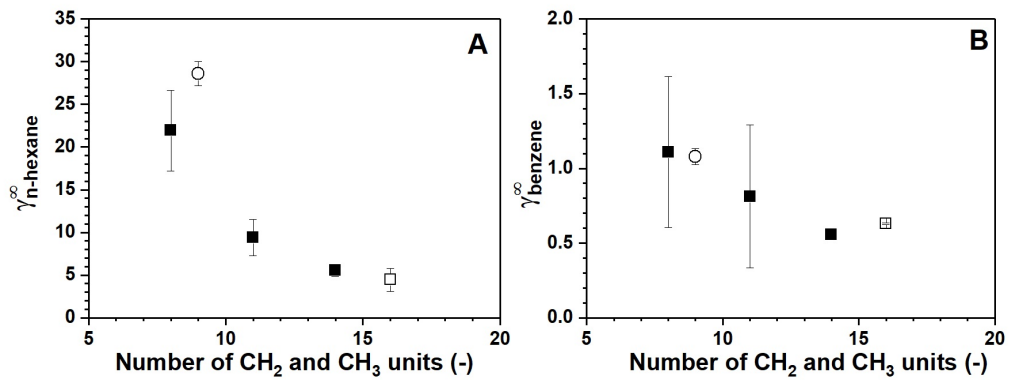

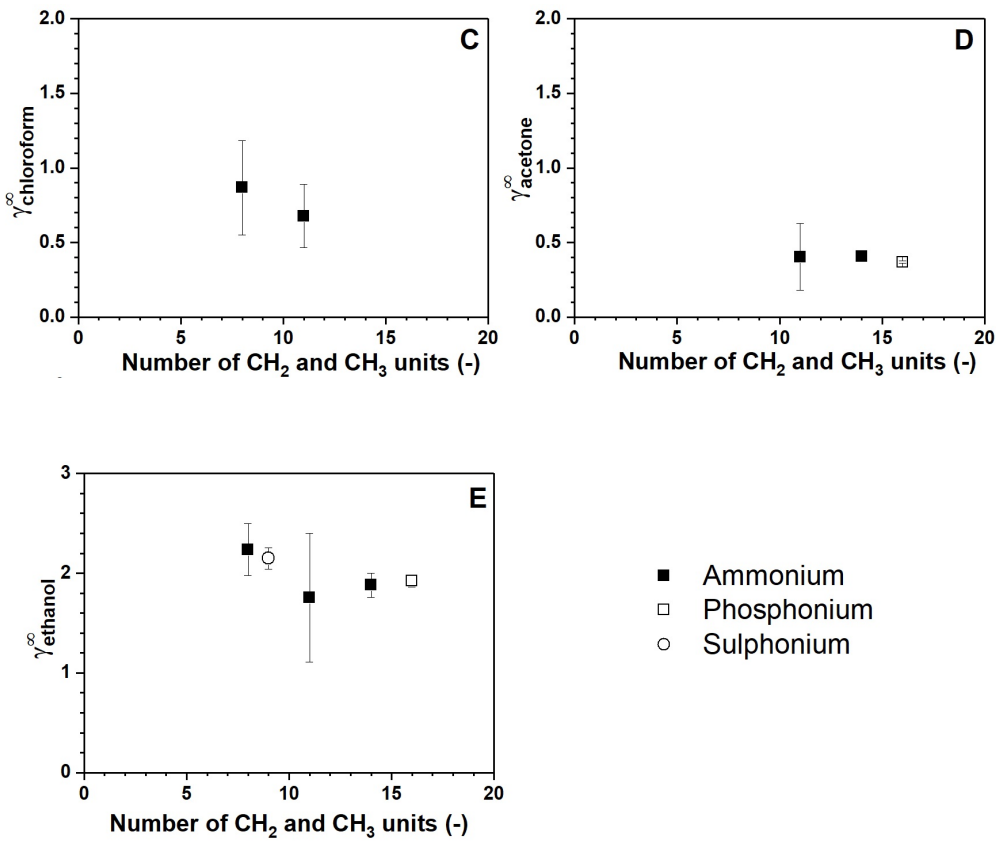

- Ammonium

- Phosphonium

- Sulphonium

Figure 3.5: The comparison of the $\gamma_{i}^{\infty}$ of $(A)$ n-hexane, (B) benzene, (C) chloroform, (D) acetone and (E) ethanol in ammonium, phosphonium and sulphonium ionic liquids with a variation of functionalized alkyl tails with a bis(trifluoromethanesulfonyl)imide $\left[\mathrm{NTf}_{2}\right]^{-}$ anion at $298.15 \mathrm{~K}$.

and a more rigid liquid structure than the phosphonium equivalent, which makes the anion less mobile. The higher mobility of the anions in phosphonium ILs induces more intermolecular interactions with the solutes and consequently a larger $\gamma_{i}^{\infty}$ for the non-polar solutes and slightly lower $\gamma_{i}^{\infty}$ for polar solutes. This effect will be more significant at low IL molar weights, otherwise, the intermolecular interactions of the ILs will be dominated by the alkyl tails. The differences observed by Carvalho et al. ${ }^{112}$ are most likely still present in our comparison, even though we could not unequivocally claim this due to the larger imposed error margins.

Following the reasoning of Carvalho et al. ${ }^{112}$, the $\gamma_{i}^{\infty}$ decrease observed for the apolar solutes (n-hexane and benzene) in multivalent cation ILs, should be caused by less mobility of the anions due to a stronger (multivalent) cation- 
anion interaction and consequently less repulsive interactions. This may be the case, as Shirota et al. ${ }^{121}$ showed that dicationic ILs have a larger density and a stronger surface tension than their monovalent equivalent, which they also attributed to stronger cation-anion interactions for the dicationic ILs. Additionally, the bridging structure between the local positively charged monovalent centers increases the hydrophobic surface of the cation and can also decrease the $\gamma_{i}^{\infty}$ of the apolar solutes.

The $\gamma_{i}^{\infty}$ of the more polar solutes (chloroform, acetone and ethanol) are lower than unity for the monovalent IL, and the presence of multivalent cations in the IL causes a further decrease. This may be explained by a higher anion mobility for the multivalent ion-containing ILs, in line with observations reported by Carvalho et al. ${ }^{112}$ It is reasonable to assume that, through steric hindrance and competitive interactions between the polar solute and the anions, the cation-anion interaction between the $2^{\text {nd }}$ (and $3^{\text {rd }}$ ) anion(s) and the cation in the IL will be less strong when solutes with higher polarity are present in the IL solvent. This consequently causes more anion mobility, which lowers the $\gamma_{i}^{\infty}$ for polar solutes even further. Furthermore, it is reasonable to assume, that the anion mobility for apolar solutes is lower than for polar solutes due to the absence of the competing polar interaction, and in this case the increased hydrophobic character of the bigger multivalent cation containing IL causes the reduction in $\gamma_{i}^{\infty}$ for apolar solutes.

To summarize, most cations show similar interactions with the selected solvent and only when the cations are functionalized the interaction can be changed significantly. Functionalization in the central cationic structure by an electronegative atom or by including a functional group in one of the alkyl tails can change certain $\gamma_{i}^{\infty}$. The functional group choice can be guided by the trends observed in the molecular solvents due to the fact the $\gamma_{i}^{\infty}$ originates from the same underlying intermolecular forces. Increasing the solvent capacity while maintaining the separation selectivity improves the separation process. Since the multivalent cationic ILs did not show a significant viscosity increase, ${ }^{108}$ and reduced $\gamma_{i}^{\infty}$ for all evaluated solutes similarly as compared to monovalent cationic ILs, the use of ILs based on multivalent cations appears to have a high potential for fluid separations. 


\subsubsection{Anions}

As every (liquid) electrolyte is bound to charge neutrality, cations are inseparable from anions. Therefore, in this second section, the effect of the molecular structure of the anion is assessed. The anionic structure can be greatly diverse, although many anions show similarities and are variations around a central atom or functional group. Twenty anions (twelve basic structures with different side groups for some of the structures) in total have been evaluated, as can be seen in Table 3.3.

Various anions can be categorized into groups, having for example a central phosphorous atom or an $-\mathrm{SO}_{3}$ end-group. This highlights the flexibility in the anion choice. Besides the selection of the anion nature, also the length of the alkyl tails can be tuned independently of anion nature. In Figure 3.6, an overview is shown incorporating the combination of twenty anions and six cations. The $\gamma_{i}^{\infty}$ for the solutes in ILs with the same anion and up to six

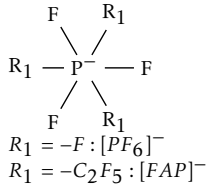

$\mathrm{R}_{1}-\mathrm{O}$

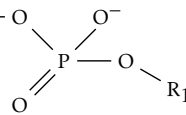

$R_{1}=-\mathrm{C}_{4} \mathrm{H}_{9}$ :

Dibutyl phosphate $[D B P]^{-}$<smiles>[R1]S(=O)(=O)[O-]</smiles>

$R_{1}=-C_{3}:\left[\mathrm{CF}_{3} \mathrm{SO}_{4}\right]^{-}$

$R_{1}=-\mathrm{C}_{6} \mathrm{H}_{4} \mathrm{CH}_{3}:[\mathrm{TOS}]^{-}$

$R_{1}=-\mathrm{OCH}_{3}:\left[\mathrm{MSO}_{4}\right]^{-}$

$R_{1}=-\mathrm{OC}_{8} \mathrm{H}_{19}:\left[\mathrm{OSO}_{4}\right]$

$R_{1}=-\mathrm{O}\left(\mathrm{C}_{2} \mathrm{H}_{4} \mathrm{O}\right)_{2} \mathrm{CH}_{3}$ :

$\left[\mathrm{MDEGSO}_{4}\right]^{-}$

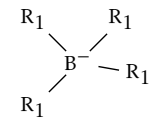

$R_{1}=-F:\left[B F_{4}\right]^{-}$

$R_{1}=-C N:\left[B(C N)_{4}\right]^{-}$

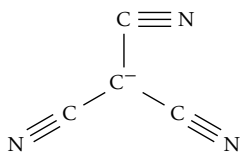

Tricyanomethanide $[T C M]^{-}$

$\mathrm{S}=\mathrm{C}=\mathrm{N}^{-}$

Thiocyanate $[\mathrm{SCN}]^{-}$
$\mathrm{R}_{1}{ }^{-\mathrm{N}^{-}}-\mathrm{R}_{1}$

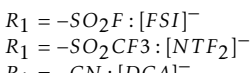

$R_{1}=-S O_{2} C F 3:\left[N T F_{2}\right]$
$R_{1}=-C N:[D C A]^{-}$
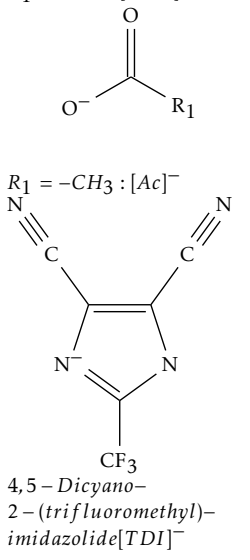


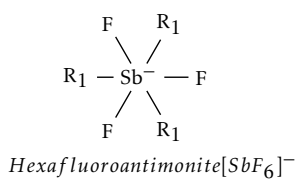

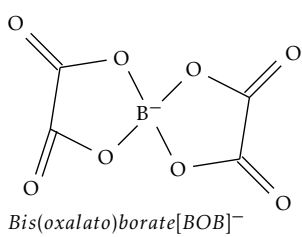

Bis(oxalato)borate $[B O B]^{-}$

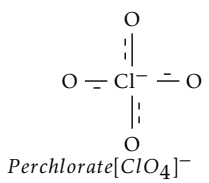

Table 3.3: The twenty anions, presented in twelve anion groups are included in the evaluation concerning the $\gamma_{i}^{\infty}$ of all solutes.

different monovalent cations show insignificant deviations independent of the corresponding anions. This confirms the earlier statement done in subsubsection 3.3.1.2. that monovalent cations without any additional functionalization do not affect the $\gamma_{i}^{\infty}$ significantly as compared to the effect that the anion has on $\gamma_{i}^{\infty}$. Interchanging monovalent cations in an IL will therefore not alter the intermolecular interactions noticeably. This is also implied by Dománska et al. ${ }^{27}$, where they underscore only the effect of the anion and not of the cation.

The largest $\gamma_{n \text {-hexane }}^{\infty}$ is obtained using a small linear anion with a lack of neutral regions and a significant electronegativity ${ }^{122}$, for example thiocyanate $[\mathrm{SCN}]^{-} .27,123,124$ This allows for a highly structured IL with strong anioncation interactions ${ }^{125}$ which induces strong net repulsion to neutral solutes. Anions with increasingly larger neutral regions, e.g. methylsulfate $\left[\mathrm{MSO}_{4}\right]$ and octylsulfate $\left[\mathrm{OSO}_{4}\right]$, mitigates these interactions and allow for a less structured packing, hence lowering the $\gamma_{n \text {-hexane }}^{\infty}{ }^{125}$

The net repulsive behavior of the ILs towards more polar solutes is less significant, due to mitigating Van der Waals interactions. It can be seen that the methylsulfate $\left[\mathrm{MSO}_{4}\right]^{-}$anion induces larger $\gamma_{\text {benzene }}^{\infty}$ and $\gamma_{\text {acetone }}^{\infty}$ than other anions. Lü et al. ${ }^{126}$ show that attractive interactions may occur on the $\mathrm{C}_{2}$ hydrogen adjacent to the sulfate structure, while the overall negative surface repels the negatively charged $\pi$-ring and the double-bonded oxygen of benzene and acetone, respectively. Together, these interactions result in a net repulsion.

Although the $\gamma_{\text {chloroform }}^{\infty}$ induced by the $\left[\mathrm{MSO}_{4}\right]^{-}$anion is not reported, it can be seen from the $\gamma_{\text {chloroform }}^{\infty}$ in the $\left[\mathrm{MDEGSO}_{4}\right]^{-}$containing IL that the sulfate 
- $[\mathrm{BMIM}]^{+} \square[\mathrm{BMPyr}]^{+} \circ[\mathrm{BMPIP}]^{+} \star\left[{ }_{\mathrm{n}} \mathrm{BMPy}\right]^{+} \diamond[\mathrm{BMMOR}]^{+} \triangleq[\mathrm{MTBDH}]^{+}$

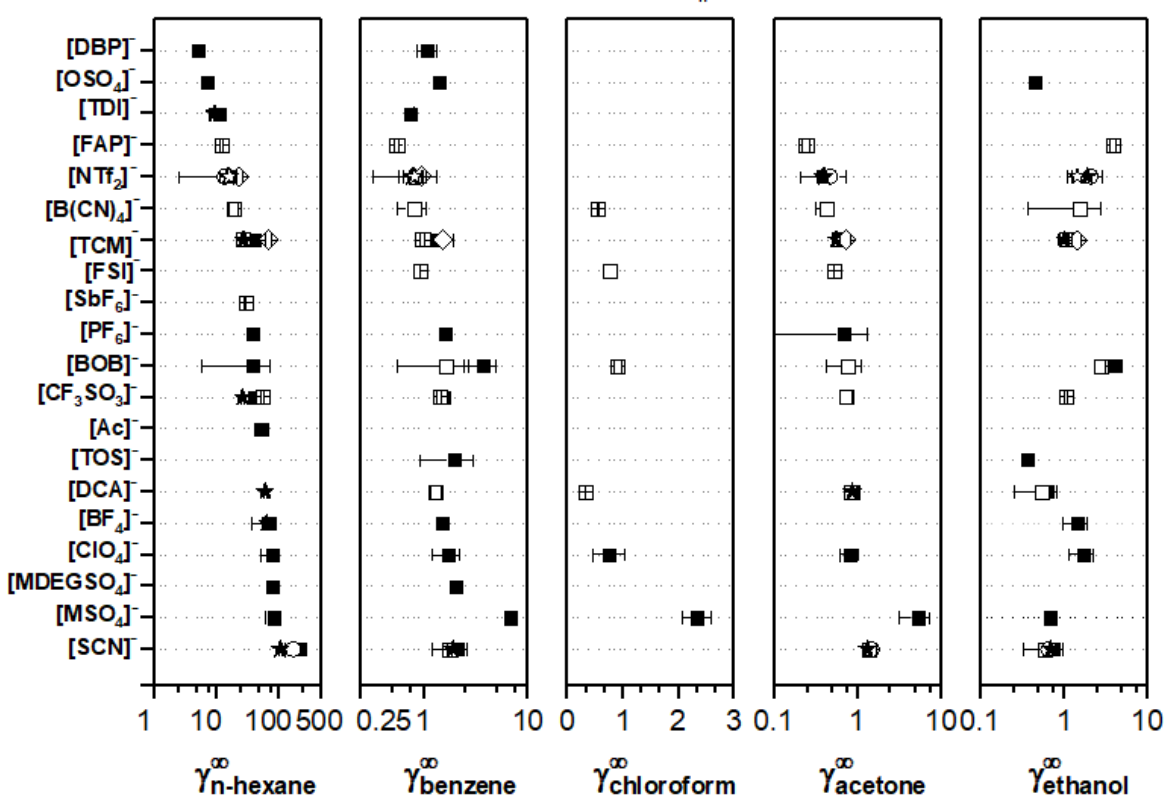

Figure 3.6: The $\gamma_{i}^{\infty}$ of (from left to right) n-hexane, benzene, chloroform, acetone and ethanol for twenty anions at $298.15 \mathrm{~K}$.

group is repulsive towards the chlorinated solute. In the case of ethanol, anions with large neutral regions and a small tendency for hydrogen bonding, such as $[\mathrm{FAP}]^{-127}$, are seen to induce the largest $\gamma_{\text {ethanol }}^{\infty}$. Small anions capable of hydrogen bonding result in a $\gamma_{\text {ethanol }}^{\infty}$ of unity or lower, for example for $[\mathrm{DCA}]^{-}$and $[\mathrm{SCN}]^{-} \cdot{ }^{128,129}$

Based on the observations in this review, two main decisions can be made in the pre-selection of anions in ILs. Both decisions affect the interactions in the ILs. Firstly, the size of the anion affects the packing and the cation-anion interaction intensity within the IL. Secondly, with the choice of the nature of the anion, hydrogen bond behavior can either be enhanced or suppressed. 


\subsection{Conclusion}

An open-source $\gamma_{i}^{\infty}$-database is compiled and presented in section 3.5, containing $77.173 \gamma_{i}^{\infty}$ values for 268 solutes and 692 solvents. From this database, five solutes ( $\mathrm{n}$-hexane, benzene, chloroform, acetone and ethanol) were selected and evaluated in detail in this study. A data analysis algorithm was presented which uses the Van 't Hoff equation to inter- and extrapolate $\gamma_{i}^{\infty}$ values at different conditions to the desired temperature, here $298.15 \mathrm{~K}$.

From the $\gamma_{i}^{\infty}$ of the five evaluated solutes in a wide range of molecular solvents and ionic liquids (ILs) various trends between the molecular solvent structure and the $\gamma_{i}^{\infty}$ were visualized. Using this visual overview, the observed trends within solvent families facilitate the pre-selection of solvents when a particular $\gamma_{i}^{\infty}$ is targeted. This approach can be applied complementary to brute force simulating thousands of potential solvents with simulation software, and helps to better understand and interpret which of the solvents found with such tools perform well. As the obtained $\gamma_{i}^{\infty}$ and observed trends were explained according to the molecular structure of both solute and solvent and the intermolecular interactions they induce.

General conclusions that can be drawn based on the trend visualization are first, that increasing the solvent molecular size can strongly affect the $\gamma_{i}^{\infty}$, especially for solutes with much less intermolecular interaction abilities than the solvent family. This also holds for ionic liquids in which the ionic interactions present an additional type of intermolecular interaction. Second, the ionic liquid section showed the importance of an appropriate anion selection, whereas the nature of the non-functionalized monovalent cation is of less importance. Besides the nature of the anion, also the molecular size of the anion, which can be altered independently from the cation, must be appropriately selected. Third, multivalent cations particularly show interesting potential for use in fluid separations, because ILs containing these cations show overall lower activity coefficients at infinite dilution than their monovalent cation analogs, thus improving the capacity without compromising the selectivity. 


\subsection{Supplementary Excel Sheet}

The actual $\gamma_{i}^{\infty}$ database, attached as the SES, is present under the tab "Raw Data", while all $\gamma_{i}^{\infty}$ used in the manuscript including the results from the data analysis algorithm are present under the tab "Data Treatment". This $\gamma_{i}^{\infty}$ database is available free of charge at https://www.scribd.com/document/492160543/SES-Chapter-3, due to the fact this chapter is not yet published.

\subsection{Nomenclature}

\begin{tabular}{|c|c|c|}
\hline$\gamma_{i}$ & $=$ & Activity Coefficient of compound i \\
\hline & $=$ & Infinite Dilution Activity Coefficient of compound i \\
\hline$\Delta H_{i}^{\infty}$ & $=$ & Infinite Dilution Dissolution Enthalpy of compound i \\
\hline$\Delta S_{i}^{\infty}$ & $=$ & Infinite Dilution Dissolution Entropy of compound i \\
\hline$\varkappa$ & $=$ & $\begin{array}{l}\text { This value is obtained from the data regression method. } \\
\text { (superscript) }\end{array}$ \\
\hline$\left[{ }_{4} B M P y\right]^{+}$ & $=$ & 1-butyl-4-methylpyridinium \\
\hline$[A c]^{-}$ & $=$ & acetate \\
\hline$\left[\mathrm{B}(\mathrm{CN})_{4}\right]^{-}$ & $=$ & tetracyanoborate \\
\hline$\left[B F_{4}\right]^{-}$ & $=$ & tetrafluoroborate \\
\hline$[B M I M]^{+}$ & $=$ & 1-butyl-3-methylimidazolium \\
\hline$[B M M o r]^{+}$ & $=$ & 1-butyl-1-methylmorpholinium \\
\hline$[B M P I P]^{+}$ & $=$ & 1-butyl-1-methylpiperidinium \\
\hline$[B M P y r]^{+}$ & $=$ & 1-butyl-1-methylpyrrolidinium \\
\hline$[B O B]^{-}$ & $=$ & bis(oxalate)borate \\
\hline$\left[\mathrm{CF}_{3} \mathrm{SO}_{3}\right]^{-}$ & $=$ & trifluoromethanesulfonate \\
\hline$\left[\mathrm{ClO}_{4}\right]^{-}$ & $=$ & perchlorate \\
\hline$[D B P]^{-}$ & $=$ & dibutylphosphate \\
\hline$[D C A]^{-}$ & $=$ & dicyanamide \\
\hline$[E M I M]^{+}$ & $=$ & 1-ethyl-3-methylimidazolium \\
\hline$[E M M O R]^{+}$ & $=$ & 1-ethyl-1-methylmorpholinium \\
\hline$[F A P]^{-}$ & $=$ & tris-(perfluoroalkyl)-trifluorophosphate \\
\hline$[F S I]^{-}$ & $=$ & bis(fluorosulfonyl)imide \\
\hline
\end{tabular}




\begin{tabular}{|c|c|}
\hline$[H O-E M I M]^{+}$ & $=1-(2$-hydroxyethyl $)-3$-methylimidazolium \\
\hline$\left[\mathrm{MDEGSO}_{4}\right]^{-}$ & $=2-(2$-methoxyethoxy)ethylsulfate \\
\hline$[M O-E M I M]^{+}$ & $=1-(2$-methoxyethyl $)-3$-methylimidazolium \\
\hline$[M O-E M P I P]^{+}$ & $=1-(2-$ methoxyethyl $)-3$-methylpiperidinium \\
\hline$\left[\mathrm{MSO}_{4}\right]^{-}$ & $=$methylsulfate \\
\hline$[M T B D H]^{+}$ & $=$methyl-1,3,5-triazabicyclo[4.4.0]dec-5-ene \\
\hline$\left[N_{R_{1} R_{2} R_{3} R_{4}}\right]^{+}$ & $=($tetra-alkyl-)ammonium \\
\hline$\left[N T f_{2}\right]^{-}$ & $=$bis(trifluoromethanesulfonyl)imide \\
\hline$[O M I M]^{+}$ & $=1$-octyl-3-methylimidazolium \\
\hline$\left[\mathrm{OSO}_{4}\right]^{-}$ & $=$octylsulfate \\
\hline$\left[\mathrm{PF}_{6}\right]^{-}$ & $=$hexafluorophosphonate \\
\hline$\left[P_{R_{1} R_{2} R_{3} R_{4}}\right]^{+}$ & $=($tetra-alkyl-)phosphonium \\
\hline$\left[R_{1} C D\right]^{+}$ & $=(\mathrm{alkyl})$ cyclopenylium \\
\hline$\left[R_{1} D A B C O\right]^{+}$ & $=($alkyl-)4-diaza[2.2.2]-bicyclooctanium \\
\hline$\left[R_{1} M T B D H\right]^{+}$ & $=($alkyl- $)($alkyl-)guanidinium superbase \\
\hline$\left[R_{1} R_{2} I M\right]^{+}$ & $=($dialkyl-)imidazolium \\
\hline$\left[R_{1} R_{2} \mathrm{Mor}^{+}\right.$ & $=($dialkyl-)morpholinium \\
\hline$\left[R_{1} R_{2} P I P\right]^{+}$ & $=($dialkyl-)piperidinium \\
\hline$\left[{ }_{n} R_{1} R_{2} P y\right]^{+}$ & $=(1$-alkyl-n-alkyl-)pyridinium \\
\hline$\left[R_{1} R_{2} \text { Pyr }\right]^{+}$ & $=($dialkyl-)pyrrolidinium \\
\hline$\left[\mathrm{SbF}_{6}\right]^{-}$ & $=$hexafluoroantimonate \\
\hline$[S C N]^{-}$ & $=$thiocyanaat \\
\hline$\left[S_{R_{1} R_{2} R_{3}}\right]^{+}$ & $=($tri-alkyl-)sulphonium \\
\hline$[T C D]^{+}$ & $=1,2,3$-Tris(diethylamino)-cyclopropenylium \\
\hline$[T C M]^{-}$ & $=$tricyanomethanide \\
\hline$[T D I]^{-}$ & $=4,5$-dicyano-2-(trifluoromethyl)-imidazolium \\
\hline$\left[\mathrm{TOS}^{-}\right.$ & $=$tosylate \\
\hline COSMO-RS & $=$ Conductor like Screening Model for Real Solvents \\
\hline DES's & $=$ Deep Eutectic Solvents \\
\hline -cation & $\begin{array}{l}=1,1^{\prime}-[1,2 \text {-ethanediylbis(oxymethylene) }] \text { bis[3-octyl- } \\
1 \text {-imidazolium }]\end{array}$ \\
\hline & $=$ Ionic Liquids \\
\hline $\mathrm{o}$-cation & $=1$-octyl-3-methylimidazolium or $[O M I M]^{+}$ \\
\hline
\end{tabular}




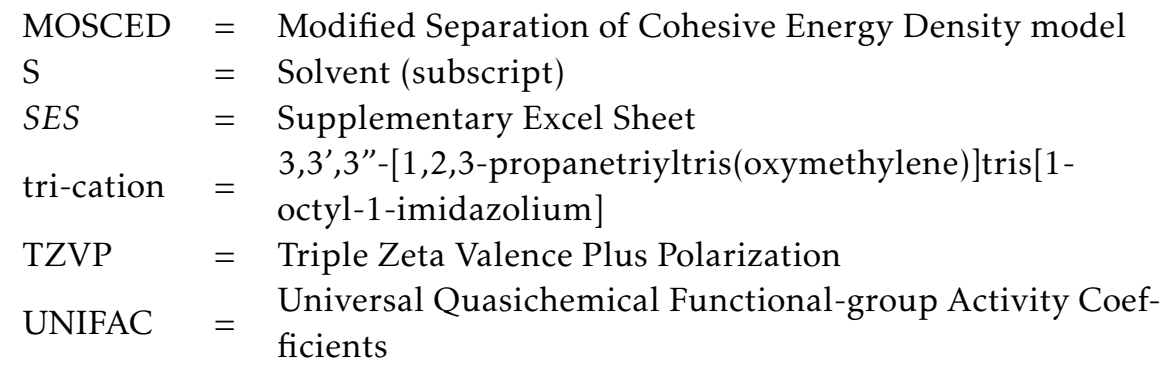

\subsection{References}

[1] A. A. Kiss, J.-P. Lange, B. Schuur, D. W. F. Brilman, A. G. van der Ham, and S. R. Kersten, "Separation technology-making a difference in biorefineries," Biomass Bioenergy, vol. 95, pp. 296-309, 2016.

[2] D. S. Sholl and R. P. Lively, "Seven chemical separations to change the world," Nature, vol. 532, no. 7600, pp. 435-437, 2016.

[3] M. Blahušiak, A. A. Kiss, K. Babic, S. R. Kersten, G. Bargeman, and B. Schuur, "Insights into the selection and design of fluid separation processes," Separation and purification technology, vol. 194, pp. 301-318, 2018.

[4] T. Brouwer and B. Schuur, "Bio-based solvents as entrainers for extractive distillation in aromatic/aliphatic and olefin/paraffin separation," Green Chem., vol. 22, no. 16, pp. 5369-5375, 2020.

[5] M. Krummen, D. Gruber, and J. Gmehling, "Measurement of activity coefficients at infinite dilution in solvent mixtures using the dilutor technique," Industrial \& Engineering Chemistry Research, vol. 39, no. 6, pp. 2114-2123, 2000.

[6] T. Hiak, K. Kurihara, and K. Kojima, "Vapor-liquid equilibria for acetone+ chloroform+ methanol and constituent binary systems at $101.3 \mathrm{kpa}$," Journal of Chemical and Engineering Data, vol. 39, no. 4, pp. 714-719, 1994.

[7] G. N. Lewis, "The law of physico-chemical change," in Proceedings of the American Academy of Arts and Sciences, vol. 37, pp. 49-69, JSTOR, 1901.

[8] P. Alessi, M. Fermeglia, and I. Kikic, "Significance of dilute regions," Fluid Phase Equilib., vol. 70, no. 2-3, pp. 239-250, 1991.

[9] S. Sandler, "Infinite dilution activity coefficients in chemical, environmental and biochemical engineering," Fluid Phase Equilib., vol. 116, no. 1-2, pp. 343-353, 1996.

[10] T. M. Letcher, "Activity coefficients at infinite dilution from gas-liquid chromatography," in Faraday Symposia of the Chemical Society, vol. 15, pp. 103-112, Royal Society of Chemistry, 1980.

[11] J.-C. Lerol, J.-C. Masson, H. Renon, J.-F. Fabries, and H. Sannier, "Accurate measurement of activity coefficient at infinite dilution by inert gas stripping and gas chromatography," Industrial \& Engineering Chemistry Process Design and Development, vol. 16, no. 1, pp. 139-144, 1977.

[12] D. Richon, P. Antoine, and H. Renon, "Infinite dilution activity coefficients of linear and branched alkanes from c1 to c9 in n-hexadecane by inert gas stripping," Industrial \& Engineering Chemistry Process Design and Development, vol. 19, no. 1, pp. 144-147, 1980.

[13] A. Hussam and P. W. Carr, "Rapid and precise method for the measurement of vapor/liquid equilibria by headspace gas chromatography," Anal. Chem., vol. 57, no. 4, pp. 793-801, 1985.

[14] J. Li and P. W. Carr, "Measurement of water-hexadecane partition coefficients by headspace gas chromatography and calculation of limiting activity coefficients in water," Anal. Chem., vol. 65, no. 10, pp. 1443-1450, 1993.

[15] C. A. Eckert and S. R. Sherman, "Measurement and prediction of limiting activity coefficients," Fluid Phase Equilib., vol. 116, no. 1-2, pp. 333-342, 1996.

[16] A. Paolo, F. Maurizio, and K. Ireneo, "A differential static apparatus for the investigation of the infinitely 


\section{LITERATURE REVIEW AND VISUALISATION}

diluted region," Fluid Phase Equilib., vol. 29, pp. 249-256, 1986.

[17] M. Gautreaux Jr and J. Coates, "Activity coefficients at infinite dilution," AIChE J., vol. 1, no. 4, pp. 496500, 1955.

[18] V. Dohnal and I. Horáková, "A new variant of the rayleigh distillation method for the determination of limiting activity coefficients," Fluid Phase Equilib., vol. 68, pp. 173-185, 1991.

[19] V. Dohnal, "14 measurement of limiting activity coefficients using analytical tools," Measurement of the Thermodynamic Properties of Multiple Phases, p. 359, 2005.

[20] A. Fredenslund, R. L. Jones, and J. M. Prausnitz, "Group-contribution estimation of activity coefficients in nonideal liquid mixtures," AIChE J., vol. 21, no. 6, pp. 1086-1099, 1975.

[21] U. Weidlich and J. Gmehling, "A modified unifac model. 1. prediction of vle, he, and. gamma.. infin.," Industrial \& engineering chemistry research, vol. 26, no. 7, pp. 1372-1381, 1987.

[22] B. L. Larsen, P. Rasmussen, and A. Fredenslund, "A modified unifac group-contribution model for prediction of phase equilibria and heats of mixing," Industrial $\mathcal{E}$ engineering chemistry research, vol. 26, no. 11 , pp. 2274-2286, 1987.

[23] M. H. Abraham, "Scales of solute hydrogen-bonding: their construction and application to physicochemical and biochemical processes," Chem. Soc. Rev., vol. 22, no. 2, pp. 73-83, 1993.

[24] J. H. Park and P. W. Carr, "Predictive ability of the mosced and unifac activity coefficient estimation methods," Anal. Chem., vol. 59, no. 21, pp. 2596-2602, 1987.

[25] F. Eckert and A. Klamt, "Fast solvent screening via quantum chemistry: Cosmo-rs approach," AIChE J., vol. 48, no. 2, pp. 369-385, 2002.

[26] T. Brouwer and B. Schuur, "Model performances evaluated for infinite dilution activity coefficients prediction at 298.15 k," Industrial E Engineering Chemistry Research, vol. 58, no. 20, pp. 8903-8914, 2019.

[27] U. Domańska, M. Wlazło, and M. Karpińska, "Activity coefficients at infinite dilution of organic solvents and water in 1-butyl-3-methylimidazolium dicyanamide. a literature review of hexane/hex-1-ene separation," Fluid Phase Equilib., vol. 417, pp. 50-61, 2016.

[28] A. Marciniak, "Influence of cation and anion structure of the ionic liquid on extraction processes based on activity coefficients at infinite dilution. a review," Fluid Phase Equilib., vol. 294, no. 1-2, pp. 213-233, 2010.

[29] A. Heintz, "Recent developments in thermodynamics and thermophysics of non-aqueous mixtures containing ionic liquids. a review," The Journal of Chemical Thermodynamics, vol. 37, no. 6, pp. 525-535, 2005.

[30] V. Dohnal, P. Vrbka, K. Řehák, A. Böhme, and A. Paschke, "Activity coefficients and partial molar excess enthalpies at infinite dilution for four esters in water," Fluid Phase Equilib., vol. 295, no. 2, pp. 194-200, 2010.

[31] G. Pierotti, C. Deal, and E. Derr, "Activity coefficients and molecular structure," Industrial E Engineering Chemistry, vol. 51, no. 1, pp. 95-102, 1959.

[32] S. P. Verevkin, A. Y. Sazonova, A. K. Frolkova, D. H. Zaitsau, I. V. Prikhodko, and C. Held, "Separation performance of biorenewable deep eutectic solvents," Industrial \& Engineering Chemistry Research, vol. 54, no. 13, pp. 3498-3504, 2015.

[33] N. Nkosi, K. Tumba, and S. Ramsuroop, "Measurements of activity coefficient at infinite dilution for organic solutes in tetramethylammonium chloride+ ethylene glycol deep eutectic solvent using gasliquid chromatography," Fluid Phase Equilibria, vol. 462, pp. 31-37, 2018.

[34] N. Nkosi, K. Tumba, and S. Ramsuroop, "Tetramethylammonium chloride+ glycerol deep eutectic solvent as separation agent for organic liquid mixtures: Assessment from experimental limiting activity coefficients," Fluid Phase Equilibria, vol. 473, pp. 98-105, 2018.

[35] N. Nkosi, K. Tumba, and S. Ramsuroop, "Activity coefficients at infinite dilution of various solutes in tetrapropylammonium bromide+ 1, 6-hexanediol deep eutectic solvent," Journal of Chemical E Engineering Data, vol. 63, no. 12, pp. 4502-4512, 2018.

[36] U. Domańska, M. Karpińska, A. Wiśniewska, and Z. Dąbrowski, "Ammonium ionic liquids in extraction of bio-butan-1-ol from water phase using activity coefficients at infinite dilution," Fluid Phase Equilib., vol. 479, pp. 9-16, 2019.

[37] P. Vrbka and V. Dohnal, "Limiting activity coefficient measurements in binary mixtures of dichloromethane and 1-alkanols (c1-c4)," Fluid Phase Equilib., vol. 411, pp. 59-65, 2016. 


\section{LITERATURE REVIEW AND VISUALISATION}

[38] J. Tellinghuisen, "Can you trust the parametric standard errors in nonlinear least squares? yes, with provisos," Biochimica et Biophysica Acta (BBA)-General Subjects, vol. 1862, no. 4, pp. 886-894, 2018.

[39] K. Murphy and S. Gill, "Calorimetric measurement of the enthalpy of dissolution of diketopiperazine in water as a function of temperature," Thermochimica acta, vol. 139, pp. 279-290, 1989.

[40] P. P. Syamala, B. Soberats, D. Görl, S. Gekle, and F. Würthner, "Thermodynamic insights into the entropically driven self-assembly of amphiphilic dyes in water," Chemical science, vol. 10, no. 40, pp. 9358-9366, 2019.

[41] C. B. Castells, D. I. Eikens, and P. W. Carr, "Headspace gas chromatographic measurements of limiting activity coefficients of eleven alkanes in organic solvents at 25 c. 1," Journal of Chemical \& Engineering Data, vol. 45, no. 2, pp. 369-375, 2000.

[42] Y. G. Dobrjakov, I. M. Balashova, and G. Maurer, "Experimental results for the limiting activity coefficients in some binary and ternary mixtures of organic components," Journal of Chemical E Engineering Data, vol. 45, no. 2, pp. 185-193, 2000.

[43] V. Dohnal and P. Vrbka, "Limiting activity coefficients in the 1-alkanol+ n-alkane systems: survey, critical evaluation and recommended values, interpretation in terms of association models," Fluid Phase Equilib., vol. 133, no. 1-2, pp. 73-87, 1997.

[44] G. Tse and S. I. Sandler, "determination of infinite dilution activity coefficients and 1-octanol/water partition coefficients of volatile organic pollutants," J. Chem. Eng. Data, vol. 39, no. 2, pp. 354-357, 1994.

[45] R. K. Kuchhal, K. L. Mallik, and P. L. Gupta, "Studies on thermodynamics of solution by gas chromatography: solubility measurements of hydrocarbons in cycloalkanols," Can. J. Chem., vol. 55, no. 7, pp. 1273-1278, 1977.

[46] J.-P. Monfort, J. Vidal, and H. Renon, " $N^{\circ}$ 108. - coefficients d'activité a dilution infinie des hydrocarbures dans deux familles de solvants les effets de la structure du solvant," Journal de Chimie Physique, vol. 67, pp. 748-756, 1970.

[47] C. Deal and E. Derr, "Selectivity and solvency in aromatics recovery," Industrial \& Engineering Chemistry Process Design and Development, vol. 3, no. 4, pp. 394-399, 1964.

[48] S. O'shea and R. Stokes, "Activity coefficients and excess partial molar enthalpies for (ethanol+ hexane) from 283 to 318 k," The Journal of Chemical Thermodynamics, vol. 18, no. 7, pp. 691-696, 1986.

[49] A. Vega and J. Coca, "Activity coefficients at infinite dilution of organic compounds in acetonitrile and methanol by liquid chromatography," J. Liq. Chromatogr., vol. 13, no. 4, pp. 789-801, 1990.

[50] M. Boussaha, K. Khimeche, and A. Dahmani, "Activity coefficients at infinite dilution for hydrocarbons in fatty alcohols determined by gas- liquid chromatography," Journal of Chemical \& Engineering Data, vol. 56, no. 4, pp. 850-858, 2011.

[51] R. Vilcu and E. Puricel, "Thermodynamic properties of some nonelectrolyte solutions at infinite dilution by gas chromatography. ii-activity coefficient at infinite dilution," Rev. Roum. Chim., vol. 43, no. 12, pp. 1121-1132, 1998.

[52] D. E. Martire and L. Z. Pollara, "Solute activity coefficients at infinite dilution and specific retention volumes measured by gas-liquid chromatography.," J. Chem. Eng. Data, vol. 10, no. 1, pp. 40-43, 1965.

[53] E. Turek, R. A. Greenkorn, and K. Chao, "Infinite dilution activity coefficients for selected binary mixtures of hydrocarbons, alcohols, and ketones," J. Chem. Eng. Data, vol. 24, no. 4, pp. 296-298, 1979.

[54] P. Alessi, I. Kikic, A. Alessandrini, and M. Fermeglia, "Activity coefficients at infinite dilution by gasliquid chromatography. 1. hydrocarbons and n-chloroparaffins in organic solvents," J. Chem. Eng. Data, vol. 27 , no. 4, pp. 445-448, 1982.

[55] D. Gruber, D. Langenheim, J. Gmehling, and W. Moollan, "Measurement of activity coefficients at infinite dilution using gas- liquid chromatography. 6. results for systems exhibiting gas- liquid interface adsorption with 1-octanol," Journal of Chemical E Engineering Data, vol. 42, no. 5, pp. 882-885, 1997.

[56] I. Landau, A. J. Belfer, and D. C. Locke, "Measurement of limiting activity coefficients using non-steadystate gas chromatography," Industrial \& engineering chemistry research, vol. 30, no. 8, pp. 1900-1906, 1991.

[57] E. R. Thomas, B. A. Newman, T. C. Long, D. A. Wood, and C. A. Eckert, "Limiting activity coefficients of nonpolar and polar solutes in both volatile and nonvolatile solvents by gas chromatography," J. Chem. Eng. Data, vol. 27, no. 4, pp. 399-405, 1982. 


\section{LITERATURE REVIEW AND VISUALISATION}

[58] E. R. Thomas, B. A. Newman, G. L. Nicolaides, and C. A. Eckert, "Limiting activity coefficients from differential ebulliometry," Journal of Chemical and Engineering Data, vol. 27, no. 3, pp. 233-240, 1982.

[59] P. Vrbka, V. Dohnal, L. M. Trejo, and M. Costas, "Molecular shape effects on limiting activity coefficients: normal, branched and cyclic alkanes in 1-propanol or 2-propanol," Fluid Phase Equilib., vol. 137, no. 1-2, pp. 133-140, 1997.

[60] L. Dallinga, M. Schiller, and J. Gmehling, "Measurement of activity coefficients at infinite dilution using differential ebulliometry and non-steady-state gas-liquid chromatography," J. Chem. Eng. Data, vol. 38, no. 1, pp. 147-155, 1993.

[61] C. S. Schacht, L. Zubeir, T. W. de Loos, and J. Gross, "Application of infinite dilution activity coefficients for determining binary equation of state parameters," Industrial \& Engineering Chemistry Research, vol. 49, no. 16, pp. 7646-7653, 2010.

[62] G. M. Lobien and J. M. Prausnitz, "Infinite-dilution activity coefficients from differential ebulliometry," Industrial \& Engineering Chemistry Fundamentals, vol. 21, no. 2, pp. 109-113, 1982.

[63] M. J. Hait, C. L. Liotta, C. A. Eckert, D. L. Bergmann, A. M. Karachewski, A. J. Dallas, D. I. Eikens, J. J. $\mathrm{Li}$, and P. W. Carr, "Space predictor for infinite dilution activity coefficients," Industrial E engineering chemistry research, vol. 32, no. 11, pp. 2905-2914, 1993.

[64] S. A. Wieczorek and J. Stecki, "Vapour pressures and thermodynamic properties of hexan-1-ol+ nhexane between 298.230 and 342.824 k," The Journal of Chemical Thermodynamics, vol. 10, no. 2, pp. 177 186,1978

[65] S. A. Wieczorek, "Vapour pressure and thermodynamic properties of dodecan-1-ol+ n-hexane between 298.230 and 342.824 k," The Journal of Chemical Thermodynamics, vol. 10, no. 2, pp. 187-194, 1978.

[66] S. A. Wieczorek, "Vapour pressures and thermodynamic properties of decan-1-ol+ n-hexane between 283.160 and 333.151 k," The Journal of Chemical Thermodynamics, vol. 11, no. 3, pp. 239-245, 1979.

[67] M. Gracia, F. Sánchez, P. Pérez, J. Valero, and C. G. Losa, "Vapour pressures of (butan-1-ol+ hexane) at temperatures between $283.10 \mathrm{k}$ and $323.12 \mathrm{k}$," The Journal of Chemical Thermodynamics, vol. 24, no. 5, pp. 463-471, 1992.

[68] M. Hongo, T. Tsuji, K. Fukuchi, and Y. Arai, "Vapor-liquid equilibria of methanol+ hexane, methanol+ heptane, ethanol+ hexane, ethanol+ heptane, and ethanol+ octane at 298.15 k," J. Chem. Eng. Data, vol. 39, no. 4, pp. 688-691, 1994.

[69] V. Rodriguez, J. Pardo, M. Lopez, F. Royo, and J. Urieta, "Vapor pressures of binary mixtures of hexane+ 1-butanol,+ 2-butanol,+ 2-methyl-1-propanol, or+ 2-methyl-2-propanol at $298.15 \mathrm{k}$," J. Chem. Eng. Data, vol. 38, no. 3, pp. 350-352, 1993.

[70] S. G. Sayegh and G. A. Ratcliff, "Excess gibbs energies of binary systems of isopentanol and n-pentanol with hexane isomers at 25. deg. c: measurement and prediction by analytical group solution model," $J$. Chem. Eng. Data, vol. 21, no. 1, pp. 71-74, 1976

[71] V. C. Smith and R. L. Robinson Jr, "Vapor-liquid equilibriums at 25. deg. in the binary mixtures formed by hexane, benzene, and ethanol," J. Chem. Eng. Data, vol. 15, no. 3, pp. 391-395, 1970.

[72] J. N. Israelachvili, "Van der waals forces between particles and surfaces," Intermolecular and surface forces, vol. 3, pp. 253-289, 2011.

[73] Y. J. Chang and E. W. Castner Jr, "Femtosecond dynamics of hydrogen-bonding solvents. formamide and n-methylformamide in acetonitrile, dmf, and water," The Journal of chemical physics, vol. 99, no. 1, pp. 113-125, 1993.

[74] R. C. Castells, A. M. Nardillo, E. L. Arancibia, and M. R. Delfino, "Solution and adsorption thermodynamics in propylene glycol by gas chromatography: A comparative study with other polyhydroxylated solvents," J. Chromatogr. A, vol. 259, pp. 413-422, 1983.

[75] A. N. Fletcher and C. A. Heller, "Self-association of alcohols in nonpolar solvents," The Journal of Physical Chemistry, vol. 71, no. 12, pp. 3742-3756, 1967.

[76] E. Arancibia and J. Catoggio, "Gas chromatographic study of solution and adsorption of hydrocarbons on glycols: I. diethylene glycol and triethylene glycol," J. Chromatogr. A, vol. 197, no. 2, pp. 135-145, 1980.

[77] E. Arancibia and J. Catoggio, "Gas chromatographic study of solution and adsorption of hydrocarbons on glycols: Ii. ethylene glycol," J. Chromatogr. A, vol. 238, no. 2, pp. 281-290, 1982.

[78] R. Figueroa, E. Roig, and H. Szmant, "Infrared study on the self-association of dimethyl sulfoxide," 


\section{LITERATURE REVIEW AND VISUALISATION}

Spectrochim. Acta, vol. 22, no. 4, pp. 587-592, 1966.

[79] R. Brakaspathy and S. Singh, "Studies on self-association of nitromethane using a cndo/force method," J. Mol. Struct. THEOCHEM, vol. 164, no. 3-4, pp. 319-324, 1988.

[80] H. H. Freedman, "Intramolecular h-bonds. i. a spectroscopic study of the hydrogen bond between hydroxyl and nitrogen," J. Am. Chem. Soc., vol. 83, no. 13, pp. 2900-2905, 1961.

[81] C. Laurence and M. Berthelot, "Observations on the strength of hydrogen bonding," Perspect. Drug Discovery Des., vol. 18, no. 1, pp. 39-60, 2000.

[82] W. Klemperer, M. W. Cronyn, A. H. Maki, and G. C. Pimentel, "Infrared studies of the association of secondary amides in various solvents," J. Am. Chem. Soc., vol. 76, no. 22, pp. 5846-5848, 1954.

[83] A. Laaksonen, P. Kusalik, and I. Svishchev, "Three-dimensional structure in water- methanol mixtures," J. Phys. Chem. A, vol. 101, no. 33, pp. 5910-5918, 1997.

[84] K. N. Marsh, A. Deev, A. C. Wu, E. Tran, and A. Klamt, "Room temperature ionic liquids as replacements for conventional solvents-a review," Korean J. Chem. Eng., vol. 19, no. 3, pp. 357-362, 2002.

[85] B. Schuur, T. Brouwer, D. Smink, and L. M. J. Sprakel, "Green solvents for sustainable separation processes," Current Opinion in Green and Sustainable Chemistry, vol. 18, pp. 57-65, 2019.

[86] L. Crowhurst, P. R. Mawdsley, J. M. Perez-Arlandis, P. A. Salter, and T. Welton, "Solvent-solute interactions in ionic liquids," Physical Chemistry Chemical Physics, vol. 5, no. 13, pp. 2790-2794, 2003.

[87] D. C. Khara and A. Samanta, "Fluorescence response of coumarin-153 in n-alkyl-nmethylmorpholinium ionic liquids: Are these media more structured than the imidazolium ionic liquids?," The Journal of Physical Chemistry B, vol. 116, no. 45, pp. 13430-13438, 2012.

[88] M. H. Ibrahim, M. Hayyan, M. A. Hashim, A. Hayyan, and M. K. Hadj-Kali, "Physicochemical properties of piperidinium, ammonium, pyrrolidinium and morpholinium cations based ionic liquids paired with bis (trifluoromethylsulfonyl) imide anion," Fluid Phase Equilib., vol. 427, pp. 18-26, 2016.

[89] P. J. Griffin, J. L. Freyer, N. Han, N. Geller, X. Yin, C. D. Gheewala, T. H. Lambert, L. M. Campos, and K. I. Winey, "Ion transport in cyclopropenium-based polymerized ionic liquids," Macromolecules, vol. 51, no. 5, pp. 1681-1687, 2018.

[90] C. Hanke, A. Johansson, J. Harper, and R. Lynden-Bell, "Why are aromatic compounds more soluble than aliphatic compounds in dimethylimidazolium ionic liquids? a simulation study," Chem. Phys. Lett., vol. 374, no. 1-2, pp. 85-90, 2003.

[91] C. Hanke, N. Atamas, and R. Lynden-Bell, "Solvation of small molecules in imidazolium ionic liquids: a simulation study," Green Chem., vol. 4, no. 2, pp. 107-111, 2002.

[92] K. Fumino, A. Wulf, and R. Ludwig, "The cation-anion interaction in ionic liquids probed by far-infrared spectroscopy," Angew. Chem. Int. Ed., vol. 47, no. 20, pp. 3830-3834, 2008.

[93] K. Paduszyński and M. Królikowska, "Effect of side chain functional group on interactions in ionic liquid systems: Insights from infinite dilution thermodynamic data," The Journal of Physical Chemistry B, vol. 121, no. 43, pp. 10133-10145, 2017.

[94] B. Yoo, W. Afzal, and J. M. Prausnitz, "Henry's constants and activity coefficients of some organic solutes in 1-butyl, 3-methylimidazolium hydrogen sulfate and in 1-methyl, 3-trimethylsilylmethylimidazolium chloride," The Journal of Chemical Thermodynamics, vol. 57, pp. 178-181, 2013.

[95] U. Domańska and A. Marciniak, "Activity coefficients at infinite dilution measurements for organic solutes and water in the 1-hexyloxymethyl-3-methyl-imidazolium and 1, 3-dihexyloxymethylimidazolium bis (trifluoromethylsulfonyl)-imide ionic liquids-the cation influence," Fluid Phase Equilib., vol. 286, no. 2, pp. 154-161, 2009.

[96] J. Zhang, Q. Zhang, B. Qiao, and Y. Deng, "Solubilities of the gaseous and liquid solutes and their thermodynamics of solubilization in the novel room-temperature ionic liquids at infinite dilution by gas chromatography," Journal of Chemical E Engineering Data, vol. 52, no. 6, pp. 2277-2283, 2007.

[97] K. Paduszyński and M. Królikowski, "An effect of cation's cyano group on interactions between organic solutes and ionic liquids elucidated by thermodynamic data at infinite dilution," J. Mol. Liq., vol. 243, pp. 726-736, 2017.

[98] A.-L. Revelli, F. Mutelet, J.-N. Jaubert, M. Garcia-Martinez, L. M. Sprunger, W. E. Acree Jr, and G. A. Baker, "Study of ether-, alcohol-, or cyano-functionalized ionic liquids using inverse gas chromatography," Journal of Chemical \& Engineering Data, vol. 55, no. 7, pp. 2434-2443, 2010.

[99] A. Marciniak and M. Wlazło, "Activity coefficients at infinite dilution and physicochemical properties 


\section{LITERATURE REVIEW AND VISUALISATION}

for organic solutes and water in the ionic liquid 1-(2-hydroxyethyl)-3-methylimidazolium trifluorotris (perfluoroethyl) phosphate," The Journal of Chemical Thermodynamics, vol. 64, pp. 114-119, 2013.

[100] E. F. Órfão, V. Dohnal, and A. Blahut, "Infinite dilution activity coefficients of volatile organic compounds in two ionic liquids composed of the tris (pentafluoroethyl) trifluorophosphate ([fap]) anion and a functionalized cation," The Journal of Chemical Thermodynamics, vol. 65, pp. 53-64, 2013.

[101] F. Mutelet, J.-N. Jaubert, M. Rogalski, M. Boukherissa, and A. Dicko, "Thermodynamic properties of mixtures containing ionic liquids: Activity coefficients at infinite dilution of organic compounds in 1propyl boronic acid-3-alkylimidazolium bromide and 1-propenyl-3-alkylimidazolium bromide using inverse gas chromatography," Journal of Chemical E Engineering Data, vol. 51, no. 4, pp. 1274-1279, 2006.

[102] Z. Bensaid, F. Mutelet, M. Bouroukba, and A. Negadi, "Experimental and theoretical study of interaction between organic compounds and 1-(4-sulfobutyl)-3-methylimidazolium based ionic liquids," Fluid Phase Equilib., vol. 378, pp. 34-43, 2014.

[103] H. Shirota and E. W. Castner, "Why are viscosities lower for ionic liquids with- ch2si (ch3) 3 vs- ch2c (ch3) 3 substitutions on the imidazolium cations?," The Journal of Physical Chemistry B, vol. 109, no. 46, pp. 21576-21585, 2005.

[104] F. Mutelet, J.-C. Moise, and A. Skrzypczak, "Evaluation of the performance of trigeminal tricationic ionic liquids for separation problems," Journal of Chemical \& Engineering Data, vol. 57, no. 3, pp. 918-927, 2012.

[105] F. Mutelet, P. Carre, and A. Skrzypczak, "Study of interaction between organic compounds and mono or dicationic oxygenated ionic liquids using gas chromatography," Fluid Phase Equilib., vol. 387, pp. 59-72, 2015.

[106] F. Mutelet, D. Alonso, S. Ravula, G. A. Baker, B. Jiang, and W. E. Acree Jr, "Infinite dilution activity coefficients of solutes dissolved in anhydrous alkyl (dimethyl) isopropylammonium bis (trifluoromethylsulfonyl) imide ionic liquids containing functionalized-and nonfunctionalized-alkyl chains," J. Mol. Liq., vol. 222, pp. 295-312, 2016.

[107] K. T. Heydar, M. Nazifi, A. Sharifi, M. Mirzaei, H. Gharavi, and S. H. Ahmadi, "Determination of activity coefficients at infinite dilution of solutes in new dicationic ionic liquids based on morpholine using gas-liquid chromatography," Chromatographia, vol. 76, no. 3-4, pp. 165-175, 2013.

[108] J. L. Anderson, R. Ding, A. Ellern, and D. W. Armstrong, "Structure and properties of high stability geminal dicationic ionic liquids," J. Am. Chem. Soc., vol. 127, no. 2, pp. 593-604, 2005.

[109] U. Domańska and K. Paduszyński, "Gas-liquid chromatography measurements of activity coefficients at infinite dilution of various organic solutes and water in tri-iso-butylmethylphosphonium tosylate ionic liquid," The Journal of Chemical Thermodynamics, vol. 42, no. 6, pp. 707-711, 2010.

[110] T. M. Letcher and P. Reddy, "Determination of activity coefficients at infinite dilution of organic solutes in the ionic liquid, tributylmethylphosphonium methylsulphate by gas-liquid chromatography," Fluid phase equilibria, vol. 260, no. 1, pp. 23-28, 2007.

[111] U. Domańska, M. Wlazło, M. Karpińska, and M. Zawadzki, "New ionic liquid [p4, 4, 4, 4][ntf2] in bio-butanol extraction on investigation of limiting activity coefficients," Fluid Phase Equilibria, vol. 475, pp. 89-94, 2018.

[112] P. J. Carvalho, S. P. Ventura, M. L. Batista, B. Schröder, F. Gonçalves, J. Esperança, F. Mutelet, and J. A. Coutinho, "Understanding the impact of the central atom on the ionic liquid behavior: phosphonium vs ammonium cations," The Journal of chemical physics, vol. 140, no. 6, p. 064505, 2014.

[113] T. M. Letcher and P. Reddy, "Determination of activity coefficients at infinite dilution of organic solutes in the ionic liquid, trihexyl (tetradecyl)-phosphonium tris (pentafluoroethyl) trifluorophosphate, by gasliquid chromatography," Fluid phase equilibria, vol. 235, no. 1, pp. 11-17, 2005.

[114] U. Domańska, M. Wlazło, M. Karpińska, and M. Zawadzki, "High selective water/butan-1-ol separation on investigation of limiting activity coefficients with $[\mathrm{p} 8,8,8,8][\mathrm{ntf} 2]$ ionic liquid," Fluid Phase Equilibria, vol. 449, pp. 1-9, 2017.

[115] M. Wlazło, M. Karpińska, and U. Domańska, "Separation of water/butan-1-ol mixtures based on limiting activity coefficients with phosphonium-based ionic liquid," The Journal of Chemical Thermodynamics, vol. 113, pp. 183-191, 2017.

[116] E. L. Arancibia, R. C. Castells, and A. M. Nardillo, "Thermodynamic study of the behaviour of two 


\section{LITERATURE REVIEW AND VISUALISATION}

molten organic salts as stationary phases in gas chromatography," Journal of Chromatography A, vol. 398, pp. 21-29, 1987.

[117] S. P. Verevkin, D. H. Zaitsau, B. Tong, and U. Welz-Biermann, "New for old. password to the thermodynamics of the protic ionic liquids," Physical Chemistry Chemical Physics, vol. 13, no. 28, pp. 12708-12711, 2011.

[118] J. Ziemblińska-Bernart, P. Bielecki, and W. Wasiak, "Measurements of activity coefficients at infinite dilution for organic solutes in two quaternary ammonium-based ionic liquids [dda][clo4] and [dda][bf4]," Fluid Phase Equilibria, vol. 482, pp. 99-107, 2019.

[119] U. Domańska, A. Wiśniewska, Z. Dąbrowski, and M. Karpińska, "Separation of binary mixtures based on limiting activity coefficients data using specific ammonium-based ionic liquid and modelling of thermodynamic functions," Fluid Phase Equilibria, vol. 460, pp. 155-161, 2018.

[120] W. E. Acree Jr, G. A. Baker, F. Mutelet, and J.-C. Moise, "Partition coefficients of organic compounds in four new tetraalkylammonium bis (trifluoromethylsulfonyl) imide ionic liquids using inverse gas chromatography," Journal of Chemical E Engineering Data, vol. 56, no. 9, pp. 3688-3697, 2011.

[121] H. Shirota, T. Mandai, H. Fukazawa, and T. Kato, "Comparison between dicationic and monocationic ionic liquids: liquid density, thermal properties, surface tension, and shear viscosity," Journal of Chemical E Engineering Data, vol. 56, no. 5, pp. 2453-2459, 2011.

[122] A. Blahut, M. Sobota, V. Dohnal, and P. Vrbka, "Activity coefficients at infinite dilution of organic solutes in the ionic liquid 1-ethyl-3-methylimidazolium methanesulfonate," Fluid Phase Equilib., vol. 299, no. 2, pp. 198-206, 2010.

[123] F. Allal, F. Mutelet, A. Dahmani, and B. Saidat, "Measurements of activity coefficients at infinite dilution of organic solutes in the ionic liquid 1-ethyl-3-methylimidazolium ethylphosphonate [emim] [(eto)(h) po2] using gas-liquid chromatography," J. Mol. Liq., vol. 220, pp. 243-247, 2016.

[124] A. Blahut, V. Dohnal, and P. Vrbka, "Interactions of volatile organic compounds with the ionic liquid 1-ethyl-3-methylimidazolium tetracyanoborate," The Journal of Chemical Thermodynamics, vol. 47, pp. 100-108, 2012.

[125] A. M. Fernandes, M. A. Rocha, M. G. Freire, I. M. Marrucho, J. A. Coutinho, and L. M. Santos, "Evaluation of cation- anion interaction strength in ionic liquids," The Journal of Physical Chemistry B, vol. 115, no. 14, pp. 4033-4041, 2011.

[126] R. Lü, J. Lin, and Z. Qu, "Theoretical study on interactions between ionic liquids and organosulfur compounds," Comput. Theor. Chem., vol. 1002, pp. 49-58, 2012.

[127] Q. Zhao, J. Eichhorn, W. R. Pitner, and J. L. Anderson, "Using the solvation parameter model to characterize functionalized ionic liquids containing the tris (pentafluoroethyl) trifluorophosphate (fap) anion," Anal. Bioanal.Chem., vol. 395, no. 1, pp. 225-234, 2009.

[128] J. M. Pringle, J. Golding, C. M. Forsyth, G. B. Deacon, M. Forsyth, and D. R. MacFarlane, "Physical trends and structural features in organic salts of the thiocyanate anion," J. Mater. Chem., vol. 12, no. 12, pp. 3475-3480, 2002.

[129] X. Xuan, M. Guo, Y. Pei, and Y. Zheng, "Theoretical study on cation-anion interaction and vibrational spectra of 1-allyl-3-methylimidazolium-based ionic liquids," Spectrochim. Acta, Part A, vol. 78, no. 5, pp. 1492-1499, 2011.

[130] X. Song, H. Hamano, B. Minofar, R. Kanzaki, K. Fujii, Y. Kameda, S. Kohara, M. Watanabe, S.-i. Ishiguro, and Y. Umebayashi, "Structural heterogeneity and unique distorted hydrogen bonding in primary ammonium nitrate ionic liquids studied by high-energy x-ray diffraction experiments and md simulations," The Journal of Physical Chemistry B, vol. 116, no. 9, pp. 2801-2813, 2012. 





\subsection{Introduction}

Several chemical separations have been identified by Sholl and Lively ${ }^{1}$ which, if replaced by more energy-efficient alternatives, would imply a huge leap forward towards a more sustainable society, considering that $10-15 \%$ of the world's energy usage originated from separation processes. ${ }^{1}$ Being membrane scientists, Sholl and Lively proposed mostly membrane separations as possible improvements, and for some of the mentioned separations the suggested potential gain is seen as too optimistic and a similar or even better gain can be obtained, for instance, by using heat-pump assisted distillation. ${ }^{2}$ Nevertheless, for some of the challenges, e.g. the aromatics/aliphatics separation, alternatives for traditional distillation appear to be interesting and solventbased separation processes can be very effective and efficient. ${ }^{1}$

Most separations rely on the addition of heat in a distillation tower. Although these towers are often highly effective ${ }^{2}$ and well-known to the engineers in industry, if the mixture properties are unfavorable distillation can be a very energy-intensive and costly operation. ${ }^{3}$ A known modification in distillation operation is the addition of an affinity agent, or solvent, to enhance the separation. This modification is called extractive or azeotropic distillation depending on the volatility of the solvent. ${ }^{4}$

Separation processes using affinity agents are well-known in the chemical industry. For instance, state-of-the-art solvents in the petroleum industry include Sulfolane, N-methylpyrrolidone (NMP) ${ }^{5}$ and N,N-dimethylformamide (DMF). ${ }^{6}$ Although, statements vary regarding the toxicity of $\mathrm{NMP}^{7-12}$, it has been shown to have adverse effect on the reproductive system. ${ }^{13}$ As these solvents are, at this moment, mentioned in chemical legislation $(\mathrm{REACH})^{14}$ it restricts in combination with environmental laws the presence of these chemicals in consumer products. We see this as a trigger to search for green, alternative chemicals with comparable properties, which can also enhance the energy efficiency of distillation operations and thus cause energy-savings. ${ }^{14-17}$ Next to these specific examples, many new challenges will appear in the next years due to the required shift towards a more bio-based economy. For many of the new separations in the bio-based processes, solvent-enhanced distillations are likely to yield effective fractionation processes. 
Solvent identification is however not straightforward. Countless solvent selection or computer-aided molecular design (CAMD) strategies are already described, ${ }^{18-20}$ however, these strategies generally require a specific interactive tool, ${ }^{21}$ the UNIFAC mathematical framework ${ }^{22,23}$ present in commercial software such as Aspen Plus ${ }^{\circledR}$, the COSMO-RS software ${ }^{22,24,25}$ and/or specialized software to solve mixed-integer nonlinear programming (MINP) problems. ${ }^{26}$

These approaches may not be accessible for all people who wish to develop new solvent-assisted distillations. Therefore, with this work, we present an extension to the pre-selection method based on visualization of trends in infinite dilution activity coefficients, $\gamma_{i}^{\infty} .{ }^{27}$ In that method, the visualized trends give good insights into solvent effects on the mixture constituents, but azeotrope and/or pinch point predictions cannot be done. Here, we propose to use the 3-component Margules equation ${ }^{28}$ to simulate vapor-liquid equilibria (VLE) under finite dilution conditions. Since the $\gamma_{i}^{\infty}$ database and the data handling algorithm are open source, ${ }^{27}$ and the Margules equation not too difficult, anybody with basic knowledge on thermodynamic modeling can simulate VLE using the Margules equation. This approach is thus very accessible to everyone and can be a valuable addition to the arsenal of selection methods already existing in literature.

The 3-component Margules equation has been sparsely used in the field of chemical engineering and solely Schulz and co-workers applied the equation in computing mixed micellar systems. ${ }^{29-32}$ More frequently, the equation has been used in the calculation of non-ideality of metal alloys, ${ }^{33}$ and several other geological studies of minerals. ${ }^{34-37}$ Therefore, the accuracy of the Margules equation in describing isothermal and isobaric binary and ternary VLE behavior was first studied for a wide range of compound classes, after which application of the method was studied for solvent screening in aromatic-aliphatic separations.

\subsection{Methodology}

In a previous study, ${ }^{27}$ we have developed a data handling algorithm to fit the $\gamma_{i}^{\infty}$ at $298.15 \mathrm{~K}$, but also the infinite dilution enthalpy $\left(\Delta H_{i}^{\infty}\right)$ and infinite 
dilution entropy $\left(\Delta S_{i}^{\infty}\right)$ via extra- and interpolation of thermodynamic data from other temperatures using the Van 't Hoff equation, see Equation 4.1.

$$
\ln \gamma_{i}^{\infty}=\frac{\Delta H_{i}^{\infty}}{R T}-\frac{\Delta S_{i}^{\infty}}{R}
$$

The temperature-dependent activity coefficient is essential in vapor-liquid equilibria (VLE) because it describes differences from Raoult's law. As a result of non-ideal behavior, phase splitting, pinch points and azeotropes may be observed which may aid the separation, but may also make it more difficult. ${ }^{38,39}$ In vapor-liquid separations, the temperature-dependent relative volatility $\left(\alpha_{i j}\right)$ is a key parameter and can be expressed as the product of the ideal part and the non-ideal part, see Equation 4.2. ${ }^{40}$

Finite dilution:

$$
\alpha_{i j}(T)=\frac{P_{i}^{o}}{P_{j}^{o}}\left(\frac{\gamma_{i}}{\gamma_{j}}\right)_{S}=\alpha_{i j}^{I D} S_{j i}
$$

Infinite dilution:

$$
\alpha_{i j}^{\infty}(T)=\frac{P_{i}^{o}}{P_{j}^{o}}\left(\frac{\gamma_{i}^{\infty}}{\gamma_{j}^{\infty}}\right)_{S}=\alpha_{i j}^{I D} S_{j i}^{\infty}
$$

In Equation 4.2, the ideal part, $\alpha_{i j}^{I D}$, is the ratio of the pure component vapor pressures $\left(P_{i}^{o} / P_{j}^{o}\right)$ and the non-ideal part, $S_{j i}$, is also known as the selectivity which is the ratio of the activity coefficients of both components. The ratio of activity coefficients is indicated with $\left(\gamma_{i} / \gamma_{j}\right)$ in the absence and with $\left(\gamma_{i} / \gamma_{j}\right)_{S}$ in presence of a solvent. The binary relative volatility in the presence of a solvent is called pseudo-binary relative volatility. Equation $4.2 \mathrm{a}$ can also be applied specifically in the infinite diluted case, this is indicated by the corresponding superscript in Equation 4.2b. Non-ideality in the gas phase can also be included via these fugacity coefficients $\left(\varphi_{i}\right)$, although at moderate pressures the ratio of these fugacity coefficients is often close to one, so its contribution to the relative volatility is negligible. This assumption does not hold for some systems, such as carboxylic acids, where non-ideal behavior in the vapor phase is significant.

The relative volatility as defined in Equation $4.2 \mathrm{~b}$ reflects the maximum impact a solvent can have, and any solvent to feed ratio (S:F) lower than infinite yields a lower impact. To gain insight into how much solvent would 
be needed, it is essential to understand what the target relative volatility for the intended separation is. Based on the relative volatility $\left(\alpha_{i j}\right)$ in absence of the solvent, the opportunity for energy saving by applying a solvent-based fluid separation was estimated by Blahušiak et al., ${ }^{40}$ who distinguished three operation windows for distillation, see Figure 4.1. At $\alpha_{i j}<1.3$, distillation is energy-intensive and applying a solvent-based technology can save significant energy. For the regime $1.3<\alpha_{i j}<10$ the heat duty for ordinary distillation initially still drops significantly at increasing relative volatility, but for $\alpha_{i j}>3$ the energy reduction is much less. In the last regime, $\alpha_{i j} \geq 10$, single-stage evaporation may be applied.

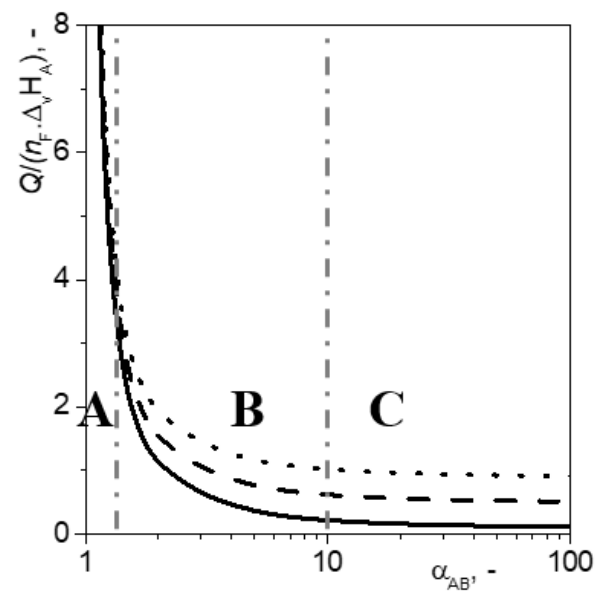

Figure 4.1: Heat duty as function of relative volatility $\left(\alpha_{A B}=\alpha_{i j}\right)$ for various molar fractions of the volatile compound $\left(x_{F A}\right)$ in the feed, normalized to the required heat to vaporize the more volatile compound. Lines: solid: $\left(x_{F A}\right)=0.1$; dashed: $\left(x_{F A}\right)=0.5$; dotted: $\left(x_{F A}\right)=0.9$. Regimes $A, B$ and $C$ indicate conditions where $(A)$ ordinary distillation is less favorable, (B) ordinary distillation suggested, $(C)$ single stage evaporation suggested. (reproduced with permission from Blahušiak et al. ${ }^{40}$ )

As the energy-requirement for distillation reduces considerably up to at a $\alpha_{i j}$ around 3, but levels off at higher $\alpha_{i j}$, it makes sense to aim for this $\alpha_{i j}$. Industrial extractive distillation cases are known to operate at lower $\alpha_{i j}$, such as dimethylcarbonate-methanol separation ${ }^{41}$ with phenol $\left(\alpha_{i j}=2.5\right)$, ethyl benzoate $\left(\alpha_{i j}=2.2\right)$ and methyl isobutyl ketone $\left(\alpha_{i j}=2.1\right)$ and the dimethoxymethane/methanol separation with n,n-dimethylformamide $\left(\alpha_{i j}=1.8\right)^{42}$, tho- 
ugh for this work, we aim for $\alpha_{i j, \min }$ of 3 as suggested by Blahušiak et. al. ${ }^{40}$ Therefore in the solvent evaluations, increasing the $\alpha_{i j}$ to a value of 3 is the target. Because the vapor-liquid behavior studied in this work are far from ideal, we apply the Blahušiak et al. ${ }^{40}$ approach over the entire compositional range and determine the minimum relative volatility present in the non-ideal vapor-liquid equilibria, $\alpha_{i j, m i n}$, of the pseudo-binary VLE. An additional consideration for solvent pre-selection is the boiling point of the solvent. This should be 40 to $50^{\circ} \mathrm{C}$ higher than the highest boiling solute, because this allows for easy recoverability of the high boiling solute from the solvent in the recovery operation. ${ }^{43}$

The minimal required selectivity that can be achieved at infinite dilution, and is defined by the required relative volatility of 3, follows from Equation 4.3.

$$
S_{j i, \min }^{\infty}=\frac{\alpha_{i j, \min }^{\infty}}{\alpha_{i j}^{I D}}
$$

This would allow for a straight determination of the $S_{j i, m i n}^{\infty}$ from the abundantly available vapor pressures and the open-source $\gamma_{i}^{\infty}$ data. However, as mentioned before, infinite dilution entails a tremendously high S:F ratio. This consequentially eliminates non-ideal effects, such as pinch point and azeotrope formation. Therefore, a correlation between $\gamma_{i}^{\infty}$ and $\gamma_{i}(x)$ that will be obtained with realistic S:F ratios is needed as well.

The extended Margules equation can describe vapor-liquid equilibria based on $\gamma_{i}^{\infty}$, and Mukhopadhyay et al. ${ }^{28}$ generalized the well-known Margules equation via a $\mathrm{p}^{\text {th }}$ order Taylor series towards multi-component systems with both symmetric and asymmetric binary interaction parameters. In Equation 4.4, the relations for the 3-component Margules equation with asymmetric binary parameters are shown.

$$
\begin{aligned}
& \left\{\begin{array}{l}
\ln \left(\gamma_{1}\right)=2\left(x_{1} x_{2} A_{21}+x_{1} x_{3} A_{31}\right)+x_{2}^{2} A_{12}+x_{3}^{2} A_{13}+x_{2} x_{3} B_{123}-2 G^{E} \\
\ln \left(\gamma_{2}\right)=2\left(x_{2} x_{3} A_{32}+x_{2} x_{1} A_{12}\right)+x_{3}^{2} A_{23}+x_{1}^{2} A_{21}+x_{3} x_{1} B_{123}-2 G^{E} \\
\ln \left(\gamma_{3}\right)=2\left(x_{3} x_{1} A_{13}+x_{3} x_{2} A_{23}\right)+x_{1}^{2} A_{31}+x_{2}^{2} A_{32}+x_{1} x_{2} B_{123}-2 G^{E}
\end{array}\right. \\
& G^{E}=x_{1} x_{2}\left(A_{12}+x_{1} A_{21}\right)+x_{1} x_{3}\left(x_{3} A_{13}+x_{1} A_{31}\right)+ \\
& x_{2} x_{3}\left(x_{3} A_{23}+x_{2} A_{32}\right)+x_{1} x_{2} x_{3} B_{123}
\end{aligned}
$$




$$
\begin{gathered}
B_{123}=0.5\left(A_{12}+A_{21}+A_{13}+A_{31}+A_{23}+A_{32}\right)-A_{123} \\
A_{i j}=\ln \left(\gamma_{i}^{\infty}\right)^{*}
\end{gathered}
$$

$*_{i}$ is infinitely diluted in compound $j$.

$A_{i j}$ is a function of $\gamma_{i}^{\infty}$ which means the activity coefficient of compound i infinitely diluted in compound $\mathrm{j}$, and the liquid molar fractions $\left(x_{i}\right) . B_{123}$ is a ternary interaction term, which is dependent on the binary interaction terms $A_{12}, A_{21}, A_{13}, A_{31}, A_{23}$ and $A_{32}$, and the ternary interaction coefficient $A_{123}$. This latter interaction coefficient cannot be completely defined by a function of binary interaction coefficients. ${ }^{28}$ Here, it is assumed that $A_{123}$ is zero, which is the same assumption as commonly made in, for instance, the nonrandom two-liquid (NRTL) model. ${ }^{44}$

This approach can be used to predict isothermal vapor-liquid equilibria, where only the $\gamma_{i}^{\infty}$ of that specific temperature is used but can also be used to predict isobaric VLE. In the latter procedure, the Van 't Hoff equation (Equation 4.1) is required to describe the temperature dependency of the $\gamma_{i}^{\infty}$. In each case, pure component vapor pressures, which can be found in online libraries such as the National Institute of Standard and Technology (NIST) ${ }^{45}$ or handbooks such as Yaw's Handbook are used. ${ }^{46}$

In the specific case of isobaric ternary vapor-liquid equilibria, the saturated vapor pressures of each component are required as well as the $\Delta H_{i}^{\infty}$ and $\Delta S_{i}^{\infty}$ of the three components (solutes and solvent). For a ternary system thus six $\Delta H_{i}^{\infty}$ and six $\Delta S_{i}^{\infty}$ parameters are required. Often all the $\Delta H_{i}^{\infty}$ and $\Delta S_{i}^{\infty}$ of the solutes in each other and in a solvent are known, however the $\Delta H_{i}^{\infty}$ and $\Delta S_{i}^{\infty}$ of the solvent in the solutes is often missing. This frequently absent link can be circumvented by assuming either an ideal solvent, the $\gamma_{i}^{\infty}$ of the solvent in the solutes is then set at one $\left(A_{31}=A_{32}=0\right)$, or by assuming a symmetric behavior of the solute and solvent and thus assuming a partly symmetric Margules form $\left(A_{31}=A_{13}\right.$ and $\left.A_{32}=A_{23}\right)$, in the screening methodology. Although both assumptions are fundamentally incorrect, this can have a minimal impact on the temperature profile for solvents with a vapor pressure that strongly deviates from the solutes. The assumption of the $\gamma_{i}^{\infty}$ for the solvent would not change the overall pressure of the system as the partial pressure 
of the solvent in extractive distillation is already small. The assumption can however impact the temperature profile if the solvent is (moderately) volatile, which subsequently can affect the temperature-dependency which impacts the $\gamma_{i}^{\infty}$ of all compounds. Furthermore, because in the equations for $\gamma_{1}$ and $\gamma_{2}$ the coefficients $A_{31}$ and $A_{32}$ are present, for those solvents where these are not available, both methods based on the assumptions have been compared. Of course, this can be avoided if all desired parameters are known and can be implemented directly.

The validity of the Margules equation is evaluated in terms of the average deviation of parameter $\chi\left(A D_{\chi}\right)$, see Equation 4.5 , which is either the vapor phase composition (y) within the xy-diagram or the temperature $(\mathrm{T})$ in the Txy-diagram.

$$
A D_{\chi}=\frac{\left(\sum^{\left.N_{\text {data }}\left|\chi_{\text {exp }}-\chi_{\text {pred }}\right|\right)}\right.}{N_{\text {data }}}
$$

\subsection{Separation Examples}

This approach can be done independently of the chosen component. From previous work, ${ }^{27}$ in which the $\gamma_{i}^{\infty}$ of 622 solutes and 999 solvents were collected, we selected several separations of classes of hydrocarbons that are industrially relevant to establish the feasibility of this approach. As summarized in Table 4.1, the separation of complex hydrocarbon streams containing the lowest boiling aromatic compound, benzene, and either a range of $\mathrm{C}_{4}$ to $\mathrm{C}_{9}$-alkanes in pyrolysis oil ${ }^{47}$ or a part of the hydrocarbon in naphtha ${ }^{48}$ is evaluated. As $\mathrm{C}_{4}$ - and $\mathrm{C}_{5}$-alkanes are easily separable from benzene, they are excluded from the assessment.

Additionally, a paraffin/olefin example (n-hexane/1-hexene separation) has been studied. Industrially, the n-butane/2-butene ${ }^{52,53}$ and n-propane/propylene ${ }^{52,54}$ separations are done, but for these systems limited $\gamma_{i}^{\infty}$ data are available. Therefore, the $\mathrm{C}_{6}$-paraffin/olefin example was evaluated instead. In the last examples, removal of polar compounds from hydrocarbon streams is evaluated in the methanol-to-olefins (MTO) process, ${ }^{49}$ and for upgrading pyrolysis oil ${ }^{50}$ or microalgal oil. ${ }^{51}$ 
Table 4.1: The binary mixtures selected for each case and the industrial relevant processes they represent.

\begin{tabular}{|c|c|c|}
\hline Case & Binary Compounds & Separation Applications \\
\hline \multirow[t]{2}{*}{1} & Benzene $-C_{6}-$ to $C_{9}$-Alkane & \multirow{2}{*}{$\begin{array}{l}\text { Separation of aromatic and aliphatic } \\
\text { compounds in for example, pyrolysis } \\
\text { oil }^{47} \text { and naphtha. } 48\end{array}$} \\
\hline & n-Hexane - 1-Hexene & \\
\hline \multirow{2}{*}{2} & n-Hexane $-C_{1}-$ to $C_{3}-$ Alkanol & \multirow{2}{*}{$\begin{array}{l}\text { Oxygenate removal from hydrocarbon } \\
\text { streams, e.g. in the MTO process }{ }^{49} \text { or to } \\
\text { upgrade pyrolysis }{ }^{50} \text { or microalgal oil }{ }^{51} \text {. }\end{array}$} \\
\hline & n-Hexane $-C_{1}-$ to $C_{2}-$ Ketones & \\
\hline
\end{tabular}

\subsection{Results}

\subsubsection{Validation of the use of the 3-component Margules equation}

In Figure 4.2, an overview is given regarding the accuracy of the Margules equation. In the form of a heat (accuracy) map, the $A D_{\chi}$,

is given for 24 molecule-type combinations for isobaric and isothermal binary VLE diagrams of which 55 and 35 systems, respectively, are assessed. For systems that only contain molecules that are not hydrogen bond donating, the $A D_{y}$ is $<5 \%$ and the $A D_{T}$ is $<4 \mathrm{~K}$. The $A D_{y}$ thus approaches typical experimental errors of several percentages.

Highly non-ideal systems such as alkane or aromatic and alcohol, or aqueous systems, show more deviation (up to $A D_{y}>10 \%$ ) and are therefore less reliable. The predictions of isobaric ternary VLE are more difficult, not only the accuracy of the experimental data may be less, due to the increased complexity of the systems, also fewer data points are available for comparison. In Figure 4.3, the validation of the ternary systems was differentiated into 4 types of solvents; non-hydrogen bonding (NHB), hydrogen bond accepting (HBA), hydrogen bond donating (HBD) and ionic liquids (ILs).

Furthermore, 6 binary systems ranging from 2 NHB, HBA or HBD solutes, and each combination thereof NHB/HBA, NHB/HBD and HBA/HBD are distinguished. A table is included in the ESI which shows each assessed system. The assumptions of either ideal solvent or (party) symmetric Margules between the solvent and solutes were assessed and the results are displayed in 


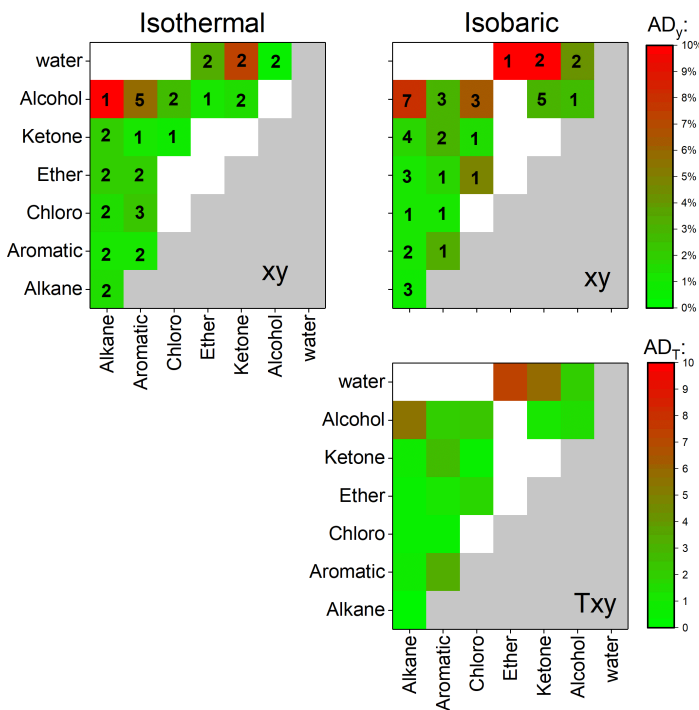

Figure 4.2: A heat map overview regarding the average deviation of the concentration profile in isothermal vapor-liquid equilibria and the average deviation of the concentration and temperature profile in isobaric vapor-liquid equilibria of binary systems. The number indications in the $A D_{\chi}$ matrices indicate the assessed number of systems.

Figure 4.3.

As can be seen in Figure 4.3, no apparent preference can be made between both assumptions. For that reason, the following methodology will be done using the (partly) symmetric Margules, which is physically more likely to be appropriate than the ideal solvent assumption as the latter is certainly not the case.

\subsubsection{Effect of S:F ratio on vapor-liquid equilibrium}

By simulating ternary systems using the three-component Margules equation the influence of the solvent-to-feed ratio (S:F ratio) on the quasi-binary VLE was studied. As can be seen in Figure 4.4, where the quasi-binary VLE of nheptane and benzene is shown, the effect of the solvent NMP increases when the S:F ratio is increased. In the binary mixture of n-heptane and benzene, benzene is the lowest boiling compound. Upon the addition of NMP, ben- 

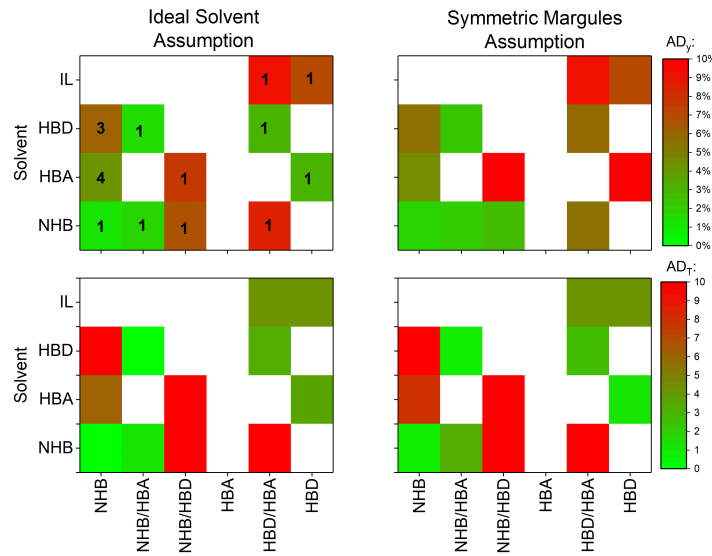

Figure 4.3: A heat map overview regarding the average deviation of the concentration and temperature profile in ternary isobaric vapor-liquid equilibria under (left) the ideal solvent assumption and (right) the (partly) symmetric Margules assumption. The number indications in the $A D_{\chi}$ matrices indicate the assessed number of systems.

zene is entrained and n-heptane is preferentially expelled to the vapor phase. At a sufficient S:F ratio, the natural boiling order is even reversed and the olefin can be separated as the bottom product. By assuming that the solvent feed temperature is not affecting the temperature profile in the column, the assumption is made that the solvent is fed at the same temperature as the column at the particular solvent feed stage.

This is only a single example showing that, using the 3-component Margules equation in combination with the open-source $\gamma_{i}^{\infty}$ values, a proper assessment of whether a solvent can increase the $\alpha_{i j, \min }$ to at least 3 can be made succesfully, and even the required S:F ratio can be estimated to some extent, as the experimental $\mathrm{S}: \mathrm{F}=2.0$ values coincide with the predicted $\mathrm{S}: \mathrm{F}=1.0$ values.

\subsubsection{Relationship between $S_{j i, m i n}^{\infty}$ and $S: F_{\text {min }}$}

The experimental determination of the $\gamma_{i}^{\infty}$ of various solutes in a solvent is often extended with the determination of specific $S_{j i}^{\infty}$ which represents industrial cases. Hence, the $S_{j i}^{\infty}$ is a commonly used indicator to establish the performance of a solvent for particular separations. ${ }^{57,58}$ However, in practice, 


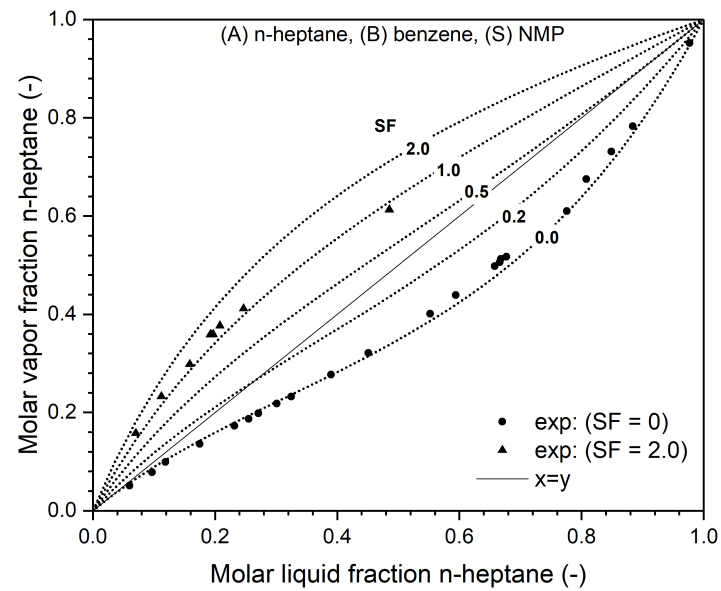

Figure 4.4: A xy-diagram of an example of the predicted solvent effect of $n$ methylpyrrolidone on the system n-heptane and benzene via the (partly symmetric) Margules equation at 1 bar. It is compared to literature data of the binary system without n-methylpyrrolidone 55 and with a solvent-to-feed ratio of 2.0. ${ }^{56}$

much lower S:F ratios are used and larger $S_{j i}$ values are required to be able to facilitate the separation adequately, as can be seen in Figure 4.5. For this scenario, ternary isothermal VLE at $298.15 \mathrm{~K}$ have been calculated in Figure 4.5, and it shows a direct correlation between these $S_{j i}^{\infty}$ and the $S: F_{m i n}$, which intuitively confirms that the $S: F_{\min }$ can be lowered as the $S_{j i}^{\infty}$ increased.

It is apparent that solely interpreting a single $S_{j i}^{\infty}$ is useful, and more information, i.e. the required S:F ratio, can be obtained by combining $S_{j i}^{\infty}$ with the Margules equation.

\subsubsection{Separation of Apolar Hydrocarbon Streams}

In the category apolar hydrocarbon separations where solvents are needed and typically applied, we find two types of separations of unsaturated hydrocarbons from saturated hydrocarbons, i.e. aromatic - aliphatic separations and olefin - paraffin separations. In both categories, when applying a solvent, typically the unsaturated hydrocarbons exhibit a lower value of the activity coefficients in the solvent than the saturated hydrocarbons, which is due to the 


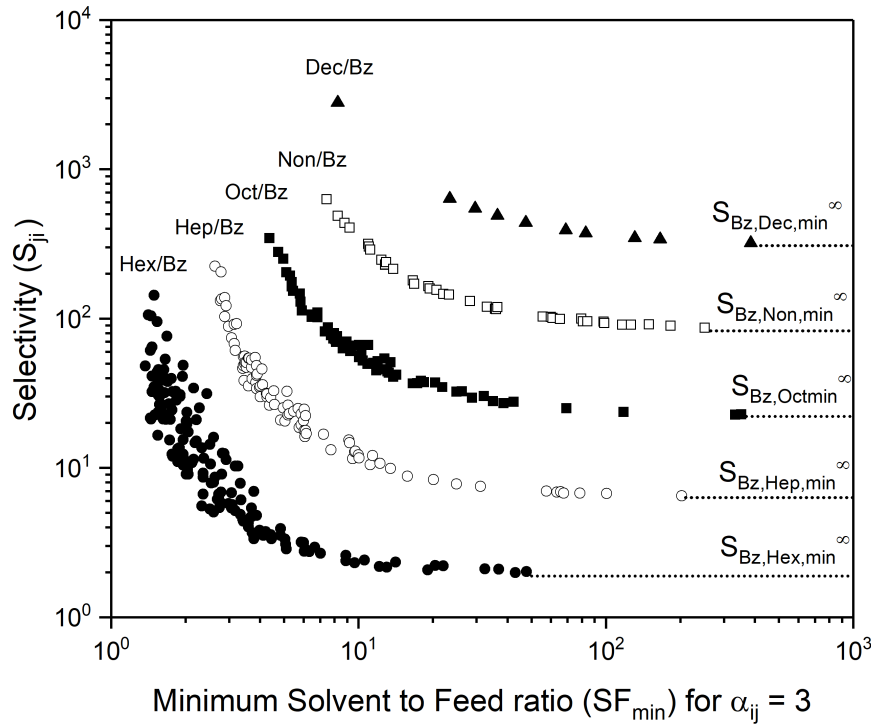

Figure 4.5: The relation between the infinitely diluted selectivity $\left(S_{j i}^{\infty}\right)$ of various aliphatic compounds over benzene and the minimal solvent to feed ratio $\left(S: F_{\text {min }}\right)$ required to obtain a minimum relative volatility $\left(\alpha_{i j, \min }\right)$ of 3 .

presence of $\pi$-electron systems in the unsaturated hydrocarbons, resulting in electrical multipole moments. ${ }^{59,60}$ The saturated hydrocarbons are (almost) completely without a polarity moment. This means that upon the addition of a polar solvent, the saturated hydrocarbons have an increased tendency to evaporate. Consequently, and ideally, these hydrocarbons shall leave the distillation column over the top. In refinery operations with hydrocarbon mixtures this means that to achieve this, for all saturated hydrocarbons and unsaturated hydrocarbons, the product of the natural relative volatility and the solvent selectivity (Equation 4.2) should favor the saturated hydrocarbons to be evaporated. Furthermore, to achieve an $\alpha_{i j \text {,min }}$ of 3 for all binary systems, e.g. for aromatics - aliphatics, this implies that for all aliphatics, including n-hexane to n-nonane, their relative volatility should be measured over the smallest and lightest boiling aromatic, benzene. To achieve such a relative volatility for $\mathrm{n}$-nonane over benzene, a significant polarity in the solvent is 
needed to repel the alkane to a greater extent than benzene and to increase the volatility of the alkane. ${ }^{27}$

\subsubsection{Aromatic - Aliphatic Separation}

The need to elevate the tendency of the heaviest aliphatic compounds to vaporize over that of benzene is a challenging matter. It has been shown at an infinite dilution that the repulsion towards aliphatic compounds increases as the molecular weight of the compound increases. For instance, in the IL n-ethyl-n-methylmorpholinium dicyanamide ${ }^{61},[\mathrm{EMMOR}]^{+}[\mathrm{DCA}]^{-}$, the $\gamma_{i}^{\infty}$ increases from $608 \pm 30$ for $n$-hexane to $2071 \pm 17$ for n-nonane at $298.15 \mathrm{~K}$ (the errors stem from the data handling algorithm described in section 3.2). However, the ideal relative volatility, $\alpha_{i j}^{I D}$, of the aliphatic compounds over benzene will decrease as a function of the molecular weight of the aliphatic compounds. The $\alpha_{i j}^{I D}$ at 298.15 of n-hexane over benzene is 1.72 , while n-nonane over benzene is $2.69 \cdot 10^{-2}$, indicating that an increasingly large selectivity is required to elevate the $\alpha_{i j}$ towards preferably 3 . This is indicated in Figure 4.5, where for the increasing molecular weight of the aliphatic component, the required S:F ratio to reach a relative volatility of 3 , strongly increases. For example, at $S_{j i}^{\infty}=100$ it follows that for n-hexane, n-heptane and n-octane the required S:F ratio increases from approximately 15 for $n$-hexane via 30 for $\mathrm{n}$-heptane to 80 for n-octane. For the larger aliphatic hydrocarbons n-nonane and n-decane the desired volatility of 3 cannot be reached at this $S_{j i}^{\infty}$, and even higher $S_{j i \text { min }}^{\infty}$ are required to obtain the desired relative volatility.

The most interesting molecular solvents and most significant ILs concerning the minimum S:F required are highlighted in Figures 4.2 and 4.3. Since no known $\gamma_{i}^{\infty}$ values are known for n-decane in benzene, it was not possible to predict solvent performances in the separation of the heaviest alkane, however, the n-nonane - benzene system could be evaluated.

Sulfolene is predicted to be one of the most suitable molecular solvent as an entrainer, with a $S: F_{\min }$ of 0.3 for hexane over benzene. However, sulfolenes are highly reactive and thermally unstable. ${ }^{62}$ Sulfolane is a widely used entrainer that is also identified, and because it does not possess a carbon-carbon double bond, it is much more stable than sulfolene. Other interesting molecular solvents in Table 4.2 are dimethylsulfoxide, ${ }^{63} \mathrm{n}$-formyl-morpholine, ${ }^{64}$ 
Table 4.2: The minimal Solvent-to-Feed ratio $\left(S: F_{\text {min }}\right)$ required to obtain an $\alpha_{i j \text {,min }}$ of of the top 15 molecular solvents for n-hexane to n-octane over benzene. No molecular solvent was found with an $\alpha_{i j, \min }$ of 3 for the benzene/n-nonane case. The full list is present in section 4.5.

\begin{tabular}{|l|l|l|l|}
\hline \multirow{2}{*}{ Molecular Solvent } & \multicolumn{3}{|l|}{ Minimum Solvent-to-Feed Ratio for $\alpha_{i j, \text { min }}$ of 3} \\
\cline { 2 - 4 } & n-Hexane & n-Heptane & n-Octane \\
\hline Ethylene Glycol & & 1.3 & 4.1 \\
2-pyrrolidone & 0.3 & 1.6 & 17 \\
Sulfolene & 0.3 & & \\
Sulfolane & 0.5 & 1.9 & 4.9 \\
Ethylene Carbonate & 0.5 & & \\
Dimethylsulfoxide & 0.5 & 2.6 & \\
Diethylene Glycol & 0.6 & 1.8 & 4.7 \\
N-formylmorpholine & 0.6 & 1.6 & \\
Triethylene Glycol & 0.7 & 2.0 & 6.2 \\
Tetraethylene Glycol & & 2.2 & \\
Propylene Carbonate & 0.7 & 2.5 & \\
Glycerol & 0.8 & 4.2 & \\
N-methylpyrrolidone & 0.8 & 3.2 & \\
N,N-dimethylformamide & 0.8 & & \\
Furfural & 0.9 & 3.8 & \\
\hline
\end{tabular}

glycols, ${ }^{65,66}$ which are all known as industrially applied entrainer. This is a strong indication of the value of this methodology, as it correctly predicts the potential of known industrial solvents. Solvents that are not preferred as entrainer (see section 4.5) for this separation are for example aniline ( $\mathrm{S}: \mathrm{F}_{\min }$ of 4.5 for $\mathrm{n}$-hexane/benzene) and $\mathrm{n}$-pentanol ( $\mathrm{S}: \mathrm{F}_{\min }$ of 2.5 for $\mathrm{n}$-hexane/benzene) Ethylene carbonate, being a possible negative emission solvent, ${ }^{67}$ may be suitable as a potential alternative entrainer for this separation case. Ethylene carbonate has already been mentioned as an extraction agent for the same purpose earlier. ${ }^{68}$

Each of the identified solvents in these assessments can be seen as the first step in the selection process for alternative entrainers. As the S:F ratio is not the only important parameter that affects the distillation operation, also the thermal stability, (see sulfolene ${ }^{62}$ ), tendency to hydrolyze in presence of water (see ethylene carbonate ${ }^{69}$ ), auto-decomposition (see ethylene glycol ${ }^{70}$ ), autocatalytic decomposition (see dimethylsulfoxide ${ }^{71}$ ), the boiling point of the 
solvent, and more, need to be considered prior to the final solvent choice.

Table 4.3: The minimal Solvent-to-Feed ratio $\left(S: F_{\text {min }}\right)$ required to obtain an $\alpha_{i j, \min }$ of 3 of the top 15 ILs for n-hexane to n-nonane over benzene. The full list is present in section 4.5.

\begin{tabular}{|c|c|c|c|c|}
\hline \multirow{2}{*}{ Ionic liquid Solvent } & \multicolumn{4}{|c|}{ Minimum Solvent-to-Feed Ratio for $\alpha_{i j, \min }$ of 3} \\
\hline & n-Hexane & n-Heptane & n-Octane & n-Nonane \\
\hline$[\mathrm{CpMPyr}]^{+}[\mathrm{SCN}]^{-}$ & & & 0.8 & 1.3 \\
\hline$[(\mathrm{HOE}) \mathrm{MIM}]^{+}[\mathrm{DCA}]^{-}$ & & 0.6 & 1.1 & 1.6 \\
\hline$[\mathrm{CpMIM}]^{+}[\mathrm{DCA}]^{-}$ & 0.3 & & 1.0 & 1.8 \\
\hline$[\mathrm{HO}-\mathrm{EMPYR}]^{+}\left[\mathrm{DMPO}_{4}\right]^{-}$ & & & & 1.8 \\
\hline$[(\mathrm{ClE}) \mathrm{MIM}]^{+}[\mathrm{DCA}]^{-}$ & & 0.6 & 1.1 & 1.8 \\
\hline$[\mathrm{EMMOR}]^{+}[\mathrm{DCA}]^{-}$ & 0.4 & 0.6 & 1.0 & 1.8 \\
\hline$[\mathrm{EMIM}]^{+}[\mathrm{SCN}]^{-}$ & 0.3 & 0.7 & 1.2 & 1.8 \\
\hline$[\mathrm{HO}-\mathrm{PPy}]^{+}[\mathrm{DCA}]^{-}$ & 0.3 & 0.7 & 1.3 & 2.1 \\
\hline$[(\mathrm{HOP}) \mathrm{MIM}]^{+}[\mathrm{DCA}]^{-}$ & 0.3 & 0.7 & 1.3 & 2.2 \\
\hline$[(\mathrm{HOP}) \mathrm{MMor}]^{+}[\mathrm{DCA}]^{-}$ & & & 1.1 & 2.3 \\
\hline$[\mathrm{EMIM}]^{+}\left[\mathrm{BF}_{4}\right]^{-}$ & 0.4 & 0.8 & 1.6 & 2.4 \\
\hline$[\mathrm{EMIM}]^{+}\left[\mathrm{MDEGSO}_{4}\right]^{-}$ & 0.3 & 0.8 & 1.5 & 2.4 \\
\hline$[\mathrm{BMIM}]^{+}[\mathrm{Cl}]^{-}$ & & & 1.2 & 2.5 \\
\hline$[\mathrm{BMIM}]^{+}[\mathrm{SCN}]^{-}$ & 0.3 & 0.7 & 1.4 & 2.6 \\
\hline$[\mathrm{MP}=\mathrm{IM}]^{+}[\mathrm{DCA}]^{-}$ & 0.4 & 0.8 & 1.5 & 2.6 \\
\hline
\end{tabular}

The removal of aromatic compounds from a hydrocarbon stream has been extensively studied over the past decades and thus it is not surprising that no new molecular solvents have been identified. This approach is however very useful in pre-selecting unconventional solvents, such as potential ILs. As can be seen in Table 4.3, small polar anions, thiocyanate $[\mathrm{SCN}]^{-}$, dicyanamide $[\mathrm{DCA}]^{-}$and tetrafluoroborate $\left[\mathrm{BF}_{4}\right]^{-}$are essential for strong repulsion of the alkanes. This observation is in agreement with the findings of Meindersma et al. ${ }^{72}$ Cation modifications can increase the repulsion even further as can be seen for the cyano-modified 1-(3-cyanopropyl)-1-methylpyrrolidinium [CpM$\mathrm{Pyr}]^{+73}$ and 1-(2-hydroxyethyl)-3-methylimidazolium cation $[(\mathrm{HOE}) \mathrm{MIM}]^{+} .{ }^{-74}$ Nevertheless, the IL with the highest potential is 1-(3-cyanopropyl)-1-methyl pyrrolidinium thiocyanate $[\mathrm{CpMPyr}]^{+}[\mathrm{SCN}]^{-}$. This IL has a cyano functional group on both the cation and the anion, which elevates the $\alpha_{i j, \min }$ of n-nonane over benzene to 3 at a S:F ratio of only 1.3, and should therefore also be adequate to increase the relative volatility of lighter aliphatic compounds.

More recently, deep eutectic solvents (DES's) have been identified as potential 


\section{SOLVENT PRE-SELECTION FOR EXTRACTIVE DISTILLATION}

Table 4.4: The minimal Solvent-to-Feed ratio $\left(S: F_{\text {min }}\right)$ required to obtain an $\alpha_{i j, \text { min }}$ of the $D E S$ 's for n-hexane to n-octane over benzene. No DES was found with an $\alpha_{i j, \min }$ of 3 for the benzene/n-nonane case.

\begin{tabular}{|l|l|l|l|}
\hline \multirow{2}{*}{ Deep eutectic Solvent pair (mole ratio) } & \multicolumn{3}{|c|}{ Minimum Solvent-to-Feed Ratio for $\alpha_{i j, \min }$ of 3} \\
\cline { 2 - 4 } & n-Hexane & n-Heptane & n-Octane \\
\hline Choline Chloride:Glycerol (1:1) & 0.3 & 0.7 & \\
Choline Chloride:Ethylene Glycol (1:3) & 0.4 & 0.7 & \\
{$\left[\mathrm{~N}_{3333}\right]^{+}[\mathrm{Br}]^{-}: 1,6$-hexanediol (1:2) } & 0.8 & 3.0 & 14 \\
\hline
\end{tabular}

${ }^{a}$ Abbreviations: $\left[\mathrm{N}_{3333}\right]^{+}[\mathrm{Br}]^{-}=$tetrapropyl ammonium bromide

replacements of ILs. In Table 4.4, it can be seen that several DES's can separate n-nonane as a distillate from benzene with a relative volatility of 3 as well. This indicates that among the DES's groups potentially good entrainers for these separations can be found as well, as indicated by i.a. Larriba et al. ${ }^{75}$ and Rodriguez et al. ${ }^{76}$ earlier.

\subsubsection{Olefin - Paraffin Separation}

The olefin and paraffin separation is a highly relevant industrial separation of apolar compounds. In Table 4.5, the assessment of the 1-hexene/n-hexane case has been shown for several relative volatilities, e.g. 2.0 and 1.5, because no solvent was able to induce a relative volatility of 3 and no molecular solvent is even seen to induce a relative volatility of 2.0. This indicates the difficulty of separating compounds based on the difference of a single unsaturated bond only.

Table 4.5: The minimal Solvent-to-Feed ratio $\left(S: F_{\text {min }}\right)$ required to obtain an $\alpha_{i j, \text { min }}$ of 1.5 of molecular solvents for 1-hexene over n-hexane.

\begin{tabular}{|l|l|}
\hline \multirow{2}{*}{ Molecular Solvent } & Minimum Solvent-to-Feed Ratio for 1-hexene/n-hexane case \\
\cline { 2 - 2 } & $\alpha_{i j, \min }=1.5$ \\
\hline 2-pyrrolidone & 3.7 \\
Dimethylsulfoxide & 3.8 \\
N-formylmorpholine & 4.8 \\
N,N-dimethylformamide & 5.5 \\
N-methylpyrrolidone & 14 \\
N-methylformamide & 18 \\
\hline
\end{tabular}


Table 4.6: The minimal Solvent-to-Feed ratio $\left(S: F_{\text {min }}\right)$ required to obtain an $\alpha_{i j \text {,min }}$ of 1.5 , 2.0 and 2.5 of the top 15 ionic liquids for 1-hexene over $n$-hexane. The full list is present in section 4.5 .

\begin{tabular}{|c|c|c|c|}
\hline \multirow{2}{*}{ Ionic liquid Solvent } & \multicolumn{3}{|c|}{ Minimum Solvent-to-Feed Ratio for 1-hexene/n-hexane case } \\
\hline & $\alpha_{i j, \min }=1.5$ & $\alpha_{i j, \min }=2.0$ & $\alpha_{i j, \min }=2.5$ \\
\hline$[\mathrm{BMIM}]^{+}[\mathrm{SCN}]^{-}$ & 1.1 & 2.5 & 5.9 \\
\hline$[\mathrm{BMPIP}]^{+}[\mathrm{SCN}]^{-}$ & 1.3 & 3.2 & \\
\hline$[\mathrm{EMIM}]^{+}[\mathrm{SCN}]^{-}$ & 1.4 & 3.3 & \\
\hline$[(\mathrm{HOP}) \mathrm{MIM}]^{+}[\mathrm{DCA}]^{-}$ & 1.6 & 4.0 & \\
\hline$[\mathrm{HO}-\mathrm{PPy}]^{+}[\mathrm{DCA}]^{-}$ & 1.7 & 4.2 & \\
\hline$[\mathrm{EMIM}]^{+}\left[\mathrm{NTf}_{2}\right]^{-}$ & 1.6 & 5.1 & \\
\hline$[\mathrm{OMIM}]^{+}\left[\mathrm{NTf}_{2}\right]^{-}$ & 2.8 & 12 & 30 \\
\hline$[\mathrm{Py}]^{+}\left[\mathrm{EOESO}_{4}\right]^{-}$ & 1.7 & 12 & 30 \\
\hline$\left[{ }_{4} \mathrm{BMPy}\right]^{+}[\mathrm{SCN}]^{-}$ & 1.7 & 14 & \\
\hline$[(\mathrm{BzM}) \mathrm{MIM}]^{+}[\mathrm{DCA}]^{-}$ & 1.8 & 16 & \\
\hline$[\mathrm{MP}=\mathrm{IM}]^{+}[\mathrm{DCA}]^{-}$ & 2.0 & 25 & \\
\hline$[\mathrm{HO}-\mathrm{PMMOR}]^{+}\left[\mathrm{NTf}_{2}\right]^{-}$ & 1.5 & 27 & \\
\hline$[\mathrm{BMMOR}]^{+}[\mathrm{TCM}]^{-}$ & 2.0 & & \\
\hline$\left[{ }_{4} \mathrm{BMPy}\right]^{+}[\mathrm{DCA}]^{-}$ & 2.2 & & \\
\hline$\left[_{\mathrm{EMIM}}\right]^{+}[\mathrm{TCM}]^{-}$ & 2.2 & & \\
\hline
\end{tabular}

${ }^{*}$ All abbreviations can be found in the symbol list.

Industrially, a process to separate n-butane/2-butene is licensed by KruppKoppers which uses a mixture of morpholine derivatives. ${ }^{48,52}$ Although this morpholine mixture is not part of the prediction results, amides such as nformylmorpholine, 2-pyrrolidone and n,n-dimethylformamide are indicated whereas $n, n$-dimethylformamide ${ }^{43,77}$ and $n$-formylmorpholine ${ }^{78}$ are shown to be adequate solvents. Dimethylsulfoxide is also predicted to be among the most preferred molecular solvents, which agrees with the liquid-liquid extraction patent by Carter et al. ${ }^{79}$ and the extractive distillation patent of Berg ${ }^{80}$ which focuses on the separation of 1-heptene/n-heptane. For the same reasons as for the aromatic - aliphatic separation, ILs with small highly polar anions, see Table 4.6 , e.g. thiocyanate $[\mathrm{SCN}]^{-}$, dicyanamide $[\mathrm{DCA}]^{-}$are preferred, though also the more hydrophobic bis(trifluoromethylsulfonyl)imide $\left[\mathrm{NTf}_{2}\right]^{-}$is seen to be able to induce a relative volatility of 1.5 or even 2.0. Overall, the ionic nature of the ILs allows for a lower S:F ratio to achieve the required relative volatility due to the additional ion-dipole interactions with the olefin. 


\subsubsection{Deoxygenation of Hydrocarbon streams}

The deoxygenation of hydrocarbon streams is required in several applications, e.g. for the upgrading of pyrolysis oil ${ }^{50,81}$ or microalgal oil ${ }^{51}$ and to purify the product stream in the methanol to olefins process. ${ }^{49}$

Table 4.7: The minimal Solvent-to-Feed ratio $\left(S: F_{\text {min }}\right)$ required to obtain an $\alpha_{i j, \min }$ of 3 of the top 15 molecular solvents for methanol, ethanol, n-propanol, 2-propanol, acetone and 2-butanone over n-hexane. The full list is present in section 4.5 .

\begin{tabular}{|c|c|c|c|c|c|c|}
\hline \multirow{2}{*}{ Molecular Solvent } & \multicolumn{6}{|c|}{ Minimum Solvent-to-Feed Ratio for $\alpha_{i j, \min }$ of 3} \\
\hline & $\mathrm{MeOH}$ & EtOH & $\mathrm{PrOH}$ & IPA & Acetone & 2-Butanone \\
\hline Dimethylsulfoxide & & 0.6 & & 0.6 & 1.6 & 0.7 \\
\hline 2-pyrrolidone & 1.0 & 0.7 & & & 2.0 & 0.5 \\
\hline N-methylformamide & 1.7 & 0.9 & & & 2.3 & 0.9 \\
\hline $\mathrm{N}$-formylmorpholine & 1.7 & 0.9 & 0.5 & 0.9 & 2.1 & 0.8 \\
\hline Ethylene Carbonate & 2.2 & 1.2 & & 1.1 & & \\
\hline N-methylpyrrolidone & 2.4 & 1.2 & 0.6 & & 15 & 1,4 \\
\hline N-ethylacetamide & 3.7 & 1.7 & & 1.5 & & 2.6 \\
\hline $\mathrm{N}, \mathrm{N}$-dimethylacetamide & & 2.0 & & 1.6 & & \\
\hline n-Octadecanol & & 2.1 & 1.2 & & 2.5 & \\
\hline Acetonitrile & & 2.2 & & & & \\
\hline Octane-1,8-diamine & & 2.7 & 9.8 & & & \\
\hline $\mathrm{N}, \mathrm{N}$-Diethylacetamide & & 2.8 & & 2.4 & & 24 \\
\hline n-Butanol & & 4.8 & 1.5 & & & 8.1 \\
\hline Acetone & & 5.0 & & & & 2.0 \\
\hline Triphenyl Phosphate & & 8.2 & 15 & & & \\
\hline
\end{tabular}

$\mathrm{MeOH}=$ Methanol, $\mathrm{EtOH}=$ Ethanol, $\mathrm{PrOH}=$ n-Propanol, IPA = 2-propanol

Oxygenates are often removed via a reactive pathway, even though a purification pathway does not reduce the value of these oxygenated chemicals. Several patents describe ways of performing this purification with a solvent that has a higher affinity towards the oxygenated solute ${ }^{82}$ or mentions methanol, ${ }^{83}$ propylene carbonate ${ }^{84}$ and dimethylsulfoxide ${ }^{85}$ as potential solvents. In our pre-selection, indeed dimethylsulfoxide, alcohols and a carbonate are identified as potential solvents for the deoxygenation of alcohols from hydrocarbons, as can be seen in Table 4.7. Additionally, the aprotic oxygenates acetone and 2-butanone are more difficult to remove than the protic oxygenates, due to the absence of hydrogen bond donating capabilities. While the required S:F ratio is higher for the aprotic oxygenates, it is still possible to separate them from n-hexane. 
Table 4.8: The minimal Solvent-to-Feed ratio $\left(S: F_{\text {min }}\right)$ required to obtain an $\alpha_{i j \text {,min }}$ of of the top 15 ILs for methanol, ethanol, n-propanol, 2-propanol, acetone and 2-butanone over n-hexane. The full list count be found in section 4.5.

\begin{tabular}{|c|c|c|c|c|c|c|}
\hline \multirow{2}{*}{ Ionic liquids Solvent } & \multicolumn{6}{|c|}{ Minimum Solvent-to-Feed Ratio for $\alpha_{i j, \min }$ of 3} \\
\hline & $\mathrm{MeOH}$ & $\mathrm{EtOH}$ & $\mathrm{PrOH}$ & IPA & Acetone & 2-Butanone \\
\hline$\left[\mathrm{N}_{1122 \mathrm{OH}}\right]^{+}[\mathrm{DEP}]^{-}$ & 0.6 & 0.5 & 0.2 & 0.4 & 0.4 & \\
\hline$[\mathrm{EMIM}]^{+}\left[\mathrm{EPO}_{3} \mathrm{H}\right]^{-}$ & 0.7 & 0.5 & 0.5 & 0.5 & & 0.6 \\
\hline$[\mathrm{BMPIP}]^{+}[\mathrm{SCN}]^{-}$ & 0.7 & 0.5 & & & 0.8 & \\
\hline$[\mathrm{HO}-\mathrm{PMMOR}]^{+}\left[\mathrm{NTf}_{2}\right]^{-}$ & 0.7 & 0.5 & 0.3 & 0.5 & 0.5 & \\
\hline$[\mathrm{BMIM}]^{+}[\mathrm{SCN}]^{-}$ & 0.7 & 0.6 & 0.4 & & & \\
\hline$[\mathrm{CpMIM}]^{+}[\mathrm{DCA}]^{-}$ & 0.8 & 0.6 & 0.4 & 0.6 & 0.8 & \\
\hline$[(\mathrm{HOP}) \mathrm{MIM}]^{+}[\mathrm{DCA}]^{-}$ & 0.8 & 0.6 & 0.8 & & 0.7 & \\
\hline$[\mathrm{EMIM}]^{+}[\mathrm{TFA}]^{-}$ & 0.8 & 0.6 & 0.5 & & & \\
\hline$[\mathrm{HO}-\mathrm{PPy}]^{+}[\mathrm{DCA}]^{-}$ & 0.8 & 0.6 & 0.5 & 0.6 & 0.7 & \\
\hline$[\mathrm{BMIM}]^{+}[\mathrm{TOS}]^{-}$ & 0.8 & 0.6 & 0.4 & & 1.6 & \\
\hline$[\mathrm{EMIM}]^{+}[\mathrm{SCN}]^{-}$ & 0.8 & 0.6 & 0.5 & & & \\
\hline$[\mathrm{EMIM}]^{+}\left[\mathrm{ESO}_{4}\right]^{-}$ & 0.8 & 0.6 & 0.5 & & 1.1 & \\
\hline$\left[{ }_{4} \mathrm{BMPy}\right]^{+}[\mathrm{SCN}]^{-}$ & 0.8 & 0.6 & & & 1.0 & \\
\hline$[\mathrm{MMIM}]^{+}\left[\mathrm{MSO}_{4}\right]^{-}$ & 0.8 & & 0.4 & & & \\
\hline$[(\mathrm{BzM}) \mathrm{MIM}]^{+}[\mathrm{DCA}]^{-}$ & 0.8 & 0.6 & 0.5 & 0.6 & 0.8 & \\
\hline
\end{tabular}

$\mathrm{MeOH}=$ Methanol, EtOH $=$ Ethanol, $\mathrm{PrOH}=$ n-Propanol, IPA = 2-propanol

In Table 4.8, it can be seen that overall the separation of oxygenates is feasible with all kinds of ILs with a low S:F ratio. $\left[\mathrm{N}_{1122 \mathrm{OH}}\right]^{+}[\mathrm{DEP}]^{-}$is observed to be the most efficient in increasing the relative volatility of all oxygenates to at least 3. However, many other ILs can perform this task with a low S:F ratio as well.

In Table 4.9, it is illustrated that DES's are just as able to separate the oxygenates from a hydrocarbon stream as ILs. An interesting observation is that the best performing IL contains a cation that is highly similar to the choline cation in the DES's. The strong repulsion of n-hexane can, among others, be attributed to the intermolecular cation-cation interaction through hydrogen bonds within the $\left[\mathrm{N}_{1122 \mathrm{OH}}\right]^{+}$-based IL and choline chloride-based DES. ${ }^{86}$ The alcohols can participate in these hydrogen-bonding interactions, which increases the relative volatility even further. This also explains why a lower relative volatility is seen with ketones, as they cannot donate a hydrogen bond, and can only interact via hydrogen bond acceptation. The $\left[\mathrm{N}_{1122 \mathrm{OH}}\right]^{+}$-based 
IL incorporates a diethylphosphate, $[\mathrm{DEP}]^{-}$, anion, while the DES has ethylene glycol as the counterpart. These counterparts induce significantly different interactions, as [DEP $]^{-}$primarily accepts hydrogen bonds, whereas ethylene glycol forms hydrogen-bond networks and can both accept- and donate hydrogen bonds. ${ }^{87}$ Overall, both solvents can entrain the oxygenates with low S:F ratios and can facilitate the removal of hydrocarbons.

Table 4.9: The minimal Solvent-to-Feed ratio $\left(S: F_{\text {min }}\right)$ required to obtain an $\alpha_{i j \text {,min }}$ of of the DES's for methanol, ethanol, n-propanol, 2-propanol, acetone and 2-butanone over n-hexane.

\begin{tabular}{|l|l|l|l|l|l|l|}
\hline \multirow{2}{*}{$\begin{array}{l}\text { Deep Eutectic Solvent pair } \\
\text { (mole ratio) }\end{array}$} & \multicolumn{4}{|c|}{ Minimum Solvent-to-Feed Ratio for $\alpha_{i j, \min }$ of 3} \\
\cline { 2 - 7 } & MeOH & EtOH & PrOH & IPA & Acetone & 2-Butanone \\
\hline CC:Ethylene Glycol (1:3) & 0.4 & 0.9 & 0.8 & 0.7 & 0.7 & 0.5 \\
CC:Glycerol (1:1) & 0.37 & 0.9 & 0.8 & 0.7 & 0.7 & 0.5 \\
CC:Glycerol (1:2) & 0,9 & 0.7 & 0.5 & 0.7 & 2.4 & 1.3 \\
{$\left[\mathrm{~N}_{3333}\right]^{+}[\mathrm{Br}]^{-}: 1,6$-hexanediol } & 1.2 & 0.7 & 0.4 & 0.8 & 0.7 & 1.1 \\
$(1: 2)$ & & & & & \\
\hline
\end{tabular}

$\mathrm{CC}=$ Choline Chloride, $\left[\mathrm{N}_{3333}\right]^{+}[\mathrm{Br}]^{-}=$tetrapropylammonium bromide, $\mathrm{MeOH}=$ Methanol, $\mathrm{EtOH}=$ Ethanol, $\mathrm{PrOH}=$ n-Propanol, $\mathrm{IPA}=2$-propanol

Thus far, solvents have been discussed that increase the volatility of the nhexane, while entraining the oxygenates. Considering that the oxygenates are minor compounds in many hydrocarbon streams, solvents that may induce the opposite effect are also evaluated, see Table 4.10.

Apolar solvents, such as $\mathrm{C}_{6}$ to $\mathrm{C}_{16}$ alkanes, and to a lesser extent toluene and chloroform, are predicted to be able to separate the oxygenates as low-boiling solute. This is in line with the earlier mentioned azeotropic distillation with alkanes, ${ }^{88-91}$ where the more polar compounds, in that case, water, could be collected over the top. At much higher S:F ratios, also the IL $[\mathrm{BMIM}]^{+}[\mathrm{BOB}]^{-}$ appears to repulse the oxygenates and entrain the hydrocarbon. This is unexpected, as the ionic nature of the ILs repel alkanes significantly, as could be seen in the apolar separations. However, the imidazolium cation in combination with the structurally similar bis(oxalato)borate $[\mathrm{BOB}]^{-}$may cause a strongly ordered cation-anion stacking ${ }^{92}$ and shields the charges sufficiently to induce a relative volatility increase towards the oxygenates. 
Table 4.10: The minimal Solvent-to-Feed ratio $\left(S: F_{\text {min }}\right)$ required to obtain an $\alpha_{i j, \text { min }}$ of 3 of solvents for $n$-hexane over methanol, ethanol, n-propanol, 2-propanol and acetone over $n$-hexane. No solvent was found with an $\alpha_{i j, \min }$ of 3 for the n-hexane/2-butanone case.

\begin{tabular}{|l|l|l|l|l|l|}
\hline \multirow{2}{*}{ Solvents } & \multicolumn{5}{|l|}{ Minimum Solvent-to-Feed Ratio for $\alpha_{i j, \min }$ of 3} \\
\cline { 2 - 6 } & MeOH & EtOH & PrOH & IPA & Acetone \\
\hline Cyclohexane & 1.5 & 3.3 & & 4.8 & \\
n-Heptane & 1.5 & 3.1 & 6.8 & 3.7 & 2.7 \\
n-Octane & 1.3 & 3.2 & 13 & 4.5 & 2.7 \\
n-Nonane & & 2.5 & & & \\
n-Hexadecane & 1.5 & 3.9 & & & \\
Sunflower Oil & 3.8 & & & & \\
Toluene & 4.2 & & & & \\
Chloroform & 9.0 & & & & \\
Diisodecyl phthalate & 12 & & & & \\
Dibutyl tetrachlorophthalate & 12 & & & & \\
n-Octadecanol & 22 & & & & \\
[BMIM $]^{+}[\text {BOB }]^{-}$ & 28 & 27 & 27 & & \\
\hline MeOH = Methanol, EtOH = Ethanol, PrOH $=$ n-Propanol, IPA = 2-propanol &
\end{tabular}

\subsection{Conclusions}

An easily accessible approach is presented which uses an open-access $\gamma_{i j}^{\infty}$ database and the 3-component Margules equation to allow fast pre-selection of solvents, including ILs and deep eutectic solvents, for extractive distillation fluid separations at isobaric conditions. In this manner, binary and ternary vapor-liquid equilibria can be determined under both isothermal and isobaric conditions and the solvent-to-feed effect can be determined. Generally, the infinite diluted selectivity $\left(S_{j i}^{\infty}\right)$ is often determined as an early indication of the applicability of the solvent for certain industrial separations. Although the $S_{j i}^{\infty}$ gives a measure of the solvent's affinity, it cannot evaluate non-idealities that occur at finite concentration, e.g. the occurrence of an azeotrope or a pinch-point. Nevertheless, via this approach, a strong correlation could be made between the $S_{j i}^{\infty}$ and the minimal Solvent-to-Feed ratio $\left(S: F_{\min }\right)$ at isothermal conditions.

The identified molecular solvents based on the proposed pre-selection methodology for industrial examples are in line with literature results or are already applied on an industrial level. This indicates the validity of this pre-selection 
method. For each separation example, various solvents were identified. It should be realized that structurally similar solvents, for which the $\gamma_{i j}^{\infty}$ are not known, can potentially perform similarly. It was seen that overall either small polar molecules (ethylene glycol, dimethylsulfoxide) and/or cyclic molecules (Sulfolane, $\mathrm{n}$-formylmorpholine) are preferred. Potential alternatives to be considered are ethylene carbonate (already present in the evaluation), dihydrolevoglucosenone ${ }^{15}$ and $\gamma$-valerolactone. ${ }^{93}$ The next step is to investigate these molecules to additional criteria such as thermal stability, tendency to hydrolyze in presence of water, auto(catalytic)-decomposition and the the boiling point of the solvent, before the final solvent choice can be made.

The method has also proven to be useful in the pre-selection of ILs, and potentially DES's. In the vast variety of possible combinations, the morpholinium and the ammonium-type cation were identified to have the highest potential to increase the relative volatilities. The similar ammonium-based ILs/DES's are highly interesting and should be the first point of attention in new solvent development, based on the choline chloride-based DES and $\left[N_{1122 O H}^{-}\right]$-based IL comparison shown. The morpholinium cation is also seen to exhibit preferential behavior and as Germani et al. ${ }^{94}$ have shown, also structurally similar DES's can be made containing a morpholinium-type HBA. Although more $\gamma_{i j}^{\infty}$ values of DES's are required to evaluate more of these solvents, their potential was shown for aromatic/aliphatic separations. 


\subsection{Electronic Supplementary Information}

All values and errors of the $\gamma_{i}^{\infty}$ used for the methodology used in this Chapter are the same as used in chapter 3.

All results concerning the determination of the $S: F_{\min }$ is available free of charge at https://www.scribd.com/document/492159366/ESI-Chapter-4, due to the fact this chapter is not yet published.

\subsection{Nomenclature}

$\begin{array}{ll}{[(\mathrm{BzM}) \mathrm{MIM}]^{+}} & =1 \text {-benzyl-3-methylimidazolium } \\ {[(\mathrm{ClE}) \mathrm{MIM}]^{+}} & =1 \text {-(2-chloroethyl)-3-methylimidazolium } \\ {[(\mathrm{HOE}) \mathrm{MIM}]^{+}} & =1 \text {-(2-hydroxyethyl)-3-methylimidazolium } \\ {[\mathrm{HO}-\mathrm{EMIM}]^{+}} & =1 \text {-(2-hydroxyethyl)-3-methylimidazolium } \\ {[(\mathrm{HOP}) \mathrm{MIM}]^{+}} & =1 \text {-(3-hydroxypropyl)-3-methylimidazolium } \\ {[(\mathrm{HOP}) \mathrm{MMor}]^{+}} & =1 \text {-(3-hydroxypropyl)-1-methylmorpholinium } \\ {[\mathrm{HO}-\mathrm{PMMor}]^{+}} & =1 \text {-(3-hydroxypropyl)-1-methylmorpholinium } \\ {\left[{ }_{4} \mathrm{BMP}\right]^{+}} & =4 \text {-methyl-n-butylpyridinium } \\ {[\mathrm{BMIM}]^{+}} & =1 \text {-butyl-3-methylimidazolium } \\ {[\mathrm{BMMOR}]^{+}} & =1 \text {-butyl-1-methylmorpholinium } \\ {[\mathrm{BMPIP}]^{+}} & =1 \text {-butyl-1-methylpiperidinium } \\ {[\mathrm{BMPyr}]^{+}} & =1 \text {-butyl-1-methylpyrrolidinium } \\ {[\mathrm{CpMIM}]^{+}} & =1 \text {-(3-cyanopropyl)-1-methylimidazolium } \\ {[\mathrm{CpMPyr}]^{+}} & =1 \text {-(3-cyanopropyl)-1-methylpyrrolidinium } \\ {[E M I M]^{+}} & =1 \text {-ethyl-3-methylimidazolium } \\ {[E M M O R]^{+}} & =1 \text {-ethyl-1-methylmorpholinium } \\ {[\mathrm{HO}-\mathrm{EMP} \mathrm{C}]^{+}} & =1 \text {-hydroxyethyl-1-methylpyrrolidinium } \\ {[\mathrm{HO}-\mathrm{PP}]^{+}} & =1 \text {-(3-Hydroxypropyl)pyridinium } \\ {[\mathrm{MMIM}]^{+}} & =1 \text {-3-dimethylimidazolium } \\ {[\mathrm{MP}=\mathrm{IM}]^{+}} & =1 \text {-allyl-3-methylimidazolium } \\ {\left[\mathrm{N}_{1,1,1,2 \mathrm{OH}}\right]^{+}} & =\text {trimethylhydroxyethyl ammonium or choline } \\ {\left[\mathrm{N}_{1,1,2,2 \mathrm{OH}}\right]^{+}} & =\text {dimethylethylhydroxyethyl ammonium } \\ & \end{array}$




\begin{tabular}{|c|c|c|}
\hline$\left[N_{3,3,3,3}\right]^{+}$ & $=$ & tetrapropyl ammonium \\
\hline$[O M I M]^{+}$ & $=$ & 1-octyl-3-methylimidazolium \\
\hline$[P y]^{+}$ & $=$ & pyridinium \\
\hline$\left[\mathrm{BF}_{4}\right]^{-}$ & $=$ & tetrafluoroborate \\
\hline$[B O B]^{-}$ & $=$ & bis(oxalato)borate \\
\hline$[\mathrm{Br}]^{-}$ & $=$ & bromide \\
\hline$[\mathrm{Cl}]^{-}$ & $=$ & chloride \\
\hline$[D C A]^{-}$ & $=$ & dicyanamide \\
\hline$[D E P]^{-}$ & $=$ & diethylphosphate \\
\hline$\left[\mathrm{EOESO}_{4}\right]^{-}$ & $=$ & ethoxyethylsulfate \\
\hline$\left[\mathrm{EPO}_{3} \mathrm{H}\right]^{-}$ & $=$ & ethylphosphonate \\
\hline$\left[\mathrm{ESO}_{4}\right]^{-}$ & $=$ & ethylsulfate \\
\hline$[L A]^{-}$ & $=$ & lactate \\
\hline$\left[\mathrm{MDEGSO}_{4}\right]^{-}$ & $=$ & diethylenegycol monomethyl ether sulfate \\
\hline$\left[\mathrm{MSO}_{3}\right]^{-}$ & $=$ & methylsulfonate \\
\hline$\left[\mathrm{MSO}_{4}\right]^{-}$ & $=$ & methylsulfate \\
\hline$\left[N T f_{2}\right]^{-}$ & $=$ & bis(trifluoromethylsulfonyl)imide \\
\hline$[S C N]^{-}$ & $=$ & thiocyanate \\
\hline$[T C M]^{-}$ & $=$ & tricyanomethanide \\
\hline$[T F A]^{-}$ & $=$ & trifluoroacetate \\
\hline $\mathrm{AAD}_{T}$ & $=$ & average deviation of temperature \\
\hline $\mathrm{AAD}_{x}$ & $=$ & average deviation of concentration \\
\hline $\mathrm{A}_{i j}$ & $=$ & $\begin{array}{l}\text { binary interaction coefficient between compounds } i \\
\text { and } j\end{array}$ \\
\hline $\mathrm{A}_{i j k}$ & $=$ & $\begin{array}{l}\text { ternary interaction coefficient between compounds, } \mathrm{i} \text {, } \\
\mathrm{j} \text { and } \mathrm{k}\end{array}$ \\
\hline$\alpha_{i j}^{I D}$ & $=$ & ideal relative volatility \\
\hline$\alpha_{i j}$ & $=$ & relative volatility of compound i over compound j \\
\hline$\alpha_{i j, \min }$ & $=$ & $\begin{array}{l}\text { minimum relative volatility of compound } i \text { over com- } \\
\text { pound } j\end{array}$ \\
\hline $\mathrm{B}_{i j k}$ & $=$ & $\begin{array}{l}\text { ternary interaction term between compounds } \mathrm{i}, \mathrm{j} \text { and } \\
\mathrm{k}\end{array}$ \\
\hline CAMD & $=$ & computer-aided molecular design \\
\hline $\mathrm{CC}$ & $=$ & choline chloride or $\left[\mathrm{N}_{1,1,1,2 \mathrm{OH}}\right]^{+}[\mathrm{Cl}]^{-}$ \\
\hline COSMO-RS & $=$ & conductor like screening model for real solvents \\
\hline
\end{tabular}




\begin{tabular}{|c|c|c|}
\hline$\Delta H_{i}^{\infty}$ & $=$ & $\begin{array}{l}\text { molar enthalpy at infinite dilution of compound } i \text { in } \\
\text { solvent } j\end{array}$ \\
\hline$\Delta S_{i}^{\infty}$ & $=$ & $\begin{array}{l}\text { molar entropy at infinite dilution of compound } i \text { in sol- } \\
\text { vent } j\end{array}$ \\
\hline DES & $=$ & deep eutectic solvent \\
\hline DMF & $=$ & n,n-dimethylformamide \\
\hline$\gamma_{i}$ & $=$ & activity coefficient of compound i \\
\hline$\gamma_{i}^{\infty}$ & $=$ & infinite dilution activity coefficient of compound i \\
\hline $\mathrm{G}^{E}$ & $=$ & excess Gibbs energy term \\
\hline HBA & $=$ & hydrogen bond acceptor \\
\hline HBD & $=$ & hydrogen bond donor \\
\hline IL & $=$ & ionic liquid \\
\hline MINP & $=$ & mixed-integer nonlinear programming \\
\hline $\mathrm{N}$ & $=$ & number of data points or systems \\
\hline NHB & $=$ & non hydrogen bonding \\
\hline NIST & $=$ & national institute of standard and technology \\
\hline NMP & $=$ & n-methylpyrrolidone \\
\hline$P_{i}^{o}$ & $=$ & saturation vapor pressure of compound i (mbar) \\
\hline $\mathrm{R}$ & $=$ & universal gas constant \\
\hline REACH & $=$ & $\begin{array}{l}\text { registration, evaluation, authorisation and restriction } \\
\text { of chemicals }\end{array}$ \\
\hline S (subscript) & $=$ & solvent \\
\hline S:F & $=$ & solvent-to-feed ratio (mole basis) \\
\hline$S: F_{\min }$ & $=$ & minimum solvent-feed ratio (mole basis) \\
\hline & $=$ & selectivity of compound $\mathrm{j}$ over compound $\mathrm{i}$ \\
\hline$S_{j i, \min }$ & $=$ & minimum Selectivity of compound $\mathrm{j}$ over compound $\mathrm{i}$ \\
\hline$S_{j i, \text { min }}^{\infty}$ & $=$ & $\begin{array}{l}\text { minimum Selectivity of compound } \mathrm{j} \text { over compound I } \\
\text { at infinite dilution }\end{array}$ \\
\hline UNIFAC & $=$ & $\begin{array}{l}\text { universal quasichemical functional-group activity coef- } \\
\text { ficients }\end{array}$ \\
\hline VLE & $=$ & vapor-liquid equilibrium \\
\hline$\chi_{\text {experimental }}$ & $=$ & experimental point \\
\hline$x_{i}$ & $=$ & molar fraction of compound i \\
\hline$\chi_{\text {model }}$ & $=$ & modeled point \\
\hline$\varphi_{i}$ & $=$ & fugacity coefficient of compound i \\
\hline
\end{tabular}




\section{SOLVENT PRE-SELECTION FOR EXTRACTIVE DISTILLATION}

\subsection{References}

[1] D. S. Sholl and R. P. Lively, "Seven chemical separations to change the world," Nature, vol. 532, no. 7600, pp. 435-437, 2016.

[2] R. Agrawal and R. T. Gooty, "Misconceptions about efficiency and maturity of distillation," AIChE Journal, p. e16294.

[3] M. Blahušiak, A. A. Kiss, S. R. Kersten, and B. Schuur, "Quick assessment of binary distillation efficiency using a heat engine perspective," Energy, vol. 116, pp. 20-31, 2016.

[4] J. D. Seader, E. J. Henley, and D. K. Roper, Separation process principles, vol. 25. Wiley New York, 1998.

[5] M. Fahim and A. Elkilani, "Prediction of optimum composition of the mixed solvent nmethylpyrrolidone/ethylene glycol for the extraction of aromatics," Separation Science and Technology, vol. 25, no. 13-15, pp. 1803-1815, 1990.

[6] Z. Lei, R. Zhou, and Z. Duan, "Process improvement on separating c4 by extractive distillation," Chemical Engineering Journal, vol. 85, no. 2-3, pp. 379-386, 2002.

[7] M. E. Andersen, R. A. Jones, R. G. Mehl, T. A. Hill, L. Kurlansik, and L. J. Jenkins Jr, "The inhalation toxicity of sulfolane (tetrahydrothiophene-1, 1-dioxide)," Toxicology and applied pharmacology, vol. 40, no. 3, pp. 463-472, 1977.

[8] H. Senoh, S. Aiso, H. Arito, T. Nishizawa, K. Nagano, S. Yamamoto, and T. Matsushima, "Carcinogenicity and chronic toxicity after inhalation exposure of rats and mice to n, n-dimethylformamide," Journal of occupational health, vol. 46, no. 6, pp. 429-439, 2004.

[9] A. Jouyban, M. A. A. Fakhree, and A. Shayanfar, "Review of pharmaceutical applications of n-methyl-2pyrrolidone," Journal of Pharmacy \& Pharmaceutical Sciences, vol. 13, no. 4, pp. 524-535, 2010.

[10] E. A. Greene, L. M. Gieg, D. L. Coy, and P. M. Fedorak, "Sulfolane biodegradation potential in aquifer sediments at sour natural gas plant sites," Water research, vol. 32, no. 12, pp. 3680-3688, 1998.

[11] S. Cai, T. Cai, S. Liu, Q. Yang, J. He, L. Chen, and J. Hu, "Biodegradation of n-methylpyrrolidone by paracoccus sp. nmd-4 and its degradation pathway," International Biodeterioration E Biodegradation, vol. 93, pp. 70-77, 2014.

[12] World Health Organization, "Concise international chemical assessment document 35 n-methyl-2pyrrolidone," World Health Organization, 2001.

[13] K. Sitarek and J. Stetkiewicz, "Assessment of reproductive toxicity and gonadotoxic potential of n-methyl2-pyrrolidone in male rats," International journal of occupational medicine and environmental health, vol. 21, no. 1, pp. 73-80, 2008.

[14] L. Bergkamp and N. Herbatschek, "Regulating chemical substances under reach: the choice between authorization and restriction and the case of dipolar aprotic solvents," Review of European, Comparative $\mathcal{E}$ International Environmental Law, vol. 23, no. 2, pp. 221-245, 2014.

[15] T. Brouwer and B. Schuur, "Bio-based solvents as entrainers for extractive distillation in aromatic/aliphatic and olefin/paraffin separation," Green Chemistry, 2020.

[16] B. Schuur, T. Brouwer, D. Smink, and L. M. J. Sprakel, "Green solvents for sustainable separation processes," Current Opinion in Green and Sustainable Chemistry, vol. 18, pp. 57-65, 2019.

[17] M. Skiborowski, "Process synthesis and design methods for process intensification," Current Opinion in Chemical Engineering, vol. 22, pp. 216-225, 2018.

[18] A. S. Alshehri, R. Gani, and F. You, "Deep learning and knowledge-based methods for computer aided molecular design-toward a unified approach: State-of-the-art and future directions," arXiv preprint arXiv:2005.08968, 2020.

[19] R. Gani, B. Nielsen, and A. Fredenslund, "A group contribution approach to computer-aided molecular design," AIChE Journal, vol. 37, no. 9, pp. 1318-1332, 1991.

[20] P. M. Harper, R. Gani, P. Kolar, and T. Ishikawa, "Computer-aided molecular design with combined molecular modeling and group contribution," Fluid Phase Equilibria, vol. 158, pp. 337-347, 1999.

[21] P. M. Piccione, J. Baumeister, T. Salvesen, C. Grosjean, Y. Flores, E. Groelly, V. Murudi, A. Shyadligeri, O. Lobanova, and C. Lothschutz, "Solvent selection methods and tool," Organic Process Research E Development, vol. 23, no. 5, pp. 998-1016, 2019.

[22] P. Kolár. J.-W. Shen, A. Tsuboi, and T. Ishikawa, "Solvent selection for pharmaceuticals," Fluid Phase Equilibria, vol. 194, pp. 771-782, 2002. 


\section{SOLVENT PRE-SELECTION FOR EXTRACTIVE DISTILLATION}

[23] E. J. Pretel, P. A. López, S. B. Bottini, and E. A. Brignole, "Computer-aided molecular design of solvents for separation processes," AIChE Journal, vol. 40, no. 8, pp. 1349-1360, 1994.

[24] F. Eckert and A. Klamt, "Fast solvent screening via quantum chemistry: Cosmo-rs approach," AIChE Journal, vol. 48, no. 2, pp. 369-385, 2002.

[25] J. Scheffczyk, C. Redepenning, C. M. Jens, B. Winter, K. Leonhard, W. Marquardt, and A. Bardow, "Massive, automated solvent screening for minimum energy demand in hybrid extraction-distillation using cosmo-rs," Chemical Engineering Research and Design, vol. 115, pp. 433-442, 2016.

[26] T. Zhou, K. McBride, S. Linke, Z. Song, and K. Sundmacher, "Computer-aided solvent selection and design for efficient chemical processes," Current Opinion in Chemical Engineering, vol. 27, pp. 35-44, 2020.

[27] T. Brouwer, S. Kersten, G. Bargeman, and B. Schuur, "Trends in solvent impact on infinite dilution activity coefficients of solutes reviewed and visualized using an algorithm to support selection of solvents for greener fluid separations," Separation and Purification Technology, (In progress).

[28] B. Mukhopadhyay, S. Basu, and M. J. Holdaway, "A discussion of margules-type formulations for multicomponent solutions with a generalized approach," Geochimica et Cosmochimica Acta, vol. 57, no. 2, pp. 277-283, 1993.

[29] E. P. Schulz and G. A. Durand, "Equation oriented mixed micellization modeling based on asymmetric margules-type formulations," Computers \& Chemical Engineering, vol. 87, pp. 145-153, 2016.

[30] R. B. Pereyra, E. P. Schulz, G. A. Durand, J. L. Rodriguez, R. M. Minardi, H. A. Ritacco, and P. C. Schulz, "Equation-oriented mixed micellization modeling of a subregular ternary surfactant system with potential medical applications," Industrial E Engineering Chemistry Research, vol. 56, no. 39, pp. 10972-10980, 2017.

[31] P. Serafini, M. F. Leyes, R. B. Pereyra, E. P. Schulz, G. A. Durand, P. C. Schulz, H. A. Ritacco, et al., "The aqueous triton $\mathrm{x}-100$-dodecyltrimethylammonium bromidemicellar mixed system. experimental results and thermodynamic analysis," Colloids and Surfaces A: Physicochemical and Engineering Aspects, vol. 559, pp. 127-135, 2018.

[32] R. B. Pereyra, G. A. Durand, M. F. Leyes, H. Ritacco, and E. P. Schulz, "Homologous mixed micellar systems with non-ideal and asymmetric thermodynamic behavior," Colloids and Surfaces A: Physicochemical and Engineering Aspects, p. 124626, 2020.

[33] A. Rohrbach and M. W. Schmidt, "Redox freezing and melting in the earth's deep mantle resulting from carbon-iron redox coupling," Nature, vol. 472, no. 7342, pp. 209-212, 2011

[34] C. DeCapitani and M. Kirschen, "A generalized multicomponent excess function with application to immiscible liquids in the system cao-sio2-tio2," Geochimica et cosmochimica acta, vol. 62, no. 23-24, pp. 37533763, 1998.

[35] R. T. Pabalan and F. P. Bertetti, "Experimental and modeling study of ion exchange between aqueous solutions and the zeolite mineral clinoptilolite," Journal of solution chemistry, vol. 28, no. 4, pp. 367-393, 1999.

[36] M. Holdaway, "Application of new experimental and garnet margules data to the garnet-biotite geothermometer," American Mineralogist, vol. 85, no. 7-8, pp. 881-892, 2000.

[37] C.-M. Wu, J. Zhang, and L.-D. Ren, "Empirical garnet-biotite-plagioclase-quartz (gbpq) geobarometry in medium-to high-grade metapelites," Journal of Petrology, vol. 45, no. 9, pp. 1907-1921, 2004.

[38] A. A. Kiss, S. J. F. Landaeta, and C. A. I. Ferreira, "Towards energy efficient distillation technologiesmaking the right choice," Energy, vol. 47, no. 1, pp. 531-542, 2012.

[39] M. Doherty and M. Malone, "Conceptual design of distillation systems mcgraw-hill," New York, 2001.

[40] M. Blahušiak, A. A. Kiss, K. Babic, S. R. Kersten, G. Bargeman, and B. Schuur, "Insights into the selection and design of fluid separation processes," Separation and purification technology, vol. 194, pp. 301-318, 2018.

[41] C.-C. Hu and S.-H. Cheng, "Development of alternative methanol dimethyl carbonate separation systems by extractive distillation-a holistic approach," Chemical Engineering Research and Design, vol. 127, pp. 189-214, 2017.

[42] Q. Wang, B. Yu, and C. Xu, "Design and control of distillation system for methylal/methanol separation. part 1: Extractive distillation using $\mathrm{dmf}$ as an entrainer," Industrial \& engineering chemistry research, vol. 51, no. 3, pp. 1281-1292, 2012.

[43] Z. Lei, B. Chen, and Z. Ding, Special distillation processes. Elsevier, 2005. 


\section{SOLVENT PRE-SELECTION FOR EXTRACTIVE DISTILLATION}

[44] I. Nagata and J. Nakajima, "Modification of the nrtl model for ternary and quaternary liquid-liquid equilibrium calculations," Fluid phase equilibria, vol. 70, no. 2-3, pp. 275-292, 1991.

[45] D. Siderius, "Nist standard reference simulation website," 2012.

[46] C. L. Yaws, The Yaws handbook of vapor pressure: Antoine coefficients. Gulf Professional Publishing, 2015.

[47] F. Abushwireb, H. Elakrami, and M. Emtir, "Recovery of aromatics from pyrolysis gasoline by conventional and energy-integrated extractive distillation," Computer Aided Chemical Engineering, vol. 24, p. 1071, 2007.

[48] J. Liu, X. Chen, S. Zhao, X. Cao, and B. Shen, "Multicycle investigation of normal paraffin separation from naphtha to improve olefin and aromatic feed," Industrial \& Engineering Chemistry Research, vol. 54, no. 50, pp. 12664-12670, 2015.

[49] P. Barger, "Methanol to olefins (mto) and beyond," CATALYTIC SCIENCE SERIES, vol. 3, pp. 239-260, 2002.

[50] F. de Miguel Mercader, M. Groeneveld, S. Kersten, N. Way, C. Schaverien, and J. Hogendoorn, "Production of advanced biofuels: Co-processing of upgraded pyrolysis oil in standard refinery units," Applied Catalysis B: Environmental, vol. 96, no. 1-2, pp. 57-66, 2010

[51] C. Zhao, T. Brück, and J. A. Lercher, "Catalytic deoxygenation of microalgae oil to green hydrocarbons," Green Chemistry, vol. 15, no. 7, pp. 1720-1739, 2013.

[52] R. B. Eldridge, "Olefin/paraffin separation technology: a review," Industrial \& engineering chemistry research, vol. 32, no. 10, pp. 2208-2212, 1993.

[53] G. Emmrich, "Advances in the separation of c4 hydrocarbons: separation of paraffinic and olefinic c4 hydrocarbons," Krupp Koppers Tech. Publ, 1986.

[54] R. KUMAR, J. M. Prausnitz, and C. J. King, "Process design considerations for extractive distillation: separation of propylene-propane," ACS Publications, 1972.

[55] T. Michishita, Y. Arai, and S. Saito, "Vapor-liquid equilibria of hydrocarbons at atmospheric pressure," Kagaku Kogaku, vol. 35, no. 1, pp. 111-116, 1971.

[56] B. Blanco, M. T. Sanz, S. Beltran, J. L. Cabezas, and J. Coca, "Vapor- liquid equilibria of the ternary system benzene+ n-heptane+ n-methylpyrrolidone (nmp) at $101.33 \mathrm{kpa}$," Journal of Chemical E Engineering Data, vol. 47, no. 5, pp. 1167-1170, 2002.

[57] U. Domańska, M. Karpińska, A. Wiśniewska, and Z. Dąbrowski, "Ammonium ionic liquids in extraction of bio-butan-1-ol from water phase using activity coefficients at infinite dilution," Fluid Phase Equilibria, vol. 479, pp. 9-16, 2019.

[58] A. Marciniak, "Influence of cation and anion structure of the ionic liquid on extraction processes based on activity coefficients at infinite dilution. a review," Fluid phase equilibria, vol. 294, no. 1-2, pp. 213-233, 2010.

[59] K. Shimizu, M. F. Costa Gomes, A. A. Padua, L. P. N. Rebelo, and J. N. Canongia Lopes, "On the role of the dipole and quadrupole moments of aromatic compounds in the solvation by ionic liquids," The Journal of Physical Chemistry B, vol. 113, no. 29, pp. 9894-9900, 2009.

[60] C. A. Hunter, K. R. Lawson, J. Perkins, and C. J. Urch, "Aromatic interactions," Journal of the Chemical Society, Perkin Transactions 2, no. 5, pp. 651-669, 2001.

[61] U. Domańska, M. Karpińska, and M. Wlazło, "Thermodynamic study of molecular interaction-selectivity in separation processes based on limiting activity coefficients," The Journal of Chemical Thermodynamics, vol. 121, pp. 112-120, 2018.

[62] R. Kuchhal, P. Dogra, K. Sharma, K. Jauhri, and P. Gupta, "Determination of 3-sulfolene in sulfolane by reaction gas chromatography," Fresenius' Zeitschrift für analytische Chemie, vol. 286, no. 3-4, pp. 219-221, 1977.

[63] J. C. Gentry, L. Berg, J. C. McIntyre, and R. W. Wytcherley, "Process to recover benzene from mixed hydrocarbons by extractive distillation," Mar. 21 1995. US Patent 5,399,244.

[64] H. Zhu, X.-l. Shi, and W.-y. Zhou, "Process simulation and parameter optimization of separating aromatics and non-aromatics by extractive distillation with n-formylmorpholine," Journal of East China University of Science and Technology (Natural Science Edition), vol. 34, no. 3, pp. 309-31, 2008.

[65] G. Somekh and B. Friedlander, "Tetraethylene glycol—a superior solvent for aromatics extraction," ACS Publications, 1970.

[66] R. M. Butler and J. A. Bichard, "Separation of aromatics from hydrocarbon streams," Dec. 17 1963. US 


\section{SOLVENT PRE-SELECTION FOR EXTRACTIVE DISTILLATION}

Patent 3,114,783.

[67] M. North, P. Villuendas, and C. Young, "A gas-phase flow reactor for ethylene carbonate synthesis from waste carbon dioxide," Chemistry-A European Journal, vol. 15, no. 43, pp. 11454-11457, 2009.

[68] M. Mohsen-Nia and F. M. Doulabi, "Separation of aromatic hydrocarbons (toluene or benzene) from aliphatic hydrocarbon (n-heptane) by extraction with ethylene carbonate," The Journal of Chemical Thermodynamics, vol. 42, no. 10, pp. 1281-1285, 2010.

[69] W. Peppel, "Preparation and properties of the alkylene carbonates," Industrial \& Engineering Chemistry, vol. 50, no. 5, pp. 767-770, 1958.

[70] O. Yamamoto, T. Sasamoto, and M. Inagaki, "Indium tin oxide thin films prepared by thermal decomposition of ethylene glycol solution," Journal of materials research, vol. 7, no. 9, pp. 2488-2491, 1992.

[71] Y. Deguchi, M. Kono, Y. Koizumi, Y.-i. Izato, and A. Miyake, "Study on autocatalytic decomposition of dimethyl sulfoxide (dmso)," Organic Process Research E Development, vol. 24, no. 9, pp. 1614-1620, 2020.

[72] G. W. Meindersma, A. R. Hansmeier, and A. B. de Haan, "Ionic liquids for aromatics extraction. present status and future outlook," Industrial \& Engineering Chemistry Research, vol. 49, no. 16, pp. 7530-7540, 2010.

[73] K. Paduszyński, M. Królikowski, and P. Orzeł, "Thermodynamic properties of infinitely diluted solutions of organic solutes in in silico designed task-specific ionic liquid," Journal of Molecular Liquids, vol. 279, pp. 733-739, 2019.

[74] K. Paduszynéski and M. Kroélikowska, "Effect of side chain functional group on interactions in ionic liquid systems: Insights from infinite dilution thermodynamic data," The Journal of Physical Chemistry B, vol. 121, no. 43, pp. 10133-10145, 2017.

[75] M. Larriba, M. Ayuso, P. Navarro, N. Delgado-Mellado, M. Gonzalez-Miquel, J. Garciéa, and F. Rodríguez, "Choline chloride-based deep eutectic solvents in the dearomatization of gasolines," ACS Sustainable Chemistry \& Engineering, vol. 6, no. 1, pp. 1039-1047, 2018.

[76] N. R. Rodriguez, P. F. Requejo, and M. C. Kroon, "Aliphatic-aromatic separation using deep eutectic solvents as extracting agents," Industrial \& Engineering Chemistry Research, vol. 54, no. 45, pp. 11404$11412,2015$.

[77] D. H. Sarno, “Extractive distillation with dimethylformamide," July 25 1961. US Patent 2,993,841.

[78] L. Kerker and R. Malzkorn, "Method for separating butenes and butanes by extractive distillation provided with a polar extraction agent," May 11 2006. US Patent App. 10/527,322.

[79] C. O. Carter, "Separating olefins from paraffins with dimethyl sulfoxide extractant," May 12 1981. US Patent 4,267,034.

[80] L. Berg, "Separation of heptane from 1-heptene by extractive distillation," Aug. 22 1995. US Patent $5,443,697$.

[81] F. de Miguel Mercader, M. J. Groeneveld, S. R. Kersten, C. Geantet, G. Toussaint, N. W. Way, C. J. Schaverien, and K. J. Hogendoorn, "Hydrodeoxygenation of pyrolysis oil fractions: process understanding and quality assessment through co-processing in refinery units," Energy E environmental science, vol. 4, no. 3, pp. 985-997, 2011.

[82] L. A. Baird, D. B. Galloway, and T. N. Kalnes, "Methods of and apparatuses for upgrading a hydrocarbon stream including a deoxygenated pyrolysis product," Nov. 13 2014. US Patent App. 13/890,343.

[83] J. P. De Wet, W. Jansen, and P. Jacobson, "Extraction of oxygenates from a hydrocarbon stream," Dec. 16 2008. US Patent 7,465,846.

[84] R. C. Binning and J. T. Kelly, "Extraction of alcohols with propylene carbonate," Dec. 22 1959. US Patent $2,918,486$.

[85] P. N. Rylander, "Solvent extraction of oil-soluble water-immiscible alcohols using dimethylsulfoxide," Sept. 27 1960. US Patent 2,954,392.

[86] A. Knorr, K. Fumino, A.-M. Bonsa, and R. Ludwig, "Spectroscopic evidence of 'jumping and pecking'of cholinium and h-bond enhanced cation-cation interaction in ionic liquids," Physical Chemistry Chemical Physics, vol. 17, no. 46, pp. 30978-30982, 2015.

[87] A. Kaiser, O. Ismailova, A. Koskela, S. E. Huber, M. Ritter, B. Cosenza, W. Benger, R. Nazmutdinov, and M. Probst, "Ethylene glycol revisited: Molecular dynamics simulations and visualization of the liquid and its hydrogen-bond network," Journal of molecular liquids, vol. 189, pp. 20-29, 2014.

[88] A. Chianese and F. Zinnamosca, "Ethanol dehydration by azeotropic distillation with a mixed-solvent 
entrainer," The Chemical Engineering Journal, vol. 43, no. 2, pp. 59-65, 1990.

[89] V. Gomis, A. Font, R. Pedraza, and M. Saquete, "Isobaric vapor-liquid and vapor-liquid-liquid equilibrium data for the system water+ ethanol+ cyclohexane," Fluid Phase Equilibria, vol. 235, no. 1, pp. 7-10, 2005.

[90] V. Gomis, A. Font, and M. D. Saquete, "Vapour-liquid-liquid and vapour-liquid equilibrium of the system water+ ethanol+ heptane at $101.3 \mathrm{kpa}$," Fluid phase equilibria, vol. 248, no. 2, pp. 206-210, 2006.

[91] S. Young, "Lxxiii.- the preparation of absolute alcohol from strong spirit," Journal of the Chemical Society, Transactions, vol. 81, pp. 707-717, 1902.

[92] Y.-L. Wang, A. Laaksonen, and M. D. Fayer, "Hydrogen bonding versus $\pi-\pi$ stacking interactions in imidazolium-oxalatoborate ionic liquid," The Journal of Physical Chemistry B, vol. 121, no. 29, pp. 71737179, 2017.

[93] K. Yan, Y. Yang, J. Chai, and Y. Lu, "Catalytic reactions of gamma-valerolactone: A platform to fuels and value-added chemicals," Applied Catalysis B: Environmental, vol. 179, pp. 292-304, 2015.

[94] R. Germani, M. Orlandini, M. Tiecco, and T. Del Giacco, "Novel low viscous, green and amphiphilic n-oxides/phenylacetic acid based deep eutectic solvents," Journal of Molecular Liquids, vol. 240, pp. 233$239,2017$. 




\subsection{Introduction}

The global community relies on the chemical industry for the production of goods from complex raw materials, such as oil and biomass. The separation processes required in these production routes account for up to $50 \%$ of the total energy costs in refineries ${ }^{1}$, and improving the efficiency of separations can significantly reduce the environmental impact of the chemical industry. ${ }^{2}$ This can only be achieved when the separation processes are understood on the molecular level, which includes a good description of thermodynamic equilibria. An accurate description of these equilibria is possible with models such as UNIQUAC and NRTL, but requires labor-intensive experimental data. For the initial stages of process design, including solvent selection and/or design, less labor-intensive approaches for understanding intermolecular interactions are desired. A range of predictive models is available to provide engineers with first estimates for (inter-)molecular behavior. ${ }^{3-11}$

Activity coefficients $(\gamma)$ describe the thermodynamic non-ideality between two substances due to intermolecular interactions. These intermolecular interactions are induced by van der Waals interactions ${ }^{12-14}$ and electrostatic interactions, such as intermolecular or intramolecular hydrogen bonding effects ${ }^{15}$, consequently causing either a positive or negative deviation from Raoult's law. Net attractive interactions result in an $\gamma$ below unity, and net repulsive interactions result in a $\gamma$ above unity. Activity coefficients are however composition-dependent and a limiting case is where a solute is infinitely diluted in a solvent. The non-ideal behavior of the solute at infinite dilution is solely induced by solvent-solute interaction, i.e., the effect of the molecular properties of the solvent on the activity coefficient of the solute. The activity coefficient in this limiting case can be used as an appropriate indicator of intermolecular interactions and is called the $\gamma_{i}^{\infty} \cdot{ }^{16}$

Various methods are in use to estimate activity coefficients. Eight models were evaluated, as these are most commonly used, see Figure 5.1. Seven of them have many similarities and one has a completely separate theoretical framework. Three solvation models (SMs) are chosen, which are, in order of increasing complexity, the Hildebrand parameter ${ }^{7}$, the Hansen Solubility Parameters (HSP) ${ }^{8}$, and the MOdified Separation of Cohesive Energy Density 
(MOSCED) model. ${ }^{6}$ These models attempt to describe the intermolecular interaction strength by increasingly more molecular parameters. The Group Contribution Methods (GCMs) are similar in form to SMs, but differ in origin. GCMs attempt to describe the intermolecular interactions by the empirical fitting of binary interaction coefficients of segments of the interacting molecules. The three GCMs that are included in this work are the original UNIversal Quasichemical Functional-group Activity Coefficients (UNIFAC) method ${ }^{11}$, and two modifications thereof (Lyngby ${ }^{5}$ and Dortmund ${ }^{4}$ ).

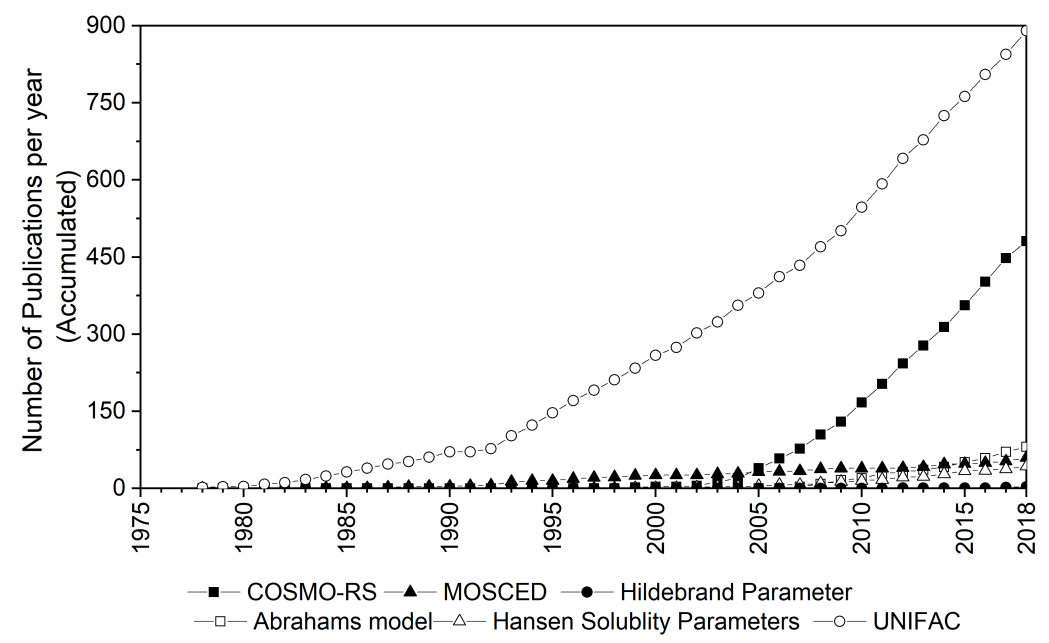

Figure 5.1: Number of publications where both the model and activity coefficient is mentioned extracted from Scopus. The search terms where "model" AND "infinite dilution activity coefficient" retrieved on December 3, 2018.

Despite these differences, all of these models still use the same entropic formulations. Next to these, a software package called the COnductor-like Screening MOdel for Realistic Solvents (COSMO-RS) is also evaluated. COSMO-RS has an entirely different theoretical framework and does not require any input parameters from the user besides the molecular structures. Similar to GCMs, COSMO-RS also divides molecules into segments. COSMO-RS divides the surface of molecules, as calculated by the quantum chemical density func- 
tional theory (DFT) approach in segments, and calculates the interaction energy for each segment. The molecular properties are then calculated by taking the integral over all segments. ${ }^{10}$

GCMs such as variations on UNIFAC, and COSMO-RS are most commonly applied, as can be seen in Figure 5.1. However, this does not imply that these models are always the most accurate in predicting the $\gamma_{i}$. Because the existing literature is inconclusive, ${ }^{6,17-24}$ the aim of this contribution is to extensively compare the performance of all these fundamentally different approaches for prediction of the $\gamma_{i}^{\infty}$ of (a)polar solutes in (a)polar solvents. The performances of all evaluated models in predictions for a variety of chemical systems were evaluated and explained based on their fundamental assumptions. Examples of such assumptions include that the entropy of the system does not differ from the ideal entropy, that the volume of the molecule does not change in a changing environment, or that there is no distinction between hydrogenbond-accepting and hydrogen-bond-donating molecules.

The extensive evaluation of model performances yielded insight into the applicability of the models for systems with variations in intermolecular interactions and which models give the most accurate description of $\gamma_{i}^{\infty}$ at $298.15 \mathrm{~K}$. A heuristic approach for the model choice is given for all binary combinations of solute and solvent classes, e.g., apolar compounds, aromatic compounds, halogenated compounds, polar aprotic compounds, and polar protic compounds.

\subsection{Theoretical Framework}

In this section, all of the models that were compared for the prediction of $\gamma_{i}^{\infty}$ are described. The models can be categorized into SMs, GCMs, Linear Solvation Energy Relations (LSERs), and COSMO-RS predictions that are of statistical thermodynamic nature. Because both the solvation models and the GCMs make use of combinatorial and residual contributions that find their origin in the Flory-Huggins model; this model and the variations thereof are first discussed. 


\subsubsection{Flory-Huggins-Based Models}

Nonideal behavior in mixtures can be induced by intermolecular interactions such as polarity, as well as by shape differences, ${ }^{15}$ The simplest cause of nonideal behavior is due to shape differences without polarity differences. This situation occurs in alkane mixtures for which activity coefficients can be described by the Flory-Huggins theory (Equation 5.1), where the combinatorial contribution to the activity coefficient, $\gamma_{i}^{c}$ is formulated solely in terms of molecular volume differences, ${ }^{25,26}$

$$
\ln \gamma_{i}^{c}=\ln \left(\frac{\Phi_{i}}{x_{i}}\right)+1-\frac{\Phi_{i}}{x_{i}}
$$

where $\Phi_{i}$ and $x_{i}$ are the volume fraction and molar fraction of compound i, respectively.

The Flory-Huggins combinatorial approach assumes a very large number of nearest-neighbor sites, hence ignoring the fact that neighboring sites can be occupied by a segment of the same molecule. Consequently, the Flory-Huggins correlation overestimates the combinatorial contribution. ${ }^{27}$ The StavermannGuggeheim modification attempts to correct this by incorporating the probability of vacant sites for polymer segments, although the combinatorial term is still overestimated, because the coordination number of all molecules is set. ${ }^{28}$ The Kikic modification attempted to correct the correlation by adding an exponent to the number of lattice sites, ${ }^{30}$ but this resulted in an underprediction of the combinatorial term. Recently, Krooshof et al. ${ }^{29}$ generalized the approach of Guggenheim and set loose the fixed coordination number. In this work, the Krooshof generalization was however not used and the industrial standard model, with the Guggenheim or Kikic description, was used.

When there is also a difference in the polarity of the molecules in the mixture, a residual correction can be added, $\gamma_{i}^{R}$. This can be described by the Flory-Huggins free-energy parameter $\chi_{i j}$, as equated in Equation 5.2. The $\gamma_{i}$ resulting from both combinatorial and residual terms is given in Equation 5.3,

$$
\begin{gathered}
\ln \gamma_{i}^{R}=\chi_{i j} \Phi_{i}^{2} \\
\ln \gamma_{i}=\ln \gamma_{i}^{C}+\ln \gamma_{i}^{R}
\end{gathered}
$$


A wide range of models has been developed that vary in their formulation of $\gamma_{i}^{C}$ and $\gamma_{i}^{R}$. In the next subsections, the most relevant solvation models and GCMs are described.

\subsubsection{Solvation Models}

In an early attempt to describe and understand the strength of intermolecular interactions, Hildebrand ${ }^{7}$ defined the cohesive pressure or cohesive energy density (c) as the net result of the sum of all intermolecular interactions between the molecules. As a measurable quantity for the cohesive energy density in liquids below their boiling point, the molar vaporization energy $\left(\Delta U_{v a p}\right)$ or enthalpy $\left(\Delta H_{v a p}\right)$ is considered, ${ }^{31}$ and correlated to the Hildebrand parameter $(\delta)$, according to Equation 5.4,

$$
\delta=\sqrt{c}=\sqrt{\frac{\Delta U_{v a p}}{V_{m, i}}}=\sqrt{\frac{\Delta H_{v a p}-R T}{V_{m, i}}}
$$

where $V_{m, i}$ is the molar volume of the molecule $i$.

The cohesive pressure is the sum of all attractive interactions, which must be broken to vaporize the liquid, and large $\delta$ values are therefore obtained for highly polar substances and small $\delta$ values are obtained for weakly interacting substances (e.g., fluorocarbons). ${ }^{31}$ Considering mixtures, the difference in $\delta$ of the constituents of that mixture can be interpreted as the difference in nature of these molecules and may be used as a measure for nonideality. In the Hildebrand-Scatchard equation (Equation 5.5), ${ }^{7}$ the difference in $\delta$ is used in the expression for the Flory-Huggins free-energy parameter $\left(\chi_{i j}\right)$,

$$
\chi_{i j}=\frac{V_{m, j}}{R T}\left(\delta_{i}-\delta_{j}\right)^{2}
$$

where $\delta_{i}$ and $\delta_{j}$ are, respectively, the Hildebrand parameters of the solute $\mathrm{i}$ and solvent $\mathrm{j}$. Hansen ${ }^{8}$ proposed an extension of the Hildebrand parameter by separating the dispersion $\left(\delta_{D}\right)$, polar $\left(\delta_{P}\right)$, and hydrogen bonding $\left(\delta_{H B}\right)$ contribution. These three parameters are called the Hansen solubility parameters (HSP) and are linked to the Hildebrand parameter, as defined in Equation 5.6.

$$
\delta_{i}^{2}=\delta_{D, i}^{2}+\delta_{P, i}^{2}+\delta_{H B, i}^{2}
$$


Often, the dispersive component was determined by homomorph methods, which estimate the dispersive parameter by evaluating an apolar molecule with almost the same size and shape of the polar compound. ${ }^{31}$ The remainder can be subtracted from the Hildebrand parameter and split into the polar and hydrogen-bonding term. By optimizing the miscibility description an optimal split between both terms was chosen. ${ }^{31}$ Common practice in using HSP is to plot the solute and solvents in a 3D Hansen space. The spatial distance between solute and solvent can be correlated to the solvation capability of the solvent, where shorter distances in the Hansen space allow better solubility. Hansen ${ }^{32}$ also suggested that the Flory-Huggins parameter can be determined using Equation 5.7,

$$
\chi_{i j}=\alpha \frac{V_{m, i}}{R T}\left[\left(\delta_{D, i}-\delta_{D, j}\right)^{2}+0.25\left(\delta_{P, i}-\delta_{P, j}\right)^{2}+\left(\delta_{H B, i}-\delta_{H B, j}\right)^{2}\right]
$$

where, initially, $\alpha$ was taken to be 1 , although Lindvig et al. ${ }^{9}$ showed that an $\alpha$ value of 0.6 increases the average accuracy of the model.

The Modified Separation of Cohesive Energy Density (MOSCED) model may be one of the most-extensive solvation models. ${ }^{20}$ In the MOSCED model, additional contributions to the Flory-Huggins parameter are considered that arise from significant variations in the cybotactic region due to the local organization, as a result of electrostatic interactions, such as hydrogen bonding. This local organization causes the geometric mean assumption not to be valid anymore for highly polar and associating compounds. ${ }^{20}$ To account for hydrogen bonding, the MOSCED model distinguishes acidic $(\alpha)$ and basic ( $\beta$ ) contributions to hydrogen bonding. Similar to the HSP model, the summation of the terms results in the Hildebrand parameter, as can be seen in Equation $5.8,{ }^{33}$

$$
\delta_{i}^{2}=\lambda_{i}^{2}+\tau_{i}^{2}+(\alpha \beta)_{i}^{2}
$$

where the dispersion constant $\lambda_{i}$ and polarity constant $\tau_{i}$ are identical to the HSP parameters $\delta_{D, i}$ and $\delta_{P, i}$, respectively. In addition, the interaction between induced dipoles is accounted for by the induction parameter, $q_{i}$. The model furthermore contains two empirical asymmetry factors: $\psi$ and $\xi$. More information on the MOSCED parameters can be found in section 12.1. ${ }^{6}$ The 
resulting MOSCED-based equation for the Flory-Huggins parameter is given in Equation 5.9.

$$
\chi_{i j}=\frac{V_{m, j}}{R T}\left(\left(\lambda_{i}-\lambda_{j}\right)+\frac{q_{i}^{2} q_{j}^{2}\left(\tau_{i}^{T}-\tau_{j}^{T}\right)^{2}}{\psi_{i}}+\frac{\left(\alpha_{i}^{T}-\alpha_{j}^{T}\right)\left(\beta_{i}^{T}-\beta_{j}^{T}\right)}{\xi_{i}}\right)
$$

\subsubsection{Group Contribution Methods (GCMs)}

Also, the GCMs of UNIFAC and modifications thereof are the sum of a combinatorial part and a residual part. Each GCM model uses a different description for the combinatorial term. The UNIFAC and the modified UNIFAC(Do) models use the Guggenheim-Stavermann term ${ }^{34}$ (Equation 5.10a and 5.10b), while the modified UNIFAC(Ly) uses the Kikic modification, ${ }^{30}$ as given in Equation 5.10c,

UNIFAC:

$$
\begin{aligned}
\ln \gamma_{i}^{c} & =\ln \Phi_{i}+1-\Phi_{i}-F \\
\ln \gamma_{i}^{c} & =\ln \Phi_{i}^{\prime}+1-\Phi_{i}^{\prime}-F \\
\ln \gamma_{i}^{c} & =\ln \Phi_{i}^{\prime \prime}+1-\Phi_{i}^{\prime \prime} \\
F & =\left(\frac{z}{2}\right) q_{i}\left[1-\frac{\Phi_{i}}{\theta_{i}}+\ln \left(\frac{\Phi_{i}}{\theta_{i}}\right)\right]
\end{aligned}
$$

mod. UNIFAC (Do):

where:

where $\Phi_{i}, \theta_{i}$, and $q_{i}$ are, respectively, the volume fraction, surface fraction, and the coordination number (z), which is often set at 10 . The modified UNIFAC(Do) model also has a modified volume fraction, more information on the equations can be found in section 12.2. The residual contribution of all UNIFAC models is determined via Equation 5.11a and 5.11b,

$$
\begin{gathered}
\ln \gamma_{i}^{R}=\sum_{k} v_{k}^{(i)}\left(\ln \Gamma_{k}-\ln \Gamma_{k}^{(i)}\right) \\
\ln \Gamma_{k}=Q_{k}\left[1-\ln \left(\sum_{m} \theta_{m} \Psi_{m k}\right)-\sum_{m} \frac{\theta_{m} \Psi_{k m}}{\sum_{n} \theta_{n} \Psi_{n m}}\right]
\end{gathered}
$$

where $\Gamma_{k}$ is the overall activity of moiety $\mathrm{k}, \Gamma_{k}^{(i)}$ the activity of moiety k solely surrounded by moiety i, $v_{k}^{(i)}$ the occurrence of each moiety $\mathrm{k}$ in surrounded 
by moiety i, $Q_{k}$ the van der Waals surface of group $\mathrm{k}$, and $\Psi_{k m}$ the group binary interaction parameter. ${ }^{4,5,11}$ The exact mathematical framework is given in section 12.2.

\subsubsection{Linear Solvation Energy Relationship (LSER)}

Linearly combining solute and solvent descriptors was pioneered by Kamlet, Abboud, and Taft, ${ }^{35-39}$ and later Abraham ${ }^{3}$ introduced a now widely used LSER that consisted of five solute and five solvent descriptors (Equation 5.12a). An extension is made for ILs, where both the cation and anion have five unique solvent descriptors (Equation 5.12b). ${ }^{40}$ The Abraham model can be used to obtain either the gas-solvent partition coefficient $\left(K_{S}\right)$ or the water-solvent partition coefficient $\left(P_{S}\right)$.

$$
\begin{gathered}
\left\{\begin{array}{l}
{ }^{10} \log \left(P_{S}\right)=c+e E+s S+a A+b B+v V \\
10 \log \left(K_{S}\right)=c+e E+s S+a A+b B+l L
\end{array}\right. \\
\left\{\begin{array}{c}
{ }^{10} \log \left(P_{S}\right)=c+\left(e_{c}+e_{a}\right) E+\left(s_{c}+s_{a}\right) S+\left(a_{c}+a_{a}\right) A+ \\
\left(b_{c}+b_{a}\right) B+\left(v_{c}+v_{a}\right) V \\
{ }^{10} \log \left(K_{S}\right)=c+\left(e_{c}+e_{a}\right) E+\left(s_{c}+s_{a}\right) S+\left(a_{c}+a_{a}\right) A+ \\
\left(b_{c}+b_{a}\right) B+\left(l_{c}+l_{a}\right) L
\end{array}\right.
\end{gathered}
$$

The capital variables in Equation 5.12a and 5.12b are defined as the solute descriptors and the lowercase variables are the solvent descriptors. While the c-variable is a fitting constant, the latter terms are respectively the excess molar refraction $\left(\mathrm{dm}^{3} \mathrm{~mol}^{-1} / 10\right)$, the dipolarity/polarizability, hydrogen-bond acidity and basicity, the McGowan characteristic volume $\left(\mathrm{dm}^{3} \mathrm{~mol}^{-1} / 100\right)$, and the gas-hexadecane partition coefficient at $298.15 \mathrm{~K}$. The descriptors describe the tendency to interact via $\sigma$ - and $\pi$-electrons (e/E), the tendency to interact with (induced) multipole moments (s/S), the tendency to accept hydrogen bonds or donate electrons $(\mathrm{A} / \mathrm{b})$, the tendency to donate hydrogen bonds or accept electrons $(\mathrm{a} / \mathrm{B})$, and the tendency to either form $(\mathrm{V} / \mathrm{L})$ or the work required to form $(\mathrm{v} / \mathrm{l})$ cavities.

The determination of solute and solvent descriptors is done by multilinear regression of experimental $\gamma_{i}^{\infty}$ data of either a set of solutes in a solvent or 
a solute in various solvents. The gas-solvent partition coefficient can consequently be linked to the $\gamma_{i}^{\infty}$ parameter by Equation 5.13: ${ }^{40}$

$$
{ }^{10} \log \left(\gamma_{i}^{\infty}\right)=\log \left(\frac{R T}{P_{j}^{o} V_{m, j}}\right)-\log \left(K_{S}\right)
$$

where $P_{j}^{o}$ and $V_{m, j}$ are, respectively, the vapor pressure and molar volume of the pure solvent.

\subsubsection{Conductor-like Screening Model for Real Solvents.}

The ab initio method developed by Klamt et al., ${ }^{41}$ called COSMO-RS, predicts chemical potentials, which can be used to calculate the value of $\gamma_{i}^{\infty}$. The first step is always to perform quantum mechanical calculations to obtain the state of the geometrically optimized molecule. This step must be done only once, and the result can be stored in a database. The second step estimates the interaction energy of the optimized molecules with other molecules and can henceforth estimate molecular properties such as the $\gamma_{i}^{\infty}$ parameter. ${ }^{41}$

The energy of this state can be determined via dielectric continuum solvation methods. However, empirical parameters (e.g., atomic radii) are required to construct the molecular cavity within the conductor exterior. COSMO-RS implements element-specific radii, which are $17 \%$ larger than van der Waals radii. The state of the molecule is consequently determined using any SelfConsistent Field (SCF) model, e.g., Hartree-Fock (HF) and density functional theory (DFT). Combining the COSMO approach with a SCF model results in not only the total energy of the molecule, but also the polarization charge density, or $\sigma{ }^{41}$ The $\sigma$-profile is "frozen" into place, while the conductor environment is "squeezed out". A thin film of a conductor is left in the places where different molecules will have an interface. The sum of the $\sigma$-value at the interface, $\left(\sigma+\sigma^{\prime}\right)$, is then the net polarization charge density. As the conductor is removed, the polarization charge density differences resemble intermolecular interactions with local contact energy, which may be described by Equation 5.14.

$$
E_{\text {contact }}\left(\sigma, \sigma^{\prime}\right)=E_{\text {misfit }}\left(\sigma, \sigma^{\prime}\right)+E_{H B}\left(\sigma, \sigma^{\prime}\right)
$$


An interaction distinction is made between the misfit energy $\left(E_{\text {misfit }}\right)$ and the energy that is due to hydrogen bonding effects $\left(E_{H B}\right)$. Both energy terms dissipate when the conjugant polarization charge densities are equal. If not, the misfit between both $\sigma$-values represents the electrostatic interaction energy between those segments. Additional interaction energy can be induced by two very polar surfaces with opposite signs via hydrogen bonding. The capability of COSMO-RS to predict a large number of chemical potentials of solutes in either a pure or mixed solvent enabled fast and versatile predictions regarding various equilibria and also $\gamma_{i}^{\infty} .{ }^{41}$

\subsection{Methods}

For all $\gamma_{i}^{\infty}$ predictions, a systematic assessment was done at $298.15 \mathrm{~K}$ and all model specific-parameters were imported from literature sources, as can be seen in section 5.6. All simulations with COSMO-RS were performed with COSMOthermX C30_1705, in which a pure solvent phase was defined and the activity coefficient of the solute in that phase was estimated. Molecules that were not available in the databases were created with TurboMole TmoleX 3.4, using the TZVPD-Fine parametrization, while molecular conformers were disregarded.

\subsection{Results}

\subsubsection{General Averaged Model Predictions}

The accuracy of all models was determined by comparing the predictions with experimental values taken from the literature. An extensive overview of all experimental data is presented in the ESI. The accuracy of the models is evaluated by determining the average relative deviation (ARD) between the predicted and experimental $\gamma_{i}^{\infty}$ values, as given in Equation 5.15.

$$
A R D=\frac{\sum_{i=1}^{N}\left|\frac{\gamma_{i, \text { odel }}^{\infty}-\gamma_{i, \text { exp }}^{\infty}}{\gamma_{i, \text { exp }}^{\infty}}\right|}{N}
$$

The ARD for prediction of $\gamma_{i}^{\infty}$ for all solutes in molecular solvents and ILs by each model, and their 95\% confidence intervals, are depicted in Figure 5.2. 

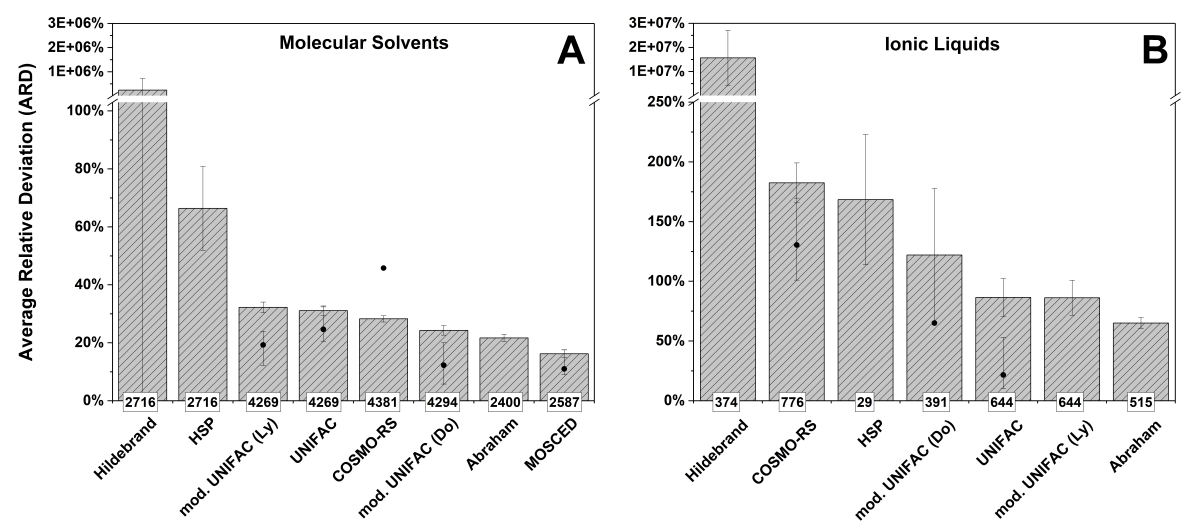

Figure 5.2: Evaluation of various predictive models for $\gamma_{i}^{\infty}$ for $(A)$ molecular solvents and (B) ionic liquids (ILs) at $298.15 \mathrm{~K}$. On the $y$-axis, the ARD is presented within the boxes the total amount of comparisons made. The experimental $\gamma_{i}^{\infty}$ can be found in section 5.6. The integrated scatter plot depicts similar comparison made in the literature for various models, e.g., modified UNIFAC(Ly), 18,21,23 UNIFAC, 17,18,20-23,42,43, COSMO-RS, 21,44 modified UNIFAC(Do), ${ }^{17,18,23,24,45-47}$ and MOSCED. ${ }^{6,17,19,20,22}$

For molecular solvents, eight predictive models have been evaluated; for ILs, seven predictive models due to lack of MOSCED parameters for ILs have been evaluated. The ARD of the various models differs significantly, as can be seen in Figure 5.2. For both the molecular solvents and the ILs, the most inaccurate model is the Hildebrand model. Evidently, using only the evaporation enthalpy and the molar volume is insufficient to accurately describe $\gamma_{i}^{\infty}$ in systems where intermolecular interactions such as hydrogen bonding occur. ${ }^{7}$ This accumulates in a significant ARD of $>10^{5} \%$ in the $\gamma_{i}^{\infty}$ prediction.

Using the HSP to calculate the $\gamma_{i}^{\infty}$ with Equation 5.7 is a significant improvement, compared to the Hildebrand model (Equation 5.5), which is due to taking into account hydrogen bonding and polarity effects. ${ }^{8}$ Still, an ARD of $66.4 \pm 14.4 \%$ is observed for molecular solvents. This may be explained by the inability to differentiate between hydrogen acidity and basicity effects. ${ }^{6}$ Further refining the model using hydrogen acidity and hydrogen basicity, as 
well as polarizability effects, as taken into account in the MOSCED model, which shows from Figure 5.2a to be, on average, the most accurate model, with an ARD of $16.2 \pm 1.35 \%$. Unfortunately, no parameters for ILs are available, and therefore this model could not be evaluated for ILs. The three group contribution models that were also evaluated showed comparable ARD values of $32.2 \pm 1.84 \%, 31.1 \pm 1.66 \%$, and $24.3 \pm 1.63 \%$, respectively, for the modified UNIFAC(Ly), UNIFAC, and modified UNIFAC(Do) for molecular solvents. The ARD of COSMO-RS is within $28.3 \pm 1.07 \%$, which is similar to that observed for the GCM methods. The Abraham model is more accurate than GCM methods and COSMO-RS with an ARD of $21.7 \pm 1.19 \%$. The better accuracy of the Abraham model is due to a more elaborate description of the various intermolecular interactions via all descriptors.

For ILs, the ARD of all models (see Figure 5.2b) increase due to the presence of not only dispersion, dipole, and hydrogen bonding interactions, but also ionic interactions between the ionic species and the solute. The ARD of the HSP model is determined to be $168 \pm 54.5 \%$, while the GCM methods perform better with an ARD of $86.2 \pm 14.6 \%, 86.5 \pm 15.7 \%$, and $122 \pm 55.9 \%$, respectively, for the modified UNIFAC(Ly), UNIFAC, and modified UNIFAC(Do). Although COSMO-RS performance for molecular solvents is comparable to that of the GCMs, for ILs, the ARD is larger (182 $\pm 16.7 \%)$. The larger ARD for ILs is known to be (at least partly) caused by neglecting long-range ion-ion interactions and insufficient description of extreme polarization charge densities of ions. ${ }^{10}$ The Abraham model performs most accurately for ILs, with an ARD value of $65.1 \pm 4.50 \%$. The accuracy of the Abraham model is interesting for solvent screening purposes, because of the availability of ion-specific Abraham parameters for 60 cations and 17 anions, allowing rapid assessment of 1020 ILs, since they are binary combinations of these ions. (see the section 5.6).

The ARDs reported in Figure 5.2 appear to be larger than the errors described in various literature sources. ${ }^{6,17-24,42,43,45-48}$ Similar comparisons have been made by Gmehling et al., ${ }^{18}$ who assessed the accuracy of the UNIFAC models, and Thomas et al., 22 who assessed the accuracy of the MOSCED model. They reported lower ARD values, correspondingly $25.8 \%$ (instead of $31.1 \pm 1.66 \%$ ) and $9.10 \%$ (instead of $16.2 \pm 1.35 \%$ ). Because the error calculation method 
is the same, and only the used dataset differs, the logical conclusion is that the dataset used in this work includes $\gamma_{i}^{\infty}$ with a higher average error margin. This will be the case for each of the assessed models; hence, these error margins in the dataset will not affect the comparison of the relative accuracies between all models. For comparison with the work of Gmehling et al. ${ }^{18}$, there is a difference in the selected data, because they state that $\gamma_{i}^{\infty}$ values of $>100$ were excluded, whereas, in this manuscript, these values were included.

\subsubsection{Molecular Solvents}

Although from the averaged model predictions, one general guideline for model selection can be distilled, a more detailed analysis of subgroups of solutes and solvents allows one to provide a more-sophisticated directive to the use of thermodynamic models for the prediction of $\gamma_{i}^{\infty}$ for various specific chemical families. To this end, all solvents and solutes were classified into five categories, i.e., aliphatic compounds, aromatic compounds, compounds containing a halogen atom, polar aprotic compounds and polar protic compounds, and the model accuracies were evaluated per combination of solvent and solute class.

In Table 5.1, all model evaluations are shown per combination of solvent and solute categories. Comparison of the Hildebrand, HSP, and MOSCED models clearly shows that models with increasing complexity, i.e., taking hydrogen bonding and polarity into account, and describing the hydrogen bonding basicity and acidity separately, as well as including polarizability, predict $\gamma_{i}^{\infty}$ with increasing accuracy. All of these models show the largest ARD for protic compounds, including amines, alcohols, and aldehydes, which is a logical result due to the number and type of intermolecular interactions occurring in these systems.

There is no single model that predicts $\gamma_{i}^{\infty}$ most accurately for all solvent and solute category combinations. Each of the models, except for the Hildebrand and HSP models, most accurately predicts a category of solute-solvent pairs. COSMO-RS performs best in systems with only (induced) dipole interactions and in the absence of hydrogen bonding formation. When polarity and hydrogen bonding systems are concerned, COSMO-RS becomes less accurate. 
Table 5.1: Accuracy of the Hildebrand Solubility Parameter, Hansen Solubility Parameter, MOSCED model, Abraham model, COSMO-RS, UNIFAC, mod. UNIFAC (Ly) and mod. UNIFAC (Do) differentiated towards aliphatic, aromatic, halogen, aprotic polar, and protic polar compounds in molecular solvents. ${ }^{a}$

\begin{tabular}{|c|c|c|c|c|c|c|}
\hline \multicolumn{7}{|c|}{ Solute } \\
\hline & & Aliphatic & Aromatic & Halogen & Aprotic polar & Protic polar \\
\hline \multirow{5}{*}{$\begin{array}{l}\frac{\vec{D}}{D} \\
\frac{D}{0} \\
\infty\end{array}$} & Aliphatic & $20,5 \%$ & $28,3 \%$ & $>100 \%$ & $>300 \%$ & $>10^{5} \%$ \\
\hline & Aromatic & $40,3 \%$ & $17,0 \%$ & $14,8 \%$ & $>100 \%$ & $>500 \%$ \\
\hline & Halogen & $56,5 \%$ & $29,2 \%$ & $32,5 \%$ & $73,7 \%$ & $>100 \%$ \\
\hline & Aprotic polar & $>100 \%$ & $>100 \%$ & $>100 \%$ & $>100 \%$ & $>100 \%$ \\
\hline & Protic polar & $>100 \%$ & $51,6 \%$ & $45,2 \%$ & $>100 \%$ & $67,7 \%$ \\
\hline \multicolumn{7}{|c|}{ Hansen Solubility Parameters } \\
\hline & & \multicolumn{5}{|c|}{ Solute } \\
\hline & & Aliphatic & Aromatic & Halogen & Aprotic polar & Protic polar \\
\hline \multirow{5}{*}{$\begin{array}{l}\vec{z} \\
\frac{\vec{D}}{0} \\
\infty\end{array}$} & Aliphatic & $22,3 \%$ & $43,3 \%$ & $44,7 \%$ & $64,5 \%$ & $84,5 \%$ \\
\hline & Aromatic & $31,1 \%$ & $18,2 \%$ & $20,4 \%$ & $28,7 \%$ & $75,5 \%$ \\
\hline & Halogen & $32,9 \%$ & $25,1 \%$ & $30,5 \%$ & $70,0 \%$ & $62,4 \%$ \\
\hline & Aprotic polar & $47,3 \%$ & $64,3 \%$ & $47,1 \%$ & $39,8 \%$ & $62,4 \%$ \\
\hline & Protic polar & $>100 \%$ & $57,7 \%$ & $45,2 \%$ & $>300 \%$ & $27,8 \%$ \\
\hline \multicolumn{7}{|c|}{ MOSCED model } \\
\hline & & \multicolumn{5}{|c|}{ Solute } \\
\hline & & Aliphatic & Aromatic & Halogen & Aprotic polar & Protic polar \\
\hline \multirow{5}{*}{$\begin{array}{l}\underset{D}{D} \\
\frac{D}{0} \\
\dot{D}\end{array}$} & Aliphatic & $7,4 \%$ & $6,7 \%$ & $7,7 \%$ & $39,5 \%$ & $89,1 \%$ \\
\hline & Aromatic & $14,3 \%$ & $19,6 \%$ & $9,7 \%$ & $24,2 \%$ & $>100 \%$ \\
\hline & Halogen & $18,1 \%$ & $9,8 \%$ & $18,3 \%$ & $23,2 \%$ & $37,3 \%$ \\
\hline & Aprotic polar & $15,7 \%$ & $14,8 \%$ & $15,8 \%$ & $15,0 \%$ & $37,3 \%$ \\
\hline & Protic polar & $24,6 \%$ & $16,7 \%$ & $32,7 \%$ & $29,8 \%$ & $19,7 \%$ \\
\hline \multicolumn{7}{|c|}{ Abraham model } \\
\hline & & \multicolumn{5}{|c|}{ Solute } \\
\hline & & Aliphatic & Aromatic & Halogen & Aprotic polar & Protic polar \\
\hline \multirow{5}{*}{$\frac{\overrightarrow{0}}{\stackrel{D}{D}}$} & Aliphatic & $17,8 \%$ & $11,8 \%$ & $6,8 \%$ & $46,3 \%$ & $12,5 \%$ \\
\hline & Aromatic & $11,8 \%$ & $20,0 \%$ & $13,0 \%$ & $22,9 \%$ & $27,9 \%$ \\
\hline & Halogen & $34,6 \%$ & $31,8 \%$ & $16,1 \%$ & $34,9 \%$ & $31,7 \%$ \\
\hline & Aprotic polar & $21,2 \%$ & $21,2 \%$ & $21,7 \%$ & $22,4 \%$ & $31,7 \%$ \\
\hline & Protic polar & $20,6 \%$ & $17,5 \%$ & $22,3 \%$ & $39,5 \%$ & $34,1 \%$ \\
\hline \multicolumn{7}{|c|}{ COSMO-RS } \\
\hline & & \multicolumn{5}{|c|}{ Solute } \\
\hline & & Aliphatic & Aromatic & Halogen & Aprotic polar & Protic polar \\
\hline \multirow{5}{*}{$\begin{array}{l}\frac{\vec{Z}}{D} \\
\frac{D}{0} \\
\infty\end{array}$} & Aliphatic & $8,6 \%$ & $15,4 \%$ & $20,4 \%$ & $35,6 \%$ & $45,2 \%$ \\
\hline & Aromatic & $10,7 \%$ & $13,2 \%$ & $26,7 \%$ & $24,4 \%$ & $56,9 \%$ \\
\hline & Halogen & $27,6 \%$ & $36,6 \%$ & $15,7 \%$ & $31,4 \%$ & $33,4 \%$ \\
\hline & Aprotic polar & $32,7 \%$ & $34,4 \%$ & $32,5 \%$ & $19,9 \%$ & $33,4 \%$ \\
\hline & Protic polar & $36,3 \%$ & $32,0 \%$ & $35,0 \%$ & $38,1 \%$ & $23,6 \%$ \\
\hline
\end{tabular}

105 Towards Sustainable Solvent-Based Affinity Separations 
COMPARISON OF $\gamma^{\infty}$ PREDICTION METHODS

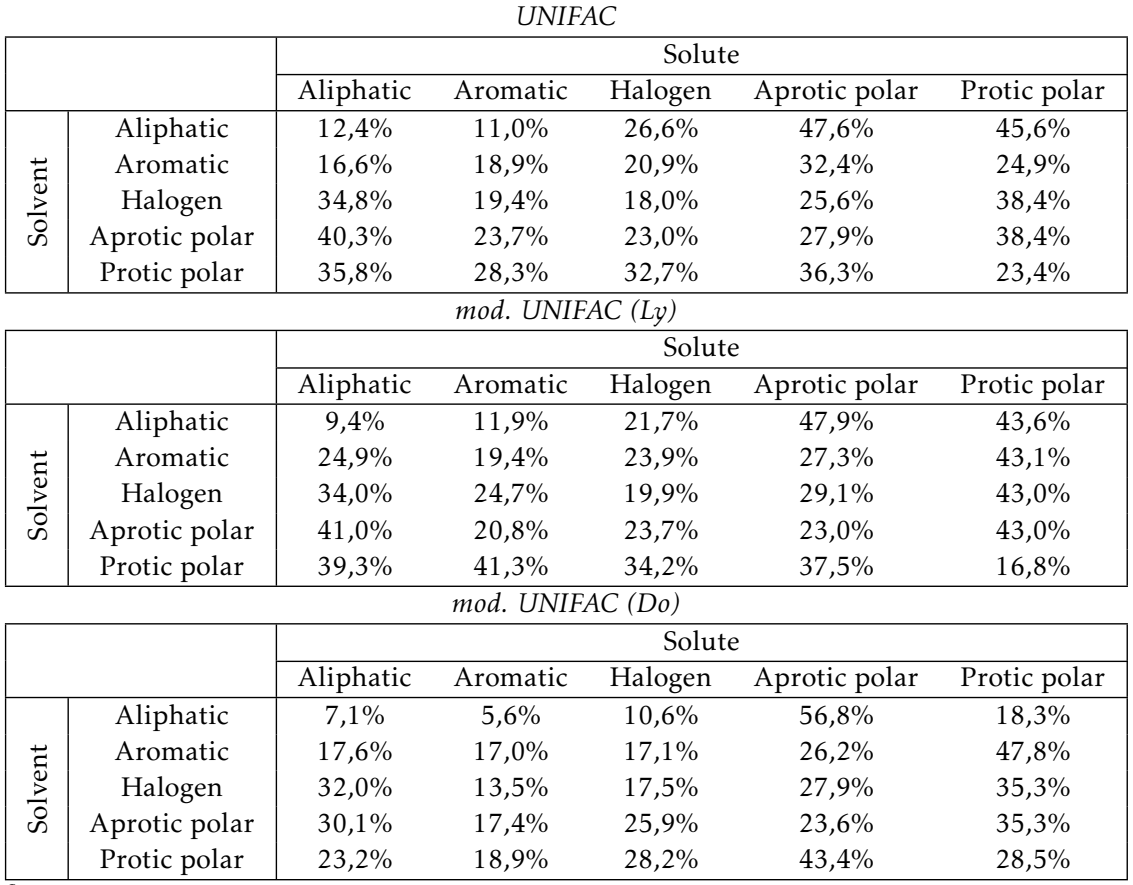

${ }^{a}$ All 25 binary solute-solvent combinations have been made at $298.15 \mathrm{~K}$. The colors are indicative: white, ARD $<100 \%$; light gray, $100 \%<\mathrm{ARD}<300 \%$; medium gray, $300 \%$ $<\mathrm{ARD}<500 \%$; dark gray, $500 \%<\mathrm{ARD}<10^{3} \%$; and black, ARD $>10^{5} \%$.

The MOSCED and Abraham models perform much better in hydrogen bonding systems, because of the multiple parameters that describe these directional interactions. The various UNIFAC models appear to be most accurate for a few categories of chemical interaction systems, which may arise from the empirical nature of the UNIFAC models based on fitting the model parameters to experimental data. The variation between the UNIFAC models can also arise from the different fitting procedures for the determination of their empirical constants. Finally, the differences in the formulation of their combinatorial term can induce variation in activity coefficient prediction.

\subsubsection{Ionic Liquids}

Overall, the ARD in predicted $\gamma_{i}^{\infty}$ in ILs is larger than that observed in molecular solvents. Not only is the additional electrostatic intermolecular interac- 
tion of the charges on the ions with the solutes responsible for this, but also the additional competition between the solute-related intermolecular interactions and the interactions between the ions in the IL plays an important role. Furthermore, ILs with a cation containing, besides the central ionic moiety, also a second moiety (e.g. ether, hydroxyl, or unsaturated bond), are collectively evaluated as functionalized ionic liquids (FILS).

\subsubsection{Cations}

A systematic analysis was made for various classes of cations, and the cation class-specific model performances are listed in Table 5.2 and 5.3. A larger ARD is generally obtained for FILs, because of the fact additional intermolecular and intramolecular interactions occur with the moieties present on the cation tails. Also, COSMO-RS has severe difficulties in predicting accurate $\gamma_{i}^{\infty}$ values. Analogous to the trends observed in molecular solvents, the ARD increase from apolar to polar solutes, because of hydrogen bonding effects. Overall, the performance of the Abraham model is superior to that of the other models, although some systems can be more accurately described using a variant of UNIFAC. For instance, the predictions for aliphatic, aromatic, and halogen solutes in imidazolium cations are more accurately predicted with modified UNIFAC(Do). This is most likely due to the large dataset available for imidazolium cations, hence improving the empirical fit of the modified UNIFAC(Do).

Table 5.2: Accuracy of COSMO-RS, UNIFAC, mod. UNIFAC (Ly), mod. UNIFAC (Do) and Abraham model differentiated towards aliphatic, aromatic, halogen, aprotic polar, and protic polar compounds in non-functionalized ionic liquids cations. ${ }^{a}$

\begin{tabular}{|c|c|c|c|c|c|c|}
\hline \multicolumn{7}{|c|}{ COSMO-RS } \\
\hline & & & & Solu & & \\
\hline & & Aliphatic & Aromatic & Halogen & Aprotic polar & Protic polar \\
\hline \multirow{5}{*}{ 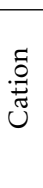 } & \multirow{5}{*}{$\begin{array}{l}\text { Imidazolium } \\
\text { Pyrrolidinium } \\
\text { Pyridinium } \\
\text { Phosphonium } \\
\text { Sulphonium }\end{array}$} & $198 \%$ & $273 \%$ & $291 \%$ & $115 \%$ & $217 \%$ \\
\hline & & $60 \%$ & $182 \%$ & & $37 \%$ & $100 \%$ \\
\hline & & $85 \%$ & $204 \%$ & & $63 \%$ & $104 \%$ \\
\hline & & $218 \%$ & $127 \%$ & & $46 \%$ & $16 \%$ \\
\hline & & $69 \%$ & $223 \%$ & & $154 \%$ & $139 \%$ \\
\hline
\end{tabular}


COMPARISON OF $\gamma^{\infty}$ PREDICTION METHODS

\begin{tabular}{|c|c|c|c|c|c|c|}
\hline \multicolumn{7}{|c|}{ UNIFAC } \\
\hline & & \multicolumn{5}{|c|}{ Solute } \\
\hline & & Aliphatic & Aromatic & Halogen & Aprotic polar & Protic polar \\
\hline \multirow{5}{*}{ 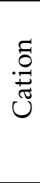 } & Imidazolium & $64 \%$ & $60 \%$ & $59 \%$ & $44 \%$ & $156 \%$ \\
\hline & Pyrrolidinium & $27 \%$ & $37 \%$ & & $26 \%$ & $94 \%$ \\
\hline & Pyridinium & $106 \%$ & $44 \%$ & & $327 \%$ & $594 \%$ \\
\hline & Phosphonium & & & & & \\
\hline & Sulphonium & $30 \%$ & $118 \%$ & & $29 \%$ & $94 \%$ \\
\hline \multicolumn{7}{|c|}{ mod. UNIFAC (Ly) } \\
\hline & & \multicolumn{5}{|c|}{ Solute } \\
\hline & & Aliphatic & Aromatic & Halogen & Aprotic polar & Protic polar \\
\hline \multirow{5}{*}{ : } & Imidazolium & $67 \%$ & $65 \%$ & $64 \%$ & $45 \%$ & $142 \%$ \\
\hline & Pyrrolidinium & $32 \%$ & $34 \%$ & & $29 \%$ & $89 \%$ \\
\hline & Pyridinium & $109 \%$ & $41 \%$ & & $309 \%$ & $508 \%$ \\
\hline & Phosphonium & & & & & \\
\hline & Sulphonium & $34 \%$ & $138 \%$ & & $28 \%$ & $88 \%$ \\
\hline \multicolumn{7}{|c|}{ mod. UNIFAC (Do) } \\
\hline & & \multicolumn{5}{|c|}{ Solute } \\
\hline & & Aliphatic & Aromatic & Halogen & Aprotic polar & Protic polar \\
\hline \multirow{4}{*}{ نี } & Imidazolium & $40 \%$ & $33 \%$ & $8 \%$ & $222 \%$ & $103 \%$ \\
\hline & Pyrrolidinium & $62 \%$ & $66 \%$ & & $27 \%$ & $53 \%$ \\
\hline & Pyridinium & $59 \%$ & $228 \%$ & & $47 \%$ & $51 \%$ \\
\hline & $\begin{array}{l}\text { Phosphonium } \\
\text { Sulphonium }\end{array}$ & & $11 \%$ & & & \\
\hline \multicolumn{7}{|c|}{ Abraham model } \\
\hline \multirow{7}{*}{ : } & & \multicolumn{5}{|c|}{ Solute } \\
\hline & & Aliphatic & Aromatic & Halogen & Aprotic polar & Protic polar \\
\hline & Imidazolium & $56 \%$ & $60 \%$ & $60 \%$ & $36 \%$ & $86 \%$ \\
\hline & Pyrrolidinium & $51 \%$ & $54 \%$ & & $54 \%$ & $69 \%$ \\
\hline & Pyridinium & $51 \%$ & $48 \%$ & & $27 \%$ & $30 \%$ \\
\hline & Phosphonium & & & & & \\
\hline & Sulphonium & $54 \%$ & $70 \%$ & & $7 \%$ & $30 \%$ \\
\hline
\end{tabular}

${ }^{a}$ All 25 binary solute-solvent combinations have been made at $298.15 \mathrm{~K}$. The colors are indicative: white, ARD $<100 \%$; light gray, $100 \%<\mathrm{ARD}<300 \%$; medium gray, $300 \%$ $<\mathrm{ARD}<500 \%$; dark gray, $500 \%<\mathrm{ARD}<10^{3} \%$; and black, $\mathrm{ARD}>10^{5} \%$. 
Table 5.3: Accuracy of COSMO-RS, UNIFAC, mod. UNIFAC (Ly), mod. UNIFAC (Do) and Abraham models differentiated towards aliphatic, aromatic, halogen, aprotic polar, and protic polar compounds in functionalized ionic liquids cations.

COSMO-RS

\begin{tabular}{|c|c|c|c|c|c|c|}
\hline & \multicolumn{5}{|c|}{ Solute } \\
\hline & & Aliphatic & Aromatic & Halogen & Aprotic polar & Protic polar \\
\hline \multirow{4}{*}{ 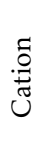 } & Imidazolium & $238 \%$ & $322 \%$ & $166 \%$ & $170 \%$ & $128 \%$ \\
\hline & Pyrrolidinium & $112 \%$ & & & $53 \%$ & \\
\hline & Pyridinium & $194 \%$ & & & & \\
\hline & Morpholinium & $67 \%$ & & & & \\
\hline
\end{tabular}

\begin{tabular}{|c|c|c|c|c|c|c|}
\hline \multicolumn{7}{|c|}{ UNIFAC } \\
\hline & & \multicolumn{5}{|c|}{ Solute } \\
\hline & & Aliphatic & Aromatic & Halogen & Aprotic polar & Protic polar \\
\hline \multirow{4}{*}{$\underset{\tilde{J}}{\stackrel{\Xi}{\Xi}}$} & Imidazolium & $48 \%$ & $81 \%$ & $102 \%$ & $208 \%$ & $183 \%$ \\
\hline & Pyrrolidinium & $77 \%$ & & & & \\
\hline & Pyridinium & $80 \%$ & & & & \\
\hline & Morpholinium & & & & & \\
\hline
\end{tabular}

\begin{tabular}{|c|c|ccccc|}
\hline \multicolumn{2}{|c|}{} & \multicolumn{5}{c|}{ mod. UNIFAC(Ly) } \\
\cline { 3 - 6 } \multicolumn{2}{|c|}{} & Aliphatic & Aromatic & Halogen & Aprotic polar & Protic polar \\
\hline \multirow{0}{*}{} & Imidazolium & $51 \%$ & $90 \%$ & $113 \%$ & $189 \%$ & $164 \%$ \\
& Pyrrolidinium & $79 \%$ & & & & \\
\hline & Pyridinium & $80 \%$ & & & & \\
& Morpholinium & & & & & \\
\hline
\end{tabular}

\begin{tabular}{|c|c|c|c|c|c|c|}
\hline & & & mod. UNII & $C(D o)$ & & \\
\hline & & & & Solu & & \\
\hline & & Aliphatic & Aromatic & Halogen & Aprotic polar & Protic polar \\
\hline & Imidazolium & $59 \%$ & $29 \%$ & $99 \%$ & $527 \%$ & $578 \%$ \\
\hline Еี & Pyrrolidinium & & & & & \\
\hline 苞 & Pyridinium & $28 \%$ & & & & \\
\hline & Morpholinium & & & & & \\
\hline
\end{tabular}

\begin{tabular}{|c|c|ccccc|}
\hline \multicolumn{5}{|c|}{} & \multicolumn{5}{c|}{ Abraham model } \\
\cline { 3 - 6 } \multicolumn{2}{|c|}{} & Aliphatic & Aromatic & Halogen & Aprotic polar & Protic polar \\
\hline \multirow{2}{*}{} & Imidazolium & $98 \%$ & $90 \%$ & $67 \%$ & $78 \%$ & $116 \%$ \\
\multirow{\Xi}{*}{} & Pyrrolidinium & $30 \%$ & & & & \\
& Pyridinium & $19 \%$ & & & & \\
& Morpholinium & & & & & \\
\hline
\end{tabular}

${ }^{a}$ All 25 binary solute-solvent combinations have been made at $298.15 \mathrm{~K}$. The colors are indicative: white, $\mathrm{ARD}<100 \%$; light gray, $100 \%<\mathrm{ARD}<300 \%$; medium gray, $300 \%$ $<\mathrm{ARD}<500 \%$; dark gray, $500 \%<\mathrm{ARD}<10^{3} \%$; and black, ARD $>10^{5} \%$. 


\subsubsection{Anions}

The nature of the anion in ILs has been identified as a key factor determining the $\gamma_{i}^{\infty}$ parameter for solutes, ${ }^{49}$ therefore, it is also important to list the anion category- specific ARD in the predictions of $\gamma_{i}^{\infty}$, which is done in Table 5.4. By combining the information in Table 5.2, 5.3 and 5.4, it becomes clear that the large ARD observed with various UNIFAC models and the Abraham model originate from very large ARD observed for a few anions. ARD values of $>100 \%$ are caused by the bis- (trifluoromethane)sulfonimide $\left[N T f_{2}\right]^{-}$, tetrafluoroborate $\left[\mathrm{BF}_{4}\right]^{-}$, and diethylene glycolmonomethyl ether sulfate $[M D$ $\left.\mathrm{EGSO}_{4}\right]^{-}$anions, which indicates that improving these correlations will greatly improve the overall average accuracy of these models. COSMO-RS appears to have difficulties in each anion, indicating that the problems of COSMO-RS do not arise from a particular intermolecular interaction induced by one or more specific anion(s).

Table 5.4: Accuracy of COSMO-RS, UNIFAC, mod. UNIFAC (Ly), mod. UNIFAC (Do) and Abraham model differentiated towards aliphatic, aromatic, halogen, aprotic polar, and protic polar compounds in various anions.

\begin{tabular}{|c|c|c|c|c|c|c|}
\hline \multicolumn{7}{|c|}{ COSMO-RS } \\
\hline & & \multicolumn{5}{|c|}{ Solute } \\
\hline & & Aliphatic & Aromatic & Halogen & Aprotic polar & Protic polar \\
\hline \multirow{11}{*}{ 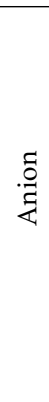 } & \multirow{10}{*}{$\begin{array}{c}{\left[\mathrm{NTf}_{2}\right]^{-}} \\
{\left[\mathrm{BF}_{4}\right]^{-}} \\
{[\mathrm{SCN}]^{-}} \\
{\left[\mathrm{CF}_{3} \mathrm{SO}_{3}\right]^{-}} \\
{\left[\mathrm{MDEGSO}_{4}\right]^{-}} \\
{\left[\mathrm{OSO}_{4}\right]^{-}} \\
{\left[\mathrm{PF}_{6}\right]^{-}} \\
{\left[\mathrm{B}(\mathrm{CN})_{4}\right]^{-}} \\
{[\mathrm{TFA}]^{-}} \\
{\left[\mathrm{DMPO} \mathrm{PO}_{4}\right]^{-}}\end{array}$} & $159 \%$ & $211 \%$ & $163 \%$ & $154 \%$ & $162 \%$ \\
\hline & & $504 \%$ & $468 \%$ & & $206 \%$ & $216 \%$ \\
\hline & & $123 \%$ & $274 \%$ & & $48 \%$ & $104 \%$ \\
\hline & & $88 \%$ & $139 \%$ & & $116 \%$ & $84 \%$ \\
\hline & & $184 \%$ & $118 \%$ & $526 \%$ & $46 \%$ & $16 \%$ \\
\hline & & $246 \%$ & $125 \%$ & $206 \%$ & & $199 \%$ \\
\hline & & $208 \%$ & $371 \%$ & & & $9 \%$ \\
\hline & & $241 \%$ & $330 \%$ & & $137 \%$ & $337 \%$ \\
\hline & & $287 \%$ & $263 \%$ & & & \\
\hline & & $112 \%$ & & & $53 \%$ & \\
\hline & {$[D C A]$} & $194 \%$ & & & & \\
\hline
\end{tabular}




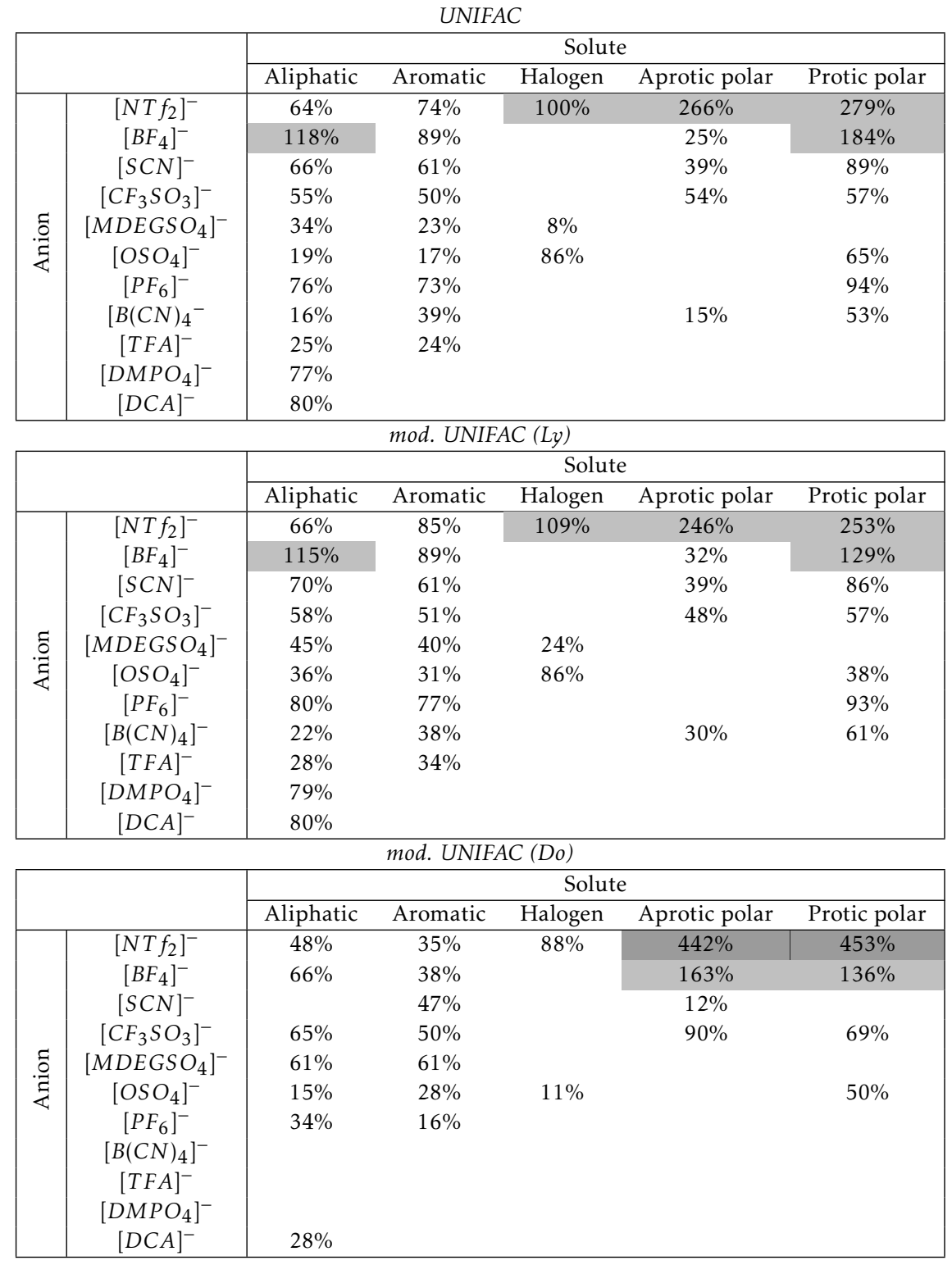


Abraham model

\begin{tabular}{|c|c|c|c|c|c|c|}
\hline & \multicolumn{5}{|c|}{ Solute } \\
\hline & & Aliphatic & Aromatic & Halogen & Aprotic polar & Protic polar \\
\hline \multirow{11}{*}{ 苞 } & {$\left[N T f_{2}\right]^{-}$} & $80 \%$ & $102 \%$ & $64 \%$ & $68 \%$ & $114 \%$ \\
\hline & {$\left[B F_{4}\right]^{-}$} & $69 \%$ & $21 \%$ & & $33 \%$ & $114 \%$ \\
\hline & {$[S C N]^{-}$} & $61 \%$ & $48 \%$ & & $42 \%$ & $64 \%$ \\
\hline & {$\left[\mathrm{CF}_{3} \mathrm{SO}_{3}\right]^{-}$} & $41 \%$ & $46 \%$ & & $24 \%$ & $41 \%$ \\
\hline & {$\left[\mathrm{MDEGSO}_{4}\right]^{-}$} & & & $124 \%$ & & \\
\hline & {$\left[\mathrm{OSO}_{4}\right]^{-}$} & $28 \%$ & $26 \%$ & $19 \%$ & & $30 \%$ \\
\hline & {$\left[P F_{6}\right]^{-}$} & $57 \%$ & $98 \%$ & & & $11 \%$ \\
\hline & {$\left[B(C N)_{4}\right]^{-}$} & $52 \%$ & $57 \%$ & & $17 \%$ & $56 \%$ \\
\hline & {$[T F A]^{-}$} & $61 \%$ & $54 \%$ & & & \\
\hline & {$\left[\mathrm{DMPO}_{4}\right]^{-}$} & $30 \%$ & & & & \\
\hline & {$[D C A]^{-}$} & $28 \%$ & & & & \\
\hline
\end{tabular}

\subsection{Model Selection}

In Table 5.5, for each combination of chemical systems, the model that most accurately predicts for that combination of chemical classes is listed. However, this is not the only selection criteria of importance. Solvation models, such as MOSCED and the Abraham model, can only be used when all molecular parameters are known. GCMs and COSMO-RS are much more flexible, in the sense that (almost) every molecular structure can be drawn and the $\gamma_{i}^{\infty}$ parameter can be predicted. To improve the applicability range of MOSCED and the Abraham model, recent efforts are made to predict the molecular parameters for MOSCED by using a $\mathrm{GCM}^{50}$ or by using quantum mechanical charge density calculations. ${ }^{51,52}$ Moreover, isobaric vapor-liquid predictions using MOSCED have been shown to outperform UNIFAC. ${ }^{33}$ Regarding the Abraham model, it has been shown that solute parameters can be predicted by multilinear regression analysis and computational neural networks. ${ }^{53}$ The limited temperature range of, often, only $298.15 \mathrm{~K}$ is a drawback for SMs and LSER, and attempts have been made toward temperature-independent parameters; ${ }^{54}$ however, this is not generalized yet.

It should be taken into consideration that the accuracy for predicting $\gamma_{i}^{\infty}$ by 
Table 5.5: An overview of the most accurate predictive model of each specific category of binary molecular solvent - solute mixtures ${ }^{a}$

\begin{tabular}{|c|c|c|c|c|c|c|}
\hline \multicolumn{7}{|c|}{ Best practice } \\
\hline & & \multicolumn{5}{|c|}{ Solute } \\
\hline & & Aliphatic & Aromatic & Halogen & Aprotic polar & Protic polar \\
\hline \multirow{5}{*}{$\begin{array}{l}\overrightarrow{0} \\
\frac{\vec{D}}{0} \\
\dot{0}\end{array}$} & Aliphatic & m.UNI(Do) & m.UNI(Do) & Abraham & COSMO & Abraham \\
\hline & Aromatic & COSMO & COSMO & MOSCED & Abraham & UNIFAC \\
\hline & Halogen & MOSCED & MOSCED & COSMO & MOSCED & Abraham \\
\hline & Aprotic polar & MOSCED & MOSCED & MOSCED & MOSCED & Abraham \\
\hline & Protic polar & Abraham & MOSCED & Abraham & MOSCED & m.UNI(Ly) \\
\hline
\end{tabular}

GCMs can be improved when only $\gamma_{i}^{\infty}$ data are regressed and not the thermodynamic data of other forms (excess enthalpy for example). However, this will reduce the accuracy of other thermodynamic properties. ${ }^{4}$ Therefore, a suggestion could be made to regress a separate $\gamma_{i}^{\infty}$-specific GCM that can obtain the most accurate $\gamma_{i}^{\infty}$ predictions. Overall, the model choice for the most accurate $\gamma_{i}^{\infty}$ must be a stepwise procedure. First, it should be ascertained whether all molecular parameters of the chosen molecules are available in the literature. If this is not the case, they may be predicted using theoretical or regression methods, although the accuracy of these methods should always be taken into consideration. When satisfactory molecular parameters are available, the best practice matrix in Table 5.5 can be used to select the best model. When the molecular parameters are lacking or are questionable (strongly deviating from the same parameters for comparable molecules), then GCMs or COSMORS should be used for the prediction. Regarding ILs, the Abrahams model is the most accurate model when the molecular parameters are known. Otherwise, GCMs of COSMO-RS must be used, although this will significantly increase the probability of deviation from the true value. Lastly, the application should be taken into consideration. GCMs and COSMO-RS can predict a much wider range of molecular properties than the SMs and LSER. 


\subsection{Conclusions}

Several models have been assessed for their ability to predict the infinite dilution activity coefficient $\left(\gamma_{i}^{\infty}\right)$ for solutes of various classes, in molecular solvents categorized in the same classes, and in ionic liquids (ILs). A larger ARD was observed for ILs than for molecular solvents, because of the additional ionic interactions. Overall on average, the MOSCED model was the most accurate model for the prediction of $\gamma_{i}^{\infty}$ of all solute classes in molecular solvents, with an ARD of $16.2 \pm 1.35 \%$. The UNIFAC group contribution methods (GCMs), COSMO-RS, and the Abraham models perform comparably, with ARD values of 24.3-32.2\%. Models using the Hildebrand parameter and the Hansen solubility parameters (HSP) are significantly less accurate, because of an insufficient description of intermolecular interactions such as hydrogen bonds. To predict the $\gamma_{i}^{\infty}$ in ILs, overall, the Abraham model is the most accurate model, with an ARD value of $65.1 \pm 4.50 \%$. The GCMs are less accurate, with ARD values of $86.2-122 \%$, while COSMO-RS is far less accurate, with an ARD value of $182 \pm 16.7 \%$, because of a deficient description of long-range interactions.

Upon classification of solutes and molecular solvents and evaluating the model prediction accuracy for each of the solvent and solute classes, it is observed that each of the models, except for the Hildebrand parameter and HSP, is most accurate for specific classes of binary solute-solvent pairs, although the accuracy decreases with the polarity of the solute. For ILs, using the overall averages, the Abraham model is most accurate, although several cations are more accurately described with modified UNIFAC (Ly) or modified UNIFAC (Do). The large ARD values from the UNIFAC models and the Abraham model are mainly due to large ARD values for the $\left[\mathrm{NTF}_{2}\right]^{-},\left[\mathrm{BF}_{4}\right]^{-}$, and $\left[\mathrm{MDEGSO} \mathrm{O}_{4}\right]^{-}$ anions. Hence, improving the prediction of these anions will greatly increase their overall prediction accuracy. Also, the most accurate model for molecular solvents (MOSCED) could not be assessed for ILs. Therefore, an extension of MOSCED toward ILs may become an accurate tool in predicting accurate $\gamma_{i}^{\infty}$ values in ILs. These evaluation results are applicable when each molecular parameter is either known or accurately predicted. If so, the most accurate model for estimation of $\gamma_{i}^{\infty}$ is dependent on both the solute and solvent categories under evaluation. Still, using a $\gamma_{i}^{\infty}$ model to predict $\gamma_{i}^{\infty}$ for IL screening 
should be done with caution, since these, on average, easily exceed deviations of $65 \%$.

\subsection{Electronic Supplementary Information}

All Electronic Supplementary Information is available free of charge on the ACS Publications website at DOI: 10.1021/acs.iecr.9b00727. Specific parameters, equations, and predictions for the various models; all experimental $\gamma_{i}^{\infty}$ used in the comparison, along with the corresponding references.

\subsection{Nomenclature}

$\begin{array}{ll}\mathrm{AD} & =\text { average deviation } \\ \mathrm{ARD} & =\text { average relative deviation } \\ \mathrm{UNIQUAC} & =\text { Universal Quasichemical } \\ \text { UNIFAC } & =\text { UNIQUAC Functional-group Activity Coefficients } \\ \text { COSMO-RS } & =\text { Conductor like Screening Model for Real Solvents } \\ \mathrm{DFT} & =\text { density functional theory } \\ \mathrm{ESI} & =\text { electronic Supporting Information } \\ \text { MOSCED } & =\text { Modified Separation of Cohesive Energy Density } \\ \mathrm{ILs} & =\text { ionic liquids } \\ \mathrm{FILs} & =\text { functionalized ionic liquids } \\ \mathrm{NRTL} & =\text { nonrandom two-liquid model } \\ \mathrm{GCM} & =\text { group contribution method } \\ \mathrm{HSP} & =\text { Hansen solubility parameters } \\ \mathrm{HF} & =\text { Hartree-Fock } \\ \mathrm{SCF} & =\text { self-consistent field } \\ \mathrm{SM} & =\text { solvation models } \\ \mathrm{TZVPD}-\mathrm{Fine} & =\text { fine grid triple- } \zeta \text { valence polarized basis set } \\ {\left[\mathrm{NTf}_{2}\right]^{-}} & =\text {bis(trifluoromethylsulfonyl)imide } \\ {\left[\mathrm{BF}_{4}\right]^{-}} & =\text {tetrafluoroborate } \\ {\left[\mathrm{SCN}^{-}\right.} & =\text {thiocyanate } \\ {\left[\mathrm{CF}_{3} \mathrm{SO}_{3}\right]^{-}} & =\text {trifluoromethanesulfone }\end{array}$




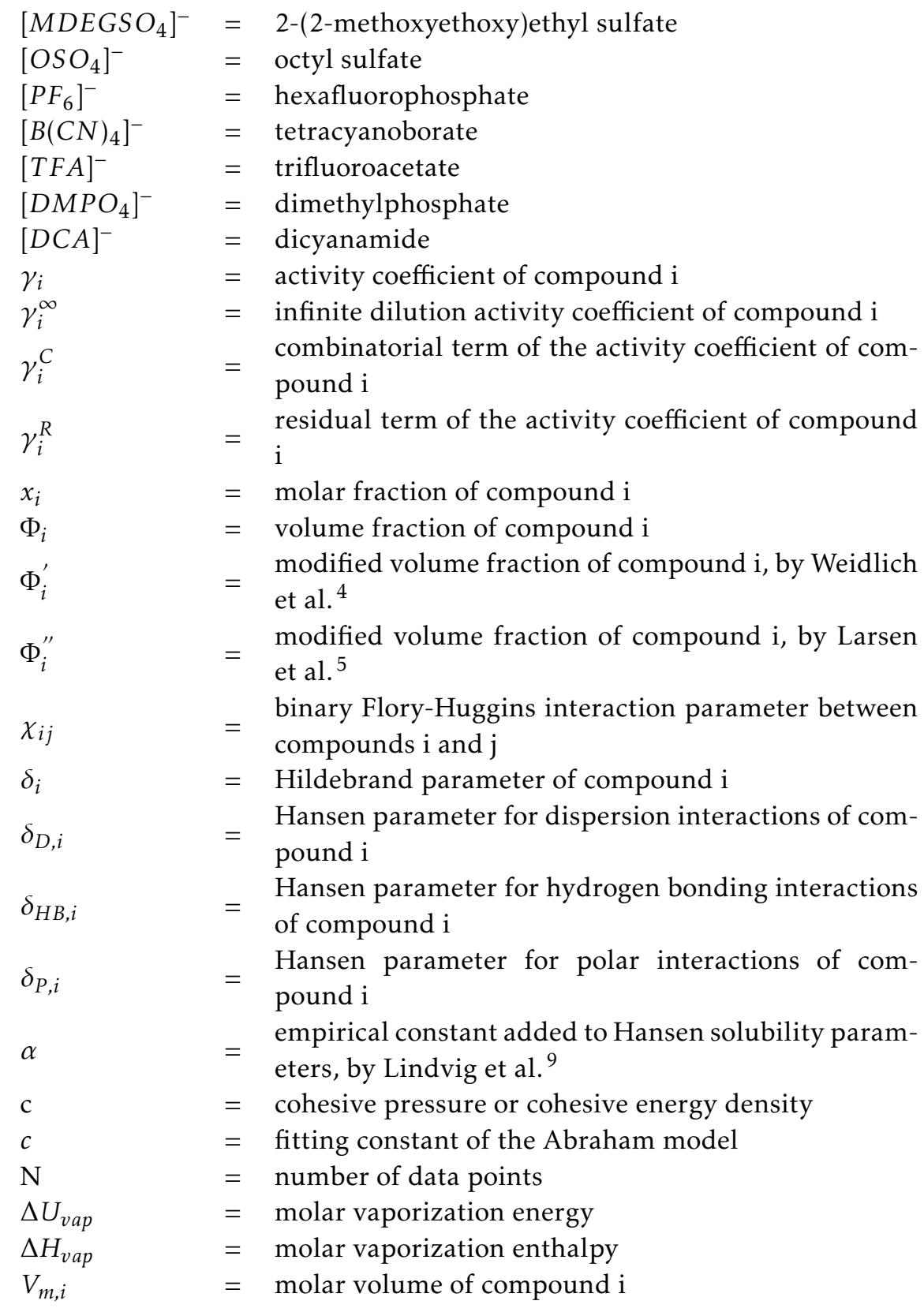




\begin{tabular}{|c|c|c|}
\hline $\mathrm{T}$ & $=$ & temperature $(\mathrm{K})$ \\
\hline $\mathrm{R}$ & $=$ & universal gas constant; $\mathrm{R}=8.3145 \mathrm{JK}^{-1} \mathrm{~mol}^{-1}$ \\
\hline $\mathrm{Z}$ & $=$ & coordination number \\
\hline$\lambda_{i}$ & $=$ & MOSCED dispersion constant for compound i \\
\hline$\tau_{i}$ & $=$ & MOSCED polarity constant for compound i \\
\hline$q_{i}$ & $=$ & MOSCED induction constant for compound i \\
\hline$\alpha_{i}$ & $=$ & MOSCED hydrogen bond acidity constant for compound i \\
\hline$\alpha_{i}^{T}$ & $=$ & $\begin{array}{l}\text { temperature-corrected MOSCED hydrogen bond acidity con- } \\
\text { stant for compound i }\end{array}$ \\
\hline$\beta_{i}$ & $=$ & MOSCED hydrogen bond basicity constant for compound i \\
\hline$\beta_{i}^{T}$ & $=$ & $\begin{array}{l}\text { temperature-corrected MOSCED hydrogen bond basicity con- } \\
\text { stant for compound i }\end{array}$ \\
\hline$\xi_{i}$ & $=$ & MOSCED empirical asymmetric constant for compound i \\
\hline$\Psi_{i}$ & $=$ & MOSCED empirical asymmetric constant for compound i \\
\hline$\theta_{i}$ & $=$ & surface fraction of compound $\mathrm{i}$ \\
\hline$q_{i}$ & $=$ & coordination number of compound $\mathrm{i}$ \\
\hline$v_{k}^{(i)}$ & $=$ & occurrence of each moiety $\mathrm{k}$ in surrounded by moiety $\mathrm{i}$ \\
\hline$\Gamma_{k}$ & $=$ & overall activity of moiety $\mathrm{k}$ \\
\hline$\Gamma_{k}^{(i)}$ & $=$ & activity of moiety k solely surrounded by moiety i \\
\hline$\hat{Q}_{k}$ & $=$ & van der Waals surface of moiety $\mathrm{k}$ \\
\hline$R_{k}$ & $=$ & van der Waals volume of moiety $\mathrm{k}$ \\
\hline$\Psi_{m k}$ & $=$ & group binary interaction parameter between moiety $\mathrm{m}$ and $\mathrm{k}$ \\
\hline$e_{c / a}, E$ & $=$ & $\begin{array}{l}\text { Abraham descriptors for } \sigma \text { - and } \pi \text {-electron interactions (sub- } \\
\text { scripts c and a indicate cationic and anionic species, resp.) }\end{array}$ \\
\hline$s_{c / a}, S$ & $=$ & $\begin{array}{l}\text { Abraham descriptors for (induced) multipole moments in- } \\
\text { teractions (subscripts c and a indicate cationic and anionic } \\
\text { species, resp.) }\end{array}$ \\
\hline$a_{c / a}, A$ & $=$ & $\begin{array}{l}\text { Abraham descriptors for tendency to accept hydrogen or do- } \\
\text { nate electron (subscripts c and a indicate cationic and anionic } \\
\text { species, resp.) }\end{array}$ \\
\hline$b_{c / a}, B$ & $=$ & $\begin{array}{l}\text { Abraham descriptors for tendency to donate hydrogen or ac- } \\
\text { cept electron (subscripts c and a indicate cationic and anionic } \\
\text { species, resp.) }\end{array}$ \\
\hline
\end{tabular}




\begin{tabular}{|c|c|c|}
\hline$v_{c / a}, V$ & $=$ & $\begin{array}{l}\text { Abraham descriptors for the work/tendency required to } \\
\text { form cavities (subscripts c and a indicate cationic and anionic } \\
\text { species, resp.) }\end{array}$ \\
\hline$l_{c / a}, L$ & $=$ & $\begin{array}{l}\text { Abraham descriptors for the work/tendency required to } \\
\text { form cavities (subscripts c and a indicate cationic and anionic } \\
\text { species, resp.) }\end{array}$ \\
\hline$P_{i}^{O}$ & $=$ & vapor pressure of the pure solvent \\
\hline$K_{S}$ & $=$ & gas-solvent partition coefficient \\
\hline$P_{S}$ & $=$ & water-solvent partition coefficient \\
\hline$E_{\text {contact }}$ & $=$ & local contact energy \\
\hline$E_{\text {misfit }}$ & $=$ & misfit energy \\
\hline$E_{H B}$ & $=$ & energy due to hydrogen bonding effects \\
\hline$\sigma$ & $=$ & polarization charge density \\
\hline$\sigma^{\prime}$ & $=$ & polarization charge density on the opposite side \\
\hline
\end{tabular}

\subsection{References}

[1] A. A. Kiss, J.-P. Lange, B. Schuur, D. W. F. Brilman, A. G. van der Ham, and S. R. Kersten, "Separation technology-making a difference in biorefineries," Biomass and Bioenergy, vol. 95, pp. 296-309, 2016.

[2] D. S. Sholl and R. P. Lively, "Seven chemical separations to change the world," Nature, vol. 532, no. 7600, pp. 435-437, 2016.

[3] M. H. Abraham, "Scales of solute hydrogen-bonding: their construction and application to physicochemical and biochemical processes," Chemical Society Reviews, vol. 22, no. 2, pp. 73-83, 1993.

[4] U. Weidlich and J. Gmehling, "A modified unifac model. 1. prediction of vle, he, and. gamma.. infin.," Industrial \& engineering chemistry research, vol. 26, no. 7, pp. 1372-1381, 1987.

[5] B. L. Larsen, P. Rasmussen, and A. Fredenslund, "A modified unifac group-contribution model for prediction of phase equilibria and heats of mixing," Industrial \& engineering chemistry research, vol. 26, no. 11, pp. 2274-2286, 1987.

[6] M. J. Lazzaroni, D. Bush, C. A. Eckert, T. C. Frank, S. Gupta, and J. D. Olson, "Revision of mosced parameters and extension to solid solubility calculations," Industrial E engineering chemistry research, vol. 44, no. 11, pp. 4075-4083, 2005.

[7] J. H. Hildebrand et al., Solubility of Non-electrolytes. Reinhold Pub., 1936.

[8] C. M. Hansen, "Three dimensional solubility parameter-key to paint-component affinities: Dyes, emulsifiers, mutual solubility and compatibility, and pigments.," J. Paint. Technol., vol. 39, p. 505, 1967.

[9] T. Lindvig, M. L. Michelsen, and G. M. Kontogeorgis, "A flory-huggins model based on the hansen solubility parameters," Fluid Phase Equilibria, vol. 203, no. 1-2, pp. 247-260, 2002.

[10] A. Klamt, F. Eckert, and W. Arlt, "Cosmo-rs: an alternative to simulation for calculating thermodynamic properties of liquid mixtures," Annual review of chemical and biomolecular engineering, vol. 1, pp. 101-122, 2010.

[11] A. Fredenslund, R. L. Jones, and J. M. Prausnitz, "Group-contribution estimation of activity coefficients in nonideal liquid mixtures,” AIChE Journal, vol. 21, no. 6, pp. 1086-1099, 1975.

[12] F. London, "The general theory of molecular forces," Transactions of the Faraday Society, vol. 33, pp. 8b-26, 1937. 
[13] P. Debye, "Van der waals cohesion forces," Physikalische Zeitschrift, vol. 21, pp. 178-187, 1920.

[14] W. Keesom, "Van der waals attractive force," Physikalische Zeitschrift, vol. 22, pp. 129-141, 1921.

[15] J. N. Israelachvili, Intermolecular and surface forces. Academic press, 2015.

[16] P. Alessi, M. Fermeglia, and I. Kikic, "Significance of dilute regions," Fluid Phase Equilibria, vol. 70, no. 23, pp. 239-250, 1991.

[17] C. B. Castells, P. W. Carr, D. I. Eikens, D. Bush, and C. A. Eckert, "Comparative study of semitheoretical models for predicting infinite dilution activity coefficients of alkanes in organic solvents," Industrial $\mathcal{E}$ engineering chemistry research, vol. 38, no. 10, pp. 4104-4109, 1999.

[18] J. Gmehling, J. Li, and M. Schiller, "A modified unifac model. 2. present parameter matrix and results for different thermodynamic properties," Industrial \& Engineering Chemistry Research, vol. 32, no. 1, pp. 178193, 1993.

[19] M. J. Hait, C. L. Liotta, C. A. Eckert, D. L. Bergmann, A. M. Karachewski, A. J. Dallas, D. I. Eikens, J. J. $\mathrm{Li}$, and P. W. Carr, "Space predictor for infinite dilution activity coefficients," Industrial E engineering chemistry research, vol. 32, no. 11, pp. 2905-2914, 1993.

[20] J. H. Park and P. W. Carr, "Predictive ability of the mosced and unifac activity coefficient estimation methods," Analytical Chemistry, vol. 59, no. 21, pp. 2596-2602, 1987.

[21] R. Putnam, R. Taylor, A. Klamt, F. Eckert, and M. Schiller, "Prediction of infinite dilution activity coefficients using cosmo-rs," Industrial E engineering chemistry research, vol. 42, no. 15, pp. 3635-3641, 2003.

[22] E. R. Thomas and C. A. Eckert, "Prediction of limiting activity coefficients by a modified separation of cohesive energy density model and unifac," Industrial E Engineering Chemistry Process Design and Development, vol. 23, no. 2, pp. 194-209, 1984.

[23] E. C. Voutsas and D. P. Tassios, "Prediction of infinite-dilution activity coefficients in binary mixtures with unifac. a critical evaluation," Industrial \& engineering chemistry research, vol. 35, no. 4, pp. 1438$1445,1996$.

[24] Z. Xue, T. Mu, and J. Gmehling, "Comparison of the a priori cosmo-rs models and group contribution methods: original unifac, modified unifac (do), and modified unifac (do) consortium," Industrial E engineering chemistry research, vol. 51, no. 36, pp. 11809-11817, 2012.

[25] P. J. Flory, "Thermodynamics of high polymer solutions," The Journal of chemical physics, vol. 10, no. 1, pp. 51-61, 1942.

[26] M. L. Huggins, "Some properties of solutions of long-chain compounds.," The Journal of Physical Chemistry, vol. 46, no. 1, pp. 151-158, 1942.

[27] S. Sayegh and J. Vera, "Lattice-model expressions for the combinatotial entropy of liquid mixtures: a critical discussion," The Chemical Engineering Journal, vol. 19, no. 1, pp. 1-10, 1980.

[28] G. J. Krooshof, R. Tuinier, and G. de With, "Generalization of guggenheim's combinatorial activity coefficient equation," Journal of Molecular Liquids, vol. 266, pp. 467-471, 2018.

[29] G. J. P. Krooshof, "Combinatorial and dispersion activity coefficient models for molecular solutions," 2019.

[30] I. Kikic, P. Alessi, P. Rasmussen, and A. Fredenslund, "On the combinatorial part of the unifac and uniquac models," The Canadian Journal of Chemical Engineering, vol. 58, no. 2, pp. 253-258, 1980.

[31] A. Barton, "M.(1991) handbook of solubility parameters and other cohesion parameters."

[32] C. M. Hansen, Hansen solubility parameters: a user's handbook. CRC press, 2007.

[33] P. Dhakal, S. N. Roese, E. M. Stalcup, and A. S. Paluch, "Application of mosced to predict limiting activity coefficients, hydration free energies, henry's constants, octanol/water partition coefficients, and isobaric azeotropic vapor-liquid equilibrium," Journal of Chemical \& Engineering Data, vol. 63, no. 2, pp. 352-364, 2018.

[34] A. Staverman, "The entropy of high polymer solutions. generalization of formulae," Recueil des Travaux Chimiques des Pays-Bas, vol. 69, no. 2, pp. 163-174, 1950.

[35] J. L. Abboud, M. J. Kamlet, and R. Taft, "Regarding a generalized scale of solvent polarities," Journal of the American Chemical Society, vol. 99, no. 25, pp. 8325-8327, 1977.

[36] M. J. Kamlet, J. L. Abboud, and R. Taft, "The solvatochromic comparison method. 6. the. pi.* scale of solvent polarities," Journal of the American Chemical Society, vol. 99, no. 18, pp. 6027-6038, 1977.

[37] M. J. Kamlet, P. W. Carr, R. Taft, and M. H. Abraham, "Linear solvation energy relationships. 13. relationship between the hildebrand solubility parameter,. delta. h, and the solvatochromic parameter,. pi.," 
Journal of the American Chemical Society, vol. 103, no. 20, pp. 6062-6066, 1981.

[38] M. J. Kamlet and R. Taft, "The solvatochromic comparison method. i. the. beta.-scale of solvent hydrogenbond acceptor (hba) basicities," Journal of the American chemical Society, vol. 98, no. 2, pp. 377-383, 1976.

[39] R. Taft, J.-L. M. Abboud, and M. J. Kamlet, "Solvatochromic comparison method. 20. linear solvation energy relationships. 12. the d. delta. term in the solvatochromic equations," Journal of the American Chemical Society, vol. 103, no. 5, pp. 1080-1086, 1981.

[40] L. Sprunger, M. Clark, W. E. Acree, and M. H. Abraham, "Characterization of room-temperature ionic liquids by the abraham model with cation-specific and anion-specific equation coefficients," Journal of chemical information and modeling, vol. 47, no. 3, pp. 1123-1129, 2007.

[41] F. Eckert and A. Klamt, "Fast solvent screening via quantum chemistry: Cosmo-rs approach," AIChE Journal, vol. 48, no. 2, pp. 369-385, 2002.

[42] J. Wang, W. Sun, C. Li, and Z. Wang, "Correlation of infinite dilution activity coefficient of solute in ionic liquid using unifac model," Fluid Phase Equilibria, vol. 264, no. 1-2, pp. 235-241, 2008.

[43] Z. Lei, C. Dai, X. Liu, L. Xiao, and B. Chen, "Extension of the unifac model for ionic liquids," Industrial \& engineering chemistry research, vol. 51, no. 37, pp. 12135-12144, 2012.

[44] R. Kato and J. Gmehling, "Systems with ionic liquids: Measurement of vle and $\gamma^{\infty}$ data and prediction of their thermodynamic behavior using original unifac, mod. unifac (do) and cosmo-rs (ol)," The Journal of Chemical Thermodynamics, vol. 37, no. 6, pp. 603-619, 2005.

[45] S. Nebig, R. Bölts, and J. Gmehling, "Measurement of vapor-liquid equilibria (vle) and excess enthalpies (he) of binary systems with 1-alkyl-3-methylimidazolium bis (trifluoromethylsulfonyl) imide and prediction of these properties and $\gamma^{\infty}$ using modified unifac (dortmund)," Fluid phase equilibria, vol. 258, no. 2, pp. 168-178, 2007.

[46] S. Nebig, V. Liebert, and J. Gmehling, "Measurement and prediction of activity coefficients at infinite dilution $\left(\gamma^{\infty}\right)$, vapor-liquid equilibria (vle) and excess enthalpies (he) of binary systems with 1, 1-dialkylpyrrolidinium bis (trifluoromethylsulfonyl) imide using mod. unifac (dortmund)," Fluid phase equilibria, vol. 277, no. 1, pp. 61-67, 2009.

[47] K. Paduszyński and U. Domańska, "Extension of modified unifac (dortmund) matrix to piperidinium ionic liquids," Fluid Phase Equilibria, vol. 353, pp. 115-120, 2013.

[48] S. Nebig and J. Gmehling, "Prediction of phase equilibria and excess properties for systems with ionic liquids using modified unifac: Typical results and present status of the modified unifac matrix for ionic liquids," Fluid phase equilibria, vol. 302, no. 1-2, pp. 220-225, 2011.

[49] G. W. Meindersma, A. J. Podt, and A. B. de Haan, "Selection of ionic liquids for the extraction of aromatic hydrocarbons from aromatic/aliphatic mixtures," Fuel Processing Technology, vol. 87, no. 1, pp. 59-70, 2005.

[50] P. Dhakal, S. N. Roese, E. M. Stalcup, and A. S. Paluch, "Gc-mosced: A group contribution method for predicting mosced parameters with application to limiting activity coefficients in water and octanol/water partition coefficients," Fluid Phase Equilibria, vol. 470, pp. 232-240, 2018.

[51] S. Diaz-Rodriguez, S. M. Bozada, J. R. Phifer, and A. S. Paluch, "Predicting cyclohexane/water distribution coefficients for the sampl5 challenge using mosced and the smd solvation model," Journal of computeraided molecular design, vol. 30, no. 11, pp. 1007-1017, 2016.

[52] J. R. Phifer, K. J. Solomon, K. L. Young, and A. S. Paluch, “Computing mosced parameters of nonelectrolyte solids with electronic structure methods in smd and sm8 continuum solvents," AIChE Journal, vol. 63, no. 2, pp. 781-791, 2017.

[53] J. Jover, R. Bosque, and J. Sales, "Determination of abraham solute parameters from molecular structure," Journal of chemical information and computer sciences, vol. 44, no. 3, pp. 1098-1106, 2004.

[54] C. Mintz, T. Ladlie, K. Burton, M. Clark, W. E. Acree Jr, and M. H. Abraham, "Characterization of the partitioning of gaseous solutes into humic acid with the abraham model and temperature-independent equation coefficients," QSAR E Combinatorial Science, vol. 27, no. 4, pp. 483-491, 2008. 





\subsection{Introduction}

For the design of separation columns, including distillation columns, knowing the equilibrium between two phases is vital. The vapor-liquid equilibrium (VLE) is for instance required for an accurate design of a distillation column, while the liquid-liquid equilibrium (LLE) is for a liquid-liquid extraction column. We will focus on the equilibrium between the vapor and liquid phase. Experimental measurements of these equilibria are common techniques, but laborious. Practitioners in industry and academia require a significant amount of samples and measurements are time-consuming. ${ }^{1}$ Hence, finding and/or developing an alternative method that requires only a few measurements, which are ideally uncomplicated, could be a way of saving not only time but also money. Ten Kate et al. ${ }^{2}$ showed this may be possible via the correlation of spectroscopic results and a liquid phase activity coefficient model, they applied UNIQUAC. In this chapter, it is attempted to develop a comparable method, though from another angle which is based around the idea of the measurement of the heat of mixing between two components.

An approach is formulated which can convert the mixing heat, or also called the excess molar enthalpy $\left(H^{E}\right)$, via a thermodynamic description to a prediction of the isobaric VLE behavior. In essence, three types of componentspecific parameters describe the VLE behavior as can be seen in Equation 6.1 for a binary case,

$$
\alpha_{i j}=\frac{P_{i}^{0}}{P_{j}^{0}}\left(\frac{\gamma_{i} \varphi_{j}}{\gamma_{j} \varphi_{i}}\right)=\alpha_{i j}^{I D} S_{j i}
$$

which are the pure component vapor pressure $\left(P_{i}^{0}\right)$, the activity coefficient $\left(\gamma_{i}\right)$ and the fugacity coefficient $\left(\varphi_{i}\right)$. The vapor pressure describes the temperaturedependent volatility of a compound in its pure form and is the only parameter of significance in an ideal case. The ratio of these vapor pressures is therefore referred to as the ideal relative volatility $\left(\alpha_{i j}^{I D}\right)$. In an ideal mixture, where the assumption is that there is no distinction between all compounds and therefore all intermolecular interactions appear to be equal, Raoult's law will be followed $\left(P_{i}=P_{i}^{0} x_{i}\right)$. This law states that the partial pressure $\left(P_{i}\right)$ of a compound is directly proportional to the molar fraction of the compound in the 
liquid phase $\left(x_{i}\right)$ and the pure-component vapor pressure $\left(P_{i}^{0}\right){ }^{3}$

This is, however, not always applicable, as most mixtures do depart from ideality as the compounds differ in chemical nature. This requires a distinction between the different compounds and the corresponding molecular properties, which ultimately results in distinct intermolecular interactions that cannot be ignored. The activity and fugacity coefficients describe this deviation or departure from ideality in resp. the liquid and the vapor phase. This is taken into account in the modified Raoult's law, see Equation 6.2, ${ }^{4}$

$$
\varphi_{i} P_{i}=P_{i}^{0} a_{i}=P_{i}^{0} x_{i} \gamma_{i}
$$

where the molar fraction of the compound is replaced by the activity of the compound $\left(a_{i}\right)$, which is, in turn, the multiplication of the molar fraction and the activity coefficient of that specific compound $\left(\gamma_{i}\right)$. The expression of the activity of each compound in each phase is a crucial requirement for describing equilibrium, as was referred to in chapter 2 , since at this dynamic equilibrium the activity of each compound in each phase is by definition always equal, to allow for no net transfer of the compound between the phases.

When differences in intermolecular interactions are insignificant, near-ideal behavior can be observed. This occurs when the $\gamma_{i}$ and $\varphi_{i}$ both approach 1. Deviation from this situation can arise when either net attractive interactions occur $\left(\gamma_{i}\right.$ or/and $\left.\varphi_{i}<1\right)$ or net repulsive interactions are induced $\left(\gamma_{i}\right.$ or/and $\varphi_{i}>1$ ). Possible consequences of this non-ideal behavior can manifest in pinch-point and/or azeotrope formation which complicates the separation of that mixture via traditional distillation. A pinch-point is a (local) reduction of the relative volatility which makes the separation more difficult, as the achieved concentration increase in the vapor phase is lessened, though not infeasible as the vapor- and liquid composition do not reach equality. In the (worst) case, the vapor and liquid compositions become equal and no separation is possible. This is called an azeotrope.

The pure-component vapor pressures of molecules needed for the VLE description, see Equation 6.1, are extensively tabulated using for instance Antoine coefficients, see Yaws Handbook ${ }^{5}$ or the National Institute of Standards 
and Technology of the U.S. Department of Commerce (NIST) database. ${ }^{6}$ The activity and fugacity coefficients are however not always available, because they are composition- and temperature-dependent. A limiting case is the infinite dilution activity coefficient, $\gamma_{i}^{\infty}$. By describing the $\gamma_{i}^{\infty}$, the composition dependency is eliminated and the non-ideality of a compound (or solute) within a solvent that is (almost) pure can be described with a single value at a certain temperature. For a VLE diagram, the activity coefficient is, however, required over the entire composition range and, still, the measurement of new $\gamma_{i}^{\infty}$ is not easy and specialized equipment is required. ${ }^{7}$ Therefore it was chosen to investigate an alternative method where new experimental data is effectively obtained while using only small quantities of chemicals through the measurement of the heat that is either released or absorbed during the mixing of liquids, or also named the excess molar enthalpy $\left(H^{E}\right)$.

The method developed in this chapter describes how to correlate $H^{E}$ to the activity coefficient $\left(\gamma_{i}\right.$, the derivative of the excess Gibbs energy) and the fugacity coefficient $\left(\varphi_{i}\right)$. To make this possible, it is necessary to formulate the excess (molar) Gibbs energy $\left(\mathrm{Jmol}^{-1}\right)$, Equation 6.3,

$$
G^{E}=H^{E}-T S^{E}
$$

While the $H^{E}\left(\mathrm{Jmol}^{-1}\right.$, specifically a mol of the entire mixture) can be directly measured as the heat of mixing, the excess entropy $\left(S^{E}, \mathrm{Jmol}^{-1} \mathrm{~K}^{-1}\right)$ is not directly measurable. There are, however, many models available which define and describe the entropy. ${ }^{8}$ For this reason, the entropy can mathematically be described using a thermodynamic model. Pinpointing and modeling the appropriate thermodynamic models which can accurately describe the entropy is for this method essential and the core of this method.

Hanks et al. ${ }^{9}$ already mentioned almost 20 years ago the possibility of using the NRTL or Wilson model to predict VLE diagrams from excess molar enthalpy. The limitation of the Wilson equation was however seen to be that accurate results can only occur when the maximum $H^{E}$ was lower than 0.69 $\mathrm{kJmol}^{-1},{ }^{10}$ which was also stated by Voňka et al. ${ }^{11}$ The NRTL equation suffers from a significant limitation that in the case of extreme parameters $\left(\sim 10^{6}\right)$, the NRTL equation degenerates towards an ideal solution model, and accurate 
predictions are only made if the maximum $H^{E}$ is lower than $0.42 \mathrm{~kJ} / \mathrm{mol} .{ }^{10}$ Additionally, Voňka et al. stated the inability of NRTL equation to fit specifically S-shaped entropic contributions. ${ }^{11}$ These observations direct towards a conclusion that the approach would work for systems relatively close to ideal, with small $H^{E}$ and a subsequent neglectable excess entropy $\left(\mathrm{S}^{E}\right)$. This seems to be confirmed by the results of Calzón et al. ${ }^{12}$ who showed that the VLE of n-octane and hexane isomers can be accurately predicted from the excess molar enthalpy using either the Wilson equation or the NRTL model with a fixed non-randomness factor $\left(\alpha_{i j}\right)$.

Simultaneous representation of the excess molar enthalpy $\left(H^{E}\right)$ and the isobaric VLE has been considered an important goal in the application of cubic Equations of States (cEoS), and was seen to be accurate for some systems. Excess molar enthalpy can be correlated with high accuracy and may even outperform liquid phase activity coefficient models. ${ }^{13,14}$ However, only crude estimations could be obtained via cross-prediction between VLE and $H^{E}$. Using binary interaction parameters (BIPs) obtained from $H^{E}$ correlations to predict VLE was seen to be the least accurate. ${ }^{13,14}$ This was, however, only checked for a single system, and a systematic approach for developing cEoS parameters based on HE data has not been reported to the best of our knowledge.

In this chapter, both the use of activity coefficient models and the cEoS models are evaluated on their usefulness for predicting VLE from HE data. In the following subsections, first, the theory on both the liquid phase activity coefficient models and the cubic equations of state (cEoS) models including variations with associative terms will be introduced. Then, the applicability of these models will be investigated to correlate the activity coefficients with $H^{E}$, allowing for the prediction of the VLE behavior.

\subsection{Thermodynamic models}

\subsubsection{Liquid phase activity coefficient models}

Several liquid phase activity coefficient models of varying complexity are known which are based on the molar Gibbs energy, such as the van Laar model, ${ }^{15}$ Wilson model, ${ }^{16}$ Margules model, ${ }^{17}$ Universal Quasichemical (UNI- 
QUAC) model ${ }^{18}$ and Non-Random Two-Liquid (NRTL) model. ${ }^{19}$ The Gibbs energy can be defined as the summation of the Gibbs energy of an ideal solution $\left(G^{I D}\right)$ and an excess term which accounts for the non-ideal behavior $\left(G^{E}\right)$, see Equation 6.4,

$$
G=G^{I D}+G^{E}
$$

where the $G^{I D}$ can subsequently be defined as a summation of all molar Gibbs energies $\left(\bar{G}_{i}\right)$ multiplied by the specific molar fraction, $x_{i}$. The excess term of the Gibbs energy $\left(G^{E}\right)$ is related to the activity coefficient at constant temperature and pressure, as the latter is the partial derivative, as can be seen in Equation 6.5,

$$
R T \ln \gamma_{i}=\left(\frac{\partial G^{E}}{\partial x_{i}}\right)_{T, P}=\bar{G}^{E}
$$

In a binary system, the well-known Gibbs-Duhem equation can be used to convert the excess Gibbs energy of a binary system into the individual excess molar Gibbs energies.

Each liquid activity coefficient model has a different manner of incorporating interaction parameters in the activity coefficient description to estimate/predict the non-ideality in a mixture. Because we are specifically interested in the correlation between the Gibbs energy and the excess molar enthalpy $\left(H^{E}\right)$, we need to describe how the Gibbs energy changes as a function of the temperature and pressure. By following the Gibbs-Helmholtz relation, see Equation 6.6, a generic expression which correlates the Gibbs energy and the enthalpy, the excess Gibbs energy can be correlated with the excess molar enthalpy $\left(H^{E}\right){ }^{20}$

$$
\left(\frac{\left(\partial G^{E} / T\right)}{\partial T}\right)_{P}=-\frac{H^{E}}{T^{2}}
$$

\subsection{2 cubic Equation of State}

The second type of model incorporated in this work is the Equation of State (EoS). These models are mathematical constructions that detail the dependence of three observable parameters, namely temperature $(T)$, pressure $(P)$, 
and (molar) volume $\left(\mathrm{V}\right.$ or $\left.V_{m}=\mathrm{V} / \mathrm{n}\right)$. The most simple EoS is the ideal gas law, see Equation 6.7, which was first stated by Claperyon in $1834,{ }^{21}$

$$
P V=n R T \vee P V_{m}=R T
$$

This law incorporates the three observable parameters, the molar amount (n), and the universal gas constant, R. Both academia and industry use EoS to calculate thermodynamic properties. Accurate temperature, pressure, and composition profiles can be determined for a wide range of mixtures and corresponding processes. ${ }^{22}$ Cubic Equations of States (cEoS) are the most popular class and originates from the Van der Waals (VdW) equation of state. Van der Waals for the first time formulated a thermodynamic model for both fluid phases as the ideal gas law does not differentiate between gas and vapor, see Equation 6.8 , and though is still generally only applied to gasses. ${ }^{23}$

$$
P=\frac{R T}{V_{m}-b}-\frac{a}{V_{m}^{2}}
$$

From a statistical point of view, these parameters can be obtained by a LennardJones type of potential, where the hard-core volume of the molecule can be considered to be a repulsive parameter (b) and the intermolecular attraction parameter (a) is associated with the $\epsilon$ parameter which is a representation of the intermolecular interactions.

Since Van der Waals in 1873 published his dissertation, numerous adaptions of the VdW cEoS have been published to include more extreme conditions and/or to accurately incorporate increasingly more complex molecules behaving non-ideal. Commonly applied adaptations are the (Soave-)RedlichKwong, ${ }^{24,25}$ Peng-Robinson, ${ }^{26}$ and the Petal-Teja ${ }^{27}$ cEoS, though many others are present in literature and they all originate and follow the Van der Waals mathematical framework. These equations are named cubic as they can be rewritten as a cubic function of the molar volume, expressed as the compressibility factor $(Z)$. This $Z$-value is indicative of the non-ideality of the fluid, and is defined according to Equation 6.9,

$$
Z=\frac{P V_{m}}{R T}
$$


This definition allows quick comparison with ideal fluids because, for an ideal fluid, the Z-value is equal to unity, which results in the ideal gas law. For nonideal cases where two fluid phases can co-exist, to describe the system, the $\mathrm{Z}$-value is essential.

In the mathematical framework of the cEoS the Z-values of both fluid phases can be determined by finding the three roots of which the smallest and largest root each correlate to resp. the liquid $\left(Z_{L}\right)$ phase and the gas or vapor phase $\left(Z_{V}\right)$ in subcritical conditions. The middle root does not have a physical meaning. The determination of the $\mathrm{Z}$-value allows the description of a variety of other thermodynamic quantities arising from the deviation or departure from ideality. Collectively these quantities are known as departure functions. All these departure functions have the form seen in Equation 6.10,

$$
X_{\text {dep }}=X-X^{i g}
$$

Where the departure function of quantity $X\left(X_{d e p}\right)$ is always the difference between the absolute quantity $(\mathrm{X})$ and of a reference state. In the mathematical framework of cEoS, this reference state is an ideal gas (ig).

For this work, we are interested in the excess molar enthalpy and the fugacity. These quantities can be derived from the compressibility description as a function of i.a. the molar volume. ${ }^{28}$ Deriving the departure functions from cEoS is not straight-forward, and requires some elaboration, which is covered in chapter 12, which is an Appendix dedicated to more details concerning thermodynamics. In conclusion, the excess molar enthalpy and fugacity as a function of the compressibility factor relation are seen in resp. Equation 6.11 and Equation 6.12,

$$
\begin{gathered}
H_{\text {dep }}=H^{E}=H-H^{i g}=R T \int_{0}^{\rho}-T\left(\frac{\partial Z}{\partial T}\right)_{\rho} \frac{d \rho}{\rho}+(Z-1) \\
\ln f_{i}=\int_{0}^{\rho}(Z-1) \frac{d \rho}{\rho}+(Z-1)-\ln Z
\end{gathered}
$$

where it can be seen that each quantity is a function of the compressibility factor $(Z)$, the universal gas constant $(R)$, the temperature $(T)$ and the molar density $(\rho)$ which is the inverse of the molar volume $\left(V_{m}\right)$. Upon the choice of 
the Z-factor, the fugacity can be distinguished between the liquid- or vapor phase fugacity. These quantities are at isobaric conditions, though isochoric relations can also be derived.

Mixing rules are introduced to extend the cEoS description from pure components towards mixtures. These relations describe the way pure component parameters, for instance, the $a$ and $b$ parameters, of the Van der Waals equation vary as a function of the composition. These mixing rules are in a general form of,

$$
M=\sum_{i}^{n} \sum_{j}^{n} x_{i} x_{j} m_{i j}
$$

where $m_{i j}$ can be all binary interaction parameters which are a function of pure component parameters, such as a and b resp. the binary attraction and repulsion term. There are various mixing rules, which deviate in the manner of the attraction and/or repulsion term description. The most simple mixing rule is the linear average of the pure component parameters, which does not include any binary interaction parameters (BIPs). More rigorous mixing rules are often used, which do include one or multiple BIPs which can be fitted to best describe a specific mixture.

More complex equations of states attempt to include the high non-ideality of i.a. hydrogen bonding with an associative term. These models are for example PC-SAFT ${ }^{29}$ or the Cubic equation of state Plus Association (CPA) model. ${ }^{30}$ These models add the associative term $\left(Z_{\text {ass }}\right)$, see Equation 6.14 which is described by Michelsen and Hendriks. ${ }^{31}$

$$
\frac{P V_{m}}{R T}=Z=Z_{r e p}+Z_{a t t}+Z_{a s s}\left(\epsilon^{A_{i} B_{j}}, \beta^{A_{i} B_{j}}\right)
$$

In the center of this term is a correlation between the amount of bonded-and non-bonded sites, which is a way of describing the self-association of components. For an accurate description, 2 additional physical pure component compounds are required. The association interaction is a function of the association energy $\left(\epsilon^{A_{i} B_{j}}\right)$ and volume $\left(\beta^{A_{i} B_{j}}\right)$, where $A_{i}$ and $B_{j}$ are specified binding sites for the association for components i and j. Additionally, vari- 
ous association schemes can be chosen which increases the flexibility of this model even further. ${ }^{30}$

\subsection{Methodology}

In this proposed methodology, we evaluate various thermodynamic models that can fit excess molar enthalpy $\left(H^{E}\right)$ by fitting the binary interaction parameter(s) (BIP(s)), and via the subsequent entropic description by these models, can predict the Gibbs energy which in turn sets the activity- and fugacity coefficients to allow for a VLE prediction, see Figure 6.1.

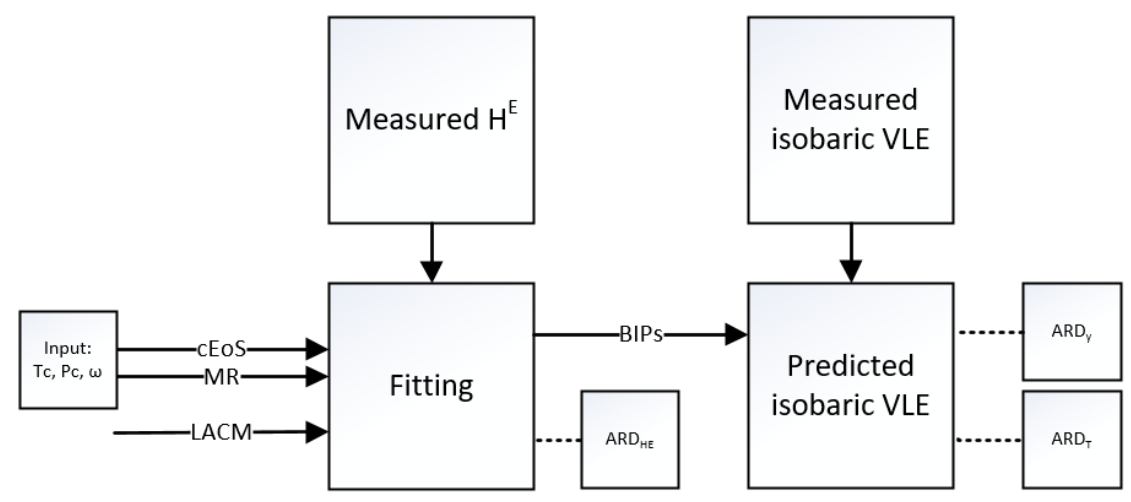

Figure 6.1: A schematic representation of the proposed methodology where either a cubic equation of state ( $c E O S)$ in combination with mixing rule (MR) with critical constants as pure-component input parameters or a liquid phase activity coefficient model (LACM) is fitted to experimental excess molar enthalpy $\left(H^{E}\right)$ which determines the binary interaction parameter(s) $(B I P(s))$. This allows for a prediction of the isobaric vapor-liquid equilibrium (VLE) which can be compared with the experimental equivalent. The average relative deviation (ARD) of the $H^{E}$, concentration ( $y$ ) and temperature $(T)$ profile eventually determined.

To assess the applicability of this methodology properly, the following four steps have been established:

1. Experimental data collection: the excess molar enthalpy or heat of mixing $\left(H^{E}\right)$, isobaric VLE data and the necessary constants (e.g. $\mathrm{T}_{C}, \mathrm{P}_{C}$ and $\omega$ ) of as many different binary systems as possible have been collected. This is 
essential, as this allows for the assessment of the applicability range of the methodology.

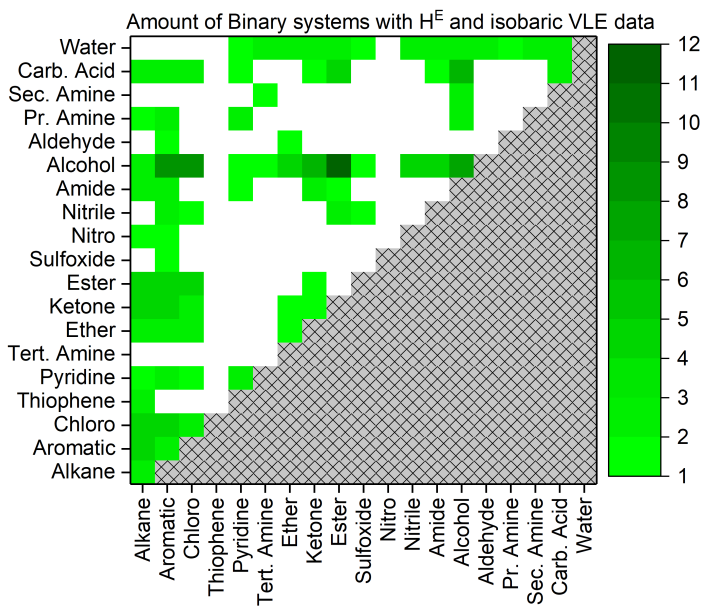

Figure 6.2: An overview of 204 binary systems, which is a combination of two molecules with a specific functional group. Additionally, the color indication represents the amount binary system that has experimental excess molar enthalpy $\left(H^{E}\right)$ and experimental isobaric vapor-liquid equilibrium (VLE). All experimental data are from 913 research articles and can be found in section 6.6

In Figure 6.2, an overview of the types of molecules is presented in which all types of evaluated binary systems (204 in total) are categorized on the functional groups present in either compound. Both experimental excess molar enthalpy and isobaric vapor-liquid equilibrium (VLE) data are required to assess the methodology of fitting the $H^{E}$ to predict the isobaric VLE behavior (xy- and Txy-diagrams) regarding their accuracy.

2. Enthalpy Fitting: Each of the binary systems, represented in Figure 6.2 is individually fitted with a thermodynamical model. During this fitting, the binary interaction parameters (BIPs) are found. This thermodynamic model can either be a liquid activity coefficient model of a cEoS with a mixing rule, shown in the previous sections. To illustrate the procedure, a single system (nheptane / 2-butanone) is fitted with a single thermodynamic model, i.e. the Peng-Robinson (PR) cEoS with the Stryjek-Vera Margules-type mixing rule. 
The fit of the experimental $H^{E 32-36}$ with this model can be seen in Figure 6.3. The fitting was done by minimizing the overall deviation relative to the experimental $H^{E}$ by variation of the binary interaction parameters (BIPs) in the mixing rule.

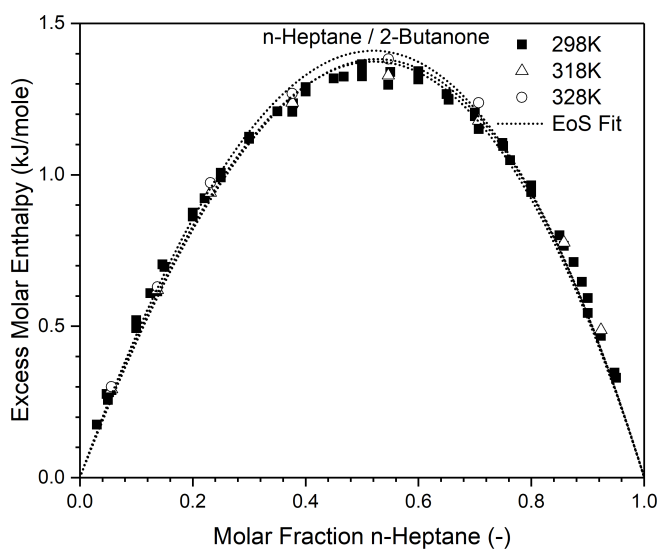

Figure 6.3: Experimental excess molar enthalpy ${ }^{32-36}$ of the binary n-heptane/2-butanone mixture at $298 \mathrm{~K}, 318 \mathrm{~K}$ and $328 \mathrm{~K}$ was fitted with the Peng-Robinson equation of state with Stryjek-Vera Margules-type mixing rule.

As can be seen in Figure 6.3, this thermodynamic model accurately describes the $H^{E}$, while the difference in $H^{E}$ at each of the temperatures is insignificant in this case. This does not immediately mean that the differences in the activity- and fugacity coefficients are also insignificant. This is evaluated in the third step.

3. Activity- and fugacity coefficient prediction: Following the fitting of the $H^{E}$ at different temperatures, the temperature-dependent BIPs can be either used directly, be averaged if they do not change significantly, or a temperaturedependent correlation can be made. In this case, the average was used of the fitted BIPs. In Figure 6.4, the activity coefficients and fugacity coefficients for the same binary system $n$-heptane/2-butanone are shown.

It can be seen, that there are some differences in the activity coefficient as a 

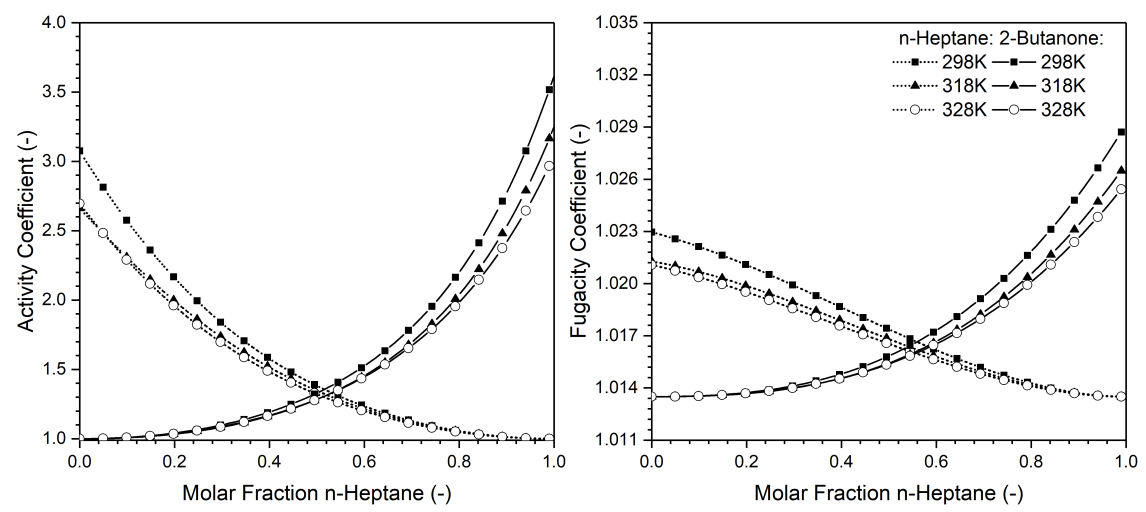

Figure 6.4: Predicted (left) activity and (right) fugacity coefficients of the binary mixture n-heptane and 2-butanone at 298K, $318 \mathrm{~K}$ and $328 \mathrm{~K}$ was fitted with the Peng-Robinson equation of state with Stryjek-Vera Margules-type mixing rule.

function of the temperature, while a neglectable deviation is seen in the $\mathrm{fu}$ gacity coefficient. The non-ideality decreases as the temperature increases, which is due to the temperature dependency of the entropy. Additionally, the fugacity coefficients are much smaller than the activity coefficients, indicating that non-ideality in the vapor phase is less pronounced. This is due to the fact the vapor density is much smaller compared to the liquid phase, hence the probability of molecules to interact is much smaller. Also, it can be seen that the fugacity coefficient is not 1 in the pure component situation. This is a direct consequence of the different definitions of the fugacity coefficient compared to the activity coefficient.

4. Vapor-liquid equilibrium prediction: The obtained temperature-dependent activity and fugacity coefficients are essential for the accurate temperature (Txy) profile and the concentration (xy) profile of an isobaric vapor-liquid equilibrium (VLE). For each composition, a Van 't Hoff type correlation (see Equation 6.15) was made to allow inter-and extrapolation of the non-ideality to other temperatures,

$$
\ln \gamma_{i}^{x}=\frac{\Delta H_{i}^{x}}{R T}-\frac{\Delta S_{i}^{x}}{R}
$$




$$
\varphi_{i}^{y} P y_{i}=\gamma_{i}^{x} x_{i} P_{i}^{0}
$$

where at either the liquid or vapor composition $\left(x_{i}\right.$ or $\left.y_{i}\right)$ a specific molar enthalpy $\left.\left(\Delta H_{i}^{x}\right)\right)$ and entropy $\left(\Delta S_{i}^{x}\right)$ is determined. This is done for both the activity- $\left(\gamma_{i}^{x}\right)$ and the fugacity $\left(\varphi_{i}^{y}\right)$ coefficient. By doing this, the non-ideal behavior predicted by the fitted thermodynamic model is expressed and combined with the phase criterion of equal activity, see Equation 6.16. Because all parameters in Equation 6.16 are temperature-dependent and the temperature profile is composition-dependent, this system is iteratively solved to obtain a temperature profile that corresponds to the isobaric situation. These profiles, of the same n-heptane/2-butanone mixture, are shown in Figure 6.5.
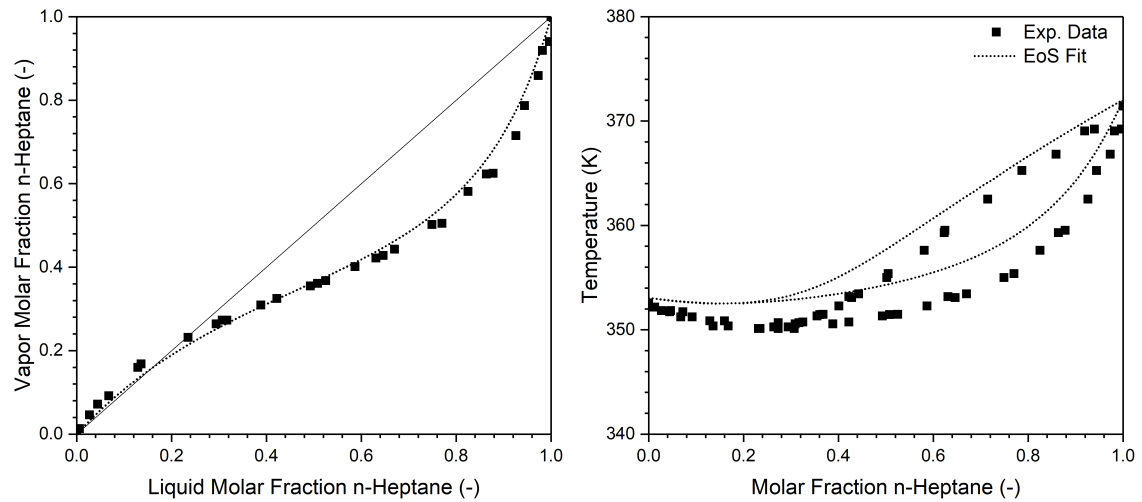

Figure 6.5: The comparison between the experimental vapor-liquid equilibrium data 37,38 and the predicted (left) concentration ( $x y)$ and (right) temperature (Txy) profile of the binary mixture n-heptane and 2-butanone which was fitted with excess molar enthalpy data ${ }^{32-36}$ at $298 \mathrm{~K}, 318 \mathrm{~K}$ and $328 \mathrm{~K}$ was fitted with the Peng-Robinson equation of state with StryjekVera Margules-type mixing rule.

The accuracy of the methodology is determined by assessing the average relative deviation (ARD), though also the absolute average deviation (AAD) can be determined, see Equation 6.17,

$$
A R D_{\chi}=\frac{\left(\frac{\sum^{N_{\text {data }}\left|\chi_{\text {exp }}-\chi_{\text {pred }}\right|}}{\chi_{\text {exp }}}\right)}{N_{\text {data }}} \wedge A A D_{\chi}=\frac{\left(\sum^{\left.N_{\text {data }}\left|\chi_{\text {exp }}-\chi_{\text {pred }}\right|\right)}\right.}{N_{\text {data }}}
$$


where $\chi$ represents either the vapor concentration in the $x y$-diagram $(y)$, the temperature in the Txy-diagram $(\mathrm{T})$, or the excess molar enthalpy $\left(H^{E}\right)$. The relative deviation between each experimental data point $\left(\chi_{\exp }\right)$ and the predicted data point $\left(\chi_{\text {pred }}\right)$ is summed up and averaged over the number of data points $\left(N_{\text {data }}\right)$.

Although the prediction is not perfect, still the azeotropic point is predicted correctly, and only a small ARD of 7.05\%, defined in Equation 6.17, which corresponds to an $\mathrm{AAD}$ of $1.56 \%$, is present in the $\mathrm{xy}$-diagram. A temperature minimum, positive azeotrope, is also correctly predicted in the Txy-diagram, although an absolute average deviation of 2.03 Kelvin is seen, which is on average $<1 \%$ of the absolute temperature.

The developed four-step methodology, shown for the n-heptane/2-butanone system, will be applied to assess liquid phase activity models and cubic equations of state, and the accuracy will be shown for these models. This accuracy will be dependent on several factors, such as the quality and quantity of the excess enthalpy data $\left(H^{E}\right)$, the complexity of the model, and the complexity of the molecular interactions in the system.

\subsection{Results}

The results will be shown in three parts. In the first part (section 6.4.1), liquid activity coefficient models will be shown and their applicability in our methodology will be discussed. The remainder of this section (section 6.4.2) will be about the performance of the cubic equations of state, and specifically towards different binary systems (section 6.4.2.1) and the type of cubic equation of state (section 6.4.2.2).

\subsubsection{Liquid Activity Coefficient models}

Liquid phase activity coefficient models are the first to be discussed and are often a favorite in the fitting of highly non-ideal VLE behavior. ${ }^{39}$ Hence, this is not the first time that VLE is predicted from excess molar enthalpy using liquid phase activity coefficient models. ${ }^{9-12}$ The UNIQUAC model has been excluded from the assessment as this model requires additional compound- 
specific volume- and surface parameters. The NRTL model is beside the UNIQUAC model, the most well-used liquid phase activity coefficient model and will be discussed first.

Consistently, in NRTL fitting procedures the non-randomness factor $\left(\alpha_{i j}\right)$ is kept constant, otherwise, convergence issues arise. This is a clear disadvantage, as an a priori guess of the $\alpha_{i j}$ is not always present.
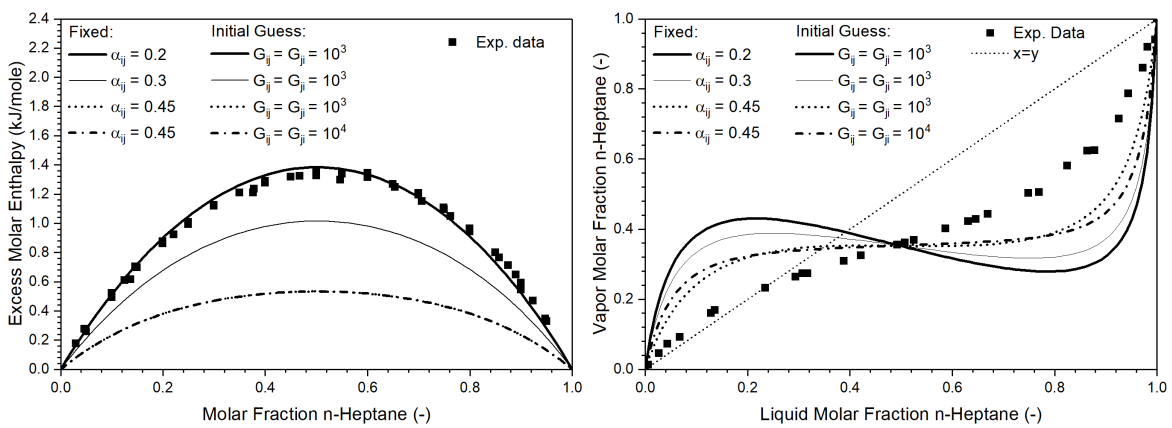

Figure 6.6: Experimental (left) $H^{E}$ at $298.15 K^{32-36}$ and (right) vapor-liquid equilibrium data 37,38 is compared with predicted excess molar enthalpy and concentration (xy) using the NRTL-model which was fitted from experimental $H^{E}$ data and with different nonrandomness factors $\left(\alpha_{i j}\right)$ and/or different initial guess values.

Additionally, which is not stated in the articles that couple the $H^{E}$ and the phase equilibria prediction is the initial guess dependency. Stevens and coworkers ${ }^{40}$ show the complexity of the $\Delta$-Gibbs surface and the existence of local minima. In Figure 6.6, the NRTL model is fitted to the same experimental HE data, while changing either the non-randomness factor $\left(\alpha_{i j}\right)$ or the initial guess value of the interaction parameter $\left(G_{j i}=G_{i j}\right)$.

Multiple starting values, either different $\alpha_{i j}$ or guess values $G_{i j}$ and $G_{j i}$, result in different vapor-liquid equilibrium and excess molar enthalpy predictions. Most strikingly, the best fit of the $H^{E}$, results in the least accurate VLE prediction. This is a highly unwanted result if this methodology aims to predict unknown VLE behavior from known $H^{E}$ experimental data. Similar dependencies were shown by Nicolaides et al. ${ }^{13}$ In Figure 6.7, also the Wilson and 
Van Laar models are additionally fitted and the vapor-liquid equilibrium prediction is shown and compared with a prediction of the NRTL model. As can be seen, the most complex model (NRTL) does not necessarily obtain the most accurate prediction. The Wilson seems also not to be able to fit the $\mathrm{H}^{E}$ well, while still a lower deviation is seen in the xy profile compared to the NRTL model with an $\alpha_{i j}$ of 0.2 .
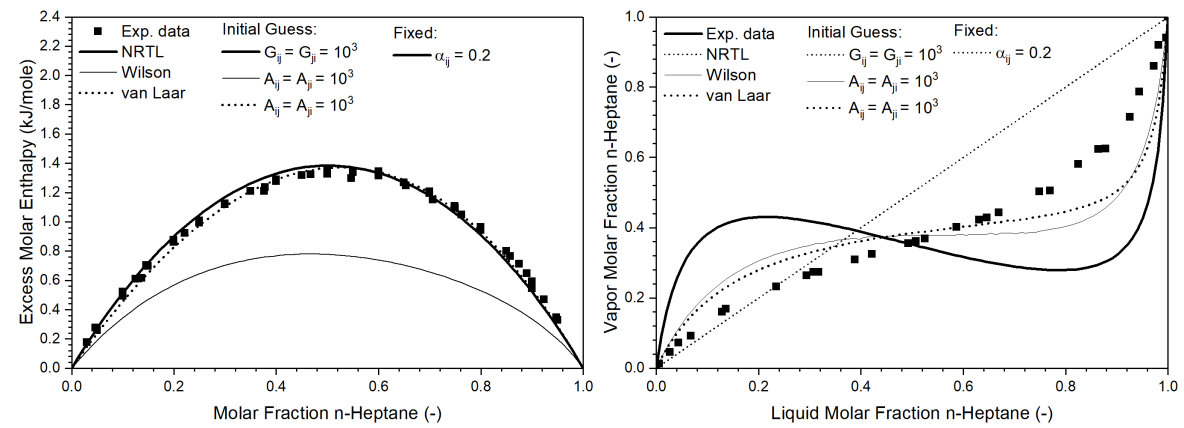

Figure 6.7: Experimental (left) $H^{E}$ at $298.15 K^{32-36}$ and experimental vapor-liquid equilibrium data 37,38 and the predicted concentration $(x y)$ using the NRTL $\left(\alpha_{i j}=0.2\right.$, init. guess: $G_{i j}=10^{3}$ ), Wilson (init. guess: $A_{i j}=10^{3}$ ) and Van Laar (init. guess: $A_{i j}=10^{3}$ ) models which was fitted from experimental $H^{E}$ data.

This same trend is seen in the NRTL model at higher $\alpha_{i j}$ values, in Figure 6.6. The van Laar equation seems to be accurately corresponding with the experimental $H^{E}$ data, with a similar VLE behavior prediction as to the Wilson equation. Together with the disadvantage of the Wilson model of needing liquid molar volumes of the components in the mixture, makes it is a reasonable conclusion that the van Laar model may be preferred over the Wilson equation.

Overall, liquid phase activity coefficient models have difficulties predicting non-ideality from excess molar enthalpy data. Tan et al. ${ }^{41}$ also signified the inherent disadvantage of using a model based on the excess Gibbs energy to predict VLE behavior from excess molar enthalpy as the procedure requires a differentiation step. This will result in a substantial loss of accuracy if experimental data points are not perfect. Hence, a more robust model is preferred 
in the methodology. The "best" performing model can be considered to be the van Laar model, ${ }^{15}$ which is derived from the well-known Van der Waals equation. However, it is known that the van Laar model is not able to represent multicomponent mixtures. ${ }^{42}$ The Van der Waals cubic equation of state, and many others, can be the robust model needed for this approach.

\subsection{2 cubic Equation of State}

In this section, the performance of cubic equations of state (cEoS) are systematically evaluated as a thermodynamic model in the methodology proposed in the previous section. During this assessment, three different possible errors are identified and separately discussed. A deviation between the modeled and experimental HE data points will induce an error. A large deviation in this early stage is an indication that the thermodynamic model is not physically representing the binary system. The second and third errors are seen between the experimental and the predicted VLE behavior. In both the concentration profile (xy) and in the temperature profile (Txy), errors can occur. Each error will be assessed by the average relative deviation (ARD), see Equation 6.17. In the case of a certain function group combination or a specific equation of state and mixing rule combination which includes multiple binary systems, then the overall performance is assessed by averaging Equation 6.17 over the amount of specific binary systems $\left(N_{\text {sys }}\right)$, see Equation 6.18 ,

$$
A R D_{\chi}=\frac{\sum^{N_{s y s}}\left(\frac{\left(\frac{\sum^{N_{\text {data }}\left|\chi_{\text {exp }}-\chi_{\text {pred }}\right|}}{\chi_{\exp }}\right)}{N_{\text {data }}}\right)}{N_{s y s}}
$$

To explain the procedure of analyzing the applicability of a specific equation of state - mixing rule combination to describe VLE profiles for mixtures of certain classes of molecules, this is first done for one combination, the SoaveRedlich-Kwong cEoS with the one-parameter Van der Waals mixing rule. Afterward, a more detailed investigation into various cubic equations of state and mixture rule combinations will be made. 


\subsubsection{Performance of Soave-Redlich-Kwong cEoS for VLE prediction of various Functional Groups}

The predictive performance overview for the Soave-Redlich-Kwong cEoS with the one-parameter Van der Waals mixing rule is represented in the form of a heat-map in Figure 6.8. Each cell in this map represents a combination of two functional groups that are present on either one of the components in the binary mixture. The color indicates the predictive accuracy, where green indicates an $A R D_{y}$ of $\leq 10 \%$ and increasingly intense red indicates a more significant $A R D_{y}$. A distinction can be made between functional groups of which the vapor-liquid equilibrium can be predicted with significantly higher accuracy, and those for which the prediction is inaccurate $\left(A R D_{y}>10 \%\right)$.

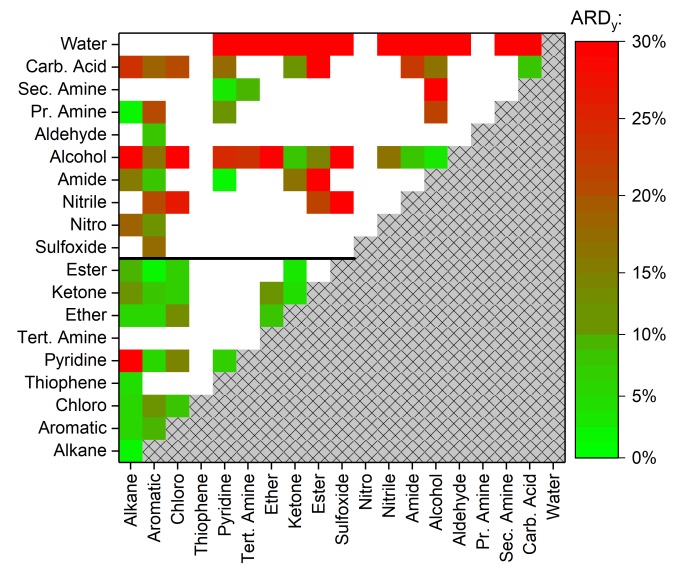

Figure 6.8: The average of all average relative deviation in the predicted and experimental concentration in the isobaric VLE profile $\left(A R D_{y}\right)$ for the Soave-Redlich-Kwong Equation of States in combination with the 1-parameter Van der Waals mixing rule, specified for each functional group combination

Since equations of state have difficulties in the description of self-association networks mainly trough hydrogen bonds, such as with water, ${ }^{43}$ carboxylic acid, ${ }^{44}$ amines, ${ }^{45}$ aldehydes, ${ }^{46}$ alcohols, ${ }^{46,47}$ amides, ${ }^{48}$ nitriles, ${ }^{49}$ or via strong dipolar interactions, such as with nitro compounds ${ }^{50}$ and dimethylsulfoxide. ${ }^{51}$ Additionally, formate esters, ${ }^{52}$ chloroform ${ }^{53}$ and acetone ${ }^{54}$ are known to selfassociate. 
It is therefore clear that this approach using this cEoS is more robust than the approach with activity coefficient models, as it does not have the initial guess dependency seen in the liquid phase activity coefficient models, and accurate for binary systems that are not able to self-associate.

Several systems can however be accurately described by this cEoS, as shown in Figure 6.8. These systems comprise alkanes, aromatic compounds, chlorinated compounds (excluding chloroform), thiophenes, pyridines, ethers, ketones (excluding acetone) and esters (excluding formates). All these molecules are not able to self-associate and the excess molar enthalpy can therefore be fitted by the cEoS and accurately predict the isobaric VLE behavior. That doesn't mean that all self-associating compounds cannot be described by any cEoS. As can be seen in Figure 6.8, the diagonal line through the matrix represents similar compounds and exhibits smaller deviations compared to dissimilar compounds located further from the diagonal line.

In the next section, not only the effect of different cEoS and mixing rules are assessed, but also a distinction will be made between assessing the binary mixtures which are inapt in self-association (section 6.4.2.2) and mixtures that form liquid networks via association interactions (section 6.4.2.2).

\subsubsection{Effect of different Equation of State and Mixing Rule}

Equations of State are versatile models, as they can quite easily be adjusted with new PVT-equations that deviate from the initial Van der Waals equation. Furthermore, also the mixing rules can be varied, e.g. to better cope with the association in the system. In an attempt to evaluate the usefulness of cEoS to predict VLE while fitting on $H^{E}$ widely inclusive, in this section, a total of twelve different cEoS were each combined with eight mixing rules (MR). The evaluated combinations include, 
cubic Equation of State (cEoS):

1. Van der Waals ${ }^{23}(\mathrm{VdW})$

2. Redlich-Kwong ${ }^{24}$ (RK)

3. Soave-Redlich-Kwong ${ }^{24,25}$ (SRK)

4. Peng-Robinson ${ }^{26}$ (PR)

5. Peng-Robinson-Stryjek-Vera ${ }^{55}$ (PRSV)

6. Petal-Teja ${ }^{27}$ (PT)

7. Petal-Teja-Valderrama ${ }^{58}$ (PTV)

8. Esmaeilzadeh-Roshanfekr ${ }^{60}$ (ER)

9. Nasrifar-Moshfeghian ${ }^{62}$ (NM)

10. Twu-Sim-Tassone ${ }^{63}$ (TST)

11. Harmens-Knapp ${ }^{64}$ (HK)

12. Trebble-Bishnoi ${ }^{65}$ (TB)
Mixing rule (MR):

1. 1-parameter Van der Waals ${ }^{23}$ (VdW1)

2. 2-parameter Van der Waals ${ }^{23}$ (VdW2)

3. Adachi-Sugie ${ }^{56}$ (AS)

4. Huron-Vidal ${ }^{57}(\mathrm{HV})$

5. Panagiotopoulos-Reid ${ }^{59}$ (PR)

6. Sandoval ${ }^{61}$

7. Stryjek-Vera Margules-type ${ }^{55}$ (SVm)

8. Stryjek-Vera van Laar-type ${ }^{55}$ $(\mathrm{SVvL})$

In the case of the instability of the methodology, in essence, a convergence issue, when using a cEoS/MR combination in more than $10 \%$ of the assessed systems, the combination is indicated in the following heatmaps as undesired.

Non-self-associating mixtures In Figure 8 , an overview of the accuracy of the methodology is given using the heatmap approach. For each average relative deviation (ARD) within the methodology, this is done, thus in the fitting of the excess molar enthalpy $\left(A R D_{H^{E}}\right)$ and the prediction of the concentration profile $\left(A R D_{v}\right)$ and temperature profile $\left(A R D_{T}\right)$ in the VLE behavior. The Petal-Teja (PT) ${ }^{27}$ and Esmaeilzadeh-Roshanfekr (ER) ${ }^{60}$ cEoS show convergence issues in the fitting of the $H^{E}$, hence are identified to be not preferred for this methodology. The Petal-Teja-Valderrama (PTV) ${ }^{58} \mathrm{cEoS}$, which is a generalization of the PT cEoS is more accurate (and robust) than the PT cEoS. This is due to the fact the PT cEoS has fewer known parameters for nonself-associating binary systems included in this work. Whereas, the PTV cEoS can, via its generalization of parameters, include all non-self-associative binary mixtures and therefore the deviation shown is an average of more binary systems that are accurately described. The 4 -parameter Trebble-Bishnoi ${ }^{65}$ is also less accurate, indicating that a 4-parameters $\mathrm{cEoS}$ is over-parameterized for describing these systems and a cEoS with fewer parameters is preferred. Regarding the mixing rules, not much difference can be seen, however, the 

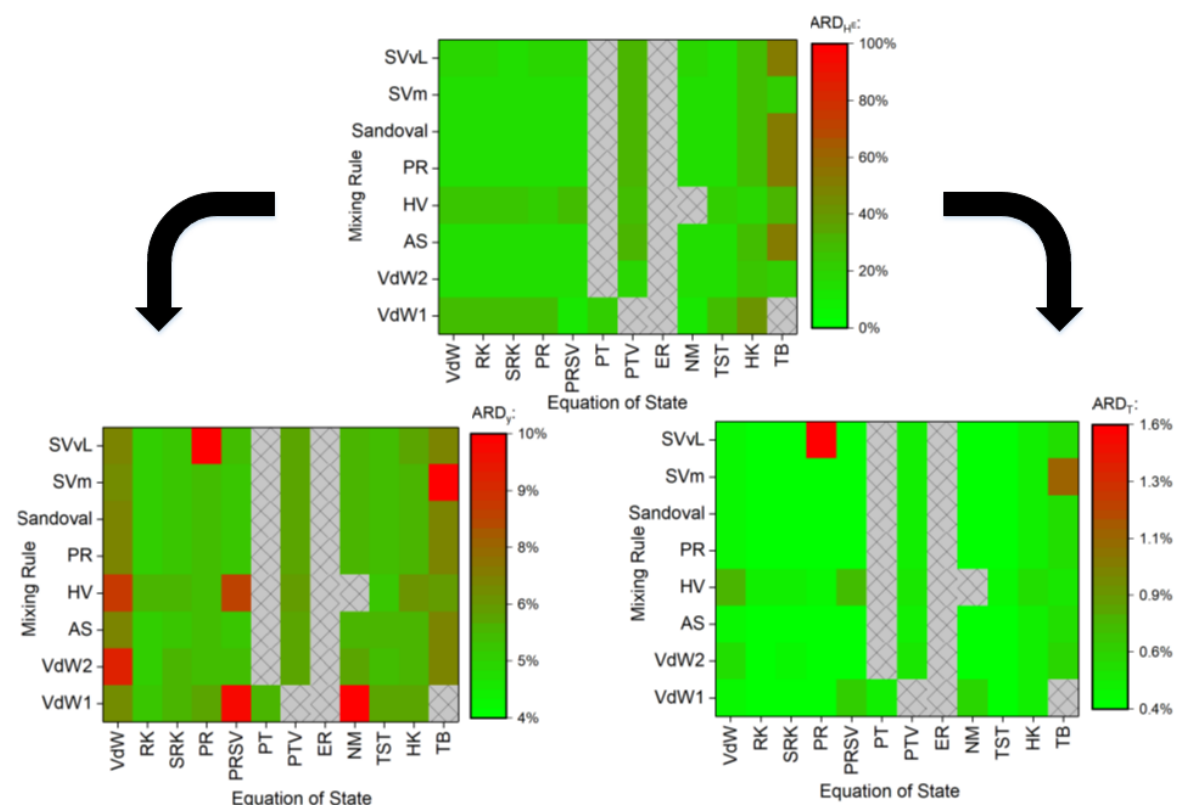

Figure 6.9: The ARD of the (top) excess molar enthalpy ( $A R D_{H^{E}}$, scale $\left.0-100 \%\right)$, (bottom left) concentration $\left(A R D_{y}\right.$, scale $\left.0-10 \%\right)$ and (bottom right) temperature $\left(A R D_{T}\right.$, scale 0 $-1.6 \%$ ) for twelve cubic Equation of States (cEoS) and eight mixing rules (MR) specified for non-self-associating mixtures. The undesired cEoS/MR combination is indicated with grey boxes.

Huron-Vidal (HV) and the 1-parameter Van der Waals (VdW1) rules are seen to have a slightly larger $A R D_{H^{E}}$. This is due to respectively, the initial guess problems as the HV mixing rule is strongly associated with the NRTL model and the overly simple 1-parameter rule which only describes (almost) symmetric enthalpic behavior for similarly sized components. ${ }^{66}$

The prediction of the non-ideal VLE behavior can be seen to be quite accurate in Figure 8, as numerous cEoS and mixing rule combinations have an ARD of resp. $\sim 5 \%$ and $<1 \%$ in the concentration and temperature profile. Though, it can be seen that the Huron-Vidal (HV), ${ }^{57}$ the Van der Waals (VdW1 and VdW2 $)^{23}$ and Stryjek-Vera van Laar-type $(\mathrm{SVvL})^{67}$ are seen to deviate more 
than other combinations. Where the VdW1 mixing rule is most likely an oversimplification, and the other mixing rules (VdW2, HV and SVvL) are either over-complicated or have convergence issues, see local minima, which are also seen in the liquid phase activity coefficient models. Overall, the most common cEoS, e.g. (Soave-)Redlich-Kwong (RK or SRK) ${ }^{24,25}$ and Peng-Robinson $(\mathrm{PR})^{26}$, are seen to be the most accurate though other cEoS can be used such as Twu-Sim-Tassone cEoS. ${ }^{68}$ The mixing rule choice has a less significant impact, though the above-mentioned mixing rules are less preferred.

Self-associating mixtures In Figure 6.10, it can be seen that $H^{E}$ can be correlated to approximately the same accuracy as for non-self-associative mixtures. The Petal-Teja (PT) $\operatorname{cEoS}^{27}$ appears nevertheless to be slightly less accurate in combination with several mixing rules. Again the EsmaeilzadehRoshanfekr (ER) $\mathrm{cEoS}^{60}$ is not stable, also Trebbe-Bishnoi $\mathrm{cEoS}^{65}$ and the Nasrifar-Moshfeghian ${ }^{62}$ i.c.w. the Huron-Vidal MR is unable to converge. Overall, the Huron-Vidal (HV) and the 1-parameter Van der Waals (VdW1) rules are seen to have a slightly larger $A R D_{H^{E}}$, either due to over-simplicity in the first MR, and complexity in the latter MR.

Several equations of state are observed to be more accurate to predict the nonideal VLE behavior of these self-associating mixtures, see Figure 6.10, such as the Peng-Robinson-Styrjek-Vera (PRSV) ${ }^{67}$, Petal-Teja $\left.(\mathrm{PT})^{27}\right]$ and the PetalTeja-Valderrama (PTV). ${ }^{58}$ Lowering the average relative deviation in the concentration profile from $>60 \%$ (seen in various cEoS) to $\sim 20 \%$. The PRSV-and PT-equation of states accomplished this adding pure-component parameters, especially for high polar components.

Although, this limits the applicability of these equations of state, as not only the critical parameters are required. The PTV-equation of state is a generalization of the PT-equation of state, where Valderamma ${ }^{58}$ generalized the additional parameters in terms of the critical parameters, hence significantly increasing the applicability window. For this reason, the PTV-equation of state is preferable to the original PT-equation of state.

The (original) Van der Waals equation of state appears to have a lower overall deviation than the well-known (Soave-)Redlich-Kwong ${ }^{24,25}$ (RK, SRK) and Peng-Robinson ${ }^{26}$ (PR), though this not a fair comparison. The VdW-equation 

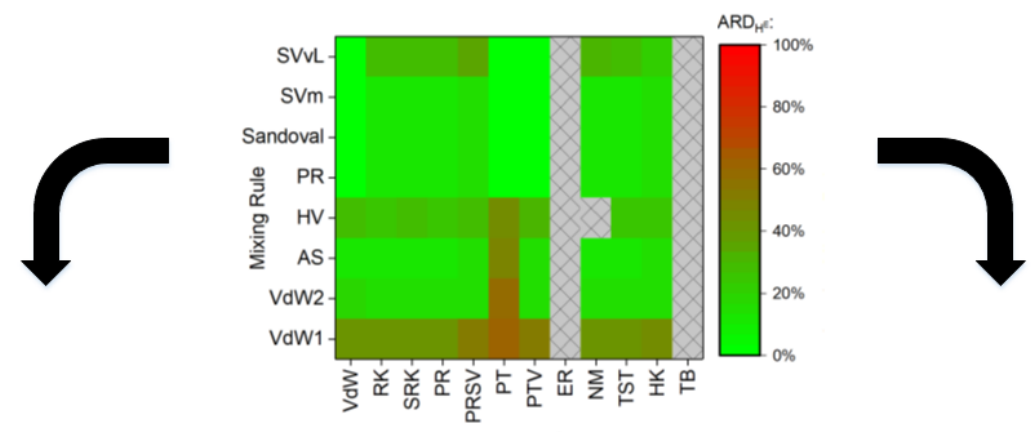

$A R D_{y}$ : Equation of State

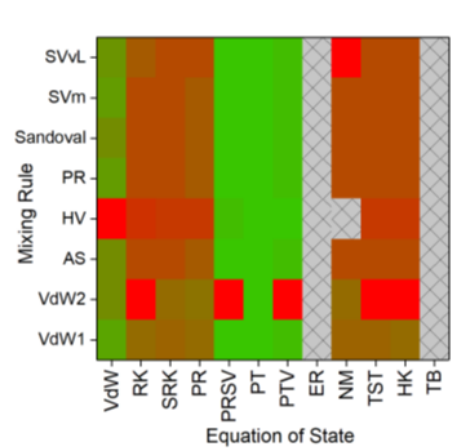
ARD $_{y}:$ Equatio
$\square$

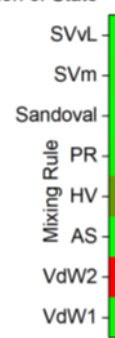

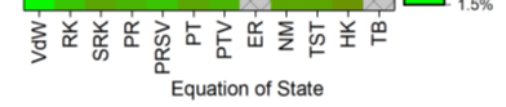

Figure 6.10: The ARD of the (top) excess molar enthalpy $\left(A R D_{H^{E}}\right.$, scale $\left.0-100 \%\right)$, (bottom left) concentration $\left(A R D_{y}\right.$, scale $\left.0-100 \%\right)$ and (bottom right) temperature $\left(A R D_{T}\right.$, scale $0-3.2 \%)$ for twelve cubic Equation of States (cEoS) and eight mixing rules (MR) specified for self-associating mixtures. The undesired cEoS/MR combination is indicated with grey boxes.

of state is much more unstable and could fit much less (between 79 and 104) binary systems than the other equation of states (between 197 and 201). Hence, as many binary systems containing self-associative components are excluded in the VdW-equation of state evaluation, the overall accuracy appears to be greater. The inaccuracy of the $\mathrm{VdW}$-equation of state can also be seen in the increased inaccuracy of only the systems with non-self-associative compounds.

The severe inaccuracies seen in the self-associative mixtures can be reduced using the complex EoS which includes associative terms, such as PC-SAFT. As 

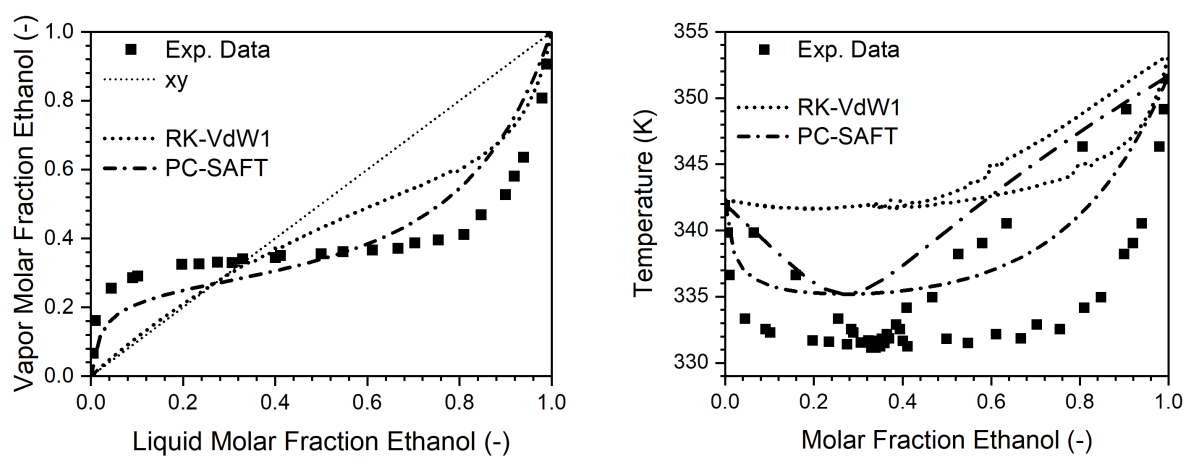

Figure 6.11: The comparison between the experimental vapor-liquid equilibrium data 69,70 and the predicted (left) concentration ( $x y$ ) and (right) temperature (Txy) profile of the binary mixture ethanol and n-hexane which was fitted with excess molar enthalpy data ${ }^{71-73}$ at $298 \mathrm{~K}, 308 \mathrm{~K}$ and $318 \mathrm{~K}$ was fitted with the Redlich-Kwong (RK) equation of state with1parameter Van der Waals (VdW1) mixing rule and PC-SAFT. PC-SAFT pure-component parameters were used from Spyriouni et al. ${ }^{74}$

can be seen in Figure 6.11, where an example of the n-hexane/ethanol system is shown. The PC-SAFT model predicts more accurately the azeotropic behavior of the system, as it decreases the ARD within the concentration profile from $42 \%$ to $25 \%$ and the ARD within the temperature profile from $3.1 \%$ to $1.2 \%$. This is still not satisfactory. There can however be refinements, as only the $2 \mathrm{~B}$-association scheme ${ }^{30}$ is included in the Aspen Plus ${ }^{\circledR}$ software package. Also, a variation of pure-components parameters are present in literature and appropriate parameter choice is essential for accurate VLE predictions.

\subsection{Conclusion}

It is possible to predict the non-ideal vapor-liquid equilibrium behavior from the excess molar enthalpy via a thermodynamic model. However, not all binary systems can be accurately described. The preferred thermodynamic models are cubic equations of state, and not liquid phase activity coefficient models as they are prone to local optimization minima which reduce the predictive accuracies. Although, it has been shown that for nearly ideal systems, where the excess entropy can be neglected, these models can be applied. In us- 
ing cubic equations of state, in general, most mixing rules perform similarly, though it can be seen that the 2-parameter Van der Waals (VdW2), HuronVidal (HV) and Stryjek-Vera Van Laar-type (SVvL) are seen to be less stable and robust, hence may be less accurate in the predictive ability. Various cubic equations of state and mixing rules can be used, such as the most common RK-, SRK- and PR-equation of states, though PTV-, Nasrifar-Moshfeghian ${ }^{62}$ (NM), Twu-Sim-Tassone ${ }^{68}$ (TST) and Harmens-Knapp ${ }^{64}$ (HK) cubic equations of states can also be used. Also, various mixing rules can be used, though VdW2-, HV- and SVvL-mixing rules are not preferred. Mixtures without (self-)associative compounds can be accurately predicted without an initial guess value problem. Unfortunately, this excluded a large number of highly common mixtures containing for instance alcohols, or (and most challenging) aqueous mixtures. The accuracy of mixtures with self-associative behavior can be 10 times less accurate in the concentration profile and twice less accurate in the temperature profile. Thus, part of the envisioned approach is realized by cubic equation of states. The approach can be completed by the addition of the PC-SAFT and/or CPA model, which includes associative terms, though a systematic validation including various association schemes needs to be done.

\subsection{Electronic Supplementary Data-Analysis}

For the validation of this approach, experimental Excess Molar Enthalpy $\left(H^{E}\right)$ and isobaric vapor-liquid equilibria (VLE) were used from literature. Due to the fact, $\mathbf{9 1 3}$ articles are behind all relevant information and this would have resulted in a large number of reference pages. It was chosen not to include these references and data in this printed version. The reference overview was published online at https://www.scribd.com/document/484671815/AllReferences-of-Chapter-6. While, all data points is published online in an Excel sheet; https://www.scribd.com/document/484672433/All-ReferencesData-of-Chapter-6 (with the associated references). 


\subsection{Nomenclature}

$\alpha_{i j}=$ Relative volatility of component $\mathrm{i}$ and $\mathrm{j}$

$\beta^{A_{i} B_{j}}=$ Association volume function between $A_{i}$ and $B_{j}$

$\epsilon^{A_{i} B_{j}}=$ Association energy function between $A_{i}$ and $B_{j}$

$\Delta H_{i}^{x}=$ Excess molar enthalpy of component $\mathrm{i}$ at a molar fraction of $x_{i}$

$\Delta S_{i}^{x}=$ Excess molar entropy of component $\mathrm{i}$ at a molar fraction of $x_{i}$

$\omega=$ Acentric factor

$\gamma_{i}=$ Activity coefficient of component $\mathrm{i}$

$\gamma_{i}^{x}=$ Activity coefficient of component $\mathrm{i}$ at a molar fraction of $x_{i}$

$\gamma_{i}^{\infty}=$ Infinite dilution activity coefficient of component $\mathrm{i}$

$\varphi_{i} \quad=$ Fugacity coefficient of component $\mathrm{i}$

$\varphi_{i}^{y}=$ Fugacity coefficient of component $\mathrm{i}$ at a molar vapor fraction of

$\rho \quad=\quad \begin{aligned} & y_{i} \\ & \rho\end{aligned} \quad$ olar density

a $=$ Van der Waals interaction parameter

$\mathrm{AAD}=$ Average absolute deviation

$A_{i} \quad=$ Association binding site $\mathrm{A}$ for component $\mathrm{i}$

$A_{i j}=$ Van Laar or Wilson binary interaction parameter

$\mathrm{ARD}=$ Average relative deviation

AS $=$ Adachi-Sugie

$\mathrm{b}=$ Van der Waals volume parameter

BIP $=$ Binary interaction parameter

$B_{j} \quad=$ Association binding site $\mathrm{B}$ for component $\mathrm{j}$

cEoS $=$ Cubic equation of state

$\mathrm{CPA}=$ Cubic equation of state plus association

$\mathrm{ER}=$ Esmaeilzadeh-Roshanfekr

$f_{i} \quad=$ Fugacity

$G^{E} \quad=$ Excess Gibbs energy

$\bar{G}^{E} \quad=$ Excess molar Gibbs energy

$G_{i j}=$ NRTL binary interaction parameter

$\mathrm{H} \quad=$ Enthalpy

$H^{\text {dep }}=$ Enthalpy Departure function

$H^{E} \quad=$ Excess molar enthalpy

$H^{i g} \quad=$ Ideal gas enthalpy 


$\begin{array}{ll}\mathrm{HK} & =\text { Harmens-Knapp } \\ \mathrm{HV} & =\text { Huron-Vidal } \\ \mathrm{LLE} & =\text { Liquid-Liquid equilibrium } \\ \mathrm{M} & =\text { Mixing rule function } \\ m_{i j} & =\text { Binary interaction parameter function } \\ \mathrm{MR} & =\text { Mixing rule } \\ \mathrm{n} & =\text { Amount of mole } \\ \mathrm{n} & =\text { Numbers of components } \\ N_{\text {data }} & =\text { Number of data points } \\ N_{\text {sys }} & =\text { Number of systems } \\ \mathrm{NM} & =\text { Nasrifar-Moshfeghian } \\ \mathrm{NRTL} & =\text { Non-random two-Liquid } \\ \mathrm{P} & =\text { Pressure (bar) } \\ P_{i}^{0} & =\text { Pure component (i) vapor pressure } \\ P_{c} & =\text { Critical pressure (bar) } \\ \mathrm{PC-SAFT} & =\text { Perturbed-chain statistical associating fluid theory } \\ \mathrm{PR} & =\text { Peng-Robinson } \\ \mathrm{PR} & =\text { Panagiotopoulos-Reid } \\ \mathrm{PRSV} & =\text { Peng-Robinson-Stryjek-Vera } \\ \mathrm{PT} & =\text { Petal-Teja } \\ \mathrm{PTV} & =\text { Petal-Teja-Valderrama } \\ \mathrm{R} & =\text { Universal gas constant } \\ \mathrm{RK} & =\text { Redlich-Kwong } \\ S^{E} & =\text { Excess entropy } \\ S_{j i} & =\text { Selectivity of component j over i } \\ \mathrm{SRK} & =\text { Soave-Redlich-Kwong } \\ \mathrm{SVm} & =\text { Stryjek-Vera Margules-type } \\ \mathrm{SVvL} & =\text { Stryjek-Vera van Laar-type } \\ \mathrm{T} & =\text { Absolute temperature } \\ \mathrm{TB} & =\text { Trebble-Bishnoi } \\ T_{c} & =\text { Critical temperature } \\ \mathrm{TST} & =\text { Twu-Sim-Tassone } \\ \mathrm{UNIQUAC} & =\text { Universal quasichemical } \\ \mathrm{VdW} & =\text { Van der Waals } \\ & \end{array}$




$\begin{array}{ll}\text { VdW1 } & =1 \text {-parameter Van der Waals } \\ \text { VdW2 } & \text {-parameter Van der Waals } \\ \text { VLE } & =\text { Vapor-liquid equilibrium } \\ V_{m} & =\text { Molar volume } \\ \mathrm{X} & =\text { quantity X } \\ X^{\text {dep }} & =\text { Departure function of quantity X } \\ X^{i g} & =\text { Ideal gas function of quantity X } \\ x_{i} & =\text { Molar liquid fraction of component i } \\ y_{i} & =\text { Molar vapor fraction of component i } \\ Z & =\text { Compressibility function } \\ Z_{a s s} & =\text { Association term of compressibility factor } \\ Z_{a t t} & =\text { Attraction term of compressibility factor } \\ Z_{L} & =\text { Compressibility factor of liquid phase } \\ Z_{r e p} & =\text { Repulsion term of compressibility factor } \\ Z_{V} & =\text { Compressibility factor of vapor phase }\end{array}$

\subsection{References}

[1] A. Muhlbauer and J. Raal, "Measurement and thermodynamic interpretation of high-pressure vapour-liquid equilibria in the toluene co2 system," Fluid phase equilibria, vol. 64, pp. 213-236, 1991.

[2] A. J. ten Kate, J. Gerretzen, H.-J. van Manen, G. M. Kontogeorgis, and G. Bargeman, "Methodology to predict thermodynamic data from spectroscopic analysis," Industrial E Engineering Chemistry Research, 2020.

[3] F.-M. Raoult, "Loi générale des tensions de vapeur des dissolvants," CR Hebd. Seances Acad. Sci, vol. 104, pp. 1430-1433, 1887.

[4] G. N. Lewis and M. Randall, Thermodynamics and the free energy of chemical substances. McGraw-Hill, 1923.

[5] C. L. Yaws, The Yaws handbook of vapor pressure: Antoine coefficients. Gulf Professional Publishing, 2015.

[6] D. Siderius, "Nist standard reference simulation website," 2012.

[7] J.-C. Lerol, J.-C. Masson, H. Renon, J.-F. Fabries, and H. Sannier, "Accurate measurement of activity coefficient at infinite dilution by inert gas stripping and gas chromatography," Industrial E Engineering Chemistry Process Design and Development, vol. 16, no. 1, pp. 139-144, 1977.

[8] A. Wehrl, "General properties of entropy," Reviews of Modern Physics, vol. 50, no. 2, p. 221, 1978.

[9] R. W. Hanks, A. C. Gupta, and J. J. Christensen, "Calculation of isothermal vapor-liquid equilibrium data for binary mixtures from heats of mixing," Industrial E Engineering Chemistry Fundamentals, vol. 10, no. 3, pp. 504-509, 1971.

[10] R. W. Hanks, R. L. Tan, and J. J. Christensen, "Limits on the simultaneous correlation of ge and he data by the nrtl, lemf and wilson's equations," Thermochimica Acta, vol. 23, no. 1, pp. 41-55, 1978.

[11] P. VOŇKA, J. P. NOVÁK, J. SUŠKA, and J. PICK, "An a priori analysis of temperature dependence of wilson and nrtl equations," CHEMICAL ENGINEERING COMMUNICATIONS, vol. 2, no. 1, pp. 51-55, 1975.

[12] J. G. Calzón, C. Pando, and J. Renuncio, "Simultaneous correlation of vapor-liquid equilibrium and excess enthalpies for binary mixtures of n-hexane and n-octane with hexane isomers," Thermochimica acta, vol. 106, pp. 219-231, 1986. 


\section{VLE PREDICTION FROM THE HEAT OF MIXING}

[13] G. L. Nicolaides and C. A. Eckert, “Optimal representation of binary liquid mixture nonidealities," Industrial \& Engineering Chemistry Fundamentals, vol. 17, no. 4, pp. 331-340, 1978.

[14] H. Orbey and S. I. Sandler, "A comparison of various cubic equation of state mixing rules for the simultaneous description of excess enthalpies and vapor-liquid equilibria," Fluid Phase Equilibria, vol. 121, no. 1-2, pp. 67-83, 1996.

[15] J. Van Laar, "Zur theorie der dampfspannungen von binären gemischen," Zeitschrift für Physikalische Chemie, vol. 83, no. 1, pp. 599-608, 1913.

[16] G. M. Wilson, "Vapor-liquid equilibrium. xi. a new expression for the excess free energy of mixing.," Journal of the American Chemical Society, vol. 86, no. 2, pp. 127-30, 1964

[17] M. Margules, "Uber die zusammensetzung der gesattigten dampfe von mischungen," Sitzungsber Akad Wiss Wien, vol. 104, pp. 1243-1278, 1895.

[18] D. S. Abrams and J. M. Prausnitz, "Statistical thermodynamics of liquid mixtures. new expression for the excess gibbs energy of partly or completely miscible systems.," AIChE Journal, vol. 21, no. 1, pp. 116-28, 1975.

[19] H. Renon and J. M. Prausnitz, "Local compositions in thermodynamic excess functions for liquid mixtures.," AIChE Journal, vol. 14, no. 1, pp. 135-44, 1968.

[20] J. M. Prausnitz, R. N. Lichtenthaler, and E. G. De Azevedo, Molecular thermodynamics of fluid-phase equilibria. Pearson Education, 1998.

[21] É. Clapeyron, "Mémoire sur la puissance motrice de la chaleur," Journal de l'École polytechnique, vol. 14, pp. 153-190, 1834.

[22] I. G. Economou, "Cubic and generalized van der waals equations of state," Applied Thermodynamics of Fluids, vol. 4, no. 1, p. 53, 2010.

[23] J. D. Van der Waals, Over de Continuiteit van den Gas-en Vloeistoftoestand, vol. 1. Sijthoff, 1873.

[24] O. Redlich and J. N. Kwong, "On the thermodynamics of solutions. v. an equation of state. fugacities of gaseous solutions.," Chemical reviews, vol. 44, no. 1, pp. 233-244, 1949.

[25] G. Soave, "Equilibrium constants from a modified redlich-kwong equation of state," Chemical engineering science, vol. 27, no. 6, pp. 1197-1203, 1972.

[26] D.-Y. Peng and D. B. Robinson, "A new two-constant equation of state," Industrial \& Engineering Chemistry Fundamentals, vol. 15, no. 1, pp. 59-64, 1976.

[27] N. C. Patel and A. S. Teja, "A new cubic equation of state for fluids and fluid mixtures," Chemical Engineering Science, vol. 37, no. 3, pp. 463-473, 1982.

[28] J. R. Elliott and C. T. Lira, Introductory chemical engineering thermodynamics, vol. 184. Prentice Hall PTR Upper Saddle River, NJ, 1999.

[29] J. Gross and G. Sadowski, "Application of the perturbed-chain saft equation of state to associating systems," Industrial \& engineering chemistry research, vol. 41, no. 22, pp. 5510-5515, 2002.

[30] G. M. Kontogeorgis, M. L. Michelsen, G. K. Folas, S. Derawi, N. von Solms, and E. H. Stenby, "Ten years with the cpa (cubic-plus-association) equation of state. part 1. pure compounds and self-associating systems," Industrial \& engineering chemistry research, vol. 45, no. 14, pp. 4855-4868, 2006.

[31] M. L. Michelsen and E. M. Hendriks, "Physical properties from association models," Fluid phase equilibria, vol. 180 , no. $1-2$, pp. 165-174, 2001

[32] D. Hanson and M. Van Winkle, "Relation of binary heats of mixing and distribution of ketone between phases in some ketone-water-solvent ternaries.," Journal of Chemical and Engineering Data, vol. 5, no. 1, pp. 30-34, 1960.

[33] J. Biroš, A. Živnỳ, and J. Pouchlỳ, "Heats of mixing of butanone and chloroform with alkanes: binary systems," Collection of Czechoslovak Chemical Communications, vol. 43, no. 3, pp. 829-836, 1978.

[34] O. DUSART, S. PIEKARSKI, and J. GROLIER, "Enthalpies of normal-alkyl alkanoates and 2-alkanones in homologous series with a normal alkane," JOURNAL DE CHIMIE PHYSIQUE ET DE PHYSICO-CHIMIE BIOLOGIQUE, vol. 76, no. 5, pp. 433-437, 1979.

[35] O. Kiyohara, Y. P. Handa, and G. C. Benson, "Thermodynamic properties of binary mixtures containing ketones iii. excess enthalpies of n-alkanes+ some aliphatic ketones," The Journal of Chemical Thermodynamics, vol. 11, no. 5, pp. 453-460, 1979.

[36] R. Fuchs, L. Krenzer, and J. Gaube, "Excess properties of binary mixtures composed of a polar component and an alkane," Berichte der Bunsengesellschaft für physikalische Chemie, vol. 88, no. 7, pp. 642-649, 1984. 


\section{VLE PREDICTION FROM THE HEAT OF MIXING}

[37] H. H. Steinhauser and R. R. White, "Vapor-liquid equilibria data for ternary mixtures: methyl ethyl ketonn-heptane-toluene system," Industrial E Engineering Chemistry, vol. 41, no. 12, pp. 2912-2920, 1949.

[38] E. Lladosa, N. F. Martínez, J. B. Montón, and J. de la Torre, "Measurements and correlation of vapourliquid equilibria of 2-butanone and hydrocarbons binary systems at two different pressures," Fluid phase equilibria, vol. 307, no. 1, pp. 24-29, 2011.

[39] Y. Demirel and H. Gecegörmez, "Simultaneous representation of excess enthalpy and vapor-liquid equilibrium data by the nrtl and uniquac models," Fluid Phase Equilibria, vol. 65, pp. 111-133, 1991.

[40] Z. Li, K. A. Mumford, Y. Shang, K. H. Smith, J. Chen, Y. Wang, and G. W. Stevens, "Analysis of the nonrandom two-liquid model for prediction of liquid-liquid equilibria," Journal of Chemical \& Engineering Data, vol. 59, no. 8, pp. 2485-2489, 2014.

[41] R. L. Tan, R. W. Hanks, and J. J. Christensen, "The prediction of isothermal phase equilibria for non-ideal multicomponent mixtures from heats of mixing," Thermochimica Acta, vol. 21, no. 2, pp. 157-170, 1977

[42] D.-Y. Peng, "Extending the van laar model to multicomponent systems," The Open Thermodynamics Journal, vol. 4, no. 1, 2010

[43] R. Bentwood, A. Barnes, and W.-J. Orville-Thomas, "Studies of intermolecular interactions by matrix isolation vibrational spectroscopy: Self-association of water," Journal of Molecular Spectroscopy, vol. 84, no. 2, pp. 391-404, 1980.

[44] H. T. Flakus and A. Tyl, "Polarized ir spectra of the hydrogen bond in acetic acid crystals," Chemical Physics, vol. 336, no. 1, pp. 36-50, 2007.

[45] J. Spencer, W. Wolbach, J. Hovick, L. Ansel, and K. Modarress, "Hydrogen bonding by alcohols and amines," Journal of solution chemistry, vol. 14, no. 11, pp. 805-814, 1985.

[46] F. Besseau, M. Luçon, C. Laurence, and M. Berthelot, "Hydrogen-bond basicity p k hb scale of aldehydes and ketones," Journal of the Chemical Society, Perkin Transactions 2, no. 1, pp. 101-108, 1998.

[47] W. M. Bartcak, "Model of the self-association of primary alcohols," Berichte der Bunsengesellschaft für physikalische Chemie, vol. 83, no. 10, pp. 987-992, 1979.

[48] D. A. Dixon, K. D. Dobbs, and J. J. Valentini, "Amide-water and amide-amide hydrogen bond strengths," The Journal of Physical Chemistry, vol. 98, no. 51, pp. 13435-13439, 1994.

[49] A. Loewenstein and Y. Margalit, "Nuclear magnetic resonance studies of nitriles and isocyanides: Acetonitrile and methyl isocyanide," The Journal of Physical Chemistry, vol. 69, no. 12, pp. 4152-4156, 1965.

[50] R. Brakaspathy and S. Singh, "Studies on self-association of nitromethane using a cndo/force method," Journal of Molecular Structure: THEOCHEM, vol. 164, no. 3-4, pp. 319-324, 1988.

[51] R. Figueroa, E. Roig, and H. Szmant, "Infrared study on the self-association of dimethyl sulfoxide," Spec trochimica Acta, vol. 22, no. 4, pp. 587-592, 1966.

[52] G. V. Tiers, J. Stevens, and W. L. Stebbings, "Nmr detection of oriented association via dilution shifts in tetramethylsilane solvent. 2. aliphatic esters," Magnetic resonance in chemistry, vol. 37, no. 9, pp. 613-619, 1999.

[53] C. M. Huggins, G. C. Pimentel, and J. N. Shoolery, "Proton magnetic resonance studies of chloroform in solution: evidence for hydrogen bonding," The Journal of Chemical Physics, vol. 23, no. 7, pp. 1244-1247, 1955.

[54] B. Tiffon, B. Ancian, and J.-E. Dubois, "Natural abundance $17 \mathrm{o} \mathrm{mm}$ as a tool for intermolecular interaction studies: acetone self-association," Chemical Physics Letters, vol. 73, no. 1, pp. 89-93, 1980.

[55] R. Stryjek and J. Vera, "Prsv-an improved peng-robinson equation of state with new mixing rules for strongly nonideal mixtures," The Canadian Journal of Chemical Engineering, vol. 64, no. 2, pp. 334-340, 1986.

[56] Y. Adachi and H. Sugie, "A new mixing rule—modified conventional mixing rule," Fluid Phase Equilibria, vol. 28 , no. 2, pp. 103-118, 1986.

[57] M.-J. Huron and J. Vidal, "New mixing rules in simple equations of state for representing vapour-liquid equilibria of strongly non-ideal mixtures," Fluid Phase Equilibria, vol. 3, no. 4, pp. 255-271, 1979.

[58] J. O. Valderrama, "A generalized patel-teja equation of state for polar and nonpolar fluids and their mixtures," Journal of chemical engineering of Japan, vol. 23, no. 1, pp. 87-91, 1990.

[59] A. Panagiotopoulos and R. Reid, "New mixing rule for cubic equations of state for highly polar, asymmetric systems," ACS Publications, 1986.

[60] F. Esmaeilzadeh and M. Roshanfekr, "A new cubic equation of state for reservoir fluids," Fluid Phase 


\section{VLE PREDICTION FROM THE HEAT OF MIXING}

Equilibria, vol. 239, no. 1, pp. 83-90, 2006.

[61] R. Sandoval, G. Wilczek-Vera, and J. Vera, "Prediction of ternary vapor-liquid equilibria with the prsv equation of state," Fluid Phase Equilibria, vol. 52, pp. 119-126, 1989.

[62] K. Nasrifar and M. Moshfeghian, "A new cubic equation of state for simple fluids: pure and mixture.," Fluid Phase Equilibria, vol. 190, no. 1-2, pp. 73-88, 2001.

[63] C. H. Twu, J. E. Coon, and J. R. Cunningham, "An approach for the extension of a 3-parameter cubic equation of state to heavy hydrocarbons," Fluid phase equilibria, vol. 104, pp. 83-96, 1995.

[64] A. Harmens and H. Knapp, "Three-parameter cubic equation of state for normal substances," Industrial E Engineering Chemistry Fundamentals, vol. 19, no. 3, pp. 291-294, 1980.

[65] M. A. Trebble and P. R. Bishnoi, "Development of a new four-parameter cubic equation of state.," Fluid Phase Equilibria, vol. 35, no. 1-3, pp. 1-18, 1987.

[66] R. L. Scott and P. H. van Konynenburg, "Static properties of solutions. van der waals and related models for hydrocarbon mixtures," Discussions of the Faraday society, vol. 49, pp. 87-97, 1970.

[67] R. Stryjek and J. Vera, "Prsv2: a cubic equation of state for accurate vapor-liquid equilibria calculations," The Canadian Journal of Chemical Engineering, vol. 64, no. 5, pp. 820-826, 1986.

[68] C. H. Twu, W. D. Sim, and V. Tassone, "A versatile liquid activity model for srk, pr and a new cubic equation-of-state tst," Fluid Phase Equilibria, vol. 194, pp. 385-399, 2002.

[69] J. Sinor and J. H. Weber, "Vapor-liquid equilibria at atmospheric pressure. systems containing ethyl alcohol, n-hexane, benzene, and methylcyclopentane.," Journal of Chemical and Engineering Data, vol. 5, no. 3, pp. 243-247, 1960.

[70] L. Kudryavtseva and M. Susarev, "Liquid-vapor equilibriums in the systems acetone-hexane and hexaneethyl alcohol at 35, 45, and 55 and 760mmhg," Zh. Prikl. Khim, vol. 36, pp. 1471-1477, 1963.

[71] I. Brown, W. Fock, and F. Smith, "Heats of mixing. v. systems of n-alcohols with n-hexane," Australian Journal of Chemistry, vol. 17, no. 10, pp. 1106-1118, 1964.

[72] V. Bykov, "Heats of mixing of liquids," Zh. Fiz. Khim, vol. 13, pp. 1013-1019, 1939.

[73] R. Stokes and C. Burfitt, "Enthalpies of dilution and transfer of ethanol in non-polar solvents," The Journal of Chemical Thermodynamics, vol. 5, no. 5, pp. 623-631, 1973.

[74] T. Spyriouni, X. Krokidis, and I. G. Economou, "Thermodynamics of pharmaceuticals: Prediction of solubility in pure and mixed solvents with pc-saft," Fluid phase equilibria, vol. 302, no. 1-2, pp. 331-337, 2011. 





\subsection{Introduction}

Well-known industrial solvents in the petroleum industry are Sulfolane, ${ }^{1} \mathrm{n}$ methylpyrrolidone (NMP) ${ }^{2,3}$ and N,N-dimethylformamide (DMF). ${ }^{4}$ The application of these traditional solvents is not always as benign as desired; for instance, NMP is going to be banned for certain industrial applications due to the REACH legislation. ${ }^{5}$ Therefore, increasingly more attention has been given to the search for alternative, more benign, solvents. For example, ionic liquids (ILs), ${ }^{6}$ deep eutectic solvents (DES's) ${ }^{7}$ and switchable solvents ${ }^{8}$ are among the studied alternatives. Bio-based solvents may be considered another class of solvents, including both natural DES's (mixtures exhibiting an eutectic behavior) ${ }^{9,10}$ and single-component bio-based solvents. ${ }^{11,12}$ The singlecomponent solvents are most similar to traditional solvents in terms of molecular properties but they differ in the feedstock.

In this contribution, our study to find bio-based alternative solvents for extractive distillation is described, aiming at replacing fossil-based solvents to minimize the environmental impact associated with solvent production. In the comparison of the sustainability aspect of bio-based solvents and traditional solvents, the difference in the feedstock is apparent. In contrast to traditional solvents that are almost all derived from fossil oil, ${ }^{13}$ the feedstock for bio-based solvents is diverse, and includes lignocellulosic biomass, ${ }^{14}$ fermentation broths ${ }^{15}$ or (air-captured) carbon dioxide. ${ }^{16}$ On the condition that access to such bio-based chemicals involves clean processes, this approach can lessen the impact on the environment due to the use of carbon from the short carbon cycle. ${ }^{17}$

As lignocellulosic biomass consists mainly of $\mathrm{C}_{5^{-}}$and $\mathrm{C}_{6}$-sugars and lignin, a large variety of platform chemicals may be derived from them. Access to highly interesting chemistry can be realized by pyrolysis; see for example the route to dihydrolevoglucosenone in Figure 7.1. Upon further refinement, from biomass-derived sugars, for instance, propylene glycol, levulinic acid, $\gamma$-valerolactone, glycerol and furfural can be produced. ${ }^{14}$ With an additional synthetic step, the variety of accessible bio-based chemicals increases even further, e.g. nucleophilic addition of methanol to produce cyclopentyl methyl ether, ${ }^{18}$ fermentation of glycerol to propionic acid, ${ }^{19}$ trimerization of acetone 
to isophorone, ${ }^{20}$ and esterification of acetic acid and glycerol to triacetin ${ }^{21}$ and levulinic acid and ethanol to ethyl levulinate. ${ }^{22}$ Fast (catalytic) pyrolysis or hydrolysis of lignin can yield aromatic chemicals such as guaiacol, ${ }^{23}$ phenol ${ }^{24}$ and acetophenone. ${ }^{25}$ Ethylene carbonate can be produced by the cycloaddition of carbon dioxide to epoxides. ${ }^{16,17}$

Dihydrolevoglucosenone, or Cyrene, shown in Figure 7.1, has been mentioned as a promising bio-based alternative polar aprotic compound. It was synthesized in 1978 by Brimacombe et al. ${ }^{26}$ by the reduction of levoglucose-none and also shown by the group of Weckhuysen. ${ }^{27}$ Levoglucosenone itself can be obtained by the fast pyrolysis of cellulose. ${ }^{28-31}$ The recent rediscovery of Cyrene has resulted in various application assessments, including as a solvent for several reactions (fluorination, ${ }^{31}$ Menschutkins-, ${ }^{31}$ Sonogashira- and Cacchi-type annulation, ${ }^{32,33}$ basic reactions, ${ }^{32}$ acyl substitution, ${ }^{32}$ SuzukiMiyaura cross-coupling, ${ }^{32,34}$ amide synthesis, ${ }^{32,35}$ urea synthesis, ${ }^{36}$ MOF synthesis, ${ }^{37}$ solid-phase synthesis ${ }^{38}$ ), as a starting material for platform chemicals, ${ }^{39}$ as a hydrotropic solvent due to the capabilities via its germinal diol ${ }^{40}$ and as a solvent for liquid exfoliation in graphene processing. ${ }^{41}$

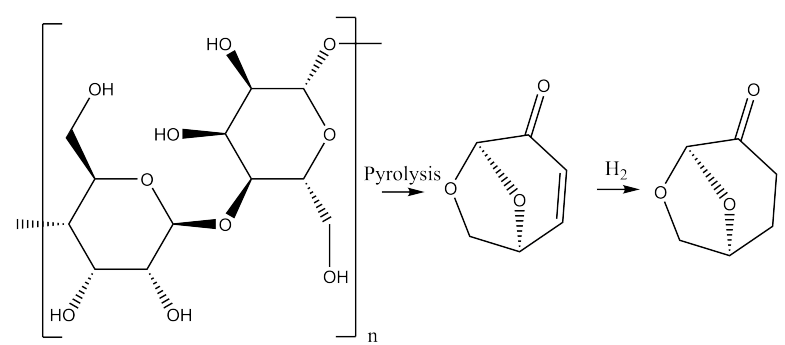

Figure 7.1: Synthetic steps of a bio-based solvent via pyrolysis of cellulose to levoglucosenone which is subsequently hydrogenated to dihydrolevoglucosenone (Cyrene). ${ }^{32}$

We decided to include Cyrene in the aforementioned range of bio-based solvents to be evaluated as an entrainer in two highly relevant industrial extractive distillation processes. The separation of methylcyclohexane $(\mathrm{MCH})$ and toluene is a model system for the separation of aromatics and aliphatics. Although this particular separation is challenging due to the close boiling nature of the binary mixture, it also represents a wider range of separations in a complex industrial hydrocarbon mixture. Relatively low-boiling 
aromatic compounds (BTX, i.e. benzene, toluene, and xylenes) are to be entrained from a wide range of aliphatic compounds which can be as volatile as the BTX compounds, but also much heavier. The addition of a solvent must therefore achieve a reversal of the boiling point order, hence separation of all aliphatic compounds over the top of the distillation column as the distillate. ${ }^{42,43}$ For this challenging task, many solvents do not show high-enough selectivity. ${ }^{43}$ The solvent screening results of this study will include a comparison with Sulfolane to identify which of the bio-based solvents perform similarly or better, and may be applied in a wider range of separations of aromatics and aliphatics. Furthermore, for promising solvents, the application as an entrainer in another challenging separation problem, the olefin/paraffin separation, ${ }^{44}$ will be investigated, for which $n$-heptane and 1-heptene were chosen as the model system.

A first estimate, or performance prediction, was performed using the modified UNIFAC (Do) model, ${ }^{45}$ known to be among the best predicting models for vapor-liquid equilibria. ${ }^{46}$

\subsection{Experimental Section}

\subsubsection{Materials}

All purchased chemicals were used without any additional purification. From Honeywell methylcyclohexane (Reagent Grade, 99\%) was purchased, while toluene (ACS, Reag.Ph.Eur) was purchased from VWR Chemicals. Merck was the supplier for acetone (LiChrosolv) and ethylene glycol (Empure, Reag.Ph.Eur.). Acros Organics supplied us with $\gamma$-valerolactone (98\%), levulinic acid $(98+\%)$, triacetin $(99 \%)$ and tributyl phosphate $(99+\%)$. n-Heptane $(99 \%)$ was purchased from Alfa Aesar and d-chloroform (99.5\%) was supplied Cambridge Isotope Laboratories, Inc. We are grateful for the Circa Group who supplied us with Cyrene. The remainder was purchased from Sigma Aldrich; Sulfolane $(99 \%)$, propylene glycol $(\geq 99.5 \%)$, propionic acid $(\geq 99.5 \%)$, methyl salicylate $(>99 \%)$, ethylene carbonate $(98 \%)$, isophorone $(97 \%)$, guaiacol $(\geq 99 \%)$, phenol ( $\geq 99 \%)$, furfural $(99 \%)$, acetophenone (99\%), 1-heptene (99\%) and n-methylpyrrolidone (99.5\%). 


\subsubsection{Experimental setup}

Fischer Labodest VLE602 ebulliometers, see for an ebulliometer example in Figure 7.2, were used for the measurement of the isobaric vapor-liquid equilibria (VLE). Each mixture, containing the binary mixture and optionally a solvent, was heated to reach an equilibrium temperature at a pre-set pressure. For each measurement, a total amount of about $85 \mathrm{~g}$ of the liquid was added to the ebulliometer, which ensured adequate liquid and vapor flows throughout the ebulliometer system.

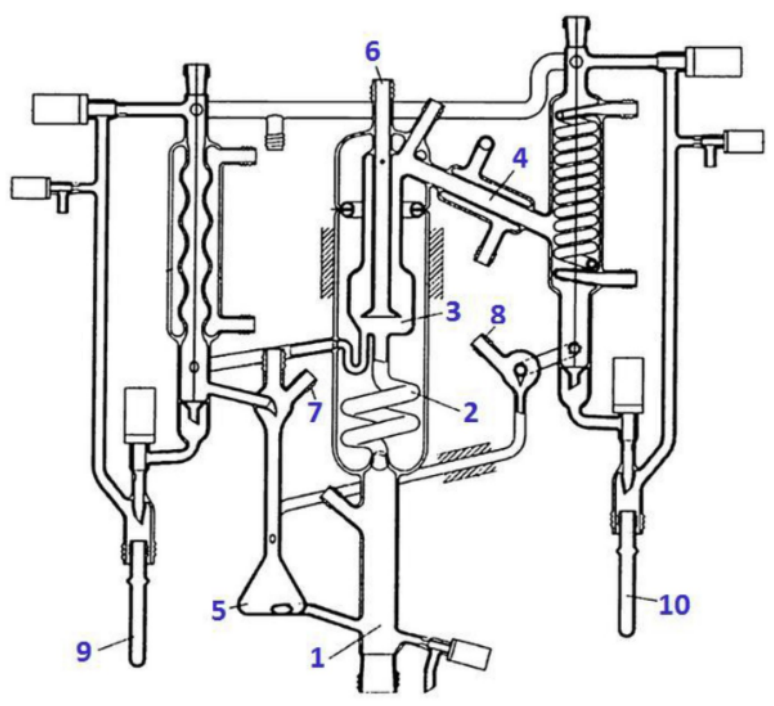

Figure 7.2: A schematic representation of an ebulliometer. (1) Heating bulb, (2) circulation (Cottrell) pump, (3) Equilibrium chamber, (4) Condenser, (5) Mixing Chamber, (6) Temperature sensor, (7) Liquid phase sampling point, (8) Condensed vapor phase sampling point, (9 and 10) Alternative (not used) sampling points. Copied from Srirachat et al. ${ }^{47}$

Each measurement was left to equilibrate for approximately $60 \mathrm{~min}$, and after reaching the equilibrium, $0.5-1.0 \mathrm{~mL}$ of liquid samples were taken from the liquid and condensed vapor flows. A solvent-to-feed ratio of 1 was used if not specified otherwise. A 50/50 wt. \% mixture of $\mathrm{MCH}$ and toluene was used for the screening of the bio-based solvents, while a 90/10 wt. \% mixture was used for the measurements with n-heptane/1-heptene. Distillation results are 
typically reported in mole fractions, so these were calculated as well.

\subsubsection{Analysis Method}

\subsubsection{Gas Chromatography}

A Thermo Scientific Trace 1300 gas chromatograph with two parallel ovens and an autosampler TriPlus 100 Liquid Samples was used for the analyses. The samples of the methylcyclohexane/toluene system were analyzed using an Agilent DB-1MS column $(60 \mathrm{~m} \times 0.25 \mathrm{~mm} \times 0.25 \mu \mathrm{m})$ with an injection volume of $1 \mu \mathrm{l}$ diluted in analytical acetone. A ramped temperature profile was used, following the program; an initial temperature of $50^{\circ} \mathrm{C}$, with a ramp of $10{ }^{\circ} \mathrm{C} / \mathrm{min}$ to $200^{\circ} \mathrm{C}$. The second ramp of $50{ }^{\circ} \mathrm{C} / \mathrm{min}$ to $320^{\circ} \mathrm{C}$ finished the program, which lasts $20 \mathrm{~min}$. The FID temperature was $330^{\circ} \mathrm{C}$. A column flow of $2 \mathrm{ml} / \mathrm{min}$ with a split ratio of 5, an airflow of $350 \mathrm{ml} / \mathrm{min}$, a helium make-up flow of $40 \mathrm{ml} / \mathrm{min}$ and a hydrogen flow of $35 \mathrm{ml} / \mathrm{min}$ was used.

\subsubsection{2 ${ }^{1} \mathrm{H}-\mathrm{NMR}$}

The samples of the $\mathrm{n}$-heptane/1-heptene system were analyzed by proton $\mathrm{Nu}$ clear Magnetic Resonance $\left({ }^{1} \mathrm{H}-\mathrm{NMR}\right)$ spectroscopy using a Bruker $400 \mathrm{MHz}$ spectrometer. The samples were diluted in deuterated chloroform (d-chloroform). The intensities of the characteristic peaks of n-heptane, 1-heptene, Cyrene and NMP of respectively $0.74 \mathrm{ppm}, 5.74 \mathrm{ppm}, 3.95 \mathrm{ppm}$ and 2.80 ppm were used to determine the composition.

\subsection{Results and Discussion}

The potential of various bio-based solvents to increase the relative volatility in the $\mathrm{MCH}$-toluene binary mixture was evaluated experimentally by measuring the pseudo-binary vapor-liquid equilibrium (VLE), pseudo-binary meaning that the composition of the solvent is not taken into account in the calculations for the $\mathrm{MCH}$-toluene binary mixture. The relative volatility $\left(\alpha_{i j}\right)$ is the ratio of the activity coefficients $\left(\gamma_{i}\right)$ and the saturated vapor pressures $\left(P_{i}^{0}\right)$ of both compounds, as shown in Equation 7.1. For more information see, subsection 2.3.1. 


$$
\alpha_{i j}=\frac{P_{i}^{0}}{P_{j}^{0}}\left(\frac{\gamma_{i}}{\gamma_{j}}\right)
$$

The saturated vapor pressures are pure component properties, whereas the activity coefficients are dependent on the mixture composition, and hence, are affected by the presence of a solvent. By predicting the activity coefficients using the mod. UNIFAC (Do) model, ${ }^{45}$ the corresponding effect of the solvent on the relative volatility can be predicted. All relative volatilities mentioned in this paper are pseudo-binary relative volatilities, i.e. the solvent is not taken into account. This is a common practice in studies on entrainer performance in extractive distillation, and mostly those solvents with much higher boiling points than the mixtures are selected. ${ }^{2,48}$

\subsubsection{Relative Volatility Screening}

The effect of the bio-based solvents in this study on the relative volatility in the $\mathrm{MCH}$-toluene binary mixture was studied at a composition of 50/50 wt. $\%$ of $\mathrm{MCH}$ and toluene. The predicted relative volatility using the mod. UNIFAC (Do) model is compared with the experimentally obtained values using a dynamic equilibrium measurement with an ebulliometer. The parity between the model and the experiment is shown in Figure 7.3. Several bio-based solvents, such as furfural, $\gamma$-valerolactone, phenol and levulinic acid, perform very well, showing only slightly lower relative volatilities than was observed with Sulfolane.

Among these solvents, furfural is already a known extractive distillation solvent in the purification of $\mathrm{C}_{4}$-hydrocarbons, ${ }^{52}$ and phenol has been mentioned decades ago. ${ }^{53}$ Levulinic acid and $\gamma$-valerolactone have, to the best of our knowledge, not been identified as potential entrainers in the separation of aromatics and aliphatics by extractive distillation. Numerous other solvents induce significantly lower relative volatility, which is either the result of a lack of polarity or significant intramolecular hydrogen bond formation. Exceptionally well-performing is Cyrene, which shows a relative volatility of $\mathrm{MCH}$ over toluene of $3.17 \pm 0.16$, which is higher than the relative volatility observed with Sulfolane. This is an indication that Cyrene is likely to perform similarly to or even better than Sulfolane. 


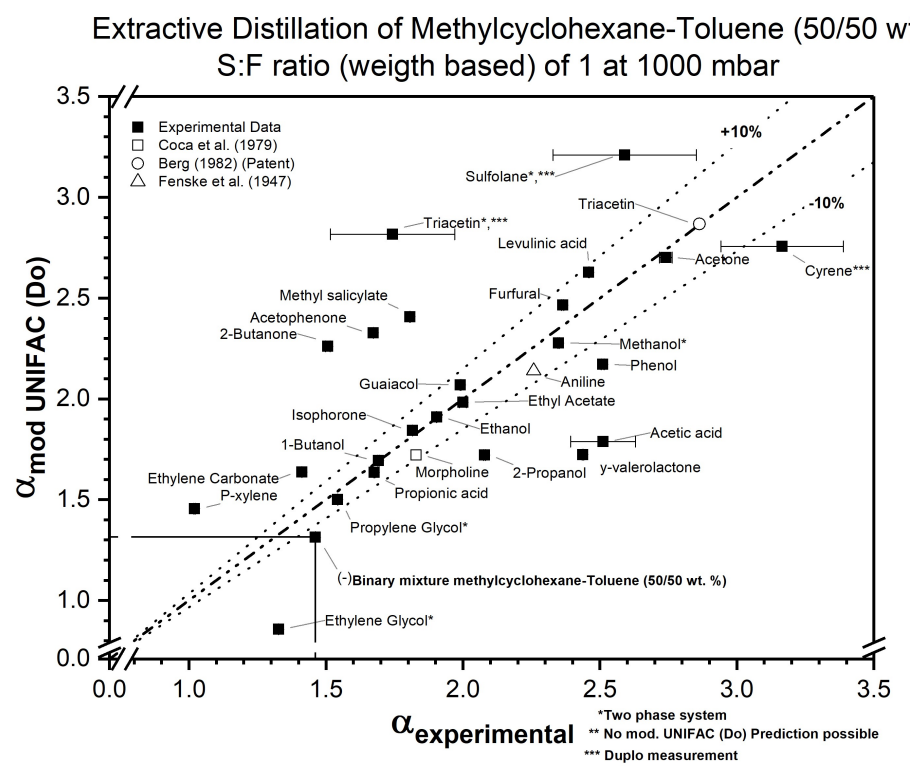

Figure 7.3: The screening results of twenty-four bio-based solvents regarding the relative volatility of a 50/50 wt. \% MCH/toluene mixture with a solvent-to-feed ratio of 1 (mass basis) at 1000 mbar. On the $x$-axis, the experimental relative volatility is plotted against the relative volatility predicted by the mod. UNIFAC (Do) model on the y-axis. Additional literature values are included. ${ }^{49-51}$ The error bars indicate the standard deviation of duplo measurements.

Several biobased solvents are however too volatile to be used as an extractive distillation agent, such as $\mathrm{p}$-xylene $(\mathrm{bp}=412 \mathrm{~K}), 1$-butanol $(\mathrm{bp}=390 \mathrm{~K})$, 2-propanol ( $\mathrm{bp}=356 \mathrm{~K}), 2$-butanone $(\mathrm{bp}=353 \mathrm{~K})$, acetic acid $(\mathrm{bp}=391 \mathrm{~K})$, ethyl acetate $(\mathrm{bp}=350 \mathrm{~K})$, ethanol $(\mathrm{bp}=351 \mathrm{~K})$, propionic acid $(\mathrm{bp}=414 \mathrm{~K})$, methanol $(\mathrm{bp}=338 \mathrm{~K})$ and acetone $(\mathrm{bp}=329 \mathrm{~K})$. Even tough acetone does enhances the relative volatility significantly.

From Figure 7.3, it can further be concluded that the mod. UNIFAC (Do) predictive model, even though being among the best predictive models for this task, ${ }^{46}$ shows significant deviations in the predictions. Although many predictions are accurate within a deviation of $10 \%$, there are several solvents for which a larger inaccuracy was observed. From the previous work, ${ }^{46}$ at 
infinite dilution, the activity coefficient deviation of the mod. UNIFAC (Do) model was on an average $24.3 \%$. This prediction is however more accurate for similar molecules, but can also be highly inaccurate, for instance between aliphatic compounds and aprotic and protic compounds (56.8\% deviation). These trends are shown in Figure 7.3, where the performance prediction of the aprotic polar solvent, acetophenone, is $>10 \%$. The deviation decreases if the polar character is decreased, such as in isophorone. Overall, these results are in agreement with the earlier conclusions at infinite dilution. ${ }^{46}$

\subsubsection{Vapor-Liquid Equilibrium of MCH-TOL-Cyrene}

Based on the excellent results for the $\mathrm{MCH}$-toluene separation, the use of Cyrene for extractive distillation of this mixture was further studied for the entire pseudo-binary composition range and compared with the effect of Sulfolane on the $\mathrm{MCH}$-toluene pseudo-binary VLE. For each measurement, the solvent-to-feed (S:F) ratio was maintained at 1 (mass basis) and the pressure was varied between 1000, 800 and 500 mbar. In Figure 7.4. It can be seen that at smaller $\mathrm{MCH}$ mole fractions, until approximately 0.4 , the relative volatility induced by Cyrene appears to be comparable with that of Sulfolane, or slightly less. However, at higher fractions of $\mathrm{MCH}$, with Sulfolane, a distinct pinch point is observed, whereas with Cyrene in that part of the diagram, a much higher relative volatility is observed, resulting in the absence of the pinch point or at least a much less severe pinch point.

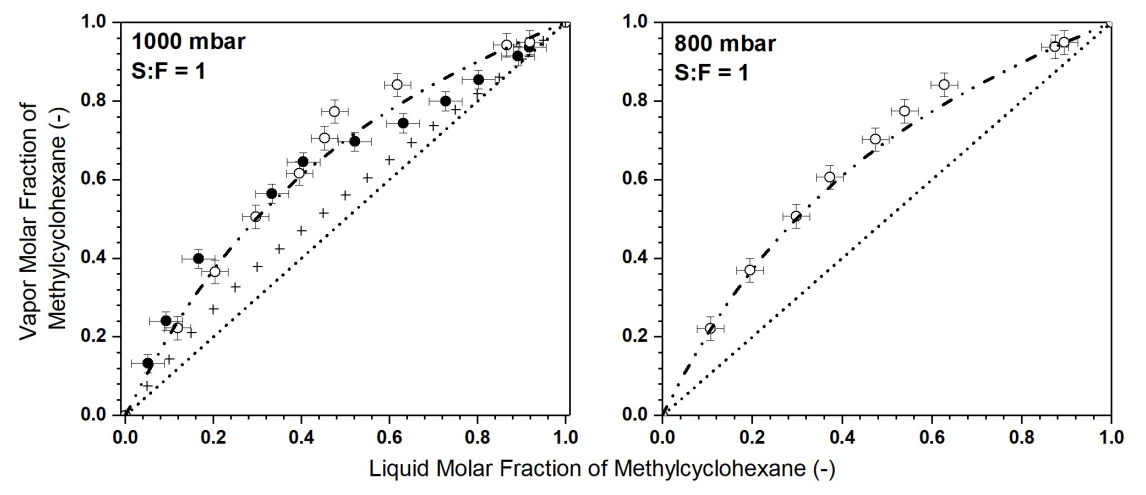




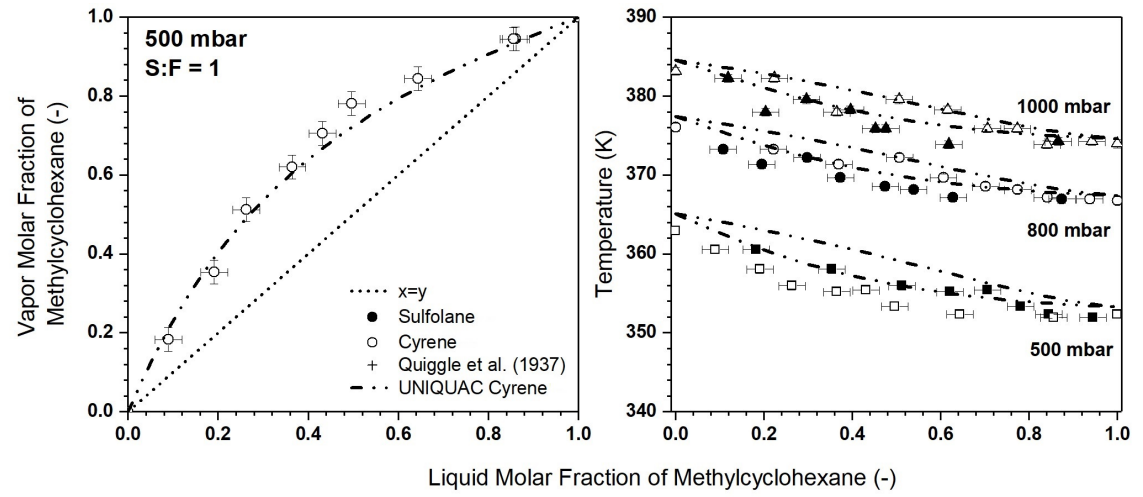

Figure 7.4: The pseudo-binary isobaric vapour liquid equilibrium ( $x y$ - and Txy-) diagrams with Sulfolane and Cyrene as the solvents with a solvent-to-feed (S:F) ratio of 1 on mass basis at 1000, 800 and 500 mbar. The literature values of Quiggle et al. ${ }^{54}$ were used as the binary reference.

This is likely due to phase splitting that can occur for Sulfolane at high $\mathrm{MCH}$ content, while for Cyrene this is not observed. Phase splitting reduces interactions of the solvent towards both toluene and $\mathrm{MCH}$, hence diminishing the solvent effects on the relative volatility and resulting in a pinch point. Furthermore, an insignificant Cyrene fraction was found in the vapor phase, which varies between 0.07 and 1.62 wt. \% mainly depending on the solventto-feed ( $\mathrm{S}: \mathrm{F})$ ratio and the operational pressure. The stability of Cyrene was confirmed by ${ }^{1} \mathrm{H}-\mathrm{NMR}$ (see Figure 7.5) after its recovery using a rotary evaporator. 


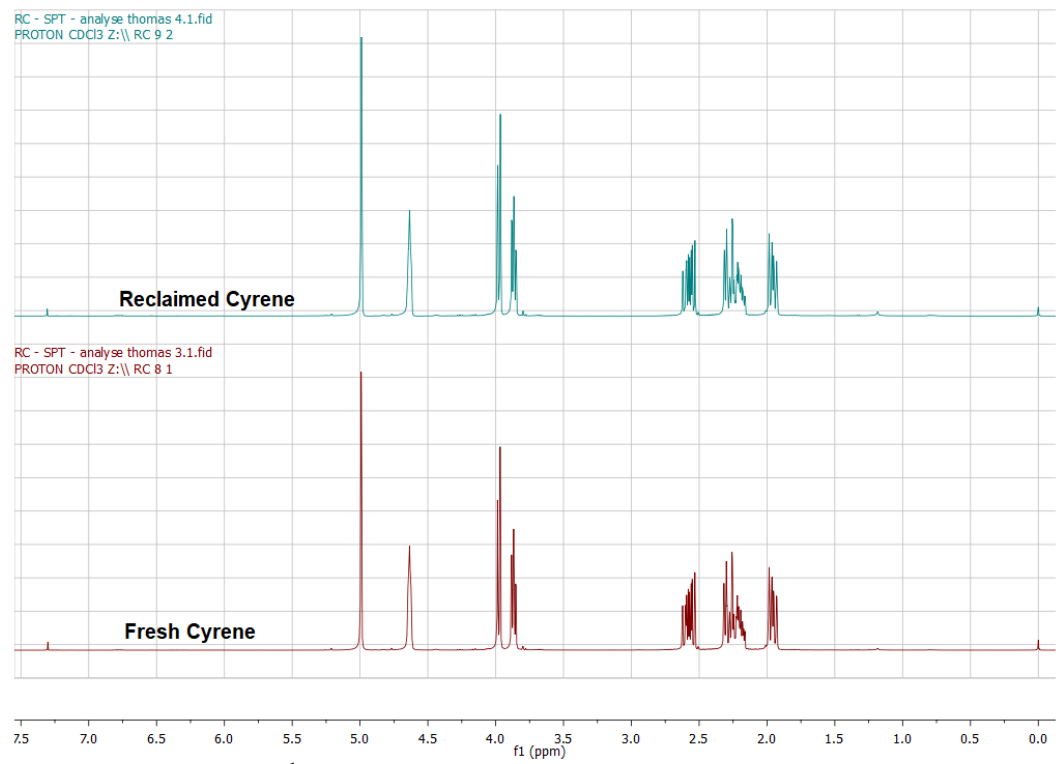

Figure 7.5: The ${ }^{1} H$-NMR spectrum of used and fresh Cyrene compared.

To explain the observations in the VLE experiments, the charge distributions in n-heptane, 1-heptene, toluene, $\mathrm{MCH}$ and Cyrene have been simulated using the COSMO-RS software (Conductor like Screening Model for Realistic Solvents). Based on density functional theory, the molecular geometries have been optimized, and then the screening charge around the surface of the molecules was calculated and plotted. For the five molecules in this study, the so-called $\sigma$-profiles are shown in Figure 7.6, together with the surfaces. Negative screening charge density indicates an electropositive region, while positive screening charge density corresponds with an electronegative region. Cyrene is the most polar of the displayed molecules, which is reflected in both a peak at a positive screening charge density and a peak at a negative screening charge density. $\mathrm{n}$-Heptane and $\mathrm{MCH}$, in contrast, exhibit a single peak around 0 , exemplary for their apolar character. This charge mismatch causes net repulsive interactions, resulting in high activity coefficients.

The $\pi$-orbitals in the unsaturated hydrocarbons responsible for the electric quadrupole moments result in screening charge profiles that are off-centered, 
i.e. with clear maxima at the positive screening charge, and most pronounced for toluene, also at the negative screening charge. The presence of these positive and negative screening charges induces attractive dipole-dipole interactions, and for this reason, both unsaturated hydrocarbons are less repelled by Cyrene than their corresponding saturated hydrocarbons. As a result, their activity coefficients are lower which results in an increased relative volatility, as indeed is shown in Figure 7.4 for the MCH-toluene system.

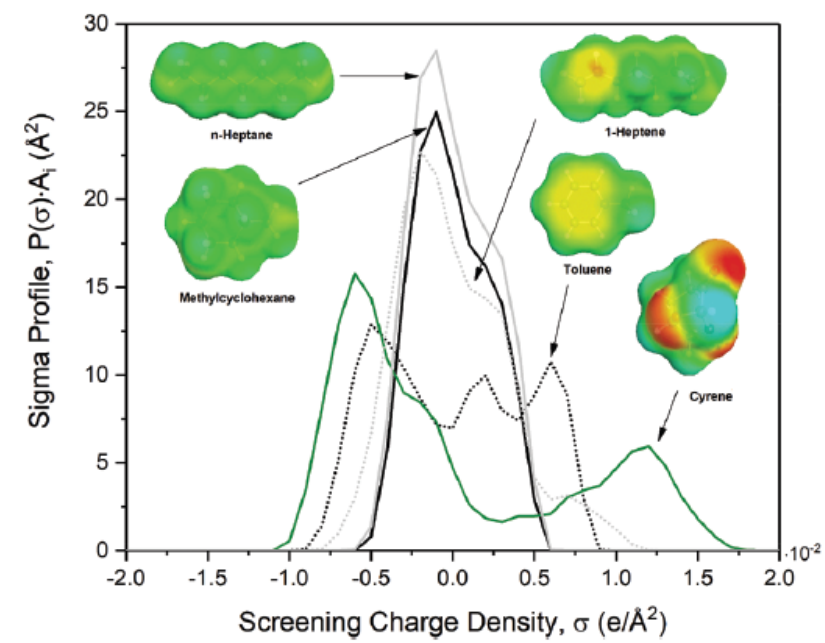

Figure 7.6: The charge distribution ( $\sigma$-profile) of toluene, methylcyclohexane, n-heptane, 1-heptene and Cyrene. Calculated with COSMOthermX C30_1705 using the TZVPparameterization.

These results are additionally fitted using the UNIQUAC model for eventual process simulations. This model requires however the Van der Waals area $\left(\mathrm{r}_{i}\right)$ and volume $\left(\mathrm{q}_{i}\right)$ of each component. These parameters are known for methylcyclohexane and toluene, however not of Cyrene.

The unknown parameters are estimated with Density Functional Theory with a B3LYP $6-311+\mathrm{G}^{* *}$ parameterization in combination with the methodology of Banerjee et al. ${ }^{55}$

The equilibrium line from the fitted UNIQUAC model was used as input for the energy estimations. The energy requirements of a distillation column 


\section{BIOBASED ENTRAINERS FOR APOLAR SEPARATIONS}

Table 7.1: The UNIQUAC parameters for methylcyclohexane, toluene and Cyrene and the fitted binary interaction coefficients.

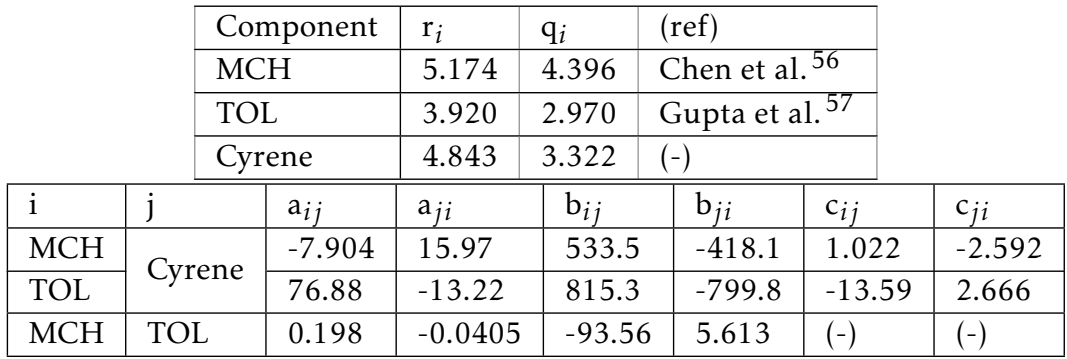

${ }^{*}$ The pure component vapor pressure of Cyrene has been used from. ${ }^{58}$

(reboiler and condenser) are highly dependent on the minimum reflux ratio $\left(\mathrm{R}_{\text {min }}\right)$, which influences the amount of liquid that needs to be evaporated in the reboiler. The $\mathrm{R}_{\min }$ was estimated by the graphical McCabe-Thiele approach $^{59}$ and found to be 2.21 for Sulfolane and only 1.25 for Cyrene, see Figure 7.7. This shows the strong effect of removing the pinch point when replacing Sulfolane with Cyrene, resulting in a significant decrease of $43 \%$ in $\mathrm{R}_{\text {min }}$
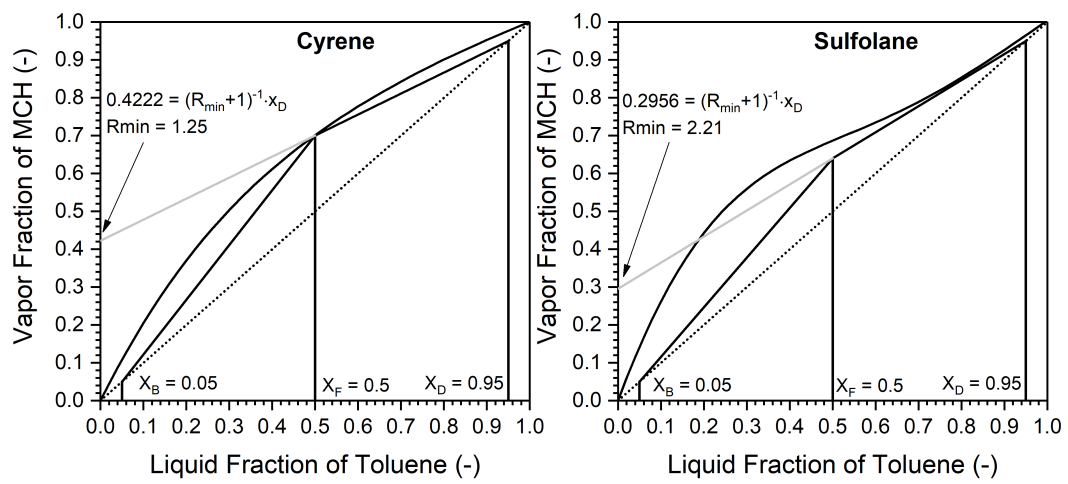

Figure 7.7: McCabe-Thiele method and the determination of the $R_{\text {min. }}$. For more information see subsection 2.3.1. 
which could correspond to a projected energy savings in the reboiler duty of maximum $30 \%$, depending on the exact conditions of operation, such as solvent feed temperatures and excluding the use of an anti-solvent such as water.

\subsubsection{Olefin/Paraffin Separation: n-Heptane and 1-Heptene}

Based on the potential of Cyrene as a bio-based alternative for Sulfolane, there may be other applications where Cyrene can replace polar non-protic entrainers. An important class is the separation of olefin/paraffin. Therefore the evaluation of Cyrene was extended towards olefin/paraffin separation. The model system of n-heptane and 1-heptene was selected because of the experimentally convenient boiling temperatures, and was examined at a single binary composition of $90 \mathrm{wt}$. \% n-heptane and $10 \mathrm{wt}$. \% 1-heptene. This is the composition where the solvent effect for the $\mathrm{MCH}$-toluene separation with Cyrene was the largest.

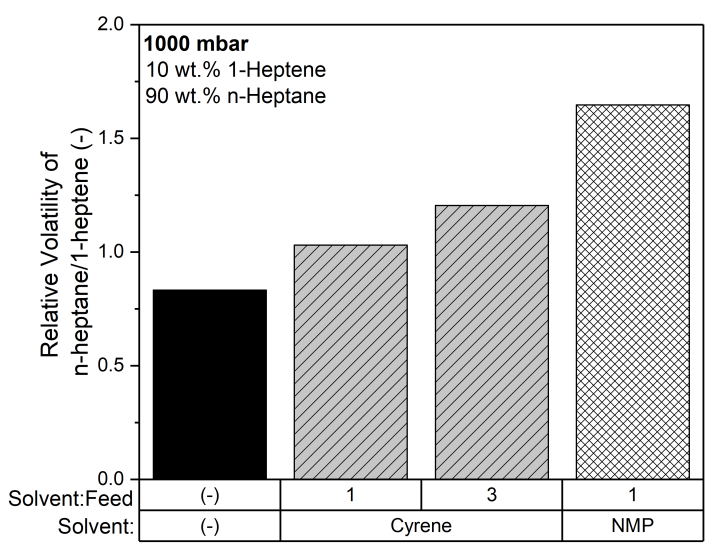

Figure 7.8: The relative volatility of n-heptane over 1-heptene without a solvent, with Cyrene at a $S: F$ ratio of 1 and 3 and with n-methylpyrrolidone (NMP) at 1000 mbar and $S: F=1$ with a feed composition of $90 \mathrm{wt}$. \% n-heptane and $10 \mathrm{wt}$. \% 1-heptene. S:F ratios are all on mass basis. These are single experiments. An overall uncertainty of experimental and analytical error of $3 \%$ was found for similar experiments 
As can be seen in Figure 7.8, Cyrene increases the relative volatility from 0.83 to $1.03(\mathrm{~S}: \mathrm{F}=1$ on mass basis) and $1.20(\mathrm{~S}: \mathrm{F}=3)$ due to the impact of the difference in screening charge distributions between n-heptane and 1-heptene, as shown in Figure 7.6. The experiments thus showed that it was possible to achieve the desired natural boiling order reversal effect. In comparison with one of the industrial standards, NMP, which induces a higher relative volatility of 1.65 (S:F ratio = 1), the performance of Cyrene is lower. This is due to the less pronounced positive screening charge area of 1-heptene compared to toluene; see Figure 7.6. Nevertheless, the effect of Cyrene can be further enhanced by using a larger S:F ratio.

Furthermore, we speculate that the effect of the solvent will be more pronounced in the industrially relevant separation of butadiene, ${ }^{44}$ as butadiene has twice the number of unsaturated bonds in comparison with 1-heptene. This allows for significantly more dipole interactions of the solvent via the $\pi$-bonds, which lowers the activity coefficient, and thus increases the relative volatility towards the saturated compound. This has been shown by De Oliveira et al. for 1,3-butadiene and isobutene in the presence of NMP. ${ }^{60,61}$ Based on the observed results for the studied systems, we project that the biobased solvent Cyrene has the potential of phasing out toxic solvents such as $\mathrm{NMP}^{62}$ in extractive distillation applications, though detailed energy requirements via rigorous process simulations are required for verification.

\subsection{Conclusion}

From a wide-range screening of bio-based solvents to separate a 50/50 wt. $\%$ mixture of $\mathrm{MCH}$ and toluene, Cyrene was seen to most effectively entrain toluene to induce an excellent relative volatility of $3.17 \pm \pm 0.16$, being even higher than the industrial state-of-the-art Sulfolane. Especially at higher $\mathrm{MCH}$ fractions, Cyrene significantly induces the relative volatility in the system, whereas the use of Sulfolane in this composition range results in a pinch point. The absence of the pinch point when using Cyrene lowers the minimum reflux ratio from 2.21 for Sulfolane to 1.25 for Cyrene, corresponding to an expected energy usage reduction of approximately $30 \%$.

The potential of Cyrene was additionally evaluated for the olefin/paraffin sep- 
aration of $\mathrm{n}$-heptane and 1-heptene. Based on the observed relative volatility towards n-heptane of 1.03 and 1.20 for the S:F ratio of 1 and 3 respectively, we expect that the use of Cyrene for the industrially highly relevant butadiene splitting is also suitable. This offers the opportunity to replace NMP, which is subject to strong environmental restrictions.

\subsection{Nomenclature}

$\begin{array}{ll}\text { Cyrene } & =\text { Dihydrolevoglucosenone } \\ \text { DMF } & =\text { n,n-Dimethylformamide } \\ \text { FID } & =\text { Flame Ionization Detection } \\ \text { MCH } & =\text { Methylcyclohexane } \\ \text { Mod. UNIFAC (Do) } & =\text { Dortmund modification of UNIFAC } \\ \text { NMP } & =\text {-Methylpyrrolidone } \\ \text { NMR } & =\text { Nuclear Magnetic Resonance } \\ \text { REACH } & =\text { Registration, Evaluation, Authorisation and Re- } \\ \text { S:F Ratio } & =\text { Striction of Chemicals } \\ \text { Sulfolane } & =\text { Tetrahydrothiophene-1, 1-dioxide } \\ \text { TOL } & =\text { Toluene } \\ \text { TZVP } & =\text { Triple valence plus polarization } \\ \text { UNIFAC } & =\text { UNIQUAC functional-group activity coefficients } \\ \text { UNIQUAC } & =\text { Universal quasichemical } \\ \text { VLE } & =\text { Vapour Liquid equilibrium } \\ \alpha_{i j} & =\text { Relative volatility (-) } \\ P_{i}^{O} & =\text { Pure component vapor pressure (bar) } \\ x_{i} & =\text { Molar fraction of compound i }\end{array}$

\subsection{References}

[1] Y. J. Choi, K. W. Cho, B. W. Cho, and Y.-K. Yeo, "Optimization of the sulfolane extraction plant based on modeling and simulation," Industrial E engineering chemistry research, vol. 41, no. 22, pp. 5504-5509, 2002.

[2] M. Fahim and A. Elkilani, "Prediction of optimum composition of the mixed solvent nmethylpyrrolidone/ethylene glycol for the extraction of aromatics," Separation Science and Technology, vol. 25, no. 13-15, pp. 1803-1815, 1990. 


\section{BIOBASED ENTRAINERS FOR APOLAR SEPARATIONS}

[3] R. J. Noe, B. R. Beadle, and L. E. Sullivan, “Aromatics recovery by extractive distillation," Oct. 8 2013. US Patent 8,552,247.

[4] Z. Lei, R. Zhou, and Z. Duan, "Process improvement on separating c4 by extractive distillation," Chemical Engineering Journal, vol. 85, no. 2-3, pp. 379-386, 2002.

[5] J. Sherwood, T. J. Farmer, and J. H. Clark, "Catalyst: Possible consequences of the n-methyl pyrrolidone reach restriction," Chem, vol. 4, no. 9, pp. 2010-2012, 2018.

[6] Z. Lei, C. Dai, J. Zhu, and B. Chen, "Extractive distillation with ionic liquids: a review," AIChE Journal, vol. 60, no. 9, pp. 3312-3329, 2014.

[7] N. R. Rodriguez, A. S. Gonzalez, P. M. Tijssen, and M. C. Kroon, "Low transition temperature mixtures (lttms) as novel entrainers in extractive distillation," Fluid Phase Equilibria, vol. 385, pp. 72-78, 2015.

[8] B. Schuur, M. Nijland, M. Blahušiak, and A. Juan, "Co2-switchable solvents as entrainer in fluid separations," ACS sustainable chemistry E engineering, vol. 6, no. 8, pp. 10429-10435, 2018.

[9] Y. Liu, J. B. Friesen, J. B. McAlpine, D. C. Lankin, S.-N. Chen, and G. F. Pauli, "Natural deep eutectic solvents: properties, applications, and perspectives," Journal of natural products, vol. 81, no. 3, pp. 679 690, 2018.

[10] B. Sharma, N. Singh, and J. P. Kushwaha, "Natural deep eutectic solvent-mediated extractive distillation for separation of acetonitrile+ water azeotropic mixture," Journal of Chemical E Engineering Data, vol. 65, no. 4, pp. 1497-1505, 2020.

[11] F. Jérôme and R. Luque, Bio-based solvents. John Wiley \& Sons, 2017.

[12] B. Schuur, T. Brouwer, D. Smink, and L. M. Sprakel, "Green solvents for sustainable separation processes," Current Opinion in Green and Sustainable Chemistry, vol. 18, pp. 57-65, 2019.

[13] E. Clark, "Sulfolane and sulfones," Kirk-Othmer encyclopedia of chemical technology, 2000.

[14] F. H. Isikgor and C. R. Becer, "Lignocellulosic biomass: a sustainable platform for the production of biobased chemicals and polymers," Polymer Chemistry, vol. 6, no. 25, pp. 4497-4559, 2015.

[15] J.-Y. Dai, Y.-Q. Sun, and Z.-L. Xiu, "Separation of bio-based chemicals from fermentation broths by salting-out extraction," Engineering in Life Sciences, vol. 14, no. 2, pp. 108-117, 2014.

[16] M. North, P. Villuendas, and C. Young, "A gas-phase flow reactor for ethylene carbonate synthesis from waste carbon dioxide," Chemistry-A European Journal, vol. 15, no. 43, pp. 11454-11457, 2009.

[17] Y. P. Patil, P. J. Tambade, S. R. Jagtap, and B. M. Bhanage, "Carbon dioxide: a renewable feedstock for the synthesis of fine and bulk chemicals," Frontiers of Chemical Engineering in China, vol. 4, no. 2, pp. 213-235, 2010.

[18] K. Watanabe, N. Yamagiwa, and Y. Torisawa, "Cyclopentyl methyl ether as a new and alternative process solvent," Organic process research \& development, vol. 11, no. 2, pp. 251-258, 2007.

[19] A. Ekman and P. Börjesson, "Environmental assessment of propionic acid produced in an agricultural biomass-based biorefinery system," Journal of Cleaner Production, vol. 19, no. 11, pp. 1257-1265, 2011.

[20] C. Kelkar and A. Schutz, "Efficient hydrotalcite-based catalyst for acetone condensation to $\alpha$ isophorone-scale up aspects and process development," Applied clay science, vol. 13, no. 5-6, pp. 417432, 1998 .

[21] S. Kale, U. Armbruster, S. Umbarkar, M. Dongare, and A. Martin, "Esterification of glycerol with acetic acid for improved production of triacetin using toluene as an entrainer," STA, vol. 11, no. 206, pp. 274-5, 2013.

[22] D. Fernandes, A. Rocha, E. Mai, C. J. Mota, and V. T. Da Silva, "Levulinic acid esterification with ethanol to ethyl levulinate production over solid acid catalysts," Applied Catalysis A: General, vol. 425, pp. 199-204, 2012.

[23] X. Li, L. Su, Y. Wang, Y. Yu, C. Wang, X. Li, and Z. Wang, "Catalytic fast pyrolysis of kraft lignin with hzsm-5 zeolite for producing aromatic hydrocarbons," Frontiers of Environmental Science E Engineering, vol. 6, no. 3, pp. 295-303, 2012.

[24] S. Nenkova, T. Vasileva, and K. Stanulov, "Production of phenol compounds by alkaline treatment of technical hydrolysis lignin and wood biomass," Chemistry of Natural Compounds, vol. 44, no. 2, pp. 182$185,2008$.

[25] C. Amen-Chen, H. Pakdel, and C. Roy, "Production of monomeric phenols by thermochemical conversion of biomass: a review," Bioresource technology, vol. 79, no. 3, pp. 277-299, 2001.

[26] J. S. Brimacombe, B. JS, T. LCN, et al., "The stereochemistry of the reduction of 1, 6-anhydro-3, 4-dideoxy- 


\section{BIOBASED ENTRAINERS FOR APOLAR SEPARATIONS}

beta-d-glycero-hex-3-enopyranos-2-ulose (levoglucosenone) with lithium aluminium hydride.," 1978.

[27] C. Sener, D. D. Petrolini, D. J. McClelland, J. He, M. R. Ball, Y. Liu, L. Martins, J. A. Dumesic, G. W. Huber, B. M. Weckhuysen, et al., "Catalytic hydrogenation of dihydrolevoglucosenone to levoglucosanol with a hydrotalcite/mixed oxide copper catalyst," Green Chemistry, vol. 21, no. 18, pp. 5000-5007, 2019.

[28] F. Cao, T. J. Schwartz, D. J. McClelland, S. H. Krishna, J. A. Dumesic, and G. W. Huber, "Dehydration of cellulose to levoglucosenone using polar aprotic solvents," Energy \& Environmental Science, vol. 8, no. 6, pp. 1808-1815, 2015.

[29] S. H. Krishna, D. J. McClelland, Q. A. Rashke, J. A. Dumesic, and G. W. Huber, "Hydrogenation of levoglucosenone to renewable chemicals," Green chemistry, vol. 19, no. 5, pp. 1278-1285, 2017.

[30] S. Kudo, N. Goto, J. Sperry, K. Norinaga, and J.-i. Hayashi, "Production of levoglucosenone and dihydrolevoglucosenone by catalytic reforming of volatiles from cellulose pyrolysis using supported ionic liquid phase," ACS Sustainable Chemistry E Engineering, vol. 5, no. 1, pp. 1132-1140, 2017.

[31] J. Sherwood, A. Constantinou, L. Moity, C. R. McElroy, T. J. Farmer, T. Duncan, W. Raverty, A. J. Hunt, J. H. Clark, et al., "Dihydrolevoglucosenone (cyrene) as a bio-based alternative for dipolar aprotic solvents," Chemical Communications, vol. 50, no. 68, pp. 9650-9652, 2014.

[32] J. E. Camp, "Bio-available solvent cyrene: Synthesis, derivatization, and applications," ChemSusChem, vol. 11, no. 18, pp. 3048-3055, 2018.

[33] K. L. Wilson, A. R. Kennedy, J. Murray, B. Greatrex, C. Jamieson, and A. J. Watson, "Scope and limitations of a dmf bio-alternative within sonogashira cross-coupling and cacchi-type annulation," Beilstein journal of organic chemistry, vol. 12, no. 1, pp. 2005-2011, 2016.

[34] K. L. Wilson, J. Murray, C. Jamieson, and A. J. Watson, "Cyrene as a bio-based solvent for the suzukimiyaura cross-coupling," Synlett, vol. 29, no. 05, pp. 650-654, 2018.

[35] K. L. Wilson, J. Murray, C. Jamieson, and A. J. Watson, "Cyrene as a bio-based solvent for hatu mediated amide coupling," Organic \& biomolecular chemistry, vol. 16, no. 16, pp. 2851-2854, 2018.

[36] L. Mistry, K. Mapesa, T. W. Bousfield, and J. E. Camp, "Synthesis of ureas in the bio-alternative solvent cyrene," Green Chemistry, vol. 19, no. 9, pp. 2123-2128, 2017.

[37] J. Zhang, G. B. White, M. D. Ryan, A. J. Hunt, and M. J. Katz, "Dihydrolevoglucosenone (cyrene) as a green alternative to $\mathrm{n}$, n-dimethylformamide (dmf) in mof synthesis," ACS Sustainable Chemistry \& Engineering, vol. 4 , no. 12, pp. 7186-7192, 2016.

[38] S. Lawrenson, M. North, F. Peigneguy, and A. Routledge, "Greener solvents for solid-phase synthesis," Green Chemistry, vol. 19, no. 4, pp. 952-962, 2017.

[39] G. Bonneau, A. A. Peru, A. L. Flourat, and F. Allais, “Organic solvent-and catalyst-free baeyer-villiger oxidation of levoglucosenone and dihydrolevoglucosenone (cyrene $\left.{ }^{\circledR}\right)$ : a sustainable route to (s)- $\gamma$ hydroxymethyl- $\alpha, \beta$-butenolide and (s)- $\gamma$-hydroxymethyl- $\gamma$-butyrolactone," Green chemistry, vol. 20, no. 11, pp. 2455-2458, 2018.

[40] M. De Bruyn, V. L. Budarin, A. Misefari, S. Shimizu, H. Fish, M. Cockett, A. J. Hunt, H. Hofstetter, B. M. Weckhuysen, J. H. Clark, et al., "Geminal diol of dihydrolevoglucosenone as a switchable hydrotrope: A continuum of green nanostructured solvents," ACS Sustainable Chemistry E Engineering, vol. 7, no. 8, pp. 7878-7883, 2019.

[41] H. J. Salavagione, J. Sherwood, V. Budarin, G. Ellis, J. Clark, P. Shuttleworth, et al., "Identification of high performance solvents for the sustainable processing of graphene," Green Chemistry, vol. 19, no. 11, pp. 2550-2560, 2017.

[42] F. Abushwireb, H. Elakrami, and M. Emtir, "Recovery of aromatics from pyrolysis gasoline by conventional and energy-integrated extractive distillation," Computer Aided Chemical Engineering, vol. 24, p. 1071, 2007.

[43] M. Blahušiak, A. A. Kiss, K. Babic, S. R. Kersten, G. Bargeman, and B. Schuur, "Insights into the selection and design of fluid separation processes," Separation and purification technology, vol. 194, pp. 301-318, 2018.

[44] R. B. Eldridge, “Olefin/paraffin separation technology: a review," Industrial E engineering chemistry research, vol. 32, no. 10, pp. 2208-2212, 1993.

[45] U. Weidlich, J. Gmehling, and A. M. U. Model, “1. prediction of vle, he, and gamma infinta dilution," Ind. Eng. Chem. Res, vol. 26, pp. 1372-1381, 1987.

[46] T. Brouwer and B. Schuur, "Model performances evaluated for infinite dilution activity coefficients pre- 


\section{BIOBASED ENTRAINERS FOR APOLAR SEPARATIONS}

diction at 298.15 k," Industrial \& Engineering Chemistry Research, vol. 58, no. 20, pp. 8903-8914, 2019.

[47] W. Srirachat, K. Maneeintr, U. Pancharoen, and S. Kheawhom, "Isobaric vapor-liquid equilibrium for binary system related to the organophosphoric extractant of d2ehpa + n-dodecane and tbp + n-dodecane at 0.13, 2.40 and $6.67 \mathrm{kpa}$," Vacuum, vol. 160, pp. $60-69,2019$.

[48] Q. Wang, J. Y. Chen, M. Pan, C. He, C. C. He, B. J. Zhang, and Q. L. Chen, "A new sulfolane aromatic extractive distillation process and optimization for better energy utilization," Chemical Engineering and Processing-Process Intensification, vol. 128, pp. 80-95, 2018.

[49] J. Coca and J. J. Pis, "Effect of morpholine on the vapor-liquid equilibrium of the system methylcyclohexane-toluene," Journal of Chemical and Engineering Data, vol. 24, no. 2, pp. 103-105, 1979.

[50] L. Berg, "Separation of toluene from non-aromatic hydrocarbons by extractive distillation," Dec. 141982. US Patent 4,363,704.

[51] M. Fenske, C. Carlson, and D. Quiggle, "Solvent separation of hydrocarbon mixtures by vapor-liquid extraction," Industrial \& Engineering Chemistry, vol. 39, no. 10, pp. 1322-1328, 1947.

[52] C. Buell and R. Boatright, "Furfural extractive distillation," Industrial \& Engineering Chemistry, vol. 39, no. 6, pp. 695-705, 1947.

[53] G. R. Lake, “Separation of hydrocarbons by distillation," Aug. 27 1946. US Patent 2,406,695.

[54] D. Quiggle and M. R. Fenske, "Vapor-liquid equilibria of methylcyclohexane-toluene mixtures," Journal of the American Chemical Society, vol. 59, no. 10, pp. 1829-1832, 1937.

[55] T. Banerjee, M. K. Singh, R. K. Sahoo, and A. Khanna, "Volume, surface and uniquac interaction parameters for imidazolium based ionic liquids via polarizable continuum model," Fluid Phase Equilibria, vol. 234, no. 1-2, pp. 64-76, 2005.

[56] D. Chen, $\mathrm{H}$. Ye, and $\mathrm{H}$. Wu, "Liquid-liquid equilibria of methylcyclohexane-benzene-nformylmorpholine at several temperatures," Fluid phase equilibria, vol. 255, no. 2, pp. 115-120, 2007.

[57] S. Gupta, B. Rawat, A. Goswami, S. Nanoti, and R. Krishna, "Isobaric vapour-liquid equilibria of the systems: Benzene-triethylene glycol, toluene-triethylene glycol and benzene-n-methylpyrrolidone," Fluid phase equilibria, vol. 46, no. 1, pp. 95-102, 1989.

[58] Z. S. Baird, P. Uusi-Kyyny, J.-P. Pokki, E. Pedegert, and V. Alopaeus, "Vapor pressures, densities, and pc-saft parameters for 11 bio-compounds," International Journal of Thermophysics, vol. 40, no. 11, p. 102, 2019.

[59] W. L. McCabe, J. C. Smith, and P. Harriott, Unit operations of chemical engineering, vol. 5. McGraw-hill New York, 1967.

[60] J. V. de Oliveira and A. C. Uller, "Solubility of 1, 3-butadiene and methyl propene in n-methyl-2pyrrolidone," Fluid phase equilibria, vol. 46, no. 2-3, pp. 267-280, 1989.

[61] J. V. de Oliveira and A. C. Uller, "Solubility of pure 1, 3 butadiene and methyl propene and their mixtures in pure n-methyl-2-pyrrolidone and in its aqueous solutions," Fluid phase equilibria, vol. 118, no. 1, pp. 133-141, 1996.

[62] L. Malley, G. Kennedy, G. Elliott, T. Slone, W. Mellert, K. Deckardt, K. Kuttler, B. Hildebrand, M. Banton, R. Parod, et al., "Chronic toxicity and oncogenicity of $\mathrm{n}$-methylpyrrolidone (nmp) in rats and mice by dietary administration," Drug and chemical toxicology, vol. 24, no. 4, pp. 315-338, 2001. 




\subsection{Introduction}

Distillation is the workhorse of the chemical industry as it can separate many, complex, mixtures with high efficiencies. ${ }^{1,2}$ However, the efficiency of a traditional distillation column is reduced by non-ideal behavior, such as a pinchpoint, or even made infeasible when an azeotrope is present. Improving the efficiency of these distillation operations can be achieved by smart de$\operatorname{sign}^{3,4}$ and/or by the addition of a solvent that can break the azeotrope and/or remove the pinch point. Enhancing the distillation technique with a solvent has been done throughout the years and is called either extractive or azeotropic distillation, where the solvent in extractive distillation is typically high-boiling and in azeotropic distillation typically low-boiling. ${ }^{5}$ Common examples for extractive distillation are the separation of aliphatic and aromatic compounds with Sulfolane ${ }^{6}$ and the separation of olefin and paraffins with n-methylpyrrolidone (NMP). ${ }^{7}$ Azeotropic distillation is applied for example to dehydration of alcohol with benzene ${ }^{8,9}$ and acetic acid dehydration with ethyl acetate. ${ }^{10,11}$

To facilitate enhanced solvent-based distillations such as extractive distillation while omitting the use of toxic solvents, there is a need for more benign alternative solvents. Recently, we have reported the use of biobased solvent Cyrene for extractive distillation of distilling unsaturated hydrocarbons from saturated hydrocarbons. ${ }^{12}$ Not only in apolar hydrocarbon mixtures, but also in polar mixtures azeotropes occur, and solvents are needed to fully fractionate azeotropic mixtures. We report here a study on the use of alternative solvents produced from sustainable, biobased feedstocks for the separation of acetone and diisopropyl ether. This separation is relevant in the industrial process of catalytic dehydrogenation of 2-propanol to produce acetone. ${ }^{13} \mathrm{~A}$ side-reaction herein is the dehydration of 2-propanol to diisopropyl ether, ${ }^{14}$ and the removal of diisopropyl ether from the acetone product is challenging as an azeotrope is present. ${ }^{14}$

In the case of acetone $\left(\mathrm{bp}=56^{\circ} \mathrm{C}\right)$ and diisopropyl ether $\left(\mathrm{bp}=69^{\circ} \mathrm{C}\right)$, a temperature-minimum, or positive, azeotrope is present. This means that the vapor pressure of the high boiling compound (diisopropyl ether) is higher than in the ideal situation and a positive deviation is observed from Raoult's 
law. ${ }^{15,16}$ This is due to the fact diisopropyl ether has a larger tendency to enter the vapor phase, a consequence of net repulsive intermolecular interactions which is mathematically described with a $\gamma_{i}>1$.

Since both compounds are polar but not protic, this case study adds to the series of studies we completed earlier on the more apolar systems, ${ }^{17}$ on mixtures of hydrogen bond donating and hydrogen bond accepting groups ${ }^{18}$ and the highly polar and highly hydrogen bond donating systems of carboxylic acids. ${ }^{17,18}$ In Figure 8.1, the molecular structures of acetone and diisopropyl ether are shown.
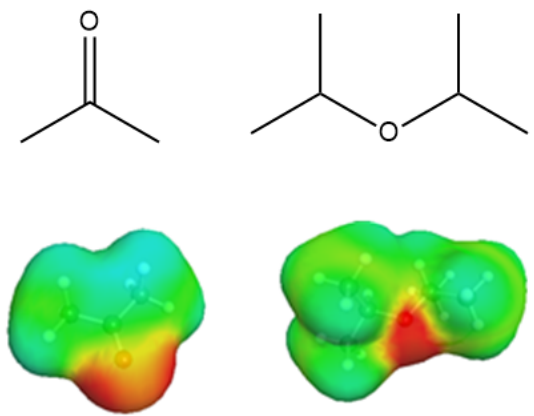

Figure 8.1: The molecular structures acetone and diisopropyl ether. The electron density profiles of the 3D-molecule rendering was done with COSMOthermX C30_1705 using the TZVP-parameterization

Generally, multiple inter- and intramolecular interactions may occur in mixtures, ranging from strong hydrogen bonds to dipole interactions and dispersive, London, interactions. ${ }^{19}$ Within the binary mixture of acetone and diisopropyl ether (or more generally in ether and ketone systems), no hydrogen bonds are possible, though dipole interactions occur between the ketone and ether molecules, but also between the ketones molecules and between ether molecules. These dipole interactions are strongly related to the dipole moment of the compounds. Due to the fact, the dipole moment of acetone $\left(3.68 \mathrm{D}^{20}\right)$ is much larger compared to diisopropyl ether $\left(1.13 \mathrm{D}^{21}\right)$, acetone molecules will preferentially interact with themselves, hence diisopropyl ether will tend to escape a phase with primarily acetone molecules. 
This is the reason that the positive azeotrope in the system occurs at higher acetone concentrations. The addition of a solvent can either introduce more dipole interactions (a polar aprotic solvent), can introduce more dipole interactions and hydrogen bond interactions (a polar protic solvent) or can reduce the relative extent of dipole interactions (apolar solvent).

In Figure 8.2, an overview has been presented where the solvent affinity is mapped within ketone and ether mixtures. ${ }^{14,22-27}$ The solvent effect on the two aprotic polar compounds, or more specifically between a ketone and ether, is assessed in several combinations. Overall, oxygenated solvents such as alcohols, ${ }^{22,23}$ butyronitrile ${ }^{28}$ and ketones ${ }^{25,28}$ have more affinity towards the ketone than the ether. This is due to the fact these solvents have dipole moments and/or hydrogen bonding donating capabilities, which preferentially interact with the larger dipole moment of acetone.
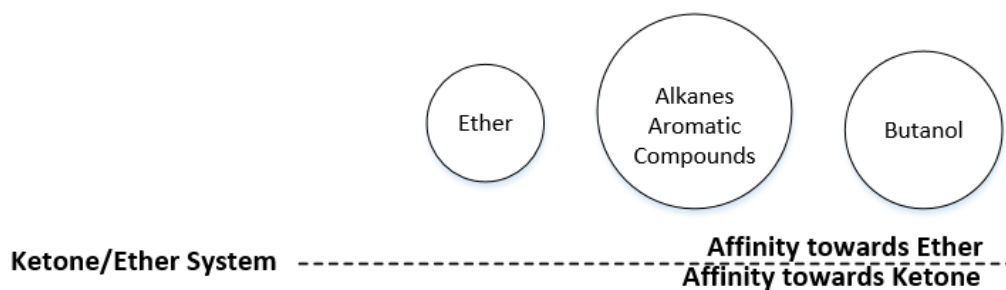

Affinity towards Ether Áffinity towards Kètone
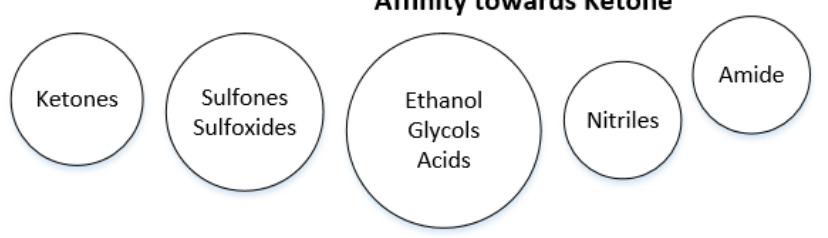

Figure 8.2: The qualitative literature overview of solvent effects in vapor-liquid equilibria concerning two aprotic compounds (ketones and ethers) ${ }^{14,22-27}$. The positioning is not on scale and relative to the other class.

n-Butanol is observed to have the opposite affinity, due to the long hydrocarbon tail. ${ }^{28}$ Observations by Berg et al. ${ }^{14}$ are similar, as they propose nitriles, alcohols, glycols, dimethylsulfoxide (DMSO), Sulfolane, n,n-dimethylformamide and combinations thereof as possible ketone entrainers. Additionally, Zhao 
simulated the extractive distillation of diisopropyl ether and acetone with ethylene glycol as entrainer as part of a larger Hybrid Azeotropic-Extractive Distillation process. ${ }^{29}$ Apolar solvents such as alkanes, ${ }^{26,27,30}$ ethers ${ }^{28}$ and aromatic compounds ${ }^{28}$ have more affinity towards ethers, because these solvents are structurally more similar to ethers. They do not possess (large) dipole moment, and dispersive interactions are predominant. By the addition of these solvents, the relative extent of the dipole interactions is reduced, which lowers the net repulsive interactions toward diisopropyl ether. Consequently, the ethers are entrained instead of the ketone molecules.

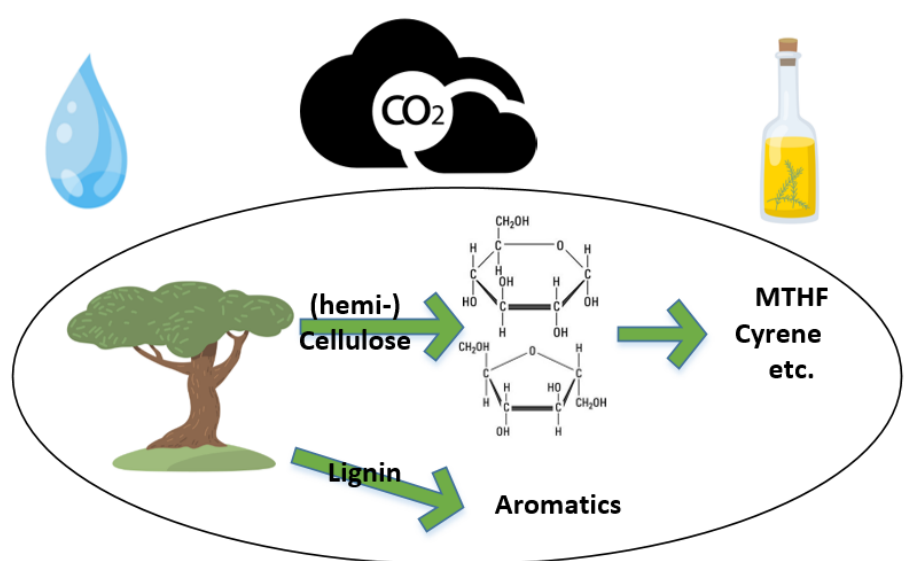

Figure 8.3: A graphical presentation of sustainable recourses, such as water, (atmospheric or captures) $\mathrm{CO}_{2}$, natural oils and lignocellulosic materials where (hemi-)cellulose can be converted to pentose $\left(C_{5}\right)$, hexose $\left(C_{6}\right)$ sugars and consequently in biobased molecules such as 2-methyltetrahydrofuran (MTHF) and Cyrene, and lignin can be converted to aromatics.

It thus appears that many solvent classes can possibly break the azeotrope in the acetone/diisopropyl ether mixture. Here, we report our studies aiming to find solvents that can break the azeotrope, and also can be made from sustainable resources. Several bio-based sources are available, such as natural oils, lignocelullosic materials, of which sugars and lignin can be obtained, (atmospheric or captured) $\mathrm{CO}_{2}$ and water, see Figure 8.3. Biobased solvents are for example, DL-limonene which can be obtained from natural oils present in citrus peel or fruit juices ${ }^{31}$, already has annual commercial production of 
$60 \mathrm{kton} /$ year and costs about $9-10 \$ / \mathrm{kg}^{32}$ and ethylene carbonate which can be synthesized using waste $\mathrm{CO}_{2}$ emissions over a heterogeneous catalyst. ${ }^{33,34}$ These two, but also many other biobased chemicals, have been assessed in this work for the separation of acetone and diisopropyl ether using extractive distillation.

\subsection{Theory}

A key parameter in the assessment and design of distillation columns is the relative volatility $\left(\alpha_{i j}\right)$. This parameter describes the relative tendency of the components in the mixture to escape the liquid phase and enter the vapor phase. In Equation 8.1, the mathematical description can be seen where the $\alpha_{i j}$ is the product of the non-ideal part $\left(\frac{\gamma_{i}}{\gamma_{j}}\right)$ and the ideal part $\left(\frac{P_{i}^{0}}{P_{j}^{0}}\right) \cdot{ }^{5}$

$$
\alpha_{i j}=\frac{\gamma_{i} P_{i}^{0}}{\gamma_{j} P_{i}^{0}}
$$

The activity coefficients $\left(\gamma_{i}\right)$ are indicative of the intermolecular interactions within the mixture and describe either net attractive interactions $\left(\gamma_{i}<1\right)$ or repulsive interactions $\left(\gamma_{i}>1\right)$ between the solute $\mathrm{i}$ and the solvent. The ideal part is comprised of the ratio of the pure component vapor pressures $\left(P_{i}^{o}\right)$ of both compounds. The addition of a solvent changes the activity coefficients and consequently alters the relative volatility. Although the vapor phase fugacity coefficients $\left(\varphi_{i}\right)$ are also present in the non-ideal part of Equation 8.1, these parameters approach 1 for the molecules considered in this study at atmospheric pressures and will therefore be neglected from now on.

\subsection{Thermodynamic models}

Next to the experimental evaluation of the biobased solvents, also the performance of a state-of-the-art predictive method, namely modified Dortmund UNIFAC, ${ }^{35}$ was performed during the solvent screening. This method is a group contribution method (GCM) which predicts the activity coefficients via the sum of a combinatorial $\left(\gamma_{i}^{c}\right)$ and a residual term $\left(\gamma_{i}^{R}\right)$. The combinatorial 
term uses the Guggenheim-Stavermann term, ${ }^{36}$ and the residual term. Details of the modified Dortmund UNIFAC mathimatical framework is present in Appendix, section 12.2. This framework requires the determination of the $\phi, \phi^{\prime}$ and $\theta$ which are respectively the volume-, modified volume- and surface fractions. Additionally, $\Gamma_{k}, \Gamma_{k}^{(i)}, v_{k}^{(i)}, Q_{k}, R_{k}$ and $\Psi_{n m}$ are respectively the overall activity of moiety $\mathrm{k}$, the overall activity of moiety $\mathrm{k}$ solely surrounded by moiety $i$, the occurrence of each moiety $k$ in surrounded by moiety $i$, the Van der Waals volume of group $\mathrm{k}$, the Van der Waals surface of group $\mathrm{k}$ and the group binary interaction parameter which may include temperature (in)dependent parameters $\left(a_{n m}, b_{n m}\right.$ and $\left.c_{n m}\right) .{ }^{35,37,38}$ The coordination number $(q)$ is often set at 10 .

The experimentally determined (quasi-) binary vapor-liquid equilibria were fitted with the UNIQUAC and Non-Random Two-Liquid (NRTL) model. The UNIQUAC model uses the same mathematical framework, though the molecular volume $\left(q_{k}\right)$ and molecular surface $\left(r_{k}\right)$ parameters are fixed from literature values or estimations, ${ }^{39}$ and binary interaction parameters are fitted instead of estimated via the group contribution method. The molecular volume and surface parameters are $\mathrm{q}=2.34$ and $\mathrm{r}=2.57$ [44] for acetone ${ }^{40}, \mathrm{q}=$ 4.088 and $r=4.7421$ for diisopropyl ether ${ }^{41}$, and $q=5.592$ and $r=6.736$ for DL-limonene. ${ }^{42}$

The NRTL model was developed by Renon and Prausnitz, ${ }^{43}$ which replaced the Flory-Huggins ${ }^{44,45}$ volumetric expression within modified the Wilson equation ${ }^{46}$ to the local composition theory which is similar to the quasichemical theory of Guggenheim. ${ }^{47}$ This resulted in, equations 8 to 10;

$$
\begin{gathered}
\ln \gamma_{i}=\frac{\sum_{j} x_{j} \tau_{j i} G_{j i}}{\sum_{k} x_{k} G_{k i}}+\sum_{j} \frac{x_{j} G_{i j}}{\sum_{k} x_{k} G_{k j}}\left(\tau_{i j}-\frac{\sum_{m} x_{m} \tau_{m j} G_{m j}}{\sum_{k} x_{k} G_{k j}}\right) \\
\ln G_{i j}=-\alpha_{i j} \tau_{i j} \\
\tau_{i j}=a_{i j}+\frac{b_{i j}}{T}+\frac{c_{i j}}{T^{2}}
\end{gathered}
$$

Where the non-randomness factors, $a_{i j}$, are generally set equal to $0.2,0.3$ or 0.45 to represent physically feasible values and to predict multi-component 
systems from their binaries. ${ }^{48}$ The dimensionless interaction parameter $\tau_{i j}$ may include temperature (in)dependent parameters $\left(a_{i j}, b_{i j}\right.$ and $\left.c_{i j}\right)$. The temperature-dependent vapor pressures located in the Aspen Plus ${ }^{\circledR}$ V10 Databank were used for acetone and diisopropyl ether, while experimental temperature-dependent vapor pressures of D-limonene was used. ${ }^{49}$

\subsection{Materials and Methods}

\subsubsection{Chemicals}

In this work, the diisopropyl ether (Emsure, ACS, Reag. Ph. Eur.) and acetone (LiChrosolv) were both purchased at Merck. 2-Butanone (Emplura), ethylene glycol (Emsure, Reag.Ph.Eur), 2-methyltetrahydrofuran (Emplura), methanol (LiChrosolv), ethanol (Emsure) and DL-Limonene ( $\geq 95 \%)$ were purchased at Merck. Sigma Aldrich supplied the solvents Sulfolane (99\%), propylene glycol ( $\geq 99.5 \%)$, propionic acid $(\geq 99.5 \%)$, guaiacol ( $\geq 99 \%)$, ethylene carbonate $(98 \%)$, phenol $(\geq 99 \%)$, furfural $(99 \%)$, acetophenone (99\%), isophorone $(97 \%)$, vanillin $(\geq 97 \%)$, catechol $(\geq 99 \%)$, acetic acid ( $\geq 99 \%)$, dimethylsulfoxide ( $\geq 99.9 \%)$, ethyl acetate $(99.9 \%)$, n-butanol ( $\geq 99.4 \%)$, 4-methyl-2pentanone ( $\geq 98.5 \%)$, n-pentanol $(\geq 99.9 \%)$, ethyl levulinate $(99 \%)$, cumene $(98 \%)$ and glycerol $(\geq 99 \%)$. Acros Organics provided $\gamma$-valerolactone $(98 \%)$, levulinic acid $(98+\%)$, triacetin $(99 \%)$, tributyl phosphate $(99+\%)$, while 2-propanol (LC-MS ChromaSolv) and 2-methyl-2-propanol ( $\geq 99.7 \%)$ were purchased at Fluka. p-Xylene was bought at VWR chemicals, and Cyrene was provided by the Circa Group. MilliQ water was additionally used.

\subsubsection{Experimental Methods}

The measurements were carried out using 2 Fischer Labodest VLE602 ebulliometers where the pressure was controlled. Each mixture, comprised of the binary system and (optionally) a solvent, was introduced in the ebulliometer and consequently 1000 mbar was set. The temperature was tracked, and the mixture was left to equilibrate for approximately $60 \mathrm{~min}$. A total amount of $85 \pm 5$ grams liquid was needed in the ebulliometer to guarantee sufficient liquid and vapor flow through the set-up. An aliquot of 0.5-1.0 mL of liquid sample was collected of the liquid and condensed vapor flow. If a solvent 
was used, a solvent to feed ratio of 1 (on a mass basis) was kept constant, and the VLE diagrams were displayed as pseudo-binary system, where the compositions of acetone and diisopropyl ether sum up to unity. The (near) azeotropic composition of the diisopropyl ether/acetone system at 16/84 mol $\%$ was used.

\subsubsection{Analysis}

A Thermo Scientific Trace 1300 gas chromatograph with two parallel ovens and an autosampler TriPlus 100 Liquid Samples were used for the analyses. All samples were analyzed using an Agilent DB-WAX column $(60 \mathrm{~m} \times$ $0.25 \mathrm{~mm} \times 0.25 \mu \mathrm{m})$ with an injection volume of $1 \mu \mathrm{l}$. The system of acetone/diisopropyl ether was diluted in analytical ethanol. A TCD detector (with $200^{\circ} \mathrm{C}$ ) and a ramped temperature profile were used, following the program in which the initial temperature was $30^{\circ} \mathrm{C}$, starting immediately after injection with a ramp of $10^{\circ} \mathrm{C} / \mathrm{min}$ to $60^{\circ} \mathrm{C}$, followed by a second ramp of 5 ${ }^{\circ} \mathrm{C} / \mathrm{min}$ to $80^{\circ} \mathrm{C}$ and a third ramp of $50^{\circ} \mathrm{C} / \mathrm{min}$ to $250^{\circ} \mathrm{C}$ with a $2 \mathrm{~min}$ hold on the final temperature which finished the program, which lasts $15 \mathrm{~min}$. A column flow of $2 \mathrm{ml} / \mathrm{min}$ with a split ratio of 100 , an airflow of $350 \mathrm{ml} / \mathrm{min}$, a helium make-up flow of $40 \mathrm{ml} / \mathrm{min}$ and a hydrogen flow of $35 \mathrm{ml} / \mathrm{min}$ was used.

\subsection{Results}

\subsubsection{Relative Volatility Screening near azeotropic composition}

The separation of acetone and diisopropyl ether was screened in this section. At a single composition containing 16 mol.\% diisopropyl ether, the effect of 35 (biobased) solvents were evaluated (the results are displayed in Figure 8.4). This composition was chosen as this is (near) the azeotropic inflection point of the binary mixture, and in this situation, both components are (almost) equally volatile. Near the azeotropic point, the majority of the polar solvents enhance the relative volatility of diisopropyl ether, as can be seen in Figure 8.4. Diisopropyl ether relative volatility increase is due to hydrogen bonds and/or stronger dipole-dipole interactions of these solvents with acetone compared to diisopropyl ether, which lowers the acetone activity coef- 


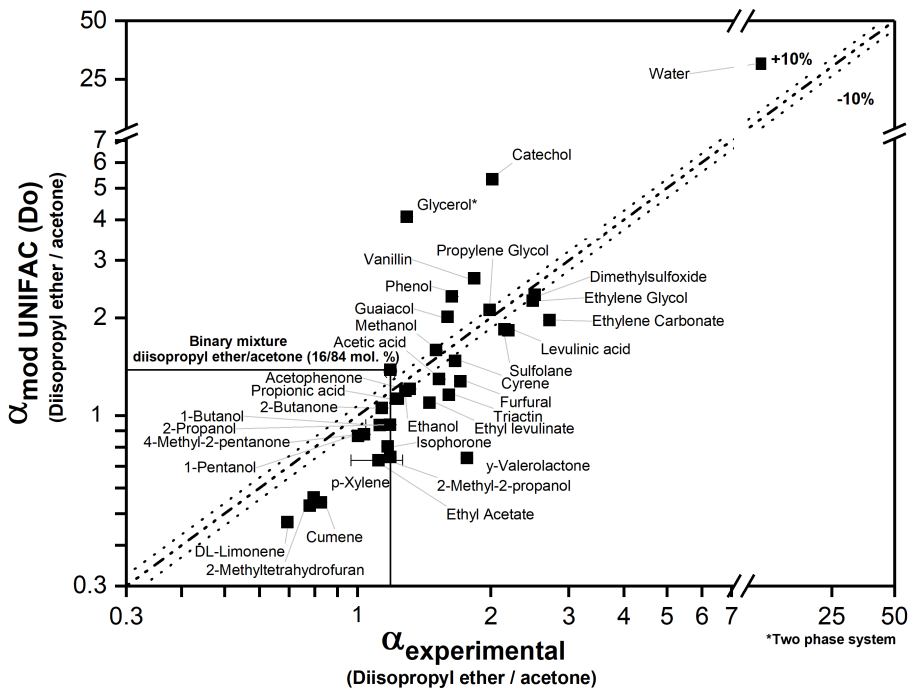

Figure 8.4: The screening of 35 (biobased) solvent for the extractive Distillation of diisopropyl ether/acetone (16/84 mol. \%) with a S:F ratio (mass based) of 1 at $1000 \mathrm{mbar}$. The experimental relative volatility is depicted on the $x$-axis, while the predicted relative volatility is depicted on the $y$-axis.

ficient more than that of diisopropyl ether. Water, dimethylsulfoxide, ethylene glycol and ethylene carbonate are experimentally shown to induce the largest relative volatility towards diisopropyl ether. Mod. UNIFAC (Do) can be seen in Figure 8.4 to generally underpredict the relative volatility increases of diisopropyl ether over acetone with apolar solvents. The relative volatility increase of diisopropyl ether over acetone is overpredicted for the multifunctional glycerol and catechol solvents, and water as solvent. The effect of various solvents on the relative volatility of acetone and diisopropyl ether are predicted generally to exceed $10 \%$ deviation.

Ethylene glycol has already been shown to be an adequate entrainer, ${ }^{14}$ while dimethylsulfoxide is not preferred due to its toxicity ${ }^{50}$ and auto-catalytic decomposition tendency ${ }^{51}$. Hence, water and ethylene carbonate are potential biobased solvents to distill diisopropyl ether as the top product. Apolar solvents were found to repel acetone, reversing the natural boiling point order. 
The most effective biobased apolar solvent is observed to be DL-limonene, although also cumene, 2-methyl tetrahydrofuran and p-xylene show similar effect, entraining diisopropyl ether. From the large variety of biobased solvents that have been assessed, several are less preferred due to possible recovery difficulties resulting from their boiling point. Recovery difficulties can be minimized by applying a solvent with a boiling point 40 to $50^{\circ} \mathrm{C}$ higher than the highest boiling solute. ${ }^{52}$ These solvents include 2 -methyltetrahydrofuran (bp: $\left.80^{\circ} \mathrm{C}\right)$, ethanol $\left(78^{\circ} \mathrm{C}\right)$, ethyl acetate $\left(77^{\circ} \mathrm{C}\right), 2$-propanol $\left(83^{\circ} \mathrm{C}\right)$, 2-butanone $\left(80^{\circ} \mathrm{C}\right)$, 2-methyl-2-propanol or tert-butanol $\left(83^{\circ} \mathrm{C}\right)$ and methanol $\left(64.7^{\circ} \mathrm{C}\right)$. Excluding these, only DL-limonene and ethylene carbonate pass the boiling point criterion. Nevertheless, water is also evaluated as a potential, biobased entrainer for this separation. This was done as it allows a comparison of three solvents which either are inept in hydrogen bonding (DL-limonene), is a hydrogen bond acceptor (ethylene carbonate) or a hydrogen bond donor and acceptor (water). For a complete process design and optimization of process conditions, full phase equilibria (vapor-liquid (VL) and liquid-liquid (LL)) that need to be determined. ${ }^{53}$ Only the vapor-liquid equilibria of the selected solvents will be further discussed in the next section, hence the complete liquid-liquid equilibria of these solvents are kept out of the scope.

\subsubsection{Vapor-Liquid Equilibria of Diisopropyl ether - Acetone - Ethylene Carbonate/DL-Limonene/water}

In Figure 8.5, the (pseudo) binary vapor-liquid equilibria of acetone, diisopropyl ether and optionally a solvent is shown. It was also attempted to fit NRTL and UNIQUAC equations, which unfortunately was not successful for some systems due to (partial) immiscibility of diisopropyl ether with ethylene carbonate and water. From an extractive distillation perspective liquid phase splitting is unwanted. For the systems where good correlations with the experimental data were found, the found parameters are shown in Table 8.1. Around the azeotropic point, it can indeed be seen that water and ethylene carbonate induce significant relative volatility towards diisopropyl ether.

Unfortunately, the intense induced non-ideality does not eliminate the azeotrope, but shifts the azeotrope towards lower acetone fractions. This is a consequence of repelling the high boiling compound, diisopropyl ether, to a greater extent than the lower boiling compound, acetone. This is seen at 


\section{BIOBASED ENTRAINERS FOR POLAR SEPARATIONS}
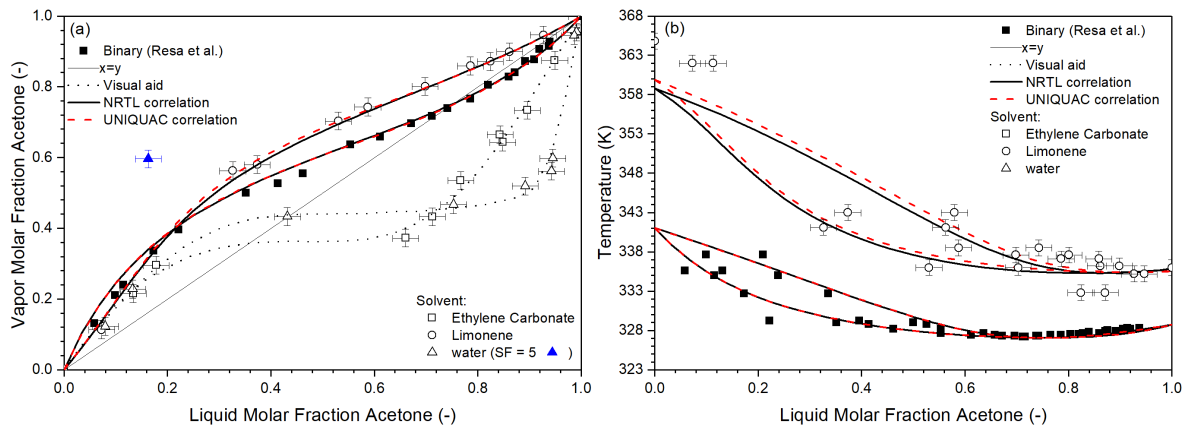

Figure 8.5: The (a) $x y$-and (b) Txy-diagrams of the (Quasi-) binary vapor-liquid equilibria of diisopropyl ether and acetone with a S:F ratio (mass based) of 1 (or 5) at 1000 mbar with the solvents, ethylene carbonate, DL-limonene and water. The standard deviation is determined by an experimental duplicate measurement. The NRTL and UNIQUAC correlations for the binary and DL-limonene system are present in Table 8.1, while visual aid guide-lines are added for the ternary systems with water and ethylene carbonate. All experimental data is present in Table 8.2.

Table 8.1: The NRTL and UNIQUAC parameters of the binary acetone-diisopropyl ether (DIPE) and the solvent DL-limonene

\begin{tabular}{|c|c|c|c|c|c|c|}
\hline \multicolumn{7}{|c|}{ NRTL } \\
\hline Compound i & Compound j & $A_{i j}$ & $A_{j i}$ & $B_{i j}$ & $B_{j i}$ & $C_{i j} / \alpha_{i j}$ \\
\hline Acetone & DIPE & 0,5686 & 0,3931 & 2,0750 & $-0,4741$ & 0,5 \\
\hline Acetone & \multirow{2}{*}{ DL-Limonene } & $-24,531$ & 31,709 & 8362,2 & -10000 & 0,3 \\
\hline DIPE & & $-9,7604$ & $-4,6236$ & 4057,3 & 1221 & 0,2 \\
\hline \multicolumn{7}{|c|}{ UNIQUAC } \\
\hline Compound i & Compound $\mathrm{j}$ & $\overline{A_{i j}}$ & $A_{j i}$ & $B_{i j}$ & \multicolumn{2}{|c|}{$B_{j i}$} \\
\hline Acetone & DIPE & 0,18578 & $-0,3263$ & 8,0123 & \multicolumn{2}{|c|}{$-105,86$} \\
\hline Acetone & \multirow{2}{*}{ DL-Limonene } & $-6,83415$ & 17,7539 & 2431,1 & \multicolumn{2}{|c|}{$-6447,1$} \\
\hline DIPE & & 0,1655 & 4,995 & 163,27 & \multicolumn{2}{|c|}{-213057} \\
\hline
\end{tabular}

${ }^{*}$ No adequate NRTL and UNIQUAC correlation could be obtained with ethylene carbonate and water, due to the (partial) immiscibility of diisopropyl ether in these solvents. The root-mean-square deviation of all liquidand vapor fractions within the ternary system is $7.6 \cdot 10^{-3}$ and $4.9 \cdot 10^{-3}$ for respectively the NRTL and UNIQUAC correlations.

a solvent to feed (S:F) ratio of 1 (on a mass basis). In the case of water as a solvent, applying a S:F ratio of 5 increases the relative volatility towards ace- 
tone at $\sim 20 \mathrm{~mol} \%$ acetone, though still an azeotrope may be present as water is shown to repel diisopropyl ether, which is more pronounced at higher acetone molar fractions.

Table 8.2: The pseudo binary liquid and vapor molar fractions at $1000 \mathrm{mbar}$ for the acetone (1), diisopropyl ether (2), and the solvent DL-limonene, ethylene carbonate and water. From a duplicate measurement it was found that the experimental standard deviation in the concentration is $2.5 \mathrm{~mol} . \%$

Solvent: DL-limonene

\begin{tabular}{|c|c|c|c|c|}
\hline$x_{1}$ & $x_{2}$ & $y_{1}$ & $y_{2}$ & $\mathrm{~T}(\mathrm{~K})$ \\
\hline 0,659 & 0,000 & 0,984 & 0,000 & 336,15 \\
\hline 0,630 & 0,050 & 0,935 & 0,053 & 335,35 \\
\hline 0,559 & 0,090 & 0,888 & 0,100 & 336,35 \\
\hline 0,476 & 0,130 & 0,848 & 0,139 & 337,25 \\
\hline 0,430 & 0,186 & 0,791 & 0,196 & 337,75 \\
\hline 0,346 & 0,243 & 0,733 & 0,254 & 338,65 \\
\hline 0,333 & 0,295 & 0,692 & 0,293 & 336,15 \\
\hline 0,216 & 0,362 & 0,570 & 0,414 & 343,15 \\
\hline 0,198 & 0,409 & 0,552 & 0,429 & 341,25 \\
\hline 0,038 & 0,486 & 0,110 & 0,862 & 362,15 \\
\hline 0,000 & 0,504 & 0,000 & 0,964 & 364,95 \\
\hline
\end{tabular}

Solvent: water

\begin{tabular}{|c|c|c|c|c|}
\hline$x_{1}$ & $x_{2}$ & $y_{1}$ & $y_{2}$ & $\mathrm{~T}(\mathrm{~K})$ \\
\hline 0,257 & 0,000 & 0,782 & 0,000 & 336,55 \\
\hline 0,210 & 0,002 & 0,759 & 0,036 & 337,05 \\
\hline 0,176 & 0,002 & 0,754 & 0,044 & 337,65 \\
\hline 0,163 & 0,010 & 0,487 & 0,381 & 327,05 \\
\hline 0,160 & 0,019 & 0,452 & 0,418 & 327,15 \\
\hline 0,131 & 0,043 & 0,416 & 0,474 & 327,75 \\
\hline 0,077 & 0,102 & 0,378 & 0,496 & 328,15 \\
\hline 0,023 & 0,148 & 0,207 & 0,700 & 331,25 \\
\hline 0,012 & 0,142 & 0,093 & 0,668 & 332,55 \\
\hline 0,000 & 0,149 & 0,000 & 0,917 & 334,75 \\
\hline
\end{tabular}

Solvent: Ethylene Carbonate

\begin{tabular}{|c|c|c|c|c|}
\hline$x_{1}$ & $x_{2}$ & $y_{1}$ & $y_{2}$ & $\mathrm{~T}(\mathrm{~K})$ \\
\hline 0,608 & 0,000 & 1,000 & 0,000 & 342,25 \\
\hline 0,558 & 0,030 & 0,874 & 0,126 & 341,55 \\
\hline 0,517 & 0,060 & 0,733 & 0,267 & 338,95 \\
\hline 0,453 & 0,081 & 0,643 & 0,357 & 338,45 \\
\hline 0,440 & 0,134 & 0,535 & 0,465 & 336,05 \\
\hline 0,392 & 0,158 & 0,433 & 0,567 & 335,05 \\
\hline 0,317 & 0,163 & 0,372 & 0,628 & 335,05 \\
\hline 0,087 & 0,400 & 0,295 & 0,705 & 336,05 \\
\hline 0,064 & 0,416 & 0,216 & 0,784 & 337,65 \\
\hline
\end{tabular}

DL-limonene is capable of breaking the azeotrope at this S:F ratio, by repelling the low boiling acetone more than the high boiling diisopropyl ether, though a pinch-point remains. At room temperature DL-limonene is miscible with acetone $^{54}$ and was also seen, during experimentation, to be miscible with the 
less polar DIPE. This was also seen in the NRTL and UNIQUAC correlations in which the activity coefficient of both solutes are above unity and the ratio of the activity coefficients $\left(\gamma_{\text {acetone }} / \gamma_{\text {DIPE }}\right)$ were at an equimolar ratio resp. 1.19 and 1.21. Also it has been shown by Pakdel et al. ${ }^{55}$ that DL-limonene is stable up to $210^{\circ} \mathrm{C}$, and only decomposes around $450^{\circ} \mathrm{C}$ which is much higher than the distillation temperature. The solvent to feed ratio was kept constant on mass basis which is a fair comparison on industrial level, but has implication on a molecular level. Smaller solvents (water) will be much more abundant than larger solvents (ethylene carbonate). Hence, a direct comparison of intermolecular interactions is not appropriate between the solvents.

\subsection{Conclusion}

The industrial separation of two aprotic polar compounds, acetone and diisopropyl ether, via extractive distillation was evaluated. After a literature overview, where it was seen that polar hydrogen-bonding solvents have more affinity towards the more dipolar aprotic polar compounds (acetone) compared to the less polar aprotic compounds (diisopropyl ether), while apolar solvents entrain the less polar diisopropyl ether. In the acetone/diisopropyl ether separation, water and ethylene carbonate induce the largest relative volatility towards diisopropyl ether near the binary azeotropic point, while DL-limonene induces the largest relative volatility towards acetone. In the full (quasi-) binary vapor-liquid equilibrium, the azeotrope was only broken by the DL-limonene since it was selectively repelling the low boiling compound (acetone) instead of the other solvents, though a pinch-point remains. This shows that experimentally determining the solvent effect at the azeotropic point is not sufficient to assess the performance of the solvent, as the azeotrope can shift towards lower low boiling solute fractions if the heavy boiling compound is selectively repelled by the solvent. DL-limonene was found to be most adequate as a biobased azeotrope breaker for the acetone/diisopropyl ether system. 


\subsection{Nomenclature}

\begin{tabular}{|c|c|c|}
\hline$\alpha_{i j}$ & $=$ & Relative Volatility \\
\hline$\alpha_{i j}$ & $=$ & Non-Randomness factor \\
\hline $\mathrm{a}_{n m}$ or $\mathrm{a}_{i j}$ & $=$ & $\begin{array}{l}\text { Temperature independent interaction parame- } \\
\text { ter }\end{array}$ \\
\hline $\mathrm{b}_{n m}$ or $\mathrm{b}_{i j}$ & $=$ & Temperature dependent interaction parameter \\
\hline Bp & $=$ & Boiling point \\
\hline $\mathrm{c}_{n m}$ or $\mathrm{c}_{i j}$ & $=$ & Temperature dependent interaction parameter \\
\hline$\gamma_{i}$ & $=$ & Activity coefficient of compound i \\
\hline$\gamma_{i}^{c}$ & $=$ & $\begin{array}{l}\text { Combinatorial term of the activity coefficient of } \\
\text { compound i }\end{array}$ \\
\hline$\gamma_{i}^{R}$ & $=$ & $\begin{array}{l}\text { Residual term of the activity coefficient of com- } \\
\text { pound i }\end{array}$ \\
\hline DMSO & $=$ & Dimethylsulfoxide \\
\hline mod. UNIFAC (Do) & $=$ & $\begin{array}{l}\text { Modified UNIQUAC Functional-group Activity } \\
\text { Coefficient Dortmund }\end{array}$ \\
\hline MTHF & $=$ & 2-Methyltetrahydrofuran \\
\hline NMP & $=$ & n-Methylpyrrolidone \\
\hline NRTL & $=$ & Non-Random Two-Liquid Model \\
\hline$v_{k}^{(i)}$ & $=$ & $\begin{array}{l}\text { Occurrence of each moiety } k \text { in surrounded by } \\
\text { moiety } i\end{array}$ \\
\hline$\phi$ & $=$ & Volume fraction \\
\hline$\phi^{\prime}$ & $=$ & Modified volume fraction \\
\hline$\Phi_{k}$ & $=$ & Overall activity of moiety $\mathrm{k}$ \\
\hline$\Phi_{k}^{(i)}$ & $=$ & $\begin{array}{l}\text { Activity of moiety k solely surrounded by moi- } \\
\text { ety i }\end{array}$ \\
\hline$P_{i}^{o}$ & $=$ & Vapor pressure of compound i \\
\hline$\Psi_{n m}$ & $=$ & Group binary interaction parameter \\
\hline$q_{i}$ & $=$ & Coordination number (general equal to 10 ) \\
\hline$Q_{k}$ or $q_{i}$ & $=$ & Van der Waals volume of group $\mathrm{k}$ or molecule i \\
\hline$R_{k}$ or $r_{i}$ & $=$ & Van der Waals surface of group k or molecule i \\
\hline
\end{tabular}




$\begin{array}{ll}\text { S:F Ratio } & =\text { Solvent to feed ratio (on mass basis) } \\ \text { Sulfolane } & =\text { Tetrahydrothiophene-1,1-dioxide } \\ \mathrm{T}(\mathrm{K}) & =\text { Absolute temperature } \\ \tau_{i j} & =\text { Dimensionless interaction parameter } \\ \theta & =\text { Surface fraction } \\ \mathrm{UNIQUAC} & =\text { Universal quasichemical } \\ \varphi_{i} & =\text { Fugacity coefficient of compound } \mathrm{i} \\ x_{i} & =\text { liquid weight fraction of component } \mathrm{i} \\ y_{i} & =\text { vapour weight fraction of component } \mathrm{i}\end{array}$

\subsection{References}

[1] R. Agrawal and R. T. Gooty, "Misconceptions about efficiency and maturity of distillation," AIChE Journal, p. e16294, 2020.

[2] A. A. Kiss and R. Smith, "Rethinking energy use in distillation processes for a more sustainable chemical industry," Energy, p. 117788, 2020.

[3] A. A. Kiss, "Distillation technology-still young and full of breakthrough opportunities," Journal of Chemical Technology E Biotechnology, vol. 89, no. 4, pp. 479-498, 2014.

[4] H. Wang, C. Cui, H. Lyu, and J. Sun, "Design and economic evaluation of energy-saving industrial distillation processes for separating close-boiling cyclohexanone-cyclohexanol mixture," Separation and Purification Technology, vol. 211, pp. 279-289, 2019.

[5] M. Blahušiak, A. A. Kiss, K. Babic, S. R. Kersten, G. Bargeman, and B. Schuur, "Insights into the selection and design of fluid separation processes," Separation and purification technology, vol. 194, pp. 301-318, 2018.

[6] Y. J. Choi, K. W. Cho, B. W. Cho, and Y.-K. Yeo, "Optimization of the sulfolane extraction plant based on modeling and simulation," Industrial E engineering chemistry research, vol. 41, no. 22, pp. 5504-5509, 2002.

[7] Y. Kim, S. Kim, and B. Lee, "Simulation of 1, 3-butadiene extractive distillation process using n-methyl2-pyrrolidone solvent," Korean Journal of Chemical Engineering, vol. 29, no. 11, pp. 1493-1499, 2012.

[8] A. Chianese and F. Zinnamosca, "Ethanol dehydration by azeotropic distillation with a mixed-solvent entrainer," The Chemical Engineering Journal, vol. 43, no. 2, pp. 59-65, 1990.

[9] S. Young, "Lxxiii.— the preparation of absolute alcohol from strong spirit," Journal of the Chemical Society, Transactions, vol. 81, pp. 707-717, 1902.

[10] E. Reyhanitash, T. Brouwer, S. R. Kersten, A. van der Ham, and B. Schuur, "Liquid-liquid extraction-based process concepts for recovery of carboxylic acids from aqueous streams evaluated for dilute streams," Chemical Engineering Research and Design, vol. 137, pp. 510-533, 2018.

[11] W. D. Seider, J. D. Seader, and D. R. Lewin, PRODUCT \& PROCESS DESIGN PRINCIPLES: SYNTHESIS, ANALYSIS AND EVALUATION, (With CD). John Wiley \& Sons, 2009.

[12] T. Brouwer and B. Schuur, "Bio-based solvents as entrainers for extractive distillation in aromatic/aliphatic and olefin/paraffin separation," Green Chemistry, vol. 22, no. 16, pp. 5369-5375, 2020.

[13] S. Lokras, P. Deshpande, and N. Kuloor, "Catalytic dehydrogenation of 2-propanol to acetone," Industrial E Engineering Chemistry Process Design and Development, vol. 9, no. 2, pp. 293-297, 1970.

[14] L. Berg and A.-I. Yeh, "Separation of isopropyl ether from acetone by extractive distillation," July 101984. US Patent $4,459,179$.

[15] G. N. Lewis and M. Randall, Thermodynamics and the free energy of chemical substances. McGraw-Hill, 1923. 


\section{BIOBASED ENTRAINERS FOR POLAR SEPARATIONS}

[16] F.-M. Raoult, "Loi générale des tensions de vapeur des dissolvants," CR Hebd. Seances Acad. Sci, vol. 104, 1887.

[17] L. M. Sprakel, P. Kamphuis, A. L. Nikolova, D. J. Keijsper, and B. Schuur, "Solvent selection for extractive distillation processes to separate close-boiling polar systems," Chemical Engineering Research and Design, vol. 144, pp. 123-134, 2019.

[18] T. Brouwer, R. van Lin, A. ten Kate, B. Schuur, and G. Bargeman, "The influence of solvent and acid properties on the relative volatility and separation selectivity for extractive distillation of close-boiling acids," Industrial \& Engineering Chemistry Research, (submitted).

[19] J. N. Israelachvili, Intermolecular and surface forces. Academic press, 2011.

[20] R. G. Pereyra, M. L. Asar, and M. A. Carignano, "The role of acetone dipole moment in acetone-water mixture," Chemical Physics Letters, vol. 507, no. 4-6, pp. 240-243, 2011.

[21] G. Arivazhagan, R. Shanmugam, and A. Elangovan, "Molecular interaction study of the diisopropyl etherpropionic acid mixture by spectroscopic and dielectric studies," Spectrochimica Acta Part A: Molecular and Biomolecular Spectroscopy, vol. 81, no. 1, pp. 172-177, 2011.

[22] M.-J. Lee and C.-H. Hu, "Isothermal vapor-liquid equilibria for mixtures of ethanol, acetone, and diisopropyl ether," Fluid phase equilibria, vol. 109, no. 1, pp. 83-98, 1995.

[23] S. Bernatová, J. Pavlíček, and I. Wichterle, "Isothermal vapour-liquid equilibria in the binary and ternary systems composed of tert-butyl methyl ether, 3, 3-dimethyl-2-butanone and 2, 2-dimethyl-1-propanol," Fluid phase equilibria, vol. 278, no. 1-2, pp. 129-134, 2009.

[24] H. Kirss, M. Kuus, and E. Siimer, "Isobaric vapor- liquid equilibria of the ternary system methylbutyl ketone+ 1-pentanol+ anisole," Journal of Chemical E Engineering Data, vol. 54, no. 7, pp. 2128-2131, 2009.

[25] J. M. Resa, S. Echebarría, M. A. Betolaza, A. Ruiz, and B. Moradillo, "Isobaric vapor- liquid equilibria of 3-pentanone with acetone and isopropyl ether at $101.3 \mathrm{kpa}$," Journal of Chemical \& Engineering Data, vol. 41, no. 1, pp. 63-65, 1996.

[26] A. Mejía, H. Segura, M. Cartes, L. Cifuentes, and M. Flores, "Phase equilibria and interfacial tensions in the systems methyl tert-butyl ether+ acetone+ cyclohexane, methyl tert-butyl ether+ acetone and methyl tert-butyl ether+ cyclohexane," Fluid phase equilibria, vol. 273, no. 1-2, pp. 68-77, 2008.

[27] J. Pavlíček, A. Andresová, G. Bogdanić, and I. Wichterle, "Vapour-liquid equilibria in binary and ternary systems composed of 2, 3-dimethylbutane, diisopropyl ether, and 3-methyl-2-butanone at 313.15, 323.15 and 313.15 k," Fluid Phase Equilibria, vol. 344, pp. 59-64, 2013.

[28] J. Resa, C. González, and A. Ruiz, "Experiments of extractive distillation at laboratory scale for the rupture of the azeotropic mixture acetone+ isopropyl ether," Separation and purification technology, vol. 18, no. 2, pp. 103-110, 2000.

[29] T. Zhao, M. Li, J. Yang, K. Ma, Z. Zhu, and Y. Wang, "Separation of acetone/isopropyl ether/water ternary mixture via hybrid azeotropic-extractive distillation," Chemical Engineering Transactions, vol. 61, pp. 661666, 2017.

[30] A. Mejía, H. Segura, M. Cartes, and C. Calvo, "Vapor-liquid equilibria and interfacial tensions for the ternary system acetone $+2,2$ '-oxybis [propane]+ cyclohexane and its constituent binary systems," Fluid phase equilibria, vol. 270, no. 1-2, pp. 75-86, 2008.

[31] V. Negro, G. Mancini, B. Ruggeri, and D. Fino, "Citrus waste as feedstock for bio-based products recovery: Review on limonene case study and energy valorization," Bioresource Technology, vol. 214, pp. 806-815, 2016.

[32] E. Jongedijk, K. Cankar, M. Buchhaupt, J. Schrader, H. Bouwmeester, and J. Beekwilder, "Biotechnological production of limonene in microorganisms," Applied microbiology and biotechnology, vol. 100, no. 7, pp. 2927-2938, 2016.

[33] M. North, P. Villuendas, and C. Young, "A gas-phase flow reactor for ethylene carbonate synthesis from waste carbon dioxide," Chemistry-A European Journal, vol. 15, no. 43, pp. 11454-11457, 2009.

[34] A. Decortes, A. M. Castilla, and A. W. Kleij, "Salen-complex-mediated formation of cyclic carbonates by cycloaddition of $\mathrm{co} 2$ to epoxides," Angewandte Chemie International Edition, vol. 49, no. 51, pp. 9822 9837, 2010.

[35] U. Weidlich and J. Gmehling, "A modified unifac model. 1. prediction of vle, he, and. gamma.. infin.," Industrial \& engineering chemistry research, vol. 26, no. 7, pp. 1372-1381, 1987. 


\section{BIOBASED ENTRAINERS FOR POLAR SEPARATIONS}

[36] A. Staverman, "The entropy of high polymer solutions. generalization of formulae," Recueil des Travaux Chimiques des Pays-Bas, vol. 69, no. 2, pp. 163-174, 1950.

[37] A. Fredenslund, R. L. Jones, and J. M. Prausnitz, "Group-contribution estimation of activity coefficients in nonideal liquid mixtures," AIChE Journal, vol. 21, no. 6, pp. 1086-1099, 1975.

[38] B. L. Larsen, P. Rasmussen, and A. Fredenslund, "A modified unifac group-contribution model for prediction of phase equilibria and heats of mixing," Industrial \& engineering chemistry research, vol. 26, no. 11, pp. 2274-2286, 1987.

[39] T. Banerjee, M. K. Singh, R. K. Sahoo, and A. Khanna, "Volume, surface and uniquac interaction parameters for imidazolium based ionic liquids via polarizable continuum model," Fluid Phase Equilibria, vol. 234, no. 1-2, pp. 64-76, 2005.

[40] T. Anderson and J. Prausnitz, "Application of the uniquac equation to calculation of multicomponent phase equilibria. 1. vapor-liquid equilibria," Industrial \& Engineering Chemistry Process Design and Development, vol. 17, no. 4, pp. 552-561, 1978.

[41] H.-C. Ku and C.-H. Tu, "Vapor-liquid equilibria for binary and ternary mixtures of diisopropyl ether, ethanol, and 2, 2, 4-trimethylpentane at $101.3 \mathrm{kpa,"} \mathrm{Fluid} \mathrm{phase} \mathrm{equilibria,} \mathrm{vol.} \mathrm{248,} \mathrm{no.} \mathrm{2,} \mathrm{pp.} \mathrm{197-205,}$ 2006.

[42] F. Gironi, I. Gonzalez Farias, and L. Lamberti, "Liquid-liquid equilibria for the water+ ethanol+ citral and water+ ethanol+ limonene systems at 293 k," Journal of Chemical and Engineering Data, vol. 40, no. 3, pp. 578-581, 1995.

[43] H. Renon and J. M. Prausnitz, "Local compositions in thermodynamic excess functions for liquid mixtures," AIChE journal, vol. 14, no. 1, pp. 135-144, 1968.

[44] P. J. Flory, "Thermodynamics of high polymer solutions," The Journal of chemical physics, vol. 10, no. 1, pp. 51-61, 1942.

[45] M. L. Huggins, "Solutions of long chain compounds," The Journal of chemical physics, vol. 9, no. 5, pp. 440$440,1941$.

[46] G. M. Wilson, "Vapor-liquid equilibrium. xi. a new expression for the excess free energy of mixing," Journal of the American Chemical Society, vol. 86, no. 2, pp. 127-130, 1964.

[47] E. A. Guggenheim, Mixtures: the theory of the equilibrium properties of some simple classes of mixtures, solutions and alloys. Clarendon Press, 1952.

[48] F. A. Mato, R. B. Mato, and F. Mato, "A simple expression for the nonrandomness parameter. alpha. ij in the nrtl equation for completely miscible systems," Industrial E engineering chemistry research, vol. 28, no. 9, pp. 1441-1446, 1989.

[49] R. A. Clará, A. C. G. Marigliano, and H. N. Sólimo, "Density, viscosity, and refractive index in the range (283.15 to 353.15$) \mathrm{k}$ and vapor pressure of $\alpha$-pinene, d-limonene, $( \pm)$-linalool, and citral over the pressure range $1.0 \mathrm{kpa}$ atmospheric pressure," Journal of Chemical E Engineering Data, vol. 54, no. 3, pp. 1087$1090,2009$.

[50] I. Barbosa, R. Martins, M. S. e Melo, and A. Soares, "Acute and chronic toxicity of dimethylsulfoxide to daphnia magna," Bulletin of environmental contamination and toxicology, vol. 70, no. 6, pp. 1264-1268, 2003.

[51] Y. Deguchi, M. Kono, Y. Koizumi, Y.-i. Izato, and A. Miyake, "Study on autocatalytic decomposition of dimethyl sulfoxide (dmso)," Organic Process Research E Development, vol. 24, no. 9, pp. 1614-1620, 2020.

[52] Z. Lei, B. Chen, and Z. Ding, Special distillation processes. Elsevier, 2005.

[53] B. Thomas and S. K. Hans, "Knowledge integrating system for the selection of solvents for extractive and azeotropic distillation," Computers \& chemical engineering, vol. 18, pp. S25-S29, 1994.

[54] A. K. El-Deen and K. Shimizu, "Application of d-limonene as a bio-based solvent in low density-dispersive liquid-liquid microextraction of acidic drugs from aqueous samples," Analytical Sciences, vol. 35, no. 12, pp. 1385-1391, 2019.

[55] H. Pakdel, D. M. Pantea, and C. Roy, "Production of dl-limonene by vacuum pyrolysis of used tires," Journal of Analytical and Applied Pyrolysis, vol. 57, no. 1, pp. 91-107, 2001. 





\subsection{Introduction}

Insights in the liquid-liquid extraction (LLX) applicability of dihydrolevoglycosenone, or Cyrene, was obtained by performing LLX using four different ternary systems. Cyrene, a bio-based polar solvent, attracted recent attention as being versatile for various applications, e.g. as a medium to perform chemical reactions ${ }^{1-7}$ and to prepare membranes by phase inversion ${ }^{8}$, though no mention for LLX applications has been found as of yet.

Cyrene can be an alternative aprotic dipolar solvent ${ }^{3,8}$, solvents of this class are typically used in a range of molecular separations, from aromatic/aliphatic separation ${ }^{9-11}$ to carboxylic acid separation from water. ${ }^{12}$ Industrially important members of the solvent class of aprotic dipolar solvents include $\mathrm{N}$ methyl-pyrrolidone (NMP) and N,N-dimethylformamide (DMF). Cyrene is reported to have a much lower toxicity, ${ }^{1,16}$ and additionally since it is a biobased product, it offers chances for the chemical industry to reduce the consumption of fossil oil by replacing their fossil oil-based solvents with a biobased alternative. ${ }^{17}$ In a recent communication, the Circa Group announced a production capacity of Cyrene of $1 \mathrm{kton}$ per annum, which signifies the mass production of this new biobased solvent. ${ }^{18}$ Although, bulk prices may not be publically available, Krishna et al. state that the bulk price of Cyrene may be approximately $2 € / \mathrm{kg}^{19}$ which is comparable with traditional solvents.

Two key classes of molecular separation processes using solvents include extractive distillation (ED) and LLX. In another article ${ }^{20}$, we showed the potential of Cyrene as entrainer in ED of aromatic/aliphatic mixtures and paraffin/olefin mixtures. Similarly, next to the already proven entrainer function in extractive distillations, Cyrene may be useful for LLX as well. In order to investigate the applicability of Cyrene in LLX processes, we assessed the liquid-liquid equilibrium (LLE) behavior of several ternary systems formed with Cyrene. The investigated systems include (1) methylcyclohexane $(\mathrm{MCH})$ and toluene (TOL), (2) $\mathrm{MCH}$ and cyclohexanol (CHOH), (3) $\mathrm{MCH}$ and cyclohexanone $(\mathrm{CHO})$ and (4) $\mathrm{MCH}$ and cyclopentyl methyl ether (CPME). The molecular structures of all species used in this study are displayed in Figure 9.1.

These ternary mixtures have specifically been chosen to firstly represent aro- 


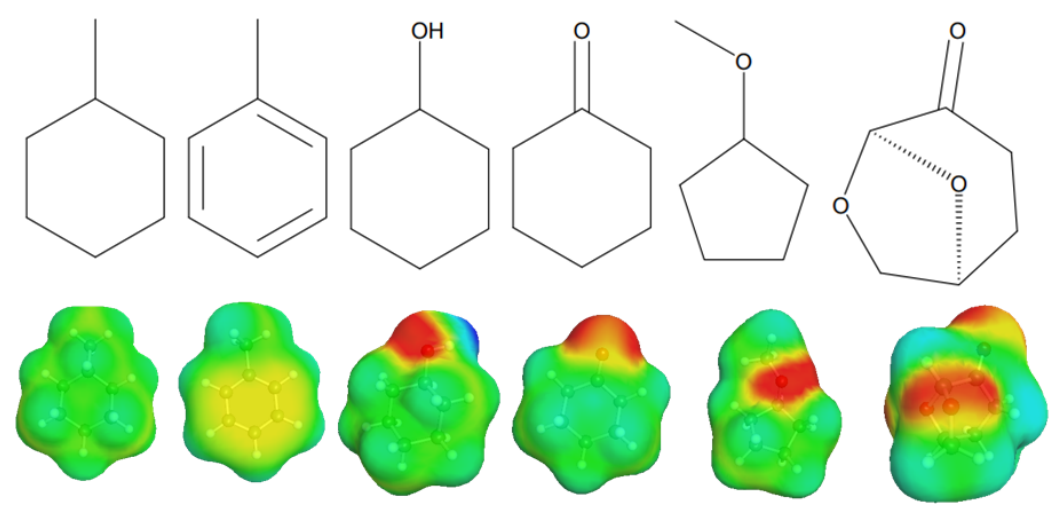

Figure 9.1: All molecules used in the Liquid-Liquid Extractions, from left to right: methylcyclohexane (MCH), toluene (TOL), cyclohexanol (CHOH), cyclohexanone (CHO), cyclopenthylmethyl ether (CPME) and Cyrene.

matics/aliphatics separations. These separations using LLX have been the subject of study for a variety of model compounds, including benzene, toluene, xylenes, (methyl)cyclohexane and n-alkanes. ${ }^{21-26}$ The model systems vary as the related industrial mixture is complex. ${ }^{27}$ The results in this study on liquid-liquid equilibria with Cyrene, $\mathrm{MCH}$ and TOL will be compared to the elaborate work done in the past concerning molecular solvents ${ }^{21,22,25}$, ionic liquids (ILs) ${ }^{11,24,28}$ and deep eutectic solvents (DES's). ${ }^{29-31}$ The separation of alcohols and ketones from aliphatics was chosen because the compounds possess either an alcohol or a ketone functionality, and they are relevant industrial chemicals, for example in the industrial oxidation process of cyclohexane to $\mathrm{CHO}$ and $\mathrm{CHOH} .{ }^{32,33} \mathrm{Kim}$ et al. and Pei et al. investigated similar systems with $\mathrm{CHO}$ and $\mathrm{CHOH}$, though used cyclohexane as hydrocarbon and studied dimethyl sulfoxide (DMSO) and water as a solvent. ${ }^{34,35}$ The last ternary mixture with MCH and CPME was chosen for the ether functionality. CPME also has the potential of being a biobased solvent. ${ }^{36-38}$ The extraction of CPME from an aliphatic stream has not been studied yet. Next to an evaluation of the extraction performance of Cyrene for each of the systems, the LLE were also correlated using the UNIQUAC model. Lastly, by maintaining $\mathrm{MCH}$ as the 
constant, it became possible to compare all the systems with each other and investigate trends between different functional groups, and thus study the applicability of Cyrene for separating molecules with these different functional groups.

\subsection{Material and Methods}

\subsubsection{Materials}

Chemicals, if not otherwise specified, were used without any additional purification. Cyclopentylmethyl ether ( $\geq 99.9 \%)$, cyclohexanone $(\geq 99.9 \%)$ and cyclohexanol (99\%) were obtained from Sigma Aldrich, while methylcylohexane (Reagent Grade. 99\%) was purchased from Honeywell. Toluene (ACS, reag.Ph.Eu) was procured from VWR Chemicals, while analytical acetone ( $\mathrm{Li}-$ Chrosolv ${ }^{\circledR}$ ) was acquired from Merck. A 1L bottle of dihydrolevoglucosenone, or Cyrene, (99.3\%) was gratefully supplied by the Circa Group for this research.

\subsubsection{Methods}

\subsubsection{Liquid-Liquid Extraction Procedure}

For the liquid-liquid extraction experiments, $10 \mathrm{~mL}$ glass vials were used. All compounds were weighed with an accuracy of $0.5 \mathrm{mg}$ on an analytical balance. Consecutively a vortex mixer and a temperature-controlled shaking bath were used in the equilibration. The mixture was shaken at $200 \mathrm{rpm}$ for at least $12 \mathrm{~h}$ at a constant temperature and subsequently settled for at least $1 \mathrm{~h}$ prior to the sample-taking. The experiments were conducted at $298.15 \mathrm{~K}$, $323.15 \mathrm{~K}$ or $348.15 \mathrm{~K}$ with a temperature variation of $0.02 \mathrm{~K}$. A solvent to feed ratio on a weight basis of 1 was maintained and the total mass of each phase was kept approximately constant at 3 grams. A sample of $0.5-1 \mathrm{~mL}$ was taken with a $2 \mathrm{~mL}$ syringe with an injection needle from both phases. Both phases were analyzed following the analysis procedure. 


\subsubsection{Analytical Procedure}

A Thermo Scientific Trace 1300 gas chromatograph with a two parallel ovens and an autosampler TriPlus for 100 liquid samples was used for all analyses. These systems were analyzed using an Agilent DB-1MS column (60m $\times 0.25 \mathrm{~mm} \times 0.25 \mu \mathrm{m}$ ) with an injection volume of $1 \mu \mathrm{l}$ diluted in analytical acetone. A ramped temperature profile was used, following the program; an initial temperature of $50^{\circ} \mathrm{C}$, with a ramp of $10{ }^{\circ} \mathrm{C} / \mathrm{min}$ to $200^{\circ} \mathrm{C}$. The second ramp of $50{ }^{\circ} \mathrm{C} / \mathrm{min}$ to $320^{\circ} \mathrm{C}$ finished the program, which lasts $20 \mathrm{~min}$. The FID temperature was $330^{\circ} \mathrm{C}$. A column flow of $2 \mathrm{ml} / \mathrm{min}$ with a split ratio of 5 , an airflow of $350 \mathrm{ml} / \mathrm{min}$, a helium make-up flow of $40 \mathrm{ml} / \mathrm{min}$ and a hydrogen flow of $35 \mathrm{ml} / \mathrm{min}$ was used.

\subsubsection{Fitting Procedure}

Each ternary system was correlated for all temperatures simultaneously with the UNIQUAC model. This model predicts the activity coefficient as the summation of the combinatorial $\left(\gamma_{i}^{c}\right)$ and residual $\left(\gamma_{i}^{R}\right)$ terms of the activity coefficient, see Equation $9.1{ }^{39}$

$$
\gamma_{i}=\gamma_{i}^{c}+\gamma_{i}^{R}
$$

The combinatorial term, using the Guggenheim-Stavermann approximation, ${ }^{40}$ accounts for the influence of shape differences between the molecules and the corresponding entropy effects. This contribution of the activity coefficient is elaborated in Equation 9.2.

$$
\begin{gathered}
\ln \gamma_{i}^{c}=\ln \left(\frac{\Phi_{i}}{x_{i}}\right)+1-\frac{\Phi_{i}}{x_{i}}-5 q_{i}\left[1-\frac{\Phi_{i}}{\theta_{i}}+\ln \left(\frac{\Phi_{i}}{\theta_{i}}\right)\right] \\
\Phi_{i}=\frac{x_{i} r_{i}}{\sum_{j} x_{j} r_{j}} \\
\theta_{i}=\frac{x_{i} q_{i}}{\sum_{j} x_{j} q_{j}}
\end{gathered}
$$

where $\Phi_{i}$ is the volume fraction, $\theta_{i}$ is the surface area fraction, $x_{i}$ is the molar fraction, $r_{i}$ is the van der Waals volume, and $q_{i}$ is the surface area of each 
component.

The residual term, see Equation 9.3, is determined using the same parameters and the additional empirical binary interaction parameters $\tau_{j i}$. This value is fitted using the temperature-independent parameter $\left(A_{i j}\right)$ and temperaturedependent parameter $\left(B_{i j}\right)$.

$$
\begin{gathered}
\ln \gamma_{i}^{R}=q_{i}\left(1-\ln \left(\frac{\sum_{j} q_{j} x_{j} \tau_{j i}}{\sum_{j} q_{j} x_{j}}\right)-\sum_{j} \frac{q_{j} x_{j} \tau_{j i}}{\sum_{k} q_{k} x_{j} \tau_{k j}}\right) \\
\tau_{i j}=A_{i j}+\frac{B_{i j}}{T(K)}
\end{gathered}
$$

For the correlation, known van der Waals volumes and surface areas were used, see Table 9.1.

Table 9.1: The UNIQUAC parameters for methylcyclohexane (MCH), toluene (TOL), cyclohexanol (CHOH), cyclohexanone (CHO), cyclopentylmethyl ether (CPME) and Cyrene.

\begin{tabular}{|l|l|l|l|}
\hline Component & $\mathrm{r}_{i}$ & $\mathrm{q}_{i}$ & (ref) \\
\hline MCH & 5,174 & 4,396 & Chen et al. $^{22}$ \\
\hline TOL & 3,920 & 2,970 & Gupta et al. ${ }^{41}$ \\
\hline CHOH & 4,274 & 3,284 & Pei et al. ${ }^{35}$ \\
\hline CHO & 4,114 & 3,340 & Pei et al. $^{35}$ \\
\hline CPME & 4,214 & 3,248 & Zhang et al. $^{42}$ \\
\hline Cyrene & 4,843 & 3,322 & $(-)$ \\
\hline
\end{tabular}

For Cyrene, the parameters were not available in the literature, and were estimated with Density Functional Theory with a B3LYP $6-311+G^{* *}$ parameterization in combination with the methodology of Banerjee et al. ${ }^{43}$

\subsection{Results}

\subsubsection{Liquid-Liquid Extraction}

The four ternary systems that were investigated in this study are presented in a subsection for each of the systems. All of the systems showed type I phase behavior ${ }^{44}$ for all temperatures investigated. For each of the ternary systems 
the selectivity $\left(S_{i j}\right)$ of the solute (i) (Equation 9.5), being toluene, cyclohexanol, cyclohexanone or CPME, over MCH (j) was examined. This selectivity is defined as the ratio of the distribution coefficients $\left(K_{D, i}\right)$ of each of the solutes, which in turn is defined as the ratio of the concentration of the solute, on a weight basis, in the solvent $\left(\left[X_{i}\right]_{S}\right)$ and the organic phase $\left(\left[X_{i}\right]_{O}\right)$ as in Equation 9.4.

$$
\begin{gathered}
K_{D, i}=\frac{\left[X_{i}\right]_{S}}{\left[X_{i}\right]_{O}} \\
S_{i j}=\frac{K_{D, i}}{K_{D, j}}
\end{gathered}
$$

All experimental results have been correlated using the UNIQUAC model using the pure component parameters as can be seen in Table 9.1. Additionally, the correlation was checked on its thermodynamic consistency using the Hessian Matrix test in section 12.5. ${ }^{26,27,45,46}$ This allows an approximate description of the binodal curve. The UNIQUAC parameters for each of the ternary systems will be disclosed in each subsection. After describing the results for each of the ternary systems individually, in the last subsection, all ternary systems are compared to enable a general description of the affinities of Cyrene towards different moieties. Additionally, rough short-cut calculations were performed of the combined $\mathrm{CHOH} / \mathrm{MCH}$ and $\mathrm{CHO} / \mathrm{MCH}$ cases to assess the potential of Cyrene in a LLX process. In section 12.4, all the weight fractions, distribution coefficients and selectivities of the ternary diagrams are displayed and/or tableted.

\subsubsection{Methylcyclohexane - Toluene}

The results for the $\mathrm{MCH}$ - toluene - Cyrene ternary system are displayed in Figure 9.2. As can be seen from the binodal curves, a significant miscibility region can be seen. For $298.15 \mathrm{~K}$, only below $35 \mathrm{wt}$. \% toluene a biphasic system is observed, which further reduces with increasing temperatures. This is in line with our work on extractive distillation at a temperature above $373 \mathrm{~K}$, where no phase splitting was observed for this system. ${ }^{20}$ A selectivity of $11.99 \pm 0.89$ was induced with a toluene concentration of $\sim 0.74$ wt. $\%$ in the Cyrene phase at $298.15 \mathrm{~K}$. This selectivity decreases to $6.76 \pm 0.65$ 

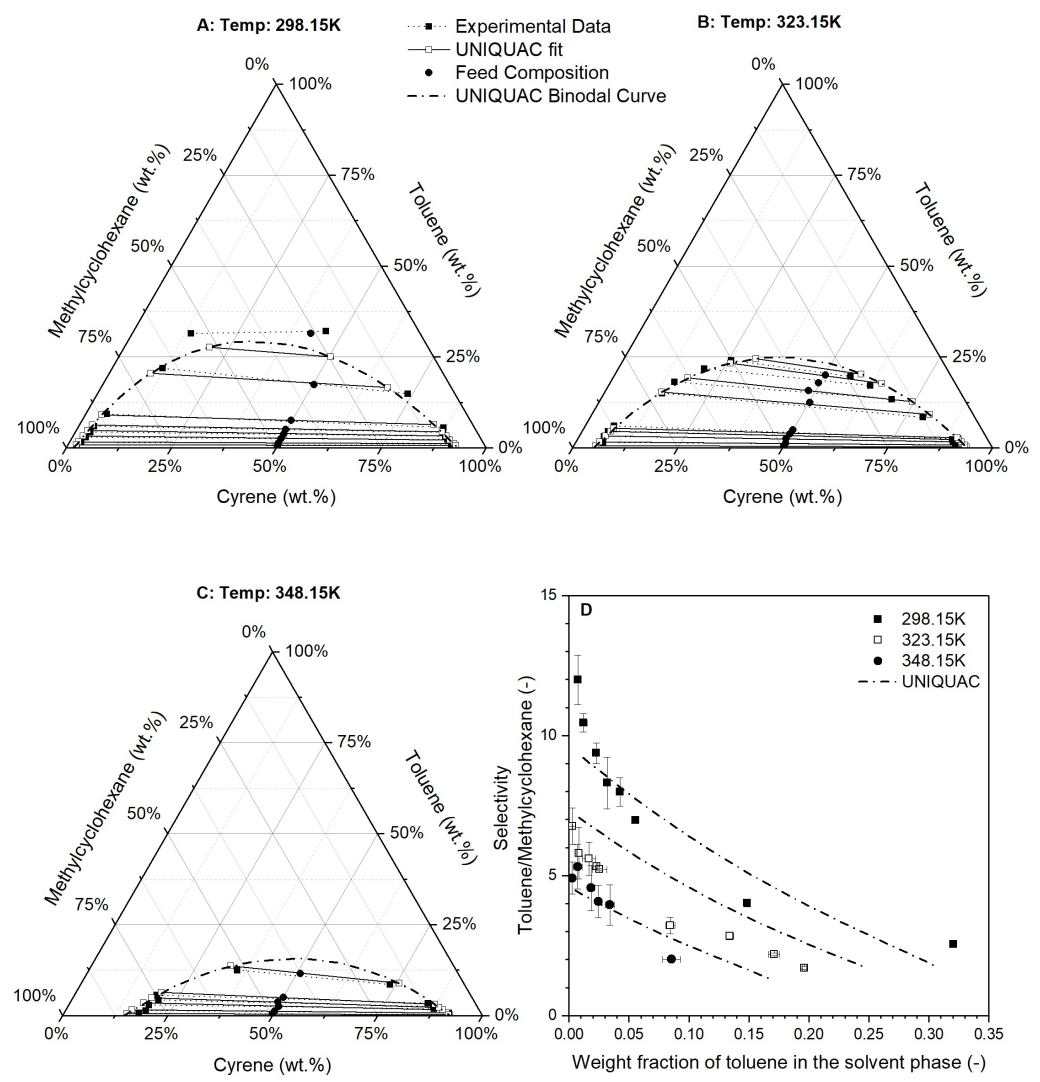

Figure 9.2: The ternary diagram of the LLE of toluene, MCH and Cyrene with the tie-lines, feed compositions and binodal curves at (a) $298.15 \mathrm{~K}$, (b) $323.15 \mathrm{~K}$ and (c) $348.15 \mathrm{~K}$, and (d) the $S_{T O L, M C H}$ of Cyrene at the same temperatures. The UNIQUAC fit is added throughout.

and $4.91 \pm 0.58$ at respectively $323.15 \mathrm{~K}$ and $348.15 \mathrm{~K}$ for similar toluene concentrations. This is due to a lower activity coefficient of $\mathrm{MCH}$ in Cyrene, a consequence of a polarity decrease of the solvent phase, which is a consequence of the higher hydrocarbon ( $\mathrm{MCH}$ and TOL) solubility at elevated temperatures which in turn is caused by the larger entropic contribution at higher temperatures. The correlated UNIQUAC parameters are given in Table 9.2.

The LLX performance of Cyrene has been put in perspective by the compari- 
Table 9.2: Correlated UNIQUAC parameter for the MCH-toluene-Cyrene system

\begin{tabular}{|c|c|cccc|}
\hline Component $\mathrm{i}$ & Component $\mathrm{j}$ & $A_{i j}$ & $A_{j i}$ & $B_{i j}$ & $B_{j i}$ \\
\cline { 1 - 5 } $\mathrm{NCH}$ & Toluene & 0 & 0 & -191 & 171.5 \\
\cline { 2 - 5 } & \multirow{2}{*}{ Cyrene } & 4.587 & -2.627 & -1749 & 773.7 \\
\cline { 1 - 1 } & & 2.708 & -4.999 & -772.6 & 1463 \\
\hline
\end{tabular}

son with solvents, such as Sulfolane, $\mathrm{n}$-formylmorpholine ${ }^{22}$, methanol ${ }^{26}$ and various ILs, ${ }^{4-49}$. As can be seen in Figure 9.3, Sulfolane is outperforming Cyrene regarding selectivity and $\mathrm{n}$-formylmorpholine ${ }^{22}$ has a higher selectivity at high toluene fractions in the solvent phase. Also, both solvents have a more significant phase split than Cyrene. A comparable performance was seen towards methanol ${ }^{26}$, though Cyrene has a more significant phase split.

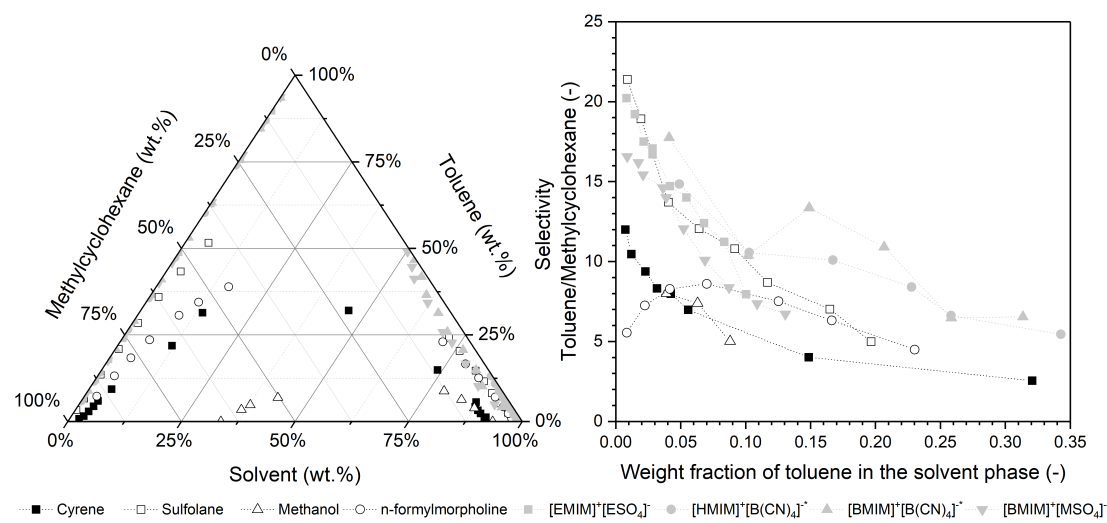

Figure 9.3: (left) A comparison of (left) the LLE and (right) $S_{i j}$ at 298.15K of toluene, $\mathrm{MCH}$ and several solvents; Cyrene, Sulfolane, methanol ${ }^{26}$, n-formylmorpholine ${ }^{22}$, $[E M I M]^{+}\left[E_{4} \mathrm{O}_{4}\right]^{-47}, \quad[\mathrm{HMIM}]^{+}\left[\mathrm{B}(\mathrm{CN})_{4}\right]^{-, * 48}, \quad[\mathrm{BMIM}]^{+}\left[\mathrm{B}(\mathrm{CN})_{4}\right]^{-, * 48}$ and $[B M I M]^{+}\left[\mathrm{MSO}_{4}\right] .{ }^{49}{ }^{*}$ These systems were measured at $293.15 \mathrm{~K}$.

The ILs induce an almost complete immiscibility, due to lower distribution coefficients compared to traditional solvents. This immiscibility is due to their ionic nature, which does not allow them to stabilize in the highly apolar hydrocarbon mixture. Additionally, for low toluene fractions in the solvent 
phase, a similar selectivity towards toluene is observed for the ILs compared to Sulfolane. Although, at higher toluene fraction the tetracyanoborate ILs ${ }^{48}$ can retain a higher selectivity compared to Sulfolane. A consequence of lower distribution coefficients in ILs is however that a larger solvent quantity is required for the LLX, and the equipment diameter will increase. On the other hand, due to the larger selectivity, fewer stages are required, reducing the equipment height. Higher selectivity means that fewer aliphatic compounds need to be boiled from the solvent in the solvent regeneration, which is beneficial for the energy requirement, which seems to be in favor of ILs. Overall, it is not straight-forward to decide which solvent is better and a more thorough process simulation including total annual cost estimation is suggested but outside the scope.

\subsubsection{Methylcyclohexane - Cyclopentylmethyl ether}

As can be seen in Figure 9.4, Cyrene induces a selectivity of $6.42 \pm 0.08,4.55 \pm 0.41$ and $3.91 \pm 0.31$ at respectively $298.15 \mathrm{~K}, 323.15 \mathrm{~K}$ and $348.15 \mathrm{~K}$ for $\sim 0.65 \mathrm{wt} . \%$ of CPME in the solvent phase.

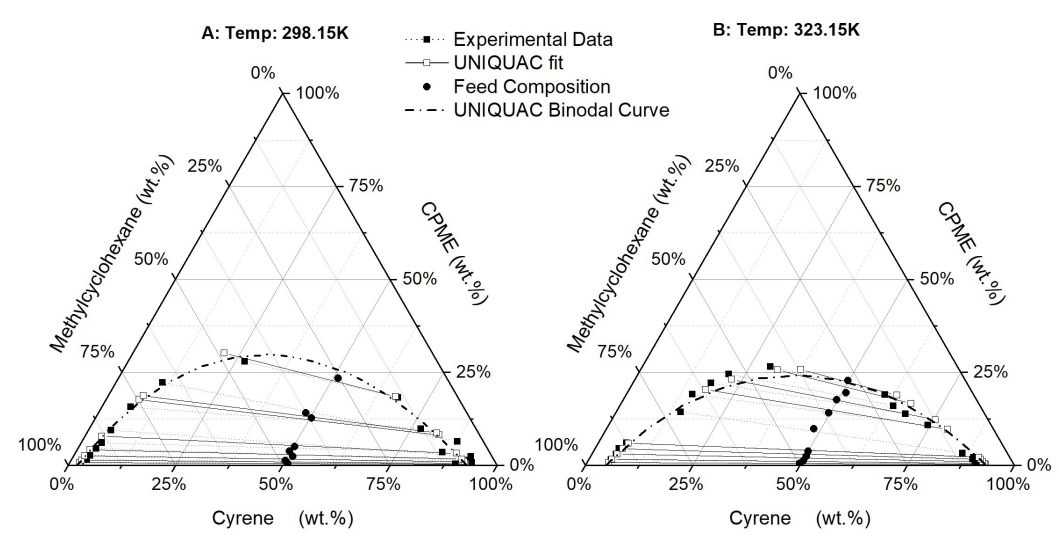



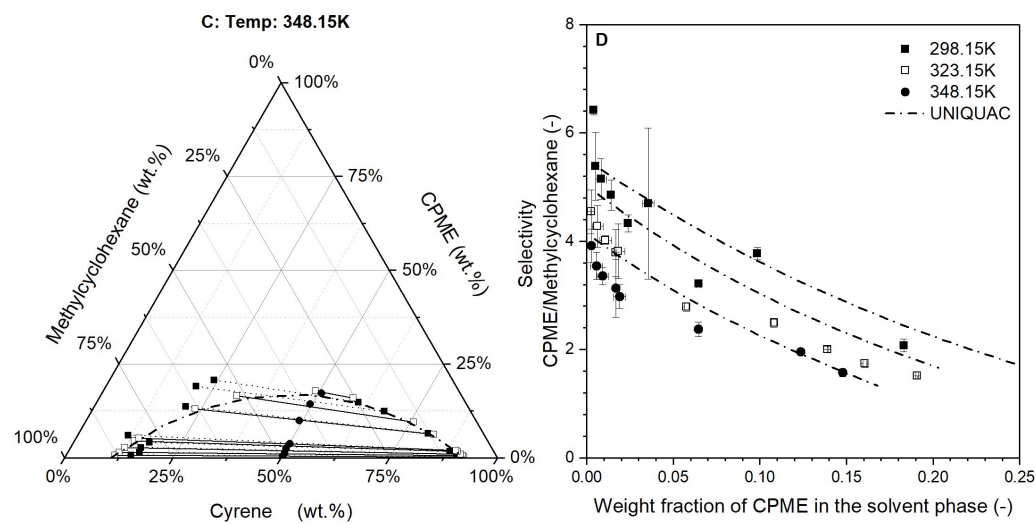

Figure 9.4: The ternary diagram of the LLE of cyclopentylmethyl ether, MCH and Cyrene with the tie-lines, feed compositions and binodal curves at (a) $298.15 \mathrm{~K}$, (b) $323.15 \mathrm{~K}$ and (c) $348.15 \mathrm{~K}$, and $(d)$ the $S_{C P M E, M C H}$ of Cyrene at the same temperatures. The UNIQUAC fit is added throughout.

The results indicate that Cyrene is selective towards the polar ether moiety over the aliphatic $\mathrm{MCH}$. A substantial miscibility region at CPME contents over $\sim 35$ wt. \% CPME is observed, which resembles the LLX-application window of the MCH-toluene case. In Table 9.3, the UNIQUAC parameters of the correlation are displayed. This indicates that the dipolar characteristics of the ether moiety induce similar intermolecular interactions as the delocalized $\pi$-system of toluene.

Table 9.3: Correlated UNIQUAC parameter for the MCH-cyclopentylmethyl ether (CPME)Cyrene system

\begin{tabular}{|c|c|cccc|}
\hline Component $\mathrm{i}$ & Component $\mathrm{j}$ & $A_{i j}$ & $A_{j i}$ & $B_{i j}$ & $B_{j i}$ \\
\cline { 1 - 5 } $\mathrm{N}$ MCH & CPME & 0 & 0 & -61.53 & 19.21 \\
\cline { 2 - 5 } & \multirow{2}{*}{ CPMrene } & 3.332 & -2.020 & -1356 & 588.3 \\
\cline { 1 - 1 } & & 2.319 & -3.522 & -661.0 & 899.1 \\
\hline
\end{tabular}




\subsubsection{Methylcyclohexane - Cyclohexanol}

The results for the system $\mathrm{MCH}-\mathrm{CHOH}$ - Cyrene are given in Figure 9.5. Cyrene induces a selectivity of $61.42 \pm 4.33,32.8 \pm 5.83$ and $16.6 \pm 2.26$ at respectively $298.15 \mathrm{~K}, 323.15 \mathrm{~K}$ and $348.15 \mathrm{~K}$ at $\sim 0.80 \mathrm{wt}$. \% of $\mathrm{CHOH}$ in the solvent phase. This is lower than observed with $\mathrm{DMSO}^{34}$ and water ${ }^{35}$, which have a selectivity of resp. 155 and 1450, at low $\mathrm{CHOH}$ concentrations. The lower selectivity of Cyrene can mainly be attributed to the larger hydrocarbon backbone of Cyrene, compared to the small DMSO and water molecules, which mitigates the multipole interactions with the relatively unselective London dispersion interactions. ${ }^{50}$ Also in the ternary system $\mathrm{MCH}-\mathrm{CHOH}-\mathrm{Cyrene}$ a large miscibility region is observed, for concentrations above $\sim 25 \mathrm{wt}$. \% cyclohexanol. Due to the large miscibility in the system, only a small operation window is available for LLX, and the two-phase region decreases at increasing temperature. The larger miscibility region indicates also that the capacity of Cyrene $\left(K_{D, C H O H}=4.64\right.$ at $\sim 0.80$ wt. \% of $\mathrm{CHOH}$ in the solvent phase) for $\mathrm{CHOH}$ is larger than water $\left(K_{\mathrm{D}, \mathrm{CHOH}}=1.60^{\dagger 35}\right)$. Cyrene would be preferred when high $\mathrm{CHOH}$ capacities are required, while water is preferred when a larger immiscibility and selectivity are required. DMSO has been shown to be quite toxic ${ }^{51}$ and is for that reason not the preferred choice. The UNIQUAC parameters for this system are present in Table 9.4.

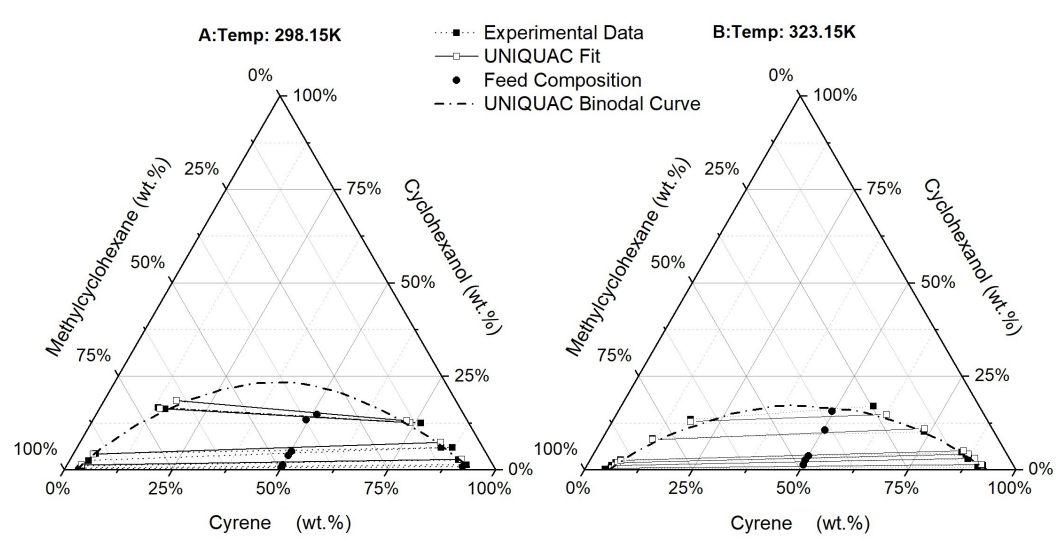



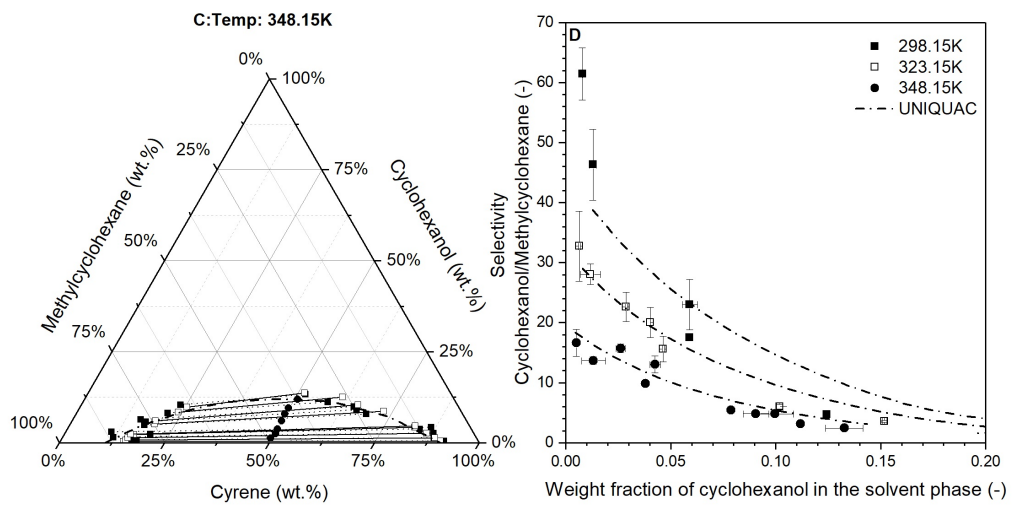

Figure 9.5: The ternary diagram of the LLE of cyclohexanol, MCH and Cyrene with the tielines, feed compositions and binodal curves at (a) 298.15K, (b) $323.15 \mathrm{~K}$ and (c) $348.15 \mathrm{~K}$, and (d) the $S_{\mathrm{CHOH}, \mathrm{MCH}}$ of Cyrene at the same temperatures. The UNIQUAC fit is added throughout.

Table 9.4: Correlated UNIQUAC parameter for the MCH-cyclohexanol-Cyrene system

\begin{tabular}{|c|c|cccc|}
\hline Component $\mathrm{i}$ & Component $\mathrm{j}$ & $A_{i j}$ & $A_{j i}$ & $B_{i j}$ & $B_{j i}$ \\
\cline { 1 - 4 } $\mathrm{MCH}$ & Cyclohexanol & -0.1112 & -0.1675 & -435.6 & 239.5 \\
\cline { 2 - 5 } & \multirow{2}{*}{ Cyrene } & 1.738 & -0.7045 & -817.2 & 153.3 \\
\cline { 1 - 3 } cyclohexanol & & 0 & 0 & -128.7 & 12.05 \\
\hline
\end{tabular}

\subsubsection{Methylcyclohexane - Cyclohexanone}

The results for the ternary system $\mathrm{MCH}-\mathrm{CHO}-$ Cyrene are given in Figure 9.6. Cyrene induces a selectivity of $44.07 \pm 8.63,32.14 \pm 2.78$ and $19.25 \pm 2.00$ at respectively $298.15 \mathrm{~K}, 323.15 \mathrm{~K}$ and $348.15 \mathrm{~K}$ for the lowest amount of $\mathrm{CHO}$ in the solvent phase $(\sim 0.60 \mathrm{wt}$. \%). Also in this case, the selectivity is lower than reported for $\mathrm{DMSO}^{34}$ and water ${ }^{35}$, which have been reported to be 42.9 and 1202. Also in this case, a significant miscibility region is observed at $\mathrm{CHO}$ contents higher than $\sim 23 \mathrm{wt}$. \%. The single-phase region is larger than compared to the previous systems, indicating a narrower LLX application window. This is due to the mutual presence of ketone functionality in $\mathrm{CHO}$ and Cyrene resulting in a significant mutual solubility. Hence Cyrene has a larger capacity for $\mathrm{CHO}\left(K_{D, C H O}=4.47\right.$ at $\sim 0.60 \mathrm{wt}$. \% of $\mathrm{CHO}$ in the solvent phase) 
than water $\left(K_{D, \mathrm{CHO}}=2.79^{\dagger 35}\right)$.
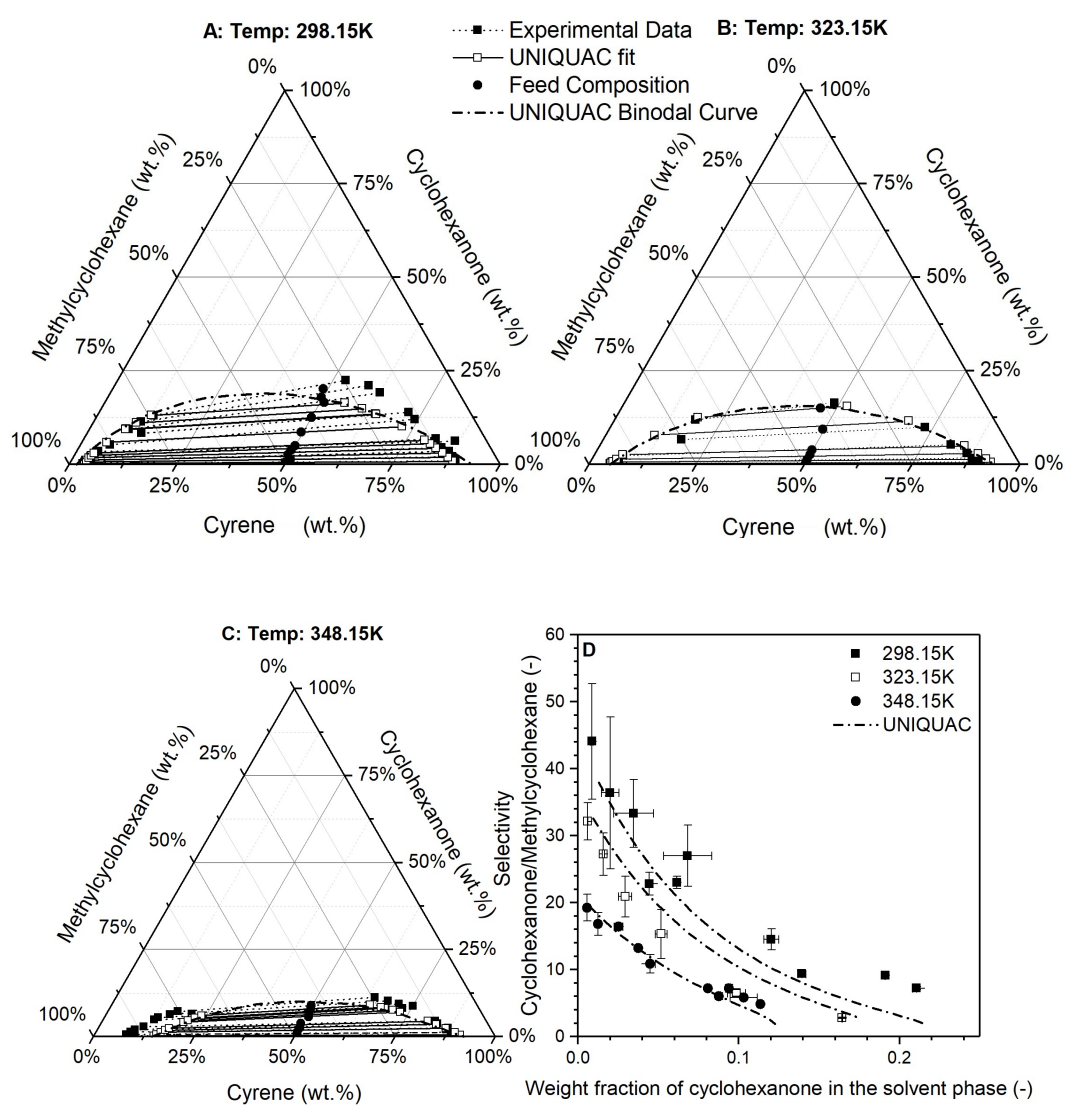

Figure 9.6: The ternary diagram of the LLE of cyclohexanone, $\mathrm{MCH}$ and Cyrene with the tielines, feed compositions and binodal curves at (a) 298.15K, (b) $323.15 \mathrm{~K}$ and (c) $348.15 \mathrm{~K}$, and (d) the $S_{C H O, M C H}$ of Cyrene at the same temperatures. The UNIQUAC fit is added throughout.

Also for this case, Cyrene and water may be preferred solvent choices, if either $\mathrm{CHO}$ capacity or immiscibly window and selectivity are the selection criteria. As previously mentioned, DMSO is toxic and is preferentially avoided. In Table 9.5, the UNIQUAC parameters of the correlation are displayed. As previously mentioned, DMSO is toxic and is preferentially avoided, though water 
appears to be an excellent solvent also for the extraction of cyclohexanone. In Table 9.5, the UNIQUAC parameters of the correlation are displayed.

Table 9.5: Correlated UNIQUAC parameter for the MCH-cyclohexanone-Cyrene system

\begin{tabular}{|c|c|cccc|}
\hline Component $\mathrm{i}$ & Component $\mathrm{j}$ & $A_{i j}$ & $A_{j i}$ & $B_{i j}$ & $B_{j i}$ \\
\hline \multirow{2}{*}{$\mathrm{MCH}$} & Cyclohexanone & -1.090 & -1.090 & 364.9 & 364.9 \\
\cline { 2 - 6 } & \multirow{2}{*}{ Cyrene } & 4.587 & -2.627 & -1749 & 773.7 \\
\cline { 1 - 3 } cyclohexanone & & 2.507 & -7.521 & -531.6 & 2133 \\
\hline
\end{tabular}

\subsubsection{Comparative Study}

By considering the combined data from all ternary systems with toluene (TOL), cyclohexanol $(\mathrm{CHOH})$, cyclohexanone $(\mathrm{CHO})$ and $\mathrm{CPME}$, from $\mathrm{MCH}$, the performance of Cyrene towards particular moieties can be evaluated. Cyrene is a bi-cyclic organic molecule in which a double ether moiety, one in each ring, and a ketone functionality are present. All moieties are aprotic and therefore can only act as a hydrogen bond acceptor and will induce next to the omnipresent London dispersion interactions also Keesom and Debye interactions. ${ }^{50}$ Comparing the results, it is concluded that selectivity order is found to be mostly $\mathrm{CHOH}>\mathrm{CHO}>>\mathrm{TOL}>\mathrm{CPME}$. A larger temperature dependency is seen for $\mathrm{CHOH}$, likely due to intra- and intermolecular hydrogen bonding, resulting in lower selectivity than $\mathrm{CHO}$ at higher temperatures.

\begin{tabular}{|c|c|c|c|c|}
\hline \multirow{2}{*}{ Comp. i } & \multirow{2}{*}{ Comp. j } & {$\left[X_{j}\right]_{S}$ (wt.\%) } & $K_{D, j}(-)$ & Selectivity (-) \\
\cline { 3 - 5 } & & \multicolumn{2}{|c|}{$(298.15 \mathrm{~K} / 323.15 \mathrm{~K} / 348.15 \mathrm{~K})$} \\
\hline \multirow{3}{*}{$\mathrm{MCH}$} & $\mathrm{CHOH}$ & $0.80 / 0.65 / 0.51$ & $4.64 / 2.94 / 1.64$ & $61.4 / 32.8 / 16.6$ \\
\cline { 3 - 5 } & $\mathrm{CHO}$ & $0.87 / 0.60 / 0.56$ & $4.47 / 3.15 / 2.20$ & $44.1 / 32.1 / 19.3$ \\
\cline { 3 - 5 } & $\mathrm{TOL}$ & $0.74 / 0.82 / 0.72$ & $0.98 / 0.54 / 0.51$ & $12.0 / 5.80 / 5.32$ \\
\cline { 3 - 5 } & $\mathrm{CPME}$ & $0.83 / 0.63 / 0.57$ & $0.30 / 0.40 / 0.40$ & $5.15 / 4.27 / 3.54$ \\
\hline
\end{tabular}

$\mathrm{CHOH}$ and $\mathrm{CHO}$ are extracted with significantly higher selectivity than toluene and CPME. This is due to respectively the hydrogen bond donating character of $\mathrm{CHOH}$ and the significant dipole moment of $2.75 \mathrm{D}^{52}$ of $\mathrm{CHO}$ which induces substantial Keesom and Debye interactions with Cyrene. Toluene and CPME do not have hydrogen bonding donating capabilities and have much 
lower dipole moments compared to $\mathrm{CHO}$, respectively $0.37 \mathrm{D}^{53}$ and $1.27 \mathrm{D}^{54}$, hence a lower selectivity is induced. Toluene does, however, exhibit a significant quadrupole moment, ${ }^{55}$ which is responsible for more extensive Keesom and Debye interactions and therefore a larger selectivity is induced compared to CPME. When the $\mathrm{CHO}$ and $\mathrm{CHOH}$ cases are combined and their extraction performances are compared, a measure of selectivity towards both solutes may be estimated for the lowest weight fractions of solute in the solvent phase. A selectivity ratio $\left(S_{\mathrm{CHOH}, \mathrm{MCH}} / S_{\mathrm{CHO}, \mathrm{MCH}}\right)$ of 1.42 and 1.2137 is obtained for resp. Cyrene and water. We speculate that Cyrene is a slightly more selective solvent for the combined extraction of $\mathrm{CHO}$ and $\mathrm{CHOH}$ than water, though this may be caused by the different alkane used in both studies. A Cyrene-based LLX process for this separation was further investigated by short-cut energy calculations in the next section.

\subsection{Process Considerations}

Liquid-Liquid Equilibria are cornerstones in an accurate description of LiquidLiquid Extractions (LLX) that arguably form the heart of LLX processes. As solvents are rarely completely immiscible and selective, several additional purification steps are required to recover the solvent and obtain a pure product. An example is given by de Graff et al. ${ }^{56}$ where two distillation columns are used to recover the solvent and pure products from a LLX column. The raffinate can also be distilled to recover the solvent, though for polar solvents the use of a water wash column to recover the solvent can be applied to save energy. Subsequently, the water is then evaporated from the solvent-rich water phase and the vapor is used to strip extracted solutes from the extract stream. ${ }^{57-59}$ To thoroughly compare Cyrene with all conventional solvents for all studied applications will require rigorous process simulations for all these process steps, and even consideration on which of the steps are required and preferred. This is beyond the scope of this paper, in which the applicability of Cyrene is explored and a first indication of the usefulness of the application is discussed based on miscibility, distribution coefficients and selectivity. On the basis of a short-cut calculation an estimation of the required heat duty will be given for the combined case of $\mathrm{MCH} / \mathrm{CHO}$ and $\mathrm{MCH} / \mathrm{CHOH}$. This case was chosen as being most interesting for industrial application in the industrial 
oxidation process of cyclohexane to $\mathrm{CHO}$ and $\mathrm{CHOH}^{32,33}$.

The MCH-TOL case which certainly is also of industrial interest was not simulated because based on the liquid-liquid equilibrium data it can be seen that both Sulfolane and ILs are clearly superior over Cyrene with regard to selectivity and immiscibility. The most significant difference between water and Cyrene is related to the recovery of the $\mathrm{CHO}$ and $\mathrm{CHOH}$ from the solvent, which boils at resp. $429 \mathrm{~K}$ and $433 \mathrm{~K}$. Cyrene is a high-boiling solvent (bp: $\left.500 \mathrm{~K}^{8}\right)$, whereas water is a low-boiling solvent (bp: $373 \mathrm{~K}$ ). Recovery of water thus implies that the solvent has to be boiled off from the solutes, whereas the solutes can be boiled off from the Cyrene. Cyrene has therefore a significant advantage over water, due to the fact the energy-penalty associated with the evaporation enthalpy of the solvent is avoided in using the high-boiling Cyrene. Also, the capacity of $\mathrm{CHO}$ and $\mathrm{CHOH}$ in water is lower compared to Cyrene. This entails a larger amount of water is required to extract a certain amount of $\mathrm{CHO}$ and/or $\mathrm{CHOH}$ than Cyrene. To estimate the magnitude of the energy advantage, a set of rough calculations on the heat duty in the recovery processes were performed. Using the LLE description by UNIQUAC, the minimum solvent to feed (S:F) ratio (on mass basis) was determined by simulation in Aspen Plus ${ }^{\circledR}$ of the LLX process with 1000 equilibrium stages, a feed containing 90 wt. $\% \mathrm{MCH}$, and obtaining $>99.9$ wt. \% $\mathrm{MCH}$ purity. Afterward, for the heat duty in the solvent recovery stage, a short-cut calculation was applied. Assuming that most of the sensible heat may be recoverable using heat exchangers, the latent heat of vaporization $\left(\Delta H_{\text {vap }}\right)$ of the most volatile compound was used as an estimate. For water as solvent, a minimum S:F ratio of 1.8 was obtained for $\mathrm{CHOH}$ and 7.3 for $\mathrm{CHO}$. Since water for these systems is a volatile solvent, evaporation of all the water resulted in a heat duty of 41.3 $\mathrm{MJ} / \mathrm{kg}_{\mathrm{CHOH}}$ and $166 \mathrm{MJ} / \mathrm{kg}_{\mathrm{CHO}}$.

For Cyrene, a lower minimum S:F ratio was required which is a direct consequence of the larger capacity towards $\mathrm{CHO}$ and $\mathrm{CHOH}$, being 1.2 for $\mathrm{CHOH}$ and $\mathrm{CHO}$. Furthermore, since Cyrene in these systems is a high boiling solvent, the solutes $\mathrm{CHOH}$ and $\mathrm{CHO}$ should be boiled off. Due to solvent leaching, $\mathrm{MCH}$ should be boiled off from the raffinate to recover the solvent, and the evaporation of $\mathrm{MCH}$ from the raffinate is included in the calculations. This resulted for $\mathrm{CHOH}$ in a heat duty of $3.86 \mathrm{MJ} / \mathrm{kg}_{\mathrm{CHOH}}$ and for $\mathrm{CHO}$ in 3.87 
$\mathrm{MJ} / \mathrm{kg}_{\mathrm{CHO}}$. These short-cut calculations show that extraction processes using Cyrene instead of water may be 11 times more efficient for the separation of $\mathrm{CHOH}$ from $\mathrm{MCH}$ and 43 times more efficient for $\mathrm{CHO}$ from $\mathrm{MCH}$. This is a rough heat duty estimate, and in an accurate process simulation, the final heat duty may be less beneficial. However, with the current figures, it shows a high potential for a significant advantage of the high boiling Cyrene over the low boiling water. The fact that most energy savings compared to water were accomplished by the higher boiling point of the solvent, suggests that for this application the use of ionic liquids (ILs) might be interesting too, on the condition that beneficial behavior is observed in LLE. However, no LLE data has been found for $\mathrm{MCH} / \mathrm{CHOH}$ or $\mathrm{CHO}$ with an IL. The separation of $\mathrm{CHO}$ and $\mathrm{CHOH}$ may also be accomplished with Cyrene due to the fact a larger selectivity is observed toward $\mathrm{CHOH}$ than $\mathrm{CHO}$. Although no phase separation is expected and LLX is not possible, other separation techniques may be used such as extractive distillation or perhaps with an extractive divided wall configuration.

\subsection{Conclusions}

Four biphasic ternary systems have been assessed in which methylcyclohexane $(\mathrm{MCH})$ and Cyrene were kept constant. As third compound toluene, cyclohexanol, cyclohexanone and cyclopentyl methyl ether (CPME) were applied. For each ternary system, a selective extraction was found at the three studied temperatures of $298.15 \mathrm{~K}, 323.15 \mathrm{~K}$ and $348.15 \mathrm{~K}$. Cyclohexanol (up to $\mathrm{S}_{\mathrm{CHOH}, \mathrm{MCH}}=61.42 \pm 4.33$ ) and cyclohexanone (up to $\mathrm{S}_{\mathrm{CHO}, \mathrm{MCH}}=44.07 \pm 8.63$ ) were most selectively extracted, while toluene (up to $\mathrm{S}_{T O L, M C H}=11.99 \pm 0.89$ ) and CPME (up to $\mathrm{S}_{C P M E, M C H}=6.42 \pm 0.08$ ) were extracted with considerably lower selectivity. While Cyrene was outperformed by Sulfolane and several ionic liquids in the extraction of toluene, the potential of Cyrene in the cyclohexanol/cyclohexanone systems was observed. Although a lower selectivity was seen than with water, due to the high boiling point of Cyrene, recovery can be much less costly. Overall, we conclude that Cyrene can be applied as biobased extraction solvent for a variety of separations, although for several systems the phase envelop is relatively narrow and narrower at higher temperatures. 


\subsection{Nomenclature}

\begin{tabular}{|c|c|c|}
\hline$[B M I M]^{+}\left[B(C N)_{4}\right]^{-}$ & $=$ & 1-butyl-3-methylimidazolium tetracyanoborate \\
\hline$[B M I M]^{+}\left[\mathrm{MSO}_{4}\right]^{-}$ & $=$ & 1-butyl-3-methylimidazolium methylsulfate \\
\hline$[E M I M]^{+}\left[E O_{4}\right]^{-}$ & $=$ & 1-ethyl-3-methylimidazolium ethylsulfate \\
\hline$[\mathrm{HMIM}]^{+}\left[\mathrm{B}(\mathrm{CN})_{4}\right]^{-}$ & $=$ & 1-hexyl-3-methylimidazolium tetracyanoborate \\
\hline$\left[X_{i}\right]_{O}$ & $=$ & Weight Fraction of compound $i$ in the organic phase \\
\hline$\left[X_{i}\right]_{S}$ & $=$ & Weight Fraction of compound $i$ in the solvent phase \\
\hline$A_{i j}$ & $=$ & Temperature independent UNIQUAC fit parameter \\
\hline$B_{i j}$ & $=$ & Temperature-dependent UNIQUAC fit parameter \\
\hline $\mathrm{Bp}$ & $=$ & Boiling point \\
\hline $\mathrm{CHO}$ & $=$ & Cyclohexanone \\
\hline $\mathrm{CHOH}$ & $=$ & Cyclohexanol \\
\hline CPME & $=$ & Cyclopentylmethyl ether \\
\hline Cyrene & $=$ & Dihydrolevoglycosenone \\
\hline $\mathrm{D}$ & $=$ & Debye \\
\hline DMF & $=$ & $\mathrm{N}, \mathrm{N}$-dimethylformamide \\
\hline DMSO & $=$ & Dimethylsulfoxide \\
\hline ED & $=$ & Extractive Distillation \\
\hline$K_{D, i}$ & $=$ & Distributation coefficient of solute i \\
\hline FID & $=$ & Flame Ionization Detector \\
\hline LLE & $=$ & Liquid-liquid equilibrium \\
\hline LLX & $=$ & Liquid-liquid extraction \\
\hline $\mathrm{MCH}$ & $=$ & Methylcyclohexane \\
\hline NMP & $=$ & N-methylpyrrolidone \\
\hline$q_{i}$ & $=$ & Van der Waals surface area of solute i \\
\hline$r_{i}$ & $=$ & Van der Waals volume of solute i \\
\hline$S_{i j}$ & $=$ & Selectivity of solute $\mathrm{i}$ over solute $\mathrm{j}$ \\
\hline S:F ratio & $=$ & Solvent to Feed ratio \\
\hline Sulfolane & $=$ & Tetrahydrothiophene-1,1-dioxide \\
\hline $\mathrm{T}(\mathrm{K})$ & $=$ & Absolute temperature \\
\hline TOL & $=$ & Toluene \\
\hline UNIFAC & $=$ & UNIQUAC functional-group Activity Coefficients \\
\hline
\end{tabular}




\section{UNIQUAC $=$ Universal Quasichemical \\ $\gamma_{i} \quad=$ Activity Coefficient of solute $\mathrm{i}$ \\ $\gamma_{i}^{C}=$ Combinatorial term of the activity Coefficient of solute $\mathrm{i}$ \\ $\gamma_{i}^{R} \quad=$ Residual term of activity Coefficient of solute i \\ $\Phi_{i} \quad=$ volume fraction \\ $\theta_{i} \quad=$ surface area fraction \\ $\tau_{i j} \quad=$ binary interaction parameter between solutes $i$ and $j$ \\ $+\quad=$ Extrapolated from corresponding literature to similar solute concentration in solvent phase}

\subsection{References}

[1] J. E. Camp, "Bio-available solvent cyrene: Synthesis, derivatization, and applications," ChemSusChem, vol. 11, no. 18, pp. 3048-3055, 2018.

[2] L. Mistry, K. Mapesa, T. W. Bousfield, and J. E. Camp, "Synthesis of ureas in the bio-alternative solvent cyrene," Green Chemistry, vol. 19, no. 9, pp. 2123-2128, 2017.

[3] J. Sherwood, A. Constantinou, L. Moity, C. R. McElroy, T. J. Farmer, T. Duncan, W. Raverty, A. J. Hunt, J. H. Clark, et al., "Dihydrolevoglucosenone (cyrene) as a bio-based alternative for dipolar aprotic solvents," Chemical Communications, vol. 50, no. 68, pp. 9650-9652, 2014.

[4] K. L. Wilson, A. R. Kennedy, J. Murray, B. Greatrex, C. Jamieson, and A. J. Watson, "Scope and limitations of a dmf bio-alternative within sonogashira cross-coupling and cacchi-type annulation," Beilstein journal of organic chemistry, vol. 12, no. 1, pp. 2005-2011, 2016.

[5] K. L. Wilson, J. Murray, C. Jamieson, and A. J. Watson, "Cyrene as a bio-based solvent for hatu mediated amide coupling," Organic E biomolecular chemistry, vol. 16, no. 16, pp. 2851-2854, 2018.

[6] K. L. Wilson, J. Murray, C. Jamieson, and A. J. Watson, "Cyrene as a bio-based solvent for the suzukimiyaura cross-coupling," Synlett, vol. 29, no. 05, pp. 650-654, 2018.

[7] J. Zhang, G. B. White, M. D. Ryan, A. J. Hunt, and M. J. Katz, "Dihydrolevoglucosenone (cyrene) as a green alternative to n, n-dimethylformamide (dmf) in mof synthesis," ACS Sustainable Chemistry E Engineering, vol. 4, no. 12, pp. 7186-7192, 2016.

[8] T. Marino, F. Galiano, A. Molino, and A. Figoli, "New frontiers in sustainable membrane preparation: Cyrene $^{\mathrm{TM}}$ as green bioderived solvent," Journal of membrane science, vol. 580, pp. 224-234, 2019.

[9] M. Blahušiak, A. A. Kiss, K. Babic, S. R. Kersten, G. Bargeman, and B. Schuur, "Insights into the selection and design of fluid separation processes," Separation and purification technology, vol. 194, pp. 301-318, 2018.

[10] Y. J. Choi, K. W. Cho, B. W. Cho, and Y.-K. Yeo, "Optimization of the sulfolane extraction plant based on modeling and simulation," Industrial \& engineering chemistry research, vol. 41, no. 22, pp. 5504-5509, 2002.

[11] Q. Wang, J. Y. Chen, M. Pan, C. He, C. C. He, B. J. Zhang, and Q. L. Chen, "A new sulfolane aromatic extractive distillation process and optimization for better energy utilization," Chemical Engineering and Processing-Process Intensification, vol. 128, pp. 80-95, 2018.

[12] E. Reyhanitash, T. Brouwer, S. R. Kersten, A. van der Ham, and B. Schuur, "Liquid-liquid extraction-based process concepts for recovery of carboxylic acids from aqueous streams evaluated for dilute streams," Chemical Engineering Research and Design, vol. 137, pp. 510-533, 2018.

[13] L. Bergkamp and N. Herbatschek, "Regulating chemical substances under reach: the choice between authorization and restriction and the case of dipolar aprotic solvents," Review of European, Comparative $\mathcal{E}$ International Environmental Law, vol. 23, no. 2, pp. 221-245, 2014.

[14] K. Lee, N. Chromey, R. Culik, J. Barnes, and P. Schneider, “Toxicity of n-methyl-2-pyrrolidone (nmp): 


\section{LIQUID-LIQUID EXTRACTIONS WITH CYRENE}

teratogenic, subchronic, and two-year inhalation studies," Fundamental and Applied Toxicology, vol. 9, no. 2, pp. 222-235, 1987.

[15] J. Sherwood, T. J. Farmer, and J. H. Clark, "Catalyst: Possible consequences of the n-methyl pyrrolidone reach restriction," Chem, vol. 4, no. 9, pp. 2010-2012, 2018.

[16] Z. R. E. J. N. Waaijers-van der Loop, S. L.; Dang, "Toxicity screening of potential bio-based polar aprotic solvents (pas)," 2018.

[17] M. Mccoy, "New solvent seeks to replace nmp," Chemical E Engineering News, vol. 97, no. 22, pp. 14-14, 2019.

[18] B. International, "Circa group to head resolute to resolve commercial bio-based solvent production," Dec. 2019.

[19] S. H. Krishna, K. Huang, K. J. Barnett, J. He, C. T. Maravelias, J. A. Dumesic, G. W. Huber, M. De Bruyn, and B. M. Weckhuysen, "Oxygenated commodity chemicals from chemo-catalytic conversion of biomass derived heterocycles," AIChE Journal, vol. 64, no. 6, pp. 1910-1922, 2018.

[20] T. Brouwer and B. Schuur, "Bio-based solvents as entrainers for extractive distillation in aromatic/aliphatic and olefin/paraffin separation," Green Chemistry, vol. 22, no. 16, pp. 5369-5375, 2020.

[21] I. Ashour and S. I. Abu-Eishah, "Liquid- liquid equilibria of ternary and six-component systems including cyclohexane, benzene, toluene, ethylbenzene, cumene, and sulfolane at $303.15 \mathrm{k}$," Journal of Chemical $\mathcal{E}$ Engineering Data, vol. 51, no. 5, pp. 1717-1722, 2006.

[22] D. Chen, $\mathrm{H}$. Ye, and $\mathrm{H}$. Wu, "Liquid-liquid equilibria of methylcyclohexane-benzene-nformylmorpholine at several temperatures," Fluid phase equilibria, vol. 255, no. 2, pp. 115-120, 2007.

[23] D. Chen, $\mathrm{H}$. Ye, and $\mathrm{H}$. Wu, "Measurement and correlation of liquid- liquid equilibria of methylcyclohexane+ toluene+ n-formylmorpholine at $(293,303,313$, and 323) k," Journal of Chemical E Engineering Data, vol. 52, no. 4, pp. 1297-1301, 2007.

[24] J. García, A. Fernández, J. S. Torrecilla, M. Oliet, and F. Rodríguez, "Liquid-liquid equilibria for \{hexane+ benzene+ 1-ethyl-3-methylimidazolium ethylsulfate at (298.2, 313.2 and 328.2) k," Fluid phase equilibria, vol. 282, no. 2, pp. 117-120, 2009.

[25] S. M. R. S. Ghannad, M. N. Lotfollahi, and A. H. Asl, "(liquid+ liquid) equilibria for mixtures of (ethylene glycol+ benzene+ cyclohexane) at temperatures $(298.15,308.15$, and 318.15$) \mathrm{k}$," The Journal of Chemical Thermodynamics, vol. 43, no. 3, pp. 329-333, 2011.

[26] M. B. Gramajo, J. H. Veliz, M. C. Lucena, and D. A. González, "Liquid-liquid equilibria of the methanol+ toluene+ methylcyclohexane ternary system at 278.15, 283.15, 288.15, 293.15, 298.15 and $303.15 \mathrm{k}$," Journal of Solution Chemistry, vol. 42, no. 10, pp. 2025-2033, 2013.

[27] W. K. Robbins and C. S. Hsu, "Petroleum, composition," Kirk-Othmer Encyclopedia of Chemical Technology, 2000.

[28] T. Zhou, Z. Wang, L. Chen, Y. Ye, Z. Qi, H. Freund, and K. Sundmacher, "Evaluation of the ionic liquids 1-alkyl-3-methylimidazolium hexafluorophosphate as a solvent for the extraction of benzene from cyclohexane:(liquid+ liquid) equilibria," The Journal of Chemical Thermodynamics, vol. 48, pp. 145-149, 2012.

[29] Y. Hou, Z. Li, S. Ren, and W. Wu, "Separation of toluene from toluene/alkane mixtures with phosphonium salt based deep eutectic solvents," Fuel Processing Technology, vol. 135, pp. 99-104, 2015.

[30] S. Ma, J. Li, L. Li, X. Shang, S. Liu, C. Xue, and L. Sun, "Liquid-liquid extraction of benzene and cyclohexane using sulfolane-based low transition temperature mixtures as solvents: Experiments and simulation," Energy \& fuels, vol. 32, no. 7, pp. 8006-8015, 2018.

[31] N. R. Rodriguez, P. F. Requejo, and M. C. Kroon, "Aliphatic-aromatic separation using deep eutectic solvents as extracting agents," Industrial \& Engineering Chemistry Research, vol. 54, no. 45, pp. 11404$11412,2015$.

[32] J. D. Druliner, S. D. Ittel, P. J. Krusic, and C. A. Tolman, "Process for producing a mixture containing cyclohexanol and cyclohexanone from cyclohexane," Apr. 20 1982. US Patent 4,326,084.

[33] U. Schuchardt, D. Cardoso, R. Sercheli, R. Pereira, R. S. Da Cruz, M. C. Guerreiro, D. Mandelli, E. V. Spinacé, and E. L. Pires, "Cyclohexane oxidation continues to be a challenge," Applied Catalysis A: General, vol. 211 , no. 1 , pp. 1-17, 2001.

[34] S. Y. Kim, J. Choe, and K. H. Song, "(liquid+ liquid) equilibria of (cyclohexane+ dimethyl sulfoxide+ 
cyclohexanone) and (cyclohexane+ dimethyl sulfoxide+ cyclohexanol) at $\mathrm{t}=303.2 \mathrm{k}$," Journal of Chemical E Engineering Data, vol. 55, no. 3, pp. 1109-1112, 2010.

[35] Y. Pei, Q. Wang, X. Gong, F. Lei, and B. Shen, "Distribution of cyclohexanol and cyclohexanone between water and cyclohexane," Fluid Phase Equilibria, vol. 394, pp. 129-139, 2015.

[36] M. C. Molina, R. Mariscal, M. Ojeda, and M. L. Granados, "Cyclopentyl methyl ether: A green co-solvent for the selective dehydration of lignocellulosic pentoses to furfural," Bioresource technology, vol. 126, pp. 321-327, 2012.

[37] T. Oshima, N. Ohkubo, I. Fujiwara, T. Horiuchi, T. Koyama, K. Ohe, and Y. Baba, "Extraction of gold (iii) using cyclopentyl methyl ether in hydrochloric acid media," Solvent Extraction Research and Development, Japan, vol. 24, no. 2, pp. 89-96, 2017.

[38] E. Yara-Varon, A.-S. Fabiano-Tixier, M. Balcells, R. Canela-Garayoa, A. Bily, and F. Chemat, "Is it possible to substitute hexane with green solvents for extraction of carotenoids? a theoretical versus experimental solubility study," RSC Advances, vol. 6, no. 33, pp. 27750-27759, 2016.

[39] G. Maurer and J. Prausnitz, "On the derivation and extension of the uniquac equation," Fluid Phase Equilibria, vol. 2, no. 2, pp. 91-99, 1978.

[40] A. Staverman, "The entropy of high polymer solutions. generalization of formulae," Recueil des Travaux Chimiques des Pays-Bas, vol. 69, no. 2, pp. 163-174, 1950.

[41] S. Gupta, B. Rawat, A. Goswami, S. Nanoti, and R. Krishna, "Isobaric vapour-liquid equilibria of the systems: Benzene-triethylene glycol, toluene-triethylene glycol and benzene-n-methylpyrrolidone," Fluid phase equilibria, vol. 46, no. 1, pp. 95-102, 1989.

[42] H. Zhang, "Measurements and comparative study of ternary liquid-liquid equilibria for water+ acrylic acid+ cyclopentyl methyl ether at $(293.15,303.15$, and 313.15$) \mathrm{k}$ and $100.249 \mathrm{kpa}$," Journal of Chemical $\mathcal{E}$ Engineering Data, vol. 60, no. 5, pp. 1371-1376, 2015.

[43] T. Banerjee, M. K. Singh, R. K. Sahoo, and A. Khanna, "Volume, surface and uniquac interaction parameters for imidazolium based ionic liquids via polarizable continuum model," Fluid phase equilibria, vol. 234, no. 1-2, pp. 64-76, 2005.

[44] R. E. Treybal, "Liquid extraction," tech. rep., 1963.

[45] B. L. Beegle, M. Modell, and R. C. Reid, "Thermodynamic stability criterion for pure substances and mixtures," AIChE Journal, vol. 20, no. 6, pp. 1200-1206, 1974.

[46] A. Marcilla, M. Serrano, J. Reyes-Labarta, and M. Olaya, "Checking liquid-liquid plait point conditions and their application in ternary systems," Industrial \& engineering chemistry research, vol. 51, no. 13, pp. 5098-5102, 2012.

[47] E. J. González, N. Calvar, E. Gómez, and Á. Domínguez, "Application of [emim][eso4] ionic liquid as solvent in the extraction of toluene from cycloalkanes: Study of liquid-liquid equilibria at $\mathrm{t}=298.15 \mathrm{k}$," Fluid Phase Equilibria, vol. 303, no. 2, pp. 174-179, 2011.

[48] J. P. Gutierrez, W. Meindersma, and A. B. De Haan, "Binary and ternary (liquid+ liquid) equilibrium for \{methylcyclohexane (1)+ toluene (2)+ 1-hexyl-3-methylimidazolium tetracyanoborate (3)/1-butyl3-methylimidazolium tetracyanoborate (3)\}," The Journal of Chemical Thermodynamics, vol. 43, no. 11, pp. 1672-1677, 2011.

[49] I. Domínguez, N. Calvar, E. Gómez, and Á. Domínguez, "Separation of toluene from cyclic hydrocarbons using 1-butyl-3-methylimidazolium methylsulfate ionic liquid at $\mathrm{t}=298.15 \mathrm{k}$ and atmospheric pressure," The Journal of Chemical Thermodynamics, vol. 43, no. 5, pp. 705-710, 2011.

[50] J. N. Israelachvili, "Van der waals forces between particles and surfaces," Intermolecular and surface forces, vol. 3, pp. 253-289, 2011.

[51] J. Galvao, B. Davis, M. Tilley, E. Normando, M. R. Duchen, and M. F. Cordeiro, "Unexpected low-dose toxicity of the universal solvent dmso," The FASEB Journal, vol. 28, no. 3, pp. 1317-1330, 2014.

[52] D. O'Reilly, E. Peterson, and D. Hogenboom, "Self-diffusion coefficients and rotational correlation times in polar liquids. v. cyclohexane, cyclohexanone, and cyclohexanol," The Journal of Chemical Physics, vol. 57, no. 9, pp. 3969-3976, 1972.

[53] A. J. Petro, "The dipole moment of the carbon-carbon bond," Journal of the American Chemical Society, vol. 80, no. 16, pp. 4230-4232, 1958.

[54] K. Watanabe, N. Yamagiwa, and Y. Torisawa, "Cyclopentyl methyl ether as a new and alternative process solvent," Organic process research \& development, vol. 11, no. 2, pp. 251-258, 2007. 
[55] M. Schauer and E. Bernstein, "Calculations of the geometry and binding energy of aromatic dimers: benzene, toluene, and toluene-benzene," The Journal of chemical physics, vol. 82, no. 8, pp. 3722-3727, 1985.

[56] R. R. De Graff and M. W. Perga, "Method for aromatic hydrocarbon recovery," Sept. 9 1969. US Patent $3,466,346$.

[57] E. A. Jones and D. B. Broughton, "Solvent extraction process for recovery of aromatic hydrocarbons," Mar. 16 1965. US Patent 3,173,966.

[58] R. D. Morin, J. B. Fishel, and A. E. Bearse, "Separation of aromatic hydrocarbons from non-aromatic hydrocarbons utilizing a lactam-water solvent," Apr. 19 1960. US Patent 2,933,448.

[59] H. L. Thompson, "Process for the extraction and recovery of aromatic hydrocarbons," Dec. 1 1970. US Patent 3,544,453.

[60] H. C. Van Ness, Classical thermodynamics of non-electrolyte solutions. Elsevier, 2015.

[61] J. M. Sørensen, T. Magnussen, P. Rasmussen, and A. Fredenslund, "Liquid-liquid equilibrium data: Their retrieval, correlation and prediction part ii: Correlation," Fluid Phase Equilibria, vol. 3, no. 1, pp. 47-82, 1979. 




\subsection{Introduction}

The fractionation of crude oils into numerous intermediates and products is practiced all around the world. Oil fractionation is an energy-intensive process due to the complexity of the feed that requires an extensive separation train. Yearly a huge amount of crude oil is being produced, (4.4 billion tons in $2019^{1}$ ), which resembles about $12.0 \%$ of the global energy usage by the petrochemical industry. ${ }^{2}$ In our path towards a more sustainable future, the elimination of crude oil will take time, and in the short term, will not be feasible as the world cannot function without carbon-based products. For the longer term, fossil-based crude oils can be replaced with bio-crude oils, ${ }^{3,4}$ but also bio-crude oils need to be refined. ${ }^{5,6}$ While in the further future the use of bio-crudes might take significant impact, further greening of traditional industrial crude processing should also be pursued to reduce environmental impact. Part of this can be realized by increasing the energy efficiency of these processes by replacing traditional solvents with bio-based solvents. ${ }^{7,8}$

Crude oil feeds, for instance, naphtha, are complex mixtures that may contain $\mathrm{C}_{6}$ - to $\mathrm{C}_{9}$-hydrocarbons, ${ }^{9,10}$ though other composition ranges are also seen. Various hydrocarbons are either close-boiling compounds, form pinch points and/or form azeotropes between each other. ${ }^{9,10}$ This is the major reason for the large energy requirements of the subsequent separation train. The motivation of separating the aromatic compounds from the aliphatic compounds apart from their individual value is that the presence of aromatic compounds hinders the production of ultra-low sulfur fuels ${ }^{11}$ which adds load on the separation train and tends to foul radiation sections and transfer line exchangers. ${ }^{12}$

Traditional distillation columns are due to the overlapping boiling ranges and azeotropes not able to facilitate all the required separations and therefore solvent-based affinity processes including liquid-liquid extraction (LLX), ${ }^{13-15}$ extractive distillation (ED) ${ }^{16,17}$ and azeotropic distillation (AD) ${ }^{18,19}$ are in use to enhance the relative volatility. Other processes have also been reported such as pervaporation, ${ }^{20,21}$ adsorption ${ }^{22,23}$ or using supported liquid membranes with ionic liquids (ILs) ${ }^{24}$ and polymeric membranes. ${ }^{25} \mathrm{Re}-$ garding solvent-based affinity processes, the solvent choice has a significant 
effect on the overall energy-efficiency of the process. The capacity, the selectivity and the boiling point of the solvent are among the selection criteria. A current state-of-the-art polar solvent used in these affinity processes is tetrahydrothiophene-1,1-dioxide or commonly known as Sulfolane. ${ }^{10}$ ILs have been widely studied as potential superior solvents, ${ }^{12,26-28}$ as shown for instance by Meindersma et al. ${ }^{12}$ who found that the LLX process can be drastically improved by using 4-methyl-N-butylpyridinium tetrafluoroborate. More recently, Deep Eutectic Solvents (DES's) are stated to be an additional new class of alternative solvents. ${ }^{29-32}$ Because DES's are composite solvents and not bound by charge neutrality as seen with ILs, leaching is not necessary the same for both (all) constituents, ${ }^{33,34}$ and the risk remains of changing the solvent composition during subsequent extraction stages. ${ }^{35}$ For this reason, a single molecule solvent may be better suited than composite solvents such as DES's for treating complex streams such as naphtha.

In this study, both LLX-based processes and ED-based processes will be compared, because both are of relevance due to the wide range of aromatic contents found in industrial applications. The number of aromatic compounds present in the feed highly depends on the nature of the feed. For example, in ethylene crackers, the aromatic content is often $10-25 \%,{ }^{12}$ while the naphtha fractions of respectively Arab and Kurdish crude oil contains about $9-15$ vol. $\%^{36}$ and 16.3 vol. $\%^{37}$ aromatic compounds. After catalytic reforming, the subsequent reformate can contain up to $55 \mathrm{wt} . \%$ of aromatic compounds ${ }^{36}$ and vacuum gas oil may contain $33.3 \mathrm{wt} . \% .{ }^{38}$ The last example is pyrolytic light naphtha oil from used tires, which can contain 51.8 wt.\% of aromatic compounds. ${ }^{39}$ This highlights the necessity of assessing processes over a wide range of aromatic content in the feed. Weissermel and Arpe ${ }^{18}$ described that for the separation of aromatic and aliphatic mixtures, three solvent-based affinity processes are preferred at different aromatic feed concentrations. Liquid-liquid extraction (LLX) processes are most suitable at an aromatic feed between $20 \%$ and $65 \%$, while extractive distillation (ED) processes are most preferred between $65 \%$ and $90 \%$. For higher aromatic content (>90\%) azeotropic distillation (AD) processes are preferred. They mention a lack of economically feasible processes for mixed hydrocarbon feeds containing $<20 \%$ of aromatic compounds. In these processes several polar solvents have been used, such as Sulfolane, ${ }^{40-42} \mathrm{n}$-methylpyrrolidone 
(NMP), ${ }^{41,43}$ n-formylmorpholine (NFM), ${ }^{42,44}$ propylene carbonate ${ }^{45,46}$ and various glycols. 47,48

In this manuscript, we compare the process performance of one of these recent biobased solvent advances (dihydrolevoglucosenone or Cyrene) with the performance of Sulfolane, one of the industrial standards for aromatics/aliphatics separations ranging from 10 to $80 \mathrm{~mol} \%$ of aromatic content. Because for Cyrene a very limited amount of binary interaction parameters are currently available, it was not possible to properly simulate processes of complex crude mixtures, and therefore the study is limited to a model system comprised of one aromatic compound (toluene, TOL) and one aliphatic compound (methylcyclohexane, $\mathrm{MCH}$ ), for which the parameters have recently been reported. ${ }^{7,8}$ Both LLX and ED processes have been compared, we report here on their process configurations, simulation results and corresponding costs.

\subsection{Solvent-Based Affinity Separation Processes}

For all solvent-based separation processes holds that after the primary separation, a solvent regeneration is necessary. In LLX-based processes, at least two, though often even more, main columns are necessary for solvent regeneration. Because the initial extraction of the feed with the solvent is not fully selective towards the target solute, additional fractionation is required upon solvent recovery, and due to solvent leaching, raffinate treatment is required. Different purification strategies have been described (and patented) to purify the product streams and recover the solvent. For instance, Van de Graff et al. ${ }^{49}$ described a combination of two distillation columns after an extraction to recover all hydrocarbons from the solvent. A water wash is often applied to remove the leached solvent from the raffinate (aliphatic) stream. To prevent significant solvent losses, this water is returned in the solvent regeneration column, where evaporation of the water enhances the distillation efficiency due to the (steam) stripping effect of the (low boiling) water. ${ }^{50-52}$ Though it has been reported that water can also sometimes added into the extraction column ${ }^{53}$, this was not done in this work.

The exact amount of unit operations, being distillation or extraction columns 


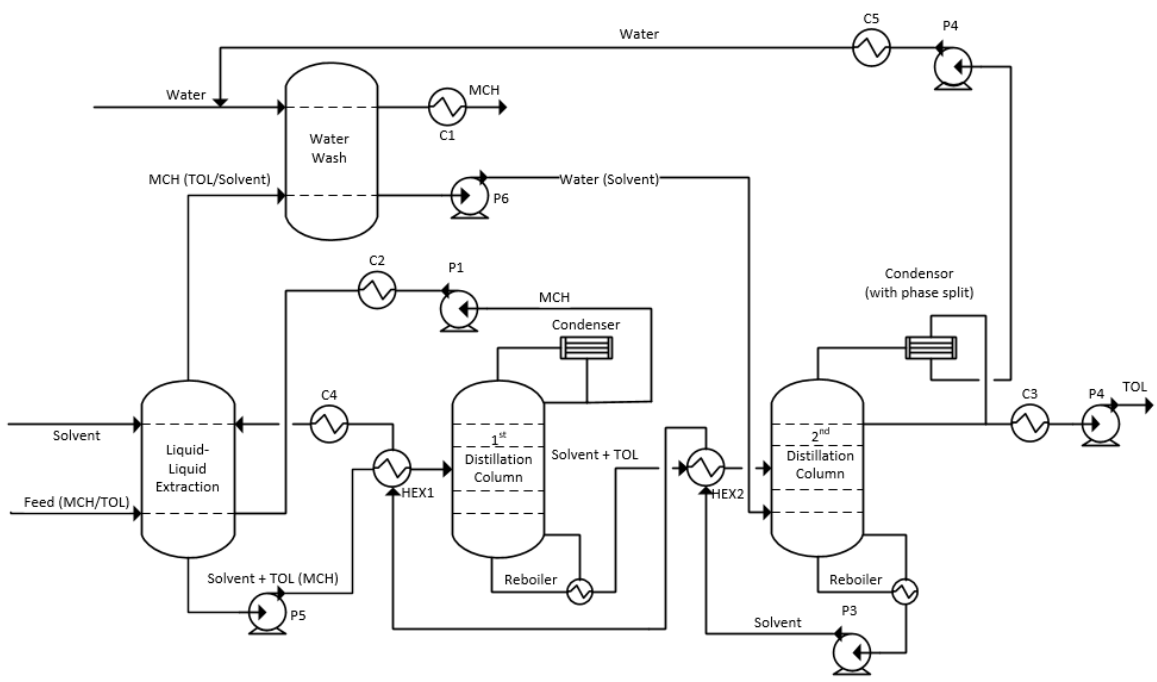

Figure 10.1: The liquid-liquid extraction (LLX) process containing an initial LLX column, where the raffinate is washed in a water wash column. The extract is led to a first distillation column to recover the co-extracted aliphatic compounds and lastly into a distillation column with an additional water inlet of the solvent containing water from the water wash column. The water that leaves over the top is decanted from the toluene product stream and recycled to the water wash column. Several heat exchangers and pumps are used to recover heat from the solvent recycle stream and adjust the pressure in the various equipment.

or decanter vessels, and the precise connections between all columns vary among the patents/processes. ${ }^{45,49-52}$ The optimal configuration may not only depend on the solvent, but also the feed composition, feed throughput, utility costs and the surface availability at the plant. As our objective is to assess the potential of Cyrene and compare it to Sulfolane, it is our main interest to make the comparison as fair as possible. Therefore, for all processes, the process configuration was identical for both solvents. For LLX-based processes, the process configuration is shown in Figure 10.1. A process was chosen wherein the solvent is washed from the raffinate with water, and the water containing the solvent is returned to the solvent recovery (SR) column, where it is applied as strip gas to strip the TOL from the solvent. Next to the SR column, in the first distillation column, the co-extracted $\mathrm{MCH}$ is distilled from the solvent, 
while TOL leaves that column in the bottom with the solvent. The distillate purity of the first distillation column is not essential as this stream is returned to the LLX column, but it should be considered because it affects the performance in the LLX process.

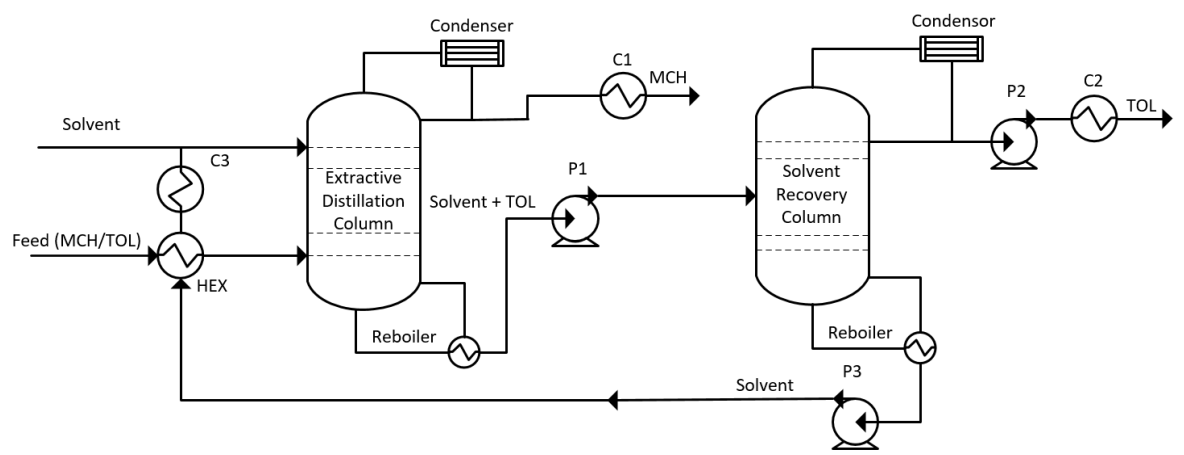

Figure 10.2: The extractive distillation (ED) process consisting of two distillation columns. The methylcyclohexane product is withdrawn from the process as the distillate of the first column, while the toluene product is withdrawn from the second column. Also, several heat exchangers and pumps are present to recover heat from the solvent recycle stream and to adjust the pressure in the various sections.

The second process, see Figure 10.2, is designed around an extractive distillation (ED) column. Generally, for ED processes the main units are distillation columns. In the (first) ED column, the feed is introduced in the bottom section of the column, while the (high boiling) solvent is introduced in the top section. The presence of the solvent elevates the relative volatility of the saturated hydrocarbon in the hydrocarbon mixture. In the second distillation column, the solvent recovery (SR) column, the solvent is recovered from the entrained part of the feed. In practice, several heat exchangers, coolers and pumps may be added when pressure is changed between each of the columns. Besides or due to the solvent choice, adaptations have been patented such as a phase-splitter in the condenser of the SR column when using a highly polar solvent which is not fully miscible with the aromatic compounds, ${ }^{54}$ and introducing side-stream withdrawal and external reflux. ${ }^{55}$ However, for a proper 
comparison as aimed at in this work, a basic ED process scheme, as can be seen in Figure 10.2, has been applied. ${ }^{49,56}$

\subsection{Process modeling and operational and capital expenditures}

\subsubsection{Equilibrium stage model}

The processes described in the previous section were modeled using equilibrium stage models to describe the vapor-liquid equilibria (VLE) and liquidliquid equilibria (LLE). The process simulation is subjected to the MESH (Material, Equilibrium, Summation and Heat balance) equations to uphold the conservation laws which was performed using the software package Aspen Plus ${ }^{\circledR}$ V10. This software package is a common tool to solve both LiquidLiquid Extraction (LLX) process ${ }^{57-59}$ and Extractive Distillation (ED) process. ${ }^{60,61}$ The RadFrac model was applied in all (extractive) distillation columns and the rigorous counter-current extraction column was used in combination with the inside-outside approach of Boston and Britt for the liquidliquid extraction columns. ${ }^{62}$ All pumps were simulated with a distinct discharge pressure of either 1 bar or 0.08 bar dependent on the location in the process. For heat integration, heat-exchangers were modeled with the Shell and Tube model and a logarithmic temperature difference of $10 \mathrm{~K}$ was assumed between the hot outlet- and cold inlet stream. ${ }^{63}$

\subsubsection{Thermodynamics and experimental data acquisition}

Accurate descriptions of VLE are essential in the simulation of each distillation operation, and in the simulations, the modified Raoult's law was used to handle non-ideal behavior. The pure component vapor pressure regressions of TOL, MCH, water and Sulfolane were used from the Aspen Plus ${ }^{\circledR}$ databank, while the recent vapor pressure data of Cyrene, ${ }^{64}$ see Figure 10.3, was manually added and regressed following the Antoine equation. In Table 10.1, the Antoine coefficients of all compounds are tabled. The boiling point of Cyrene is lower than of Sulfolane, which are respectively at 1 bar $226^{\circ} \mathrm{C}$ and $285^{\circ} \mathrm{C}$. 


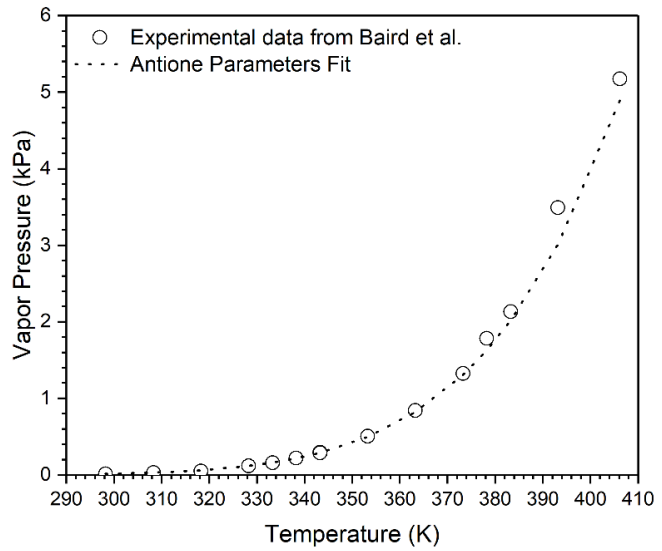

Figure 10.3: The Antoine coefficient correlation of Cyrene from experimental data obtained from Baird et al. 64

Table 10.1: Antoine parameters, $P($ bar $)=\exp \left(A-\frac{B}{T(K)+C}\right)$, of Cyrene, Sulfolane, toluene, methylcyclohexane $(\mathrm{MCH})$ and water.

\begin{tabular}{|l|c|c|c|}
\hline & A & B & C \\
\hline Cyrene & 8.029 & 3407.318 & -97.7166 \\
\hline Sulfolane & 9.904 & 4767.089 & -75.9420 \\
\hline Toluene & 9.948 & 3455.379 & -36.3863 \\
\hline MCH & 9.346 & 3068.515 & -45.1859 \\
\hline Water & 11.866 & 3933.389 & -41.3592 \\
\hline
\end{tabular}

Additional parameters, such as the density, heat capacity and enthalpy of vaporization of $\mathrm{MCH}$, TOL, Sulfolane and water were taken from the Aspen Plus ${ }^{\circledR}$ databank, while the density and enthalpy of vaporization of Cyrene were manually added to the simulator. ${ }^{64,67}$ No isobaric heat capacity $\left(C_{p}\right)$ of Cyrene could be found in literature, hence it was estimated using the Joback methodology which gave a $C_{p}$ of $1.86 \mathrm{~J} \cdot \mathrm{g}^{-1} \cdot \mathrm{mol}^{-1}$ at $303.15 \mathrm{~K}$, which is comparable, though $23 \%$ higher than the $C_{p}$ of Sulfolane being $1.51 \mathrm{~J} \cdot \mathrm{g}^{-1} \cdot \mathrm{mol}^{-1}$ at 303.15K. ${ }^{68}$ Via the Joback methodology the Cp of Sulfolane was determined to be $0.97 \mathrm{~J} \cdot \mathrm{g}^{-1} \cdot \mathrm{mol}^{-1}$ at $303.15 \mathrm{~K}$, which deviates strongly from the experimental value. Therefore, experimental determination of the $C_{p}$ of Cyrene should be done. 


\subsubsection{LLE and VLE with Sulfolane}

The aim of using thermodynamic models is to most accurately describe all equilibria. This could be realized by using either the Non-Random TwoLiquid (NRTL) model ${ }^{65}$ or the UNIQUAC model. ${ }^{66}$ Either model can be chosen, as they do no outperform each other, and can correlate VLE and LLE equilibria accurately if fitted appropriately. The ternary VLE MCH-TOL-Sulfolane were simulated with NRTL using binary interaction parameters (BIPs) present in the Aspen Plus ${ }^{\circledR}$ databank, see Figure 10.4 and Table 10.2.
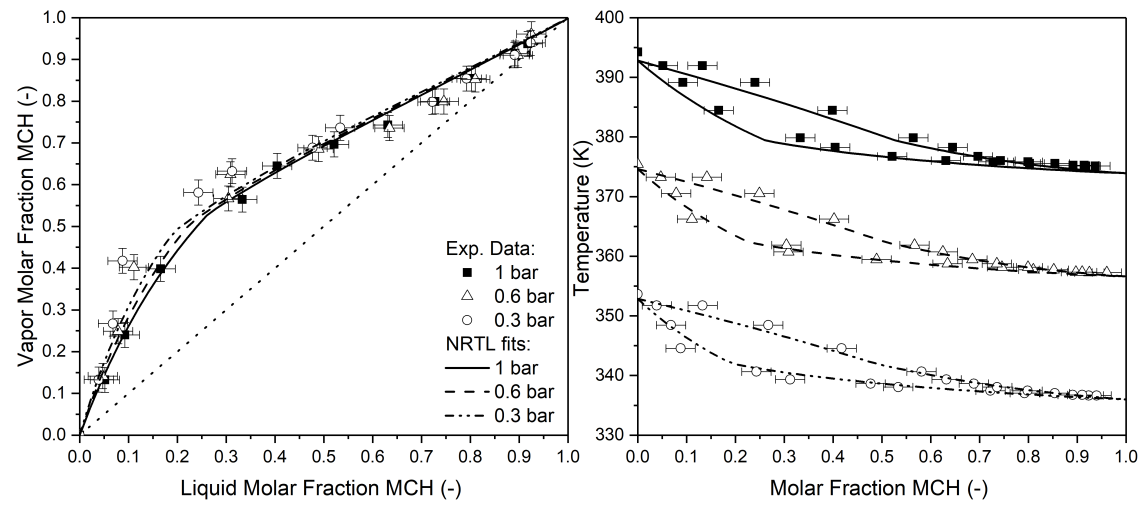

Figure 10.4: The (left) XY-diagram and (right) TXY-diagram of the (quasi)-binary VLE diagram of MCH-TOL and Sulfolane with a solvent to feed ratio of 1 on mass basis ${ }^{7}$, including a NRTL fit of which the results are located in Table 10.2

Table 10.2: Correlated (or applied) NRTL parameter for the MCH-toluene-Sulfolane VLE system. Additional, interaction parameters with water are additionally given.

\begin{tabular}{|c|c|c|c|c|c|c|c|}
\hline Comp. i & Comp. j & $\mathrm{A}_{i j}$ & $\mathrm{~A}_{j i}$ & $\mathrm{~B}_{i j}$ & $\mathrm{~B}_{j i}$ & $\mathrm{C}_{i j}$ & Originated from: \\
\hline \multirow{2}{*}{$\mathrm{MCH}$} & Toluene & 0 & 0 & -43.24 & 134.1 & 0.3 & APV100- VLE-IG \\
\hline & \multirow{2}{*}{ Sulfolane } & -3.473 & -1.702 & 2487 & 1270 & 0.28 & NISTV100 NIST-RK \\
\hline Toluene & & 1.398 & -0.331 & 71.41 & 223.1 & 0.3 & APV100- VLE-IG \\
\hline $\mathrm{MCH}$ & \multirow{3}{*}{ Water } & -9.473 & 9.765 & 4601 & 340.6 & 0.2 & APV100 LLE-ASPEN \\
\hline Toluene & & -7.236 & 3.988 & 4292 & 996.7 & 0.2 & APV100 VLE-IG \\
\hline Sulfolane & & 0 & 0 & 333.4 & 432.7 & 0.6 & APV100 VLE-IG \\
\hline
\end{tabular}

For the description of ternary LLE of MCH-TOL-Sulfolane, the second set of NRTL (NRTL-2) BIPs was required. In absence of literature data, the BIPs be- 


\section{PROCESS SIMULATION OF SOLVENT-BASED AFFINITY PROCESSES}

tween $\mathrm{MCH}$ and Sulfolane required additional experimental LLE to be fitted, see Figure 10.5 and Table 10.3. The experimental and analytical procedures are present in section 12.6 .
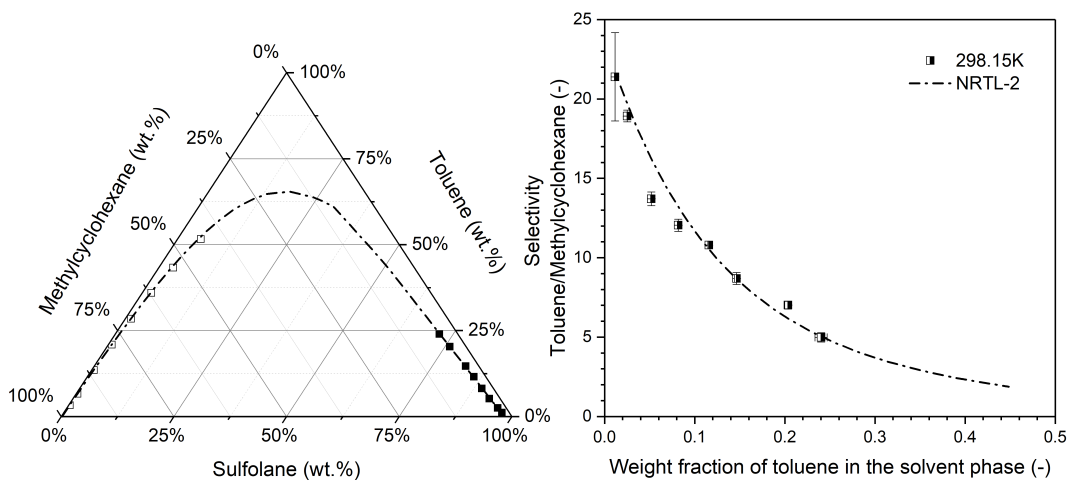

Figure 10.5: The ternary diagram of the LLE of TOL, MCH and Sulfolane with the extract phase (open) and raffinate phase (closed), and (right) the TOL, MCH of Sulfolane at 298.15K. The NRTL-2 parameters are located in Table 10.3.

Table 10.3: Correlated (or applied) NRTL-2 parameter for the MCH-TOL-Sulfolane LLE system

\begin{tabular}{|c|c|c|c|c|c|c|c|}
\hline Comp i & Comp j & $\overline{\mathrm{A}_{i j}}$ & $\overline{\mathrm{A}_{j i}}$ & $\overline{\mathrm{B}_{i j}}$ & $\mathrm{~B}_{j i}$ & $\mathrm{C}_{i j}$ & Originated from: \\
\hline \multirow{2}{*}{$\mathrm{MCH}$} & Toluene & 0,532 & $-0,839$ & 208,1 & 29,705 & 0,1 & NISTV100 NIST-RK \\
\hline & \multirow{2}{*}{ Sulfolane } & $-3,473$ & $-1,703$ & 2487 & 1270 & 0,22 & Fitted \\
\hline Toluene & & 1,398 & $-0,331$ & 71,408 & 223,1 & 0,3 & APV100 VLE-IG \\
\hline $\mathrm{MCH}$ & \multirow{3}{*}{ Water } & -9.473 & 9.765 & 4601 & 340.6 & 0.2 & APV110 LLE-ASPEN \\
\hline Toluene & & -7.236 & 3.988 & 4292 & 996.7 & 0.2 & APV110 VLE-IG \\
\hline Sulfolane & & 0 & 0 & 333.4 & 432.7 & 0.6 & APV110 VLE-IG \\
\hline
\end{tabular}

\subsubsection{LLE and VLE with Cyrene}

The ternary VLE of MCH-TOL-Cyrene was also fitted to experimental data published by Brouwer et al. ${ }^{7}$, see Figure 10.6, and simulated with NRTL using BIPs, while the BIPs of MCH-TOL were used from the Aspen Plus ${ }^{\circledR}$ databank. 
The BIPs of MCH-Cyrene and TOL-Cyrene were fitted to the ternary VLE, see Table 10.4 .
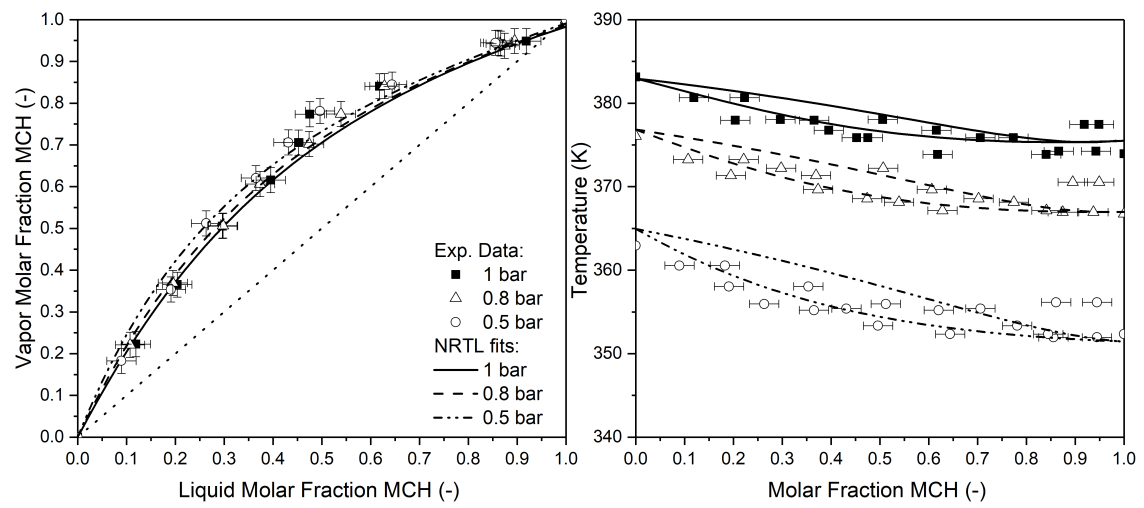

Figure 10.6: The (left) XY-diagram and (right) TXY-diagram of the (quasi)-binary VLE diagram of MCH-TOL and Cyrene with a solvent to feed ratio of 1 on mass basis, ${ }^{7}$ including a NRTL fit of which the results are located in Table 10.4.

Table 10.4: Correlated NRTL parameters for the MCH-TOL-Cyrene system. Additionally, the applied interaction parameters with water are presented.

\begin{tabular}{|l|l|l|l|l|l|l|l|}
\hline Comp. i & Comp. $\mathrm{j}$ & $\mathrm{A}_{i j}$ & $\mathrm{~A}_{j i}$ & $\mathrm{~B}_{i j}$ & $\mathrm{~B}_{j i}$ & $\mathrm{C}_{i j}$ & Originated from: \\
\hline \multirow{2}{*}{$\mathrm{MCH}$} & Toluene & 0 & 0 & 48,7154 & 48,9226 & 0,3 & APV100- VLE-Lit \\
\cline { 4 - 8 } & \multirow{2}{*}{ Cyrene } & $-4,2301$ & 18,6081 & 2158,53 & $-6064,12$ & 0,3 & Fitted \\
\cline { 4 - 8 } & & 33,2804 & $-7,00837$ & -10000 & 1631,93 & 0,1 & Fitted \\
\hline \multirow{2}{*}{ Toluene } & $-9,473$ & 9,7648 & 4601,1 & 340,627 & 0,2 & APV100 LLE-ASPEN \\
\cline { 4 - 8 } MCH & $-7,2357$ & 3,9884 & 4292,44 & 996,703 & 0,2 & APV100 VLE-IG \\
\cline { 3 - 7 } TOL & 0 & 0 & $-459,44$ & 1534,23 & 0,3 & UNIFAC Prediction \\
\hline Cyrene & & 0 & & & &
\end{tabular}

The UNIQUAC description of the ternary LLE of MCH-TOL-Cyrene, seen in Figure 10.7, was published by Brouwer et al. ${ }^{8}$ and the UNIQUAC correlations are seen in Table 10.5. Additionally, the applied interaction parameters with water are presented. 

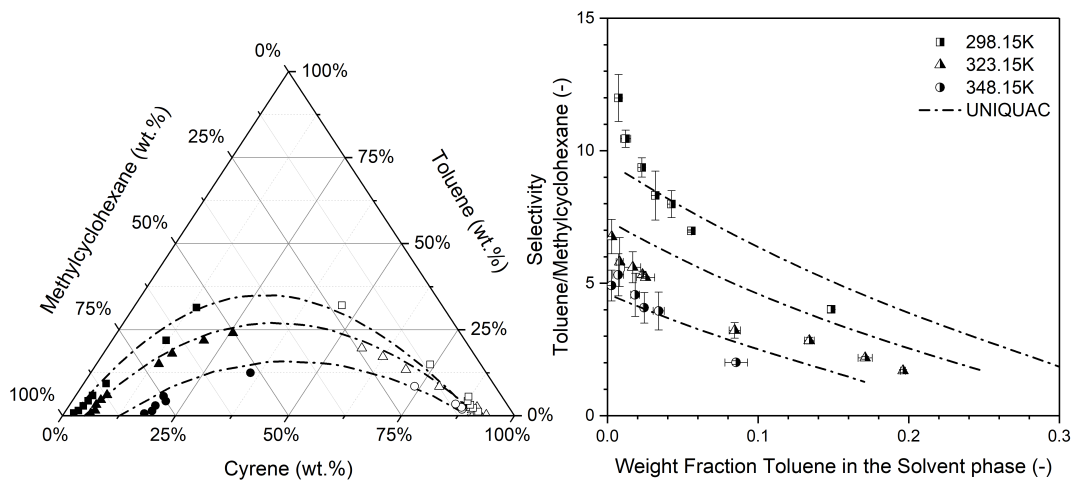

Figure 10.7: (left) The ternary diagram of the LLE of TOL, MCH and Cyrene with the extract phase (open) and raffinate phase (closed), and (right) the TOL,MCH of Cyrene at $298.15 \mathrm{~K}, 323.15 \mathrm{~K}$ and $348.15 \mathrm{~K}$. (reproduced with permission from Brouwer et al. ${ }^{8}$ ). The UNIQUAC fit parameters are located in Table 10.5.

Table 10.5: Correlated (or applied) UNIQUAC parameter for the MCH-TOL-Cyrene system. Additional, interaction parameters with water are additionally given.

\begin{tabular}{|c|c|c|c|c|c|c|}
\hline Comp. i & Comp. j & $\mathrm{A}_{i j}$ & $\mathrm{~A}_{j i}$ & $\mathrm{~B}_{i j}$ & $\mathrm{~B}_{j i}$ & Originated from: \\
\hline \multirow{2}{*}{$\mathrm{MCH}$} & Toluene & 0 & 0 & $-191,0$ & 171,5 & 8 \\
\hline & \multirow{2}{*}{ Cyrene } & 4,587 & $-2,627$ & -1749 & 773,7 & 8 \\
\hline Toluene & & 2,708 & $-4,999$ & $-772,6$ & 1463 & 8 \\
\hline $\mathrm{MCH}$ & \multirow{3}{*}{ Water } & 0 & 0 & -1208 & $-534,02$ & APV100 LLE-LIT \\
\hline TOL & & 0 & 0 & $-950,6$ & $-350,21$ & APV100 LLE-LIT \\
\hline Cyrene & & 0 & 0 & 578,867 & $-1627,09$ & UNIFAC Prediction \\
\hline
\end{tabular}

\subsubsection{Model input}

Both processes, either with Cyrene or Sulfolane, were simulated with a feed of 100 metric tons per hour, while the TOL molar fraction was varied between 10 and $80 \mathrm{~mol} \%$ at a room temperature of $293.15 \mathrm{~K}$. The product specifications of $\mathrm{MCH}$ and TOL were both set at 99.85 wt.\% which coincides with the industrial aromatics specifications. ${ }^{69}$ The countercurrent liquid-liquid extraction column and the extractive distillation column were kept at 1 bar, while the additional recovery columns are at 0.08 bar. These pressures were chosen according to rigorous simulations of Qin et al. ${ }^{70}$, and enable significant heat 
integration between the various columns. Thermal instabilities of Sulfolane and Cyrene are not present. ${ }^{7}$

\subsubsection{OPEX , CAPEX and TAC}

Economic estimation of all processes was performed by assessing the operational expenditures (OPEX), the capital expenditures (CAPEX) and the total annual costs (TAC). The energy requirements of each process were provided by the Aspen Plus ${ }^{\circledR}$ simulations, and a yearly operating time of 8400 hours per year was used. ${ }^{71}$ The costs of various utilities are shown in Table 10.6. Any costs associated with specific locations were not taken into consideration.

Table 10.6: The specifications of used utilities and the associated costs.

\begin{tabular}{|c|c|}
\hline Utility & Costs \\
\hline Chilled cooling water $^{72}$ & $4.50 € / \mathrm{GJ}$ \\
\hline Medium pressure steam $^{72}$ & $11.34 € / \mathrm{GJ}$ \\
\hline Electricity $^{73}$ & $18.97 € / \mathrm{GJ}$ \\
\hline Sulfolane bulk price $^{74}$ & $2.55 € / \mathrm{kg}$ \\
\hline Cyrene bulk price $^{75}$ & $2.00 € / \mathrm{kg}$ \\
\hline
\end{tabular}

${ }^{*}$ Conversion from $\$$ to $€$ of 0.84976 of the $20^{\text {th }}$ of October 2020 was used

${ }^{* *}$ The bulk price of Sulfolane may vary between $2500-3500$ \$/ton, 3000 \$/ton was used. ${ }^{74}$

The CAPEX was estimated using the Aspen Plus ${ }^{\circledR}$ Process Economic Analyzer (APEA), which includes a sizing tool for distillation columns and standard overall heat transfer coefficients. No further investigations were done on the type of construction materials. APEA is not able to size extraction columns. Cost estimation of the extraction columns was therefore done by taking a conventional distillation column without reboiler and condenser and analyzing the costs for different capacities and number of stages. It was stated by Peters et al. ${ }^{76}$ that the cost for extraction columns can be obtained by using the assumption that the stages for the extraction column have the same spacing as in a distillation column. This was confirmed by a literature comparison, where the tray spacing of a distillation column is $0.305-0.915 \mathrm{~m}^{76}$ and for a rotating disk contactor is $0.6096-1.2192 \mathrm{~m} .{ }^{63}$ A value of $0.6096 \mathrm{~m}$ is also used in the Aspen Plus ${ }^{\circledR}$ simulations for a distillation column. With this method, 
the cost estimation of the extraction columns could be made, see section 12.7 for the cost correlation. The solvent costs were determined by adding up the solvent content of each product stream and combining it with the bulk prices shown in Table 10.6 .

The economic analysis is finalized by the Total Annual Costs (TAC), where both the CAPEX as OPEX have been evaluated using Equation 10.1,

$$
T A C \frac{€}{y r}=O P E X+\frac{C A P E X}{P B P}
$$

where a payback period (PBP) of 3 years is applied. ${ }^{77-79}$

\subsection{Results}

To explain the interpretation of the simulation results, in the first two following sub-sections the LLX and ED processes with both solvents are elaborated for a feed containing $40 \mathrm{~mol}$ \% TOL. All other simulations with variations in the feed composition were done similarly. First (section 10.4.1) the LLX process will be discussed, where the effect of the solvent-to-feed ratio, the waterto-extract ratio, the number of extraction stages, the effect of reflux ratios in the recovery columns and the (water) feed location are shown. The OPEX of the optimized configuration is shown in section 10.4.1.1. Secondly (section 10.4.2), a similar assessment was done for ED process, where the solvent-tofeed ratio, the reflux ratios, the (solvent) feed location and the OPEX (10.4.2.1) were assessed. In section 10.4.3, the TAC (and all OPEX) is calculated and compared for all processes with a 10 to $80 \mathrm{~mol}$. \%, aromatic content range.

\subsubsection{Liquid-Liquid Extraction Process}

The LLX process includes two extraction operations, namely the main LLX column where the aromatic compound is extracted from the hydrocarbon feed, and the washing step where the leached solvent is washed from the raffinate stream. Firstly, the influence of the solvent-to-feed (SF) ratio in the LLX column and the number of equilibrium stages are assessed in Figure 10.8a. In the LLX column, the TOL impurity should be low enough to realize the $\mathrm{MCH}$ product specification. It can be seen that both the SF ratio and the number of equilibrium trays affect the TOL impurity (maximum of $1.5 \cdot 10^{-3} \mathrm{~mol} \%$ ), and 
with only 5 equilibrium stages, it is not possible to reach the allowed maximum TOL impurity within the simulated SF range for the Sulfolane process, though with a SF range higher than 3, it is possible for the Cyrene process and even higher SF ranges based on the observed trend, is expected also for the Sulfolane process. It can be seen that less amount of Cyrene is required compared to Sulfolane, which is due to the larger aromatic capacity of Cyrene. The amount of solvent can be reduced by increasing the number of equilibrium stages, and this will also affect the first distillation column where the co-extracted $\mathrm{MCH}$ needs to be distilled. In any case, a certain amount of solvent is leached into the raffinate stream, which is easily recovered by the wash column, as both Sulfolane and Cyrene as fully miscible in water in contrary to $\mathrm{MCH}$ which is highly immiscible with water.
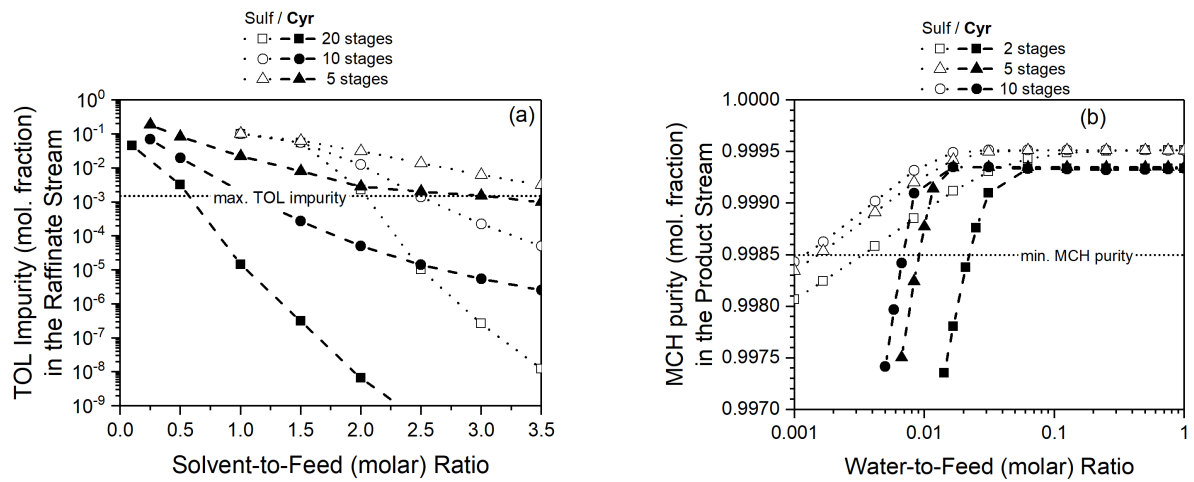

Figure 10.8: The effect of (a) the solvent-to-feed (molar) ratio of the liquid-liquid extraction (LLX) column and (b) the water-to-feed ratio in the wash column located after the LLX column with a SF ratio of 3.5 and with a $40 \mathrm{~mol} . \%$ aromatic feed and Sulfolane or Cyrene as solvent.

The WF ratio directly affects the second distillation column, as this (contaminated) water is reused as a stripping agent. ${ }^{40,80}$ The solvent-contaminated water from the water wash is sent to the $2^{\text {nd }}$ distillation column, where it evaporates to steam and strips the TOL from the solvent. This allows an efficient separation, and the water can be collected via a phase separation step after the condenser. As can be seen in Figure 10.8b, the amount of water used 
in the wash column also directly impacts the second recovery column, where the aromatic compounds are stripped with steam. It can be seen that only a small amount of water is required in the wash column to remove the leached Sulfolane or Cyrene, which is in accordance with the findings of Lee et al. ${ }^{80}$ and Wang et al. ${ }^{40}$ who determined that at least respectively $1 \mathrm{wt} . \%$ and 0.89 $1.1 \mathrm{wt}$. \% of water in Sulfolane was required for adequate stripping of the aromatic compounds.
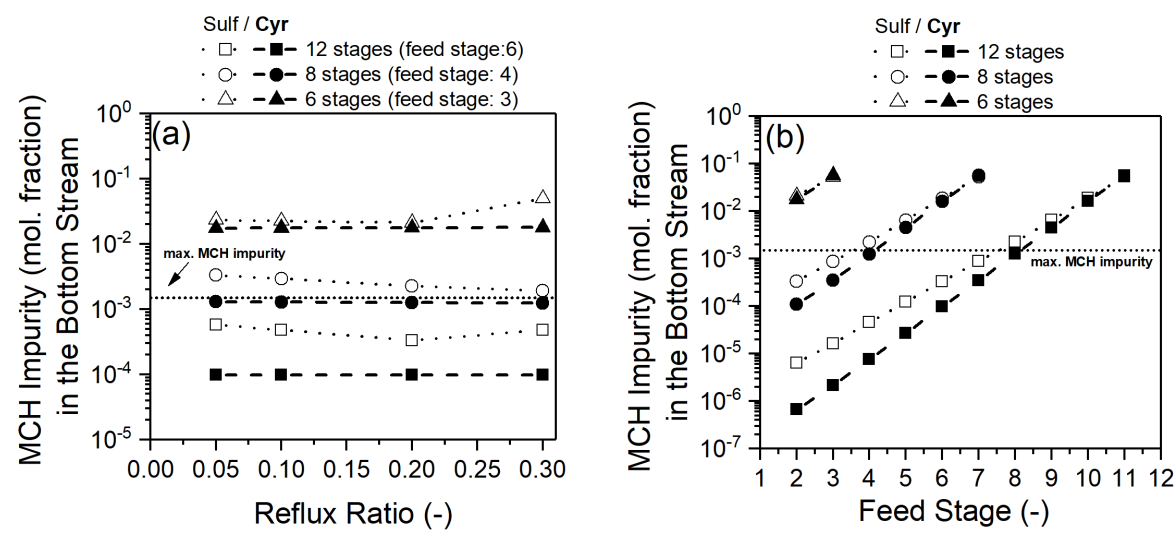

Figure 10.9: The effect of (a) the reflux ratio of the first distillation column and ( $b$ ) the effect of the feed stage with a $40 \mathrm{~mol} \%$ aromatic feed using Sulfolane or Cyrene as solvent (SF ratio of 3.5). The column was operated at 0.08 bar.

The influence of the process conditions to remove the co-extracted $\mathrm{MCH}$ in the first distillation column was investigated. In Figure 10.9, the impact of variation of the reflux ratio and the location of the feed stage in the first distillation column (keeping a SF ratio of 3.5) are displayed. From Figure 10.9a, it is clear that in the simulations with six stages the $\mathrm{MCH}$ impurity specs are never met, and more stages are needed. With eight stages it appears possible for both solvents, although in the plotted area for Sulfolane the spec is just not met at $R=0.30$. An important conclusion from this figure is that the purity in the bottom stream is largely independent of the reflux ratio, which is indicative of the small amount of co-extracted $\mathrm{MCH}$ (and some TOL) which is distilled over the top. In Figure 10.9b, it can be seen that the feed location 
has a significant influence on the $\mathrm{MCH}$ impurity in the bottom streams. The feed should be near the top of the column, this allows sufficient MCH removal.
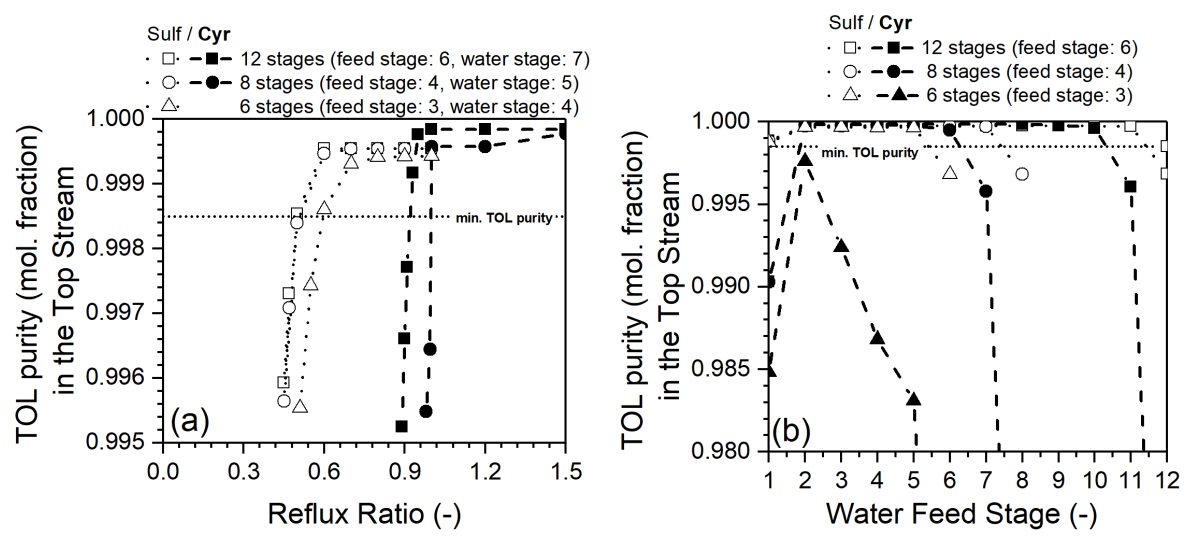

Figure 10.10: The effect of (a) the reflux ratio of the second distillation column and (b) the location of the stripping water with a 40 mol.\% aromatic feed (traces of MCH remain from the first column) using Sulfolane or Cyrene as solvent (SF ratio of 3.5, reflux ratio of 1.5, WE ratio of 0.5$)$. The toluene concentration is given after the phase separation of water. The column was operated at 0.08 bar.

Also, the impact of the reflux ratio and the water feed stage on the performance in the second distillation column was studied. In Figure 10.10a, it can be seen that Sulfolane requires a lower minimum reflux ratio than Cyrene, which is a consequence of the lower volatility of Sulfolane. Secondly, in Figure $10.10 \mathrm{~b}$, the optimal feed location of the stripping water is not very strict, although the stripping water should not be introduced near the top or bottom of the column as this would diminish the TOL purity below specification. Near the bottom, the temperature is significantly higher and causes the water to be mostly in the vapor phase which diminishes its repulsive interactions towards the hydrocarbons in the liquid phase. Also, it can be seen that only 6 equilibrium stages are inadequate when using Cyrene as a solvent. Eventually, the amount of water is kept as low as possible without compromising the stripping ability. This is required as the energy penalty of evaporating the water needs to be minimized. 
In the case of 8 equilibrium stages, the vapor concentration profiles in both distillation columns are presented for both solvents are shown in Figure 10.11. The recycling back to the LLX column of the co-extracted $\mathrm{MCH}$ as distillate is seen in Figure 10.11a and 10.11b, which simultaneously purifies the bottom fraction containing afterward solely TOL and solvent.
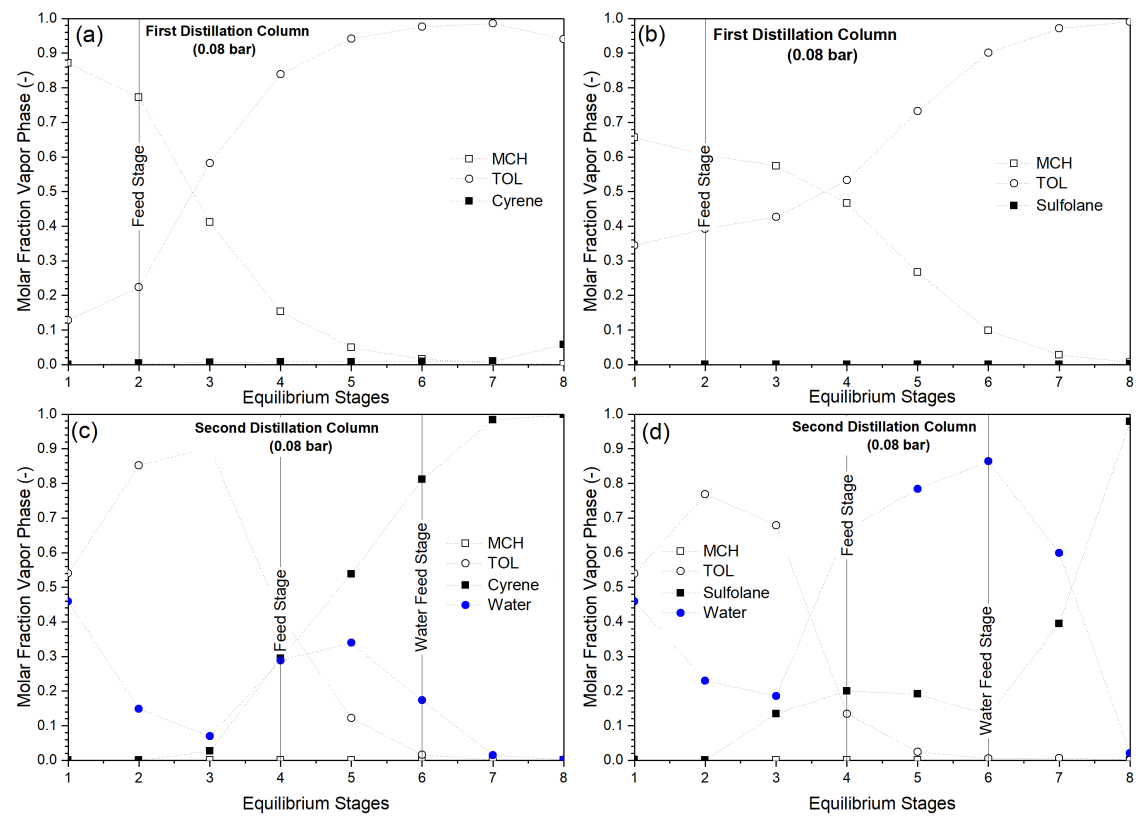

Figure 10.11: (a) The first distillation column with of the Cyrene-based LLX-process (feed: 15 mol.\% MCH, 15 mol.\% TOL, 70 mol.\% Cyrene, SF ratio of 2.5, reflux ratio of 0.1), (b) the first distillation column with of the Sulfolane-based LLX-process (feed: $4.1 \mathrm{~mol} \% \mathrm{MCH}$, $13 \mathrm{~mol} . \%$ TOL, $82 \mathrm{~mol} . \%$ Sulfolane, SF ratio of 3.25, reflux ratio of 0.62 ), (c) the second distillation column of the Cyrene-based LLX-process (feed: trace MCH, 14 mol.\% TOL, 86 mol.\% Cyrene, SF ratio of 2.5, reflux ratio of 1.4, 2.7 mol.\% (0.39 wt.\%) water relative to Cyrene, stripping water contains $9.0 \mathrm{~mol}$. \% Cyrene) (d) the second distillation column of the Sulfolane-based LLX-process (feed: trace MCH, 11 mol.\% TOL, 89 mol.\% Sulfolane, SF ratio of 3.25, reflux ratio of $0.7,3.7 \mathrm{~mol} . \%(0.55 \mathrm{wt}$. \%) water relative to Sulfolane, stripping water contains $0.9 \mathrm{~mol}$. \% Sulfolane). 
This first distillation column operates at a temperature in which the solvent largely remains liquid. The distillate contains a fraction of TOL, a consequence of a low reflux ratio, which minimized the reboiler duty and is of no consequence for the process as the distillate is returned to the LLX column where the TOL is again extracted to the solvent phase. The TOL fraction in the Sulfolane-based process is much higher, which is required to lower the impact of the pinch-point at higher $\mathrm{MCH}$ fractions. Cyrene-based processes do not have this problem and allow for a higher $\mathrm{MCH}$ purity as a top product.

In Figure 10.11c and 10.11d, the concentration profiles are plotted for the second distillation column for Cyrene and Sulfolane, respectively. The addition of the stripping water (vapor) is seen through the concentration profile of water in the vapor phase. This stripping water is contaminated with the leached solvent from the LLX raffinate stream. The water strips the TOL from the solvent and a distillate containing water and TOL which are separated via a phase splitter in the condenser. Although the molar fraction of water in the vapor phase is considerable, it is still comparatively a small weight fraction. A comparable amount of steam is introduced in the SR columns of both processes, and due to the higher temperature in the Sulfolane-based process, a larger molar vapor fraction of water is observed. A high solvent purity is required at the bottom as this is returned to the LLX column and unwanted solute recycling is prevented. Although water in the solvent recycle-stream is not necessarily detrimental for the process, the water fraction in the bottom stage of the SR column is low, due to the much lower boiling point of water compared to either solvent.

\subsubsection{OPEX}

In Figure 10.12, the OPEX of all LLX processes is shown. A distinction is made between costs associated with heating, cooling, electrical duty and solvent losses. Overall, the OPEX of the Cyrene-based LLX process is significantly higher than a Sulfolane-based LLX process. This is due to primarily the lower selectivity towards TOL, which causes additional load on the first distillation column which recovers the co-extracted $\mathrm{MCH}$ and the boiling point of Cyrene is lower than Sulfolane, which causes higher reflux requirements 
in the recovery column. Nevertheless, less Cyrene is required than Sulfolane (due to a larger capacity towards TOL) to extract all TOL. The larger capacity also causes a larger miscibility region of Cyrene with the TOL/MCH mixture and a limited operation region up to $40 \mathrm{~mol} \%$ of TOL in the feed is therefore only possible as higher aromatic concentrations will not cause a phase split which makes LLX impossible. A clear trend is observed regarding the OPEX of the Sulfolane-based LLX process with a decreasing OPEX from $80 \mathrm{~mol} \%$ to $50 \mathrm{~mol} \%$ TOL in the feed, the costs reach a minimum of around $50 \mathrm{~mol}$ $\%$ of toluene in the feed, and stay very similar to $20 \mathrm{~mol} \%$, under which it increases again. This is due to the fact the distillation costs within the process are equally distributed between both distillation columns. At lower aromatic fractions, the load is placed more on the first distillation column whereas at a higher aromatic fraction the load is shifted towards the aromatic product recovery from the solvent in the second distillation column.
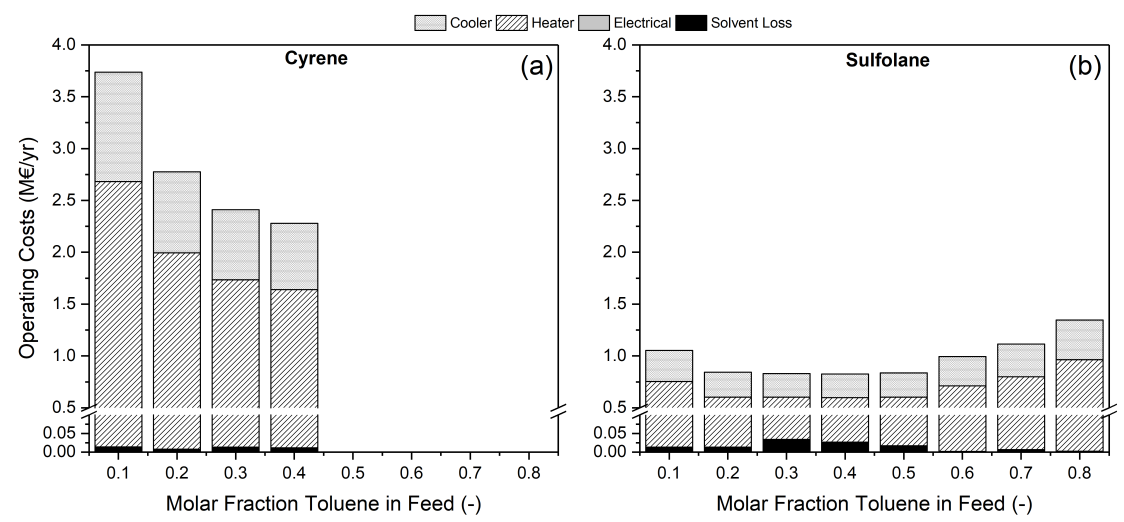

Figure 10.12: Operating costs (OPEX) of the LLX processes with a range of aromatic contents in the feed. For (a) the Cyrene and (b) the Sulfolane case.

\subsubsection{Extractive Distillation Process}

The extractive distillation (ED) process is simpler than the LLX process, as there are only two main distillation columns. In the first distillation column, 
or the Extractive Distillation (ED) column, the $\mathrm{MCH}$ is separated from the $\mathrm{TOL} /$ solvent mixture, here the key parameters are the $\mathrm{MCH}$ impurity in the bottom stream and the $\mathrm{MCH}$ purity in the top stream. As can be seen in Figure 10.13, an increasing number of equilibrium stages allows for a deeper removal of $\mathrm{MCH}$, thereby lowering the $\mathrm{MCH}$ impurity in the bottom stream with less solvent to achieve the maximum allowed $\mathrm{MCH}$ impurity in the bottom stream. Cyrene is seen to require less solvent to obtain the desired $\mathrm{MCH}$ purity than Sulfolane, due to the lack of pinch-point in the ternary VLE behavior of Cyrene-TOL-MCH. ${ }^{7}$

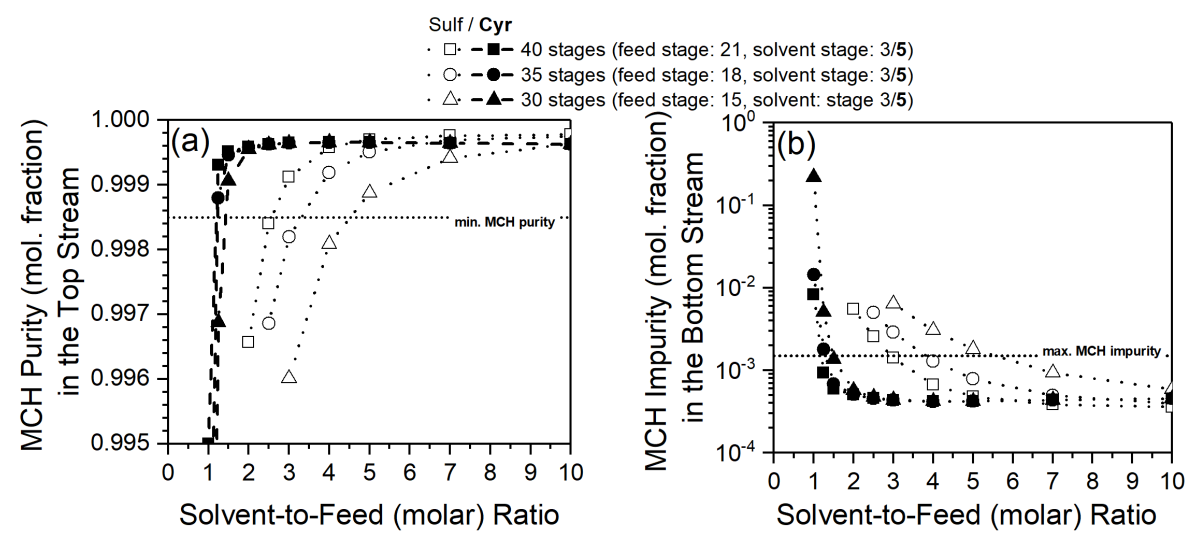

Figure 10.13: The effect of the solvent-to-feed (molar) ratio in the (first) extractive distillation (ED) column on the (a) MCH purity in the top stream and (b) the MCH impurity in the bottom stream with a $40 \mathrm{~mol}$ \% aromatic feed using Sulfolane or Cyrene as solvent and a reflux ratio of 2.0.

It can be seen in Figure 10.14, that a lower reflux ratio can be used in the Sulfolane system compared to the Cyrene system, though this is a consequence of the higher SF ratio used for the Sulfolane system. The SF ratio and reflux ratio in the Cyrene system appears to have a much smaller effect compared to the Sulfolane system. This is likely due to the fact a higher SF ratio in the Sulfolane system strongly affects the severity of the pinch-point, which is not occurring in the Cyrene system. In general, the $\mathrm{MCH}$ purity specification is obtained, and the $\mathrm{MCH}$ impurity in the bottom stream is the key parameter 
to consider, as this directly influences the toluene purity in the second distillation column.
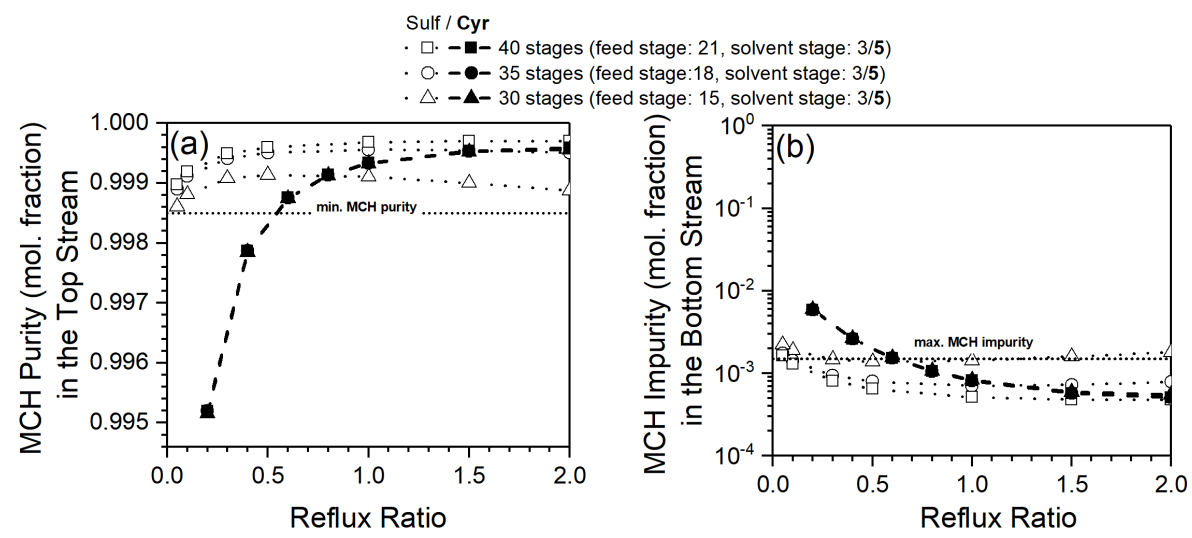

Figure 10.14: The effect of the reflux ratio in the (first) extractive distillation (ED) column on the (a) MCH purity in the top stream and (b) the MCH impurity in the bottom stream with a 40 mol.\% aromatic feed using Sulfolane or Cyrene as solvent and resp. a Solvent-toFeed ratio of 5.0 and 2.0.

In Figure 10.15, the effect of the feed location of the hydrocarbon stream in the ED column is assessed. Overall, the hydrocarbon feed should not be introduced close to the top as it reduces the rectifying ability and both solvents require the feed location to be introduced at least lower than the $15^{\text {th }}$ stage. This is necessary to not only obtain a $\mathrm{MCH}$ product purity, but also to allow sufficient removal of the $\mathrm{MCH}$ from the bottom stream. An introduction of the hydrocarbon too low in the column will result in insufficient removal of the $\mathrm{MCH}$ from the bottom stream, which consequently will result in an inability to purity the toluene product in the subsequent column.

Besides the hydrocarbon feed location, also the location at which the solvent is introduced in the ED column is essential. The effect of this location is seen in Figure 10.16. Similar trends are observed as seen in Figure 10.15, hence the introduction of the solvent too high up to column will reduce the $\mathrm{MCH}$ purity in the top below specification. While adding the solvent too low in 


\section{PROCESS SIMULATION OF SOLVENT-BASED AFFINITY PROCESSES}

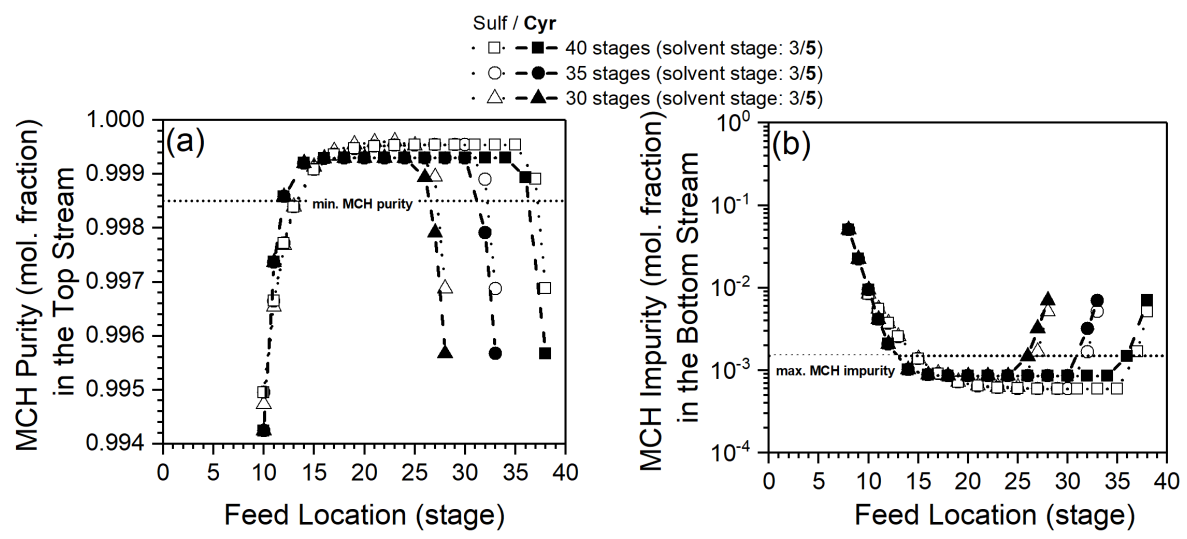

Figure 10.15: The effect of the feed location in the (first) extractive distillation (ED) column on the (a) MCH purity in the top stream and (b) the MCH impurity in the bottom stream with a $40 \mathrm{~mol} \%$ aromatic feed using Sulfolane or Cyrene as solvent and respectively a Solvent-to-Feed ratio of 5.0 and 2.0 and respectively a reflux ratio of 0.5 and 1.0.

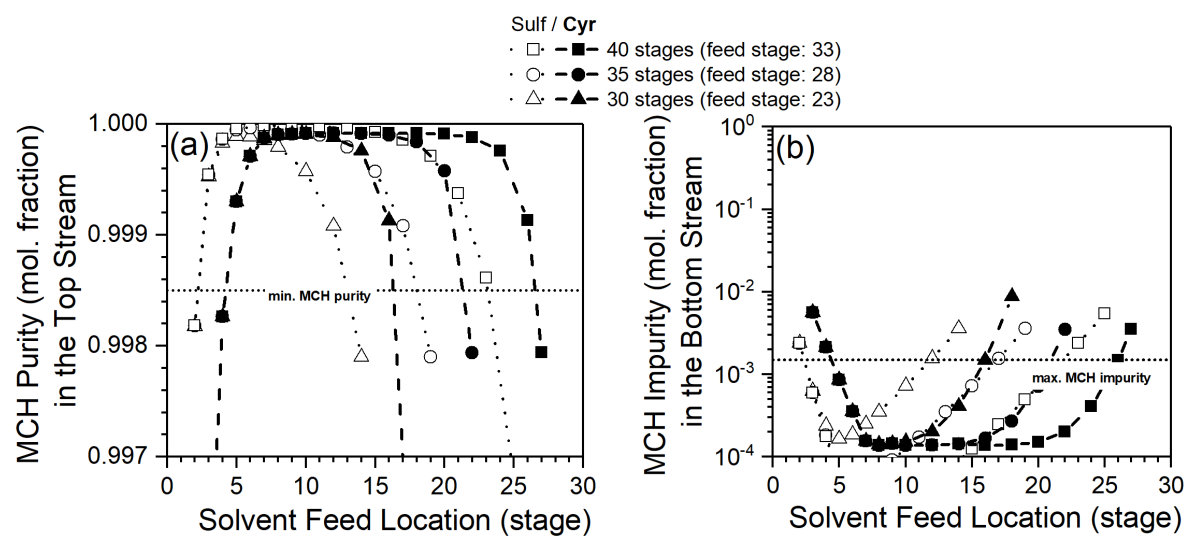

Figure 10.16: The effect of the solvent feed location in the (first) extractive distillation (ED) column on the (a) MCH purity in the top stream and (b) the MCH impurity in the bottom stream with a $40 \mathrm{~mol} \%$ aromatic feed using Sulfolane or Cyrene as solvent and respectively a Solvent-to-Feed ratio of 5.0 and 2.0 and respectively a reflux ratio of 0.5 and 1.0. 
the column will result in insufficient $\mathrm{MCH}$ removal from the bottom stream and again adversely affect the possible TOL purity in the subsequent recovery column. Sulfolane can be introduced higher up in the column due to the lower vapor pressure, while Cyrene can be introduced lower in the column as it evaporates more easily and therefore less likely to be withdrawn in the bottom stream.
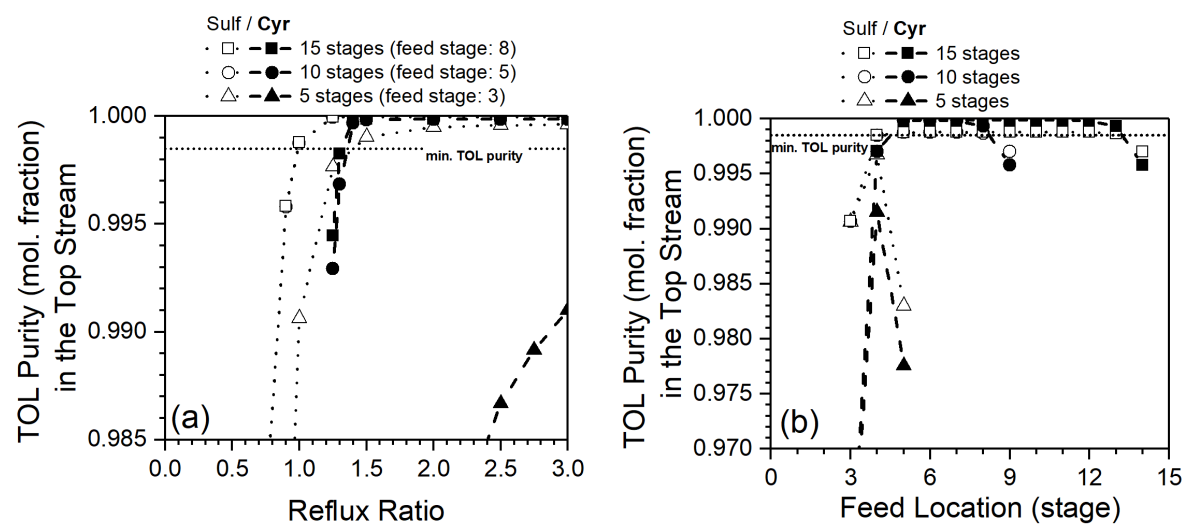

Figure 10.17: (a) The effect of the reflux ratio and (b) the feed location in the solvent recovery (SR) column on the TOL purity in the top stream with a 40 mol.\% aromatic feed using Sulfolane or Cyrene as solvent and respectively a Solvent-to-Feed ratio of 5.0 and 2.0 and in (b) a reflux ratio of 1.5 .

In the (second) distillation column or solvent recovery (SR) column, the TOL purity is the key parameter. In Figure 10.17a, the minimum reflux ratio can be seen to be slightly dependent on the number of equilibrium stages, indicating that the relative volatility of the solvent is much lower than that of the hydrocarbons. Also, fewer equilibrium stages are required compared to the ED column. Again indicating that the separation in the SR column is less difficult, which was expected based on the much larger relative volatility between solvent and TOL than between TOL and MCH. It can be seen that the Cyrenebased ED process requires more equilibrium stages and a larger reflux ratio in the SR column. This is due to the higher volatility of the Cyrene compared to Sulfolane. In Figure 10.17b, it can be seen that the feed location follows 
the same trends as seen before. A feed entrance too high up the column reduces the TOL purity and may even be insufficient to achieve the required specification.
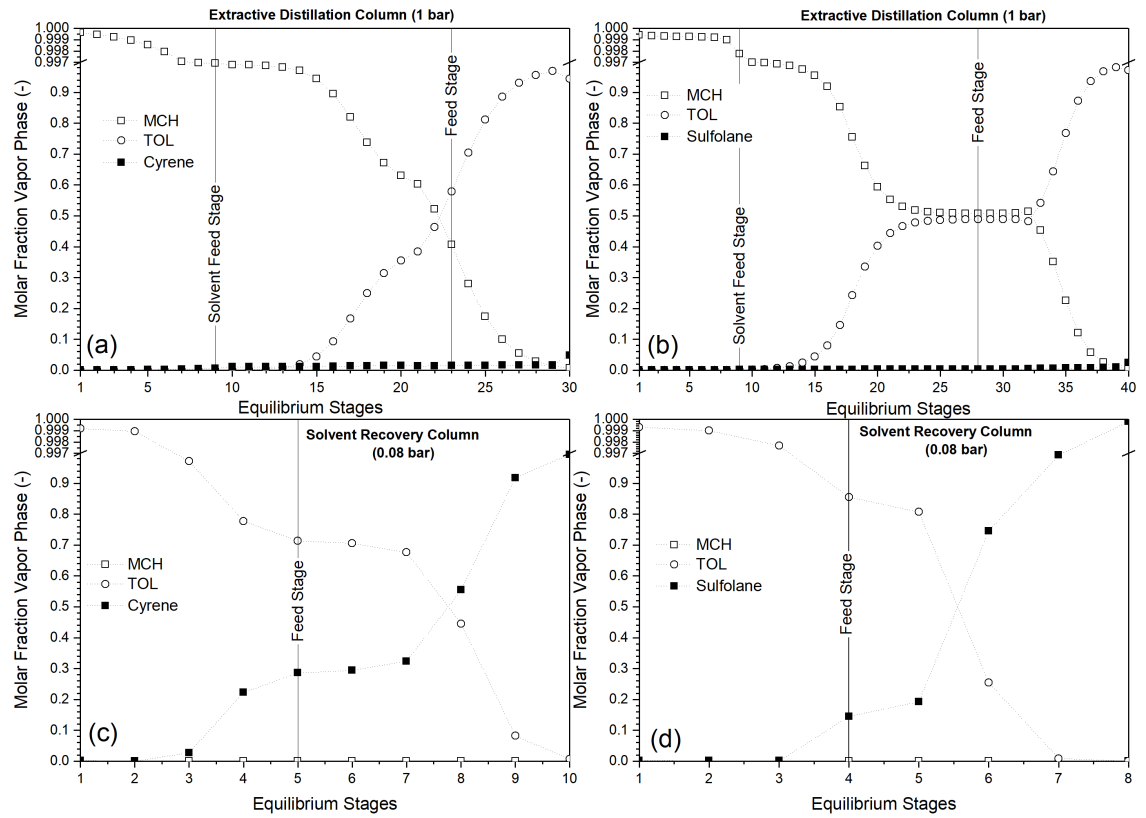

Figure 10.18: (a) The (first) extractive distillation column with of the Cyrene-based EDprocess (feed: $60 \mathrm{~mol} . \% \mathrm{MCH}, 40 \mathrm{~mol} . \%$ TOL, a SF ratio of 1.6, reflux ratio of 0.27 ), (b) the (first) extractive distillation column with of the Sulfolane-based ED-process (feed: 60 mol.\% MCH, 40 mol.\% TOL, SF ratio of 3.5, reflux ratio of 1.6), (c) the (second) distillation column of the Cyrene-based ED-process (feed: trace MCH, $20 \mathrm{~mol} \% \%$ TOL, $80 \mathrm{~mol} . \%$ Cyrene, reflux ratio of 0.78 ) and (d) the (second) distillation column of the Sulfolane-based EDprocess (feed: trace MCH, 10 mol.\% TOL, 90 mol.\% Sulfolane, reflux ratio of 0.8).

Overall, an interplay between sufficient solvent to allow an efficient $\mathrm{MCH}$ separation in the ED column and a minimization of the energy penalty in the SR column is required. In Figure 10.18, an example of the concentration profiles in each column is seen. In the ED column, it is seen that the heavy boiling solvent, which is added in the top section of the ED column, is remaining 
in the liquid phase, while the top product reaches the targeted $\mathrm{MCH}$ purity. The vapor-liquid equilibrium of $\mathrm{MCH}$ and TOL with Sulfolane present has a pinch point hence more equilibrium trays are required to obtain the $\mathrm{MCH}$ specification. In the SR column, TOL is distilled from the solvent without any stripping water. Also in this process, the purity of the recycled solvent is high to prevent unwanted solute recycling.

\subsubsection{OPEX}

In Figure 10.19, the OPEX of all ED processes is shown. Also, in this case, a distinction is made between costs associated with heating, cooling, electrical duty and solvent losses. As can be seen, both Cyrene-based and Sulfolanebased processes operate at minimum OPEX around an equimolar $\mathrm{MCH} / \mathrm{TOL}$ feed mixture. This minimum was also seen in the LLX-based process, and is again due to the load is being shared equally in this case between both distillation columns. Also, the operation window of the Cyrene-based process is larger, as it includes TOL feed composition of $10 \mathrm{~mol} \%$., due to the larger miscibility region of Cyrene compared to Sulfolane.
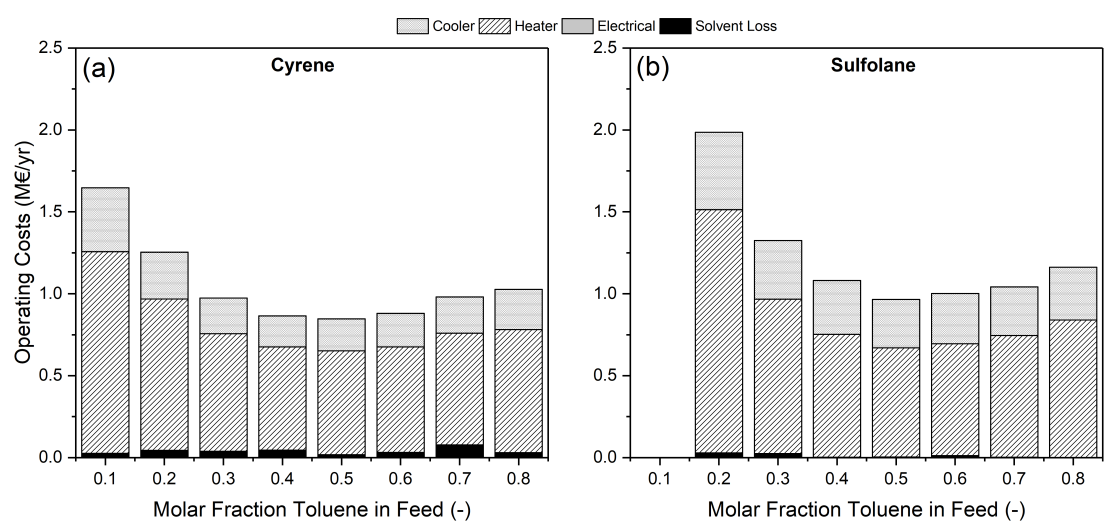

Figure 10.19: Operating costs (OPEX) of the LLX processes with a range of aromatic contents in the feed. For (a) the Cyrene and (b) the Sulfolane case.

The larger miscibility was detrimental in the LLX-process, but is an advantage 
in this process as it is not limited by liquid-liquid phase split at lower TOL concentrations. In the Cyrene-based and Sulfolane-based ED processes, the OPEX increases at higher ( $>50 \mathrm{~mol} . \%)$ TOL concentration and low concentration ( $<50 \mathrm{~mol} . \%)$. Increasing the amount of $\mathrm{MCH}$ present, upturns the load on the ED columns, as higher refluxes are required to obtain the required target purity of $\mathrm{MCH}$. Increasing the amount of TOL, increases the load on the SR column, as more TOL needs to be stripped from the solvent which also required higher reflux ratios. A small amount of solvent is lost in the product streams. Further optimization can be done to minimize these losses. Overall comparing both processes, a similar trend can be recognized in the OPEX, although a lower OPEX is seen for the Cyrene-based process, which is a combined result from the lower temperatures required in both columns and the absence of the detrimental pinch point present only in the ternary Sulfolane$\mathrm{MCH}-\mathrm{TOL}$ mixture.

\subsubsection{Total Annual Cost (TAC) Comparison}

In this comparison of the costs related to the entire process, both the OPEX and the CAPEX are taken into consideration in the TAC. A detailed equipment list and associated costs for each process can be seen in (appendix) tables $\mathrm{S} 1$ to S4 in the ESI. The CAPEX differences between the Cyrene-based LLXprocess $\left(3.11-4.67 \mathrm{M} € / \mathrm{yr}\right.$ or $3.70-5.56 € /$ ton $\left._{\text {feed }} / \mathrm{yr}\right)$ and Sulfolane-based LLX-process $\left(1.56-2.27 \mathrm{M} € /\right.$ yr or $1.85-2.70 € /$ ton $\left._{\text {feed }} / \mathrm{yr}\right)$ are significant. Cyrene exhibits unfavorable miscibility which increases the solvent volume. The CAPEX differences between the Cyrene-based ED-process $(1.41-2.25$ $\mathrm{M} € / \mathrm{yr}$ or $1.68-2.68 € /$ ton $\left._{\text {feed }} / \mathrm{yr}\right)$ and Sulfolane-based ED-process (1.58 $2.68 \mathrm{M} € /$ yr or $1.88-3.19 € /$ ton $_{\text {feed }} /$ yr) are not very large, although present due to a variance in equilibrium stages, in temperatures and solvent volume.

As can be seen in Figure 10.20 where all processes are compared, a Cyrenebased LLX-process is economically least attractive. The LLX process with Sulfolane and also the ED processes with both solvents are much more efficient and should be preferred. The same trend as described by Weissermel and Arpe $^{18}$ was observed, at the lower TOL feed concentrations for Sulfolane a LLX process is preferred over an ED process and can be seen by the lowest 
TAC of the Sulfolane-based LLX process at TOL feed concentrations of $<30$ mol.\%. If the performances of the Cyrene-based and Sulfolane-based ED processes are compared, it can be seen that the Cyrene-based ED process outperforms the Sulfolane-based ED process. This corresponds to the fact that the unfavorable pinch-point present in the Sulfolane-based processes are at higher $\mathrm{MCH}$ fractions. While the TAC difference between both processes diminishes at higher TOL feed concentrations. This signifies the potential of Cyrene to replace Sulfolane as an entrainer in ED processes.

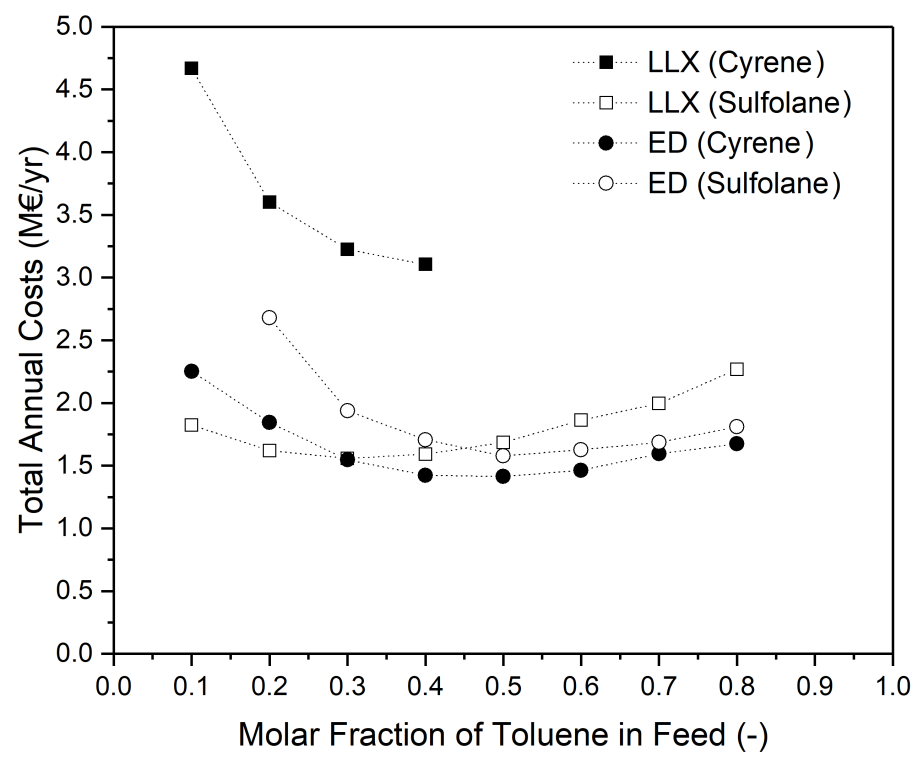

Figure 10.20: The TAC comparison of Cyrene-based LLX and ED processes and the Sulfolane-based LLX and ED processes.

Reflecting these performances on actual feedstocks, the LLX process with Sulfolane is still preferred as many feedstocks have a low aromatic content, such as $10-25 \%$ from an ethylene cracker $^{12}$ and 9-14.3 vol. \% in Arab crude oil. ${ }^{36}$ The possibility of a LLX-process using a mixture of Cyrene and Sulfolane may have potential, as Sulfolane upholds the phase-splitting, while Cyrene can potentially lower the reboiler temperatures and remove the pinch-point. Alternative processes, for these low TOL feed concentrations, are IL-based pro- 
cesses, as described by Meindersma et al. ${ }^{12}$ After catalytic reforming, the aromatic content can be elevated to typically $55 \mathrm{wt} . \%{ }^{81}$ In these situations, the Cyrene-based ED process is seen be to the most efficient, again showing the potential of Cyrene as this is a bio-based entrainer in an ED process.

\subsection{Conclusion}

The bio-based solvent dihydrolevoglucosenone commercialized as Cyrene,which was already investigated for vapor-liquid ${ }^{7}$ and liquid-liquid equilib$\mathrm{ria}^{8}$, was studied extensively as solvent in fluid separation processes for toluene and methylcyclohexane at a process level. The liquid-liquid extraction (LLX)-based and extractive distillation (ED)-based processes with Cyrene were compared to the bench-mark Sulfolane. Based on simulations of conceptual processes the total annual costs (TAC) have been calculated and compared for both solvents and both LLX and ED. The Cyrene-based LLX process was economically least attractive due to the large miscibility region, while the Sulfolane-based LLX was most efficient if the toluene feed concentration was lower than 30 mol.\%. For higher toluene feed concentration the Cyrene-based ED process is most efficient. Overall, this study showed the potential use of a bio-based solvent, Cyrene, in economically competitive separation processes in the petroleum industry. A suggestion for further research is to investigate the application of mixtures of Cyrene and Sulfolane, which can be of interest, as Sulfolane upholds the phase-splitting, while Cyrene can potentially lower the reboiler temperatures and remove the pinch-point. 


\subsection{Nomenclature}

$\begin{array}{ll}\text { AD } & =\text { Azeotropic Distillation } \\ \text { APEA } & =\text { Aspen Plus }{ }^{\circledR} \text { process economic analyzer } \\ \text { CAPEX } & =\text { Capital expenditure } \\ C_{p} & =\text { isobaric heat capacity }\left(J \cdot g^{-1} \cdot K^{-1}\right) \\ \text { Cyrene } & =\text { Dihydrolevoglucosenone } \\ \text { DES } & =\text { Deep eutectic solvent } \\ \text { ED } & =\text { Extractive distillation } \\ \text { IL } & =\text { Ionic liquid } \\ \text { LLE } & =\text { Liquid-liquid equilibrium } \\ \text { LLX } & =\text { Liquid-liquid extraction } \\ \text { MCH } & =\text { methylcyclohexane } \\ \text { NFM } & =\text { N-formylmorpholine } \\ \text { NMP } & =\text { N-methylpyrrolidone } \\ \text { NRTL } & =\text { Non-random two liquid } \\ \text { OPEX } & =\text { Operational expenditure } \\ \text { PBP } & =\text { Payback period } \\ \text { SF } & =\text { Solvent-to-Feed ratio (mass ratio) } \\ \text { SR } & =\text { Solvent recovery } \\ \text { Sulfolane } & =\text { Tetrahydrothiophene-1,1-dioxide } \\ \text { TAC } & =\text { Total annual cost } \\ \text { TOL } & =\text { Toluene } \\ \text { UNIQUAC } & =\text { Universal quasichemical } \\ \text { VLE } & =\text { Vapor-liquid equilibrium } \\ \text { WF } & =\text { Water-to-feed ratio (mass ratio) }\end{array}$

\subsection{References}

[1] International Energy Agency, "World oil supply and demand, 1971-2019," 2019.

[2] International Energy Agency, "The future of petrochemicals," 2018.

[3] A. Dimitriadis and S. Bezergianni, "Hydrothermal liquefaction of various biomass and waste feedstocks for biocrude production: A state of the art review," Renewable and Sustainable Energy Reviews, vol. 68, pp. 113-125, 2017.

[4] S. Oudenhoven, R. J. M. Westerhof, N. Aldenkamp, D. W. F. Brilman, and S. R. Kersten, "Demineralization of wood using wood-derived acid: towards a selective pyrolysis process for fuel and chemicals production," Journal of analytical and applied pyrolysis, vol. 103, pp. 112-118, 2013. 


\section{PROCESS SIMULATION OF SOLVENT-BASED AFFINITY PROCESSES}

[5] R. J. Westerhof, D. W. F. Brilman, M. Garcia-Perez, Z. Wang, S. R. Oudenhoven, W. P. van Swaaij, and S. R. Kersten, "Fractional condensation of biomass pyrolysis vapors," Energy E fuels, vol. 25, no. 4, pp. 1817$1829,2011$.

[6] X. Li, L. C. Luque-Moreno, S. R. Oudenhoven, L. Rehmann, S. R. Kersten, and B. Schuur, "Aromatics extraction from pyrolytic sugars using ionic liquid to enhance sugar fermentability," Bioresource technology, vol. 216, pp. 12-18, 2016.

[7] T. Brouwer and B. Schuur, "Bio-based solvents as entrainers for extractive distillation in aromatic/aliphatic and olefin/paraffin separation," Green Chemistry, 2020.

[8] T. Brouwer and B. Schuur, "Dihydrolevoglucosenone (cyrene $\left.{ }^{\mathrm{TM}}\right)$, a bio-based solvent for liquid-liquid extraction applications," ACS Sustainable Chemistry \& Engineering, 2020.

[9] F. Abushwireb, H. Elakrami, and M. Emtir, "Recovery of aromatics from pyrolysis gasoline by conventional and energy-integrated extractive distillation," Computer Aided Chemical Engineering, vol. 24, p. 1071, 2007.

[10] M. Blahušiak, A. A. Kiss, K. Babic, S. R. Kersten, G. Bargeman, and B. Schuur, "Insights into the selection and design of fluid separation processes," Separation and purification technology, vol. 194, pp. 301-318, 2018.

[11] M. Sharma, P. Sharma, and J. N. Kim, "Solvent extraction of aromatic components from petroleum derived fuels: a perspective review," RSC advances, vol. 3, no. 26, pp. 10103-10126, 2013.

[12] G. W. Meindersma and A. B. de Haan, "Conceptual process design for aromatic/aliphatic separation with ionic liquids," chemical engineering research and design, vol. 86, no. 7, pp. 745-752, 2008.

[13] W. Meindersma, F. Onink, A. R. Hansmeier, and A. B. de Haan, "Long term pilot plant experience on aromatics extraction with ionic liquids," Separation Science and Technology, vol. 47, no. 2, pp. 337-345, 2012.

[14] F. Onink, C. Drumm, G. W. Meindersma, H.-J. Bart, and A. B. de Haan, "Hydrodynamic behavior analysis of a rotating disc contactor for aromatics extraction with 4-methyl-butyl-pyridinium. bf 4 by cfd," Chemical Engineering Journal, vol. 160, no. 2, pp. 511-521, 2010.

[15] G. W. Meindersma, A. R. Hansmeier, and A. B. de Haan, "Ionic liquids for aromatics extraction. present status and future outlook," Industrial E Engineering Chemistry Research, vol. 49, no. 16, pp. 7530-7540, 2010.

[16] P. Navarro, I. de Dios-García, M. Larriba, N. Delgado-Mellado, M. Ayuso, D. Moreno, J. Palomar, J. García, and F. Rodríguez, "Dearomatization of pyrolysis gasoline by extractive distillation with 1-ethyl-3methylimidazolium tricyanomethanide," Fuel Processing Technology, vol. 195, p. 106156, 2019.

[17] Y. Zhang, Y. Wang, F. Chen, S. Liu, L. Zhao, J. Gao, T. Hao, and C. Xu, "Research on a dual solvent to separate olefin/aromatic-sulfide from heavy fluid catalytic cracking naphtha," Energy E Fuels, vol. 32, no. 3, pp. 4057-4064, 2018.

[18] K. Weissermel and H.-J. Arpe, Industrial organic chemistry. John Wiley \& Sons, 2008.

[19] S. Widagdo and W. D. Seider, "Journal review. azeotropic distillation," AIChE Journal, vol. 42, no. 1, pp. 96-130, 1996.

[20] H. Matuschewski and U. Schedler, "Mse-modified membranes in organophilic pervaporation for aromatics/aliphatics separation," Desalination, vol. 224, no. 1-3, pp. 124-131, 2008.

[21] F. Pithan, C. Staudt-Bickel, S. Hess, and R. N. Lichtenthaler, "Polymeric membranes for aromatic/aliphatic separation processes," ChemPhysChem, vol. 3, no. 10, pp. 856-862, 2002.

[22] R. M. Dessau, "Selective sorption of linear aliphatic compounds by zeolites," May 14 1985. US Patent $4,517,402$.

[23] A. Takahashi, F. H. Yang, and R. T. Yang, "Aromatics/aliphatics separation by adsorption: New sorbents for selective aromatics adsorption by $\pi$-complexation," Industrial E engineering chemistry research, vol. 39 , no. 10 , pp. 3856-3867, 2000.

[24] M. Matsumoto, Y. Inomoto, and K. Kondo, "Selective separation of aromatic hydrocarbons through supported liquid membranes based on ionic liquids," Journal of Membrane Science, vol. 246, no. 1, pp. 77-81, 2005.

[25] R. D. Partridge, D. G. Peiffer, D. C. Dalrymple, and W. Weissman, "Polymer membrane for separating aromatic and aliphatic compounds," Nov. 30 2010. US Patent 7,842,124.

[26] A. Arce, M. J. Earle, H. Rodríguez, and K. R. Seddon, "Separation of aromatic hydrocarbons from alkanes 


\section{PROCESS SIMULATION OF SOLVENT-BASED AFFINITY PROCESSES}

using the ionic liquid 1-ethyl-3-methylimidazolium bis $\{($ trifluoromethyl) sulfonyl $\}$ amide," Green Chemistry, vol. 9, no. 1, pp. 70-74, 2007.

[27] A. Arce, M. J. Earle, H. Rodríguez, K. R. Seddon, and A. Soto, "1-ethyl-3-methylimidazolium bis $\{($ trifluoromethyl) sulfonyl $\}$ amide as solvent for the separation of aromatic and aliphatic hydrocarbons by liquid extraction-extension to c 7-and c 8-fractions," Green Chemistry, vol. 10, no. 12, pp. 1294-1300, 2008.

[28] G. W. Meindersma, A. J. Podt, and A. B. de Haan, "Ternary liquid-liquid equilibria for mixtures of toluene+ n-heptane+ an ionic liquid," Fluid phase equilibria, vol. 247, no. 1-2, pp. 158-168, 2006.

[29] M. K. Hadj-Kali, Z. Salleh, E. Ali, R. Khan, and M. A. Hashim, "Separation of aromatic and aliphatic hydrocarbons using deep eutectic solvents: A critical review," Fluid Phase Equilibria, vol. 448, pp. 152 $167,2017$.

[30] S. Mulyono, H. F. Hizaddin, I. M. Alnashef, M. A. Hashim, A. H. Fakeeha, and M. K. Hadj-Kali, "Separation of btex aromatics from n-octane using a (tetrabutylammonium bromide+ sulfolane) deep eutectic solvent-experiments and cosmo-rs prediction," RSC Advances, vol. 4, no. 34, pp. 17597-17606, 2014.

[31] Y. Hou, Z. Li, S. Ren, and W. Wu, "Separation of toluene from toluene/alkane mixtures with phosphonium salt based deep eutectic solvents," Fuel Processing Technology, vol. 135, pp. 99-104, 2015.

[32] N. R. Rodriguez, P. F. Requejo, and M. C. Kroon, "Aliphatic-aromatic separation using deep eutectic solvents as extracting agents," Industrial \& Engineering Chemistry Research, vol. 54, no. 45, pp. 11404$11412,2015$.

[33] D. Smink, S. R. Kersten, and B. Schuur, "Recovery of lignin from deep eutectic solvents by liquid-liquid extraction," Separation and purification technology, vol. 235, p. 116127, 2020.

[34] D. Smink, S. R. Kersten, and B. Schuur, "Comparing multistage liquid-liquid extraction with cold water precipitation for improvement of lignin recovery from deep eutectic solvents," Separation and Purification Technology, vol. 252, p. 117395, 2020.

[35] F. Bezold and M. Minceva, "Liquid-liquid equilibria of $n$-heptane, methanol and deep eutectic solvents composed of carboxylic acid and monocyclic terpenes," Fluid Phase Equilibria, vol. 477, pp. 98-106, 2018.

[36] S. H. HAMID and M. A. ALI, "Comparative study of solvents for the extraction of aromatics from naphtha," Energy Sources, vol. 18, no. 1, pp. 65-84, 1996.

[37] A. R. Karim, P. Khanaqa, and D. A. Shukur, "Kurdistan crude oils as feedstock for production of aromatics," Arabian Journal of Chemistry, vol. 10, pp. S2601-S2607, 2017.

[38] N. D. Ristic, M. R. Djokic, E. Delbeke, A. Gonzalez-Quiroga, C. V. Stevens, K. M. Van Geem, and G. B. Marin, "Compositional characterization of pyrolysis fuel oil from naphtha and vacuum gas oil," Energy E Fuels, vol. 32, no. 2, pp. 1276-1286, 2018.

[39] S. Mirmiran, H. Pakdel, and C. Roy, "Characterization of used tire vacuum pyrolysis oil: nitrogenous compounds from the naphtha fraction," Journal of analytical and applied pyrolysis, vol. 22, no. 3, pp. 205215, 1992.

[40] Q. Wang, J. Y. Chen, M. Pan, C. He, C. C. He, B. J. Zhang, and Q. L. Chen, "A new sulfolane aromatic extractive distillation process and optimization for better energy utilization," Chemical Engineering and Processing-Process Intensification, vol. 128, pp. 80-95, 2018.

[41] R. Krishna, "Extraction of aromatics from $63-69^{\circ} \mathrm{C}$ naphtha fraction for food grade hexane production using sulpholane and nmp as solvents," Indian Journal of Technology, vol. 25, pp. 602-606, 1987.

[42] J. Mahmoudi and M. N. Lotfollahi, "(liquid+ liquid) equilibria of (sulfolane+ benzene+ n-hexane),(nformylmorpholine+ benzene $+\mathrm{n}$-hexane), and (sulfolane $+\mathrm{n}$-formylmorpholine+ benzene+ $\mathrm{n}$-hexane) at temperatures ranging from (298.15 to 318.15) k: Experimental results and correlation," The Journal of Chemical Thermodynamics, vol. 42, no. 4, pp. 466-471, 2010.

[43] E. Muller, B. Enkheim, and K. P. John, "Process of separating pure aromatic hydrocarbons from hydrocarbon mixtures," July 6 1971. US Patent 3,591,490.

[44] H. Zhu, X.-1. Shi, and W.-y. Zhou, "Process simulation and parameter optimization of separating aromatics and non-aromatics by extractive distillation with n-formylmorpholine," Journal of East China University of Science and Technology (Natural Science Edition), vol. 34, no. 3, pp. 309-31, 2008.

[45] S. Adolph, S. Martin, and K. K. Von, "Recovery of aromatic hydrocarbon by extractive distillation with anhydrous liquid propylene carbonate," Jan. 4 1966. US Patent 3,227,632.

[46] A. B. S. Salem and E. Z. Hamad, "Liquid-liquid equilibrium of the five component system of n-hexane- 


\section{PROCESS SIMULATION OF SOLVENT-BASED AFFINITY PROCESSES}

n-heptane- toluene-o-xylene- propylene carbonate," Fluid phase equilibria, vol. 108, no. 1-2, pp. 231-241, 1995.

[47] G. Somekh and B. Friedlander, "Tetraethylene glycol—a superior solvent for aromatics extraction," ACS Publications, 1970.

[48] G. Somekh, D. Kubek, and A. Kosseim, "Process for the separation of aromatic hydrocarbons from a mixed hydrocarbon feedstock," Jan. 30 1973. US Patent 3,714,033.

[49] R. R. De Graff and M. W. Perga, "Method for aromatic hydrocarbon recovery," Sept. 9 1969. US Patent $3,466,346$

[50] H. L. Thompson, "Process for the extraction and recovery of aromatic hydrocarbons," Dec. 1 1970. US Patent 3,544,453.

[51] R. D. Morin, J. B. Fishel, and A. E. Bearse, "Separation of aromatic hydrocarbons from non-aromatic hydrocarbons utilizing a lactam-water solvent," Apr. 19 1960. US Patent 2,933,448.

[52] E. A. Jones and D. B. Broughton, "Solvent extraction process for recovery of aromatic hydrocarbons," Mar. 16 1965. US Patent 3,173,966.

[53] G. Preusser, M. Schulze, K. Richter, and W. Huwels, "Process for recovering highly pure aromatics from a mixture of aromatics and non-aromatics," Mar. 28 1978. US Patent 4,081,355.

[54] J. C. Gentry, L. Berg, J. C. McIntyre, and R. W. Wytcherley, "Process to recover benzene from mixed hydrocarbons by extractive distillation," Mar. 21 1995. US Patent 5,399,244.

[55] T. D. Funkhouser, "Method of purifying unsaturated hydrocarbons by extractive distillation with side stream removal and solvent mix," Aug. 1 1972. US Patent 3,681,202.

[56] B. Cline, "Extractive distillation of aromatic compounds," Apr. 25 1961. US Patent 2,981,661.

[57] M. Larriba, J. de Riva, P. Navarro, D. Moreno, N. Delgado-Mellado, J. García, V. R. Ferro, F. Rodríguez, and J. Palomar, "Cosmo-based/aspen plus process simulation of the aromatic extraction from pyrolysis gasoline using the $\{[4 \mathrm{empy}][\mathrm{NTf} 2]+[\mathrm{emim}][\mathrm{DCA}]\}$ ionic liquid mixture," Separation and Purification Technology, vol. 190, pp. 211-227, 2018.

[58] E. Reyhanitash, T. Brouwer, S. R. Kersten, A. van der Ham, and B. Schuur, "Liquid-liquid extraction-based process concepts for recovery of carboxylic acids from aqueous streams evaluated for dilute streams," Chemical Engineering Research and Design, vol. 137, pp. 510-533, 2018.

[59] M. T. Fouladvand, J. Asadi, and M. N. Lotfollahi, "Simulation and optimization of aromatic extraction from lube oil cuts by liquid-liquid extraction," Chemical Engineering Research and Design, vol. 165, pp. 118-128, 2020.

[60] I. Díaz, J. Palomar, M. Rodríguez, J. de Riva, V. Ferro, and E. J. González, "Ionic liquids as entrainers for the separation of aromatic-aliphatic hydrocarbon mixtures by extractive distillation," Chemical Engineering Research and Design, vol. 115, pp. 382-393, 2016.

[61] Q. Wang, B. Zhang, C. He, C. He, and Q. Chen, "Optimal design of a new aromatic extractive distillation process aided by a co-solvent mixture," Energy Procedia, vol. 105, pp. 4927-4934, 2017.

[62] J. Boston and H. Britt, "A radically different formulation and solution of the single-stage flash problem," Computers \& Chemical Engineering, vol. 2, no. 2-3, pp. 109-122, 1978.

[63] W. D. Seider, J. D. Seader, and D. R. Lewin, PRODUCT \& PROCESS DESIGN PRINCIPLES: SYNTHESIS, ANALYSIS AND EVALUATION, (With CD). John Wiley \& Sons, 2009.

[64] Z. S. Baird, P. Uusi-Kyyny, J.-P. Pokki, E. Pedegert, and V. Alopaeus, "Vapor pressures, densities, and pc-saft parameters for 11 bio-compounds," International Journal of Thermophysics, vol. 40, no. 11, p. 102, 2019.

[65] H. Renon and J. M. Prausnitz, "Local compositions in thermodynamic excess functions for liquid mixtures," AIChE journal, vol. 14, no. 1, pp. 135-144, 1968.

[66] A. Fredenslund, R. L. Jones, and J. M. Prausnitz, "Group-contribution estimation of activity coefficients in nonideal liquid mixtures," AIChE Journal, vol. 21, no. 6, pp. 1086-1099, 1975.

[67] A. Misefari, Investigation of the spectroscopic, chemical and physical properties of Cyrene and its hydrate. $\mathrm{PhD}$ thesis, University of York, 2017.

[68] Dortmund Databank: Molar Heat Capacity Sulfolane, 2020.

[69] P.-H. Chao, H.-W. Lin, C.-H. Chen, P.-Y. Wang, Y.-F. Chen, H.-T. Sei, and T.-C. Tsai, "Precoking selectivation for improving benzene product purity in heavy aromatics transalkylation," Applied Catalysis A: General, vol. 335, no. 1, pp. 15-19, 2008. 


\section{PROCESS SIMULATION OF SOLVENT-BASED AFFINITY PROCESSES}

[70] J. Qin, Q. Ye, X. Xiong, and N. Li, "Control of benzene-cyclohexane separation system via extractive distillation using sulfolane as entrainer," Industrial E Engineering Chemistry Research, vol. 52, no. 31, pp. 10754-10766, 2013.

[71] M. T. Jongmans, E. Hermens, M. Raijmakers, J. I. Maassen, B. Schuur, and A. B. de Haan, "Conceptual process design of extractive distillation processes for ethylbenzene/styrene separation," Chemical Engineering Research and Design, vol. 90, no. 12, pp. 2086-2100, 2012.

[72] G. Towler and R. Sinnott, Chemical engineering design: principles, practice and economics of plant and process design. Elsevier, 2012.

[73] U.S. Energy Information Administration, "Electricity," 2020.

[74] Alibaba, "Sulfolane bulk price," Nov. 2020.

[75] S. H. Krishna, K. Huang, K. J. Barnett, J. He, C. T. Maravelias, J. A. Dumesic, G. W. Huber, M. De Bruyn, and B. M. Weckhuysen, "Oxygenated commodity chemicals from chemo-catalytic conversion of biomass derived heterocycles," AIChE Journal, vol. 64, no. 6, pp. 1910-1922, 2018.

[76] M. S. Peters, K. D. Timmerhaus, R. E. West, K. Timmerhaus, and R. West, Plant design and economics for chemical engineers, vol. 4. McGraw-Hill New York, 1968.

[77] L. Li, Y. Tu, L. Sun, Y. Hou, M. Zhu, L. Guo, Q. Li, and Y. Tian, "Enhanced efficient extractive distillation by combining heat-integrated technology and intermediate heating," Industrial E Engineering Chemistry Research, vol. 55, no. 32, pp. 8837-8847, 2016.

[78] W. L. Luyben and I.-L. Chien, Design and control of distillation systems for separating azeotropes. John Wiley \& Sons, 2011.

[79] J. R. Knight and M. F. Doherty, "Optimal design and synthesis of homogeneous azeotropic distillation sequences," Industrial \& engineering chemistry research, vol. 28, no. 5, pp. 564-572, 1989.

[80] F. M. Lee and D. M. Coombs, "Two-liquid-phase extractive distillation for aromatics recovery," Industrial E Engineering Chemistry Research, vol. 26, no. 3, pp. 564-573, 1987.

[81] M. Fandary, G. Aly, M. Fahim, and C. Mumford, "Extraction of btx from naphtha reformate using a mixersettler cascade," Solvent Extraction and Ion Exchange, vol. 7, no. 4, pp. 677-703, 1989.

[82] A. C. P. Alves, J. Sherwood, A. Zhenova, C. R. McElroy, A. J. Hunt, H. L. Parker, T. J. Farmer, A. Constantinou, M. B. De, A. C. Whitwood, et al., "Intelligent approach to solvent substitution: The identification of a new class of levoglucosenone derivatives.," ChemSusChem, vol. 9, no. 24, pp. 3503-3512, 2016. 



In the last years, I touched upon many different aspects of (solvent-based) separation technology. Deliberately, this thesis does not only include an experimental section, but also a fair amount of theoretical work and a simulation chapter. Still, the feeling of unfinished business remains, hence in this chapter I would like to firstly give an overview of what was incorporated in my dissertation and what has been left out, together with the main findings based on the results. Secondly, an outlook will be given based on the findings of my dissertation, and lastly, several topics will be discussed, that I have worked on, but which did not make it into this dissertation, and are worthwhile to investigate in the future.

\subsection{Conclusion and Outlook}

The aim of my dissertation was not only to assess new solvents for extractive distillation and/or liquid-liquid extraction applications, but more importantly also to develop new and more efficient ways of screening, or preselecting potential solvents for separation applications was a goal. For the screening options, both existing models and data were reviewed, and tools based on new measurements were investigated, and for those, primarily intermolecular interactions and affinity was studied. It was attempted to develop an affinity scale-approach instead of a heuristic approach to assess separation performances.

In Chapters 3, 4 and 5, the main focus was laid on the infinite dilution activity coefficient $\left(\gamma_{i}^{\infty}\right)$. This molecular descriptor is a common parameter to assess the interactions between two molecules and is used to screen, or preselect solvents. The first task was to collect a large database with reported $\gamma_{i}^{\infty}$ found in literature, which enabled us to get a clear picture of what has already been done in the past, and what can we learn from this. As the $\gamma_{i}^{\infty}$ is a temperature-dependent parameter, it is important to compare only $\gamma_{i}^{\infty}$ that were reported for the same temperature. Among all temperatures at which $\gamma_{i}^{\infty}$ were reported, most were at $298.15 \mathrm{~K}$. It was found that only $5.4 \%$ of the reported solute-solvent combinations were reported at $298.15 \mathrm{~K}$, and for all other reported temperatures, the share was even less. Since a fair comparison between solvents performances could only be obtained at the same 
temperature, it was necessary to develop a data handling algorithm to interand extrapolate data to other temperatures to make them comparable. Using the Van 't Hoff equation this interpolation and extrapolation has been realized while keeping track of the $95 \%$ confidence interval. This increased the available $\gamma_{i}^{\infty}$ at $298.15 \mathrm{~K}$ of solute-solvent combinations to $23.5 \%$ of the total database which contains 77.173 data points. Eventually, it allowed us to visualize and compare a total of 268 solutes and 692 solvents and share this ability in an open-source $\gamma_{i}^{\infty}$ database. The effect of the molecular structure of both molecular solvents and ionic liquids could be visualized and compared for numerous separation challenges of which only several are assessed in this chapter. A particular potential was identified for ionic liquids with multivalent cations. These ionic liquids show to be able to lower the activity coefficient without losing the particular selective interactions. Often these two characteristics compete with each other and this seems to be less so in this case. In the future, this database can be consulted before experimental planning and work, as it can help with the solvent choice for all thinkable separations between the 622 solute molecules.

The choice of the $\gamma_{i}^{\infty}$ as a molecular descriptor is however not perfect, as this value is indicative for infinite dilution scenarios. This limiting case does not well reflect realistic situations at real solvent-to-feed ratios (smaller than infinite), and several effects related to non-ideal vapor-liquid equilibrium behavior may be overseen which are vital in fluid-based affinity separations. These effects are for instance pinch point and azeotrope formation in an (extractive) distillation column. In the next chapter, we incorporated these effects in the $\gamma_{i}^{\infty}$-based framework by using the 3 -component Margules equation. This equation could extend the application of $\gamma_{i}^{\infty}$ in quick screening to finite concentrations. This allowed us to assess not only the selectivity of a solvent at infinite dilution, but also we could determine the minimal required Solventto-Feed ratio for efficient distillation operation. Following the suggestion of Blahušiak, ${ }^{1}$ a minimal relative volatility of 3 was a prerequisite in the entire composition range. For each assessed industrial example, several of the best performing solvents coincide with (patented) state-of-the-art solvents, indicating the validity of the approach. Next to the state-of-the-art solvents, other innovative solvents were found, showing that there are certain windows of opportunity to go beyond the current state-of-the-art concerning sustainabil- 
ity. For example, the approach showed to be useful to pre-select potential ionic liquids and deep eutectic solvents as more environmentally benign alternatives. In the validation of this methodology, only a few ternary systems could be found to validate the accuracy of the assumptions made. Therefore it would be wise to measure more ternary vapor-liquid equilibria and use the results to more extensively test the approach. Also, this approach was now applied for vapor-liquid equilibria only, though it is believed this can also be done for liquid-liquid equilibria. The ability to predict immiscibility regions, distribution coefficients and selectivities from solely the $\gamma_{i}^{\infty}$ is of great benefit for the design of liquid-liquid extraction processes.

Another aspect of using the $\gamma_{i}^{\infty}$ is the fact that specialized equipment is required to accurately measure these molecular descriptors. Therefore, in the third chapter, the research question was whether a mathematical model could predict these $\gamma_{i}^{\infty}$ accurately, and if so which model was most accurate and why. Again, the investigation spanned both molecular solvents and ionic liquids. It was found that overall the ionic nature of ionic liquids was much more difficult to capture in a model, thus the overall average relative deviation was much higher $(>65 \%)$ and the predictions of molecular solvents. The MOSCED model was found to be most accurate in the latter case with an average relative deviation of $16.2 \pm 1.35 \%$. So, predicted $\gamma_{i}^{\infty}$ for IL should always be used with extreme care, while for molecular solvents they may be useful. However, a critical side-note should be given, when using a model, such as MOSCED, as not all $\gamma_{i}^{\infty}$ can be predicted as the MOSCED parameters are required.

For that reason, an entirely different approach was developed and investigated in Chapter 6, which only requires experimental data which can be measured with less specialized equipment and only well-known input parameter are required. In this approach, we assessed a pre-selection method that requires only the measurement of the heat of mixing and via a thermodynamic model can predict the isobaric vapor-liquid behavior of a mixture. The thermodynamic model is necessary to describe the entropic behavior which is inherently defined within the model choice. Before doing experimental studies on the heat of mixing, for in total 204 binary systems the heat of mixing was found in literature, and these systems were evaluated based on 
the literature data. A range of thermodynamic models was evaluated for the various classes of compounds. The vapor-liquid equilibria of many binary mixtures could be accurately predicted from the heat of mixing by using $\mathrm{cu}$ bic Equation of States (cEoS) in combination with mixing rules. Common cEoS such as the (Soave)-Redlich-Kwong and Peng-Robinson, but also other cEoS performed adequately. It was however found that the self-association of molecules was the origin of erroneous vapor-liquid equilibrium prediction from the heat of mixing. The heat of mixing as a sole input parameter is not sufficient to capture the entropic behavior in these cases. Also, liquid activity coefficient models, such as NRTL, are not preferred due to local minima in the solutions, while cEoS are robust and could successfully be applied for non-self-associating mixtures. This approach is not yet complete, however, due to the fact the vapor-liquid equilibrium of self-associating mixtures could not yet be accurately predicted from the heat of mixing using the evaluated model. More complex models that include association behavior, such as the PC-SAFT or CPA model, are the next step and should be assessed to complete this approach.

Until Chapter 6, the primary focus lay on the assessment and development of new ways of screening or pre-selecting, new potential solvents. The actual assessment of solvents was done in the next few chapters. In Chapter 7, 25 (biobased) solvents were assessed for firstly the apolar separation of aromatic and aliphatic compounds. Although almost all solvents could enhance the relative volatility of the model system toluene (TOL)/methylcyclohexane $(\mathrm{MCH})$, only the biobased dihydrolevoglucosenone, or named Cyrene, was seen to induce similar relative volatility compared to the state-of-the-art industrial solvent Sulfolane, without any thermal degradation. The VLE of Cyrene-TOL-MCH was experimentally determined over the entire (pseudo)binary composition diagram at 1000 mbar, 800 mbar and 500 mbar and compared with the also experimentally determined Sulfolane-TOL-MCH system. It was found that the detrimental pinch-point, present in the Sulfolane system, was not found in the Cyrene-system. This promising feature could result in a reduction of the minimum reflux ratio of $43 \%$ which may correspond to a $30 \%$ reduction in the reboiler duty. Detailed process simulation was outside the scope of this chapter, but was done in Chapter 10. Cyrene was also compared with n-methylpyrrolidone (NMP) for the olefin/paraffin separation 
(n-heptane - 1-heptene), however, it was found that NMP was still far superior. Although Cyrene is not the best solvent for the olefin/paraffin separation, using Cyrene in a composite solvent with for instance NMP can be the solution that can reduce the amount of NMP needed drastically. A synergistic effect may occur by using both solvents. More importantly, another (sustainability) reason is that partly replacing NMP with Cyrene reduces the toxicity of the solvent. In this chapter, a model system n-heptane/1-heptene was applied to assess the olefin/paraffin separations due to the fact the boiling point is about $100^{\circ} \mathrm{C}$. This is however not an industrial case. The most common olefin/paraffin separation is the $\mathrm{C}_{4}$-hydrocarbon separation, and most preferably this system must be assessed. These compounds have however a boiling point below $0^{\circ} \mathrm{C}$ and therefore a set-up needs to be created which can handle low temperatures. This may take some time and effort, but will pay-off in the end.

A similar investigation into the polar separation of acetone and diisopropyl ether was done with 35 biobased solvents in Chapter 8. In this case, two types of entrainers could be distinguished, namely apolar solvents which entrained diisopropyl ether, while polar solvents could entrain acetone. In the first category, DL-limonene was most suitable in the screening experiments, while in the latter category water and ethylene carbonate were seen to induce the largest relative volatility. Complete vapor-liquid equilibria were determined for all three solvents and the NRTL and UNIQUAC correlation of the azeotrope-breaking solvent DL-limonene system were reported. The only solvent that could eliminate the azeotrope present in the binary system was DL-limonene, while water and ethylene carbonate only shifted the azeotropic point as they repelled the high-boiling compound, diisopropyl ether. This chapter shows the potential of biobased solvents for an industrial polar separation, though this is still only one example. In the future, a similar assessment should be done for more industrially relevant polar separations, which must also include aqueous separations. Eventually, a biobased alternative solvent should be made available for each (polar) separation process.

Chapter 9 describes a more extensive study on the use of Cyrene for fluid separations based on the highly promising results of Cyrene in the separation of $\mathrm{MCH}$ and TOL via extractive distillation. In this chapter, the applicability of 
Cyrene in liquid-liquid extraction (LLX) application was assessed for four binary systems; $\mathrm{MCH}-\mathrm{TOL}, \mathrm{MCH}-$ cyclohexanol $(\mathrm{CHOH}), \mathrm{MCH}$-cyclo-hexanone $(\mathrm{CHO})$ and $\mathrm{MCH}-c y c l o p e n t y l$ methyl ether (CPME). The nature of the Cyrene molecule, including a significant hydrocarbon part that is more apolar of nature in combination with the more polar oxygenate functional groups, results in a net less polar nature than for example Sulfolane, which causes a limited immiscibility region in each of the investigated systems. Where this was beneficial for extractive distillation applications, this is undesired in LLX applications. Nevertheless, this chapter showed for the first time liquid-liquid phase behavior of Cyrene. Additionally, a selectivity towards $\mathrm{CHOH}$ over $\mathrm{CHO}$ was observed, which may indicate an application of Cyrene in the industrial oxidation process of cyclohexane to $\mathrm{CHO}$ and $\mathrm{CHOH}$. Via short-cut calculations, it was found that the separation of $\mathrm{CHOH}$ and $\mathrm{CHO}$ from $\mathrm{MCH}$ could be resp. 11 and 43 times more efficient using Cyrene than another reported solvent, water. This is primarily due to the high boiling point of Cyrene, making it a high-boiling solvent instead of the low-boiling water.

Chapter $\mathbf{1 0}$ is also a continuation of the promising results of Cyrene for the separation of TOL and $\mathrm{MCH}$. In this chapter detailed process simulations were performed which allowed a thorough comparison of Cyrene and Sulfolane in an extractive distillation (ED) process and a liquid-liquid extraction (LLX) process. This could only be done using the experimental results shown in Chapters 7 and 9. The Cyrene-based LLX process was economically least feasible due to the large miscibility region reported earlier. The Cyrene-based ED process was seen to be more efficient than the Sulfolane-based equivalent due to the absence of the pinch point in the vapor-liquid equilibrium, which reduced the solvent requirements. Also, the lower boiling point of Cyrene allowed for less reboiler duty. The Sulfo-lane-based LLX-process is however still the most economically attractive option if the aromatic feed content is below $30 \mathrm{~mol} \%$, mainly due to the large immiscibility of Sulfolane and the saturated hydrocarbon. The earlier mentioned 30\% energy reduction was not achieved due to heat integration.

Although these simulations are detailed and many optimization steps have been performed, not all options are exhausted. In this chapter, we kept the same process configuration in the ED-based and LLX-based process. Several other configurations have been reported and it would be interesting to com- 
pare different process configurations for each process. In the LLX-based processes, a steam-stripping effect was introduced in the second distillation column. It should be investigated if this is optimal, as the water can also be introduced in the first distillation column, or be split in a certain ratio between both columns. The option of a dividing wall column configuration may be considered, as well as changing the model hydrocarbon feed to a realistic industrial hydrocarbon feed. The latter does however require a significant amount of experimental vapor-liquid and liquid-liquid equilibrium data of Cyrene and maybe also Sulfolane. Lastly, the liquid heat capacity of Cyrene is not known, and we were not able to measure it accurately by ourselves. Now, we estimated this using the Joback method, but it would be preferable if experimental values could be added to the process simulations.

\subsection{Reflection and Perspectives}

Several types of experiments and analyses were performed over the years, some have entered the thesis, some have not. The determination of liquidliquid equilibria (LLE), vapor-liquid equilibria (VLE), performing gas chromatography analysis (GC) and the measurement of mixing enthalpy $\left(\mathrm{H}^{E}\right)$ correspond to the chapters in this dissertation. Though several side-projects also arose during the last years, as often scientific curiosity knows no bounds. Among these projects were the measurements of solid-liquid equilibria (SLE), the chemical synthesis of biobased solvents, determining Kamlet-Taft parameters, theoretical investigation about molar Gibbs energy curves and derivatives thereof, and use of complex coacervates as a solvent. Although these subjects did not result in additional thesis chapters, I would like to discuss each of these subjects one-by-one in this perspective part of this chapter.

GC analysis: The emphasis is often laid on the experimental measurements, while in my opinion, the analysis procedure is more important. The GC analysis is a robust method, but if you are not careful, you may obtain erroneous results. As this procedure requires high temperatures, the thermal stability of compounds can form an issue. Also, inter- and intramolecular reactions can occur during the GC procedure, which may not occur during the experiment. Hence, before rigorous experimentation, the analysis procedure should always be validated before and during these analyses. Also, the retention time 
of a compound observed during a GC analysis can tell us about the interactions between the compound and the lining of the column. This can be used to determine for instance the infinite dilution activity coefficient, $\gamma^{\infty}$, of a compound in a certain solvent. ${ }^{2}$ This is regularly done in literature, though we did not manage to do this by ourselves. Hence, developing an own procedure to pack a GC column with a new, e.g. biobased, solvent and determine the $\gamma^{\infty}$ of many compounds in these solvents would be of great academic interest and would complement the current application-driven work done in our group.

$H^{E}$ experiment: The measurement of heat of mixing $\left(H^{E}\right)$ in the isothermal calorimetry (ITC) apparatus is in theory simple, though many inaccuracies can arise. Again, patience is the key, as stabilization of the baseline signal (before and) after calibration, can take up to a day. Additionally, the stabilization time after each injection can vary from $30 \mathrm{~min}$ to several hours.

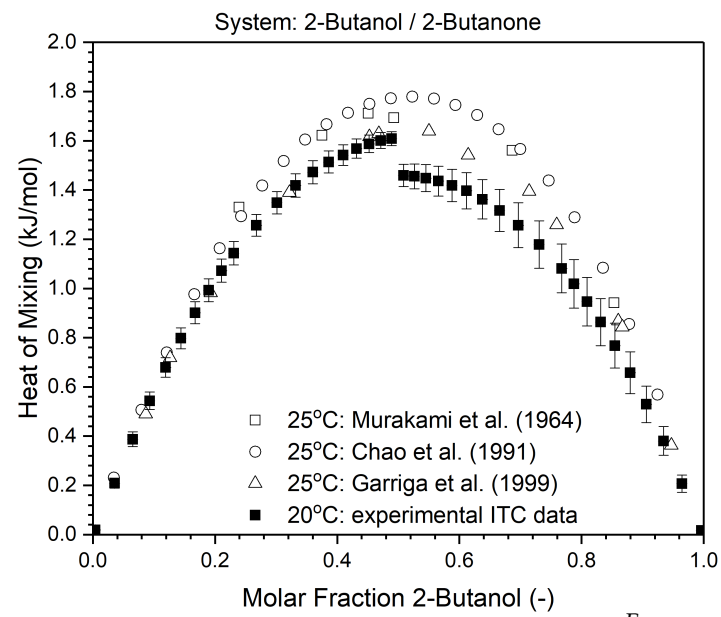

Figure 11.1: The comparison of the reported heat of mixing $\left(H^{E}\right)$ literature values at 25 ${ }^{\circ} \mathrm{C}$ reported by Murakami et al. ${ }^{3}$, Garriga et al. ${ }^{4}$ and Chao et al. ${ }^{5}$ and the experimental results using the ITC at $20^{\circ} \mathrm{C}$ of the binary system 2-butanol/2-butanone. The error margins indicate are the standard deviation between two measurements.

In this dissertation, no experimental $H^{E}$ data are reported, partly due to the fact consistently a mismatch was observed between 2 measurements, and the focus was on the mathematical description of literature data, which was given 
priority. The observed experimental mismatch, see Figure 11.1, was seen when compound 1 (in this case 2-butanol) was titrated into compound 2 (in this case 2-butanone) and vice versa, though this mismatch was seen for all mixtures. One of the identified sources of systematic error is the absolute error induced by each injection. Hence, a decrease in the number of injections lowers the systematic error. Also, the absolute error in each injection will be less significant in systems with large heat of mixings, e.g. in the mixing of acids and bases. Nevertheless, in the future, a detailed investigation into the origin of this systematic error needs to be done and a measurement protocol should be developed to measure accurately the heat of mixing of all mixtures.

Theoretical activity coefficient considerations: Understanding activity coefficients is key to understand how to design (extractive) distillation operations and liquid-liquid extractions. They describe not only the tendency to escape the phase in which a component is in, but they can also be used to predict whether a phase-split may occur or not.
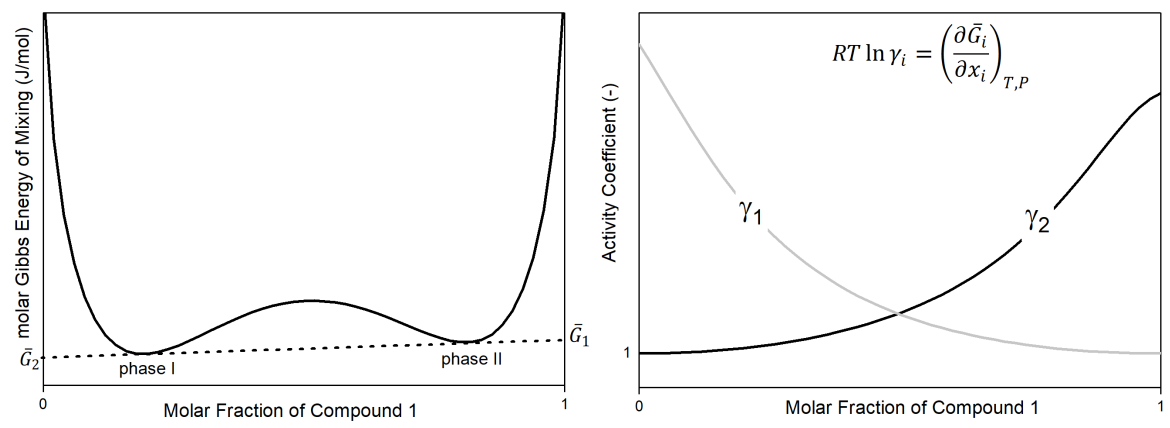

Figure 11.2: A schematic representation of a (left) liquid-liquid phase split in the molar Gibbs energy profile, and (right) of activity coefficient profile

I did not assess this feature, though it is optional. It would be highly interesting if the interplay between phase-splitting and relative volatility would be investigated. As a liquid-liquid phase split should be avoided in an extractive distillation operation, while the activity coefficients should be highly non-ideal to maximize the relative volatility. As can be seen in Figure 11.2, the Gibbs energy profile of a mixture can be determined by the summation of each 
molar Gibbs energy $\left(\bar{G}_{i}\right)$ and their corresponding molar fractions, while the activity coefficients $(\gamma)$ are the derivative of the Gibbs energy. A theoretical combination to determine where a liquid-liquid phase split occurs and which relative volatility may be obtained could create an operation window for extractive distillation purposes, and/or liquid-liquid extraction purposes. This methodology can even be combined with the 3-component Margules equation, which can link the envisioned operation window to the $\gamma^{\infty}$.

Kamlet-Taft Solvatochromic method: During the course of this dissertation, I became fascinated by the solvatochromic method developed by Kamlet, Abboud and Taft, and later also Abraham. ${ }^{6-8}$ They developed several parameters, which can provide useful information regarding intermolecular interactions that underlie spectroscopic properties. The $\alpha$ and $\beta$ respectively describe the hydrogen donating ability (acidity) and hydrogen accepting ability (basicity) of a solvent through red- or blue shift in the UV-VIS spectrum of an aromatic nitro or aniline-based dye. ${ }^{6,7} \mathrm{In}$ combination with the $\pi$-parameter, which includes polarity-polarizability effects, these parameters can give crucial information about which intermolecular interaction a solvent can induce. ${ }^{8}$ This, in turn, strongly influences the activity coefficient as could be seen in chapter 3. A systematic determination of these parameters for, for instance deep eutectic solvents (DES's) and modifications of biobased solvents will be a highly valuable addition to the overall understanding of these solvents. Specifically, it would be interesting if the exact temperature of the eutectic point seen in DES's can be described (and thus predicted) using the KamletTaft parameters. Another feature that may be explored is the cybotactic polarity increment (CPI) which can be determined by determining the Kamlet-Taft for binary mixtures. ${ }^{9}$ The cybotactic region is the local liquid structuring of a solvent surrounded by a solute, in this case, a dye. By determining KamletTaft parameters for 2 solvents and mixtures thereof, the relative strength of the liquid structure can be assessed. This can give valuable insights into the (self-) associative behavior of molecules.

SLE experiment: In recent years, deep eutectic solvents (DES's) have been reported as a new, or rather rediscovered, type of mixtures which opens up numerous possibilities in among others fluid separations. In several chapters, these DES's are mentioned though no experiments of our own were reported. 
The definition of a DES is still fluid, though as the name suggests, the eutectic point of the mixture should be deep. Deep enough that a mixture, which can consist out of two solids, can be used as a liquid at room temperature. In other words, the solid-liquid equilibrium has to be known. Together with a student, we set out to measure these SLE of particular mixtures and we managed to replicate the results with the simple use of a cooling unit with a poly glycol solvent and a rudimentary sample suspension set-up, see Figure 11.3.

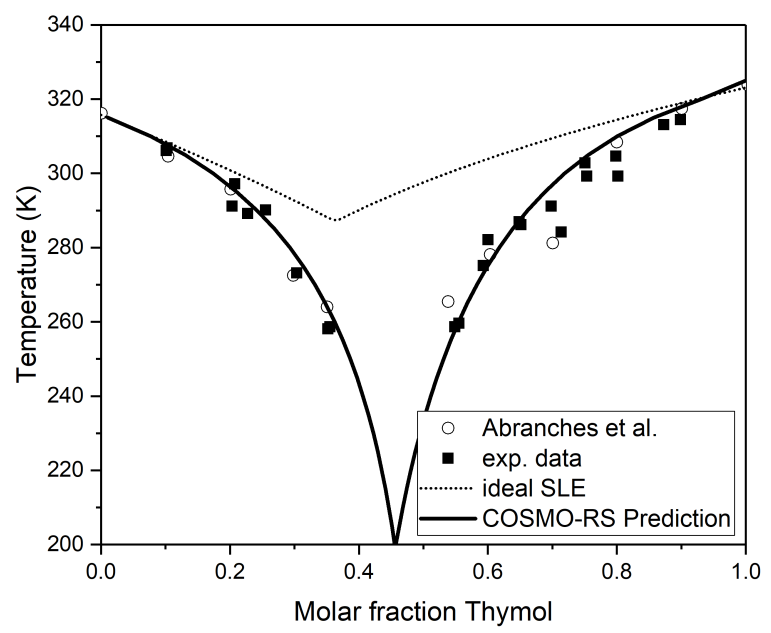

Figure 11.3: Experimental determined solid-liquid equilibrium (SLE) from thymol and menthol compared with literature values by Abranches et al. ${ }^{10}$ Also the ideal SLE is shown as well as a prediction of COSMO-RS.

It is however tricky to measure the equilibrium between solid and liquid phases. First of all, water should always be taken into consideration. Hygroscopic molecules attract water and this will greatly influence the SLE behavior. Secondly, the liquid viscosity increases as the temperature drops. Consequently, the diffusion kinetics slow down considerably, and the risk is real that the equilibrium state is not reached. Switching to a differential scanning calorimetry (DSC) measurement may be key in establishing more accurate (and reliable) SLE data, however, very low temperatures are preferable 
and are not often possible in standard DSC apparatus. Our rudimentary setup could however be upgraded with another coolant and more insulation, to lower the temperature even further, as often SLE data is not reported below $-15^{\circ} \mathrm{C}$ and many eutectic points fall far below this temperature. It is my opinion, that DES's can only be used in fluid separation applications if the SLE of this solvent is accurately determined experimentally and it is justified to call a certain mixture and a deep eutectic mixture.

Synthesis of biobased solvents: Although a huge amount of (biobased) solvents can be purchased from chemical vendors, still many (new) molecules that can be used as solvents are not commercially available or are too expensive to be synthesized by external companies. The combination of synthesis of new (biobased) solvent and the application thereof in fluid separations is highly academically interesting. In the last few years, we also set out to do just that.

The first attempt to synthesizing our own (biobased) solvent was according to an article from Alves et al. ${ }^{11}$ They stated a synthetic route to convert Cyrene, which we use extensively throughout this dissertation, into a new class of molecules called Cygnet, as can be seen in Figure 11.4.
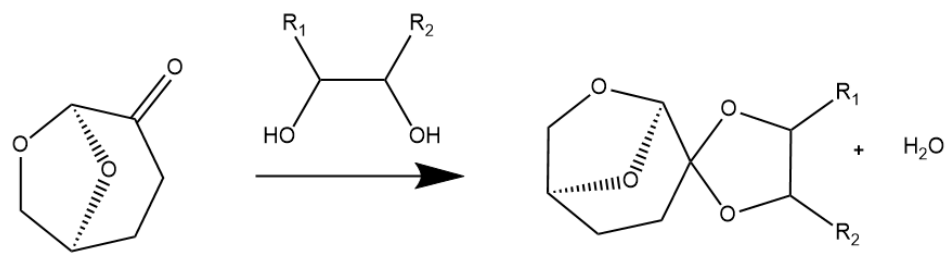

Figure 11.4: The conversion of Cyrene (left) to a new class of molecules called Cygnets (right)

At this moment, Cygnet molecules are being synthesized and in the process of being applied in various fluid separation applications. A simple synthesis procedure needs to be established to produce quantities of $\sim 100$ gram of Cygnet with a minimum required purity of $\sim 99 \%$. If this is achieved, the real objective can begin which is to investigate the potential of Cygnet molecules in fluid separation processes.

Also, following the article by Byrne et al., ${ }^{12}$ a (biobased) ether, named 2,2,5,5- 
tetramethyltetrahydrofuran (TMTHF), was synthesized in a one-pot synthesis from the readily available 2,5-dimethylhexane-2,5-diol. A ${ }^{1} \mathrm{H}-\mathrm{NMR}$ analysis confirmed only traces of the reagent, indicating a highly pure TMTHF product was produced. This furan solvent, which has strong similarities with the common solvent tetrahydrofuran (THF) and the less harmful, biobased, alternative 2-methyltetrahydrofuran (2-MTHF), is shown to be immiscible with water and can therefore be a highly interesting hydrophobic solvent for future applications.

Complex Coacervates: It was several years ago, that I got introduced to the "strange" world of complex coacervates. These complex coacervates can be seen as a bundle of polyelectrolyte molecules (anions and cations) which can be seen as a viscous, gel-like, fluid, and not like any other solvents used in this dissertation. These complex coacervates have been studies for encapsulation of biological agents, such as proteins and amino acids, ${ }^{13,14}$ though have not been assessed as extraction agents for smaller molecules. One of the applications addressed was the removal of carboxylic acids from waste water streams using complex coacervates. In preliminary experiments, we saw that these carboxylic acids could be easily extracted from water, however, the removal of these carboxylic acids from the complex coacervates was very difficult. Possibly, the carboxylic acid could be chemically bonded to one of the polyelectrolytes in the complex coacervate. To investigate this, we performed Small Angle Scattering (SANS) experiments in the Lamor neutron scattering instrument at ISIS Neutron and Muon Source in Oxfordshire.

Our results, shown in Figure 11.5, indicate that the scattering curve of the complex coacervate and the acetic acid is additive and at this q-range, which is indicative of the size of the micro-structures, no change in the structure of the complex is observed. Also, the small angle neutron scattering of complex coacervates with deuterated acetic acid was measured, these also did not show a change in complex structure in the presence of acids. We have further noticed that the formation of the complex coacervates is significantly different in $\mathrm{D}_{2} \mathrm{O}$. In $\mathrm{H}_{2} \mathrm{O}$ at the same concentrations of polyelectrolytes and acetic acid, we obtain very viscous liquid phases, whereas in $\mathrm{D}_{2} \mathrm{O}$ more precipitate-like structures are formed. Since the partitioning behavior of the acids may be different in the precipitate-like structures it is difficult to conclude this SANS 
experiment.
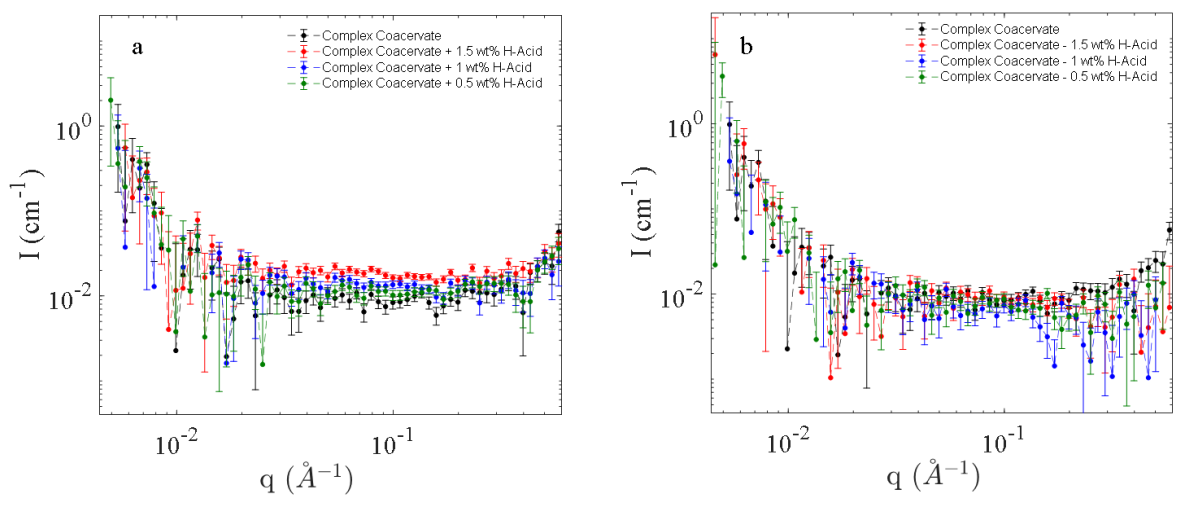

Figure 11.5: (a) SANS curves of (branched) polyethyleneimine (b-PEI)/ polyacrylic acid (PAA) complex coacervates and different amounts of $\mathrm{H}$-acetic acid, $\mathrm{D}_{2} \mathrm{O}$ was subtracted as a background. (b) SANS curves of b-PEI-/PAA complex coacervates and different amounts of $H$-acetic acid, the scattering curve of the respective acid was subtracted as a background. (Many thanks to Saskia Lindhoud for arranging all and performing the experiments with me)

Although the results were inconclusive, it gave a strong correlation that no structural changes occurred in the complex coacervate in presence of a carboxylic acid. These types of experiments are rarely used in the field of solventbased affinity separations, though it may open-up an alternative way of directly observed structural effects as the result of extracted solutes, such as carboxylic acids.

Student Supervision: During my time as a PhD-student I had the privilege to work together with a lot of students, though specifically, I supervised 11 BSc. students and 13 MSc. students with their thesis. Many of them did not directly do something relevant for my work, while others worked from a "hunch" or an idea I had. Nevertheless, I always gave them a lot of freedom to work and figure out stuff by themselves. This was maybe not always the easiest or time-efficient way of performing scientific research, but it is (in my opinion) by far the best way. It enabled them to work independently, be cre- 
ative with solving problems, and figure out things without only calling for help. In the end, not only did the students learn a lot but also did they learn me loads of things. As a perspective, I would highly stress to not micromanage students, don't give them preassigned lists of experiments which he/she should do and only give them a general assignment with not many details.

Overall, I set out to assess not only new solvents for extractive distillation and/or liquid-liquid extraction applications, but also develop an affinity scaleapproach instead of a heuristic approach to assess separation performances. This dissertation showed several developments in pre-selecting approaches using an affinity scale, but also the experimental search and evaluation of (biobased) solvents for (a)polar separation via extractive distillation and liquidliquid extraction, and the simulation of both processes for the apolar separation. Although, I collected, visualized and used many solvents for my assessments. Almost all these solvents were already more or less known from literature. Hence, the greatest possibility is the combination of biobased solvent synthesis, phase behavior evaluations and correlations (VLE, LLE, SLE) and process simulations. Additionally, the use of (entirely or partly) biobased composite solvents and also complex coacervates must be evaluated not only on their phase behavior and factors that influence the phase behavior but also on the process simulation level. Lastly, I set out to develop a method to predict vapor-liquid equilibria from the heat of mixing. As could be seen in this dissertation, this was only partly successful, though still, I am convinced that more complex thermodynamic models that include association effect can complete this method and learn us a great deal about the inherent entropic description within these models. 


\section{CONCLUSION, REFLECTION AND PERSPECTIVE}

\subsection{References}

[1] M. Blahušiak, A. A. Kiss, K. Babic, S. R. Kersten, G. Bargeman, and B. Schuur, "Insights into the selection and design of fluid separation processes," Separation and purification technology, vol. 194, pp. 301-318, 2018.

[2] J.-C. Lerol, J.-C. Masson, H. Renon, J.-F. Fabries, and H. Sannier, "Accurate measurement of activity coefficient at infinite dilution by inert gas stripping and gas chromatography," Industrial E Engineering Chemistry Process Design and Development, vol. 16, no. 1, pp. 139-144, 1977.

[3] S. Murakami, K. Amaya, and R. Fujishiro, "Heats of mixing for binary mixtures. the energy of hydrogen bonding between alcohol and ketone molecules," Bulletin of the Chemical Society of Japan, vol. 37, no. 12, pp. 1776-1780, 1964.

[4] R. Garriga, S. Martınez, P. Pérez, and M. Gracia, "Vapour pressures at several temperatures, and excess functions att $=298.15 \mathrm{k}$ of (butanone+ 2-butanol)," The Journal of Chemical Thermodynamics, vol. 31, no. 1, pp. 117-127, 1999.

[5] J. Chao and M. Dai, "Studies of thermodynamic properties of binary mixtures containing an alcohol xvi. excess molar enthalpies of each of (one of the four butanols+ methyl ethyl ketone or methyl isobutyl ketone) at the temperature 298.15 k," The Journal of Chemical Thermodynamics, vol. 23, no. 2, pp. 117$121,1991$.

[6] M. J. Kamlet and R. Taft, "The solvatochromic comparison method. i. the. beta.-scale of solvent hydrogenbond acceptor (hba) basicities," Journal of the American chemical Society, vol. 98, no. 2, pp. 377-383, 1976.

[7] R. Taft and M. J. Kamlet, "The solvatochromic comparison method. 2. the. alpha.-scale of solvent hydrogen-bond donor (hbd) acidities," Journal of the American Chemical Society, vol. 98, no. 10, pp. 2886$2894,1976$.

[8] M. H. Abraham, M. J. Kamlet, and R. W. Taft, "Linear solvation energy relationships. part 19. correlation of the free energies of solution of 41 solutes in select solvents with hildebrand's solubility parameter, $\delta$ $\mathrm{h}$, and with the solvatochromic parameter, $\pi$," Journal of the Chemical Society, Perkin Transactions 2, no. 8, pp. 923-928, 1982.

[9] M. J. Kamlet, E. G. Kayser, M. E. Jones, J. L. Abboud, J. W. Eastes, and R. Taft, "The solvatochromic comparison method. 4. dilution studies," The Journal of Physical Chemistry, vol. 82, no. 23, pp. 2477-2483, 1978.

[10] D. O. Abranches, M. A. Martins, L. P. Silva, N. Schaeffer, S. P. Pinho, and J. A. Coutinho, "Phenolic hydrogen bond donors in the formation of non-ionic deep eutectic solvents: the quest for type v des," Chemical Communications, vol. 55, no. 69, pp. 10253-10256, 2019.

[11] A. C. P. Alves, J. Sherwood, A. Zhenova, C. R. McElroy, A. J. Hunt, H. L. Parker, T. J. Farmer, A. Constantinou, M. B. De, A. C. Whitwood, et al., "Intelligent approach to solvent substitution: The identification of a new class of levoglucosenone derivatives.," ChemSusChem, vol. 9, no. 24, pp. 3503-3512, 2016.

[12] F. Byrne, B. Forier, G. Bossaert, C. Hoebers, T. J. Farmer, J. H. Clark, and A. J. Hunt, “2, 2, 5, 5tetramethyltetrahydrofuran (tmthf): a non-polar, non-peroxide forming ether replacement for hazardous hydrocarbon solvents," Green Chemistry, vol. 19, no. 15, pp. 3671-3678, 2017.

[13] S. Lindhoud and M. M. Claessens, "Accumulation of small protein molecules in a macroscopic complex coacervate," Soft Matter, vol. 12, no. 2, pp. 408-413, 2016.

[14] S. Lindhoud, R. de Vries, W. Norde, and M. A. C. Stuart, "Structure and stability of complex coacervate core micelles with lysozyme,” Biomacromolecules, vol. 8, no. 7, pp. 2219-2227, 2007. 




\subsection{Appendix A: Detailed Description of MOSCED}

The MOSCED has 5 adjustable parameters for each molecule. The dispersion constant $\lambda_{i}$ and polarity constant $\tau_{i}$. The interaction between induced dipoles is accounted for by the induction parameter, $q_{i}$. To account for hydrogen bonding, the MOSCED model distinguishes acidic $\left(\alpha_{i}\right)$ and basic $\left(\beta_{i}\right)$ contributions to hydrogen bonding. These parameters, $\alpha_{i}, \beta_{i}$ and $\tau_{i}$, are temperaturecorrected via the following empirical correlation. ${ }^{1}$

$$
\begin{aligned}
\alpha_{i}^{T} & =\alpha_{i} \frac{293}{T}^{0.8} \\
\beta_{i}^{T} & =\beta_{i} \frac{293}{T}^{0.8} \\
\tau_{i}^{T} & =\tau_{i} \frac{293}{T}^{0.4}
\end{aligned}
$$

The 2 empirical asymmetry terms, $\psi_{i}$ and $\xi_{i}$, are defined as;

$$
\begin{gathered}
P O L=q_{i}^{4}\left(1.15-1.15 \exp \left(-0.002337\left(\tau_{i}^{T}\right)^{3}\right)\right)+1 \\
\xi_{i}=0.68(P O L-1)+\left(3.24-2.4 \exp \left(-0.002687\left(\alpha_{i} \beta_{i}\right)^{1.5}\right)\right)^{(293 / T)^{2}} \\
\psi_{i}=P O L+0.002629 \alpha_{i}^{T} \beta_{i}^{T}
\end{gathered}
$$

Lastly, an empirical correction of the combinatorial term has been added. To account for the inaccuracies of the Guggenheim-Stavermann approach;

$$
\begin{gathered}
a a=0.953-0.002314\left(\left(\tau_{i}^{T}\right)^{2}-\alpha_{i}^{T} \beta_{i}^{T}\right) \\
\ln \gamma_{i}^{c}=d_{12}=\ln \left(\frac{\Phi_{i}}{x_{i}}\right)^{a a}+1-\left(\frac{\Phi_{i}}{x_{i}}\right)^{a a}
\end{gathered}
$$




\subsection{Appendix B: Additional UNIFAC Equations}

Regarding the combinatorial term, the surface fraction description $\theta_{i}$, is kept the same;

$$
\theta_{i}=\frac{\sum_{j} v_{m}^{(i)} Q_{k}}{\sum_{j} x_{j} v_{m}^{(j)} Q_{k}} \wedge X_{m}=\frac{\sum_{j} v_{m}^{(i)} x_{j}}{\sum_{j} \sum_{n} v_{n}^{(j)} x_{j}} \wedge \theta_{m}=\frac{Q_{m} X_{m}}{\sum_{n} Q_{n} X_{n}}
$$

where volume fraction, $\Phi_{i}$, differs in each UNIFAC variation UNIFAC:

$$
\Phi_{i}=\frac{\sum_{j} v_{k}^{(i)} R_{k}}{\sum_{j} x_{j} \sum_{j} v_{k}^{(j)} R_{k}}
$$

UNIFAC (Ly):

$$
\Phi_{i}^{\prime \prime}=\frac{\left(\sum_{j} v_{k}^{(i)} R_{k}\right)^{\frac{2}{3}}}{\sum_{j} x_{j}\left(\sum_{j} v_{k}^{(j)} R_{k}\right)^{\frac{2}{3}}}
$$

UNIFAC (Do):

$$
\Phi_{i}^{\prime}=\frac{\left(\sum_{j} v_{k}^{(i)} R_{k}\right)^{\frac{3}{4}}}{\sum_{j} x_{j}\left(\sum_{j} v_{j}^{(i)} R_{k}\right)^{\frac{3}{4}}}
$$

In the residual term, the group binary interaction parameter $\Psi$, is made temperaturedependent by the temperature-independent group binary interaction parameter $a_{n m}$ for the UNIFAC and mod. UNIFAC (Ly) variations.

$$
\Psi_{n m}=\exp \left(\frac{-a_{n m}}{T}\right)
$$

and by the temperature independent group binary interaction parameters $a_{n m}, b_{n m}$ and $c_{n m}$ for the mod. UNIFAC (Do) variation

$$
\Psi_{n m}=\exp \left(\frac{-a_{n m}+b_{n m} T+c_{n m} T^{2}}{T}\right)
$$




\subsection{Appendix C: Experimental Vapor-Liquid Equilibrium Data}

Table 12.1: Experimental VLE-data concerning the methylcyclohexane (MCH) - toluene (TOL) in presence of either Cyrene or Sulfolane at 1000 mbar, including the weight fractions in each phase of each solute and the temperature

\begin{tabular}{|c|c|c|c|c|c|c|c|c|c|}
\hline \multicolumn{5}{|c|}{ Quasi Binary System } & \multicolumn{5}{|c|}{ Quasi Binary System } \\
\hline \multicolumn{5}{|c|}{ Pressure: 1000 mbar } & \multicolumn{5}{|c|}{ Pressure: 1000 mbar } \\
\hline \multicolumn{5}{|c|}{ Solvent: Sulfolane $(\mathrm{S}: \mathrm{F}=1)$} & \multicolumn{5}{|c|}{ Solvent: Cyrene ( $\mathrm{S}: \mathrm{F}=1)$} \\
\hline \multicolumn{2}{|c|}{$\mathrm{MCH}^{* *}$} & \multicolumn{2}{|c|}{$\mathrm{TOL}^{* *}$} & Temp. & \multicolumn{2}{|c|}{$\mathrm{MCH}^{* *}$} & \multicolumn{2}{|c|}{$\mathrm{TOL}^{* *}$} & Temp. \\
\hline \multicolumn{2}{|c|}{ (liquid) (gas) } & \multicolumn{2}{|c|}{ (liquid) (gas) } & $(\mathrm{K})$ & \multicolumn{2}{|c|}{ (liquid) (gas) } & \multicolumn{2}{|c|}{ (liquid) (gas) } & $(\mathrm{K})$ \\
\hline 0.000 & 0.000 & 1.000 & 1.000 & 394.3 & 0.000 & 0.000 & 1.000 & 1.000 & 383.2 \\
\hline 0.051 & 0.132 & 0.949 & 0.868 & 392.0 & 0.119 & 0.223 & 0.881 & 0.777 & 380.7 \\
\hline 0.093 & 0.240 & 0.907 & 0.760 & 389.2 & 0.204 & 0.365 & 0.796 & 0.635 & 378.0 \\
\hline 0.166 & 0.399 & 0.834 & 0.601 & 384.5 & 0.296 & 0.506 & 0.704 & 0.494 & 378.1 \\
\hline 0.333 & 0.564 & 0.667 & 0.436 & 379.9 & 0.396 & 0.616 & 0.604 & 0.384 & 376.8 \\
\hline 0.404 & 0.645 & 0.596 & 0.355 & 378.3 & 0.452 & 0.706 & 0.548 & 0.294 & 375.9 \\
\hline 0.521 & 0.697 & 0.479 & 0.303 & 376.8 & 0.476 & 0.773 & 0.524 & 0.227 & 375.9 \\
\hline 0.631 & 0.743 & 0.369 & 0.257 & 376.1 & 0.618 & 0.841 & 0.382 & 0.159 & 373.9 \\
\hline 0.728 & 0.799 & 0.272 & 0.201 & 375.9 & 0.919 & 0.949 & 0.081 & 0.051 & 377.5 \\
\hline 0.802 & 0.854 & 0.198 & 0.146 & 375.6 & 0.866 & 0.943 & 0.134 & 0.057 & 374.3 \\
\hline 0.892 & 0.914 & 0.108 & 0.086 & 375.3 & 1.000 & 1.000 & 0.000 & 0.000 & 374.0 \\
\hline 0.918 & 0.937 & 0.082 & 0.063 & 375.2 & & & & & \\
\hline
\end{tabular}


Table 12.2: Experimental VLE-data concerning the methylcyclohexane (MCH) - toluene (TOL) in presence of Cyrene at 800 and 500 mbar, including the weight fractions in each phase of each solute and the temperature

\begin{tabular}{|c|c|c|c|c|c|c|c|c|c|}
\hline \multicolumn{5}{|c|}{ Quasi Binary System } & \multicolumn{5}{|c|}{ Quasi Binary System } \\
\hline \multicolumn{5}{|c|}{ Pressure: 800 mbar } & \multicolumn{5}{|c|}{ Pressure: $500 \mathrm{mbar}$} \\
\hline \multicolumn{5}{|c|}{ Solvent: Cyrene (S:F = 1) } & \multicolumn{5}{|c|}{ Solvent: Cyrene (S:F = 1) } \\
\hline \multicolumn{2}{|c|}{$\mathrm{MCH}^{* *}$} & \multicolumn{2}{|c|}{$\mathrm{TOL}^{* *}$} & \multirow{2}{*}{$\begin{array}{l}\text { Temp. } \\
(\mathrm{K})\end{array}$} & \multicolumn{2}{|c|}{$\mathrm{MCH}^{* *}$} & \multicolumn{2}{|c|}{$\mathrm{TOL}^{* * *}$} & Temp. \\
\hline (liquic & (gas) & (liquic & (gas) & & (liquid & (gas) & (liquid & (gas) & $(\mathrm{K})$ \\
\hline 0.000 & 0.000 & 1.000 & 1.000 & 376.0 & 0.000 & 0.000 & 1.000 & 1.000 & 363.0 \\
\hline 0.107 & 0.221 & 0.893 & 0.779 & 373.3 & 0.089 & 0.183 & 0.911 & 0.817 & 360.5 \\
\hline 0.195 & 0.369 & 0.805 & 0.631 & 371.3 & 0.191 & 0.354 & 0.809 & 0.646 & 358.0 \\
\hline 0.298 & 0.507 & 0.702 & 0.493 & 372.2 & 0.263 & 0.512 & 0.737 & 0.488 & 356.0 \\
\hline 0.373 & 0.606 & 0.627 & 0.394 & 369.7 & 0.365 & 0.621 & 0.635 & 0.379 & 355.2 \\
\hline 0.474 & 0.702 & 0.526 & 0.298 & 368.5 & 0.431 & 0.706 & 0.569 & 0.294 & 355.4 \\
\hline 0.539 & 0.774 & 0.461 & 0.226 & 368.2 & 0.496 & 0.781 & 0.504 & 0.219 & 353.3 \\
\hline 0.628 & 0.841 & 0.372 & 0.159 & 367.2 & 0.644 & 0.845 & 0.356 & 0.155 & 352.3 \\
\hline 0.895 & 0.949 & 0.105 & 0.051 & 370.5 & 0.861 & 0.945 & 0.139 & 0.055 & 356.2 \\
\hline 0.875 & 0.937 & 0.125 & 0.063 & 367.0 & 0.855 & 0.944 & 0.145 & 0.056 & 352.0 \\
\hline 1.000 & 1.000 & 0.000 & 0.000 & 366.8 & 1.000 & 1.000 & 0.000 & 0.000 & 352.3 \\
\hline
\end{tabular}

${ }^{\star *}$ The error of each data point is approx. 0.03 . 


\subsection{Appendix D: Experimental Liquid-Liquid Equilibrium Data}

Table 12.3: Experimental LLE-data concerning the methylcyclohexane (MCH) - toluene (TOL)-Cyrene (Cy) ternary system, including the weight fractions in each phase of each solute, the distribution coefficient $\left(K_{D, i}\right)$ of $\mathrm{MCH}$ and toluene and the selectivity of toluene over $\mathrm{MCH}\left(S_{i j}\right)$ at $298.15 \mathrm{~K}, 323.15 \mathrm{~K}$ and $348.15 \mathrm{~K}$.

\begin{tabular}{|c|c|c|c|c|c|c|c|c|}
\hline $\mathrm{Cy}$ & TOL & $\mathrm{MCH}$ & $\mathrm{Cy}$ & TOL & $\mathrm{MCH}$ & $\mathrm{MCH}$ & TOL & $\mathrm{TOL} / \mathrm{MCH}$ \\
\hline \multicolumn{9}{|c|}{ (wt. \%) } \\
\hline $2.12 \%$ & $0.76 \%$ & $97.10 \%$ & $91.30 \%$ & $0.74 \%$ & $7.94 \%$ & $0.082 \pm 0.003$ & $0.981 \pm 0.031$ & $11.990 \pm 0.885$ \\
\hline $2.81 \%$ & $1.50 \%$ & $95.70 \%$ & $91.40 \%$ & $1.21 \%$ & $7.37 \%$ & $0.077 \pm 0.001$ & $0.802 \pm 0.013$ & $10.455 \pm 0.327$ \\
\hline $3.17 \%$ & $2.86 \%$ & $94.00 \%$ & $89.70 \%$ & $2.28 \%$ & $8.00 \%$ & $0.085 \pm 0.002$ & $0.795 \pm 0.015$ & $9.370 \pm 0.364$ \\
\hline $3.54 \%$ & $4.35 \%$ & $92.10 \%$ & $88.70 \%$ & $3.18 \%$ & $8.10 \%$ & $0.088 \pm 0.005$ & $0.732 \pm 0.042$ & $8.310 \pm 0.921$ \\
\hline $3.71 \%$ & $5.90 \%$ & $90.40 \%$ & $87.60 \%$ & $4.25 \%$ & $8.20 \%$ & $0.090 \pm 0.003$ & $0.720 \pm 0.026$ & $7.987 \pm 0.512$ \\
\hline $6.68 \%$ & $15.20 \%$ & $78.10 \%$ & $60.60 \%$ & $20.80 \%$ & $18.60 \%$ & $0.238 \pm 0.017$ & $1.363 \pm 0.071$ & $5.725 \pm 0.700$ \\
\hline $14.00 \%$ & $31.40 \%$ & $54.60 \%$ & $45.80 \%$ & $32.10 \%$ & $22.20 \%$ & $0.401 \pm 0.028$ & $1.021 \pm 0.056$ & $2.548 \pm 0.319$ \\
\hline $5.03 \%$ & $9.30 \%$ & $85.70 \%$ & $87.10 \%$ & $5.57 \%$ & $7.35 \%$ & $0.086 \pm 0.000$ & $0.598 \pm 0.003$ & $6.974 \pm 0.047$ \\
\hline $12.00 \%$ & $21.90 \%$ & $66.10 \%$ & $74.00 \%$ & $14.90 \%$ & $11.20 \%$ & $0.169 \pm 0.003$ & $0.679 \pm 0.009$ & $4.017 \pm 0.129$ \\
\hline
\end{tabular}

\begin{tabular}{|c|c|c|c|c|c|c|c|c|}
\hline \multicolumn{9}{|c|}{ Temperature: $323.15 \mathrm{~K}$} \\
\hline \multicolumn{3}{|c|}{ Organic Phase } & \multicolumn{3}{|c|}{ Solvent Phase } & \multicolumn{2}{|c|}{$K_{D, i}$} & $S_{[i j]}$ \\
\hline $\mathrm{Cy}$ & TOL & $\mathrm{MCH}$ & $\mathrm{Cy}$ & TOL & $\mathrm{MCH}$ & $\mathrm{MCH}$ & TOL & $\mathrm{TOL} / \mathrm{MCH}$ \\
\hline \multicolumn{9}{|c|}{ (wt. \%) } \\
\hline $5.90 \%$ & $0.64 \%$ & $93.50 \%$ & $93.60 \%$ & $0.28 \%$ & $6.08 \%$ & $0.065 \pm 0.002$ & $0.441 \pm 0.025$ & $6.760 \pm 0.646$ \\
\hline $6.49 \%$ & $1.52 \%$ & $92.00 \%$ & $90.70 \%$ & $0.82 \%$ & $8.48 \%$ & $0.093 \pm 0.006$ & $0.538 \pm 0.049$ & $5.804 \pm 0.924$ \\
\hline $5.89 \%$ & $3.18 \%$ & $90.90 \%$ & $89.80 \%$ & $1.68 \%$ & $8.53 \%$ & $0.094 \pm 0.005$ & $0.528 \pm 0.030$ & $5.603 \pm 0.587$ \\
\hline $6.20 \%$ & $4.61 \%$ & $89.20 \%$ & $89.20 \%$ & $2.33 \%$ & $8.44 \%$ & $0.095 \pm 0.001$ & $0.505 \pm 0.008$ & $5.331 \pm 0.125$ \\
\hline $6.84 \%$ & $6.06 \%$ & $87.10 \%$ & $90.50 \%$ & $2.54 \%$ & $6.98 \%$ & $0.080 \pm 0.000$ & $0.419 \pm 0.002$ & $5.223 \pm 0.039$ \\
\hline $13.80 \%$ & $15.10 \%$ & $71.10 \%$ & $79.20 \%$ & $8.45 \%$ & $12.40 \%$ & $0.174 \pm 0.006$ & $0.561 \pm 0.032$ & $3.218 \pm 0.293$ \\
\hline $15.20 \%$ & $18.10 \%$ & $66.70 \%$ & $69.30 \%$ & $13.40 \%$ & $17.30 \%$ & $0.261 \pm 0.004$ & $0.740 \pm 0.022$ & $2.839 \pm 0.127$ \\
\hline $20.40 \%$ & $21.80 \%$ & $57.80 \%$ & $62.40 \%$ & $17.10 \%$ & $20.50 \%$ & $0.358 \pm 0.005$ & $0.783 \pm 0.007$ & $2.188 \pm 0.052$ \\
\hline $25.70 \%$ & $24.10 \%$ & $50.20 \%$ & $56.40 \%$ & $19.60 \%$ & $23.90 \%$ & $0.480 \pm 0.004$ & $0.815 \pm 0.019$ & $1.698 \pm 0.054$ \\
\hline
\end{tabular}

\begin{tabular}{|c|c|c|c|c|c|c|c|c|}
\hline \multicolumn{3}{|c|}{ Organic Phase } & \multicolumn{3}{|c|}{ Solvent Phase } & \multicolumn{2}{|c|}{$K_{D, i}$} & $S_{i j}$ \\
\hline $\mathrm{Cy}$ & TOL & $\mathrm{MCH}$ & $\mathrm{Cy}$ & TOL & $\mathrm{MCH}$ & $\mathrm{MCH}$ & TOL & $\mathrm{TOL} / \mathrm{MCH}$ \\
\hline \multicolumn{9}{|c|}{ (wt. \%) } \\
\hline $17.80 \%$ & $0.60 \%$ & $81.60 \%$ & $92.00 \%$ & $0.28 \%$ & $7.74 \%$ & $0.094 \pm 0.005$ & $0.461 \pm 0.029$ & $4.913 \pm 0.578$ \\
\hline $19.10 \%$ & $1.41 \%$ & $79.40 \%$ & $91.60 \%$ & $0.72 \%$ & $7.67 \%$ & $0.096 \pm 0.004$ & $0.513 \pm 0.057$ & $5.320 \pm 0.796$ \\
\hline $19.10 \%$ & $2.92 \%$ & $78.00 \%$ & $87.50 \%$ & $1.84 \%$ & $10.70 \%$ & $0.138 \pm 0.011$ & $0.630 \pm 0.064$ & $4.564 \pm 0.813$ \\
\hline $20.70 \%$ & $4.25 \%$ & $75.00 \%$ & $87.10 \%$ & $2.44 \%$ & $10.50 \%$ & $0.141 \pm 0.007$ & $0.575 \pm 0.052$ & $4.076 \pm 0.576$ \\
\hline $19.60 \%$ & $5.62 \%$ & $74.80 \%$ & $85.30 \%$ & $3.40 \%$ & $11.30 \%$ & $0.153 \pm 0.011$ & $0.606 \pm 0.067$ & $3.953 \pm 0.715$ \\
\hline $35.40 \%$ & $12.50 \%$ & $52.20 \%$ & $73.70 \%$ & $8.54 \%$ & $17.80 \%$ & $0.341 \pm 0.001$ & $0.685 \pm 0.020$ & $2.011 \pm 0.066$ \\
\hline
\end{tabular}




\section{APPENDICES}

Table 12.4: Experimental LLE-data concerning the methylcyclohexane $(\mathrm{MCH})$ - cyclohexanol $(\mathrm{CHOH})-\mathrm{Cyrene}(\mathrm{Cy})$ ternary system, including the weight fractions in each phase of each solute, the distribution coefficient $\left(K_{D, i}\right)$ of $M C H$ and toluene and the selectivity of toluene over $\mathrm{MCH}\left(S_{i j}\right)$ at $298.15 \mathrm{~K}, 323.15 \mathrm{~K}$ and $348.15 \mathrm{~K}$.

Temperature: $298.15 \mathrm{~K}$

\begin{tabular}{|c|c|c|c|c|c|c|c|c|}
\hline \multicolumn{3}{|c|}{ Organic Phase } & \multicolumn{3}{|c|}{ Solvent Phase } & \multicolumn{2}{|c|}{$K_{D, i}$} & \multirow{2}{*}{$\frac{S_{i j}}{\mathrm{CHOH} / \mathrm{MCH}}$} \\
\hline $\mathrm{Cy}$ & $\mathrm{CHOH}$ & $\mathrm{MCH}$ & $\mathrm{Cy}$ & $\mathrm{CHOH}$ & $\mathrm{MCH}$ & $\mathrm{MCH}$ & $\mathrm{CHOH}$ & \\
\hline \multicolumn{6}{|c|}{ (wt. \%) } & & & \\
\hline $3.25 \%$ & $0.17 \%$ & $96.60 \%$ & $91.90 \%$ & $0.80 \%$ & $7.31 \%$ & $0.076 \pm 0.002$ & $4.638 \pm 0.207$ & $61.423 \pm 4.334$ \\
\hline $3.42 \%$ & $0.44 \%$ & $96.10 \%$ & $92.50 \%$ & $1.30 \%$ & $6.17 \%$ & $0.064 \pm 0.003$ & $2.971 \pm 0.258$ & $46.305 \pm 5.874$ \\
\hline $3.57 \%$ & $1.03 \%$ & $95.40 \%$ & $90.10 \%$ & $2.62 \%$ & $7.30 \%$ & $0.076 \pm 0.037$ & $2.552 \pm 0.542$ & $33.371 \pm 23.195$ \\
\hline $4.42 \%$ & $2.46 \%$ & $93.10 \%$ & $84.40 \%$ & $5.90 \%$ & $9.72 \%$ & $0.104 \pm 0.004$ & $2.395 \pm 0.339$ & $23.022 \pm 4.175$ \\
\hline $5.90 \%$ & $4.23 \%$ & $89.90 \%$ & $87.00 \%$ & $5.90 \%$ & $7.15 \%$ & $0.079 \pm 0.000$ & $1.383 \pm 0.003$ & $17.529 \pm 0.098$ \\
\hline $13.50 \%$ & $16.60 \%$ & $69.90 \%$ & $76.40 \%$ & $12.40 \%$ & $11.10 \%$ & $0.162 \pm 0.004$ & $0.763 \pm 0.010$ & $4.701 \pm 0.185$ \\
\hline
\end{tabular}

Temperature: $323.15 \mathrm{~K}$

\begin{tabular}{|c|c|c|c|c|c|c|c|c|}
\hline \multicolumn{3}{|c|}{ Organic Phase } & \multicolumn{3}{|c|}{ Solvent Phase } & \multicolumn{2}{|c|}{$K_{D, i}$} & \multirow{2}{*}{$\begin{array}{c}S_{i j} \\
\mathrm{CHOH} / \mathrm{MCH}\end{array}$} \\
\hline $\mathrm{Cy}$ & $\mathrm{CHOH}$ & $\mathrm{MCH}$ & $\mathrm{Cy}$ & $\mathrm{CHOH}$ & $\mathrm{MCH}$ & $\mathrm{MCH}$ & $\mathrm{CHOH}$ & \\
\hline \multicolumn{6}{|c|}{ (wt. \%) } & & & \\
\hline $4.62 \%$ & $0.22 \%$ & $95.20 \%$ & $90.80 \%$ & $0.65 \%$ & $8.51 \%$ & $0.090 \pm 0.005$ & $2.941 \pm 0.363$ & $32.763 \pm 5.834$ \\
\hline $5.89 \%$ & $0.55 \%$ & $93.60 \%$ & $91.70 \%$ & $1.18 \%$ & $7.08 \%$ & $0.076 \pm 0.001$ & $2.132 \pm 0.105$ & $28.074 \pm 1.684$ \\
\hline $5.63 \%$ & $1.22 \%$ & $93.10 \%$ & $87.40 \%$ & $2.88 \%$ & $9.74 \%$ & $0.105 \pm 0.002$ & $2.369 \pm 0.214$ & $22.626 \pm 2.467$ \\
\hline $6.31 \%$ & $1.91 \%$ & $91.80 \%$ & $86.40 \%$ & $4.03 \%$ & $9.61 \%$ & $0.105 \pm 0.003$ & $2.105 \pm 0.199$ & $20.039 \pm 2.520$ \\
\hline $7.07 \%$ & $2.61 \%$ & $90.30 \%$ & $85.10 \%$ & $4.64 \%$ & $10.30 \%$ & $0.114 \pm 0.007$ & $1.779 \pm 0.139$ & $15.644 \pm 2.131$ \\
\hline $17.90 \%$ & $13.50 \%$ & $68.60 \%$ & $73.60 \%$ & $10.20 \%$ & $16.20 \%$ & $0.36 \pm 0.006$ & $1.268 \pm 0.028$ & $3.521 \pm 0.134$ \\
\hline $11.50 \%$ & $8.39 \%$ & $80.10 \%$ & $58.40 \%$ & $17.10 \%$ & $24.60 \%$ & $0.202 \pm 0.004$ & $1.216 \pm 0.051$ & $6.017 \pm 0.372$ \\
\hline
\end{tabular}

Temperature: $348.15 \mathrm{~K}$

\begin{tabular}{|c|c|c|c|c|c|c|c|c|}
\hline \multicolumn{3}{|c|}{ Organic Phase } & \multicolumn{3}{|c|}{ Solvent Phase } & \multicolumn{2}{|c|}{$K_{D, i}$} & \multirow{2}{*}{$\begin{array}{c}S_{i j} \\
\mathrm{CHOH} / \mathrm{MCH}\end{array}$} \\
\hline $\mathrm{Cy}$ & $\mathrm{CHOH}$ & $\mathrm{MCH}$ & $\mathrm{Cy}$ & $\mathrm{CHOH}$ & $\mathrm{MCH}$ & $\mathrm{MCH}$ & $\mathrm{CHOH}$ & \\
\hline \multicolumn{6}{|c|}{ (wt. \%) } & & & \\
\hline $17.30 \%$ & $0.31 \%$ & $82.40 \%$ & $91.40 \%$ & $0.51 \%$ & $8.14 \%$ & $0.099 \pm 0.006$ & $1.643 \pm 0.116$ & $16.623 \pm 2.263$ \\
\hline $18.00 \%$ & $0.77 \%$ & $81.20 \%$ & $88.50 \%$ & $1.32 \%$ & $10.20 \%$ & $0.126 \pm 0.003$ & $1.722 \pm 0.034$ & $13.706 \pm 0.597$ \\
\hline $12.00 \%$ & $1.50 \%$ & $86.50 \%$ & $87.80 \%$ & $2.62 \%$ & $9.56 \%$ & $0.111 \pm 0.003$ & $1.742 \pm 0.036$ & $15.753 \pm 0.725$ \\
\hline $20.40 \%$ & $2.41 \%$ & $77.20 \%$ & $83.90 \%$ & $3.80 \%$ & $12.30 \%$ & $0.160 \pm 0.000$ & $1.577 \pm 0.017$ & $9.866 \pm 0.129$ \\
\hline $10.90 \%$ & $2.99 \%$ & $86.10 \%$ & $86.40 \%$ & $4.24 \%$ & $9.35 \%$ & $0.109 \pm 0.000$ & $1.422 \pm 0.146$ & $13.047 \pm 1.392$ \\
\hline $17.90 \%$ & $4.87 \%$ & $77.30 \%$ & $69.10 \%$ & $7.87 \%$ & $23.00 \%$ & $0.299 \pm 0.008$ & $1.617 \pm 0.050$ & $5.411 \pm 0.311$ \\
\hline $17.60 \%$ & $5.78 \%$ & $76.60 \%$ & $66.30 \%$ & $9.05 \%$ & $24.70 \%$ & $0.322 \pm 0.011$ & $1.565 \pm 0.003$ & $4.857 \pm 0.182$ \\
\hline $16.20 \%$ & $6.37 \%$ & $77.40 \%$ & $65.10 \%$ & $10.00 \%$ & $24.90 \%$ & $0.324 \pm 0.003$ & $1.564 \pm 0.036$ & $4.822 \pm 0.158$ \\
\hline $21.70 \%$ & $8.11 \%$ & $70.10 \%$ & $58.40 \%$ & $11.20 \%$ & $30.40 \%$ & $0.437 \pm 0.005$ & $1.380 \pm 0.024$ & $3.154 \pm 0.095$ \\
\hline $23.70 \%$ & $10.40 \%$ & $65.90 \%$ & $52.00 \%$ & $13.30 \%$ & $34.80 \%$ & $0.527 \pm 0.015$ & $1.280 \pm 0.004$ & $2.430 \pm 0.077$ \\
\hline
\end{tabular}


Table 12.5: Experimental LLE-data concerning the methylcyclohexane (MCH) - cyclohexanone (CHO)-Cyrene $(\mathrm{Cy})$ ternary system, including the weight fractions in each phase of each solute, the distribution coefficient $\left(K_{D, i}\right)$ of $\mathrm{MCH}$ and toluene and the selectivity of toluene over $\mathrm{MCH}\left(S_{i j}\right)$ at $298.15 \mathrm{~K}, 323.15 \mathrm{~K}$ and $348.15 \mathrm{~K}$.

Temperature: $298.15 \mathrm{~K}$

\begin{tabular}{|c|c|c|c|c|c|c|c|c|}
\hline \multicolumn{3}{|c|}{ Organic Phase } & \multicolumn{3}{|c|}{ Solvent Phase } & \multicolumn{2}{|c|}{$K_{D, i}$} & $S_{i j}$ \\
\hline Cy & $\mathrm{CHO}$ & $\mathrm{MCH}$ & $\mathrm{Cy}$ & $\mathrm{CHO}$ & $\mathrm{MCH}$ & $\mathrm{MCH}$ & $\mathrm{CHO}$ & $\mathrm{CHO} / \mathrm{MCH}$ \\
\hline \multicolumn{9}{|c|}{ (wt. \%) } \\
\hline $3.18 \%$ & $0.19 \%$ & $96.60 \%$ & $89.30 \%$ & $0.87 \%$ & $9.79 \%$ & $0.101 \pm 0.005$ & $4.471 \pm 0.655$ & $44.069 \pm 8.632$ \\
\hline $3.72 \%$ & $0.52 \%$ & $95.80 \%$ & $87.90 \%$ & $2.01 \%$ & $10.10 \%$ & $0.105 \pm 0.013$ & $3.831 \pm 0.715$ & $36.392 \pm 11.351$ \\
\hline $3.39 \%$ & $0.99 \%$ & $95.60 \%$ & $86.50 \%$ & $3.46 \%$ & $10.00 \%$ & $0.105 \pm 0.005$ & $3.515 \pm 0.359$ & $33.347 \pm 5.067$ \\
\hline $4.44 \%$ & $1.61 \%$ & $93.90 \%$ & $84.20 \%$ & $4.44 \%$ & $11.30 \%$ & $0.121 \pm 0.004$ & $2.754 \pm 0.113$ & $22.826 \pm 1.720$ \\
\hline $4.04 \%$ & $2.06 \%$ & $93.90 \%$ & $81.70 \%$ & $6.83 \%$ & $11.50 \%$ & $0.122 \pm 0.004$ & $3.306 \pm 0.463$ & $27.002 \pm 4.556$ \\
\hline $6.94 \%$ & $5.24 \%$ & $87.80 \%$ & $74.20 \%$ & $12.00 \%$ & $13.80 \%$ & $0.158 \pm 0.001$ & $2.293 \pm 0.227$ & $14.515 \pm 1.565$ \\
\hline $5.20 \%$ & $3.37 \%$ & $91.40 \%$ & $86.60 \%$ & $6.16 \%$ & $7.27 \%$ & $0.079 \pm 0.002$ & $1.828 \pm 0.030$ & $23.006 \pm 0.905$ \\
\hline $12.70 \%$ & $8.31 \%$ & $79.00 \%$ & $71.90 \%$ & $13.90 \%$ & $14.10 \%$ & $0.179 \pm 0.004$ & $1.676 \pm 0.014$ & $9.37 \pm 0.276$ \\
\hline $9.32 \%$ & $9.29 \%$ & $81.40 \%$ & $62.70 \%$ & $19.10 \%$ & $18.20 \%$ & $0.225 \pm 0.001$ & $2.059 \pm 0.059$ & $9.153 \pm 0.312$ \\
\hline $11.10 \%$ & $11.30 \%$ & $77.60 \%$ & $59.00 \%$ & $21.10 \%$ & $19.90 \%$ & $0.258 \pm 0.003$ & $1.862 \pm 0.032$ & $7.216 \pm 0.220$ \\
\hline $13.20 \%$ & $13.00 \%$ & $73.80 \%$ & $53.10 \%$ & $22.40 \%$ & $24.50 \%$ & $0.335 \pm 0.018$ & $1.719 \pm 0.039$ & $5.134 \pm 0.395$ \\
\hline
\end{tabular}

Temperature: $323.15 \mathrm{~K}$

\begin{tabular}{|ccc|ccc|cc|c|}
\hline \multicolumn{7}{|c|}{ Organic Phase } & \multicolumn{3}{c|}{ Solvent Phase } & \multicolumn{2}{c|}{$K_{D, i}$} & $S_{i j}$ \\
\hline Cy & CHO & MCH & Cy & CHO & MCH & MCH & CHO & CHO/MCH \\
\hline \multicolumn{7}{|c|}{ (wt. $\%$ ) } \\
\hline $4.90 \%$ & $0.19 \%$ & $94.90 \%$ & $90.10 \%$ & $0.60 \%$ & $9.26 \%$ & $0.098 \pm 0.001$ & $3.145 \pm 0.245$ & $32.139 \pm 2.781$ \\
$5.14 \%$ & $0.53 \%$ & $94.30 \%$ & $88.20 \%$ & $1.58 \%$ & $10.20 \%$ & $0.109 \pm 0.005$ & $2.960 \pm 0.216$ & $27.242 \pm 3.163$ \\
$6.51 \%$ & $1.20 \%$ & $92.30 \%$ & $86.30 \%$ & $2.94 \%$ & $10.80 \%$ & $0.117 \pm 0.006$ & $2.452 \pm 0.223$ & $20.900 \pm 3.043$ \\
$6.84 \%$ & $2.29 \%$ & $90.90 \%$ & $81.50 \%$ & $5.18 \%$ & $13.30 \%$ & $0.024 \pm 0.000$ & $1.611 \pm 0.105$ & $67.216 \pm 4.614$ \\
$18.20 \%$ & $6.61 \%$ & $75.20 \%$ & $68.60 \%$ & $11.40 \%$ & $20.00 \%$ & $0.147 \pm 0.016$ & $2.261 \pm 0.303$ & $15.331 \pm 3.671$ \\
$18.90 \%$ & $11.80 \%$ & $69.30 \%$ & $48.90 \%$ & $16.40 \%$ & $34.70 \%$ & $0.270 \pm 0.006$ & $1.722 \pm 0.083$ & $6.391 \pm 0.459$ \\
\hline
\end{tabular}

Temperature: $348.15 \mathrm{~K}$

\begin{tabular}{|lcl|ccc|cc|c|}
\hline \multicolumn{3}{|c|}{ Organic Phase } & \multicolumn{3}{c|}{ Solvent Phase } & \multicolumn{2}{c|}{$K_{D, i}$} & $S_{i j}$ \\
\hline Cy & CHO & MCH & Cy & CHO & MCH & MCH & CHO & CHO/MCH \\
\hline \multicolumn{7}{|c}{ (wt. $\%)$} \\
$10.30 \%$ & $0.25 \%$ & $89.50 \%$ & $89.30 \%$ & $0.56 \%$ & $10.20 \%$ & $0.114 \pm 0.002$ & $2.202 \pm 0.196$ & $19.253 \pm 1.997$ \\
$7.86 \%$ & $0.65 \%$ & $91.50 \%$ & $88.40 \%$ & $1.24 \%$ & $10.40 \%$ & $0.114 \pm 0.003$ & $1.913 \pm 0.143$ & $16.815 \pm 1.731$ \\
$8.60 \%$ & $1.33 \%$ & $90.10 \%$ & $87.00 \%$ & $2.53 \%$ & $10.50 \%$ & $0.116 \pm 0.001$ & $1.909 \pm 0.039$ & $16.454 \pm 0.464$ \\
$9.35 \%$ & $2.01 \%$ & $88.60 \%$ & $83.80 \%$ & $3.74 \%$ & $12.40 \%$ & $0.140 \pm 0.001$ & $1.858 \pm 0.012$ & $13.239 \pm 0.187$ \\
$11.10 \%$ & $2.81 \%$ & $86.00 \%$ & $82.90 \%$ & $4.50 \%$ & $12.70 \%$ & $0.147 \pm 0.007$ & $1.601 \pm 0.122$ & $10.865 \pm 1.373$ \\
$21.20 \%$ & $6.51 \%$ & $72.30 \%$ & $75.10 \%$ & $8.77 \%$ & $16.10 \%$ & $0.224 \pm 0.002$ & $1.348 \pm 0.109$ & $6.014 \pm 0.537$ \\
$12.70 \%$ & $4.82 \%$ & $82.40 \%$ & $72.90 \%$ & $8.08 \%$ & $19.00 \%$ & $0.232 \pm 0.002$ & $1.677 \pm 0.043$ & $7.237 \pm 0.260$ \\
$13.40 \%$ & $5.46 \%$ & $81.20 \%$ & $71.30 \%$ & $9.38 \%$ & $19.30 \%$ & $0.239 \pm 0.011$ & $1.717 \pm 0.057$ & $7.193 \pm 0.578$ \\
$15.80 \%$ & $6.40 \%$ & $77.80 \%$ & $68.20 \%$ & $10.30 \%$ & $21.50 \%$ & $0.278 \pm 0.002$ & $1.612 \pm 0.028$ & $5.804 \pm 0.149$ \\
$17.40 \%$ & $7.24 \%$ & $75.40 \%$ & $64.40 \%$ & $11.30 \%$ & $24.20 \%$ & $0.323 \pm 0.006$ & $1.567 \pm 0.043$ & $4.852 \pm 0.231$ \\
\hline
\end{tabular}




\section{APPENDICES}

Table 12.6: Experimental LLE-data concerning the methylcyclohexane (MCH) - cyclopentylmethyl ether (CPME)-Cyrene $(C y)$ ternary system, including the weight fractions in each phase of each solute, the distribution coefficient $\left(K_{D, i}\right)$ of $M C H$ and toluene and the selectivity of toluene over $\mathrm{MCH}\left(S_{i j}\right)$ at $298.15 \mathrm{~K}, 323.15 \mathrm{~K}$ and $348.15 \mathrm{~K}$.

Temperature: $298.15 \mathrm{~K}$

\begin{tabular}{|c|c|c|c|c|c|c|c|c|}
\hline \multicolumn{3}{|c|}{ Organic Phase } & \multicolumn{3}{|c|}{ Solvent Phase } & \multicolumn{2}{|c|}{$K_{D, i}$} & \multirow{2}{*}{$\begin{array}{c}S_{i j} \\
\mathrm{CPME} / \mathrm{MCH}\end{array}$} \\
\hline $\mathrm{Cy}$ & CPME & $\mathrm{MCH}$ & $\mathrm{Cy}$ & CPME & $\mathrm{MCH}$ & $\mathrm{MCH}$ & CPME & \\
\hline \multicolumn{6}{|c|}{ (wt. \%) } & & & \\
\hline $2.62 \%$ & $0.65 \%$ & $96.70 \%$ & $90.10 \%$ & $0.41 \%$ & $9.51 \%$ & $0.098 \pm 0.001$ & $0.632 \pm 0.003$ & $6.419 \pm 0.083$ \\
\hline $3.61 \%$ & $1.54 \%$ & $94.90 \%$ & $93.60 \%$ & $0.52 \%$ & $5.91 \%$ & $0.062 \pm 0.003$ & $0.337 \pm 0.020$ & $5.385 \pm 0.626$ \\
\hline $3.77 \%$ & $2.73 \%$ & $93.50 \%$ & $93.70 \%$ & $0.83 \%$ & $5.49 \%$ & $0.059 \pm 0.002$ & $0.303 \pm 0.013$ & $5.146 \pm 0.373$ \\
\hline $4.27 \%$ & $4.58 \%$ & $91.10 \%$ & $92.80 \%$ & $1.41 \%$ & $5.81 \%$ & $0.064 \pm 0.001$ & $0.309 \pm 0.013$ & $4.851 \pm 0.280$ \\
\hline $4.83 \%$ & $6.08 \%$ & $89.10 \%$ & $85.40 \%$ & $3.55 \%$ & $11.00 \%$ & $0.124 \pm 0.019$ & $0.584 \pm 0.084$ & $4.696 \pm 1.392$ \\
\hline $6.75 \%$ & $15.70 \%$ & $77.50 \%$ & $77.30 \%$ & $9.85 \%$ & $12.80 \%$ & $0.166 \pm 0.003$ & $0.628 \pm 0.010$ & $3.772 \pm 0.116$ \\
\hline $27.20 \%$ & $27.90 \%$ & $44.90 \%$ & $67.70 \%$ & $18.30 \%$ & $14.00 \%$ & $0.316 \pm 0.009$ & $0.656 \pm 0.018$ & $2.076 \pm 0.116$ \\
\hline $5.24 \%$ & $9.50 \%$ & $85.30 \%$ & $92.60 \%$ & $2.40 \%$ & $4.97 \%$ & $0.058 \pm 0.001$ & $0.252 \pm 0.004$ & $4.326 \pm 0.157$ \\
\hline $10.80 \%$ & $22.30 \%$ & $66.90 \%$ & $87.50 \%$ & $6.47 \%$ & $6.03 \%$ & $0.090 \pm 0.000$ & $0.290 \pm 0.001$ & $3.210 \pm 0.013$ \\
\hline
\end{tabular}

Temperature: $323.15 \mathrm{~K}$

\begin{tabular}{|c|c|c|c|c|c|c|c|c|}
\hline \multicolumn{3}{|c|}{ Organic Phase } & \multicolumn{3}{|c|}{ Solvent Phase } & \multicolumn{2}{|c|}{$K_{D, i}$} & \multirow{2}{*}{$\frac{S_{i j}}{\mathrm{CPME} / \mathrm{MCH}}$} \\
\hline $\mathrm{Cy}$ & CPME & $\mathrm{MCH}$ & $\mathrm{Cy}$ & CPME & $\mathrm{MCH}$ & $\mathrm{MCH}$ & CPME & \\
\hline \multicolumn{6}{|c|}{ (wt. \%) } & & & \\
\hline $5.09 \%$ & $0.75 \%$ & $94.20 \%$ & $92.50 \%$ & $0.26 \%$ & $7.27 \%$ & $0.077 \pm 0.003$ & $0.350 \pm 0.016$ & $4.545 \pm 0.405$ \\
\hline $5.14 \%$ & $1.56 \%$ & $93.30 \%$ & $90.50 \%$ & $0.63 \%$ & $8.85 \%$ & $0.095 \pm 0.004$ & $0.404 \pm 0.020$ & $4.274 \pm 0.388$ \\
\hline $5.65 \%$ & $2.99 \%$ & $91.40 \%$ & $90.60 \%$ & $1.10 \%$ & $8.35 \%$ & $0.091 \pm 0.002$ & $0.366 \pm 0.001$ & $4.017 \pm 0.084$ \\
\hline $5.57 \%$ & $4.50 \%$ & $89.90 \%$ & $89.40 \%$ & $1.68 \%$ & $8.89 \%$ & $0.099 \pm 0.005$ & $0.374 \pm 0.024$ & $3.787 \pm 0.430$ \\
\hline $6.54 \%$ & $6.04 \%$ & $87.40 \%$ & $89.40 \%$ & $2.20 \%$ & $8.38 \%$ & $0.079 \pm 0.004$ & $0.301 \pm 0.023$ & $3.816 \pm 0.503$ \\
\hline $15.00 \%$ & $14.40 \%$ & $70.60 \%$ & $86.30 \%$ & $3.34 \%$ & $10.40 \%$ & $0.144 \pm 0.003$ & $0.400 \pm 0.003$ & $2.788 \pm 0.076$ \\
\hline $15.30 \%$ & $19.10 \%$ & $65.60 \%$ & $74.40 \%$ & $10.80 \%$ & $14.80 \%$ & $0.227 \pm 0.003$ & $0.566 \pm 0.011$ & $2.492 \pm 0.083$ \\
\hline $18.20 \%$ & $22.20 \%$ & $59.60 \%$ & $67.60 \%$ & $13.90 \%$ & $18.50 \%$ & $0.313 \pm 0.004$ & $0.627 \pm 0.007$ & $2.003 \pm 0.050$ \\
\hline $21.10 \%$ & $24.60 \%$ & $54.30 \%$ & $63.70 \%$ & $16.10 \%$ & $20.20 \%$ & $0.375 \pm 0.005$ & $0.653 \pm 0.016$ & $1.740 \pm 0.068$ \\
\hline $29.80 \%$ & $26.60 \%$ & $43.60 \%$ & $60.30 \%$ & $19.10 \%$ & $20.60 \%$ & $0.473 \pm 0.000$ & $0.717 \pm 0.001$ & $1.515 \pm 0.003$ \\
\hline
\end{tabular}

Temperature: $348.15 \mathrm{~K}$

\begin{tabular}{|c|c|c|c|c|c|c|c|c|}
\hline \multicolumn{3}{|c|}{ Organic Phase } & \multicolumn{3}{|c|}{ Solvent Phase } & \multicolumn{2}{|c|}{$K_{D, i}$} & \multirow{2}{*}{$\begin{array}{c}S_{i j} \\
\mathrm{CPME} / \mathrm{MCH}\end{array}$} \\
\hline $\mathrm{Cy}$ & CPME & $\mathrm{MCH}$ & $\mathrm{Cy}$ & CPME & $\mathrm{MCH}$ & $\mathrm{MCH}$ & CPME & \\
\hline \multicolumn{6}{|c|}{ (wt. \%) } & & & \\
\hline $15.00 \%$ & $0.69 \%$ & $84.30 \%$ & $90.90 \%$ & $0.28 \%$ & $8.77 \%$ & $0.104 \pm 0.004$ & $0.406 \pm 0.016$ & $3.913 \pm 0.310$ \\
\hline $16.60 \%$ & $1.42 \%$ & $82.00 \%$ & $90.20 \%$ & $0.57 \%$ & $9.24 \%$ & $0.113 \pm 0.004$ & $0.399 \pm 0.014$ & $3.544 \pm 0.251$ \\
\hline $16.20 \%$ & $2.79 \%$ & $81.00 \%$ & $91.00 \%$ & $0.93 \%$ & $8.03 \%$ & $0.099 \pm 0.002$ & $0.332 \pm 0.010$ & $3.357 \pm 0.158$ \\
\hline $17.60 \%$ & $4.12 \%$ & $78.30 \%$ & $88.10 \%$ & $1.69 \%$ & $10.20 \%$ & $0.131 \pm 0.010$ & $0.412 \pm 0.038$ & $3.130 \pm 0.532$ \\
\hline $11.60 \%$ & $6.06 \%$ & $82.30 \%$ & $89.40 \%$ & $1.90 \%$ & $8.74 \%$ & $0.106 \pm 0.001$ & $0.314 \pm 0.019$ & $2.976 \pm 0.216$ \\
\hline $21.10 \%$ & $13.70 \%$ & $65.20 \%$ & $80.70 \%$ & $6.46 \%$ & $12.90 \%$ & $0.198 \pm 0.003$ & $0.471 \pm 0.020$ & $2.372 \pm 0.132$ \\
\hline $20.90 \%$ & $19.00 \%$ & $60.10 \%$ & $67.60 \%$ & $12.40 \%$ & $20.00 \%$ & $0.333 \pm 0.001$ & $0.650 \pm 0.001$ & $1.953 \pm 0.010$ \\
\hline $24.10 \%$ & $20.70 \%$ & $55.20 \%$ & $60.40 \%$ & $14.80 \%$ & $24.80 \%$ & $0.453 \pm 0.007$ & $0.713 \pm 0.023$ & $1.573 \pm 0.076$ \\
\hline
\end{tabular}




\subsection{Appendix E: Thermodynamic Consistency of Liquid-liquid equilibrium}

A common thermodynamic consistency test was described by Van Ness. ${ }^{2}$ This test evaluated the coupling of activity coefficient derivatives of all components via the Gibbs-Duhem equation. Though, this can be applied in vaporliquid equilibria where the activity coefficients of each component can be estimated independently, this is not possible in liquid-liquid equilibria. ${ }^{3}$ Therefore, the test stated by Marcilla et al. ${ }^{4}$ was used in this work.

Marcilla et al. ${ }^{4}$ state criteria for the assessment of the stability of a ternary system by the second derivative of the Gibbs energy of mixing $(\mathrm{G})$ in the form of a Hessian Matrix, see Equation 12.8. A positive determinant indicates a convex Gibbs energy surface, ${ }^{3}$ which indicates a stable equilibrium. A negative result indicates however an intrinsically unstable point. The ternary spinodal curves are thereby assessed by the zero solution. This is the unstable point of phase splitting (though is still meta-stable) which must not be mistaken by the binodal curve, where it is the thermodynamic boundary between the immiscibility and miscibility region. Hence, a very small Hessian determinant indicates a stable thermodynamic solution near the spinodal curve, being the binodal curve.

$$
\begin{gathered}
G=\left[\begin{array}{cc}
\frac{\partial^{2} G}{\partial x_{i}^{2}} & \frac{\partial^{2} G}{\partial x_{i} \partial x_{j}} \\
\frac{\partial^{2} G}{\partial x_{i} \partial x_{j}} & \frac{\partial^{2} G}{\partial x_{j}^{2}}
\end{array}\right] \\
\operatorname{det}(G)=\frac{\partial^{2} G}{\partial x_{i}^{2}} \cdot \frac{\partial^{2} G}{\partial x_{j}^{2}}-2 \cdot \frac{\partial^{2} G}{\delta x_{i} \partial x_{j}}=0
\end{gathered}
$$



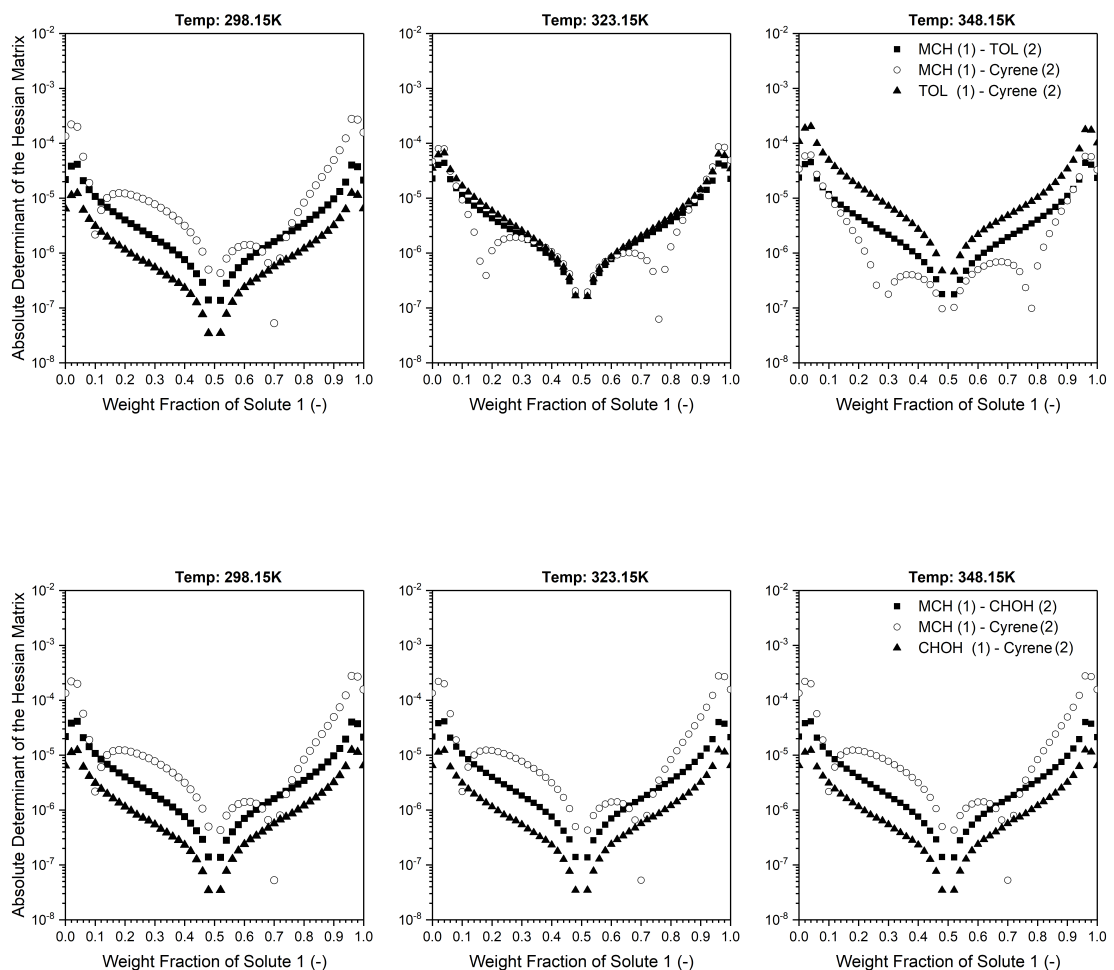

Figure 12.1: Thermodynamic consistency analysis via the determinant determination of the Hessian matrix of each binary system of the tertiary systems toluene(TOL)/cyclohexanol $(\mathrm{CHOH})$, methylcyclohexane $(\mathrm{MCH})$ and Cyrene at $298.15 \mathrm{~K}, 323.15 \mathrm{~K}$ and $348.15 \mathrm{~K}$ 

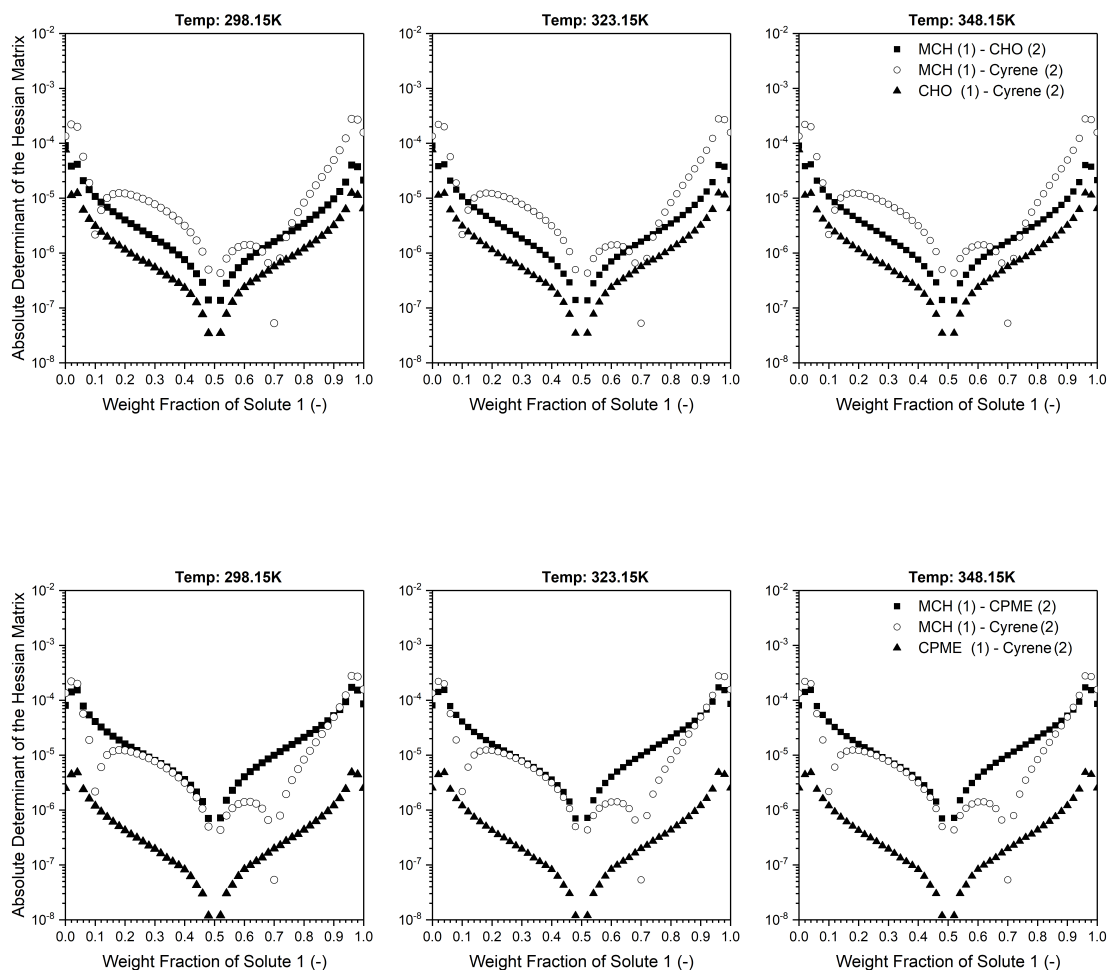

Figure 12.2: Thermodynamic consistency analysis via the determinant determination of the Hessian matrix of each binary system of the tertiary system cyclohexanone(CHO)/cyclopentylmethyl ether (CPME), methylcyclohexane (MCH) and Cyrene at $298.15 \mathrm{~K}, 323.15 \mathrm{~K}$ and $348.15 \mathrm{~K}$ 


\subsection{Appendix F: Liquid-Liquid Equilibrium Experimental Procedure}

The experimental LLE data of Sulfolane was done following this experimental and analysis procedure;

\section{Experimental Procedure:}

The liquid-liquid extraction experiments were carried out in $10 \mathrm{~mL}$ glass vials. A Mettler AT200 analytical balance was used to weigh the components with an accuracy of $0.1 \mathrm{mg}$. A fixed solvent to feed molar ratio of 1 was used with a varied mole fraction of toluene from 0.05-0.7. The two-phase systems in the glass vials were shaken vigorously in the vortex mixer and afterward shaken for 5 hours in a shaking water bath at $25 \pm 0.02^{\circ} \mathrm{C}$ and 200 rpm. Thereafter, the mixtures were left to settle overnight to guarantee that the equilibrium state was reached. Samples of the top and the bottom phase were collected with a needled syringe and analyzed.

\section{Analytical Procedure:}

A Varian CP-3800 gas chromatograph was used to analyze all samples. For the analysis, the samples were diluted with analytical acetone and an internal standard, n-nonane, was added. The gas chromatograph was equipped with a flame ionization detector $\left(280^{\circ} \mathrm{C}\right)$ and an Agilent J\&W DB- $1 \mathrm{~ms}(60 \mathrm{~m} \mathrm{x}$ $0.25 \mathrm{~mm} \times 0.25 \mu \mathrm{m})$ column was used. The analysis started at a temperature of $50^{\circ} \mathrm{C}$ and was ramped to $300^{\circ} \mathrm{C}$. The injector temperature was set at $300^{\circ} \mathrm{C}$. The used carrier gas was helium with a constant flow rate of $2.0 \mathrm{~mL} / \mathrm{min}$. All samples were analyzed three times to take the error of the gas chromatograph into account. 


\subsection{Appendix G: Details concerning the process simulations}

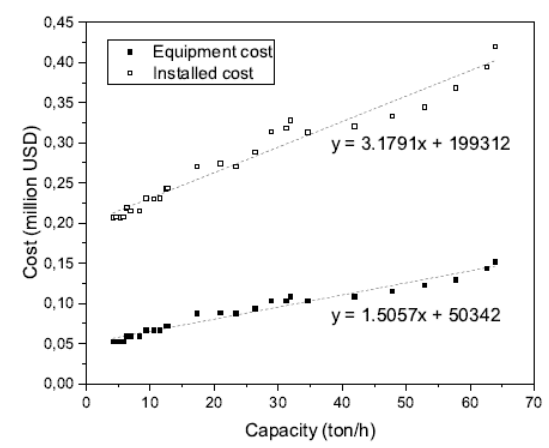

(a) Column with 10 stages

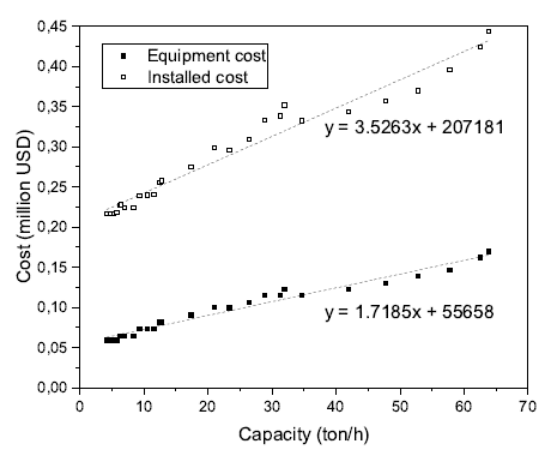

(b) Column with 12 stages.

Figure 12.3: Estimation of the equipment cost and installed cost of an extraction column as a function of the capacity and the number of stages. The $y$ and $x$ in the trend lines represent the cost $(M \$)$ and capacity $($ ton $/ h)$, respectively.

\subsection{Appendix H: Simulation results}

\subsubsection{Cyrene-based LLX process}

Table 12.7: Economical estimation overview made for Cyrene-based LLX process.

\begin{tabular}{|l|l|l|l|l|l|l|}
\hline Molar Fraction Toluene in Feed & 0,1 & 0,2 & 0,3 & 0,4 \\
\hline \multicolumn{3}{|c|}{ Process Characteristics } & 2,8 & 2,7 & 2,6 & 2,5 \\
\hline S:F ratio (mole ratio) & Stages & 12 & 12 & 12 & 12 \\
\hline \multirow{4}{*}{$\begin{array}{l}\text { Liquid-Liquid Extraction } \\
\text { Column }\end{array}$} & Hydrocarbon feed stage & 12 & 12 & 12 & 12 \\
\cline { 2 - 6 } & Solvent feed stage & 1 & 1 & 1 & 1 \\
\cline { 2 - 6 } & Side (recycle) feed stage & 11 & 11 & 11 & 11 \\
\hline
\end{tabular}




\section{APPENDICES}

\begin{tabular}{|c|c|c|c|c|c|}
\hline \multirow{5}{*}{$\begin{array}{l}2^{\text {nd }}(\mathrm{SR}) \text { Distillation } \\
\text { Column }\end{array}$} & Stages & 12 & 12 & 12 & 12 \\
\hline & Feed Stage & 5 & 5 & 5 & 5 \\
\hline & Water feed stage & 8 & 8 & 8 & 8 \\
\hline & Reflux Ratio & 4,5 & 3 & 1,4 & 1,4 \\
\hline & Pressure (bar) & 0,08 & 0,08 & 0,08 & 0,08 \\
\hline Wash Column & Water Wash (kmole/hr) & 10 & 9,5 & 8 & 25 \\
\hline \multicolumn{6}{|c|}{ Product Purities } \\
\hline \multirow{2}{*}{$\begin{array}{l}\text { Product Purity (wt. } \\
\text { fraction) }\end{array}$} & $\mathrm{MCH}$ & 0,9995 & 0,9998 & 0,9998 & 0,9999 \\
\hline & Toluene & 0,9985 & 0,9995 & 0,9995 & 0,9995 \\
\hline \multicolumn{6}{|c|}{ Process Equipment Duty } \\
\hline \multirow{2}{*}{ ED Column (MW) } & Condensor & 2,14 & 0,90 & 0,79 & 0,77 \\
\hline & Reboiler & 6,16 & 4,12 & 3,55 & 3,19 \\
\hline \multirow{2}{*}{ SR Column (MW) } & Condensor & 1,25 & 1,32 & 1,14 & 1,24 \\
\hline & Reboiler & 1,62 & 1,67 & 1,46 & 1,55 \\
\hline \multirow{5}{*}{ Coolers / Heater (MW) } & Cooler 1 & 0,02 & 0,02 & 0,02 & 0,02 \\
\hline & Cooler 2 & 0,17 & 0,07 & 0,06 & 0,05 \\
\hline & Cooler 3 & $10^{-2}$ & $10^{-2}$ & $10^{-2}$ & $10^{-2}$ \\
\hline & Cooler 4 & 4,17 & 3,44 & 2,97 & 2,62 \\
\hline & Cooler 5 & $10^{-2}$ & $10^{-2}$ & $10^{-2}$ & $10^{-2}$ \\
\hline \multirow{6}{*}{ Pumps (kW) } & Pump 1 & 1,09 & 0,60 & 0,56 & 0,55 \\
\hline & Pump 2 & 0,09 & 0,18 & 0,27 & 0,37 \\
\hline & Pump 3 & 1,11 & 1,08 & 1,05 & 1,02 \\
\hline & Pump 4 & 0,02 & 0,01 & 0,01 & 0,01 \\
\hline & Pump 5 & 0,68 & 0,46 & 0,45 & 0,45 \\
\hline & Pump 6 & $<10^{-2}$ & $<10^{-2}$ & $<10^{-2}$ & $<10^{-2}$ \\
\hline \multicolumn{6}{|c|}{ Process Equipment Costs $(\mathrm{k} €)$} \\
\hline & $\begin{array}{l}\text { Liquid-Liquid Extrac- } \\
\text { tion Column }\end{array}$ & 200 & 199 & 199 & 199 \\
\hline & $1^{\text {st }}$ Distillation Column & 1004 & 780 & 764 & 788 \\
\hline & $2^{\text {nd }}$ Distillation Column & 905 & 798 & 773 & 797 \\
\hline & Water Wash Column & 199 & 199 & 199 & 199 \\
\hline & Pumps & 207 & 196 & 198 & 198 \\
\hline & Coolers & 125 & 123 & 123 & 117 \\
\hline & Heat exchangers & 158 & 179 & 181 & 182 \\
\hline \multicolumn{6}{|c|}{ Operational Costs (OPEX) (k€/yr) } \\
\hline Solvent Make-up & & 12 & 7 & 12 & 10 \\
\hline Electrical & & 2 & 1 & 1 & 1 \\
\hline Heating & & 2668 & 1986 & 1721 & 1628 \\
\hline Cooling & & 1054 & 783 & 677 & 639 \\
\hline \multicolumn{6}{|c|}{ Capital Costs (CAPEX) (M€) } \\
\hline All Equipment & & 2,80 & 2,47 & 2,44 & 2,48 \\
\hline \multicolumn{6}{|c|}{ Total Annual Costs (TAC) $(\mathrm{M} € / \mathrm{yr})$} \\
\hline Total Annual Costs & & 4,67 & 3,60 & 3,22 & 3,11 \\
\hline
\end{tabular}




\section{APPENDICES}

\subsubsection{Sulfolane-based LLX process}

Table 12.8: Economical estimation overview made for Sulfolane-based LLX process.

\begin{tabular}{|c|c|c|c|c|c|}
\hline \multicolumn{2}{|c|}{ Molar Fraction Toluene in Feed } & 0,1 & 0,2 & 0,3 & 0,4 \\
\hline \multicolumn{6}{|c|}{ Process Characteristics } \\
\hline \multicolumn{2}{|l|}{$\mathrm{S}: \mathrm{F}$ ratio (mole ratio) } & 4,1 & 3,85 & 3,6 & 3,25 \\
\hline \multirow{4}{*}{$\begin{array}{l}\text { Liquid-Liquid } \\
\text { Extraction Column }\end{array}$} & Stages & 12 & 12 & 12 & 12 \\
\hline & Hydrocarbon feed stage & 12 & 12 & 12 & 12 \\
\hline & Solvent feed stage & 1 & 1 & 1 & 1 \\
\hline & Side (recycle) feed stage & 11 & 11 & 11 & 11 \\
\hline \multirow{4}{*}{$\begin{array}{l}1^{\text {st }}(\mathrm{ED}) \text { Distillation } \\
\text { Column }\end{array}$} & Stages & 8 & 8 & 8 & 8 \\
\hline & Feed Stage & 2 & 2 & 2 & 2 \\
\hline & Reflux Ratio & 3.2 & 2.1 & 1.0 & 0.62 \\
\hline & Pressure (bar) & 0,08 & 0,08 & 0,08 & 0,08 \\
\hline \multirow{5}{*}{$\begin{array}{l}2^{\text {nd }}(\mathrm{SR}) \text { Distillation } \\
\text { Column }\end{array}$} & Stages & 8 & 8 & 8 & 8 \\
\hline & Feed Stage & 4 & 4 & 4 & 4 \\
\hline & Water feed stage & 6 & 6 & 6 & 6 \\
\hline & Reflux Ratio & 2,5 & 1,3 & 0,9 & 0,63 \\
\hline & Pressure (bar) & 0,08 & 0,08 & 0,08 & 0,08 \\
\hline Wash Column & Water Wash $(\mathrm{kmole} / \mathrm{hr})$ & 13 & 11 & 10 & 12 \\
\hline \multicolumn{6}{|c|}{ Product Purities } \\
\hline \multirow{2}{*}{$\begin{array}{l}\text { Product Purity (wt. } \\
\text { fraction) }\end{array}$} & $\mathrm{MCH}$ & 0,9988 & 0,9987 & 0,9985 & 0,9985 \\
\hline & Toluene & 0,9990 & 0,9994 & 0,9988 & 0,9988 \\
\hline \multicolumn{6}{|c|}{ Process Equipment Duty } \\
\hline \multirow{2}{*}{ ED Column (MW) } & Condensor & 1,03 & 0,79 & 0,61 & 0,50 \\
\hline & Reboiler & 1,01 & 0,76 & 0,67 & 0,58 \\
\hline \multirow{2}{*}{ SR Column (MW) } & Condensor & 0,95 & 0,78 & 0,67 & 0,58 \\
\hline & Reboiler & 1,15 & 0,96 & 0,99 & 1,08 \\
\hline \multirow{5}{*}{ Coolers / Heater (MW) } & Cooler 1 & $<10^{-2}$ & $<10^{-2}$ & $<10^{-2}$ & $<10^{-2}$ \\
\hline & Cooler 2 & 0,01 & 0,01 & 0,02 & 0,02 \\
\hline & Cooler 3 & $<10^{-2}$ & 0,01 & 0,01 & 0,01 \\
\hline & Cooler 4 & 0,20 & 0,18 & 0,16 & 0,14 \\
\hline & Cooler 5 & $<10^{-2}$ & $<10^{-2}$ & $<10^{-2}$ & $<10^{-2}$ \\
\hline \multirow{6}{*}{ Pumps (kW) } & Pump 1 & 0,22 & 0,24 & 0,29 & 0,31 \\
\hline & Pump 2 & 0,09 & 0,19 & 0,28 & 0,37 \\
\hline & Pump 3 & 1,83 & 1,74 & 1,64 & 1,51 \\
\hline & Pump 4 & 0,02 & 0,02 & 0,02 & 0,02 \\
\hline & Pump 5 & 0,66 & 0,64 & 0,63 & 0,59 \\
\hline & Pump 6 & 0,22 & 0,24 & 0,29 & 0,31 \\
\hline
\end{tabular}




\section{APPENDICES}

\begin{tabular}{|c|c|c|c|c|c|}
\hline \multicolumn{6}{|c|}{ Process Equipment Costs $(\mathrm{k} €)$} \\
\hline & $\begin{array}{l}\text { Liquid-Liquid Extraction } \\
\text { Column }\end{array}$ & 200 & 199 & 199 & 199 \\
\hline & $1^{\text {st }}$ Distillation Column & 602 & 556 & 540 & 561 \\
\hline & $2^{\text {nd }}$ Distillation Column & 707 & 776 & 675 & 776 \\
\hline & Water Wash Column & 199 & 199 & 199 & 199 \\
\hline & Pumps & 179 & 179 & 173 & 173 \\
\hline & Coolers & 169 & 169 & 175 & 175 \\
\hline & Heat exchangers & 261 & 249 & 223 & 215 \\
\hline \multicolumn{6}{|c|}{ Operational Costs (OPEX) $(\mathrm{k} € / \mathrm{yr})$} \\
\hline Solvent Make-up & & 12 & 12 & 32 & 25 \\
\hline Electrical & & 2 & 2 & 2 & 2 \\
\hline Heating & & 740 & 590 & 569 & 572 \\
\hline Cooling & & 299 & 241 & 227 & 228 \\
\hline \multicolumn{6}{|c|}{ Capital Costs (CAPEX) (M€) } \\
\hline All Equipment & & 2,32 & 2,33 & 2,18 & 2,30 \\
\hline \multicolumn{6}{|c|}{ Total Annual Costs (TAC) (M€/yr) } \\
\hline Total Annual Costs & & 1,82 & 1,62 & 1,56 & 1,59 \\
\hline
\end{tabular}

\begin{tabular}{|c|c|c|c|c|c|}
\hline \multicolumn{2}{|c|}{ Molar Fraction Toluene in Feed } & 0,5 & 0,6 & 0,7 & 0,8 \\
\hline \multicolumn{6}{|c|}{ Process Characteristics } \\
\hline \multicolumn{2}{|l|}{ S:F ratio (mole ratio) } & 3,0 & 2,9 & 2,7 & 2,5 \\
\hline \multirow{4}{*}{$\begin{array}{l}\text { Liquid-Liquid } \\
\text { Extraction Column }\end{array}$} & Stages & 12 & 12 & 12 & 12 \\
\hline & Hydrocarbon feed stage & 12 & 12 & 12 & 12 \\
\hline & Solvent feed stage & 1 & 1 & 1 & 1 \\
\hline & Side (recycle) feed stage & 11 & 11 & 11 & 11 \\
\hline \multirow{4}{*}{$\begin{array}{l}1^{\text {st }}(\mathrm{ED}) \text { Distillation } \\
\text { Column }\end{array}$} & Stages & 8 & 8 & 8 & 8 \\
\hline & Feed Stage & 2 & 2 & 2 & 2 \\
\hline & Reflux Ratio & 0,2 & 0,5 & 0,3 & 0,25 \\
\hline & Pressure (bar) & 0,08 & 0,08 & 0,08 & 0,08 \\
\hline \multirow{5}{*}{$\begin{array}{l}2^{\text {nd }}(\mathrm{SR}) \text { Distillation } \\
\text { Column }\end{array}$} & Stages & 8 & 8 & 8 & 8 \\
\hline & Feed Stage & 4 & 4 & 4 & 4 \\
\hline & Water feed stage & 6 & 6 & 6 & 6 \\
\hline & Reflux Ratio & 0,6 & 0,35 & 0,42 & 0,5 \\
\hline & Pressure (bar) & 0,08 & 0,08 & 0,08 & 0,08 \\
\hline Wash Column & Water Wash (kmole/hr) & 10 & 8 & 7 & 6 \\
\hline \multicolumn{6}{|c|}{ Product Purities } \\
\hline \multirow{2}{*}{$\begin{array}{l}\text { Product Purity (wt. } \\
\text { fraction) }\end{array}$} & $\mathrm{MCH}$ & 0,9987 & 0,9995 & 0,9998 & 0,9999 \\
\hline & Toluene & 0,9997 & 0,9999 & 0,9999 & 0,9999 \\
\hline
\end{tabular}




\section{APPENDICES}

\begin{tabular}{|c|c|c|c|c|c|}
\hline \multicolumn{6}{|c|}{ Process Equipment Duty } \\
\hline \multirow{2}{*}{ ED Column (MW) } & Condensor & 0,47 & 0,70 & 0,94 & 1,20 \\
\hline & Reboiler & 0,58 & 0,82 & 1,08 & 1,38 \\
\hline \multirow{2}{*}{ SR Column (MW) } & Condensor & 1,06 & 1,19 & 1,20 & 1,41 \\
\hline & Reboiler & 1,12 & 1,24 & 1,23 & 1,43 \\
\hline \multirow{5}{*}{ Coolers / Heater (MW) } & Cooler 1 & $<10^{-2}$ & $<10^{-2}$ & $<10^{-2}$ & $<10^{-2}$ \\
\hline & Cooler 2 & 0,03 & 0,04 & 0,05 & 0,07 \\
\hline & Cooler 3 & 0,02 & 0,02 & 0,02 & 0,03 \\
\hline & Cooler 4 & 0,13 & 0,12 & 0,11 & 0,10 \\
\hline & Cooler 5 & $<10^{-2}$ & $<10^{-2}$ & $<10^{-2}$ & $<10^{-2}$ \\
\hline \multirow{6}{*}{ Pumps (kW) } & Pump 1 & 0,39 & 0,45 & 0,53 & 0,63 \\
\hline & Pump 2 & 0,42 & 0,47 & 0,51 & 0,55 \\
\hline & Pump 3 & 1,42 & 1,38 & 1,31 & 1,23 \\
\hline & Pump 4 & 0,02 & 0,01 & 0,01 & 0,01 \\
\hline & Pump 5 & 0,58 & 0,61 & 0,63 & 0,66 \\
\hline & Pump 6 & 0,39 & 0,45 & 0,53 & 0,63 \\
\hline \multicolumn{6}{|c|}{ Process Equipment Costs $(\mathrm{k} €)$} \\
\hline & $\begin{array}{l}\text { Liquid-Liquid Extrac- } \\
\text { tion Column }\end{array}$ & 199 & 199 & 199 & 199 \\
\hline & $1^{\text {st }}$ Distillation Column & 546 & 588 & 621 & 669 \\
\hline & $2^{\text {nd }}$ Distillation Column & 1032 & 1044 & 1085 & 1153 \\
\hline & Water Wash Column & 199 & 199 & 199 & 199 \\
\hline & Pumps & 170 & 174 & 177 & 178 \\
\hline & Coolers & 189 & 189 & 189 & 196 \\
\hline & Heat exchangers & 209 & 207 & 173 & 172 \\
\hline \multicolumn{6}{|c|}{ Operational Costs (OPEX) (k€/yr) } \\
\hline Solvent Make-up & & 16 & 0,3 & 5 & 0,2 \\
\hline Electrical & & 2 & 2 & 2 & 2 \\
\hline Heating & & 586 & 710 & 793 & 962 \\
\hline Cooling & & 234 & 283 & 316 & 382 \\
\hline \multicolumn{6}{|c|}{ Capital Costs (CAPEX) (M€) } \\
\hline All Equipment & & 2,54 & 2,60 & 2,64 & 2,77 \\
\hline \multicolumn{6}{|c|}{ Total Annual Costs (TAC) $(\mathrm{M} € /$ yr $)$} \\
\hline Total Annual Costs & & 1,69 & 1,86 & 2,00 & 2,27 \\
\hline
\end{tabular}




\section{APPENDICES}

\subsubsection{Cyrene-based ED process}

Table 12.9: Economical estimation overview made for Cyrene-based ED process.

\begin{tabular}{|c|c|c|c|c|c|}
\hline \multicolumn{2}{|c|}{ Molar Fraction Toluene in Feed } & 0,1 & 0,2 & 0,3 & 0,4 \\
\hline \multicolumn{6}{|c|}{ Process Characteristics } \\
\hline \multicolumn{2}{|c|}{ S:F ratio (molar ratio) } & 1,8 & 1,8 & 1,7 & 1,6 \\
\hline \multirow{5}{*}{$\begin{array}{l}\text { Extractive } \\
\text { Distillation } \\
\text { (ED) Column }\end{array}$} & Stages & 30 & 30 & 30 & 30 \\
\hline & Solvent Feed Stage & 10 & 10 & 10 & 10 \\
\hline & Hydrocarbon Feed Stage & 21 & 21 & 21 & 21 \\
\hline & Reflux Ratio & 0,3 & 0,25 & 0,25 & 0,27 \\
\hline & Pressure (bar) & 1 & 1 & 1 & 1 \\
\hline \multirow{4}{*}{$\begin{array}{l}\text { Solvent } \\
\text { Recovery (SR) } \\
\text { Column }\end{array}$} & Stages & 10 & 10 & 10 & 10 \\
\hline & Feed Stage & 7 & 7 & 7 & 7 \\
\hline & Reflux Ratio & 17 & 5 & 1,7 & 0,78 \\
\hline & Pressure (bar) & 0,08 & 0,08 & 0,08 & 0,08 \\
\hline \multicolumn{6}{|c|}{ Product Purities } \\
\hline \multirow{2}{*}{$\begin{array}{l}\text { Product Purity } \\
\text { (wt. fraction) }\end{array}$} & $\mathrm{MCH}$ & 0,9998 & 0,9996 & 0,9996 & 0,9994 \\
\hline & Toluene & 0,9986 & 0,9988 & 0,9992 & 0,9988 \\
\hline \multicolumn{6}{|c|}{ Process Equipment Duty } \\
\hline \multirow{2}{*}{$\begin{array}{l}\text { ED } \\
\text { Column (MW) }\end{array}$} & Condensor & 1,01 & 0,86 & 0,76 & 0,66 \\
\hline & Reboiler & 3,22 & 2,37 & 1,65 & 1,20 \\
\hline \multirow{2}{*}{$\begin{array}{l}\text { SR Column } \\
(\mathrm{MW})\end{array}$} & Condensor & 1,86 & 1,24 & 0,84 & 0,74 \\
\hline & Reboiler & 0,37 & 0,32 & 0,44 & 0,64 \\
\hline \multirow{3}{*}{ Pumps (kW) } & Pump 1 & 0,25 & 0,26 & 0,26 & 0,26 \\
\hline & Pump 2 & 0,86 & 0,86 & 0,83 & 0,79 \\
\hline & Pump 3 & 0,09 & 0,18 & 0,27 & 0,37 \\
\hline \multicolumn{6}{|c|}{ Process Equipment Costs $(\mathrm{k} €)$} \\
\hline & ED Column & 778 & 753 & 728 & 704 \\
\hline & SR Column & 675 & 657 & 639 & 621 \\
\hline & Pumps & 184 & 182 & 179 & 178 \\
\hline & Heat exchangers & 133 & 131 & 130 & 128 \\
\hline \multicolumn{6}{|c|}{ Operational Costs (OPEX) $(\mathrm{k} € / \mathrm{yr})$} \\
\hline \multicolumn{2}{|l|}{ Solvent Make-up } & 25 & 43 & 38 & 44 \\
\hline \multicolumn{2}{|l|}{ Electrical } & 0,7 & 0,7 & 0,8 & 0,8 \\
\hline \multicolumn{2}{|l|}{ Heating } & 1231 & 924 & 718 & 630 \\
\hline \multicolumn{2}{|l|}{ Cooling } & 390 & 286 & 217 & 190 \\
\hline \multicolumn{6}{|c|}{ Capital Costs (CAPEX) (M€) } \\
\hline \multicolumn{2}{|l|}{ All Equipment } & 1,82 & 1,77 & 1,72 & 1,68 \\
\hline \multicolumn{6}{|c|}{ Total Annual Costs (TAC) $(\mathrm{M} € /$ yr $)$} \\
\hline \multicolumn{2}{|c|}{ Total Annual Costs } & 2,25 & 1,84 & 1,55 & 1,42 \\
\hline
\end{tabular}




\section{APPENDICES}

\begin{tabular}{|c|c|c|c|c|c|}
\hline \multicolumn{2}{|c|}{ Molar Fraction Toluene in Feed } & 0,5 & 0,6 & 0,7 & 0,8 \\
\hline \multicolumn{6}{|c|}{ Process Characteristics } \\
\hline \multicolumn{2}{|l|}{ S:F ratio (molar ratio) } & 1,75 & 2,1 & 2,5 & 2,8 \\
\hline \multirow{5}{*}{$\begin{array}{l}\text { Extractive Distillation } \\
\text { (ED) Column }\end{array}$} & Stages & 30 & 30 & 30 & 30 \\
\hline & Solvent Feed Stage & 10 & 10 & 10 & 10 \\
\hline & Hydrocarbon Feed Stage & 21 & 21 & 21 & 21 \\
\hline & Reflux Ratio & 0,38 & 0,45 & 0,72 & 1,7 \\
\hline & Pressure (bar) & 1 & 1 & 1 & 1 \\
\hline \multirow{4}{*}{$\begin{array}{l}\text { Solvent Recovery (SR) } \\
\text { Column }\end{array}$} & Stages & 10 & 10 & 10 & 10 \\
\hline & Feed Stage & 7 & 7 & 7 & 7 \\
\hline & Reflux Ratio & 0,62 & 0,61 & 0,62 & 0,62 \\
\hline & Pressure (bar) & 0,08 & 0,08 & 0,08 & 0,08 \\
\hline \multicolumn{6}{|c|}{ Product Purities } \\
\hline \multirow{2}{*}{$\begin{array}{l}\text { Product Purity (wt. } \\
\text { fraction) }\end{array}$} & $\mathrm{MCH}$ & 0,9988 & 0,9985 & 0,9985 & 0,9986 \\
\hline & Toluene & 0,9986 & 0,9986 & 0,9986 & 0,9994 \\
\hline \multicolumn{6}{|c|}{ Process Equipment Duty } \\
\hline \multirow{2}{*}{ ED Column (MW) } & Condensor & 0,60 & 0,50 & 0,45 & 0,47 \\
\hline & Reboiler & 1,03 & 0,90 & 0,86 & 0,88 \\
\hline \multirow{2}{*}{ SR Column (MW) } & Condensor & 0,84 & 1,00 & 1,18 & 1,34 \\
\hline & Reboiler & 0,82 & 0,98 & 1,13 & 1,31 \\
\hline \multirow{3}{*}{ Pumps (kW) } & Pump 1 & 0,30 & 0,37 & 0,46 & 0,53 \\
\hline & Pump 2 & 0,84 & 0,96 & 1,10 & 1,20 \\
\hline & Pump 3 & 0,42 & 0,46 & 0,51 & 0,55 \\
\hline \multicolumn{6}{|c|}{ Process Equipment Costs $(\mathrm{k} €$ ) } \\
\hline & ED Column & 699 & 695 & 723 & 730 \\
\hline & SR Column & 639 & 656 & 698 & 744 \\
\hline & Pumps & 180 & 182 & 182 & 185 \\
\hline & Heat exchangers & 135 & 171 & 194 & 237 \\
\hline \multicolumn{6}{|c|}{ Operational Costs (OPEX) $(\mathrm{k} € / \mathrm{yr})$} \\
\hline Solvent Make-up & & 17 & 31 & 77 & 29 \\
\hline Electrical & & 0,9 & 1,0 & 1,2 & 1,3 \\
\hline Heating & & 634 & 644 & 681 & 751 \\
\hline Cooling & & 195 & 205 & 221 & 246 \\
\hline \multicolumn{6}{|c|}{ Capital Costs (CAPEX) (M€) } \\
\hline All Equipment & & 1,70 & 1,75 & 1,84 & 1,94 \\
\hline \multicolumn{6}{|c|}{ Total Annual Costs (TAC) (M€/ yr) } \\
\hline Total Annual Costs & & 1,41 & 1,46 & 1,59 & 1,67 \\
\hline
\end{tabular}




\section{APPENDICES}

\subsubsection{Sulfolane-based ED process}

Table 12.10: Economical estimation overview made for Sulfolane-based ED process.

\begin{tabular}{|c|c|c|c|c|c|}
\hline \multicolumn{2}{|c|}{ Molar Fraction Toluene in Feed } & 0,1 & 0,2 & 0,3 & 0,4 \\
\hline \multicolumn{6}{|c|}{ Process Characteristics } \\
\hline \multicolumn{2}{|l|}{ S:F ratio (molar ratio) } & & 7 & 5 & 3,5 \\
\hline \multirow{5}{*}{ ED Column } & Stages & & 40 & 40 & 40 \\
\hline & Solvent Feed Stage & & 9 & 9 & 9 \\
\hline & Hydrocarbon Feed Stage & & 33 & 33 & 33 \\
\hline & Reflux Ratio & & 1,3 & 1,6 & 1,7 \\
\hline & Pressure (bar) & & 1 & 1 & 1 \\
\hline \multirow{4}{*}{ SR Column } & Stages & & 8 & 8 & 8 \\
\hline & Feed Stage & & 4 & 4 & 4 \\
\hline & Reflux Ratio & & 1,5 & 0,8 & 0,4 \\
\hline & Pressure (bar) & & 0,08 & 0,08 & 0,08 \\
\hline \multicolumn{6}{|c|}{ Product Purities } \\
\hline \multirow{2}{*}{$\begin{array}{l}\text { Product Purity (wt. } \\
\text { fraction) }\end{array}$} & $\mathrm{MCH}$ & & 0,9999 & 0,9998 & 0,9994 \\
\hline & Toluene & & 0,9991 & 0,9992 & 0,9989 \\
\hline \multicolumn{6}{|c|}{ Process Equipment Duty } \\
\hline \multirow{2}{*}{ ED Column (MW) } & Condensor & & 1,18 & 1,39 & 1,35 \\
\hline & Reboiler & & 3,88 & 1,97 & 1,06 \\
\hline \multirow{2}{*}{ SR Column (MW) } & Condensor & & 1,90 & 0,88 & 0,74 \\
\hline & Reboiler & & 0,45 & 0,78 & 1,13 \\
\hline Cooler (MW) & Cooler 1 & & 0,38 & 0,33 & 0,28 \\
\hline \multirow{3}{*}{ Pumps (kW) } & Pump 1 & & 2,85 & 2,15 & 1,61 \\
\hline & Pump 2 & & 0,19 & 0,28 & 0,37 \\
\hline & Pump 3 & & 1,38 & 0,94 & 0,65 \\
\hline \multicolumn{6}{|c|}{ Process Equipment Costs $(\mathrm{k} €)$} \\
\hline & ED Column & & 960 & 902 & 918 \\
\hline & SR Column & & 789 & 592 & 608 \\
\hline & Pumps & & 132 & 133 & 123 \\
\hline & Coolers & & 51 & 58 & 65 \\
\hline & Heat exchangers & & 83 & 83 & 97 \\
\hline \multicolumn{6}{|c|}{ Operational Costs (OPEX) (k€/ yr) } \\
\hline Solvent Make-up & & & 26 & 23 & 0,8 \\
\hline Electrical & & & 2,5 & 1,9 & 1,5 \\
\hline Heating & & & 1485 & 942 & 750 \\
\hline Cooling & & & 472 & 358 & 328 \\
\hline \multicolumn{6}{|c|}{ Capital Costs (CAPEX) (M€) } \\
\hline All Equipment & & & 2,09 & 1,84 & 1,88 \\
\hline \multicolumn{6}{|c|}{ Total Annual Costs (TAC) (M€/ yr) } \\
\hline Total Annual Costs & & & 2,68 & 1,94 & 1,71 \\
\hline
\end{tabular}




\section{APPENDICES}

\begin{tabular}{|c|c|c|c|c|c|}
\hline \multicolumn{2}{|c|}{ Molar Fraction Toluene in Feed } & 0,5 & 0,6 & 0,7 & 0,8 \\
\hline \multicolumn{6}{|c|}{ Process Characteristics } \\
\hline \multicolumn{2}{|c|}{ S:F ratio (molar ratio) } & 2,6 & 2,5 & 2,5 & 2,4 \\
\hline \multirow{5}{*}{ ED Column } & Stages & 40 & 40 & 40 & 40 \\
\hline & $\begin{array}{ll}\text { Solvent } & \text { Feed } \\
\text { Stage } & \end{array}$ & 9 & 9 & 9 & 9 \\
\hline & $\begin{array}{l}\text { Hydrocarbon } \\
\text { Feed Stage }\end{array}$ & 33 & 33 & 33 & 33 \\
\hline & Reflux Ratio & 2 & 3,5 & 5,5 & 1,3 \\
\hline & Pressure (bar) & 1 & 1 & 1 & 1 \\
\hline \multirow{4}{*}{ SR Column } & Stages & 8 & 8 & 8 & 8 \\
\hline & Feed Stage & 4 & 4 & 4 & 4 \\
\hline & Reflux Ratio & 0,3 & 0,3 & 0,3 & 8 \\
\hline & Pressure (bar) & 0,08 & 0,08 & 0,08 & 0,08 \\
\hline \multicolumn{6}{|c|}{ Product Purities } \\
\hline \multirow{2}{*}{$\begin{array}{l}\text { Product Purity } \\
\text { (wt. fraction) }\end{array}$} & $\mathrm{MCH}$ & 0,9992 & 0,9986 & 0,9985 & 0,9989 \\
\hline & Toluene & 0,9991 & 0,9988 & 0,9993 & 0,9997 \\
\hline \multicolumn{6}{|c|}{ Process Equipment Duty } \\
\hline \multirow{2}{*}{$\begin{array}{l}\text { ED } \\
\text { Column (MW) }\end{array}$} & Condensor & 1,17 & 1,21 & 1,04 & 1,12 \\
\hline & Reboiler & 0,77 & 0,71 & 0,75 & 0,89 \\
\hline \multirow{2}{*}{ SR Column (MW) } & Condensor & 0,72 & 0,81 & 0,93 & 1,07 \\
\hline & Reboiler & 1,18 & 1,28 & 1,42 & 1,56 \\
\hline Cooler (MW) & Cooler 1 & 0,24 & 0,19 & 0,14 & 0,09 \\
\hline \multirow{3}{*}{ Pumps (kW) } & Pump 1 & 1,27 & 1,23 & 1,23 & 1,23 \\
\hline & Pump 2 & 0,43 & 0,47 & 0,51 & 0,55 \\
\hline & Pump 3 & 0,49 & 0,49 & 0,51 & 0,53 \\
\hline \multicolumn{6}{|c|}{ Process Equipment Costs (k€) } \\
\hline & ED Column & 895 & 891 & 924 & 918 \\
\hline & SR Column & 591 & 617 & 639 & 657 \\
\hline & Pumps & 116 & 116 & 115 & 117 \\
\hline & Coolers & 65 & 65 & 65 & 65 \\
\hline & Heat exchangers & 101 & 121 & 122 & 121 \\
\hline \multicolumn{6}{|c|}{ Operational Costs (OPEX) $(\mathrm{k} € / \mathrm{yr})$} \\
\hline \multicolumn{2}{|l|}{ Solvent Make-up } & 1,9 & 11 & 0,5 & 0,4 \\
\hline \multicolumn{2}{|l|}{ Electrical } & 1,3 & 1,3 & 1,3 & 1,3 \\
\hline \multicolumn{2}{|l|}{ Heating } & 667 & 682 & 744 & 839 \\
\hline \multicolumn{2}{|l|}{ Cooling } & 295 & 307 & 296 & 321 \\
\hline \multicolumn{6}{|c|}{ Capital Costs (CAPEX) (M€) } \\
\hline \multicolumn{2}{|l|}{ All Equipment } & 1,84 & 1,88 & 1,93 & 1,94 \\
\hline \multicolumn{6}{|c|}{ Total Annual Costs (TAC) $(\mathrm{M} € /$ yr $)$} \\
\hline \multicolumn{2}{|l|}{ Total Annual Costs } & 1,58 & 1,63 & 1,69 & 1,81 \\
\hline
\end{tabular}




\subsection{Appendix I: Thermodynamic Background}

Heat and work are everyday concepts that everybody knows. Though it was not until it was discovered that heat can be transformed into work and vice versa, that the science of thermodynamics appeared. Its initially purely practical usefulness was to increase the efficiency of engines. Although, nowadays thermodynamics are used in (almost) every field, from the study of the galaxy to the extremely small molecular scale. ${ }^{5}$ The universal applicability of thermodynamics was already told by Lewis et al. ${ }^{5}$ almost 100 years ago and even stated the choice of solvents in the chemical industry as an example, which is exactly our aim!

Thermodynamics describes the manner of a system, which is a general term used to indicate specific compound(s) in (a) certain phase(s) under certain conditions, is dependent on main measurable variables such as pressure (P), volume $(\mathrm{V})$ and temperature $(\mathrm{T})$. The pressure and temperature are intensive properties, meaning that they do not depend on the size of the system. While the volume, is an extensive property and is dependent on the system size. Other quantities are also known, such as the mass (intensive), density (extensive) and others. Thermodynamics is the study of all these quantities and most importantly how they behave if the system changes. For instance, an infinitely small change in the volume $(\mathrm{V})$ can be written as a function of the temperature $(\mathrm{T})$ and pressure $(\mathrm{P})$, see Equation 12.10.

$$
d V=\left(\frac{\partial V}{\partial T}\right)_{P} d T+\left(\frac{\partial V}{\partial P}\right)_{T} d P
$$

This relation shows that the volume of a system can change by changing of temperature or pressure. If the volume is fixed however as seen in Equation 12.11;

$$
\left(\frac{\partial V}{\partial T}\right)_{P} d T=-\left(\frac{\partial V}{\partial P}\right)_{T} d P
$$

then the thermodynamic relation allows the prediction of the temperature change if the pressure is adjusted and vice versa. Imagine the usefulness of this relation when you want to know how cold aerosols are when they leave the pressurized deodorant container. This is just a single example, though 
these relations are in essence thermodynamics at its finest. In this short chapter about thermodynamics, a very small fraction will be explained and much background information is left out. For the interested reader, I would highly recommend reading the manuscript of Lewis and Randall from 1923 which is called "Thermodynamic and the free energy of chemical substances". 5

As mentioned before thermodynamics describes the interplay between various (among others) measurable quantities. Pressure, temperature and volume are easily understandable concepts, though 4 additional quantities are highly important for our purposes but less known to everyone. These quantities are the internal energy $(\mathrm{U})$, enthalpy $(\mathrm{H})$, entropy $(\mathrm{S})$ and the Gibbs energy $(\mathrm{G})$, of which some have been shortly before in Equation 6.3. These quantities are quite essential in the chemical engineering field and therefore will be shortly introduced.

1. Internal energy $(\mathrm{U})$, is a quantity that describes simply how much energy a thermodynamic system holds, for instance considering a molecule. The internal energy can be interpreted as the kinetic energy originated from vibrations, rotations and translations, and the potential energy within the chemical bonds of the molecule. The internal energy is defined as the difference between a reference (zero) state and the state of interest.

2. Enthalpy $(\mathrm{H})$, is a thermodynamic quantity that includes not only the internal energy of a system or molecule, but also the work that is required to occupy space which is the product of volume and pressure $(H=U+P V))$. The total enthalpy is highly difficult to determine as it includes the internal (kinetic and potential) energy. Therefore, generally the difference between a reference state and the state of interest is determined.

3. Entropy (S), is the quantity firstly coined by Clausius ${ }^{6,7}$ and can be interpreted in various ways. It can be considered a measure of chaos that is proportional to the number of possible microscopic configurations $(\Omega)$ ) in the system, $\left(S=k_{B} \ln \Omega\right)$ expressed by Boltzmann. ${ }^{8}$ This aligns with the second law of thermodynamics postulates which states; "The entropy of an isolated system will never decrease over time", which means 
the path to more chaos is spontaneous and the creation of order is not spontaneous. Following this law, for some processes, it is impossible to restore the system to its original state, these processes are called "irreversible" processes. As such, the entropy can also be interpreted as the extend of irreversibility ${ }^{5}$. This can be defined as the received heat, q, divided over the absolute temperature. As the change in entropy describes how far the process is from being reversible, the change in entropy is $d S=q / T$. This is also the exact original definition used by Clausius ${ }^{7}$ to formulate the entropy.

4. Gibbs energy $(G)$, this quantity describes the maximum amount of work that can be done in a "reversible" process. This reversible process is defined as such that no overall entropy change occurs. In accordance with the second law of thermodynamics, which is not violated as the entropy is not decreased but stays constant. Thus after a change in the system, the system can be restored to its original state. It is a measure of the internal energy, the occupied space, but also compensates for the temperature and the entropy of the system; $G=H-T S$. Also, this quantity is often determined relative to a standard state, therefore generally a $\Delta G$ is determined.

These quantities are not only subjected to temperature, volume and pressure changes, as shown in Equation 12.10. Also composition changes affect these quantities when a thermodynamic system includes a mixture. For instance the change in the Gibbs energy can dependent on changes in the composition of $\mathrm{i}$ number of components where $x_{i}$ is the total amount of moles of component $\mathrm{i}$, see Equation 12.12;

$$
d G=\left(\frac{\partial G}{\partial x_{i}}\right)_{T, P} d x_{1}+\left(\frac{\partial G}{\partial x_{2}}\right)_{T, P} d x_{2}+\ldots+\left(\frac{\partial G}{\partial x_{i}}\right)_{T, P} d x_{i}
$$

where the overall change in Gibbs energy is the summation of its partial derivative towards each component multiplied by the change in that specific concentration. A common nomenclature of the partial quantity, in this case the molar Gibbs energy is a bar superscript, as can be seen in Equation 12.12;

$$
d G=\bar{G}_{1} d x_{1}+\bar{G}_{2} d x_{2}+\ldots+\bar{G}_{i} d x_{i}
$$


These equations still describe the change in the Gibbs energy and can be integrated if all molar ratios are kept equal, which results in Equation 12.14;

$$
G=\bar{G}_{1} x_{1}+\bar{G}_{2} x_{2}+\ldots+\bar{G}_{i} x_{i}
$$

In the specific binary case, where only two components are present and the total amount of moles are kept equal the relation in Equation 12.15 can be obtained, which is commonly known as the Gibbs-Duhem equation;

$$
\bar{G}_{1} x_{2}=-\bar{G}_{2} x_{2} \text {, which is } \frac{\bar{G}_{1}}{\bar{G}_{2}}=\frac{-x_{2}}{x_{1}}
$$

This relation enables the description of the interplay between the change in the molar Gibbs energies of two components in the same mixture. This has as a consequence that the molar Gibbs energies are equal at a molar fraction of 0.5 , and if one of the curves exhibits a maximum, the other variable will have a minimum. The Gibbs-Duhem equation is essential in the developed approach (see chapter 6) to convert the Gibbs energy of a binary system into molar Gibbs energies.

In the special case of infinite dilution, a mathematical problem arises. If a component is infinitely diluted in a binary system and thus $x_{2} \Rightarrow 0$, then either $\bar{G}_{1} \Rightarrow 0$ or $\bar{G}_{2} \Rightarrow-\infty$. This mathematical discontinuity is a limitation of the (molar) Gibbs energy and therefore Lewis introduced the fugacity, $f_{i}{ }^{5}$

The molar Gibbs energy, $\bar{G}_{i}$, and the fugacity, $f_{i}$, are two manners of describing the tendency of a compound to escape the phase it is in. A system with 2 phases is in equilibrium with each other if the $\bar{G}_{i}$ or $f_{i}$ are equal to each other. Also the vapor pressure can be used to describe this, namely the vapor pressure of ice and water are equal at boiling point. Though, this is only valid for ideal gases, hence the fugacity defined by Lewis is an "ideal" or "corrected" vapor pressure. The relation between the $\bar{G}_{i}$ and the $f_{i}$ was defined by Lewis ${ }^{5}$ to be, see Equation 12.16 .

$$
\bar{G}_{i}=R T \ln f_{i}+B
$$

where $\mathrm{B}$ is term that is solely dependent on the temperature. 
Due to the fact, the fugacity is directly related to the partial pressure, in the limited case that a component is infinitely diluted, $n_{2} \Rightarrow 0$, also the partial pressure will go to zero, which entails that also $f_{2} \Rightarrow 0$. Hence, by using the fugacity $\left(f_{i}\right)$ and not the molar Gibbs energy, $\bar{G}_{i}$, the discontinuity at the extremes is eliminated. ${ }^{5}$

The tendency to escape, $f_{i}$, is of great interest to chemical engineers as it helps the understanding of, for instance the behavior of fluids in distillation- and liquid-liquid extraction columns. The effect of pressure (P), temperature (T) and volume $(\mathrm{V})$ are always considered, as they affect the $f_{i}$ of the components directly. It is highly interesting to note, that Lewis ${ }^{5}$ also mentioned that the shape or curvature of the liquid phase also affects the $f_{i}$. Though this may often be neglected, the $f_{i}$ is greater as the radius of a liquid droplet decreases. Hence, fine dispersedness of the liquid phase could in essence also increase the performance of fluid separation columns. This is also shown by a more recent paper by Zhang et al. ${ }^{9}$. Although, this factor will not be included in this work as it goes into too much detail regarding process equipment design, it needs to be recognized and may be an additional pathway to manipulate separation performances via the design of gas and/or liquid dispersion.

The absolute fugacity is however not often used, though often the nomenclature can be confusing. Lewis proposed the relative fugacity, called the activity, to be;

$$
a_{i}=\frac{f_{i}}{f_{i}^{0}}
$$

where the $f_{i}^{0}$ is the fugacity in a chosen reference state. This correlates to the relation of the difference in $\bar{G}_{i}$ and the reference state $\bar{G}_{i}^{0}$ to be;

$$
\bar{G}_{i}-\bar{G}_{i}^{0}=R T \ln a_{i}
$$

The definition of the activity is defined differently for the gas- and the liquid phase.

1. Gas phase: due to fact the activity is proportional to the partial pressure, which in turn is proportional to the fugacity. The activity is equalized to the fugacity, where the reference state is chosen to be as such that the $f_{i}^{0}=1$. As the gas phase fugacity of a certain component is proportional 
to the partial pressure $\left(P_{i}^{o}=y_{i} P\right)$, the fugacity is defined as; $f_{i}=\varphi_{i} y_{i} P$, where $\varphi_{i}$ is the fugacity coefficient.

2. Liquid phase: the activity is in this phase proportional to the mole fraction, and by definition, the activity is unity when the molar fraction $x_{i}$ is unity, thus $a_{i} / x_{i}=1$ for pure components. For solutions, the activity is defined as; $a_{i}=\gamma_{i} x_{i}$, where $\gamma_{i}$ is the activity coefficient.

Summarizing, the non-ideality seen in phase equilibria can be described via the fugacity derived from the above-mentioned thermodynamic correlations. In the next sections, two types of models will be discussed which apply these thermodynamic correlations to correlate actual phase equilibria. First, liquid activity coefficients models will be discussed which originate from $\gamma_{i}$ representations, while secondly Equations of State (EoS) will be discussed which originally attempts to predict correctly the pressure, volume and temperature (PVT) interplay and consequently can estimate the non-ideality parameters.

\subsubsection{Liquid Activity Coefficient models}

Several liquid activity coefficient models of varying complexity are known which are based on the molar Gibbs energy, such as the van Laar model ${ }^{10}$, Wilson model ${ }^{11}$, Margules model ${ }^{12}$, Universal Quasichemical (UNIQUAC) model $^{13}$ and Non-Random Two-Liquid (NRTL) model ${ }^{14}$. Though it was previously shown in the Gibbs-Duhem equation (Equation 12.13) that the Gibbs energy can be described as the summation of all molar Gibbs energies. The Gibbs energy can also be defined as the summation of the Gibbs energy of an ideal solution $\left(G^{I D}\right)$ and an excess term that accounts for the non-ideal behavior $\left(G^{E}\right)$;

$$
G=G^{I D}+G^{E}
$$

where, the $G^{I D}$ can subsequently be defined as a summation of all molar Gibbs energies $\left(\bar{G}_{i}\right)$ multiplied by the specific molar fraction, and the ideal entropic term;

$$
G^{I D}=\sum_{i=1}^{n} x_{i} \bar{G}_{i}+R T \sum_{i=1}^{n} x_{i} \ln x_{i}
$$


consequently, the Gibbs is defined as

$$
G=\sum_{i=1}^{n} x_{i} \bar{G}_{i}+R T \sum_{i=1}^{n} x_{i} \ln x_{i}+G^{E}
$$

or,

$$
G=\sum_{i=1}^{n} x_{i}\left(\bar{G}_{i}+R T \ln x_{i}+\bar{G}^{E}\right)
$$

The excess term of the Gibbs energy $\left(G^{E}\right)$ is related to the activity coefficient as it is the partial derivative of it, see Equation 12.21;

$$
R T \ln \gamma_{i}=\left(\frac{\partial G^{E}}{\partial x_{i}}\right)_{T, P}=\bar{G}^{E}
$$

Each liquid activity coefficient model has a different manner of incorporating interaction parameters in the activity coefficient description to estimate/predict the non-ideality in a mixture. More details can be found in section 12.9.2. In our case, we are specifically interested in also the excess molar enthalpy $\left(H^{E}\right)$. Therefore, we first need to describe the manner in which the Gibbs energy changes as a function of the temperature and pressure. By following the derivation, firstly made by Gibbs and Helmholtz, as can be seen in Equation 12.22;

$$
d\left(\frac{G}{T}\right)=\left(\frac{(\partial G / T)}{\partial T}\right)_{P} d T+\left(\frac{(\partial G / T)}{\partial P}\right)_{T} d P
$$

this can be rewritten as;

$$
d\left(\frac{G}{T}\right)=-\frac{H}{T^{2}} d T+\frac{V}{T} d P
$$

This relation holds also for the Excess Gibbs energy. By performing this derivation, a well-known thermodynamic relation is obtained at isobaric conditions, see Equation 12.23, which can correlate the measurable excess molar enthalpy $\left(H^{E}\right)$ which the Gibbs energy in Liquid Activity Coefficient models. This equation is known as the Gibbs-Helmholtz equation;

$$
\left(\frac{\left(\partial G^{E} / T\right)}{\partial T}\right)_{P}=-\frac{H^{E}}{T^{2}}
$$




\subsubsection{Equations of State}

An Equation of State (EoS) is a mathematical construction that details the dependence of 3 observable parameters, temperature $(\mathrm{T})$, pressure $(\mathrm{P})$ and (molar) volume (V or $\left.V_{m}\right)$. The most simple EoS is the ideal gas law, see Equation 12.24, which was first stated by Clapeyron in $1834^{15}$;

$$
P V=n R T \vee P V_{m}=R T
$$

The universal gas constant, $R$, is equal to $8.3145 \mathrm{Jmol}^{-1} \mathrm{~K}^{-1}$ and can be derived from combining the fact that all substances behave ideally when the pressure approaches 0 and the triple point temperature of water. This law is accurate for ideal gases, and was formulated by combining Boyle's law which described an isothermal situation $\left(P_{1} V_{1}=P_{2} V_{2}\right)$, Charles' Law which describes the isobaric state $\left(V_{m, 1} / T_{1}=V_{m, 2} / T_{2}\right)$, the isochoric state is described by Amonton's Law $\left(P_{1} / T_{1}=P_{2} / T_{2}\right)$ and Avogadro's Law is valid at constant pressure and temperature $\left(V_{1} / n_{1}=V_{2} / n_{2}\right)$.

Equations of State (EoS) are widely used in both academia and industry to calculate thermodynamic properties. Accurate temperature, pressure and composition profiles can be determined for a wide range of mixtures and corresponding processes. ${ }^{16}$ Cubic Equation of States (cEoS) are the most popular class and originate from the van der Waals equation of state, which for the first time formulated a thermodynamic model for both fluid phases. ${ }^{17}$

Johannes Diderik van der Waals started his dissertation ${ }^{17}$ with the fascination to understand the quantity in the theory of capillary force which described the molecular pressure on the surface of an entrapped liquid. He developed the theoretical framework as a necessity, as he said (in Dutch);"Daar mij geen weg open schijnt om langs proefondervindelijken weg het bedrag dier constante te vinden, was het noodig om zo door theoretische beschouwingen the bepalen". Translated, he explained in the dissertation preface that the behavior of that quantity could not be found via an experimental route, hence a theoretical framework needed to be made. Eventually, Van der Waals postulated the first equation of state which does not assume that molecules possess no volume and do not interact (ideal gas law), and takes into account the molecular size (b) and attractive interactions (a), see Equation $12.25 ;{ }^{17}$ 


$$
P=\frac{R T}{V_{m}-b}-\frac{a}{V_{m}^{2}}
$$

From a statistical point of view, these parameters can be obtained by a LennardJones type of potential, where the hard-core volume of the molecule is can be considered to be a repulsive parameter (b) and the intermolecular attraction parameter (a) is associated with the $\epsilon$ parameter which is a representation of the intermolecular interactions. The absolute values of the interaction parameters are determined by conditions set at the critical point (C.P.), see Equation 12.26 and for derivative details see subsection 12.11.1;

$$
\left(\frac{\partial P}{\partial V_{m}}\right)_{T_{c}}=\left(\frac{\partial^{2} P}{\partial V_{m}^{2}}\right)_{T_{c}}=0
$$

For the Van der Waals equation the attractive (a) and repulsive (b) purecomponent constants are ultimately determined to be;

$$
\begin{gathered}
a=\frac{27 R^{2} T_{c}^{2}}{64 P_{c}} \\
b=\frac{R T_{c}}{8 P_{c}}
\end{gathered}
$$

Since Van der Waals in 1873 published his dissertation, numerous adaptions of the Van der Waals equation have been published to include more extreme conditions and/or to accurately incorporate increasingly more non-ideal molecules (see section 12.10.4). Well-known adaptations are the (Soave-)RedlichKwong, ${ }^{18,19}$ Peng-Robinson ${ }^{20}$ and the Petal-Teja ${ }^{21}$ cEoS, though many others are present in literature and they all originate and follow the Van der Waals mathematical framework.

In Figure 12.4, the equilibrium between two non-ideal fluid phases, see gas and liquid, is represented by the binodal curve. It shows the gas and liquid volumes at which both phases co-exists at various temperatures. Between the binodal curve are the results of the "Van der Waals loop", a prediction of the cubic Equation of State, which describes the state between both phases. This oscillation or "loop" contradicts the experimental observations, as there are no 3 stable volumes at a given pressure, but only one for each fluid phase. Also 


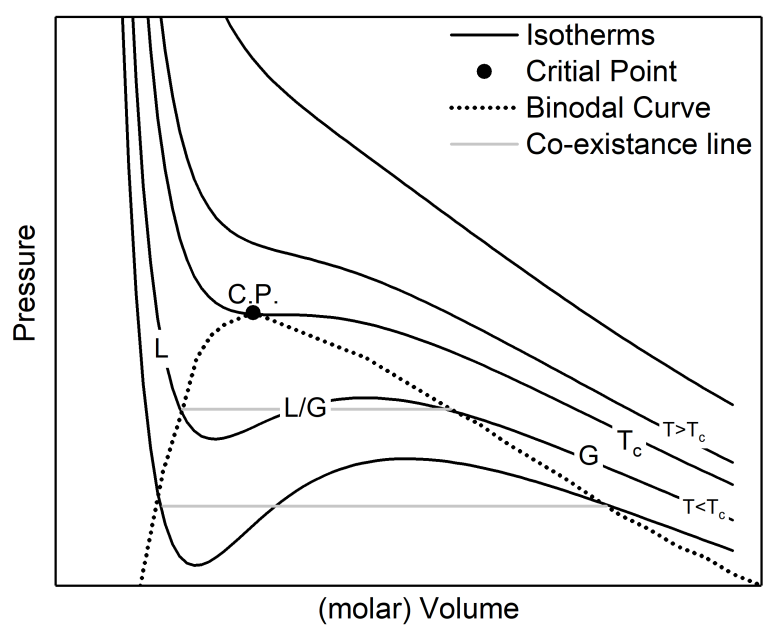

Figure 12.4: The gas-liquid equilibrium profile of a pure component as a function of the pressure and volume. Additionally, the critical point (C.P. or C) and the binodal curve are depicted.

the positive slope $\left(\partial P / \partial V_{m}\right)_{T}>0$ between the minimum and the maximum of the "loop" would mean that when the pressure increases, also the molar volume does, which is doesn't make sense. Hence, the horizontal line through this "loop" is called the co-existence line. This described the phase-splitting behavior by equalizing both surface areas beneath and above the co-existing line following the Maxwell equal area rule. ${ }^{22}$ This equalization is justified as the PV-diagram corresponds to mechanical work and the work done "left" and "right" of the inflection point and should be equal as it is a reversible process. This Equation of State predicts the "loops" seen in Figure 12.4 and a particular branch are the cubic Equation of States, of which the Van der Waals equation is one. These equations are named cubic as they can be rewritten as a cubic function of the molar volume, or the compressibility factor $(Z)$. This $Z$-value is indicative of the non-ideality of the fluid, and is associated with the ideal gas law as seen in Equation 12.28;

$$
Z=\frac{P V_{m}}{R T}
$$


For an ideal fluid, the Z-value is equal to one, which results in the ideal gas law. For non-ideal cases, as seen in Figure 12.4, where two fluid phases can co-exist and the Z-value is essential. (note: the ideal gas law does not predict a distinction between gas and liquid)

In the mathematical framework of the cEoS the Z-values of both fluid phases can be determined by solving the cubic equation (see Equation 12.29) and finding the three roots.

$$
Z^{3}+\xi_{1} Z^{2}+\xi_{2} Z^{2}+\xi_{3}=0
$$

in this cubic equation, each $\xi$ value is dependent on the type cEoS, see section 12.11.12. Three types of solutions can be obtained, when the cEoS are solved. The subcritical isotherm solution $\left(T<T_{c}\right)$ has three different roots, of which the smallest and largest roots correlate to resp. the liquid $\left(Z_{L}\right)$ phase and the gas or vapor phase $\left(Z_{V}\right)$. The middle root does not have a physical meaning as it corresponds to the inflection point seen in Figure 12.4. The critical isotherm solution $\left(T=T_{c}\right)$ has three equal real root solutions at precisely the critical point, though if the pressure deviates a unique real root will be obtained with two complex conjugates. Supercritical solutions $\left(T>T_{c}\right)$ obtain a single real root and two complex conjugates, as only one phase exists above the critical point.

The determination of the Z-value allows the description of a variety of other thermodynamic quantities which arise from the deviation or departure from ideality. Collectively these quantities are known as departure functions. For this work, shown in chapter 6, we are interested in the excess molar enthalpy and the fugacity. These quantities are described in Equation 12.30 and Equation $12.31 i^{23}$

$$
\begin{gathered}
H_{d e p}=H^{E}=H-H^{i g}=R T \int_{0}^{\rho}-T\left(\frac{\partial Z}{\partial T}\right) \frac{d \rho}{\rho}+(Z-1) \\
\ln f_{i}=\int_{0}^{\rho}(Z-1) \frac{d \rho}{\rho}+(Z-1)-\ln Z
\end{gathered}
$$

where it can be seen that each quantity is a function of the compressibility factor $(\mathrm{Z})$, the universal gas constant $(\mathrm{R})$, the temperature $(\mathrm{T})$ and the molar 
density $(\rho)$ which is the inverse of the molar volume $\left(V_{m}\right)$. Upon the choice of the $\mathrm{Z}$-factor, the fugacity can be distinguished between the liquid- or vapor phase fugacity. These quantities are at isobaric conditions, though isochoric can also be derived.

Additionally, other thermodynamic properties, such as the heat capacity, isothermal compressibility coefficients, etc., can be determined at various temperatures, volumes and pressure. The principle of predicting unknown properties of many fluids from known properties of a few is called the Corresponding State Principle (CSP) and is considered the most important by-product of the Van der Waals equation of state. ${ }^{24}$ Until now, solely pure fluids have been considered, though the extension towards binary mixture (and further) can be made. For our needs, the enthalpy departure function corresponds to the heat of mixing or excess molar enthalpy $H^{E}$, while the departure of the fugacity from the pure component fugacity is a measure of the activity coefficient $\left(\gamma_{i}\right)$ in the liquid phase and the fugacity coefficient $\left(\varphi_{i}\right)$ in the gas phase.

The Gibbs-Duhem equation, seen in Equation 12.15, describes the equilibrium between multiple phases, where the molar Gibbs energy, $\bar{G}_{i}$, or in other words chemical potential, $\mu_{i}$, of each phase is equal. Darken ${ }^{25}$, additionally showed that this equation can be applied to distinguish the individual partial quantity in a multi-component system from the overall quantity. The overall fugacity $(f)$, can be differentiated into the partial coefficients, both in the gas$\left(\varphi_{i}\right)$ or liquids $\left(\gamma_{i}\right)$ phase for each component, as can be seen in Equation 12.32 for a binary case;

$$
\ln f_{1}=\ln f+\left(1-x_{1}\right)\left(\frac{\partial \ln f}{\partial x_{1}}\right), \ln f_{2}=\ln f+x_{1}\left(\frac{\partial \ln f}{\partial x_{1}}\right)
$$

Mixing rules are introduced to extend the EoS description from pure components towards mixtures. These relations describe the way pure component parameters, for instance, the a and $b$ parameters, of the Van der Waals equation vary as a function of the composition. These mixing rules are in a general form of; 


$$
M=\sum_{i}^{n} \sum_{j}^{n} x_{i} x_{j} m_{i j}
$$

where $m_{i j}$ can be all binary interaction parameters which are a function of pure component parameters, such as a and $\mathrm{b}$ resp. the binary attraction and repulsion term. There are various mixing rules, which deviate in the manner of the attraction and/or repulsion term description. The most simple mixing rule is the linear average of the pure component parameters, e.g. $a=x_{1} a_{1}+$ $x_{2} a_{2}$, which do not include any binary interaction parameter. Though more rigorous mixing rules are often used, as can be seen in 1-parameter Van der Waals mixing rule in Equation 12.34;

$$
a=x_{1}^{2} a_{1}+x_{2}^{2} a_{2}+2\left(x_{1} x_{2} \sqrt{a_{1} a_{2}}\left(1-K_{i j}\right)\right)
$$

where the attractive parameter (a) is a function of the composition, $x_{i}$, the pure component a-parameters, and the binary interaction parameter (BIP), $K_{i j}$. This is however just one of the many types of mixing rules, and more described in section 12.11.12.

\subsection{Liquid Activity Models}

Each model will be separately explained and the equation will show the binary mixture formulation, though each equation can be generalized to cover multicomponent mixtures.

\subsubsection{Margules}

Margules ${ }^{12}$ introduced a simple description of the Gibbs energy in mixtures, and decades later after Lewis ${ }^{5}$ introduced the fugacity concept, this equation could also be used to describe the activity coefficients. Margules used a power series expansion to describe the Gibbs energy for mixtures;

$$
\frac{G^{E}}{R T}=x_{i} x_{j}\left(A_{j i} x_{i}+A_{i j} x_{j}\right)+x_{i}^{2} x_{j}^{2}\left(B_{j i} x_{i}+B_{i j} x_{j}\right)+\ldots+x_{i}^{m} x_{j}^{m}\left(M_{j i} x_{i}+M_{i j} x_{j}\right)
$$

where $x_{i}$ is the molar fraction of component i. Generally, higher order parameters $\left(B_{i j} \rightarrow M_{i j}\right)$ are considered neglectable and therefore equalized to zero. 
This model can be distinguished between a symmetrical and asymmetrical variant. In the asymmetrical variant, 2 interaction parameters are introduced (when considering a binary mixture), namely $A_{i j}$ and $A_{j i}$;

$$
\begin{aligned}
& \ln \left(\gamma_{i}\right)=x_{j}^{2}\left(A_{i j}+2 x_{i}\left(A_{j i}-A_{i j}\right)\right) \\
& \ln \left(\gamma_{j}\right)=x_{i}^{2}\left(A_{j i}+2 x_{j}\left(A_{i j}-A_{j i}\right)\right)
\end{aligned}
$$

In a limited case, where $A_{i j}=A_{j i}=A$, Equation 12.36 reduces to the symmetric Margules equation;

$$
\begin{aligned}
& \ln \left(\gamma_{i}\right)=x_{j}^{2} A \\
& \ln \left(\gamma_{j}\right)=x_{i}^{2} A
\end{aligned}
$$

An important realization of the Margules equation is the fact that $A_{i j}=\ln \gamma_{i}^{\infty}$ and $A_{j i}=\ln \gamma_{j}^{\infty}$. where in $\gamma_{i}^{\infty}$ is the infinitely dilution activity coefficient of component i. A feature that is used in chapter 4.

A direct correlation of the Margules equation between the excess molar enthalpy $H^{E}$, via the Gibbs-Duhem equation (see Equation 12.23), and the excess molar Gibbs energy is however not possible. As the Gibbs-Duhem equation required a temperature derivation of the molar Gibbs energy description, which in the Margules case is temperature-independent. Hence, an ideal situation will always occur in which the excess molar enthalpy is equal to zero.

\subsubsection{Van Laar}

The Van Laar equation was developed by Johannes van Laar, ${ }^{10}$ and was derived from the Van der Waals equation of state, which will be elaborated upon in a later section. Van Laar obtained, from the Van der Waals equation, the excess molar enthalpy,

$$
H^{E}=\frac{b_{i} x_{i} b_{j} x_{j}}{b_{i} x_{i}+b_{j} x_{j}}\left(\frac{\sqrt{a_{i}}}{b_{i}}-\frac{\sqrt{a_{j}}}{b_{j}}\right)^{2}
$$


where $\mathrm{a}$ and $\mathrm{b}$ are resp. the attraction and hard-core volume (or repulsion) term of the Van der Waals equation of state. Eventually, the a-parameters were excluded from the equation and a reduced form became the van Laar equation;

$$
\frac{G^{E}}{R T}=\frac{A_{i j} x_{i} A_{j i} x_{j}}{A_{i j} x_{i}+A_{j i} x_{j}}
$$

Identically to the Margules equation, an asymmetric and symmetric variant is present where also two binary interaction parameters are introduced, namely $A_{i j}$ and $A_{j i}$;

$$
\begin{aligned}
& \ln \left(\gamma_{i}\right)=A_{i j}\left(\frac{A_{j i} x_{j}}{A_{i j} x_{i}+A_{j i} x_{j}}\right)^{2} \\
& \ln \left(\gamma_{j}\right)=A_{j i}\left(\frac{A_{i j} x_{i}}{A_{i j} x_{i}+A_{j i} x_{j}}\right)^{2}
\end{aligned}
$$

In the symmetric variant, again $A_{i j}=A_{j i}=A$, and the Van Laar equation will reduce to the same equation as the symmetric Margules equation, see Equation 12.37 .

The difference is however in the description of the binary interaction parameters. As in the Margules equation it was a function of the infinite dilution activity coefficient $\left(\gamma_{i}^{\infty}\right)$, this is not the case in the Van Laar model. In this model the temperature-dependent $A_{i j}$ parameter is a function of the temperatureindependent $\dot{A}_{i j}$ parameter, the universal gas constant and the temperature, see Equation 12.41

$$
A_{i j}=\frac{\dot{A}_{i j}}{R T} \wedge A_{j i}=\frac{\dot{A}_{j i}}{R T}
$$

Though this decouples the activity coefficient and the binary interaction coefficient, it allows the description of the excess molar enthalpy as the Gibbs energy equation by Van Laar is temperature-dependent. Following the GibbsHelmholtz equation, the excess molar enthalpy can be rewritten as;

$$
H^{E}=R T \frac{A_{i j} x_{i} A_{j i} x_{j}}{A_{i j} x_{i}+A_{j i} x_{j}}
$$




\subsubsection{Wilson}

Wilson proposed an activity coefficient-based model which could fit highly non-ideal, though miscible, mixtures ${ }^{11}$ The equation takes into account both the molecular size and intermolecular forces, and applied a local composition approach. This entailed that locally, the composition of the mixtures may be different than the overall composition. Wilson assumed however a the FloryHuggins volumetric expression. ${ }^{26,27}$ For a binary mixture, the Gibbs Excess energy is given by;

$$
\frac{G^{E}}{R T}=-x_{i} \ln \left(x_{i}+A_{i j} x_{j}\right)-x_{j} \ln \left(x_{j}+A_{j i} x_{i}\right)
$$

Following the Gibbs-Duhem equation, the activity coefficients are therefore defined as;

$$
\begin{aligned}
& \ln \left(\gamma_{i}\right)=-\ln \left(x_{i}+A_{i j} x_{j}\right)+x_{j}\left(\frac{A_{i j}}{x_{i}+A_{i j} x_{j}}-\frac{A_{j i}}{x_{j}+A_{j i} x_{i}}\right) \\
& \ln \left(\gamma_{j}\right)=-\ln \left(x_{j}+A_{j i} x_{i}\right)-x_{i}\left(\frac{A_{i j}}{x_{i}+A_{i j} x_{j}}-\frac{A_{j i}}{x_{j}+A_{j i} x_{i}}\right)
\end{aligned}
$$

where the temperature-dependent binary interaction parameter $\left(A_{i j}\right.$ and $\left.A_{j i}\right)$ are defined as;

$$
\begin{aligned}
& A_{i j}=\frac{v_{j, L}}{v_{i, L}} \exp \left(-\frac{\dot{A}_{i j}}{R T}\right) \\
& A_{j i}=\frac{v_{i, L}}{v_{j, L}} \exp \left(-\frac{\dot{A}_{j i}}{R T}\right)
\end{aligned}
$$

which in turn are a function of the liquid molar volume $\left(v_{i, L}\right)$ and the temperature-independent binary interaction coefficient $\left(\dot{A}_{i j}\right)$

Lastly, following the Gibbs-Helmholtz equation, the excess molar enthalpy is defined as;

$$
H^{E}=-\left(x_{i}\left(x_{i}+A_{i j} x_{j}\right)+x_{j}\left(x_{j}+A_{j i} x_{i}\right)\right)+\frac{x_{i} x_{j}}{R T}\left(\dot{A}_{i j} A_{i j}+\dot{A}_{j i} A_{j i}\right)
$$




\subsubsection{Non-Random Two Liquid (NRTL) model}

Not only the Wilson equation, also the Non-Random Two Liquid (NRTL) model proposed by Renon and Prausnitz ${ }^{14}$ uses the local composition approach to describe highly non-ideal components. Though where Wilson used a Flory-Huggins volumetric description ${ }^{26,27}$, the NRTL model assumed also for this term a local composition expression and introduced a non-randomness factor $(\alpha)$.

$$
G^{E}=\sum_{i=1}^{n} x_{i} \frac{\sum_{j=1}^{n} x_{j} g_{j i} \tau_{j i}}{\sum_{k=1}^{n} x_{k} g_{k i}}
$$

where

$$
\ln g_{j i}=-\alpha_{j i} \tau_{j i}
$$

and

$$
\tau_{j i}=\frac{G_{j i}}{R T}
$$

Via the Gibbs-Duhem equation, for a binary mixture, this reduces to an activity coefficient description of;

$$
\begin{aligned}
& \ln \left(\gamma_{i}\right)=x_{j}^{2}\left(\tau_{j i}\left(\frac{G_{j i}}{x_{i}+x_{j} G_{j i}}\right)^{2}+\frac{\tau_{i j} G_{i j}}{\left(x_{j}+x_{i} G_{i j}\right)^{2}}\right) \\
& \ln \left(\gamma_{j}\right)=x_{i}^{2}\left(\tau_{i j}\left(\frac{G_{i j}}{x_{j}+x_{i} G_{i j}}\right)^{2}+\frac{\tau_{j i} G_{j i}}{\left(x_{i}+x_{j} G_{i j}\right)^{2}}\right)
\end{aligned}
$$

These equations reduce to the symmetric Margules and Van Laar equation, when the non-randomness factor is zero $\left(\alpha_{i j}=0\right)$

Lastly, via the Gibbs-Helmholtz equation, the excess molar enthalpy of a binary mixture is described as;

$$
H^{E}=x_{i} x_{j}\left(\frac{g_{j i} G_{j i}\left(x_{i}+x_{j} g_{j i}-x_{i} \tau_{j i} \alpha_{j i}\right)}{\left(x_{i}+x_{j} g_{j i}\right)^{2}}+\frac{g_{i j} G_{i j}\left(x_{j}+x_{i} g_{i j}-x_{j} \tau_{i j} \alpha_{i j}\right)}{\left(x_{j}+x_{i} g_{i j}\right)^{2}}\right)
$$




\subsection{1 cubic Equation of States (cEOS)}

\subsubsection{Van der Waals (VdW) EoS}

Van der Waals tackled two of the most elemental simplifications of the ideal gas law, which is that the molecules don't occupy any space, i.e. are point sources, and all molecules are isolated and thereby do not interact. For this reason, all substances behave ideally as the pressure goes to 0 , where all molecules are infinity far apart and molecular volume and interactions are neglectable. Van der Waals corrected this firstly by stating that molecules can be considered as hard spheres that occupy space. The available space is hence reduced. For this reason, the term $\left(V_{m}-b\right)$ is introduced, where $\mathrm{b}$ is the excluded volume that originated from the molecule. The excluded volume is however not the same as the actual volume of the molecules, but about $4 \mathrm{x}$ as large due to the fact 2 hard spheres cannot overlap in space.

The second adaptation is the attractive force between the molecules. A homogeneous density and a very small range of these forces were the assumptions made. The force exerted on the molecules is identified to be inversely proportional to the square of the density and so the additional term of $a / V_{m}^{2}$ was introduced. Hence, Van der Waals formulated ${ }^{17}$;

$$
P=\frac{R T}{V_{m}-b}-\frac{a}{V_{m}^{2}}
$$

One of the features of the Van der Waals EoS is the fact it is cubic by nature, it can be rewritten as;

$$
V_{m}^{3}-\left(b+\frac{R T}{P}\right) V_{m}^{2}+\frac{a}{P} V_{m}-\frac{a b}{P}=0
$$

Solving this cubic equation at a certain temperature gives the corresponding molar gas and liquid volumes. This will be discussed in a later section. At the critical point, only 1 solution will however be present, as no distinction between gas and liquid are possible anymore. In that case a criterion of $\left(V_{m}-\right.$ $\left.V_{m, c}\right)^{3}=0$ where the $V_{m, c}$ is the molar volume at the critical point. Expanding this criterion gives the following expression;

$$
V_{m}^{3}-3 V_{m} V_{m}^{2}+3 V_{m}^{2} V_{m}-V_{m}^{3}=0
$$


As this closely resembles the cubic expression of the Van der Waals EoS, the next correlations can be found;

$$
V_{m, c}^{3}=\frac{a b}{P_{c}} \wedge 3 V_{m, c}^{2}=\frac{a}{P_{c}} \wedge 3 V_{m, c}=b+\frac{R T_{c}}{P_{c}}
$$

Which, consequently, allows the description of the critical parameters as a function of the pure-components parameters ( $a$ and $b$ );

$$
V_{m, c}=3 b \wedge P_{c}=\frac{a}{27 b^{2}} \wedge T_{c}=\frac{8 a}{27 b R}
$$

Inversely, after rearrangement, the pure-component parameters can also be defined as a function of the critical parameter;

$$
a=\frac{27 R^{2} T_{c}^{2}}{64 P_{c}} \wedge b=\frac{R T_{c}}{8 P_{c}}
$$

If this is applied to the compressibility factor, which is $Z=P V_{m} / R T$, in the Van der Waals EoS at critical conditions. The results will be, independent of the pure-component parameters, 0.375 . This means that all compounds behave the same at the critical point according to the Van der Waals EoS. This is the law of Corresponding States, or Corresponding States Principle (CSP), which states that all fluids have approximately the same compressibility factor, and thus behave similarly, at the same reduced temperature $\left(T_{r}=T / T_{c}\right)$ and pressure $\left(P_{r}=P / P_{c}\right)$.

The Van der Waals EoS has however short-comings, as the Van der Waals equation can be rewritten as $P=R T \rho-a \rho^{2}$, there are densities $(\rho)$ that are equal to the inverse of the molar volume $\left(V_{m}\right)$, at which the pressure becomes negative. This is of course not possible and highlights the need for more detailed EoS that can describe a wider range.

\subsubsection{Redlich-Kwong (RK) EoS}

Redlich and Kwong ${ }^{18}$ published an empirical equation that resembles the Van der Waals equation with some adjustments. The performance of the new equation was compared with, among others, the Van der Waals equation for the description of the compressibility factor of ethane and was found to be 
more accurate at both low and high pressures. This new Equation of State by Redlich and Kwong is; ${ }^{18}$

$$
P=\frac{R T}{V_{m}-b}-\frac{a}{\sqrt{T} V_{m}\left(V_{m}+b\right)}
$$

with the pure-component parameter description;

$$
a=0.42748 \frac{R^{2} T_{c}^{2.5}}{P_{c}} \wedge b=0.08664 \frac{R T_{c}}{P_{c}}
$$

\subsubsection{Soave-Redlich-Kwong (SRK) EoS}

Soave ${ }^{19}$ stated that the Redlich-Kwong EoS was the best two-parameter EoS for the prediction of pure-component properties, though the accuracy drops for multi-component vapor-liquid equilibria (VLE) predictions. Soave ascribed the inaccuracy to the temperature-dependency description of the Redlich-Kwong EoS. Hence, the postulation was made that an improvement in the saturation condition of pure compounds, which is highly temperature dependent, also improved the temperature-dependency of mixtures which ultimately improves the VLE prediction. The first modification was made to Equation 12.56, where the $a / \sqrt{T}$ was replaced by a general $a(T)$ term. The temperature-dependent vapor pressures of a number of hydrocarbons were fitted with the general $a(T)$ term with an additional pure-component parameter, namely the acentric factor $(\omega)$. This factor describes the non-sphericity of molecules and is defined as a function of the reduced saturation pressures (at a reduced temperature of 0.7) and was introduced by Pitzer et al. ${ }^{28}$. In the end, Soave fitted a $3^{r d}$-order-polynomial function with the acentric factor and established the $\alpha\left(T_{r}, \omega\right)$-function.

$$
P=\frac{R T}{V_{m}-b}-\frac{a(T)}{V_{m}\left(V_{m}+b\right)}
$$

with the pure-component parameter description;

$$
\begin{gathered}
a=0.42748 \frac{\alpha\left(T_{r}, \omega\right) R^{2} T_{c}^{2}}{P_{c}} \wedge b=0.08664 \frac{R T_{c}}{P_{c}} \\
\alpha=\left(1+\left(1-\sqrt{T_{r}}\right)\left(0.48+1.574 \omega-0.176 \omega^{2}\right)\right)^{2}
\end{gathered}
$$




\subsubsection{Peng-Robinson (PR) EoS}

Although Peng and Robinson ${ }^{20}$ recognized the ability of the Soave-RedlichKwong EoS to fairly accurately predict VLE behavior and vapor densities, they also stated that this equation fails to predict liquid densities. The PengRobinson EoS, therefore, improves the liquid density prediction as well as the vapor pressure and the VLE description. The appropriate choice of the general $a(T)$ - or $\alpha$-function was stated to be essential in improving the descriptions, hence Peng and Robinson proposed the following equations. Note that a similar $\alpha$-function has been obtained compared to the Soave's $\alpha$-function;

$$
P=\frac{R T}{V_{m}-b}-\frac{a(T)}{V_{m}\left(V_{m}+b\right)+b\left(V_{m}-b\right)}
$$

with the pure-component parameter description;

$$
\begin{gathered}
a=0.45724 \frac{\alpha\left(T_{r}, \omega\right) R^{2} T_{c}^{2}}{P_{c}}, b=0.0778 \frac{R T_{c}}{P_{c}} \\
\alpha=\left(1+\left(1-\sqrt{T_{r}}\right)\left(0.37464+1.54226 \omega-0.26992 \omega^{2}\right)\right)^{2}
\end{gathered}
$$

\subsubsection{Peng-Robinson-Stryjek-Vera (PRSV) EoS}

In a series of articles, ${ }^{29,30}$ Stryjek and Vera showed modifications of the PengRobinson Equation of State. They focused on the $\alpha$-function in which Peng and Robinson ${ }^{20}$ determined a single $3^{r d}$-order-polynomial function with the acentric factor similar to the Soave function. ${ }^{19}$. They recognized large errors for components with large acentric factors, which increased rapidly when the temperature deviated from the critical point. Stryjek and Vera modified the $\alpha$-function to;

$$
\begin{gathered}
\alpha=\kappa_{0}+\kappa_{1}\left(1+\sqrt{T_{r}}\right)\left(0.7-T_{r}\right) \\
\kappa_{0}=0.378893+1.4897153 \omega-0.17131848 \omega^{2}+0.0196554 \omega^{3}
\end{gathered}
$$

where, an additional (totally empirical) pure-component parameter was introduced $\kappa_{1}$ and are valid between a certain indicated temperature range, 
namely mainly below 0.7 of the reduced temperature. ${ }^{30}$ In a subsequent article $^{29}$, Stryjek and Vera postulated another Equation of State, namely the PRSV2, in which 2 more additional pure-component parameters are introduced. This EoS was however not simulated, as over-fitting is in my view unnecessary.

\subsubsection{Twu - Sim - Tassone (TST) EoS}

Twu, Sim and Tassone ${ }^{31}$ proposed a 2-parameter equation of state in combination with a generalized alpha function.

$$
P=\frac{R T}{V_{m}-b}-\frac{a(T)}{\left(V_{m}+3 b\right)+\left(V_{m}-0.5 b\right)}
$$

with the pure-component parameter description;

$$
a=0.470507 \frac{\alpha\left(T_{r}, \omega\right) R^{2} T_{c}^{2}}{P_{c}} \wedge b=0.0740740 \frac{R T_{c}}{P_{c}}
$$

The generalized alpha function was proposed to be a linear function of the acentric factor, $\omega$, to improve extrapolation possibilities towards heavy hydrocarbon fraction or naphtha. ${ }^{31}$ A differentiation was made between suband supercritical conditions. We limit to sub-critical conditions;

$$
\alpha\left(T_{r}, \omega\right)=\alpha^{(0)}+\omega\left(\alpha^{(1)}-\alpha^{(0)}\right)
$$

where:

$$
\begin{aligned}
& \alpha^{(0)}=T_{r}^{N^{(0)}\left(M^{(0)}-1\right)} \exp \left(L^{(0)}\left(1-T_{r}^{N^{(0)} M^{(0)}}\right)\right) \\
& \alpha^{(1)}=T_{r}^{N^{(1)}\left(M^{(1)}-1\right)} \exp \left(L^{(1)}\left(1-T_{r}^{N^{(1)} M^{(1)}}\right)\right)
\end{aligned}
$$

The $\alpha$-parameters of the generalized $\alpha$-function is;

\subsubsection{Nasrifar-Moshfeghian (NM) EoS}

Nasirifar and Moshfeghian ${ }^{32}$ deliberately proposed a 2-parameter equation of state due to the fact additional parameters can be nonphysical.

$$
P=\frac{R T}{V_{m}-b}-\frac{a(T)}{V_{m}^{2}+2 V_{m} b-2 b^{2}}
$$




\begin{tabular}{|c|c|c|}
\hline \multirow{2}{*}{$\alpha$} & \multicolumn{2}{|c|}{$T_{r} \leq 1$} \\
\cline { 2 - 3 } & $\alpha^{(0)}$ & $\alpha^{(1)}$ \\
\hline $\mathrm{L}$ & 0,196545 & 0,704001 \\
\hline $\mathrm{M}$ & 0,906437 & 0,790407 \\
\hline $\mathrm{N}$ & 1,26251 & 2,13086 \\
\hline
\end{tabular}

with the pure-component parameter description;

$$
a=0.497926 \frac{\alpha\left(T_{r}, \omega\right) R^{2} T_{c}^{2}}{P_{c}} \wedge b=0.094451 \frac{R T_{c}}{P_{c}}
$$

A Soave-type ${ }^{19}$ of $\alpha$-function was proposed, which included the pseudo triple point temperature $\left(T_{p t}\right)$. Though this is an additional parameter, it is a physical parameter. Nevertheless, including this temperature point was not done in our work and the original $\alpha$-function of Soave was used.

\subsubsection{Petal-Teja (PT) EoS}

Petal and Teja ${ }^{21}$ recognized the successful SRK and PR Equations of States, though continued on the refinement of the assumption that the critical compressibility factors of all substances are identical. They were not the first to tackle this assumption by incorporating substance-dependent critical compressibility factors. ${ }^{33,34}$ Petal and Teja proposed therefore a new Equation of State with additional pure component dependent parameters, $\mathrm{F}$ and $\zeta$.

$$
P=\frac{R T}{V_{m}-b}-\frac{a(T)}{V_{m}\left(V_{m}+b\right)+c\left(V_{m}-b\right)}
$$

This equation form is not new, and is the same as the three-parameter EoS of Harmens and Knapp ${ }^{35}$. Also it is quite similar to the PR Equation of State if the c-parameter was equal to the b-parameter. Besides the "normal" set of constraints for the 2-parameter EoS, which are the zero solutions of the first order and second order derivatives of the pressure to the molecular volume at the critical temperatures, see Equation 12.26, an additional third constrain is imposed which is the component-specific compressibility factor at critical conditions; 


$$
\frac{P_{c} V_{c}}{R T_{c}}=\zeta_{c}
$$

The critical compressibility factor was however not chosen to be the experimentally determined value, but the value was adjusted to increase accuracy. This is the same approach as Schmidt and Wenzel. ${ }^{34}$.

Application of the constraints at critical conditions yield the a-, b- and cparameters to be;

$$
\begin{gathered}
a(T)=\Omega_{a} \frac{\alpha\left(T_{r}, \omega\right) R^{2} T_{c}^{2}}{P_{c}} \\
b=\Omega_{b} \frac{R T_{c}}{P_{c}} \\
c=\Omega_{c} \frac{R T_{c}}{P_{c}}
\end{gathered}
$$

where:

$$
\begin{gathered}
\Omega_{c}=1-3 \zeta_{c} \\
\Omega_{a}=3 \zeta_{c}^{2}+3\left(1-2 \zeta_{c}\right) \Omega_{b}+\Omega_{b}^{2}+1-3 \zeta_{c}
\end{gathered}
$$

and $\Omega_{b}$ is the smallest root of the cubic equation

$$
\Omega_{b}^{3}+\left(2-3 \zeta_{c}\right) \Omega_{b}^{2}+3 \zeta_{c}^{2} \Omega_{b}-\zeta_{c}^{3}=0
$$

For the $\alpha$-function, Petal and Teja chose the same function as Soave ${ }^{19}$ proposed, though adapted to include the pure-component specific parameter, F;

$$
\alpha=\left(1+F\left(1-\sqrt{T_{r}}\right)\right)^{2}
$$

\subsubsection{Petal-Teja-Valderrama (PTV) EoS}

Valderrama ${ }^{36}$ stated several shortcomings of the Petal-Teja Equation of State, namely the validity of the 2 additional empirical constants, $\mathrm{F}$ and $\zeta$, which had been correlated to apolar compounds, and the complexity of the mathematical framework which differs from the other 2-parameter equation of States. Valderrama kept the form of the PT equation of state, but generalized 
the a-, b- and c-parameters by a linear correlation of the critical compressibility factor, $Z_{c}$ or $\zeta_{c}$.

$$
\begin{aligned}
& \Omega_{a}=0.66121-0.76105 \zeta_{c} \\
& \Omega_{b}=0.02207+0.20868 \zeta_{c} \\
& \Omega_{c}=0.57765-1.87080 \zeta_{c}
\end{aligned}
$$

Additionally, Valderrama found a strong correlation of the empirical F-parameter with the product of the acentric factor, $\omega$, and the critical compressibility factor, $\zeta_{c}$.

$$
F=0.46283+3.58230\left(\omega \zeta_{c}\right)+8.19417\left(\omega \zeta_{c}\right)^{2}
$$

\subsubsection{Esmaeilzadeh-Roshanfekr (ER) EoS}

The equation of state proposed by Esmaeilzadeh and Roshanfekr ${ }^{37}$ follows the line of Petal and Teja and contains 3-parameters, see Equation 12.74, and is an attempt to improve the performance of equations of state on reservoir fluids.

$$
P=\frac{R T}{V_{m}-b}-\frac{a(T)}{V_{m}\left(V_{m}+c\right)+c\left(V_{m}-c\right)}
$$

The following mathematical, which is solved at critical conditions, was proposed which ultimately resulted in an improved saturated liquid density, compared to the PTV, PT and PR equations of state, though the PTV equation of state was more accurate for the saturated vapor density.

$$
\begin{gathered}
a(T)=\Omega_{a} \frac{\alpha\left(T_{r}, \omega\right) R^{2} T_{c}^{2}}{P_{c}} \\
b=\Omega_{b} \frac{R T_{c}}{P_{c}} \\
c=\Omega_{c} \frac{R T_{c}}{P_{c}}
\end{gathered}
$$


where:

$$
\begin{gathered}
\Omega_{b}=2 \Omega_{c}-1+3 \zeta_{c} \\
\Omega_{a}=3 \zeta_{c}^{2}+\Omega_{c}^{2}+2 \Omega_{b} \Omega_{c}+2 \Omega_{c}
\end{gathered}
$$

and $\Omega_{c}$ is the smallest root of the cubic equation

$$
\Omega_{c}^{3}+\left(3 \zeta_{c}-\frac{5}{8}\right) \Omega_{c}^{2}+\left(3 \zeta_{c}^{2}-\frac{3}{4} \zeta_{c}\right) \Omega_{c}+\zeta_{c}^{3}-\frac{3}{8} \zeta_{c}^{2}=0
$$

where, the $\zeta_{c}$ was generalized to

$$
\zeta_{c}=0.3284438-0.0690264 \omega+0.0078711 \omega^{2}
$$

For the $\alpha$-function, Esmaeilzadeh and Roshanfekr ${ }^{37}$ chose a similar function as Soave ${ }^{19}$ proposed and generalized it to;

$$
\alpha=\left(m_{1}+m_{2}\left(1-\sqrt{T_{r}}\right)\right)^{2}
$$

where,

$$
\begin{aligned}
& m_{1}=0.999035-0.01061842 \omega-0.0081174 \omega^{2} \\
& m_{2}=0.4400108+1.5297151 \omega-0.4710752 \omega^{2}
\end{aligned}
$$

\subsubsection{Harmens - Knapp (HK) EoS}

Harmens and Knapp preferred the following 3-parameter equation of state. This form was chosen as $\mathrm{c}=1$ reduces to the Redlich-Kwong equation of state and $c=2$ reduces to Peng-Robinson equation of state. ${ }^{35}$

$$
P=\frac{R T}{V_{m}-b}-\frac{a(T)}{V_{m}^{2}+V_{m} c b-(c-1) b^{2}}
$$

Similar to the other 3-parameter equation of states, the following parameterframework, which is solved at critical conditions, is present;

$$
\begin{gathered}
a(T)=\Omega_{a} \frac{\alpha\left(T_{r}, \omega\right) R^{2} T_{c}^{2}}{P_{c}} \\
b=\Omega_{b} \frac{R T_{c}}{P_{c}}
\end{gathered}
$$




$$
c=1+\frac{1-4 \zeta_{c}}{\beta_{c} \zeta_{c}}
$$

where:

$$
\begin{gathered}
\Omega_{a}=1-3 \zeta_{c}+3 \zeta_{c}^{2}+\beta_{c} \zeta_{c}\left(3-6 \zeta_{c}+\beta_{c} \zeta_{c}\right) \\
\Omega_{b}=\beta_{c} \zeta_{c} \\
\zeta_{c}=0.3211-0.080 \omega+0.0384 \omega^{2} \\
\beta_{c}=0.10770 \zeta_{c}+0.76405 \zeta_{c}-1.24828 \zeta_{c}^{2}+0.96210 \zeta_{c}^{3}
\end{gathered}
$$

Additionally, they expanded the Soave-function ${ }^{19}$ towards;

$$
\alpha=\left(1+A\left(1-\sqrt{T_{r}}\right)-B\left(1-\frac{1}{T_{r}}\right)\right)^{2}
$$

where, if $\omega \leq 0.2$;

$$
A=0.50+0.27767 \omega+2.17225 \omega^{2}, B=-0.22+0.338 \omega-0.845 \omega^{2}
$$

and, if $\omega>0.2$;

$$
A=0.41311+1.14654 \omega, B=0.0118
$$

\subsubsection{Trebble - Bishnoi (TB) EoS}

In the previous equations of state, either compressibility factor $\left(\zeta_{c}\right)$ and the critical repulsion $\left(\beta_{c}\right.$ or $b_{c}$ ) term were kept constant (2-parameter equation of state), or one of these terms was kept constant (3-parameter equation of state). Trebble and Bishnoi ${ }^{38}$ chose to keep both terms variable, hence creating a 4 parameter equation of state.

$$
P=\frac{R T}{V_{m}-b}-\frac{a(T)}{\left.V_{m}^{2}+(b+c) V_{m}-b c-d^{2}\right)}
$$

Similar to the 3-parameter equation of states, the 4-parameter equation of state framework, which is solved at critical conditions, is as following;

$$
a(T)=\Omega_{a} \frac{\alpha\left(T_{r}, \omega\right) R^{2} T_{c}^{2}}{P_{c}}
$$




$$
\begin{aligned}
& b=\Omega_{b} \frac{R T_{c}}{P_{c}} \\
& c=\Omega_{c} \frac{R T_{c}}{P_{c}} \\
& d=\Omega_{d} \frac{R T_{c}}{P_{c}}
\end{aligned}
$$

where:

$$
\begin{gathered}
\Omega_{a}=3 \zeta_{c}+2 \Omega_{b} \Omega_{c}+\Omega_{b}+\Omega_{c}+\Omega_{b}^{2}+\Omega_{d}^{2} \\
\Omega_{c}=-3 \zeta_{c}+1 \\
\Omega_{d}=0.341 V_{c}-0.005
\end{gathered}
$$

and $\Omega_{b}$ is the smallest root of the cubic equation

$$
\Omega_{b}^{3}+\left(2-3 \zeta_{c}\right) \Omega_{b}^{2}+3 \zeta_{c}^{2} \Omega_{b}-\left(\Omega_{d}^{2}+\zeta_{c}^{2}\right)=0
$$

The $\alpha$-function of Soave ${ }^{19}$ was used in this equation of state.

\subsection{Generalization of cEoS}

Generalization of various Equation of States allows the creation of an universal mathematical framework that allows the usage of various EoS in the same manner. The generic cubic EoS can be written as ${ }^{39}$;

$$
P=\frac{R T}{V_{m}-b}-\frac{a(T)}{(V-\epsilon b)(V+\sigma b)}
$$

Again, the $\mathrm{a}(\mathrm{T})$ and $\mathrm{b}$ values are determined from the critical point, as shown in Equation 12.26. This results in;

$$
b=\Omega \frac{R T_{c}}{P_{c}} \wedge a\left(T_{c}\right)=\Psi \frac{R^{2} T_{c}^{2}}{P_{c}}
$$

of which the $a(T)$-term is extended to other temperatures via;

$$
a(T)=\Psi \frac{\alpha\left(T_{r}, \omega\right) R^{2} T_{c}^{2}}{P_{c}}
$$


The $\Omega$ and $\Psi$ are component independent and specific to a particular Equation of State.

$$
Z^{3}+((\sigma+\epsilon) \beta-(1+\beta)) Z^{2}+\beta(q+\epsilon \sigma \beta-(1+\beta)(\sigma+\epsilon)) Z-\beta^{2}(q+(1+\beta) \epsilon \sigma)
$$

where;

$$
\beta=\frac{b P}{R T}=\Omega \frac{P_{r}}{T_{r}} \wedge q=\frac{a(T)}{b R T}=\frac{\Psi \alpha\left(T_{r}, \omega\right)}{\Omega T_{r}},
$$

Table 12.11: A summary of the Equation of State specific parameters

\begin{tabular}{c|cccc} 
EoS & $\sigma$ & $\epsilon$ & $\Omega$ & $\Psi$ \\
\hline VdW & 0 & 0 & 0.12500 & 0.42188 \\
RK & 1 & 0 & 0.08664 & 0.42748 \\
SRK & 1 & 0 & 0.08664 & 0.42748 \\
PR & $1+\sqrt{2}$ & $1-\sqrt{2}$ & 0.07780 & 0.45724 \\
PRSV & $1+\sqrt{2}$ & $1-\sqrt{2}$ & 0.07780 & 0.45724 \\
TST & 3 & -0.5 & 0.07741 & 0.47051 \\
NM & $1+\sqrt{3}$ & $-2 /(1+\sqrt{3})$ & 0.09445 & 0.49793 \\
\hline PT & $\left(f+\sqrt{f^{2}+g}\right) / 2$ & $-2(f-1)^{2} /\left(f+\sqrt{f^{2}+g}\right)$ & $\Omega_{b}$ & $\Omega_{a}$ \\
PTV & $\left(f+\sqrt{f^{2}+g}\right) / 2$ & $-2(f-1)^{2} /\left(f+\sqrt{f^{2}+g}\right)$ & $\Omega_{b}$ & $\Omega_{a}$ \\
ER & $(f-1)(1+\sqrt{2})$ & $(1-f)(1+\sqrt{2})$ & $\Omega_{b}$ & $\Omega_{a}$ \\
HK & $\left(c+\sqrt{c^{2}+i}\right) / 2$ & $-(i / 2) /\left(c+\sqrt{c^{2}+i}\right)$ & $\Omega_{b}$ & $\Omega_{a}$ \\
\hline TB & $\left(f+\sqrt{f^{2}+4 m}\right) / 2$ & $-2 m /\left(f+\sqrt{f^{2}+4 m}\right)$ & $\Omega_{b}$ & $\Omega_{a}$
\end{tabular}

Abbreviations: $\mathrm{f}=c / b+1, \mathrm{~g}=4 c / b, \mathrm{~h}=c(4+c), \mathrm{j}=c+4 b, \mathrm{i}=4(c-1), \mathrm{k}=$ $c+3 b, \mathrm{~m}=c / b+d^{2} / b^{2}$

\subsection{Mixing Rules}

Equation of State models have been developed to predict pure component properties, such as the density. To extend these models towards mixtures, additional correlations have been introduced in an attempt to preserve the accuracy of these models. This is however quite difficult as many kinds of interactions can be induced between molecules, such as dipolar interactions and 
most severely hydrogen bond formation. A serious shortcoming of some mixing rules is described by Michelsen and Kistenmacher. ${ }^{40}$ They showed that a mixing rules can be invariant towards over-defined mixtures. For example, a $50 / 50 \%$ binary mixture of compounds $A$ and $B$, is the same mixture as ternary mixtures of $50 / 25 / 25 \%$ of compounds A, B and (the same) B. A mixing rule can however offer different results. This is named the Michelsen-Kistenmacher syndrome. In this work, we consider 8 mixing rules. These are chosen to reflect the variety of the much more mixing rules reported in literature and a different selection of rules can also be made;

1. 1-parameter Van der Waals (VdW1): it is a simple rule which is most widely used for mainly non-polar and slightly polar mixtures;

$$
\begin{gathered}
a=\sum_{i} \sum_{j} x_{i} x_{j}\left(\sqrt{a_{i} a_{j}}\left(1-K_{i j}\right)\right) \\
b=\sum_{i} x_{i} b_{i}
\end{gathered}
$$

Only 1 binary interactions parameter, $K_{i j}$, is incorporated in the attraction term and a linear average of the molecular volume, $b$, is incorporated.

2. 2-parameter Van der Waals (VdW2): this is a small extension of the previous rule. The attractive term description has been kept constant, though the molecular volume description is changed to;

$$
b=\frac{\sum_{i} \sum_{j} x_{i} x_{j}\left(b_{i}+b_{j}\right)\left(1-L_{i j}\right)}{2}
$$

where $L_{i j}$ a second binary interaction parameter is.

3. Adachi - Sugie (AS): proposed a new form of a mixing rule which originates from a Redlich-Kister type of equation; ${ }^{41}$

$$
a=\sum_{i} \sum_{j} x_{i} x_{j} \sqrt{a_{i} a_{j}}\left(1-K_{i j}+L_{i j}\left(x_{i}-x_{j}\right)\right)
$$

where two binary interaction parameter are introduced for the attractive interactions term. A linear average of the b-parameter was maintained (see Equation 12.87b). 
4. Panagiotopoulos - Reid (PR): proposed an empirical modification of the Van der Waals mixing rule, namely; ${ }^{42}$

$$
\left.a=\sum_{i} \sum_{j} x_{i} x_{j} \sqrt{a_{i} a_{j}}\left(1-K_{i j}+\left(K_{i j}-K_{j i}\right) x_{i}\right)\right)
$$

where the normally symmetric $K_{i j}$ is replaced by an asymmetric $K_{i j}$. This is however an apparent symmetry, as the final $a$-parameter is symmetric meaning that a $50 / 50 \% \mathrm{~A} / \mathrm{B}$ mixture is the same as a $50 / 50 \%$ B/A mixture.

5. Sandoval: proposed a generalized equivalent of the Margules-type of mixing rule; ${ }^{43}$

$$
a=\sum_{i} \sum_{j} x_{i} x_{j} \sqrt{a_{i} a_{j}}\left(1-\left(K_{i j} x_{i}+L_{i j} x_{j}\right)-\frac{\left(K_{i j}+L_{i j}\right)\left(1-x_{i}-x_{j}\right)}{2}\right)
$$

Also here, a linear average of the b-parameter is used (see Equation 12.87b).

6. Stryjek-Vera $(\mathrm{SVm})$ : proposed a nonsymmetric binary interaction parameter is a similar form as the Margules equation; ${ }^{30}$

$$
a=\sum_{i} \sum_{j} x_{i} x_{j} \sqrt{a_{i} a_{j}}\left(1-K_{i j} x_{i}+K_{j i} x_{j}\right)
$$

where, the b-parameter is again assumed to be the linear average (see Equation 12.87b).

7. Stryjek-Vera (SVvL): proposed a nonsymmetric binary interaction parameter is a similar form as the van Laar equation; ${ }^{30}$

$$
a=\sum_{i} \sum_{j} x_{i} x_{j} \sqrt{a_{i} a_{j}}\left(1-\frac{K_{i j} K_{j i}}{K_{i j} x_{i}+K_{j i} x_{j}}\right)
$$

where, the b-parameter is again assumed to be the linear average (see Equation 12.87b).

8. Huron-Vidal Huron and Vidal ${ }^{44}$ introduced a mixing rule which applied the local composition approach previously seen in the Wilson and 
NRTL equations. Hence, exactly the same equation is used to describe the Gibbs energy at infinite pressure as in the NRTL equation;

$$
g_{\infty}^{E}=\sum_{i=1}^{n} x_{i} \frac{\sum_{j=1}^{n} x_{j} G_{j i} \tau_{j i}}{\sum_{k=1}^{n} x_{k} G_{k i}}
$$

where

$$
\tau_{j i}=b_{j} \exp \left(-\alpha_{j i} \frac{G_{j i}}{R T}\right)
$$

In this mixing rule, the $b_{j}$-parameter is different from the Gibbs excess models, and this links the volume, or repulsion, parameter of the equation of state together with the attraction term. Finally, Huron and Vidal ${ }^{44}$ showed these mixing rules;

$$
a=b \sum_{i=1}^{n} x_{i}\left(\frac{a_{i}}{b_{i}}-\frac{1}{\sqrt{2}} \sum_{i=1}^{n} x_{i} \frac{\sum_{j=1}^{n} x_{j} G_{j i} \tau_{j i}}{\sum_{k=1}^{n} x_{k} G_{k i}}\right)
$$

and

$$
b=\sum_{i} x_{i} b_{i}
$$

Note that when the non-randomness factor $\left(\alpha_{j i}\right)$ is equalized to 0 , then a combination of the Van der Waals mixing rules are obtained again.

\subsection{Departure Function Derivations}

\subsubsection{Internal Energy}

The non-ideal behavior of a fluid, or the departure from ideality, can be described by following a pathway. A pathway of a function, e.g. the internal energy, relative to the ideal gas function whereby firstly the temperature, pressure and volume are kept constant, and secondly the total deviation with a variation in the volume is subtracted in the ideal situation at isobaric conditions. ${ }^{23}$

$$
U_{d e p}=\left(U-U^{i g}\right)=\left(U-U^{i g}\right)_{T V}-\int_{V}^{V^{i g}}\left(\frac{\partial U}{\partial V}\right)_{T}^{i g} d V
$$


Also, the first right-hand-side term can be written as an integral, which reaches from infinity to the volume of the non-ideal fluid;

$$
U_{d e p}=\left(U-U^{i g}\right)=\int_{\infty}^{V}\left(\left(\frac{\partial U}{\partial V}\right)_{T}-\left(\frac{\partial U}{\partial V}\right)_{T}^{i g}\right) d V-\int_{V}^{V^{i g}}\left(\frac{\partial U}{\partial V}\right)_{T}^{i g} d V
$$

The interal energy of an ideal gas is not volume dependent, thus;

$$
U_{d e p}=\left(U-U^{i g}\right)=\int_{\infty}^{V}\left(\frac{\partial U}{\partial V}\right)_{T} d V
$$

For non-ideal fluids, the volume dependency of the internal energy can be analyzed as follows;

$$
\left(\frac{\partial U}{\partial V}\right)_{T}=\left(\frac{\partial S}{\partial V}\right)_{T}\left(\frac{\partial U}{\partial S}\right)_{T}+\left(\frac{\partial U}{\partial V}\right)\left(\frac{\partial T}{\partial T}\right)
$$

With one of the Maxwell relations; $(\partial S / \partial V)_{T}=(\partial P / \partial T)_{V}$ and the known relations of $(\partial U / \partial S)_{T}=T$ and $(\partial U / \partial V)=-P$.

$$
\begin{gathered}
\left(\frac{\partial U}{\partial V}\right)_{T}=\left(\frac{\partial P}{\partial T}\right)_{V}\left(\frac{\partial U}{\partial S}\right)_{T}+\left(\frac{\partial U}{\partial V}\right)\left(\frac{\partial T}{\partial T}\right) \\
\left(\frac{\partial U}{\partial V}\right)_{T}=T\left(\frac{\partial P}{\partial T}\right)_{V}-P \\
U_{\text {dep }}=\left(U-U^{i g}\right)=\int_{\infty}^{V}\left(T\left(\frac{\partial P}{\partial T}\right)_{V}-P\right) d V
\end{gathered}
$$

For convenience, the departure function needs to be rewritten to density and the compressibility factor, resp. $\rho=1 / V$ and Z. Firstly, converting the equation to the compressibility variable. Knowing that the result has to be in the form of $(\partial Z / \partial T)_{V}$, via integration by substitution. The following correlation is obtained;

$$
T\left(\frac{\partial Z}{\partial T}\right)_{V}=T\left(\left(\frac{\partial P}{\partial T}\right)_{V}\left(\frac{\partial Z}{\partial P}\right)_{V}+\left(\frac{\partial Z}{\partial T}\right)\left(\frac{\partial T}{\partial T}\right)\right)
$$




$$
\begin{gathered}
T\left(\frac{\partial Z}{\partial T}\right)_{V}=T\left(\frac{V}{R T}\left(\frac{\partial P}{\partial T}\right)_{V}-\frac{P V}{R T^{2}}\right) \\
T\left(\frac{\partial Z}{\partial T}\right)_{V}=T\left(\frac{V}{R}\left(\frac{\partial P}{\partial T}\right)_{V}-Z\right) \\
\frac{R T^{2}}{V}\left(\frac{\partial Z}{\partial T}\right)_{V}+\frac{Z R T}{V}=T\left(\frac{\partial P}{\partial T}\right)_{V} \\
\frac{R T^{2}}{V}\left(\frac{\partial Z}{\partial T}\right)_{V}+P=T\left(\frac{\partial P}{\partial T}\right)_{V}
\end{gathered}
$$

Putting this back in to the departure function.

$$
\begin{array}{r}
U_{d e p}=\left(U-U^{i g}\right)=\int_{\infty}^{V}\left(\frac{R T^{2}}{V}\left(\frac{\partial Z}{\partial T}\right)_{V}+P-P\right) d V \\
U_{d e p}=\left(U-U^{i g}\right)=R T \int_{\infty}^{V}\left(\frac{T}{V}\left(\frac{\partial Z}{\partial T}\right)_{V}\right) d V
\end{array}
$$

Now, the transformation from the volume to density via integration by substitution;

$$
\begin{gathered}
\rho=\frac{1}{V} \rightarrow-\frac{1}{\rho^{2}} d \rho=d V \\
U_{d e p}=\left(U-U^{i g}\right)=-R T \int_{0}^{\rho}\left(T\left(\frac{\partial Z}{\partial T}\right)\right) \frac{d \rho}{\rho}
\end{gathered}
$$

\subsubsection{Entropy}

The non-ideal behavior of a fluid, or the departure from ideality, can be described by following a pathway. A pathway of a function, e.g. the entropy, relative to the ideal gas function firstly at which the temperature, pressure and volume are kept constant, and secondly the total deviation with a variation in the volume is subtracted in the ideal situation at isobaric conditions.

$$
S_{d e p}=\left(S-S^{i g}\right)=\left(S-S^{i g}\right)_{T V}-\int_{V}^{V^{i g}}\left(\frac{\partial S}{\partial V}\right)_{T}^{i g} d V
$$


Also, the first right-hand-side term can be written as an integral, which reaches from infinity to the volume of the non-ideal fluid;

$$
S_{d e p}=\left(S-S^{i g}\right)=\int_{\infty}^{V}\left(\left(\frac{\partial S}{\partial V}\right)_{T}-\left(\frac{\partial S}{\partial V}\right)_{T}^{i g}\right) d V-\int_{V}^{V^{i g}}\left(\frac{\partial S}{\partial V}\right)_{T}^{i g} d V
$$

Following one of the Maxwell relations; $(\partial S / \partial V)_{T}=(\partial P / \partial T)_{V}$

$$
S_{d e p}=\left(S-S^{i g}\right)=\int_{\infty}^{V}\left(\left(\frac{\partial P}{\partial T}\right)_{V}-\left(\frac{\partial P}{\partial T}\right)_{V}^{i g}\right) d V-\int_{V}^{V^{i g}}\left(\frac{\partial P}{\partial T}\right)_{T}^{i g} d V
$$

First solving the ideal gas terms, knowing that $P=\frac{R T}{V} \rightarrow\left(\frac{\partial P}{\partial T}\right)_{V}=\frac{R}{V}$

$$
\begin{gathered}
S_{d e p}=\left(S-S^{i g}\right)=\int_{\infty}^{V}\left(\left(\frac{\partial P}{\partial T}\right)_{V}-\frac{R}{V}\right) d V-\int_{V}^{V^{i g}}\left(\frac{R}{V}\right) d V \\
S_{d e p}=\left(S-S^{i g}\right)=\int_{\infty}^{V}\left(\left(\frac{\partial P}{\partial T}\right)_{V}-\frac{R}{V}\right) d V+R \ln \left(\frac{V}{V^{i g}}\right)
\end{gathered}
$$

Furthermore, the $\frac{V}{V^{i g}}$ term, can be rewritten via $V=\frac{Z R T}{P}$ for an ideal gas $Z=1$, to $\frac{V}{V^{i g}}=Z$;

$$
\begin{gathered}
S_{d e p}=\left(S-S^{i g}\right)=\int_{\infty}^{V}\left(\left(\frac{\partial P}{\partial T}\right)_{V}-\frac{R}{V}\right) d V+R \ln (Z) \\
\left.S_{d e p}=\left(S-S^{i g}\right)=R\left(\int_{\infty}^{V}\left(\frac{1}{R}\left(\frac{\partial P}{\partial T}\right)_{V}-\frac{1}{V}\right) d V+\ln (Z)\right)\right)
\end{gathered}
$$

For convenience, the departure function needs to be rewritten to density and the compressibility factor, resp. $\rho=\frac{1}{V}$ and Z.

Firstly, converting the equation to the compressibility variable. Knowing that the result has to be in the form of $(\partial Z / \partial T)_{V}$, via integration by substitution. The following correlation is obtained; 


$$
\begin{gathered}
T\left(\frac{\partial Z}{\partial T}\right)_{V}=T\left(\left(\frac{\partial P}{\partial T}\right)_{V}\left(\frac{\partial Z}{\partial P}\right)_{V}+\left(\frac{\partial Z}{\partial T}\right)\left(\frac{\partial T}{\partial T}\right)\right) \\
T\left(\frac{\partial Z}{\partial T}\right)_{V}=T\left(\frac{V}{R T}\left(\frac{\partial P}{\partial T}\right)_{V}-\frac{P V}{R T^{2}}\right) \\
T\left(\frac{\partial Z}{\partial T}\right)_{V}=T\left(\frac{V}{R}\left(\frac{\partial P}{\partial T}\right)_{V}-Z\right) \\
\frac{T}{V}\left(\frac{\partial Z}{\partial T}\right)_{V}+\frac{Z}{V}=\frac{1}{R}\left(\frac{\partial P}{\partial T}\right)_{V}
\end{gathered}
$$

Putting this back into the departure function;

$$
S_{\text {dep }}=\left(S-S^{i g}\right)=R\left(\int_{\infty}^{V}\left(\frac{T}{V}\left(\frac{\partial Z}{\partial T}\right)_{V}+\frac{Z}{V}-\frac{1}{V}\right) d V+\ln (Z)\right)
$$

Now, the transformation from the volume to density via integration by substitution;

$$
\begin{gathered}
\rho=\frac{1}{V} \rightarrow-\frac{1}{\rho^{2}} d \rho=d V \\
S_{d e p}=\left(S-S^{i g}\right)=R\left(\int_{0}^{\rho}-\frac{\left(T \rho\left(\frac{\partial Z}{\partial T}\right)_{\rho}+Z \rho-\rho\right) d \rho}{\rho^{2}}+\ln (Z)\right) \\
S_{d e p}=\left(S-S^{i g}\right)=R\left(\int_{0}^{\rho}-T\left(\frac{\partial Z}{\partial T}\right)_{\rho}-(Z-1) \frac{d \rho}{\rho}+\ln (Z)\right)
\end{gathered}
$$

\subsubsection{Enthalpy}

Knowing the fact that the enthalpy is related to the internal energy in the following manner;

$$
H=U+P V
$$

Then, the departure function for enthalpy holds for; 


$$
\begin{gathered}
H_{d e p}=U_{d e p}+(P V)_{d e p} \\
\frac{H-H^{i g}}{R T}=\frac{U-U^{i g}}{R T}+\frac{P V-(P V)^{i g}}{R T}
\end{gathered}
$$

As the ideal gas law is $P V=R T$;

$$
\frac{H-H^{i g}}{R T}=\frac{U-U^{i g}}{R T}+\frac{P V-R T}{R T}
$$

Then substitute in the result for the internal energy;

$$
H_{d e p}=H-H^{i g}=R T\left(\int_{0}^{\rho}-T\left(\frac{\partial Z}{\partial T}\right) \frac{d \rho}{\rho}+(Z-1)\right)
$$

\subsubsection{Fugacity}

The excess Gibbs energy has an enthalpic and entropic contribution;

$$
G^{E}=G_{d e p}=H_{d e p}-T S_{d e p}
$$

Additionally, the excess Gibbs energy is a function of the fugacity.

$$
G^{E}=G_{d e p}=R T \ln \varphi
$$

By combining the enthalpic and entropic departure functions (Equation 12.126 and Equation 12.129), the departure function of the fugacity is obtained;

$$
\begin{aligned}
& R T \ln f=R T\left(\int_{0}^{\rho} T\left(\frac{\partial Z}{\partial T}\right)_{\rho} \frac{d \rho}{\rho}+(Z-1)\right)- \\
& R T\left(\int_{0}^{\rho}-T\left(\frac{\partial Z}{\partial T}\right)_{\rho}-(Z-1) \frac{d \rho}{\rho}-\ln (Z)\right)
\end{aligned}
$$

which results in finally;

$$
\ln f=\int_{0}^{\rho}(Z-1) \frac{d \rho}{\rho}+(Z-1)-\ln (Z)
$$




\section{APPENDICES}

\subsection{References}

[1] M. J. Lazzaroni, D. Bush, C. A. Eckert, T. C. Frank, S. Gupta, and J. D. Olson, "Revision of mosced parameters and extension to solid solubility calculations," Industrial E engineering chemistry research, vol. 44, no. 11, pp. 4075-4083, 2005.

[2] H. C. Van Ness, Classical thermodynamics of non-electrolyte solutions. Elsevier, 2015.

[3] J. M. Sørensen, T. Magnussen, P. Rasmussen, and A. Fredenslund, "Liquid—liquid equilibrium data: Their retrieval, correlation and prediction part ii: Correlation," Fluid Phase Equilibria, vol. 3, no. 1, pp. 47-82, 1979.

[4] A. Marcilla, M. Serrano, J. Reyes-Labarta, and M. Olaya, "Checking liquid-liquid plait point conditions and their application in ternary systems," Industrial \& engineering chemistry research, vol. 51, no. 13, pp. 5098-5102, 2012.

[5] G. N. Lewis and M. Randall, Thermodynamics and the free energy of chemical substances. McGraw-Hill, 1923.

[6] R. Clausius, "Über die bewegende kraft der wärme und die gesetze, welche sich daraus für die wärmelehre selbst ableiten lassen," Annalen der Physik, vol. 155, no. 3, pp. 368-397, 1850.

[7] R. Clausius, "Über eine veränderte form des zweiten hauptsatzes der mechanischen wärmetheorie," $A n$ nalen der Physik, vol. 169, no. 12, pp. 481-506, 1854.

[8] L. Boltzmann, Über die Beziehung zwischen dem zweiten Hauptsatze des mechanischen Wärmetheorie und der Wahrscheinlichkeitsrechnung, respective den Sätzen über das Wärmegleichgewicht. Kk Hof-und Staatsdruckerei, 1877.

[9] J. Zhang and B. Wang, "Effect of capillarity at liquid-vapor interface on phase change without surfactant," International Journal of Heat and Mass Transfer, vol. 45, no. 13, pp. 2689-2694, 2002.

[10] J. Van Laar, "Zur theorie der dampfspannungen von binären gemischen," Zeitschrift für Physikalische Chemie, vol. 83, no. 1, pp. 599-608, 1913.

[11] G. M. Wilson, "Vapor-liquid equilibrium. xi. a new expression for the excess free energy of mixing.," Journal of the American Chemical Society, vol. 86, no. 2, pp. 127-30, 1964.

[12] M. Margules, "Uber die zusammensetzung der gesattigten dampfe von mischungen," Sitzungsber Akad Wiss Wien, vol. 104, pp. 1243-1278, 1895.

[13] D. S. Abrams and J. M. Prausnitz, "Statistical thermodynamics of liquid mixtures. new expression for the excess gibbs energy of partly or completely miscible systems.," AIChE Journal, vol. 21, no. 1, pp. 116-28, 1975.

[14] H. Renon and J. M. Prausnitz, "Local compositions in thermodynamic excess functions for liquid mixtures.," AIChE Journal, vol. 14, no. 1, pp. 135-44, 1968.

[15] É. Clapeyron, "Mémoire sur la puissance motrice de la chaleur," Journal de l'École polytechnique, vol. 14, pp. 153-190, 1834.

[16] I. G. Economou, "Cubic and generalized van der waals equations of state," Applied Thermodynamics of Fluids, vol. 4, no. 1, p. 53, 2010.

[17] J. D. Van der Waals, Over de Continuiteit van den Gas-en Vloeistoftoestand, vol. 1. Sijthoff, 1873.

[18] O. Redlich and J. N. Kwong, "On the thermodynamics of solutions. v. an equation of state. fugacities of gaseous solutions.," Chemical reviews, vol. 44, no. 1, pp. 233-244, 1949.

[19] G. Soave, "Equilibrium constants from a modified redlich-kwong equation of state," Chemical engineering science, vol. 27, no. 6, pp. 1197-1203, 1972.

[20] D.-Y. Peng and D. B. Robinson, "A new two-constant equation of state," Industrial E Engineering Chemistry Fundamentals, vol. 15, no. 1, pp. 59-64, 1976.

[21] N. C. Patel and A. S. Teja, "A new cubic equation of state for fluids and fluid mixtures," Chemical Engineering Science, vol. 37, no. 3, pp. 463-473, 1982.

[22] J. Clerk-Maxwell, "On the dynamical evidence of the molecular constitution of bodies," 1875.

[23] J. R. Elliott and C. T. Lira, Introductory chemical engineering thermodynamics, vol. 184. Prentice Hall PTR Upper Saddle River, NJ, 1999.

[24] T. W. Leland and P. S. Chappelear, "The corresponding states principle-a review of current theory and practice," Industrial \& Engineering Chemistry, vol. 60, no. 7, pp. 15-43, 1968.

[25] L. Darken, "Application of the gibbs-duhem equation to ternary and multicomponent systems," Journal 
of the American Chemical Society, vol. 72, no. 7, pp. 2909-2914, 1950.

[26] P. J. Flory, "Thermodynamics of high polymer solutions," The Journal of chemical physics, vol. 10, no. 1, pp. 51-61, 1942.

[27] M. L. Huggins, "Some properties of solutions of long-chain compounds.," The Journal of Physical Chemistry, vol. 46, no. 1, pp. 151-158, 1942.

[28] K. S. Pitzer, D. Z. Lippmann, R. Curl Jr, C. M. Huggins, and D. E. Petersen, "The volumetric and thermodynamic properties of fluids. ii. compressibility factor, vapor pressure and entropy of vaporization 1 ," Journal of the American Chemical Society, vol. 77, no. 13, pp. 3433-3440, 1955.

[29] R. Stryjek and J. Vera, "Prsv2: a cubic equation of state for accurate vapor-liquid equilibria calculations," The Canadian Journal of Chemical Engineering, vol. 64, no. 5, pp. 820-826, 1986.

[30] R. Stryjek and J. Vera, "Prsv: An improved peng-robinson equation of state for pure compounds and mixtures," The canadian journal of chemical engineering, vol. 64, no. 2, pp. 323-333, 1986.

[31] C. H. Twu, W. D. Sim, and V. Tassone, "A versatile liquid activity model for srk, pr and a new cubic equation-of-state tst," Fluid Phase Equilibria, vol. 194, pp. 385-399, 2002.

[32] K. Nasrifar and M. Moshfeghian, "A new cubic equation of state for simple fluids: pure and mixture.," Fluid Phase Equilibria, vol. 190, no. 1-2, pp. 73-88, 2001.

[33] G. G. Fuller, "A modified redlich-kwong-soave equation of state capable of representing the liquid state," Industrial E Engineering Chemistry Fundamentals, vol. 15, no. 4, pp. 254-257, 1976.

[34] G. Schmidt and H. Wenzel, "A modified van der waals type equation of state," Chemical Engineering Science, vol. 35, no. 7, pp. 1503-1512, 1980.

[35] A. Harmens and H. Knapp, "Three-parameter cubic equation of state for normal substances," Industrial E Engineering Chemistry Fundamentals, vol. 19, no. 3, pp. 291-294, 1980.

[36] J. O. Valderrama, "A generalized patel-teja equation of state for polar and nonpolar fluids and their mixtures," Journal of chemical engineering of Japan, vol. 23, no. 1, pp. 87-91, 1990.

[37] F. Esmaeilzadeh and M. Roshanfekr, "A new cubic equation of state for reservoir fluids," Fluid Phase Equilibria, vol. 239, no. 1, pp. 83-90, 2006.

[38] M. A. Trebble and P. R. Bishnoi, "Development of a new four-parameter cubic equation of state.," Fluid Phase Equilibria, vol. 35, no. 1-3, pp. 1-18, 1987.

[39] J. M. Smith, "Introduction to chemical engineering thermodynamics," 1950.

[40] M. Michelson, "On composition-dependent interaction coefficients," Fluid Phase Equilib., vol. 5, pp. 229 230, 1990.

[41] Y. Adachi and H. Sugie, "A new mixing rule-modified conventional mixing rule," Fluid Phase Equilibria, vol. 28, no. 2, pp. 103-118, 1986.

[42] A. Panagiotopoulos and R. Reid, "New mixing rule for cubic equations of state for highly polar, asymmetric systems," ACS Publications, 1986.

[43] R. Sandoval, G. Wilczek-Vera, and J. Vera, "Prediction of ternary vapor-liquid equilibria with the prsv equation of state," Fluid Phase Equilibria, vol. 52, pp. 119-126, 1989.

[44] M.-J. Huron and J. Vidal, "New mixing rules in simple equations of state for representing vapour-liquid equilibria of strongly non-ideal mixtures," Fluid Phase Equilibria, vol. 3, no. 4, pp. 255-271, 1979. 


The last chapter to write, though for most, the first chapter to be read. The creation of a booklet like this could never be done without the support, collaboration and all non-essential, but very important, (food and drink) activities with so many people around me over the past 5 years.

The first person I would like to thank is Boelo. The start of this adventure can be traced back to a bar in Chile. I realize now that this was already in 2014. I don't know anymore how it came to the subject of my master assignment. But, after that night I chose a subject and after my internship I started to work on liquid-liquid extractions. Not knowing, that I would stay in this research field until 2021! You are someone with an endless enthusiasm and knowledge about separation technology and life as an academic scholar. I could not have wished for a better supervisor, as you gave me a lot of freedom to explore my own ideas. Though when I needed some advice, guidance or a critical comment, you always helped me along. In the end, I am proud to deliver this dissertation and this could never happened without you. Many PhD'ers often say that 4 years of research is more than enough. I am happy to say that I am not one of them. If I could continue this research for another 4 years, I would have done this with absolute pleasure. The very pleasant collaboration between us is I think a big reason behind this. Secondly, I want to the thank Sascha. Your part in guiding me to (re)think about everything from another point of view was crucial to the quality of this work. Your openness to always discuss light subject matters (or hobbies) such as fundamental thermodynamics, helped me out tremendously. Also, your way of performing research appealed to me and together with Boelo made me the researcher I am today.

Furthermore, I want to thank all members of the SPT-group. Louis, you are a pillar within the student chemical engineering community. I can say so many things, but I will always remember the courses we gave together. It was the first time I gave lectures, and I really enjoyed doing that. Wim, I admire your infinite enthusiasm, ideas and energy in everything you do. I enjoyed the years I could work closely with you in teaching transport phenomena and thinking of new projects to prickle students to enjoy this complex theory. Jean-Paul, I enjoyed our discussions we had over the years. Your realistic vision about the sustainable future allowed me to distinguish many facts from fiction. Pilar, last year you were bombarded with many new (COVID19)- 
responsibilities and this didn't kept you from spreading the air of positivity. I enjoyed working together with you to fill-up (legally) the offices in these weird times. Lastly, I want to thank Wim, Henk, Edwin and Maik for being part of the ever so growing SPT group.

Everything can break, and definitely in the presence of me. Therefore, the skilled hands of Benno, Johan, Karst and Ronald have been indispensable. Thank you so much! Erna, I enjoyed our many talks regarding the various analysis equipments I was super-user of. I always appreciated the quick responses to my questions or notification that something broke in the lab. Yvonne, thank you for the support over the years and your essential knowledge about by-passing the hopeless, unnecessary and bureaucratic systems of the UT. How you manage to do this for all SPT members is still a mystery for me. Floris, why didn't you join us a few years earlier? I really enjoyed working with you in synthesizing new solvents, if we started earlier we could have done so many more things!

I want to thanks all committee members for agreeing to be part of my promotion committee and reading my dissertation. In particular, I want to thank Gerrald for the many, very constructive, discussions we had over the years. Your critical eye was highly valued and improved all my publications of which a couple we share. In addition, I would like to thank Antoon for the discussions about thermodynamics. I also want to thank Saskia for introducing me into the fascinating world of complex coacervates. I enjoyed our trip to Oxfordshire and working with a particle accelerator is something I will never forget.

It took 5 years to finish this dissertation. During this time I worked together, shared an office and did so many fun stuff with many fellow PhD/PDEng/PostDoc students. Though firstly, I want to mention my paranympfs. Vincent, we met back in 2009. You introduced me to the student life, we were both (a little bit) active as bartenders. Although our opinion on many subject matters differ, this doesn't withhold us of having much fun. Martijn, we know each other from 2011, though we spoke much more during the COVID19-times, where we worked back-to-back in an almost empty office. You say that nobody understands electrochemistry, though I believe if someone can figure it out, it is you. (and otherwise, just drink your Amstel beer). I am very glad 
that both of you agreed to be my paranympfs!

And here comes the summation.... Vahideh, good luck with your research and the damn difficult PHA analyses. I will keep an eye on your paper in the future! Angelo, the most awesome Swiss person I know. We met several times in Enschede, but also abroad and I really enjoyed your company. Please always remember your Dutch one-liner, may it be a nice subtitle of your thesis. Tomas, extreme (chemical) engineering, that is the first thing that comes to mind if I think of your research. High temperatures, burning stuff, right up your alley and you do it with a wide smile :). Tessa, you just started up your project and gave immediately an atmosphere boost in the office. I know that everything will work out and you can combine your interest in textiles with $\mathrm{CO}_{2}$ capture. Thimo, besides our shared interest of Formula 1, I enjoyed our many discussions about our projects. They may be very different, but I have learned much from our conversations and admire your way of navigating the maze called biomass research. Lionel, I envy your skills in simulating reactive distillation and your way of explaining complex matter simply, and I look forward to your publications. Enas, I enjoyed our trip to Barcelona when we were in Sitges. It was so much fun. Michel, my office neighbour, I will always remember our "nareis" in Peru and Bolivia. It was a great trip. Yordi, though most of the time you worked in your own bunker, I liked working with you in the PCT course. Mahsa, good luck with the centrifugal extractors and thank you for co-supervising several students. Tim, you are a wizard. Everything you touch, a computer gets a feeling. A feeling of compiling a working code which can accurately simulate complex reactors. I am very curious where your research will bring you. Shahab, many weekends we discuss at length why some Formula 1 drivers suck, and send (in)appropriate messages illustrating that. I wish you still good-luck with all your deadly cyano-compounds. Jasper, you have taken over many of my teaching responsibilities. So far I could see, you can handle it with ease. I think you will help Wim to improve the course even more! Alan, good luck with your research in modelling DESs and biomass, this is not a easy feat! Ehsan, you were my neighbor for the first 3 years. I enjoyed our joined efforts in writing up and modeling "funky" processes and your kind and always interested presence in the office and the lab. Lisette, I am always amazed how much you can do every week. I really think your days have 40 hours in it. Thank you for the many trips we had together, I always enjoyed it. Chiel, the PDEng pioneer. We go way back 
and I remember our many long evenings/nights as bartenders. You are amazing in creating new set-ups and still your potato drying set-up is being used! Pushkar, I will never forget your wedding. I was honored to attend. Also, I admire your scientific curiosity and appreciate the many discussions we had over the years. Varsha, thank you for being such a nice colleague. I always will remember your fanatic you were with card games. Marek, thank you for supervising me during my master assignment. Your detailed knowledge about separation technology was very valuable. I wish you much happiness with Sandra. Surika, I really enjoyed our trip to Florence. You are a great (supercritical) colleague to have, and not only because the African language is amazing. Martin, hidden away at the end of the office, but always knowing exactly what is happening. I was sad to miss your wedding, but we will see each other in the future as (again) colleagues! :) Rick, I always admired your attention to detail and the depth of your research. You make everything seem so simple. Also, you are immensely sociable and undoubtedly we will see each other in the future. Juraj, awesome dancing skills. That is the first time that comes to mind. Thank you for your time at SPT, I always enjoyed being around you. Natalia, I always enjoyed for company, the many sweets you made and of course the (light) alcoholic drinks you needed to share with us all. Dion, I enjoyed our trip to Sitges. Urmi, I liked our discussions and your scientific curiosity. You will do well as an (assistant) professor in India. Lastly, I would like to mention the remaining PhD'ers, Evelyn, Catarina, Maryam and An.

Over the years I had the privilege of supervising many students. Many ideas didn't end up in my dissertation, but was nonetheless essential to its completion. As Bachelor students; Joep and Peter for working on my idea of adding electrolytes in solvent extraction. Vera and Sjoerd for your extraction work. Joram, Joey and Nikki for the Deep Eutectic Solvent extraction work. Daniel, Rick and Thijs for your work in applying complex coacervates for separation cases and Remko for your process simulation work.

As Master students; Esther for being my first student to supervise. Your work could directly be applied in several chapters. Bas for your ability to conquer COSMO-RS, simulating and experimentally determining SLE behavior of hydrophobic DESs. Emma, I enjoyed our short time in chiral separations. Koen E., thank you for so much effort in the xylene isomer separations. My idea 
didn't worked out, it wasn't easy, but your research was very sound. Besides my "regular" work, I enjoyed supervising work on the magnetic extractor (or Boelo Extractor). Stef, your theoretical work into the drag of slugs through the micro channels. Styrmir, for extending the theoretical work with Jeff to greater heights in COMSOL and proposing essential set-up adaptations to solve operation issues. Bob, your experimental work in finding the operation window. Rutger and Koen W. for developing a reproduceable ferrofluid synthesis. Erik, your extractive distillation work with DESs had many troubles, but your enthusiasm will not be forgotten. The projects of Hilbert (extractive distillation of acids), Jesse (styrene/ethylbenzene separation using Cyrene with or without a divided wall column configuration), Jorrit (olefin/paraffin separation with Cyrene and Cygnet) and Simon (olefin/paraffin separation with mixed composite solvents containing Cyrene) are not yet finished, but will undoubtedly end with very nice theses.

Of course, work is not all. I want to mention Gerardo, Kristianne, Carmen, Floris, Mitchel, Robin, Roy, Steven and Wilmar. We started our studies together and still we see each other regularly. I hope this will never end :). I always enjoy a good wine/beer, much food, sometimes an (online) pubquiz together with Mariël, and the opportunity to share this with many other couples (you know who I mean) hopefully never end.

Natuurlijk kan ik de familie niet vergeten. Wout en Karin voor altijd jullie support. Al jaren snappen mijn broertjes precies wat ik doe. Protonen, ionen en neutronen doen namelijk dingen. Nou dat klopt. Veel leesplezier, Freek en Suus, Alex en Bas. Verder wil ik mijn schoonfamilie (Johan, Wilma, Nadine, Jordi, Bertwin en Aada) ook enorm bedanken (kiitos) voor alle gezelligheid over de jaren heen. Ik had me geen leukere schoonfamilie kunnen wensen.

Tenslotte, wil ik natuurlijk Mariël gigantisch in het zonnetje zetten. Wij zijn samen in het PhD avontuur gestapt. Alhoewel de afgelopen jaren onze PhD ervaring flink uiteenliepen, konden we altijd alles met elkaar bespreken. Wellicht was het soms niet zo evident, maar ik heb net zo veel aan jou gehad als jij aan mij. We hebben veel gezamelijk interesses zoals reizen en vaak uiteten gaan en ik prijs me daarom erg gelukkig met het feit dat wij hetzelfde in het leven staan. Op naar een gelukkig en erg lange toekomst, van mij kom je niet meer af. ;) 




\section{About the Author}

Thomas Brouwer was born on April $5^{\text {th }} 1991$ in Deventer, The Netherlands. He grew up in Diepenveen, after which he moved to Enschede in 2009 to study Chemical Engineering at the University of Twente. The title of his Bachelor's thesis was "Fabrication and Photocatalytic Assessment of a PDMSbased Microreactor with Focus on Atrazine as an Organic Degradation Model Compound" at the Soft Matter, Fluidics and Interfaces (SFI) group. During his master's, he did an internship at the South Africa Institute of Advanced Material Chemistry (SAIAMC) at the University of the Western Cape. He performed research on "Commissioning a Pd-membrane set-up combination with a PEMFC fuel Cell”. He did his master thesis at the Sustainable Process Technology (SPT) group at the University of Twente on "Reactive Extraction and Recovery of Levulinic Acid from an acidic aqueous solution" under the supervision of Marek Blahušiak and Boelo Schuur.

This dissertation was written at the time when he was working on "Affinity Separations" in the Sustainable Process Technology Group (SPT) under the guidance of Boelo Schuur. This project is part of the Institute of Sustainable Process Technology cluster "Energy Efficient Bulk Liquid Separation". The aim of the project is the development of Liquid-Liquid Extractions and Extractive Distillations as alternatives for traditional distillations. The emphasis will be on the fundamental understanding of affinities in

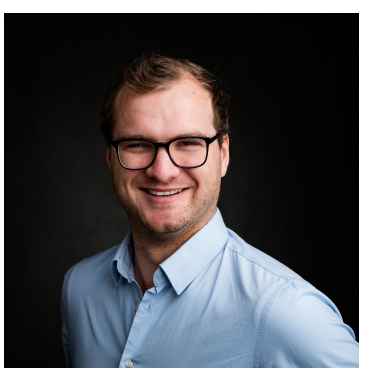
separations, though not excluded the sustainability aspects. The last 2 years of he performed this research part-time, as the remainder of the time was spent as a teacher within the SPT group. 



\section{Publications}

\section{Main Articles in Peer-reviewed Journals}

Brouwer, T. and Schuur, B., "Model performances evaluated for infinite dilution activity coefficients prediction at $298.15 \mathrm{~K}$ ", Industrial \& Engineering Chemistry Research, ACS Publications, 2019, 58, 20, 8903-8914.

Brouwer, T., Kersten, S.R.A., Bargeman, G. and Schuur, B., "Trends in Solvent Impact on Infinite Dilution Activity Coefficients of Solutes Reviewed and Visualized Using an Algorithm to Support Selection of Solvents for Greener Fluid Separations", (Article Submitted)

Brouwer, T., Kersten, S.R.A., Bargeman, G. and Schuur, B., "Solvent Pre-Selection for Extractive Distillation using Infinite Diluted Activity Coefficients and the 3component Margules Equation", (Ready for Submission)

Brouwer, T. and Schuur, B., "Bio-based Solvents as entrainers for Extractive Distillation in Aromatic/Aliphatic and Olefin/Paraffin Separation", Green Chemistry, The Royal Society of Chemistry, 2020, 22, 16, 5369-5375.

Brouwer, T. and Schuur, B., "Dihydrolevoglucosenone (Cyrene), a Biobased Solvent for Liquid-Liquid Extraction Applications", Sustainable Chemistry \& Engineering, American Chemical Society, 2020, 8, 39, 14807-14817.

Brouwer, T. and Schuur, B., "Biobased Entrainer Screening for Extractive Distillation of Acetone and Diisopropyl ether ", (Article Submitted)

Brouwer, T. and Schuur, B., "Comparison of Solvent-based Affinity Separation 
Processes with Cyrene and Sulfolane for Aromatic/Aliphatic Separations", (Article Submitted)

Brouwer, T., Crespo, E.A., Bargeman, G., ten Kate, A.J.B., Coutinho, J.A.P., Kersten, S.R.A. and Schuur, B., "Isobaric Vapor-Liquid Equilibrium prediction from the Excess Molar Enthalpy using cubic Equation of States and PC-SAFT.", (Article in Preparation)

\section{Other Articles in Peer-reviewed Journals}

Brouwer, T., Blahusiak, M., Babic, K. and Schuur, B., "Reactive extraction and recovery of levulinic acid, formic acid and furfural from aqueous solutions containing sulphuric acid", Separation and purification technology, Elsevier, 2017, 185, 186-195.

Reyhanitash, E., Brouwer, T., Kersten, S.R.A., Van der Ham, A.G.J. and Schuur, B., "Liquid-liquid extraction-based process concepts for recovery of carboxylic acids from aqueous streams evaluated for dilute streams", Chemical Engineering Research and Design, Elsevier, 2018, 137, 510-533.

Schuur, B., Brouwer, T., Smink, D. and Sprakel, L.M.J.,"Green solvents for sustainable separation processes",Current Opinion in Green and Sustainable Chemistry, Elsevier, 2019, 18, 57-65.

Schuur, B., Brouwer, T. and Sprakel, L.M.J.,"Recent developments in solvent based fluid separations", Chemical and Biomolecular Engineering, Annual Reviews, 2021,.(Article Submitted)

Van Lente, J., Pazos Urea, M., Brouwer, T., Schuur, B. and Lindhoud, S., "Complex Coacervates as Extraction Solvents", (Article Submitted)

Brouwer, T., van Lin, R., ten Kate, A.J.B., Schuur, B. and Bargeman, G., "The Influence of Solvent and Acid Properties on the Relative Volatility and Separation 
Selectivity for Extractive Distillation of Close-Boiling Acids", (Article Submitted)

Brouwer, T., Dielis, B., Bock, J.M. and Schuur, B, "Hydrophobic Deep Eutectic Solvents for Recovery of Secondary Metabolites" (working title), (Article in Preparation)

\section{Conference Contributions}

\section{Oral Presentation}

Brouwer, T. and Schuur, B., "Reactive Extraction of Levulinic acid, Formic acid and Furfural from Aqueous Solutions containing Sulphuric Acid" at DECHEMA at Cologne, Germany ( $8^{\text {th }}$ of March 2017)

Brouwer, T. and Schuur, B., "Reactive Extraction of Levulinic acid, Formic acid and Furfural from Aqueous Solutions containing Sulphuric Acid" at CHAINS at Veldhoven, The Netherlands ( $7^{\text {th }}$ of December 2017)

Brouwer, T. and Schuur, B., "Predictive Models for Infinite Diluted Activity Coefficients" at $5^{\text {th }}$ International Conference on Methods and Materials for Separation Processes "Separation Science - Theory and Practice 2018 at Kudowa Zdrój, Poland (28 ${ }^{\text {th }}$ of August 2018)

Brouwer, T., Slouwerhof, E. and Schuur, B., "Deep Eutectic Solvents: A New Generation of Extractive Distillation Agents" at $4^{\text {th }}$ International Conference on Ionic Liquids in Separation and Purification Technology, Sitges, Spain $\left(9^{\text {th }}\right.$ of September 2019)

Brouwer, T. and Schuur, B., "Evaluation of Biobased Solvents for Solvent-Based Affinity Separations" at CHAINS at Veldhoven, The Netherlands $\left(10^{\text {th }}\right.$ of December 2019)

Brouwer, T. and Schuur, B., "Biobased Solvents for the Separation of Apolar Mixtures using Extractive Distillation" at ARISE-GIN Conference, Enschede, The 
Netherlands (Digital) ( $6^{\text {th }}$ of October 2020)

\section{Poster Presentation}

Brouwer, T. and Schuur, B., "Predictive models for $\gamma^{\infty}$ " at Nederlands Procestechnologen Symposium 15 at Enschede, The Netherlands $\left(30^{\text {th }}\right.$ and $31^{\text {st }}$ of May 2018)

Brouwer, T., Oosterhoff, R.C., Engelen, T.R., Schuur, B. and Lindhoud, S., "The Extraction and Recovery of Volatile Fatty Acids with a Complex Coacervate" at CHAINS at Veldhoven, The Netherlands $\left(4^{\text {th }}\right.$ and $5^{\text {th }}$ of December 2018)

Brouwer, T. and Schuur, B., "Model Performances Evaluated for Infinite Dilution Activity Coefficients Prediction at $298.15 \mathrm{~K}$ at 12 th European Congress of Chemical Engineering at Florence, Italy $\left(15^{\text {th }}\right.$ to $19^{\text {th }}$ of September 2019) 